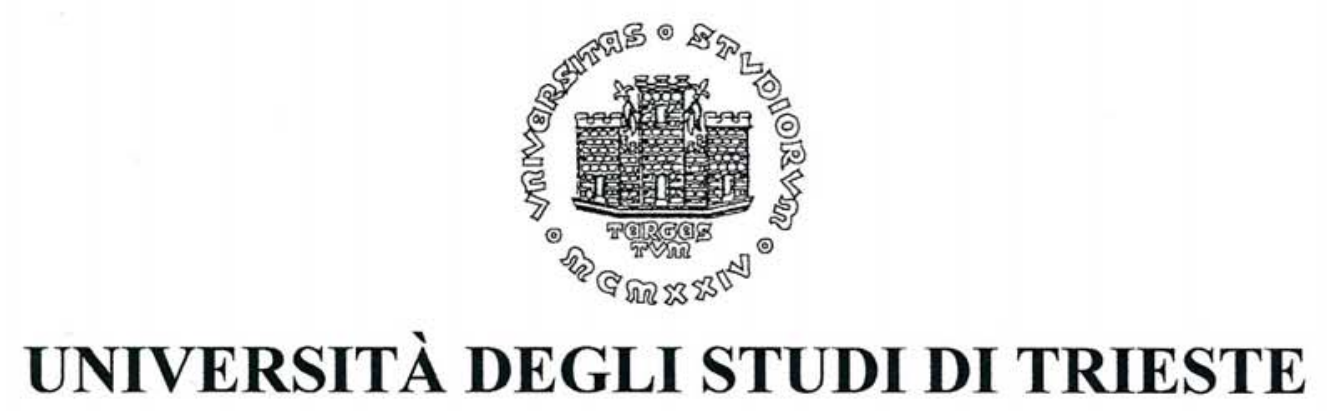

XXV CICLO DEL DOTTORATO DI RICERCA IN

SCIENZE DELL'INTERPRETAZIONE E DELLA TRADUZIONE

\title{
TERMINOLOGICAL EQUIVALENCE AND VARIATION IN THE EU MULTI-LEVEL JURISDICTION: A CASE STUDY ON VICTIMS OF CRIME
}

Settore scientifico-disciplinare: L-LIN/12

DOTTORANDA

KATIA PERUZZO

COORDINATORE

PROF. FEDERICA SCARPA

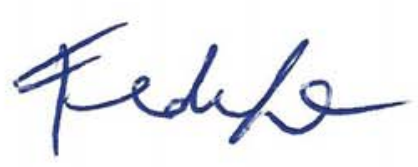

SUPERVISORE DI TESI

PROF. MARELLA MAGRIS

Mencle Reyris

CO-SUPERVISORE DI TESI

PROF. FEDERICA SCARPA

CO-SUPERVISORE DI TESI

PROF. MITJA GIALUZ

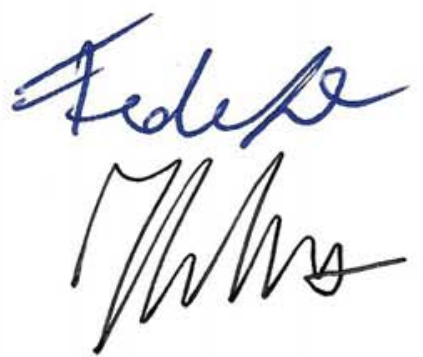




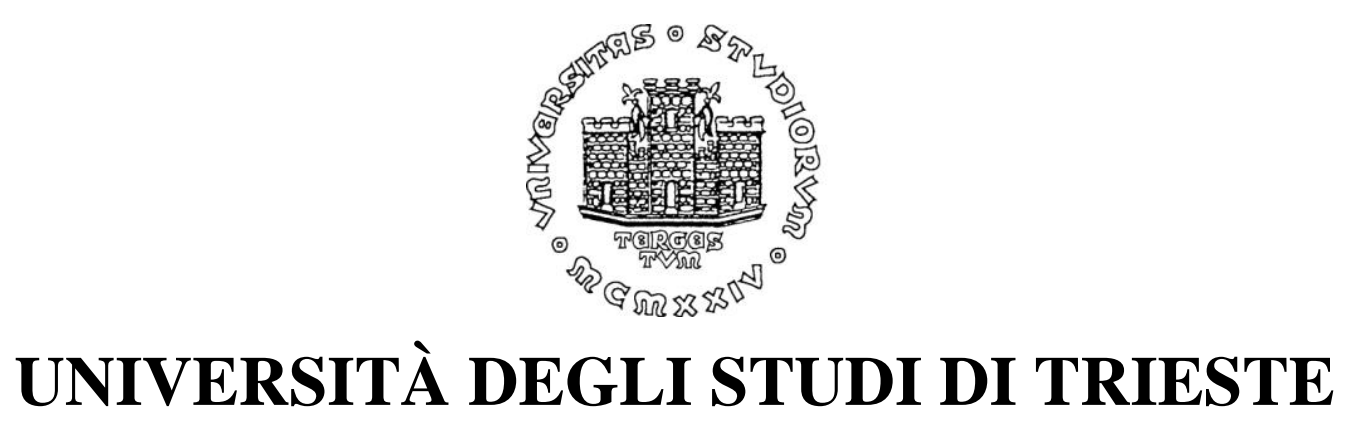

XXV CICLO DEL DOTTORATO DI RICERCA IN

SCIENZE DELL'INTERPRETAZIONE E DELLA TRADUZIONE

\section{TERMINOLOGICAL EQUIVALENCE AND VARIATION IN THE EU MULTI-LEVEL JURISDICTION: A CASE STUDY ON VICTIMS OF CRIME}

Settore scientifico-disciplinare: L-LIN/12

DOTTORANDA

KATIA PERUZZO

COORDINATORE

PROF. FEDERICA SCARPA

SUPERVISORE DI TESI

PROF. MARELLA MAGRIS

CO-SUPERVISORE DI TESI

PROF. FEDERICA SCARPA

CO-SUPERVISORE DI TESI

PROF. MITJA GIALUZ 

to the memory of my beloved grandmother,

Liliana 

There's a sign on the wall but she wants to be sure 'Cause you know sometimes words have two meanings.

Led Zeppelin, Stairway to Heaven 



\section{TABle OF CONTENTS}

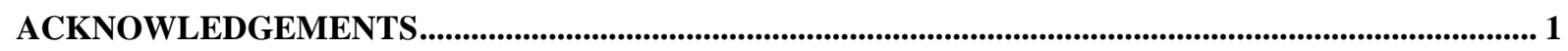

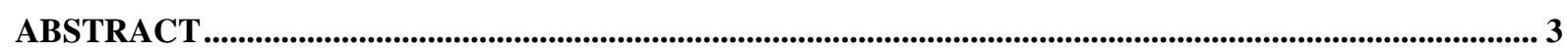

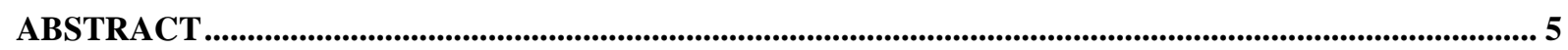

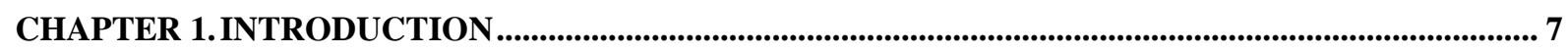

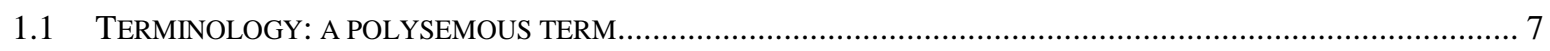

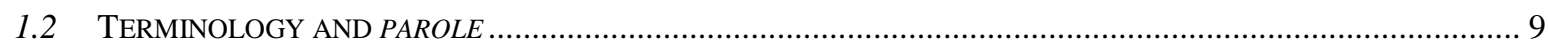

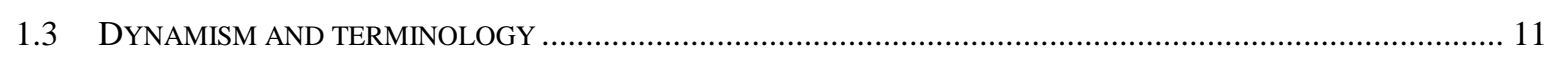

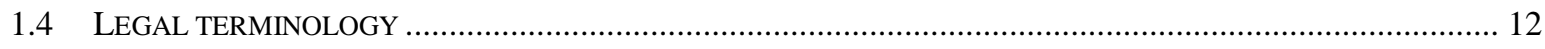

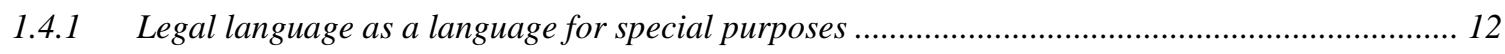

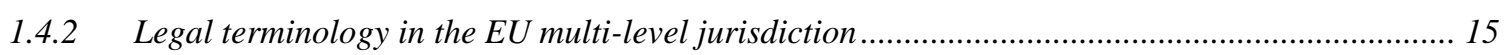

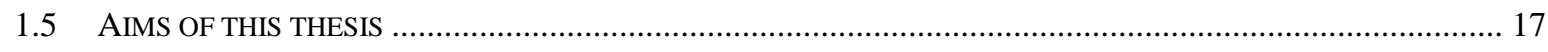

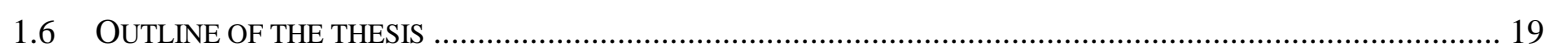

CHAPTER 2. THE AREA OF LAW: VICTIMS OF CRIME ........................................................................ 23

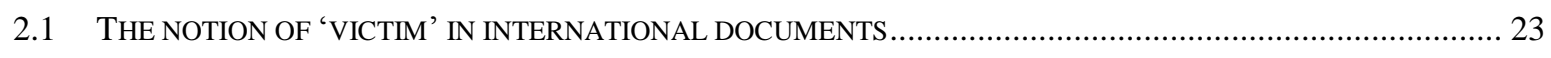

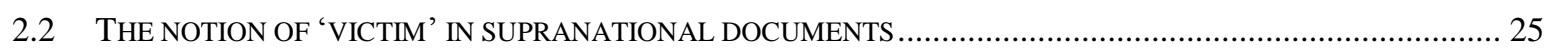

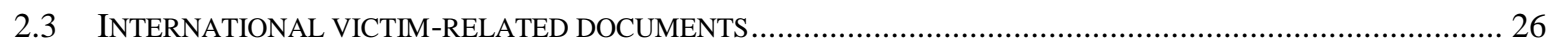

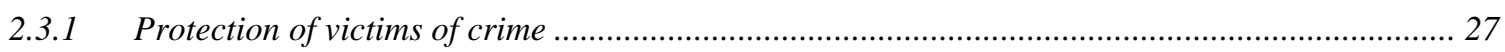

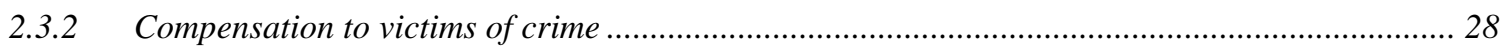

2.3.3 The position of victims of crime in criminal proceedings and their rights .................................... 29

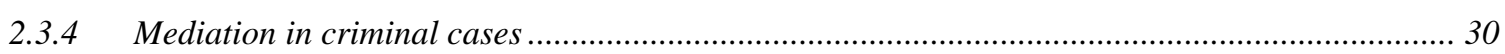

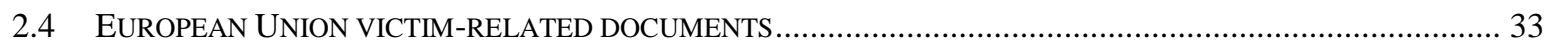

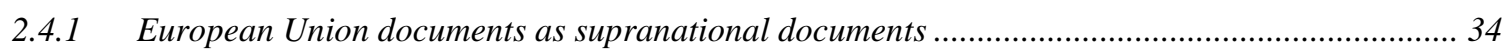

2.4.2 Victims of crime in the framework of European Union legislation ............................................... 36

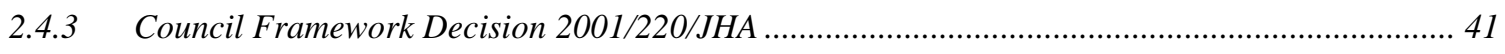

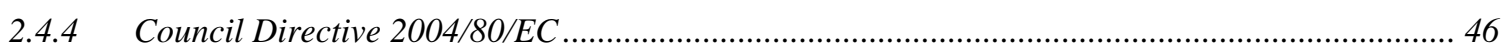

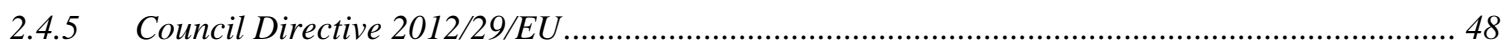

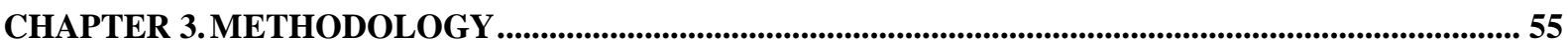

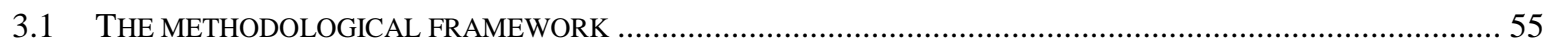

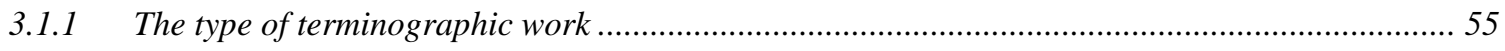

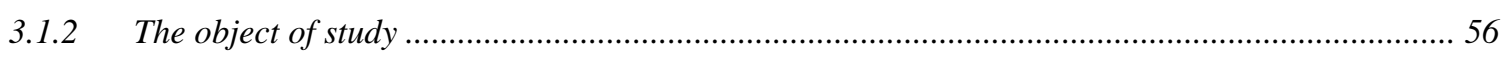

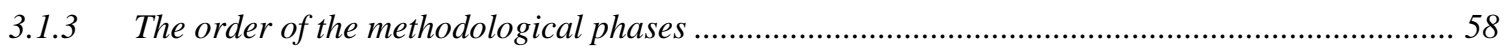

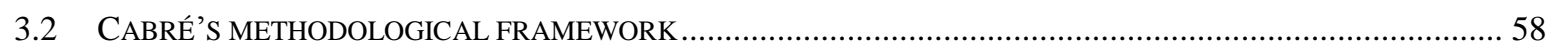

3.3 METHODOLOGICAL FRAMEWORK FOR THE ANALYSIS OF MULTILINGUAL TERMINOLOGY IN THE EU MULTI-

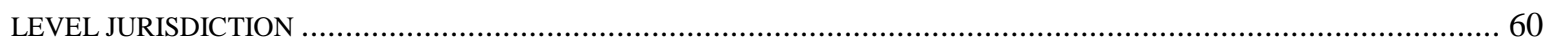

3.3.1 STEP 1. Definition of the terminographic work and the area of knowledge ................................. 61 


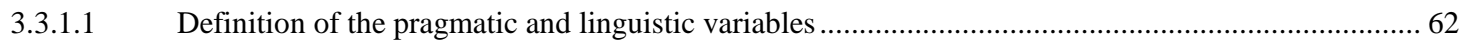

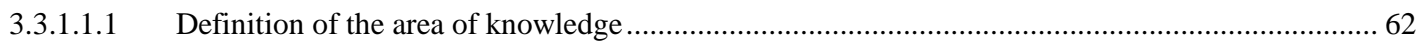

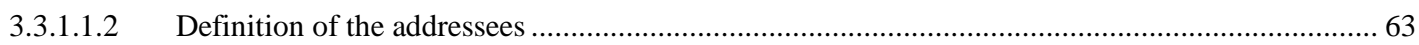

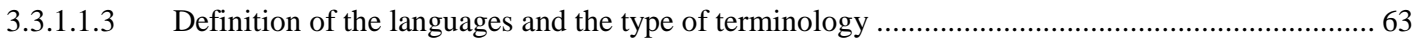

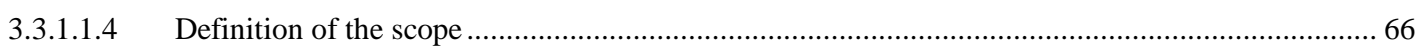

3.3.1.2 Choice of IT tools, reference materials and consultants and acquisition of information about the area

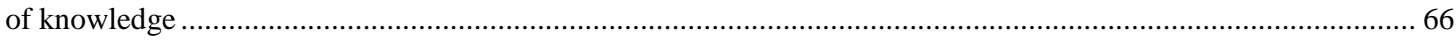

3.3.1.3 Preliminary frame-based conceptual structuring of the area of knowledge ........................................6 68

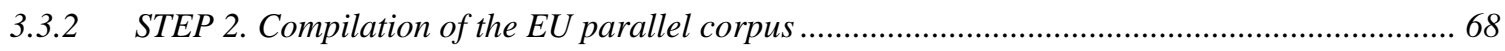

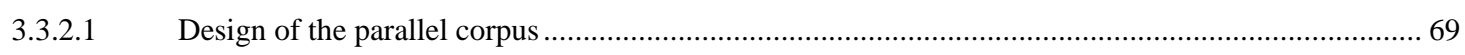

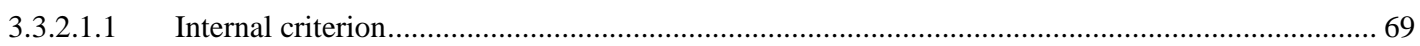

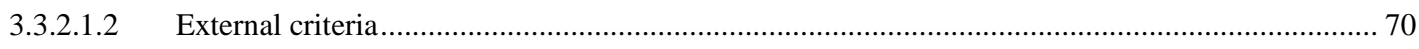

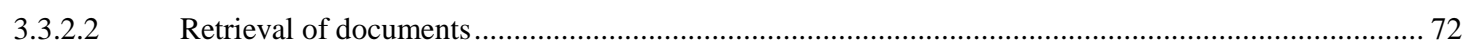

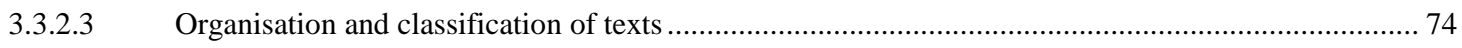

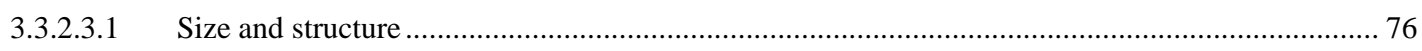

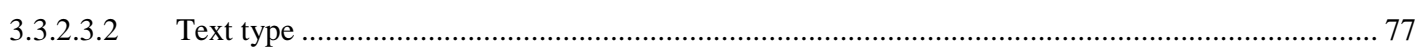

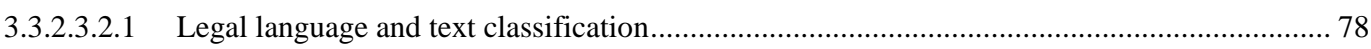

3.3.3 STEP 3. Terminographic processing of the EU corpus..................................................... 83

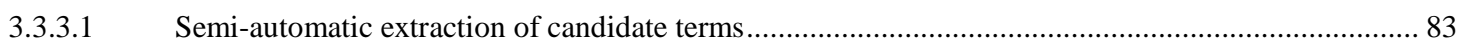

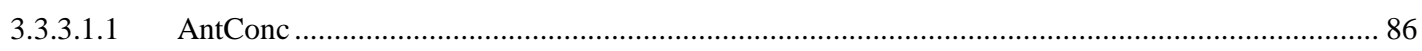

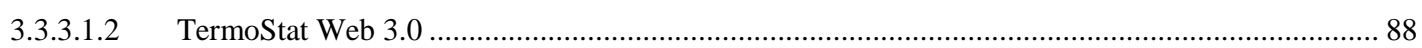

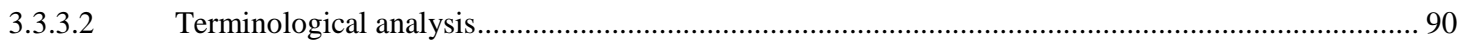

3.3.3.2.1 Bilingual cross-check and identification of translation equivalents .......................................... 90

3.3.3.2.2 Extraction of linguistic, pragmatic, and conceptual information............................................... 95

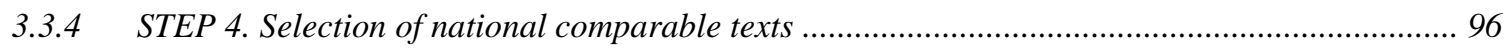

3.3.5 STEP 5. Terminographic processing of national comparable texts ........................................... 101

3.3.6 STEP 6. Population of a translation-oriented terminological knowledge base ......................... 106

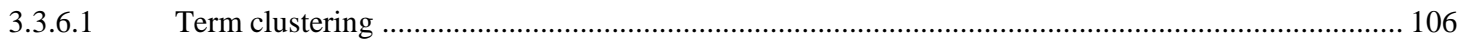

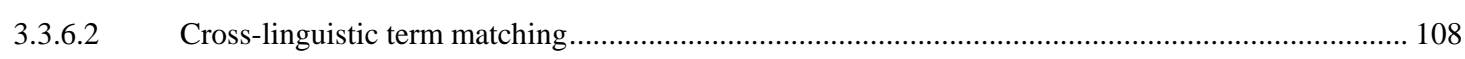

3.3.6.3 Conceptual (re)structuring of the area of knowledge................................................................... 109

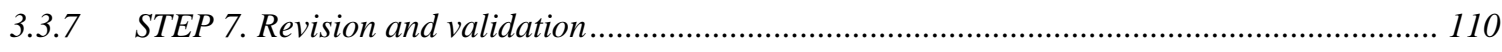

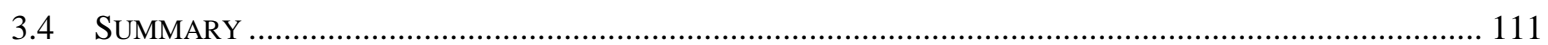

CHAPTER 4. VICTIMS OF CRIME FROM A MONOLINGUAL TERMINOLOGICAL

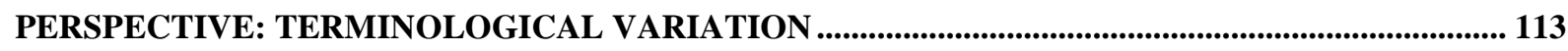

4.1 STATE OF THE ART IN THE STUDY OF TERMINOLOGICAL VARIATION .............................................. 113

4.1.1 The exclusion of terminological variation from standardisation-oriented terminology theories 113

4.1.2 The inclusion of terminological variation in terminology studies ............................................. 115

4.2 TERMINOLOGICAL VARIATION: A POLYSEMOUS TERM ..................................................................... 119

4.2.1 Terminological variation according to Ibekwe-SanJuan ..................................................... 120

4.2.2 Terminological variation according to Daille ............................................................................. 122

4.2.3 Terminological variation according to Jacquemin ............................................................. 124

4.2.4 Terminological variation according to Freixa ......................................................................... 125

4.2.4.1 Freixa's classification of causes of denominative variation.............................................................. 126 
4.3 TERMINOLOGICAL VARIATION FROM A BI- AND MULTILINGUAL PERSPECTIVE................................... 130

4.4 TERMINOLOGICAL VARIATION FROM A MULTI-JURISDICTIONAL TEXTUAL PERSPECTIVE ...................... 132

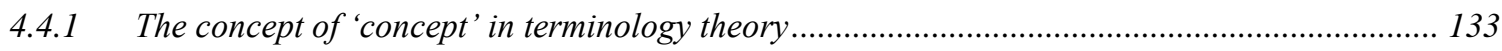

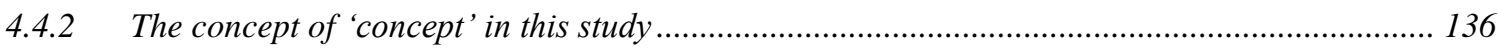

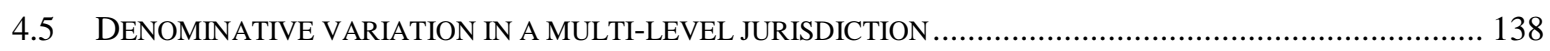

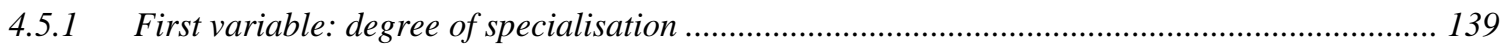

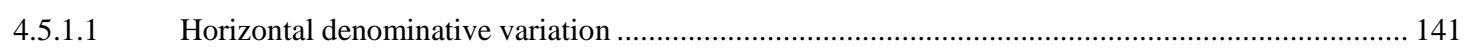

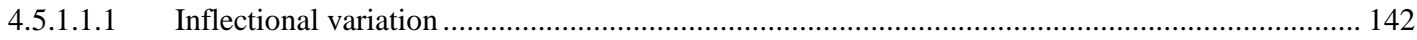

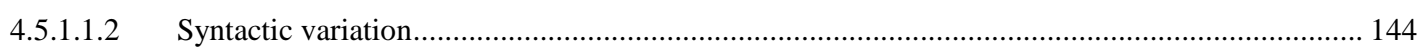

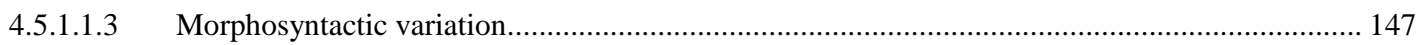

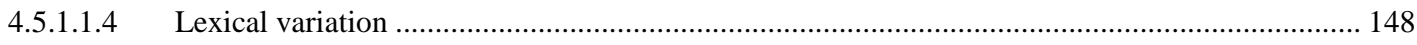

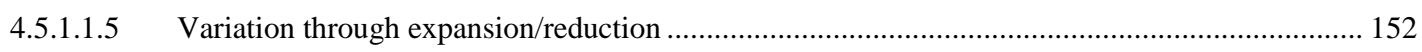

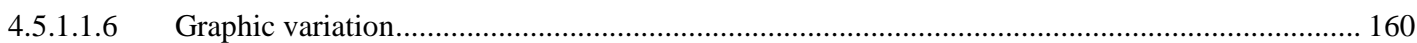

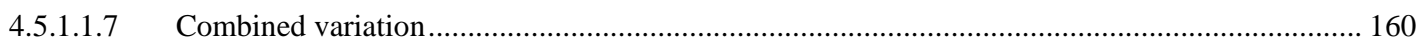

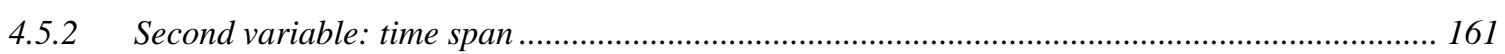

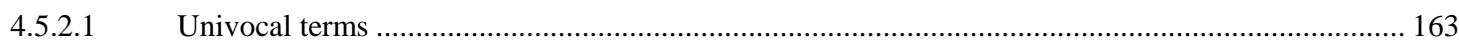

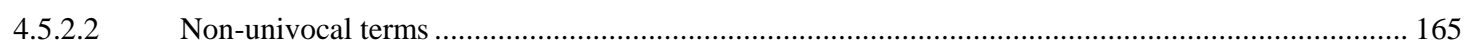

4.5.3 Third variable: conceptual (legal) system $(\mathrm{s})$............................................................ 168

4.5.4 Fourth variable: legal force ............................................................................................ 170

4.6 CONCEPTUAL VARIATION IN A MULTI-LEVEL JURISDICTION ......................................................... 172

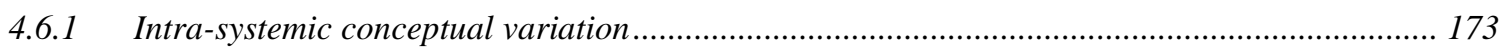

4.6.2 Inter-systemic conceptual variation ................................................................................... 175

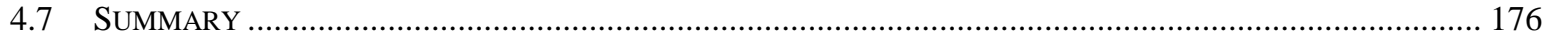

CHAPTER 5. VICTIMS OF CRIME FROM A MULTILINGUAL TERMINOLOGICAL

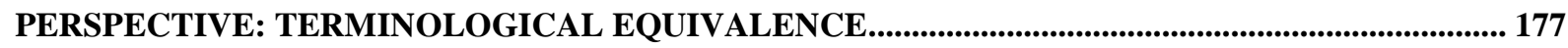

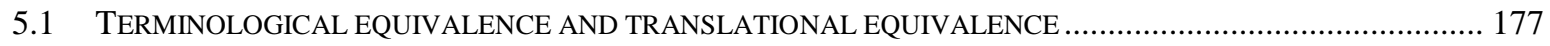

5.2 TERMINOLOGICAL EQUIVALENCE IN LEGAL TERMINOLOGY .......................................................... 179

5.3 TERMINOLOGICAL EQUIVALENCE IN THE EU MULTI-LEVEL JURISDICTION .................................... 180

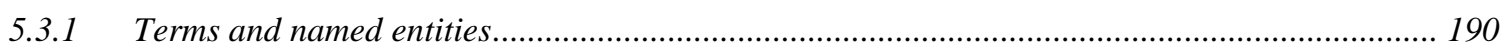

5.3.2 Degrees of equivalence and terminographic processing .................................................... 192

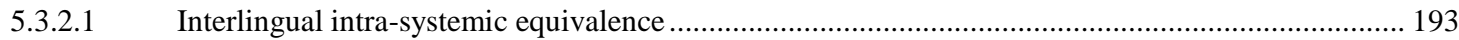

5.3.2.2 Interlingual inter-systemic equivalence ............................................................................ 194

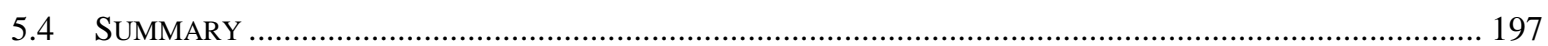

\section{CHAPTER 6. VICTIMS OF CRIME FROM A TERMINOGRAPHIC PERSPECTIVE. MULEX: A} LEGAL TRANSLATION-ORIENTED TERMINOLOGICAL KNOWLEDGE BASE............................ 199

6.1 FROM TERMINOLOGICAL DATABASES TO TERMINOLOGICAL KNOWLEDGE BASES ............................... 199

6.2 FROM TERMINOLOGICAL KNOWLEDGE BASES TO ONTOLOGIES .................................................. 201

6.3 FROM ONTOLOGIES TO ONTOLOGICAL TERMINOLOGICAL KNOWLEDGE BASES ................................... 203

6.4 MULEX: A LEGAL-TRANSLATOR ORIENTED TERMINOLOGICAL KNOWLEDGE BASE .............................209

6.4.1 MuLex: terminographic entries and graphic user interface .................................................... 213

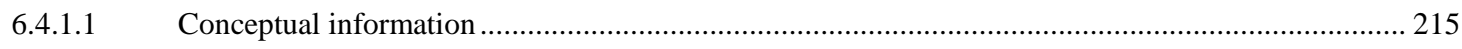




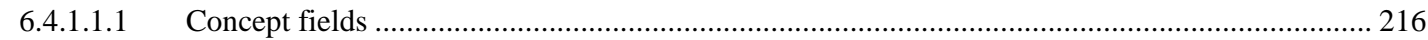

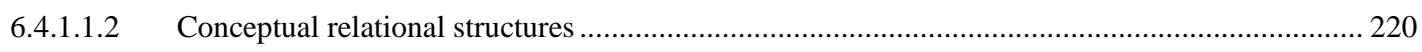

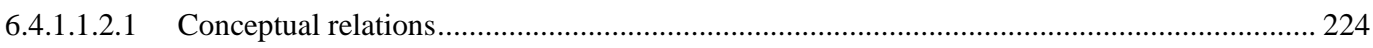

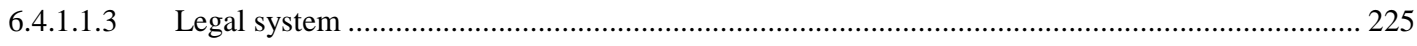

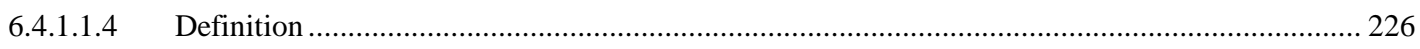

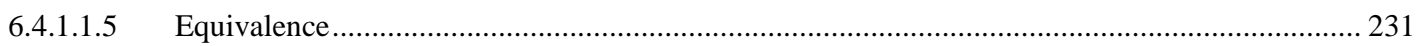

6.4.1.1.6 Term variants and notes on terminological variation .......................................................... 232

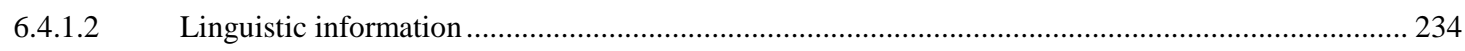

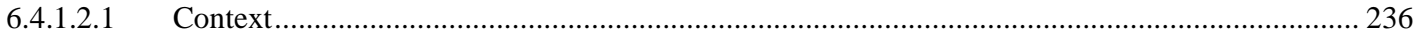

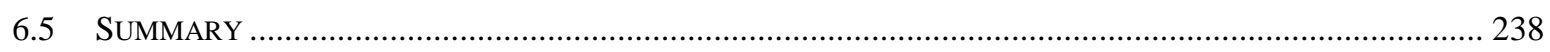

CHAPTER 7. CONCLUSIONS AND FUTURE WORK........................................................................... 241

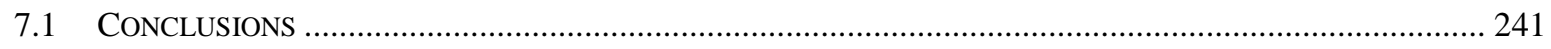

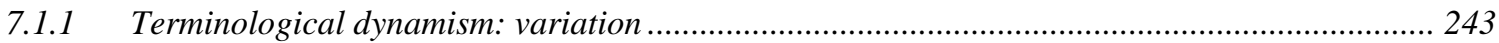

7.1.2 Terminological dynamism: equivalence ............................................................................... 245

7.1.3 Capturing terminological dynamism in MuLex................................................................ 247

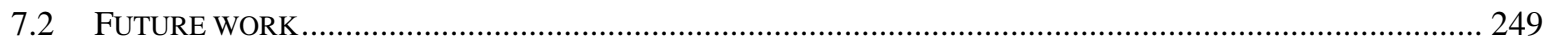

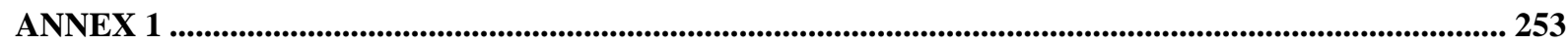

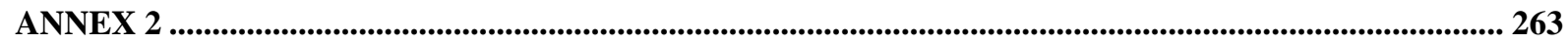

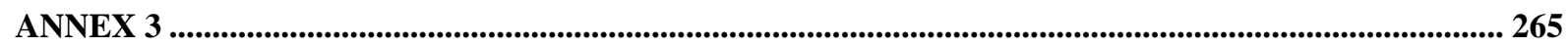

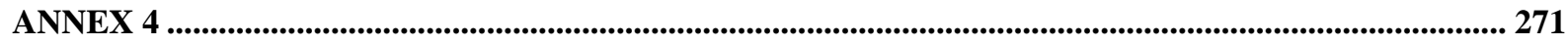

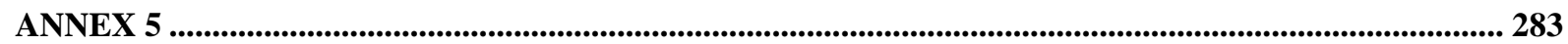

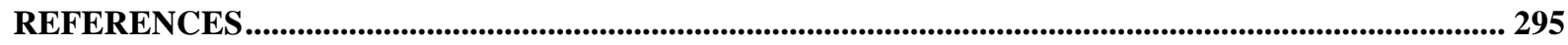




\section{LIST OF FIGURES}

Figure 3.1. Stages followed in a systematic monolingual terminological work according to Cabré (1999: 131)

Figure 3.2. Stages followed in the terminological analysis of multilingual terminology in a multi-level jurisdiction.

Figure 3.3. Bhatia's genre distinction in the legal language (Bhatia 1987: 227).

Figure 3.4. Genre distinction of the EU corpus in the classification of written legal language (blue box).

Figure 3.5. Screenshot of the word list (ranks 1-21) of the English subcorpus without footnotes generated with AntConc.

Figure 3.6. Screenshot of the word list (ranks 1-21) of the Italian subcorpus without footnotes generated with AntConc.

Figure 3.7. Cross-check for translation equivalents and terminological variants in the EU corpus bilingual display. Searched candidate terms: state compensation scheme, scheme..... 91 Figure 3.8. Cross-check for translation equivalents and terminological variants in the EU corpus bilingual display. Searched candidate terms: vittima/e particolarmente vulnerabile/i. 92 Figure 3.9. Cross-check for translation equivalents and terminological variants in the EU corpus bilingual display. Searched candidate terms: child victim(s).

Figure 3.10. Cross-check for translation equivalents and terminological variants in the EU corpus bilingual display. Searched candidate terms: violent intentional crime.

Figure 3.11. Genre distinction of national texts in the classification of written legal language (blue box).

Figure 3.12. Example of anisomorphism in conceptual relations. genotype: CHILD VICTIM. 109 Figure 5.1. Assessment of interlingual equivalence on the basis of the genotype-phenotype distinction.

Figure 5.2. Assessment of interlingual equivalence on the basis of the genotype-phenotype distinction. A case of terminological and conceptual vacuum. Example: CRIMINAL INJURIES COMPENSATION AUTHORITY.

Figure 6.1. Fields containing conceptual information in the MuLex graphic user interface

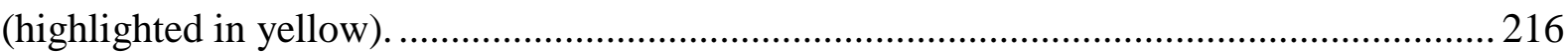

Figure 6.2. Conceptual template for the legal area of victims of crime............................. 218 Figure 6.3. Differences in conceptual relational structures related to the same concept. Searched term: Victim Support Europe.

Figure 6.4. Presence of a conceptual relational structure related to a single legal system.

Searched term: Victim Support.

Figure 6.5. Colours associated to conceptual relations in MuLex.

Figure 6.6. Different conceptual relations in a conceptual relational structure. Searched term: child victim.

Figure 6.7. "Legal system" field in the MuLex graphic user interface. 226 Figure 6.8. Visualisation of the "Term variant" an "Notes on terminological variation" fields for the Italian main term risarcimento da parte dello Stato. 
Figure 6.9. Fields containing linguistic information in the MuLex graphic user interface (highlighted in yellow).

Figure 6.10. Example of a term with one context only. Searched term: qualifying claimant. 237

Figure 6.11. Example of a term with two contexts. Searched term: assisting authority. 237 


\section{LIST OF TABLES}

Table 3.1. Distribution of number of documents and types and tokens in the EU corpus............... 76

Table 3.2. Distribution of documents in text-type categories in the EU corpus.............................83

Table 4.1. Types of variation according to the different variable taken into consideration. ...........139

Table 4.2. Possible lexical variants obtained considering a variable number of elements constituting

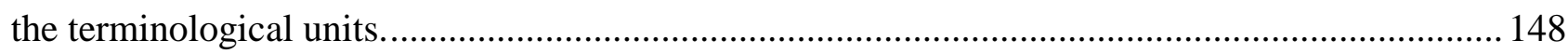

Table 4.3. Possible lexical variants obtained considering a the elements being modified in multi-

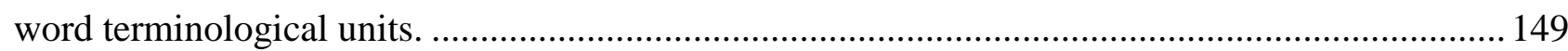

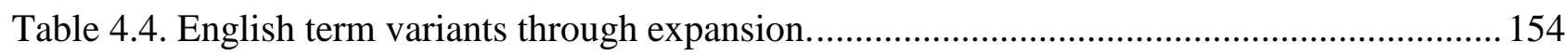

Table 4.5. Italian term variants through expansion..................................................................... 156

Table 4.6. English term variants through reduction................................................................ 158

Table 4.7. Italian term variants through reduction.................................................................. 158

Table 4.8. Correspondence of univocal terms in the EU corpus.................................................. 163

Table 4.9. Examples of behavioural patterns of English non-univocal terms. ............................... 166

Table 4.10. Examples of behavioural patterns of Italian non-univocal terms. ............................. 166

Table 4.11. Diachronic variation in the term cluster referring to the MEDIATION IN CRIMINAL

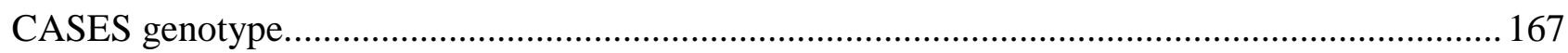

Table 4.12. Inter-systemic denominative variation in the Italian term cluster referring to the

MEDIATION IN CRIMINAL CASES genotype.......................................................... 170

Table 4.13. Denominative variation in terms of legal force in the Italian term cluster referring to the RIGHTS OF VICTIMS OF CRIME genotype............................................................. 171

Table 5.1. Types of terminological equivalence and correspondence in the EU multi-level jurisdiction.

Table 5.2. Types of terminological equivalence and correspondence in the EU multi-level jurisdiction. Example: LEGAL AID.

Table 5.3. Types of terminological equivalence and correspondence in the EU multi-level jurisdiction. Example: CIVIL PARTY.

Table 5.4. Types of terminological equivalence and correspondence in the EU multi-level jurisdiction. Example: QUALIFYING CLAIMANT.

Table 5.5. Types of terminological equivalence and correspondence in the EU multi-level jurisdiction. Example: CROSS-BORDER VICTIM.

Table 5.6. Types of terminological equivalence and correspondence in the EU multi-level jurisdiction. Example: CRIMINAL INJURIES COMPENSATION AUTHORITY.

Table 6.1. List of fields containing linguistic information in MuLex. 



\section{ACKNOWLEDGEMENTS}

My deepest gratitude goes to my supervisor, Prof. Marella Magris, whose passion for terminology and warm words have accompanied me throughout my $\mathrm{PhD}$ years. I would like to thank her for supporting me and giving me a feeling of security in all the steps of this research project. I would like to express my profound thanks to my co-supervisor, Prof. Federica Scarpa, for her close and accurate supervision, her constant encouragement and the excellent research opportunities she has provided me with. My sincere thanks go to my cosupervisor, Prof. Dr. Mitja Gialuz, who inspired me with his endless enthusiasm for criminal law and offered me the opportunity to look at the peculiarities of legal terminology from a lawyer's rather than a translator's perspective.

I am especially grateful to Prof. Dr. Rita Temmerman, for welcoming me wholeheartedly into her team at the Centre for Special Language Studies and Communication, Erasmushogeschool Brussel, and for all her wisdom and guidance during and after my stay abroad. I must also thank the whole CVC team for always making me feel like I belonged there.

I am particularly thankful to Professor Dr. Alenka Kocbek of the University of Primorska, who has followed and supported my work over the past year.

There have been many people that I have had the opportunity to collaborate or exchange ideas with in these years. I would like to thank Dr. Giuseppe Palumbo and Dr. Stefano Ondelli, for generously providing their support and advice every time I needed, and Paola Valli and Carla Quinci, for giving me courage as colleagues and friends. Special tanks go also to Prof. Pérette-Cécile Buffaria, for trusting in me and encouraging me. I am grateful to Dr. Isabel Durán-Muñoz, for motivating my interest in terminology and knowledge representation and sharing with me the joys and struggles of co-writing. My thanks go to Anne-Kathrin Schumann, for being a constant source of academic delight and surprise.

I am very thankful to Enrico Paoli, for opening my eyes to the tantalizing but at the same time bewildering world of programming, for his virtual assistance and enormous patience.

Finally, I could not have completed this research project without the support of all my friends and family. I want to express my gratitude to Marco, who has backed me up in all my decisions and whose love has offered me the stability in personal life necessary to pursue my ambitions. I would like to thank my parents, Ornella and Giorgio, for standing by my side and 
their loving support, and my sister, Alessia, who can't help being bewildered by my interest in studying and researching. I must also thank Lidia and Sandro, for being there every time I needed. My deepest love and gratitude go to my grandmother, Liliana, for her unconditional love. I feel blessed that I have had the opportunity to have someone special like her in my life. 


\section{Abstract}

This research project aims at studying the English and Italian legal terminology related to the area of law of victims of crime and embedded in the multi-level jurisdiction provided by the supranational legal system of the European Union (EU), on the one hand, and the British and Italian national legal systems, on the other. The main hypothesis is that legal language is inherently characterised by terminological dynamism, which emerges both at the linguistic level - with different terms used to refer to individual legal concepts - and at the conceptual level, where different conceptualisations of the same legal domain are reflected. Since the bilingual legal terminology that has been examined occurs within a judicial space in which several legal systems are interconnected, such dynamism is expected to manifest itself in two different linguistic settings. In the first, the terminology in a national and an EU variety of the same language is taken into consideration, while in the second setting, terminology is studied from a multilingual perspective.

In order to verify the main hypothesis, a methodological framework has been set out, on the basis of both the methodological premises for terminological analysis proposed by Cabré (1999a) and the distinction between genotypes and phenotypes introduced by Sacco (1991). Such a methodology required the compilation of a bilingual corpus of EU legal texts and a collection of national legal texts focusing on the figure of the victim of crime.

The examination of the terminology extracted has shown that in the first linguistic setting envisaged, intralingual dynamism is reflected in terminological variation, which can affect either the linguistic layer (denominative variation) or the conceptual layer (conceptual variation) of terminology, with denominative variation consisting in the co-existence of several terminological units in which no substantial difference in the phenotypes involved is produced, while in conceptual variation anisomorphism among the phenotypes can be observed. In both cases, all the terms affected by the phenomenon of terminological variation are related to the same genotype. A classification of denominative variation has been proposed based on four variables, i.e. degree of specialisation, time span, legal system, and legal force. Due to the methodology adopted in this research project, in which the EU legal terminology has been taken as the starting point for both the terminological analysis and the 
preliminary conceptual structuring of the legal area of the study, conceptual variation has emerged to be less frequent than denominative variation. By taking the legal system as a variable in the analysis of conceptual variation, such variation has been subdivided into intrasystemic variation, occurring within a single legal system, and inter-systemic variation, when the supranational and the national legal systems elaborate two conceptually different phenotypes which, in spite of their conceptual anisomorphism, can be linked to the same genotype.

In the second linguistic setting, where terminology is studied from a multilingual perspective, legal terminology has turned out to be characterised by different degrees of interlingual equivalence. On account of the embeddedness of the legal terminology examined in three different legal systems, different types and degrees of terminological equivalence have been identified and discussed: the types of terminological equivalence are intra-systemic and intersystemic equivalence, while the degrees of equivalence are absolute equivalence, relative equivalence and non-equivalence.

Another aim of this thesis was to record the collected terminological data in a legal translation-oriented terminological knowledge base (TKB). The terminology under discussion is characterised by a high degree of dependency on the legal system it refers to and the MuLex terminological knowledge base was specifically designed for helping the work of legal translators. This TKB aims at capturing the differences among the legal systems involved in the study and showing the peculiarities in the usage of legal terminology in such legal systems to its end users. For optimising the representation of the domain-specific knowledge implied by legal terminology, in MuLex terminographic entries integrate a tool enabling the graphic representation of the conceptual relational structures among the concepts analysed and recorded in the TKB. 


\section{AbSTRACT}

Il presente progetto di ricerca ha lo scopo di analizzare la terminologia giuridica in lingua inglese e italiana relativa alla figura della vittima di reato e radicata nello spazio giuridico europeo, caratterizzato dalla coesistenza dell'ordinamento giuridico sovranazionale dell'Unione europea (UE) e degli ordinamenti giuridici nazionali del Regno Unito e dell'Italia. Secondo l'ipotesi principale alla base del progetto, il linguaggio giuridico è intrinsecamente caratterizzato da un certo grado di dinamismo terminologico, che si esprime sia a livello linguistico, con una serie di termini utilizzati per riferirsi a uno stesso concetto, sia a livello concettuale, dove si riflettono le diverse concettualizzazioni della stessa area del diritto. Poiché la terminologia giuridica analizzata nella presente tesi si colloca in uno spazio giuridico che vede il sovrapporsi di vari ordinamenti, si presume che detto dinamismo si manifesti in due diversi contesti linguistici. Nel primo contesto, che è di tipo intralinguistico, viene presa in considerazione la terminologia utilizzata nelle varianti nazionale e sovranazionale della stessa lingua, mentre nel secondo contesto, di tipo interlinguistico, la terminologia è esaminata da una prospettiva multilingue.

Al fine di verificare la veridicità di tale ipotesi, è stata sviluppata una metodologia per l'analisi della terminologia giuridica in cui la distinzione tra genotipi e fenotipi introdotta da Sacco (1991) si unisce ai principi metodologici proposti da Cabré (1999a) per il lavoro terminografico. Per poter applicare detta metodologia è stato necessario costruire un corpus bilingue di testi dell'Unione europea e una collezione di testi di origine nazionale, entrambi incentrati sulla figura della vittima di reato.

L'analisi della terminologia estratta ha rivelato che, nel primo contesto linguistico, il dinamismo intralinguistico si riflette nella variazione terminologica, che può interessare sia la sfera linguistica della terminologia (variazione denominativa) sia la sfera concettuale (variazione concettuale). La variazione denominativa consiste nell'esistenza di più unità terminologiche per designare uno stesso concetto, che però non comporta modifiche sostanziali nei relativi fenotipi. Nel caso della variazione concettuale, invece, è possibile riscontrare un certo anisomorfismo nei fenotipi. In entrambi i casi, tuttavia, tutti i termini interessati dal fenomeno della variazione terminologica mantengono la relazione con uno stesso genotipo. Si è proposta una classificazione della variazione denominativa prendendo in 
considerazione quattro variabili, ossia il livello di specializzazione, il periodo temporale, l'ordinamento giuridico e la valenza giuridica. Visto l'approccio metodologico adottato nel presente progetto di ricerca, in cui la terminologia giuridica dell'Unione europea è presa come punto di partenza ai fini dell'analisi terminologica e della strutturazione preliminare del sistema concettuale relativo al dominio, la variazione concettuale è stata riscontrata con minor frequenza rispetto alla variazione denominativa. Nell'analisi del secondo tipo di variazione terminologica, ossia della variazione concettuale, è stata presa in considerazione un'unica variabile, ovvero l'ordinamento giuridico. In base a tale variabile, la variazione concettuale è stata classificata come intra-sistemica, qualora sia riscontrata nell'ambito dello stesso ordinamento giuridico, ed inter-sistemica, qualora l'ordinamento sovranazionale e quello nazionale elaborino due fenotipi concettualmente diversi che, a prescindere dalle divergenze concettuali, possono essere ricondotti allo stesso genotipo.

Nel secondo contesto linguistico, ovvero quello multilingue, la terminologia giuridica si è dimostrata caratterizzata da diversi gradi di equivalenza interlinguistica. Essendo la terminologia esaminata radicata in tre sistemi giuridici diversi, sono stati individuati due diversi tipi di equivalenza terminologica, ossia l'equivalenza intra- e inter-sistemica, e tre diversi gradi di equivalenza terminologica, ovvero l'equivalenza assoluta, l'equivalenza relativa e la non equivalenza.

Altro scopo della presente tesi era quello di registrare le informazioni terminologiche raccolte in una base di conoscenza terminologica orientata alla traduzione giuridica. Giacché la terminologia esaminata è caratterizzata da un alto tasso di dipendenza dall'ordinamento giuridico a cui fa riferimento, la base di conoscenza terminologica MuLex è stata concepita specificamente come ausilio alla traduzione giuridica. MuLex ha quindi lo scopo di esplicitare le differenze riscontrate tra i sistemi giuridici esaminati e spiegare le peculiarità dell'uso di tale terminologia giuridica agli utenti finali. Al fine di ottimizzare la rappresentazione della conoscenza soggiacente la terminologia giuridica, le schede terminografiche in MuLex sono dotate di uno strumento di visualizzazione che consente la rappresentazione grafica delle strutture relazionali concettuali che raffigurano i concetti analizzati registrati nella base di conoscenza stessa. 


\section{Chapter 1. INTRODUCTION}

The aim of Chapter 1 is to delineate the theoretical framework for the study of multilingual legal terminology embedded in the multi-level jurisdiction made of the supranational legal system of the European Union (EU), on the one hand, and the British and Italian national legal systems, on the other.

\subsection{TERMinOLOGY: A POLYSEMOUS TERM}

In order to provide the theoretical framework for the study of legal terminology in a multilevel jurisdiction, it is first of all necessary to understand how the term "terminology" is used in this doctoral thesis. In contemporary usage, the term "terminology" bears three different meanings (see Cabré 1999a: 32; Magris et al. 2002: i; Sager 1990: 3):

- the set of practices and methodologies applied for the collection, description and presentation of terms in one or more languages;

- the set of theoretical premises, arguments and conclusions required for explaining the relations between concepts and terms;

- the set of terms belonging to a single subject area.

According to the first meaning, terminology consists in an activity or practical application. In order to distinguish it from the second and third meaning of "terminology", in 1995 Alain Rey proposed the neologism "terminography" (Rey 1995: 129), which was in line with the existing distinction between lexicology and lexicography. In ISO Standard 1087-1 on terminology work, the term "terminology work" corresponds to what Rey called "terminography", since it is defined as the "work concerned with the systematic collection, description, processing and presentation of concepts [...] and their designations [...]" (ISO 1087-1 2000: Section 3.6.1). In the Standard, on the other hand, "terminography" is assigned a narrower meaning, being limited to the "part of terminology work [...] concerned with the recording and presentation of terminological data [...]" (ISO 1087-1 2000: Section 3.6.2). With reference to the practical activity, in this thesis the neologism introduced by Rey and the 


\section{Chapter 1}

adjective "terminographic" derived from it are used in the broadest sense, and the expression "terminographic work" is used as a synonym of "terminography".

A further terminological clarification is also needed with regard to the second and the third meaning mentioned above. In ISO Standard 1087-1, the second meaning is assigned to what is referred to as "terminology science" (ISO 1087-1 2000: Section 3.5.2), while the third meaning corresponds to a "set of designations [...] belonging to one special language $[\ldots]$ " (ISO 1087-1 2000: Section 3.5.1). In order to distinguish between the two, in this thesis the science is referred to as "Terminology" with a capital letter, while a set of terms is designated by the term "terminology" with a lowercase letter (see Faber 2009: 110).

So far, the term "term" has been used without further specification. The discussion on the definition of what a term is has played a central role in Terminology for almost forty years (see, among others, Akhmanova 1974; Cabré 1999a; Collet 2004a; L'Homme et al. 2003; Kageura 1995; Rey 1995). Originally, the discussion on the nature of terms in Terminology was focused mainly on the distinctive traits of terms as compared to words found in general language (see, for instance, Felber 1984). However, the dichotomy between words on the one hand and terms on the other has been appropriately questioned by several authors (see Cabré 2003; Kageura 2002; Picht \& Draskau 1985, among others). Therefore, for the purposes of this research study the theses proposed by Myking are applied to the study of terminology in general and individual terms in particular:

- There are no fixed boundaries between specialised communication and other forms of communication, and, consequently,

- There are no fixed boundaries between terms and the rest of vocabulary and phraseology. (Myking 2007: 74)

In line with this view, it can be stated that special language or language for special purposes (LSP) is not something substantially different from natural language, but is rather natural language used in a specific communicative setting. Since LSPs are thus sublanguages of a natural language, it follows that "[a]11 terms are words" and "term status is a matter of communicative behaviour" (Myking 2007: 83). As observed by Kageura, "[a]ny definition is controversial and provisional outside a specific context, and the validity of any definition of term should be supported by an explicitly declared theoretical standpoint and the concrete description of the phenomena based upon it" (Kageura 2002: 11). Therefore, while the provision of a general and universally acceptable definition is out of the scope of this research project, in this thesis a "term" is conceived in line with the definition provided by De Bessé, et al. (1997: 152), but taking Kageura's remarks into account as well (Kageura 2002: 10). 
Whereas a further illustration of the multidimensional character of terms is provided in Section 3.1.2, here it is sufficient to consider a term or terminological unit to be a lexical unit consisting of one or more than one lexical items which represents a concept inside a domain. The concept of 'concept', which is also a widely debated topic in Terminology, is not a major concern at the moment and is discussed in greater detail in Section 4.4.1.

\subsection{TERMinOLOGY AND PAROLE}

The beginnings of scientific studies in the terminological field in the 1930s are generally attributed to Eugen Wüster, who elaborated the first theoretical proposal in Terminology, which is nowadays known as the General Terminology Theory (GTT) or the traditional terminology theory and is further discussed in relation to terminological variation in Section 4.1.1. The standpoint adopted in the GTT is "essentially prescriptive in nature" (Faber 2009: 110), since its principles for the compilation and description of terminological data have been elaborated with a view to achieving unambiguous communication by means of the standardisation of scientific language. The standardisation purposes pursued by the GTT have been accompanied by a belief in the dichotomy between the conceptual realm and terminology in its third meaning, where concepts play a central role. In other words, "[a]ny terminology work starts with concepts" (Felber 1984: 98), and this establishes the precedence of concepts over terms, which are considered independent from the conceptual system. The terminographic work envisaged by Felber and the GTT in general is standardisation-oriented, which means that the principles elaborated by the GTT, though allegedly applicable to all types of terminological and terminographic studies, are not universal by reason of the bias posed by their scope. Within the GTT framework, the focus on concepts and conceptual systems was seen as crucial for the description and organization of terminological data. Moreover, in the GTT terminological information was conceived as an idealised, standardised version of LSP, since the aim pursued by the supporters of this theory was to eliminate all the sources of ambiguity or linguistic aspects which could hinder straightforward communication, such as synonymy and variation. Quoting Temmerman discussing Kageura's view of the GTT, it can be said that " $\mathrm{t}]$ he emphasis of traditional Terminology is on the language system (langue)" (Temmerman 2000a: 33).

The GTT can be said to have monopolised the theoretical debate for more than fifty years. However, the 1990s saw the emergence of new approaches - further analysed concerning 


\section{Chapter 1}

terminological variation in Section 4.1.2 - which started undermining the hegemony of the traditional terminology theory and "integrating Terminology into a wider social, communicative, and linguistic context" (Faber 2009: 112). Such alternative approaches have moved away from the standardisation-oriented practices supported by the GTT and acknowledged the need for theoretical frameworks allowing for the analysis of term behaviour in context (descriptive approach) rather than forcing the usage of a standardised terminology in context (prescriptive approach). By observing terms in their natural habitat, i.e. texts, descriptive approaches have contributed new perspectives on the concept of 'term' in Terminology (see Section 3.1.2) and have also led to the consideration of terminological phenomena that were neglected by the GTT, such as terminological variation, which is illustrated in Chapter 4. These theoretical approaches have also envisaged a wide variety of applications of terminography other than standardisation, such as information extraction and retrieval, where no precedence is assigned to the analysis of the conceptual system over terminological data found in authentic textual material. According to several authors (see Cabré 2003; L'Homme et al. 2003; Temmerman 2000a, among others), the alternative approaches to the GTT are:

- Socioterminology (Gambier 1991; Gaudin 1993), which integrates sociolinguistic principles in Terminology and focuses on terminological variation occurring in different social and situational contexts;

- Textual Terminology (Bourigault \& Slodzian 1999), which focuses on the real use of terminology in texts (see Condamines 2010: 46) by incorporating methods developed in the field of Corpus Linguistics;

- Communicative Theory of Terminology (CTT) (Cabré 2000), according to which terminological units "are at one and the same time units of knowledge, units of language and units of communication" (Cabré 2003: 183) and, therefore, the analysis of such units requires that the cognitive, linguistic as well as socio-communicative components of terms are accounted for;

- Sociocognitive Terminology (Temmerman 2000a, 2000b), in which insights from Cognitive Semantics on prototype structure, analogical thinking and metaphorisation are exploited for the reformulation of the concept of 'concept' and the elaboration of the concept of 'unit of understanding', which is necessary for explaining terminological variation occurring in different verbal, situational and cognitive contexts. 
In this research project, the detailed analysis of alternative approaches is not seen as essential for the analysis of legal terminology in the EU multi-level jurisdiction ${ }^{1}$. However, in the above mentioned terminology theories a common trait has been observed which is considered to be fundamental for the study presented in this thesis, i.e. the descriptive approach to terminology. Since the "termhood" (Kageura \& Umino 1996: 261) or "termness" (Myking 2007: 85) of a lexical unit can only be established on the basis of the communicative setting where the lexical unit is embedded, terms should be analysed in their natural habitat, i.e. at the textual level. This means that the shift from a prescriptive approach to terminology towards multiple descriptive approaches has also entailed a shift in focus from langue to parole (see Kageura 2002: 11-14). Since the aim of this study is to describe the behaviour of legal terminology in the EU, British and Italian legal systems, the selected approach is necessarily descriptive in nature and thus focuses on the usage of such terminology in the realm of parole.

\subsection{DYNAMISM AND TERMINOLOGY}

In Section 1.2, the differences in the prescriptive approach proposed by the General Theory of Terminology and the descriptive approaches developed ever since the early 1990s have been outlined. Given the shift in focus from langue to parole, it comes as no surprise that in the last two decades interest has grown for terminological phenomena that in the GTT framework were considered an impediment to unambiguous communication and therefore eliminated by means of standardisation. In the GTT, instances of synonymy and polysemy were seen as deviant forms of expression, while the ideal situation was represented by univocity, according to which only one term should be assigned to a concept and only one concept should be designated by a term. As stated by Cabré, "[b]y limiting its objectives to the achievement of univocity in professional communication, the GTT ignores the complexity of the interdisciplinary approach implied in its own foundation and denies the communicative needs of professionals for adequate terminological support" (Cabré 2000: 42). In such a static view of terminology, the concept-term relation can be conceived more as the result of a deliberate terminographic/standardisation activity than as a consequence of natural conceptual and linguistic evolution of a knowledge domain. Owing to the fact that the conceptual system is

\footnotetext{
${ }^{1}$ For a critical examination of the General Theory of Terminology and a discussion on alternative theories to it, see Cabré (2003), Durán Muñoz (2012), L’Homme et al. (2003) and Temmerman (2000a), among others.
} 


\section{Chapter 1}

independent from language and shared among the domain experts, in the GTT the one-to-one concept-term relation was seen as permanent and universal.

However, as proven by the alternative theories to the GTT mentioned in Section 1.2, it is very difficult to reconcile the univocity principle and the universality of concept-term relations with empirical data obtained by observing terminology at the parole level. Due to the static view on the conceptual system underlying terminology, the GTT requires a synchronic elaboration (see Felber 1984: 98). This means that, by adopting the GTT approach, not only linguistic phenomena such as polysemy and synonymy are eliminated by means of standardisation, but the possibility of observing terminological (conceptual and linguistic) evolution on a diachronic axis is hampered (Temmerman 1997: 62). On the other hand, in recent years it has been acknowledged that "all technical terminologies, even the most highly standardized ones, are also affected by basic lexico-semantic processes, such as the development of polysemy, synonymy and so on" (Fuertes-Olivera 2005: 43). In such cases, "the use of one term instead of another can reflect the knowledge, social and professional status of a group of users, as well as the power relationships between speakers" (Faber 2009: 113). Therefore, ever since the 1990s, terminology theories have accounted for the dynamism that affects terminology both at the conceptual and linguistic (parole) level. Such dynamism can be observed monolingually, in which case it is generally reflected in terminological variation, or multilingually, where it influences terminological equivalence. The phenomena of terminological variation and terminological equivalence are the keystones of this research project and are further discussed in Chapters 4 and 5 respectively. In order to examine them, a set of legal terms regarding the legal area of victims of crime as developed by the EU, British and Italian legal systems has been collected.

\subsection{LEGAL TERMiNOLOGY}

Since the terminology concerning victims of crime examined in this thesis falls into the broad category of legal terminology, in the following section the main characteristics of legal terminology in the EU multi-level jurisdiction will be presented.

\subsubsection{LEGAL LANGUAGE AS A LANGUAGE FOR SPECIAL PURPOSES}

The research study presented in this thesis consists in the examination of multilingual legal terminology embedded in the multi-level jurisdiction made of the EU supranational legal 
system and the British and Italian national legal systems. In order for the lexical units found in texts to be considered terms, the texts from which they are extracted need to reflect the characteristics of specialised communication. Therefore, for a lexical unit to be considered a legal term, the language used in the text from which it is retrieved should fall into the category of language for special purposes (LSP).

Longman's Dictionary of Applied Linguistics defines "languages for special" or "specific purposes", which are also labelled "special languages", as those languages which are "used for particular and restricted types of communication $[\ldots]$ and which contain lexical, grammatical, and other linguistic features which are different from ordinary language" (Richards et al. 1985: 159). Although this definition seems fairly clear, the first problem arises when one tries to distinguish between what belongs to LSP and what is, instead, part of ordinary language (also referred to as common language, language for general purposes or LGP). Actually, different currents of thought have developed out of the attempts to define and categorise LSPs, which range from authors who consider LSPs as almost closed linguistic systems which function autonomously from common language to authors who maintain that the main differences between LSPs and LGP are to be found in the deviations of LSPs from LGP, which are generally of a lexical/terminological nature. In this thesis, the second standpoint is supported, since for the purposes of this study LSPs are seen as sublanguages with specific communicative functions in relation to specialised domains. Such functions and the knowledge domain concerned determine the linguistic choices and, among these, the usage of a specific terminology.

The referential needs satisfied by terminology are usually considered the distinctive feature of LSPs and are generally mentioned as the first characteristic of LSPs ${ }^{2}$. However, it is practically impossible to draw a sharp dividing line between LSP terminology and LGP vocabulary and list the single items that belong to one lexical group or the other (see Section 1.1). Apart from lexical similarities, LSPs and LGPs share a great number of common linguistic features, such as syntactic and morphological characteristics. Therefore, following Schröder (1991: 4), in this study an LSP is considered to be not an alternative system to LGP, but rather a sublanguage of a total language with specific features or frequencies of occurrence that are not common to all the other sublanguages being part of the total language system. In this light, LSPs can be considered to represent "the totality of linguistic means used in a limited sphere of communication on a restricted subject in order to enable cognitive work to be done and mutual information to be conveyed by those acting in the said domain"

\footnotetext{
${ }^{2}$ See, for instance, Cortelazzo (1994) and Schröder (1991).
} 


\section{Chapter 1}

(Hoffmann 1987: 298). However, two remarks can be made. First of all, so far total language and its sublanguages have been considered within the Saussurian meaning of langue, i.e. regarding language and its sublanguages as an ideal system. Due to the textual approach adopted in this study, the legal language under examination is rather an instance of a sublanguage intended as parole (see Section 1.2). Secondly, Hoffman refers to "those acting in the said domain". When considering an LSP, a specialised domain is generally understood as a specific knowledge area in which a given socio-professional category of people, together with a group of people of variable size with a personal interest in it, are directly involved. However, between law and other knowledge domains a difference can be observed which lies in the fact that

Law permeates into every cell of social life. It governs everything from the embryo to exhumation. It governs the air we breathe, the food and drink that we consume, our travel, sexuality, family relationships, our property, the world of sport, science, employment, business, education, health, everything from neighbour disputes to war. (Slapper \& Kelly 2011: IX)

Since law permeates social life in such a profound way, "even when we are not consciously engaged with the law" (Calavita 2010: 49), legal language holds a very close relationship with LGP and is not necessarily restricted to a socio-professional community. This is so also from a terminological perspective. Due to the close relationship between legal provisions and the community regulated by such provisions, the vocabulary found in legal texts can be ascribed to three categories: purely technical terminology, i.e. the terminology used in the legal domain only, semi-technical terminology, comprising those lexical items which are part of the LGP vocabulary but acquire a technical meaning when applied to the legal domain ${ }^{3}$, and terms or words that refer to the regulated reality (see Megale 2008: 74-75, Sagri \& Tiscornia 2009: 1). Therefore, in several cases no clear-cut distinction between legal terminology and LGP vocabulary can be drawn. However, even though it is sometimes hard to determine whether a linguistic item (generally intended as a text) belongs to an LSP or the LGP, all the texts selected for the purposes of this study are considered as part of legal language intended as an LSP due to the highly specialised area of law they deal with (see also Mattila 2006: 3, Schröder 1991: 4, and Šarčević 1997: 8).

\footnotetext{
${ }^{3}$ For the distinction between purely technical terminology and semi technical terminology in legal language from a translational perspective, see Alcaraz Varó \& Hughes (2002: 153-162).
} 


\subsubsection{LEGAL TERMINOLOGY IN THE EU MULTI-LEVEL JURISDICTION}

When considering legal language in the light of LSPs, legal terminology intended as purely technical terminology "is the most visible and striking linguistic feature of legal language" (Cao 2007: 53). In this sense, legal terminology is used to refer to concepts that belong strictly to the legal domain. However, law is "entirely created by humans" and is thus "always linked to the culture of any particular society: it therefore constitutes a social phenomenon" (Mattila 2006: 105). As a consequence, legal concepts are human constructions that are bound to a specific legal system. Such a legal system is the product of a specific history and culture and, given the close relation between the legal system and culture, legal rules and concepts differ from legal system to legal system. This, in turn, affects the degree of comparability of legal systems and concepts and, consequently, the translatability of legal terminology.

Legal terms are therefore the linguistic reflection of the legal product of a certain culture. When the legal terminologies of two (or more) legal systems are compared, differences among the respective legal systems may emerge and the translatability of legal terms needs to be assessed case by case. As Gotti puts it, "legal terminology is so culture-bound (the reasons being at the same time historical, sociological, political and jurisprudential) that a satisfactory translation of all the legal terms of one text from one context to another is at times impossible" (Gotti 2007: 22-23). In such cases, only the comparative awareness of the cultural elements included in legal concepts allows for the solution of potential terminological pitfalls (see Palermo 2007: 141).

So far, the relationship between legal terminology and legal system has been approached from a national perspective, in the sense that legal systems have been seen in a traditional way as the product of a culture within national boundaries. However, the research project presented in this study does not account for only national legal terminologies, but also takes into consideration a further legal layer, i.e. the EU supranational legal system. Unlike systembound languages used in national texts, within the EU resort is made to a form of " $a$ cultural communication" (Tosi 2003: 129, emphasis in the original) which is governed by multilingualism ${ }^{4}$. Such a communication is considered acultural because it is not embedded in any of the national cultures of the EU Member States. The legal acts adopted by the EU institutions, which are meant to be applicable and enforceable in all the Member States, "must avoid culture-specific features" (Tosi 2003: 129) and, consequently, in them "concepts or terminology specific to any one national legal system are to be used with care" (European Parliament et al. 2003: Guideline 5). The already complex nature of EU lawmaking is further

\footnotetext{
${ }^{4}$ For an overview of the linguistic regime and the principle of multilingualism in the European Union, see Cosmai (2007: 1-18) and Wagner et al. (2002: 1-10).
} 


\section{Chapter 1}

complicated by the linguistic regime of EU institutions, which requires that the same content of a legal act is expressed in the 23 official languages of the $\mathrm{EU}^{5}$. This means that 23 different languages are used to express a single legal system, which is made of legal concepts that can be either derived from national legal concepts by means of re-contextualisation or developed ex novo at the supranational level. Given the constant elaboration and re-elaboration of legal notions within the EU jurisdiction, it can be said that the "European reality [is] in a constant process of creation" (Rollason 2003: 118, emphasis in the original).

When legal provisions with a supranational legal force are developed, they need to be expressed in a linguistic form which avoids possible ambiguities owing to the usage of legal terms rooted in national legal systems. For this reason, to refer to an EU concept "a supranational term which has no immediate national 'meaning' may be preferable" (Wagner et al. 2002: 64). The terminology specifically developed for designating EU concepts is sometimes considered to be a distinctive element of "Eurospeak", "Eurojargon" or "Eurocratese", frequently accused of being vague and obscure. However, in the case of EU legal drafting, the use of neologisms is determined by the need for designating new legal concepts and making the differences among the supranational and the national legal systems clear.

Another feature characterising the EU reality is the intrinsic vagueness of EU legal concepts. In general, vagueness in legal language is seen as an essential component of normative texts ${ }^{7}$. Vagueness, in this context, is seen as the flexibility needed for interpreting laws and adapting legal terms and concepts to "new or changed social and moral environments" (Sandrini 1999: 104). Therefore, vagueness is seen as the necessary bridge between abstract rules and concrete cases. However, "if this freedom becomes too far-flung there will be insecurity about the application of laws and citizens will not know what to expect from the administration of justice" (Sandrini 1999: 105). Therefore, a balance is needed between "anarchy and overregulation" (Endicott 2000: 195).

If, on the one hand, a certain degree of vagueness is to be expected in all legal texts, this is even more likely in the EU legal system. As pointed out by Kjær, "EU legal concepts are generally lacking the deep level structure of meaning otherwise characteristic of legal semantics. This renders the meaning of EU concepts inherently unstable, fuzzy, and vague"

\footnotetext{
${ }^{5}$ EU official languages are Bulgarian, Czech, Danish, Dutch, English, Estonian, Finnish, French, German, Greek, Hungarian, Irish, Italian, Latvian, Lithuanian, Maltese, Polish, Portuguese, Romanian, Slovak, Slovene, Spanish and Swedish.

${ }^{6}$ For an overview of equivalents for Eurospeak in other European languages, see Cosmai (2007: 24).

${ }^{7}$ On the topic of vagueness in legal language, see Bhatia et al. (2005), Endicott (2000), Simonnæs (2007) and Tiersma (1999).
} 
(Kjær 2007: 81). The reason for this lies in the fact that "vagueness is commonly found to be strategic to all-inclusiveness" (Polese \& D'Avanzo 2010: 94), which is necessary in the EU multi-level jurisdiction for the Member States to transpose at the national level the rules agreed at the EU level. In other words, while vagueness at the national level plays a central role in applying abstract legal provisions to concrete events, at the EU level it serves for making EU legal provisions sufficiently flexible for Member States to be able to implement them in their national legal systems.

On the basis of the observations made so far, the topic which will be examined in this thesis, i.e. legal terminology, features different characteristics due to the different legal systems involved and degrees of cultural embeddedness and vagueness of terms. Legal terminology is also influenced by the constant evolution of legal notions, which is necessary for adapting the legal systems to the ever-changing reality they are supposed to regulate and, in the case of national legal systems, the novelties introduced by the EU jurisdiction. Considering that legal terminology is thus subject to on-going conceptual development at different levels and embedded in different legal systems, and bearing in mind that legal language shares some common traits with LGP (see Megale 2008: 78-79), it is expected that some dynamism can be observed also as regards the legal terminology taken into consideration for this research project.

\subsection{AIMS OF THIS THESIS}

LSPs and LGP are part of a complex language system which is characterised by dynamism in terms of linguistic and knowledge evolution. Such dynamism can be reflected in vocabulary and, when vocabulary is attributed "term status" (Myking 2007: 83) on the basis of the communicative setting it is employed in, dynamism is expected to affect terminology as well. Looking form a terminological perspective, the study of the actualisation of lexical items featuring some termhood at the parole level constitutes a clue to the understanding of the phenomena in which the dynamic nature of language comes to light.

Legal language is a sui generis LSP due to its close relationship with the legal system it refers to and the metaphysical phenomenon it describes. Legal terms used in this LSP "are always tied to a scheme", which is the underlying legal system, and their meanings "are in the first place discernible by their relation to a legal system" (Ajani \& Ebers 2005: 12). Therefore, as noted by Sacco, "[1]a compresenza di più linguaggi giuridici in una sola lingua non è un fatto 


\section{Chapter 1}

raro" (Sacco 1992: 477), or, as Ajani and Ebers put is, "within a language there is not always a single legal language. Rather there are as many legal languages as there are legal systems" (Ajani \& Ebers 2005: 12). The co-existence of multiple legal languages expressed by a single language is generally acknowledged when taking into consideration different national legal systems expressed in the same language, such as the legal systems of Germany, Austria and Switzerland on the one hand and the UK, USA and Australia, New Zealand, Canada on the other (with due respect to the internal differences in federal countries). However, in the European continent the institution of the EU has implied the incorporation of a new supranational legal system which is expressed in the languages of the Member States and, from a legal standpoint, influences the legal systems of the Member States. It follows that a difference exists between comparing the legal languages and terminologies of different national legal systems and the legal languages and terminologies used to refer to national legal systems and a supranational legal system.

The main hypothesis in this thesis is therefore that legal language is intrinsically characterised by terminological dynamism, which is intended both at a linguistic and conceptual level. This means that the analysis of legal terminology should reveal, at a linguistic level, some heterogeneity in the terms used to refer to legal concepts, while at the conceptual level it is considered likely to reflect different conceptualisations of the legal domain. If multilingual legal terminology is observed within a judicial space in which several legal systems are interconnected at a supranational level such as in the EU, terminological dynamism is expected to manifest itself in two different linguistic settings. In the first setting, where a national and an EU variety of the same language co-exist, dynamism is considered to be intralingual and is supposed to be reflected in terminological variation, which can affect the linguistic layer (denominative variation) or the conceptual layer (conceptual variation) of terminology. On the other hand, in the second setting envisaged, legal terminology is observed from a multilingual perspective, in which case dynamism is considered interlingual. Due to the possible anisomorphism in the regulation of social life by the legal systems taken into account, such dynamism is deemed to be reflected in different degrees of interlingual equivalence.

The primary aim of this thesis thus consists in performing a terminological analysis of legal terminology rooted in the EU multi-legal jurisdiction in order to observe terminological dynamism both intralingually and interlingually. The main focus of the thesis is therefore on two specific terminological phenomena, i.e. terminological variation and terminological equivalence. The legal terminology under discussion is supposed to be characterised by 
different degrees of intralingual variation and interlingual equivalence. The methodological framework adopted for carrying out the terminological analysis has been specifically developed so as to take into account the co-existence of more than one legal system and the method proposed by Cabré for multilingual terminographic work has been taken as the starting point (Cabré 1999a: 129-159).

The secondary aim of this thesis is to record the terminological data retrieved during the terminological analysis in a legal translation-oriented terminological knowledge base (TKB). Since the terminology under discussion is characterised by a high degree of dependency on the legal system it refers to, the MuLex TKB has been specifically designed for legal translation purposes, aiming at capturing the peculiarities of the legal terminology analysed and making them available to possible legal translators. For optimising the representation of the domain-specific knowledge implied by legal terminology, this TKB integrates a tool for visualising conceptual relational structures in terminographic entries.

In order to pursue the above mentioned aims, the legal terminology of a specific area of law rather than legal language in general has been selected. The area of law under examination is therefore the legal subdomain of victims of crime. Since the primary aim of this thesis is to carry out a terminological analysis and the legal systems taken into consideration are the EU legal system and the British and Italian national legal systems, the languages involved in the study are English and Italian.

\subsection{OUTLINE OF THE THESIS}

In Chapter 2, the legal area of victims of crime is presented from a historical perspective. The discussion starts with an overview of the notion of 'victim' as conceived in international and EU documents and is followed by a presentation of such documents which are considered the milestones for the development of victim-related legislation. For the examination of international documents, four main topics are considered: the protection of victims of crime, compensation for victims of crime, the position of victims of crime in criminal proceedings and their rights, and mediation in criminal cases. As far as EU victim-related documents are concerned, first of all the reasons for considering them supranational rather than international documents are presented. This difference is highlighted because it determines a different legal force in the Member States, with EU acts having a higher impact on national legal systems than international documents. Then, three main EU acts are discussed which are the 


\section{Chapter 1}

cornerstones of EU legislation concerning victims of crime and their right, i.e. Council Framework Decision 2001/220/JHA, Council Directive 2004/80/EC and Council Directive 2012/29/EU.

In order to analyse the legal terminology concerning victims of crime, a methodological framework that takes into account the multidimensional nature of such terminology in terms of legal languages and legal systems involved is needed. The methodological framework adopted in this thesis, which merges the methodological premises proposed by Cabré (1999a) and the distinction between genotypes and phenotypes introduced by Sacco (1991), is presented in Chapter 3.

Chapter 4 is devoted to the first terminological phenomenon that was supposed to characterise legal terminology in the EU multi-level jurisdiction, i.e. terminological variation. In order to examine this phenomenon, first a review of the scientific discussion on how variation is conceived in Terminology is provided. Given the polysemy of the term "terminological variation", it is stated that in this study the term is used to refer to two correlated phenomena. The first phenomenon occurs when one and the same concept is referred to by means of different denominations (denominative variation), while the second occurs when the concept itself cannot be considered properly cleat-cut and the differences in the conceptualisation (conceptual variation) can be reflected in denominative variation.

In Chapter 5, the second main topic of this research study is presented, i.e. terminological equivalence. Given the embeddedness of the legal terminology under examination in three legal systems, different types and degrees of terminological equivalence are discussed. The types of terminological equivalence analysed are intra-systemic and inter-systemic equivalence, while the degrees of equivalence discussed are absolute equivalence, relative equivalence and non-equivalence.

The details concerning the features of the MuLex TKB are given in Chapter 6. MuLex has been developed specifically to contain terminological (linguistic and conceptual) information regarding legal terminology and is intended for legal translators. On the grounds of the peculiarities of legal terminology observed in Chapters 4 and 5, the TKB has been designed so as to make the differences among national and supranational legal notions clear and provide sufficient conceptual and linguistic information so as to assist legal translators in their decision-making and problem-solving tasks involved in the retrieval or formulation of translation equivalents. This has been possible also through the incorporation of a tool for the visual representation of conceptual knowledge. 
Introduction

Chapter 7, which concludes the thesis, consists of an overview of the achievement of the aims and suggests ideas for future work in the study of dynamism and representation of legal terminology in a multi-level jurisdiction. 



\section{Chapter 2. The AREA OF LAw: ViCTIMS OF CRIME}

As stated in the Chapter 1, the main aims of this study are twofold. Firstly, to analyse from a translational perspective the terminology used in EU documents within the legal area of victims of crime and, secondly, to compare such terminology to that available in texts on the same area of law but referring to the English and the Italian legal systems. However, before delving into the deeper aspects of victim-related terminology, some information on the historical development of this area of law needs to be provided. To do so, a brief overview is presented below of the most relevant legal documents that eventually led to the elaboration, within the EU, of a common core of measures specifically dedicated to victims of crime. The milestones of the victim-related legislation that will be presented below range from documents issued by international organisations to documents adopted by regional organisations, i.e. "formal institutions whose membership is limited by geography" (Pevehouse 2005: 3).

\subsection{THE NOTION OF 'VICTIM’ IN INTERNATIONAL DOCUMENTS}

Before presenting the documents in which crime victims play a central role, it seems appropriate to introduce the main notion underlying this thesis, i.e. the victim of crime. The number of international and supranational ${ }^{8}$ documents which, since the late 1970s, have dealt with victims of crime can be said to be relatively high ${ }^{9}$.

However, despite the increasing attention paid to the victim by international and supranational organisations and institutions (see Allegrezza et al. 2012: IX), no common notion of 'victim' has been elaborated at either the international or the supranational level so far. As a matter of fact, the two definitions that can be found at the international level are completely dependent on the notion of 'crime' (Allegrezza 2012: 12) and differ from each other according to the different aims pursued by the documents. From a chronological viewpoint, the first

\footnotetext{
${ }^{8}$ For a definition of the difference between "supranational" and "international" documents, see Section 2.4.1 below.

${ }^{9}$ For instance, according to del Tufo (2003: 708), the documents dealing with victims of crime issued only by the Council of Europe from 1977 to 2003 are as many as 40.
} 
international document focusing specifically on victims is the European Convention on the Compensation of Victims of Violent Crimes ${ }^{10}$, signed by the Council of Europe in Strasbourg on $24^{\text {th }}$ November 1983. As can be observed in the title, the Convention is not intended to address the area of law of victims of crime at large, but rather to focus on a certain category of victims, i.e. victims of violent crimes. Moreover, although this document is considered as a milestone in the evolution of the victim-related legislation, it does not contain any proper definition of the notion under discussion. Instead, in the following statement of the Preamble to the Convention the main features necessary for a person to be considered as a victim under the Convention are analytically enumerated; "for reasons of equity and social solidarity it is necessary to deal with the situation of victims of intentional crimes of violence who have suffered bodily injury or impairment of health and of dependants of persons who have died as a result of such crimes" (Council of Europe 1983). Despite not being a proper definition, this statement analytically enumerates the main features necessary for a person to be considered a victim under the Convention.

Moving from an international, though regional, dimension towards a wider international context, two years later the UN published its Declaration of Basic Principles of Justice for Victims of Crime and Abuse of Power ${ }^{11}$, signed by the General Assembly in its $96^{\text {th }}$ Plenary Meeting on $29^{\text {th }}$ November 1985. According to this Declaration, victims are: "persons who, individually or collectively, have suffered harm, including physical or mental injury, emotional suffering, economic loss or substantial impairment of their fundamental rights, through acts or omissions that are in violation of criminal laws operative within Member States, including those laws proscribing criminal abuse of power" (UN General Assembly 1985: Annex, Chapter A, Paragraph 1).

As in the case of the above-mentioned European Convention, the definition provided in the Declaration can be considered only functional to the Declaration itself, although it explicitly mentions the need for a national criminal law to be violated in order for an act to be considered as a crime under the Declaration. Moreover, just like the European Convention, the notion of victim also includes "the immediate family or dependants of the direct victim", to which the Declaration adds the "persons who have suffered harm in intervening to assist victims in distress or to prevent victimization" (UN General Assembly 1985: Annex, Chapter

\footnotetext{
${ }^{10}$ Council of Europe (1983) European Convention on the Compensation of Victims of Violent Crime, European Treaty Series, 116, 24.11.1983.

${ }^{11}$ UN General Assembly (1985) Declaration of Basic Principles of Justice for Victims of Crime and Abuse of Power, 96th Plenary Meeting, 29.11.1985.
} 
A, Paragraph 2). Therefore, in both cases the notion of 'victim' includes what in international and supranational terms is referred to as the "direct victim" and the "indirect victim".

\subsection{THE NOTION OF 'VICTIM' IN SUPRANATIONAL DOCUMENTS}

However, a different perspective was adopted some years later in the very first definition of 'victim' available in the supranational context of the European Union. The document at issue is the Council Framework Decision of 15 March 2001 on the standing of victims in criminal proceedings $(2001 / 220 / J H A)^{12}$, which clearly marked the beginning of what has been called by Allegrezza et al. (2012: IX), with an increasing priority being given by EU institutions to the needs and the rights of victims of crime.

Despite aiming at reaching high levels of both protection and harmonisation of treatment for victims of crime, the already-mentioned documents are of no directly applicable legal force for the Member States of the respective organisations. On the contrary, framework decisions, which can be used to provide for approximation of rules in criminal matters, are binding upon the Member States only as to the result to be achieved, thus leaving discretion as to the choice of forms and method (Spaventa 2007: 7).

In comparison to the Council of Europe and the UN documents illustrated in Section 2.1, the Council Framework Decision represents a further, legally-binding step towards the harmonisation process of victim-related issues within the EU Member States. According to Council Framework Decision 2001/220/JHA, a victim is "a natural person who has suffered harm, including physical or mental injury, emotional suffering or economic loss, directly caused by acts or omissions that are in violation of the criminal law of a Member State" (Council of the European Union 2001: Article 1(a)). This definition, however, diverges from the previously presented definitions insofar as it does not mention other possible persons that can be assimilated to the notion of 'victim' other than the direct victim.

Further discussion on victim-related issues within the EU, especially as far as compensation to crime victims ${ }^{13}$ is concerned, led to a later elaboration of the notion and to the formulation of a new definition of "victim" in Directive 2012/29/EU of the European Parliament and of the Council, which substitutes the definition in Council Framework Decision 2001/220/JHA

\footnotetext{
${ }^{12}$ Council of the European Union (2001) Council Framework Decision of 15 March 2001 on the standing of victims in criminal proceedings (2001/220/JHA), Official Journal of the European Communities, L 82, 22.3.2001, pp. 1-4.

${ }^{13}$ See, for instance, Commission of the European Communities (2001).
} 
(see Section 2.4.3 in this thesis). According to this definition, a victim is verbatim what Council Framework Decision 2001/220/JHA states a victim is, but it can also include: "family members of a person whose death was directly caused by a criminal offence and who have suffered harm as a result of that person's death" (European Parliament \& European Council 2012: Article 2(1)(a)(ii)), where "family members" may refer to "the spouse, the person who is living with the victim in a committed intimate relationship, in a joint household and on a stable and continuous basis, the relatives in direct line, the siblings and the dependants of the victim” (European Parliament \& European Council 2012: Article 2(1)(b)).

Therefore, even in the supranational context of the EU, the notion of 'victim' is moving towards the inclusion of both direct and indirect victims of a crime, thus converging with the international definitions, although not overcoming the close relation holding between a definition and the document containing it.

\subsection{INTERNATIONAL VICTIM-RELATED DOCUMENTS}

Ever since 1977 - the year of publication of what is considered to be the first victim-related document issued by an international organisation, i.e. Resolution (77) 27 on the Compensation of Victims of Crime of the Committee of Ministers of the Council of Europe ${ }^{14}$ the number of documents dealing with issues concerning the victims of crime has increased significantly. The documents of this type that are most relevant for this thesis are contained in the following, by no means exhaustive, list:

- the 1983 Council of Europe European Convention on the Compensation of Victims of Violent Crime;

- the 1985 United Nations Declaration of Basic Principles of Justice for Victims of Crime and Abuse of Power;

- $\quad$ the 1985 Recommendation R (85) 11 of the Committee of Ministers to Member States on the Position of the Victim in the Framework of Criminal Law and Procedure ${ }^{15}$;

- $\quad$ the 1987 Recommendation No. R (87) 21 of the Committee of Ministers to Member States on Assistance to Victims and the Prevention of Victimisation ${ }^{16}$;

\footnotetext{
${ }^{14}$ Committee of Ministers of the Council of Europe (1977) Resolution (77) 27 on the Compensation of Victims of Crime, 275th Meeting of the Ministers' Deputies, 28.9.1977.

${ }^{15}$ Committee of Ministers of the Council of Europe (1985) Recommendation No. R (85) 11 of the Committee of Ministers to Member States on the Position of the Victim in the Framework of Criminal Law and Procedure, 387th Meeting of the Ministers' Deputies, 28.6.1985.
} 
- $\quad$ the 1999 Recommendation No. R (99) 19 of the Committee of Ministers to Member States concerning Mediation in Penal Matters ${ }^{17}$;

- $\quad$ the 2001 United Nations Convention against Transnational Organized Crime ${ }^{18}$;

- $\quad$ the 2001 United Nations Vienna Declaration on Crime and Justice ${ }^{19}$.

A detailed examination of every single international document relevant to the topic under discussion is beyond the aim of this thesis. In what follows, the specific themes tackled by these documents are discussed only briefly after being grouped into four main categories: 1) the development of services providing support and assistance to victims of crime in order to improve their protection, 2) the harmonisation of State compensation, 3) the enhancement of the victim's position in criminal proceedings and the attribution of new rights to victims or harmonisation of existing rights, and 4) the establishment of alternative justice paradigms, such as mediation in the framework of restorative justice. Each of these four categories will be dealt with in more detail in the following four sections.

\subsubsection{PROTECTION OF VICTIMS OF CRIME}

Several international documents highlight the fact that victim protection should be pursued in two different ways. First, the criminal justice systems of the States involved should ensure the implementation of all the necessary measures to prevent victims from suffering from secondary victimisation, i.e. "the victimisation that occurs not as a direct result of the criminal act but through the response of institutions and individuals to the victim" (Committee of Ministers of the Council of Europe 2006: Appendix 1.3). Second, the governments of the Member States should take a series of measures that do not directly affect the criminal justice system, but are rather meant to produce changes in the public in general and in the public services specifically developed for victim assistance purposes. For example, the 1985 United Nations Declaration of Basic Principles of Justice for Victims of Crime and Abuse of Power calls upon Member States to take the necessary steps to "implement social, health, including mental health, educational, economic and specific crime prevention policies to reduce victimization and encourage assistance to victims in distress" (UN General Assembly 1985:

\footnotetext{
${ }^{16}$ Committee of Ministers of the Council of Europe (1987) Recommendation No. R (87) 21 of the Committee of Ministers to Member States on Assistance to Victims and the Prevention of Victimisation, 410th Meeting of the Ministers' Deputies, 17.9.1987.

${ }^{17}$ Committee of Ministers of the Council of Europe (1999) Recommendation No. R (99) 19 of the Committee of Ministers to Member States concerning Mediation in Penal Matters, 679th Meeting of the Ministers' Deputies, 15.9.1999.

${ }^{18}$ UN General Assembly (2000a) United Nations Convention against Transnational Organized Crime, 62nd Plenary Meeting, 15.11.2000.

${ }^{19}$ UN General Assembly (2001) Vienna Declaration on Crime and Justice: Meeting the Challenges of the Twenty-first Century, 81st Plenary Meeting, 4.12.2000.
} 
Point 4(a)). Likewise, among the international documents with a regional dimension, the 1987 Council of Europe Recommendation No. $R$ (87) 21 prompts the implementation of activities aimed at ascertaining "victims' needs and victimisation rates in order to gather the necessary data to assist in the development of victim assistance programmes and structures" (Committee of Ministers of the Council of Europe 1987: Recommendation 1). The same Recommendation also suggests taking all the necessary steps so as to ensure a sufficient degree of (medical, psychological, social and material) assistance and protection to victims, to provide assistance during the criminal process, to raise the consciousness of the public on victim-related issues, and to develop policies to identify particularly vulnerable groups and prevent their victimisation.

All these principles, together with other suggested steps to improve the victims' situation, are further developed in other international documents, among which the 2006 Council of Europe Recommendation Rec(2006)8 of the Committee of Ministers to member states on assistance to crime victims ${ }^{20}$ is worth mentioning. According to this Recommendation, Member States should take all the necessary measures so as to provide the widest form of assistance to victims, which includes the provision of assistance for their rehabilitation in the community, at home and in the workplace, medical care, material and psychological support, social care, counselling, and protection against secondary victimisation.

\subsubsection{COMPENSATION TO VICTIMS OF CRIME}

Ever since the beginning of the discussion on victims of crime at the international level, compensation has played a central role. In 1977, the Council of Europe issued the Resolution (77) 27 on the Compensation of Victims of Crime, which states that, for reasons of equity and social solidarity, it is necessary to harmonise national provisions regarding "the situation of those who are victims of crime and in particular of those who suffered bodily injury and of dependants of those who are killed by crime" (Committee of Ministers of the Council of Europe 1977: Preamble). It also states that, given that the possibilities of obtaining compensation available to victims are often insufficient, especially when the offender has not been identified or is without sufficient resources to compensate the victim(s), the compensation provided by the State "should include, in appropriate cases, at least loss of past and future earnings, increase of expenses, medical expenses, expenses of medical and professional rehabilitation, and funeral expenses" (Committee of Ministers of the Council of Europe 1977: Paragraph I(5)).

\footnotetext{
${ }^{20}$ Committee of Ministers of the Council of Europe (2006) Recommendation Rec(2006)8 of the Committee of Ministers to member states on assistance to crime victims, 967th Meeting of the Ministers' Deputies, 14.6.2006. 
Another international document which deals specifically with compensation is the 1983 Council of Europe European Convention on the Compensation of Victims of Violent Crime. Unlike the 1977 Resolution, the 1983 Convention narrows its field of application to a restricted group of victims and specifically addresses victims of violent intentional crimes. As opposed to the previously-mentioned document, the compensation provided to this specific group of victims also includes loss of maintenance for the dependants of the direct victim who died as a result of the crime. A very similar provision is contained in the 1985 United Nations Declaration of Basic Principles of Justice for Victims of Crime and Abuse of Power, which states that when full compensation cannot be obtained from the offender or other sources, States should provide financial compensation both to "[v]ictims who have sustained significant bodily injury or impairment of physical or mental health as a result of serious crimes" and "[t]he family, in particular dependants of persons who have died or become physically or mentally incapacitated as a result of such victimization" (UN General Assembly 1985: Annex A(12)).

The common core among the international documents dealing with compensation to crime victims can be said to be the basic principle that compensation should, in any case, be provided by the offender. However, in those cases when this is objectively impossible, other sources of compensation should be made available by the State (del Tufo 2003: 712).

\subsubsection{THE POSITION OF VICTIMS OF CRIME IN CRIMINAL PROCEEDINGS AND THEIR RIGHTS}

International organisations are engaged in the promotion of the implementation of measures that can either entail the organisation of society in general (e.g. by raising consciousness of the general public on victim-related issues and/or developing social and health services specifically trained to deal with victims of crime) or affect the criminal justice systems in particular. The category of measures devoted to improving the position of victims of crime in criminal proceedings can be considered to be included in the broader category of the protection of crime victims delineated earlier in Section 2.3.1 and falls into the second type of measures, i.e. those involving changes in the criminal justice system.

The main international document dealing specifically with these measures is the 1985 Council of Europe Recommendation No. R (85) 11 of the Committee of Ministers to Member States on the Position of the Victim in the Framework of Criminal Law and Procedure, which suggests that Member States should review their legislation and practices as regards the treatment of victims at different levels. 
The first level to be mentioned is the police level (Committee of Ministers of the Council of Europe 1985: Letter A), where great attention is paid to the following aspects: victim-oriented training of police officers, the information police should provide victims of crime with, and the need for clear and complete statements of the injuries and losses suffered by the victims in the reports to be delivered to the prosecuting authorities.

At the level of prosecution (Committee of Ministers of the Council of Europe 1985: Letter B), the questions of compensation to victims and the information to be provided to victims about the final decision concerning prosecution are tackled, together with their right to ask for a review of a decision not to prosecute and to institute private proceedings.

The next levels concern two different procedural steps, i.e. the questioning of the victim (Committee of Ministers of the Council of Europe 1985: Letter C), where victims with special needs are identified, and court proceedings (Committee of Ministers of the Council of Europe 1985: Letter D), where particular attention is devoted to the information that the victim needs to be provided with, the possibility for a criminal court to order compensation by the offender to the victim, and the victim's right to restitution.

The last level tackled by the Recommendation is the enforcement stage (Committee of Ministers of the Council of Europe 1985: Letter E), where victims should be assisted in the collection of any form of reparation.

The Recommendation also provides two further areas where Member States should improve their legislation and practices which, however, cannot be linked to any specific phase in criminal proceedings, but are rather relevant throughout criminal proceedings, as well as before the beginning and after the end of such proceedings. These two areas are the protection of privacy, which is needed in order to "protect the victim from any publicity which will unduly affect his private life or dignity" (Committee of Ministers of the Council of Europe 1985: Letter F), and the special protection of the victim against intimidation and the risk of retaliation by the offender (Committee of Ministers of the Council of Europe 1985: Letter G).

\subsubsection{MEDIATION IN CRIMINAL CASES}

Ever since the beginning of the discussion on victim-related issues in the international setting, mediation in criminal cases (or, rather, in penal cases, to use the expression more frequent in international documents) has been devoted considerable attention. Nevertheless, it was not before the publication of Recommendation No. R (99) 19 of the Committee of Ministers to member states concerning mediation in penal matters in 1999 that an international, though regional, document was entirely dedicated to this issue. Mediation is a participatory technique 
that falls within the broad category of restorative processes and is defined as follows by Recommendation No. $R$ (99) 19: "any process whereby the victim and the offender are enabled, if they freely consent, to participate actively in the resolution of matters arising from the crime through the help of an impartial third party (mediator)" (Committee of Ministers of the Council of Europe 1999: Point I).

The aims of restorative justice programmes in general and mediation in particular are the following: restoring community order and peace and repairing damaged relationships; denouncing criminal behaviour as unacceptable and reaffirming community values; supporting victims, giving them a voice, enabling their participation and addressing their needs; encouraging all concerned parties, particularly the offenders, to take responsibility; identifying restorative, forward-looking outcomes; preventing recidivism by encouraging change in individual offenders and facilitating their reintegration into the community (United Nations Office on Drugs and Crime 2006: 10).

In previous documents, victim-offender mediation was mentioned, for example, in Recommendation No. R (85) 11 on the Position of the Victim in the Framework of Criminal Law and Procedure, which recommended the governments of Member States "to examine the possible advantages of mediation and conciliation schemes" (Committee of Ministers of the Council of Europe 1985: Recommendation II.1). Likewise, the 1985 United Nations Declaration of Basic Principles of Justice for Victims of Crime and Abuse of Power suggested that "[i]nformal mechanisms for the resolution of disputes, including mediation, arbitration and customary justice or indigenous practices, should be utilized where appropriate to facilitate conciliation and redress for victims" (UN General Assembly 1985: Point 7). Given that in those years the disparity in the application of mediation in criminal cases among States was high and in some States mediation was still an uncommon practice, Recommendation No. $R$ (87) 21 on Assistance to Victims and the Prevention of Victimisation recommended that Member States encourage experiments (whether on a national or a local basis) in mediation between offenders and victims.

Twelve years later, in Recommendation No. $R$ (99) 19, the Council of Europe noted "the developments in Member States in the use of mediation in penal matters as a flexible, comprehensive, problem-solving, participatory option complementary or alternative to traditional criminal proceedings" and "the need to enhance active personal participation in criminal proceedings of the victim and the offender and others who may be affected as parties as well as the involvement of the community" (Committee of Ministers of the Council of Europe 1999: 10). The Council also highlighted the importance of mediation from a social 
and relational perspective, as by means of this restorative technique victims have the opportunity to express their legitimate interest, communicate with the offender and obtain apology and reparation, while offenders have more possibilities for reintegration and rehabilitation. The scope of Recommendation No. $R$ (99) 19 is to promote mediation as a generally available service which is to be considered as either complementary to traditional criminal proceedings or an alternative to them. On account of the fact that fundamental procedural safeguards should be applied to all forms of mediation - such as the right to legal assistance, to translation/interpretation and, in case minors are involved, to parental assistance - mediation as conceived in the Recommendation should be considered to be an umbrella term covering several techniques. As a matter of fact, the two main parties taking part in mediation are the (direct and indirect) victim and the offender (including the accused person), assisted by a facilitator or mediator, though participation of other (legal and physical) persons cannot be excluded. Apart from the number and type of participants, mediation can take various forms, such as: a sharing of views for better understanding between victim and offender; apology from the offender; voluntary decision by the offender to make reparation in favour of the victim or undertake some other action, such as community service work or participation in a rehabilitation programme (indirect reparation); resolution of any conflict between the victim and the offender, or even between their families or friends; an agreement on sanctions and undertakings which may be suggested as a sentence or court order (Committee of Ministers of the Council of Europe 1999: 16). Mediation in penal matters can be carried out either with the parties meeting either face-to-face or separately the mediator, who can be a professional or a trained lay volunteer, and can take place within a criminal justice agency or an independent community-based organisation.

Notwithstanding these differences, paragraph 7 of Appendix to Recommendation No. $R$ (99) 19 suggests the need for guidelines on the use of mediation in penal matters, which should take into account some essential aspects concerning mediation within the framework of criminal justice. These aspects can be summarised as follows (Committee of Ministers of the Council of Europe 1999: Appendix, Section IV): the need for the parties to be fully informed of their rights, the nature of the mediation process and the possible consequences of their decision before agreeing to mediation; the voluntariness of participation in mediation; confidentiality in mediation; the availability of mediation at all stages of the criminal justice process; the application of special regulations and legal safeguards to minors participating in mediation; the impossibility to apply mediation in case any of the parties involved is not capable of understanding the meaning of the process because of the party's age, degree of 
maturity or intellectual capacity; the constraint on using participation in mediation as evidence of admission of guilt in subsequent legal proceedings; the need to inform the competent criminal justice authorities of the state of the mediation procedure within a reasonable time-limit; the application of the ne bis in idem principle in mediation cases, and the need to take a decision as to how to proceed without delay when a case is referred back to the criminal justice authorities without an agreement between the parties or after failure to implement such an agreement.

The principles established by Recommendation No. $R$ (99) 19 constitute the basis for further discussion - at the international, supranational and national levels - on the possibility for the victim to be involved in the solution of the criminal case. The possibility for victims to participate in mediation processes shows the gradual acknowledgement by legal practitioners of crime as a conflict between individuals rather than between the offender and the State (Mantle et al. 2005: 2), which can end with an agreement between the parties involved instead of a criminal sanction (del Tufo 2003: 724).

From the victims' perspective, the expansion of the application of mediation - intended as the whole range of victim-offender reconciliation practices available in different jurisdictions proves that the awareness of criminal justice systems of victims' needs and expectations is increasing. This new paradigm, therefore, is intended to meet victims' needs and expectations both in terms of primary and secondary victimisation and, unlike traditional criminal proceedings which deal with two primary aspects of crime, i.e. the physical and the financial, aims at addressing the emotional impact of crime on direct and indirect victims as well (see Achilles \& Zehr 2001: 88).

\subsection{EUROPEAN UNION VICTIM-RELATED DOCUMENTS}

The previous section consisted in a brief overview of international documents dealing with victims of crime and four main victim-related aspects. In what follows, attention is again focused on the regulation of the area of law of victims of crime, but this time the discussion is limited to European Union documents, that is supranational documents only. Although the aim of this thesis is not the examination of the special nature of European Union law as compared to international sources of law, a terminological clarification needs to be made at this point as regards the expressions "international documents" and "supranational documents". 


\subsubsection{EUROPEAN UNION DOCUMENTS AS SUPRANATIONAL DOCUMENTS}

So far, the expression "international documents" has been used to refer to documents published by two organisations that are unanimously considered international organisations, namely the United Nations and the Council of Europe. As for the adjective "supranational", following Barents it can be said that "[it] is indissolubly linked to the early development of European integration", when "[i]t referred to a new type of organisation of relationships between European nation states which, contrary to the traditional forms of inter-state cooperation based on national sovereignty and voluntarism, would bring an end to 'age-old rivalries' and 'bloody conflicts"” (Barents 2004: 23). Although the word "supranational" cannot be found in the Treaty establishing the European Community (EC Treaty) ${ }^{21}$, nor in the Treaty on European Union (EU Treaty) ${ }^{22}$, “[i]n legal literature it is generally accepted that the Commission of the EC may be described as a 'supranational' institution" (Barents 2004: 32). The European Union documents mentioned in the present study and used to compile an EU corpus (see Section 3.3.2) can in fact be considered as supranational documents because they are drafted and issued by EU institutions and refer to a legal system of a sui generis nature. As an examination of the features that make European Union law a special legal order or system is beyond the scope of this study, let it just be said that the main difference between the international documents mentioned in the previous section and the documents that are discussed here resides in the power of issuing legally binding legal acts that the Member States recognised first to the European Communities and later to the European Union. The assignment of this power to a public legal body other than the national state implied the establishment of a new form of organisation of relationships between States which involved a restriction of their sovereignty, whereas in the participation in international bodies the sovereignty of Member States is totally safeguarded. This has important consequences for the application of EU law within Member States, since the European Court of Justice (ECJ) established two seminal principles of the EU legal order: direct effect of EU law and supremacy of EU law over national law (Craig \& De Búrca 2011: 63).

The principle of direct effect applies to all binding EU law, i.e. primary legislation (treaties) and secondary legislation (regulations, directives, decisions, opinions and recommendations; atypical acts; international and interinstitutional agreements, and agreements between Member States). In its broader sense, which is derived from the ground-breaking judgment in

\footnotetext{
${ }^{21}$ European Union (2006) Consolidated Version of the Treaty establishing the European Community, Official Journal of the European Union, C 321, 29.12.2006, pp. 37-186.

${ }^{22}$ European Union (2010) Consolidated Version of the Treaty on European Union, Official Journal of the European Union, C 83, 30.3.2010, pp. 13-46.
} 
the Van Gend en Loos v Netherlands Inland Revenue Administration ${ }^{23}$ case, 'direct effect' means that "provisions of binding EU law which are sufficiently clear, precise, and unconditional to be considered justiciable can be invoked and relied on by individuals before national courts" (Craig \& De Búrca 2011: 180). According to this judgment, contrary to other international treaties a new legal order was established in which not only Member States, but also "individuals could derive rights from the EEC Treaty” (Craig \& De Búrca 2011: 185).

As far as the principle of supremacy of EU law over national law is concerned, it must be said that no mention of it can be found in primary legislation earlier than the Declaration on the primacy of EU law was included in the 2007 Lisbon Treaty ${ }^{24}$. Nonetheless, ever since the early years of the existence of the European Community, the European Court of Justice, acknowledging the European Community's goals of integration and cooperation among the Member States, established that EU law could not be subordinate to the Member States' national law, as this would produce disparities (see Craig \& De Búrca 2011: 256-257). For this reason, "according to the ECJ, any norm of EU law takes precedence over any provision of national law, including the national constitutions" (Craig \& De Búrca 2011: 256). The beginnings of the supremacy doctrine can be said to date back to 1963 with the Van Gend en Loos case, whose primary interest was nevertheless on the establishment of the principle of direct effect. Only one year later, another ECJ case contributed to the formation of the supremacy doctrine, namely Costa $v E N E L^{25}$. According to the ECJ:

By contrast with ordinary international treaties, the EEC Treaty has created its own legal system which, on the entry into force of the Treaty, became an integral part of the legal systems of the Member States and which their courts are bound to apply.

By creating a Community of unlimited duration, having its own institutions, its own personality, its own legal capacity and capacity of representation on the international plane and, more particularly, real powers stemming from a limitation of sovereignty or a transfer of powers from the States to the Community, the Member States have limited their sovereign rights, albeit within limited fields, and have thus created a body of law which binds both their nationals and themselves.

The integration into the laws of each Member State of provisions which derive from the Community, and more generally the terms and the spirit of the Treaty, make it impossible for the States, as a corollary, to accord

\footnotetext{
${ }^{23}$ European Court of Justice (1963) Case 26/62, Judgment of the Court of 5 February 1963. Van Gend en Loos $v$ Netherlands Inland Revenue Administration, Reference for a preliminary ruling: Tariefcommissi, The Netherlands.

${ }^{24}$ European Union (2007) Treaty of Lisbon amending the Treaty on European Union and the Treaty establishing the European Community, Official Journal of the European Union, C 306, 17.12.2007, pp. 1-271.

${ }^{25}$ European Court of Justice (1964) Case 6/64, Judgment of the Court of 15 July 1964. Flaminio Costa $v$ E.N.E.L., Reference for a preliminary ruling: Giudice conciliatore di Milano, Italy.
} 
precedence to a unilateral and subsequent measure over a legal system accepted by them on a basis of reciprocity. Such a measure cannot therefore be inconsistent with that legal system. The executive force of Community law cannot vary from one State to another in deference to subsequent domestic laws, without jeopardizing the attainment of the objectives of the Treaty set out in Article 5 (2) and giving rise to the discrimination prohibited by Article 7 .

\section{$(\ldots)$}

The precedence of Community law is confirmed by Article 189, whereby a regulation 'shall be binding' and 'directly applicable in all Member States'. This provision, which is subject to no reservation, would be quite meaningless if a State could unilaterally nullify its effects by means of a legislative measure which could prevail over Community law.

It follows from all these observations that the law stemming from the Treaty, an independent source of law, could not, because of its special and original nature, be overridden by domestic legal provisions, however framed, without being deprived of its character as Community law and without the legal basis of the Community itself being called into question.

The transfer by the States from their domestic legal system to the Community legal system of the rights and obligations arising under the Treaty carries with it a permanent limitation of their sovereign rights, against which a subsequent unilateral act incompatible with the concept of the Community cannot prevail.

Given that a discussion about direct effect and the reasons justifying the supremacy of EU law over national law is beyond the aims of this section, let it be just said that these two principles, together with the transfer of sovereignty from Member States to EU institutions, are fundamental for understanding the differences between international and supranational sources of law and, therefore, between international and supranational documents. Consequently, whereas the international sources discussed in Section 2.3 aim at influencing victim-oriented policies within the Member States and fostering international cooperation in this regard, EU documents - being supranational in their nature - have a more direct impact on the Member States' legislation and, given the principle of direct effect, on the life of EU citizens.

\subsubsection{VICTIMS OF CRIME IN THE FRAMEWORK OF EUROPEAN UNION LEGISLATION}

As highlighted in the previous section, the relationship between EU law and the national legislation of EU Member States is regulated by two basic principles, namely the principle of direct effect and the principle of supremacy of EU legislation over national legislation. Notwithstanding the primacy of EU law, however, unlike national governments the institutions of the EU enjoy no general competence, which means that they cannot regulate 
every area of legal interest. Instead, EU institutions have what is generally referred to as "attributed competence", meaning that "the EU only has the competence conferred on it by the Treaties" (Craig \& De Búrca 2011: 73). Since the determination of EU competences represented a matter of no little disagreement, in order to avoid the uprising of conflicts on this issue the Treaty of Lisbon, which entered into force on $1^{\text {st }}$ December 2009, established that the limits of these competences are governed by the principle of conferral. Under this principle, "the Union shall act only within the limits of the competences conferred upon it by the Member States in the Treaties to attain the objectives set out therein", whereas "[c]ompetences not conferred upon the Union in the Treaties remain with the Member States" (European Union 2007: Article 3b(2)). Title I, Article 2A also established a categorisation of EU competences, which was absent in previous sources of EU law, and thus clarified the division of competences between the EU and the Member States. According to this categorisation, competences can be distinguished in exclusive competences, shared competences, and supporting competences.

As for exclusive competences, the EU is the only body to legislate and adopt binding acts in the fields listed in Article $3^{26}$ of the Treaty on the Functioning of the European Union $(\mathrm{TFEU})^{27}$, while the Member States are only allowed to apply these acts unless otherwise provided by the EU. As regards the shared competences listed in Article $4^{28}$ of the TFEU,

\footnotetext{
${ }^{26}$ Article 3 of the TFEU reads as follows:
}

1. The Union shall have exclusive competence in the following areas:

(a) customs union;

(b) the establishing of the competition rules necessary for the functioning of the internal market;

(c) monetary policy for the Member States whose currency is the euro;

(d) the conservation of marine biological resources under the common fisheries policy;

(e) common commercial policy.

2. The Union shall also have exclusive competence for the conclusion of an international agreement when its conclusion is provided for in a legislative act of the Union or is necessary to enable the Union to exercise its internal competence, or in so far as its conclusion may affect common rules or alter their scope.

${ }^{27}$ Council of the European Union (2010) Consolidated Version of the Treaty on the Functioning of the European Union, Official Journal of the European Union, C 83, 30.3.2010, pp. 47-199.

${ }^{28}$ Article 4 of the TFEU reads as follows:

1. The Union shall share competence with the Member States where the Treaties confer on it a competence which does not relate to the areas referred to in Articles 3 and 6.

2. Shared competence between the Union and the Member States applies in the following principal areas:
(a) internal market;
(b) social policy, for the aspects defined in this Treaty;
(c) economic, social and territorial cohesion;
(d) agriculture and fisheries, excluding the conservation of marine biological resources;
(e) environment;
(f) consumer protection;
(g) transport;
(h) trans-European networks;
(i) energy; (j) area of freedom, security and justice;
(k) common safety concerns in public health matters, for the aspects defined in this Treaty.
3. In the areas of research, technological development and space, the Union shall have 
both the EU and the Member States are authorised to adopt binding documents. When the Treaties confer on the Union a competence shared with the Member States in a specific area, the Union and the Member States may legislate and adopt legally binding acts in that area, but "[t]he Member States shall exercise their competence to the extent that the Union has not exercised its competence" and "[t]he Member States shall again exercise their competence to the extent that the Union has decided to cease exercising its competence" (European Union 2007: Article 2A). Finally, with regard to the supporting competences established by Article 6 of the TFEU, EU's intervention is limited to supporting, coordinating or complementing the action of the Member States. As a consequence, no legislative power is conferred on the EU in these fields.

The categorisation provided by the Treaty of Lisbon proves useful to understand how the main topic of this thesis, i.e. the area of law of victims of crime, is treated within the framework of EU law. In the pre-Lisbon Treaty era, the EU was characterised by what was known as the "three-pillar structure", in which the European Community constituted the first pillar, the Common Foreign and Security Policy the second pillar and police and judicial cooperation in criminal matters the third pillar. The Treaty of Lisbon abolished this complex structure together with the European Community, which was therefore replaced by the European Union. As a matter of fact, Title I, Article $2 \mathrm{C}$ of the Treaty, which determines the main areas that fall into the category of shared competences, mentions at letter (j) the so-called "Area of Freedom, Security and Justice" (AFSJ), which was introduced into European law under the Treaty of Amsterdam ${ }^{29}$ of 1997. This area "is conceived [...] as a series of policies" (Chalmers et al. 2010: 492), which are summarised in Article 67 of Title V of the TFEU. According to this article:

1. The Union shall constitute an area of freedom, security and justice with respect for fundamental rights and the different legal systems and traditions of the Member States.

2. It shall ensure the absence of internal border controls for persons and shall frame a common policy on asylum, immigration and external border control, based on solidarity between Member States, which is fair towards third-country nationals. For the purpose of this Title, stateless persons shall be treated as third-country nationals.

\footnotetext{
competence to carry out activities, in particular to define and implement programmes; however, the exercise of that competence shall not result in Member States being prevented from exercising theirs.

4. In the areas of development cooperation and humanitarian aid, the Union shall have competence to carry out activities and conduct a common policy; however, the exercise of that competence shall not result in Member States being prevented from exercising theirs.

${ }^{29}$ European Union (1997). Treaty of Amsterdam amending the Treaty on European Union, the Treaties establishing the European Communities and certain related acts, Official Journal of the European Union, C 340, 10.11.1997, pp. 1-308.
} 
3. The Union shall endeavour to ensure a high level of security through measures to prevent and combat crime, racism and xenophobia, and through measures for coordination and cooperation between police and judicial authorities and other competent authorities, as well as through the mutual recognition of judgments in criminal matters and, if necessary, through the approximation of criminal laws.

4. The Union shall facilitate access to justice, in particular through the principle of mutual recognition of judicial and extrajudicial decisions in civil matters.

As can be seen, the AFSJ covers different policy areas, which range from the management of the EU's external borders to judicial cooperation in civil and, what is more relevant to the purposes of this study, criminal matters. Since it includes police cooperation and the fight against crime, particularly as regards specific types of crime such as terrorism, organised crime, and trafficking in human beings, which are generally committed in cross-border situations, it follows that victims of crime, who are the persons who are directly or indirectly involved in the commission of a crime and suffer from its consequences, are also considered in the framework of the AFSJ.

Narrowing down the discussion on AFSJ to the current EU policies, the priorities for the area of freedom, security and justice for the period 2010-2014 are set out in the multiannual Stockholm Programme ${ }^{30}$, which is built on two previous programmes, i.e. the Tampere Programme $^{31}$ and the Hague Programme ${ }^{32}$. The Stockholm Programme is meant for addressing the challenges posed by the AFSJ in a comprehensive manner within the new legal framework developed by the Treaty of Lisbon. As can be seen from the title of the Stockholm Programme, i.e. An open and secure Europe serving and protecting citizens, the priority is to focus on the interests and needs of EU citizens. The priorities identified by the European Council in this document are the following: promoting European citizenship and fundamental rights; achieving a Europe of law and justice; achieving a Europe that protects, granting a more effective and efficient access to Europe in a globalised world; achieving a Europe of responsibility, solidarity and partnership in migration and asylum matters; and improving Europe's external dimension, i.e. its relations with non-EU countries.

In the Stockholm Programme, victims of crime are specifically addressed in Paragraph 2.3.4 entitled Victims of crime, including terrorism, although many other provisions of the Programme can be applied to victims, since they are expressly recognised as vulnerable

\footnotetext{
${ }^{30}$ European Council (2010) The Stockholm Programme - An Open and Secure Europe Serving and Protecting Citizens, Official Journal of the European Union, C 115, 4.5.2010, pp. 1-38.

${ }^{31}$ European Council (1999) Presidency Conclusions of Tampere European Council of 15 and 16 October 1999.

${ }^{32}$ European Council (2005) The Hague Programme: Strengthening Freedom, Security and Justice in the European Union, Official Journal of the European Union, C 53, 3.3.2005, pp. 1-14.
} 
persons or persons with specific needs in terms of special protection measures and assistance. Since the AFSJ must be realised throughout the EU, according to the Programme a series of measures is to be implemented so as to facilitate access to justice for all EU citizens, promote cooperation between judicial authorities and further develop the mutual recognition of court decisions in both civil and criminal cases. In order to achieve these aims, common minimum standards are progressively being adopted and implemented within the Member States for the purposes of approximating criminal and civil law procedures and enhancing police and judicial cooperation. Bearing in mind that the EU has a shared competence in the AFSJ, it seems quite evident that these actions focus more on the fight of cross-border crime than crime in general, since it is the cross-border form of crime that can be best tackled by means of supranational cooperation. Therefore, the types of crime that are specifically referred to in the Stockholm Programme are organised crime, trafficking in human beings, sexual abuse, sexual exploitation of children and child pornography, cyber crime, economic crime, corruption, counterfeiting and piracy, and drug trafficking. Thus, it is hardly surprising that EU documents relevant to the area of law of victims of crime which have been issued both before and after the Stockholm Programme, apart from dealing with victims of crime and their rights in general, also mention victims in close connection to these specific types of crimes. This is recognised by the European Commission itself, which stated that the EU has been "targeting specific groups of victims - victims of trafficking, child sexual exploitation and abuse, and terrorism" (European Commission 2011: 2-3).

Therefore, within the AFSJ and, more specifically, the framework of judicial cooperation in criminal matters, the discussion on victims of crime at the EU level nowadays finds its bedrock in two fundamental documents, namely the TFEU and the Stockholm Programme. However, from a historical perspective, the beginnings of a thorough consideration of victims' rights and victim-oriented measures can be traced back to the late 1990s, with the Presidency Conclusions of the European Council meeting in Tampere on 15-16 October 1999 and the Initiative of the Portuguese Republic with a view to adopting a Council Framework Decision on the standing of victims in criminal procedure ${ }^{33}$. Point 32 of the Conclusions of the Tampere meeting states that minimum standards should be adopted on the following topics: protection of crime victims, their access to justice and their right to compensation, and national programmes for assistance and protection of crime victims. However, it is the second document that has been mentioned which is fundamental in the study of the development of

\footnotetext{
${ }^{33}$ Portuguese Republic (2000) Initiative of the Portuguese Republic with a view to adopting a Council Framework Decision on the standing of victims in criminal procedure, Official Journal of the European Communities, C 243, 24.8.2000, pp. 4-8.
} 
EU victim-related legislation, as it gave the impulse for the drafting and adoption of Council Framework Decision 2001/220/JHA (see also Section 2.4.3). Since the aim of this thesis is to examine the terminology used in victim-related documents rather than provide an in-depth examination of the development of victim-related legislation within the EU, in the following sections three legal instruments adopted by the European Council are presented, namely a framework decision and two directives. The reason for choosing to illustrate these three instruments is that they represent the milestones of the development of EU victim-related legislation also because they deal with victims of crime in general, unlike other documents which take into account only certain types of victims of crime.

\subsubsection{COUNCIL FramewORK DECISION 2001/220/JHA}

Council Framework Decision of 15 March 2001 on the standing of victims in criminal proceedings (2001/220/JHA) represents a groundbreaking step in the elaboration of victimrelated legislation within the EU. Following the conclusions of the European Council meeting in Tampere (see Section 2.4.2), according to point 4 of the Preamble to the Framework Decision "Member States should approximate their laws and regulations to the extent necessary to attain the objective of affording victims of crime a high level of protection irrespective of the Member State in which they are present".

The title of the Framework Decision makes direct reference to the standing of victims in criminal proceedings. However, for the purposes of the Framework Decision itself, in order to consider and address victims' needs "in a comprehensive, coordinated manner, avoiding partial or inconsistent solutions which may give rise to secondary victimisation" (Council of the European Union 2001: Preamble, point 5), the provisions of the Framework Decision are not limited to the criminal proceedings, but may also extend to measures to be taken before or after the criminal proceedings to provide an appropriate degree of assistance to victims and mitigate the effects of crime (Council of the European Union 2001: Preamble, point 6). The main rights of victims that, according to the Framework Decision, required approximation were the right to be treated with respect for one's dignity, the right to provide and receive information, the right to understand and be understood, the right to be protected at the various stages of the criminal procedure and the right to have allowance made for the disadvantage of living in a different Member State from the one in which the crime was committed (Council of the European Union 2001: Preamble, point 8). Although not imposing any obligation on Member States to ensure victims are granted the same status as the other parties to proceedings, the Framework Decision recognised the difficult situation victims find 
themselves in after the commission of a crime and the need for establishing minimum rights and services that could ease such situation.

The first two rights granted to victims of crime according to Article 2 of the Framework Decision are the right to be respected for the sake of the dignity of the individual and the right to recognition of their rights and legitimate interests. The same Article also introduced another legal concept that would become a fundamental notion in the development of EU victim-related legislation, i.e. the concept of PARTICULARLY VULNERABLE VICTIMS.

In the Framework Decision, no definition for this legal concept is provided and the consequent absence of clear-cut conceptual boundaries has led to differences in the application of the provision of Article 2(2), which states that "[e]ach Member State shall ensure that victims who are particularly vulnerable can benefit from specific treatment best suited to their circumstances". Nevertheless, the acknowledgement of the existence of a so far not better identified group of particularly vulnerable victims has laid the basis for the elaboration of specific norms such as on the protection of victims of domestic violence or child abuse.

A further fundamental right is found in Article 3, which relates to hearings and the provision of evidence, and derives from the right of protection of personal dignity. Article 3 states that "[e]ach Member State shall safeguard the possibility for victims to be heard during proceedings and to supply evidence" and "shall take appropriate measures to ensure that its authorities question victims only insofar as necessary for the purpose of criminal proceedings". The objectives pursued by this Article are to avoid multiple hearings as far as possible and to limit the interfering in the victim's personal life by means of the questioning, unless this is strictly necessary to gather evidence about the crime. Hence, the provisions of Article 3 aim at reducing the risk of secondary victimisation.

Another right is regulated by Article 4, which is entirely devoted to the right to receive information. As regards this right, the Framework Decision provides a list of the minimum amount and type of information victims need to receive, which concerns the type of services or organisations to which they can turn for support and the type of support they can obtain, where and how they can report an offence, what happens after such a report is made and their role in the proceedings, how and under what conditions they can obtain protection, legal advice, legal aid or any other sort of advice, compensation, and any special arrangements available to victims who are resident in a State other than the State where the crime was committed. The same Article also provides for the possibility for victims to be kept informed of the outcome of their report, the conduct of the criminal proceedings regarding the person 
prosecuted for offences concerning them, and the court's sentence. The right to receive information is further complemented by Article 5 on communication safeguards, according to which victims having the status of witnesses or parties to the proceedings are to be granted all the necessary measures to minimise as far as possible communication difficulties concerning their understanding of, or involvement in, the relevant steps of the criminal proceedings in question.

Article 6 provides that access to specific assistance (advice and legal aid) should be granted to victims, while article 7 goes a step further and establishes that Member States shall afford victims who have the status of parties or witnesses the possibility of reimbursement of expenses incurred as a result of their legitimate participation in criminal proceedings. Given the role victims play in criminal proceedings, however, the right to legal aid and reimbursement of expenses regulated by the Framework Decision varies: when the victims are witnesses, they only have the right to expenses, whereas if they are parties to the proceedings, they are entitled to both rights.

Article 8 deals with the right to protection and establishes that each national legal system "shall ensure a suitable level of protection for victims" (Council of the European Union 2001: Article 8(1)). What seems most important here is that the right to protection, particularly concerning safety and protection of privacy, is extended also to "their families or persons in a similar position" (Council of the European Union 2001: Article 8(1)).

Looking at this provision through the lens of time, the inclusion of victims' family members and other people in a similar position seems quite interesting for two reasons. First of all, although in Article 1(a) the Framework Decision provides a definition for the term "victim" which refers to direct victims only, the right established by Article 8 can be applied also to people who are indirect victims in accordance to the national law applicable. It follows that, despite the harmonisation intent envisaged by the Framework Decision, national legal systems may anyway develop their own victim protection strategies and practices, leading to different treatments in different Member States. Secondly, this provision is relevant in view of the development of the legal concept of VICTIM within the EU, as illustrated in reference to the definition of victim in Section 2.2. Admittedly, when the term victim is used in the Framework Decision under discussion, only the direct victim of a crime is intended, while in Council Decision 2012/29/EU discussed in Section 2.4.5, the meaning of the term is broadened so as to include also the indirect victims such as family members or other people in a comparable position. 
In the discussion of the victim's right to protection, Article 8 goes one step further and establishes specific rules concerning the measures to adopt for the purposes of the court proceedings. The functions exercised by these measures are twofold: on the one hand, they are intended for protecting the privacy and photographic image of victims and their families or persons in a similar position, while on the other, they are adopted to avoid contact between victims and offenders within court premises, unless so required by criminal proceedings. Moreover, Article 8 mentions special measures for victims who are particularly vulnerable, which should be taken when the victim is asked to give evidence in open court and people other than the direct victim are considered.

Article 9 provides for the right to compensation in the course of criminal proceedings: "[e]ach Member State shall ensure that victims of criminal acts are entitled to obtain a decision within reasonable time limits on compensation by the offender in the course of criminal proceedings, except where, in certain cases, national law provides for compensation to be awarded in another manner" (Council of the European Union 2001: Article 9(1)). In accordance with this Article, the right to compensation of victims of crime shall be fulfilled by the offender in the first place and measures should be adopted so as to encourage the offender to provide adequate compensation (Council of the European Union 2001: Article 9(2)). At the same time, recoverable property which belongs to victims and is seized during criminal proceedings shall be returned to them without delay unless specifically required for the purpose of criminal proceedings (Council of the European Union 2001: Article 9(3)). Article 9 of Council Framework Decision 2001/220/JHA, together with the international documents dealing with compensation (already discussed in Section 2.3.2), lays the basis for the further development of EU legislation in the field of compensation to victims of crime, which is mainly embodied in Council Directive 2004/80/EC ${ }^{34}$ (see Section 2.4.4).

Under Article 10, penal mediation in the course of criminal proceedings shall be promoted by Member States for offences which they consider appropriate for this sort of measure and any agreement between the victim and the offender reached in the course of such mediation shall be taken into account. Unlike previous articles, Article 10 does not impose a duty to implement mediation in criminal cases on Member States, but is rather limited to promoting this form of alternative justice which, however, can be resorted to differently in the various Member States, given that they have the freedom to choose the offences for which they consider mediation in criminal cases a feasible and adequate way of solution. This means that while Article 10 of the Council Framework Decision proposes the adoption of a single

\footnotetext{
${ }^{34}$ Council of the European Union (2004) Council Directive 2004/80/EC of 29 April 2004 relating to compensation to crime victims, Official Journal of the European Union, L 261, 6.8.2004, pp. 15-18.
} 
alternative measure to proper criminal proceedings, this measure can still vary from State to State in accordance to the national legislation, thus still leading to an almost paradoxical situation of heterogeneous harmonisation.

As stated earlier, the Council Framework Decision was adopted to guarantee a higher and more harmonised degree of protection to victims, especially as regards specific types of victims (particularly vulnerable victims) and crimes (organised crime, terrorism, sexual abuse, among others). One particular case in which the EU is particularly involved, given its supranational nature, is when crimes are committed in cross-border situations, i.e. when the victim of the crime is not resident in the Member State in which the crime was committed. In such cases, Article 11 applies, according to which appropriate measures shall be taken by the competent authorities in the Member States involved (both the State in which the crime was committed and the State in which the victim is resident) so as to minimise the difficulties faced because of the cross-border situation. These measures consist of the recourse to video conferencing and telephone conference calls for the purpose of hearing victims resident abroad, the possibility for the victim to make a statement immediately after the commission of an offence and to make a complaint before the competent authorities of the State of residence if it was impossible to do so in the Member State where the offence was committed or, in the event of a serious offence, if the victim did not wish to do so (Council of the European Union 2001: Article 11(2)). After the competent authority to which the complaint is made transmits the complaint without delay to the competent authority in the State where the offence was committed, the complaint is dealt with in accordance with the national legislation of the latter State.

In order to make all the protection measures envisaged by the Framework Decision a reality, Article 12 provides for each Member State to "foster, develop and improve cooperation between Member States in order to facilitate the more effective protection of victims' interests in criminal proceedings, whether in the form of networks directly linked to the judicial system or of links between victim support organisations" (Council of the European Union 2001: Article 12). Compared to previous articles, in which Member States were provided with "clues" or minimum standards on how to reach the goals imposed by the Framework Decision, the wording of this provision is sufficiently comprehensive so as to include all sorts of cooperation between Member States without suggesting any binding form among the available ones, thus leaving the Member States ample discretion in the field of cooperation.

The following two articles focus more on the services and organisations who are directly involved in dealing with victims of crime, and the training people in contact with victims 
should receive. Article 13 provides for Member States to promote the involvement of victim support systems either through the provision of specially trained personnel within their public services or through recognition and funding of victim support organisations. These systems shall provide assistance and support to victims of crime in the context of proceedings, which, according to Article 1(d), should be broadly taken to include not only criminal proceedings, but also all contacts of victims with any authority, public service or victim support organisation before, during, or after the criminal process. In the course of such proceedings, the public services personnel or victim support organisations should fulfil specific tasks, such as providing victims with the necessary information, assisting victims according to their immediate needs, accompanying them during criminal proceedings, and assisting victims after the end of criminal proceeding, if they request so.

According to Article 14 the personnel involved in proceedings or otherwise in contact with victims shall receive suitable training, which should also pay particular attention to the needs of the most vulnerable victims, and such training shall apply especially to police officers and legal practitioners.

The last article focusing on the protection of victims is Article 15, which deals with the practical conditions regarding the position of victims in proceedings. According to this article, Member States "shall support the progressive creation, in respect of proceedings in general, and particularly in venues where criminal proceedings may be initiated, of the necessary conditions for attempting to prevent secondary victimisation and avoiding placing victims under unnecessary pressure". In order to do so, they shall pay particular attention to facilities within courts, police stations, public services and victim support organisations.

\subsubsection{CounCIL DiReCTIVE 2004/80/EC}

Still within the framework of the AFSJ introduced by the Treaty of Amsterdam in 1997, one of the objectives of the European Union is to guarantee that persons who enjoy free movement within the EU external borders are granted a certain degree of protection from harm in each Member State, regardless of what their State of residence is. For the purposes of reaching this goal, measures for facilitating compensation to victims of crimes were considered essential also following the European Council meeting in Tampere of 15-16 October 1999, where the need for the drawing-up of minimum standards on victims' rights to compensation for damages, including legal costs, was highlighted as a priority. As illustrated in Section 2.4.3, Article 9 of Council Framework Decision 2001/220/JHA focuses on the 
Member States' commitment to ensure victims of crime can collect compensation from the offender in the course of criminal proceedings.

However, another form of compensation is envisaged by Council Directive 2004/80/EC of 29 April 2004 relating to compensation to crime victims, namely compensation by the State. This Directive actually establishes a system of cooperation whose aim is to facilitate access to compensation to victims of crime in cross-border situations who are not able to receive compensation from the offender by reason of him or her either lacking the necessary means or not being identified or prosecuted. This system operates on the basis of the Member States' compensation schemes which are devoted to victims of violent intentional crimes and are supposed to guarantee fair and appropriate compensation to victims.

At the time when this Directive was adopted, in most Member States such compensation schemes were already available, as required by the European Convention on the Compensation of Victims of Violent Crimes of 24 November 1983.

In order to overcome the difficulties faced by victims because of the impossibility to collect compensation from the offender and the fact of being victimised in a country other than the State of residence, the Directive imposes the creation of a system of cooperation between the authorities of the Member States for the purpose of facilitating access to compensation in cross-border situations. In Council Directive 2004/80/EC, a cooperation system is envisaged in which applicants for compensation with reference to a violent intentional crime have the right to submit an application in the Member State of residence rather than in the Member State where the crime is committed (Article 1) and compensation shall be paid by the Member State in which the crime was committed (Article 2). In order to make this system work in practice, Member States establish or designate the so-called "assisting authority" and the "deciding authority". Assisting authorities are in charge of providing potential applicants with essential information on the possibilities to apply for compensation and the application forms, providing guidance and assistance as regards the supporting documentation, and receiving and transmitting applications. Deciding authorities are responsible for providing the assisting authority with information about the application for compensation (contact person, acknowledgement of receipt of the application, approximate time by which a decision on the application will be made), deciding upon the application and sending the decision both to the applicant and the assisting authority. Moreover, according to Article 9, the deciding authority can decide to hear the applicant or any other person such as a witness or an expert, also by means of telephone- or video-conferencing, or to receive a report of the hearing that was held by the assisting authority. 
Article 16 also calls for the appointment of a central contact point by each Member State for the purposes of establishing and publishing a manual containing all the necessary information for applicants for compensation, furthering cooperation and exchange of information between the assisting and deciding authorities in the Member States, and giving assistance and seeking solutions to any difficulties whenever necessary in relation to the content of the Directive.

\subsubsection{COUNCIL DiRECTIVE 2012/29/EU}

As already stated in Section 2.4.3, while being a milestone in the development of EU victimrelated legislation, Council Framework Decision 2001/220/JHA contained some provisions that showed the path to follow in the harmonisation process, but at the same time were too vague to produce factual effects. Under the Stockholm Programme (An open and secure Europe serving and protecting citizens), the Commission and the Member States were asked to examine how to improve legislation and practical support measures for the protection of victims. The consultations, studies and impact assessments (see European Commission 2011b: 5) which were consequently carried out aimed at verifying the actions to be performed to reach a higher degree of harmonisation within the EU and concluded that a new Directive was necessary to substitute Council Framework Decision 2001/220/JHA containing concrete obligations on the rights of victims.

On $18^{\text {th }}$ of May 2011, the European Commission issued a Proposal for a Directive of the European Parliament and of the Council establishing minimum standards on the rights, support and protection of victims of crime ${ }^{35}$. The Proposal was part of a legislative package aiming at strengthening the rights of victims of crime in the EU which also included a communication on strengthening victims' rights in the $\mathrm{EU}^{36}$ and a proposal for a Regulation on mutual recognition of protection measures in civil matters ${ }^{37}$.

The explanatory memorandum to this proposal acknowledges the improvements achieved in the area of law of victims of crime thanks to Council Framework Decision 2001/220/JHA (see Section 2.4.3), but also admits that the objectives set in it have not been fully reached. In order to offer victims of crime the widest protection possible and to assure them the right to assistance as well as support, the implementation of the minimum standards to be applied to

\footnotetext{
${ }^{35}$ European Commission (2011b) Proposal for a Directive of the European Parliament and of the Council Establishing Minimum Standards on the Rights, Support and Protection of Victims of Crime (COM (2011) 275 final).

${ }^{36}$ European Commission (2011a) Communication from the Commission to the European Parliament, the Council, the Economic and Social Committee and the Committee of the Regions. Strengtheening Victims' Rights in the EU (COM (2011) 274 final).

${ }^{37}$ European Commission (2011c) Proposal for a Regulation of the European Parliament and of the Council on Mutual Recognition of Protection Measures in Civil Matters (COM (2011) 276 final).
} 
all victims of crime throughout the EU was considered fundamental. In this case too, although victims of crime and their needs are tackled in general terms, the proposal stresses the importance of adopting measures which other EU policies can benefit from. Therefore, in the Proposal crimes such as human trafficking, sexual abuse and sexual exploitation of children, violence against women, terrorism, and organised crime, and the victims of these types of crimes are explicitly mentioned. However, despite being an object of special mention in the Proposal, the specific provisions on particularly vulnerable victims (e.g. adult and child victims of trafficking in human beings, child victims of sexual abuse, sexual exploitation and child pornography, victims of terrorism) contained in other EU documents are not affected by the envisaged directive.

After incorporating all the amendments necessary to reach a final version of the act in the Proposal, the Directive 2012/29/EU of the European Parliament and of the Council establishing minimum standards on the rights, support and protection of victims of crime, and replacing Council Framework Decision 2001/220/JHA was adopted on 25th October 2012.

As already stated in Section 2.1, this Directive contains a broader definition of "victim" compared to the definition provided in Council Framework Decision 2001/220/JHA. Other than the direct victim, this definition acknowledges the presence of other people who are often also affected by the crime and at risk of secondary victimisation, repeat victimisation or intimidation (Article 2(a)).

What is also noteworthy in Article 2(c) is that the notion of 'child' is provided with a definition. Whereas in previous acts children were generally accepted as a particularly vulnerable group, the notion of 'child' could be interpreted differently. For instance, in Council Framework Decision of 19 July 2002 on combating trafficking in human beings ${ }^{38}$, a "child victim" is to be considered a victim "under the age of sexual majority under national law" (Council of the European Union 2002: Article 3(2)(b)), while in other documents the United Nations Convention on the Rights of the Child ${ }^{39}$ of 1989 - establishing that a child is a person under the age of 18 - is recalled. Because no overall consensus on the notion under discussion could be established, the definition in Article 2(c), according to which a child is "any person below 18 years of age", represents a step further in the harmonisation of victimrelated legislation.

\footnotetext{
${ }^{38}$ Council of the European Union (2002) Council Framework Decision of 19 July 2002 on combating trafficking in human beings (2002/629/JHA), Official Journal of the European Communities, L 203, 1.8.2002, pp. 1-4.

${ }^{39}$ United Nations (1989) Convention on the rights of the child, adopted and opened for signature, ratification and accession by General Assembly resolution 44/25 of 20 November 1989 entry into force 2 September 1990, in accordance with article 49.
} 
Moreover, in Article 3 Directive 2012/29/EU further develops a right already mentioned in the Preamble to Council Framework Decision 2001/220/JHA, i.e. the right to understand and be understood. The Directive calls for communications to be given in a simple and accessible language, orally or in writing, on account of the personal characteristics of the victim, including any disability that may affect the ability to understand or to be understood (Article $3(2))$.

Article 4 on the right to receive information from the first contact with a competent authority extends the list of information victims are provided with from their first contact with a competent authority, also including their right to interpretation and translation. Again, the list presented in Article 4(1) is not exhaustive and the information offered to victims may vary on the basis of the specific needs and personal circumstances of the victim and the type or nature of the crime.

The language difficulties a victim can face in a cross-border situation are also addressed in Article 5 on the right of victims when making a complaint, since Member States shall ensure that "victims who wish to make a complaint with regard to a criminal offence and who do not understand or speak the language of the competent authority be enabled to make the complaint in a language that they understand or by receiving the necessary linguistic assistance" (European Parliament \& European Council 2012: Article 5(2)) and that "victims who do not understand or speak the language of the competent authority, receive translation, free of charge, of the written acknowledgement of their complaint [...], if they so request, in a language that they understand" (European Parliament \& European Council 2012: Article $5(3))$.

However, language issues are specifically dealt with in Article 7 on the right to interpretation and translation, which victims can exercise in accordance with their role in the relevant criminal justice system in criminal proceedings. In order to exercise this right, different communication means can be used, such as videoconferencing, telephone or the internet. Article 6 on the right to receive information about their case and Article 8 on the right to access victim support services further develop what in Council Framework Decision 2001/220/JHA was regulated by Article 4 (Right to receive information) and Article 13 (Specialist services and victim support organisations). Article 9 on victim support services establishes the minimum services which should be provided to victims: information, advice and support relevant to the rights of victims, including the right to access national compensation schemes for criminal injuries, and to their role in criminal proceedings, including preparation for attendance at the trial; information about or direct referral to any 
relevant specialist support services in place; emotional and, where available, psychological support; advice relating to financial and practical issues arising from the crime; and advice relating to the risk and prevention of secondary and repeat victimisation, intimidation and retaliation (Article 9(1)(a-e)). Compared to Council Framework Decision 2001/220/JHA, Directive 2012/29/EU contains much more detailed provisions, such as in Article 9(3), which again acknowledges the need for services tailored to meet the specific needs of certain groups of victims and sets that specialist support services develop and provide "shelters or any other appropriate interim accommodation for victims in need of a safe place due to an imminent risk of secondary and repeat victimisation, of intimidation and of retaliation" (Article 9(3)(a)) and "targeted and integrated support for victims with specific needs, such as victims of sexual violence, victims of gender-based violence and victims of violence in close relationships, including trauma support and counselling” (European Parliament \& European Council 2012: Article 9(3)(b)).

As far as the participation of victims in criminal proceedings is concerned, Directive $2012 / 29 / E U$ regulates a series of rights that victims are entitled to in the course or in the aftermath of criminal proceedings, but which are granted by procedural rules determined by national law. These rights are: the right to be heard during criminal proceedings and to provide evidence (Article 10); the right to a review of a decision not to prosecute (Article 11); the right to safeguards from secondary and repeat victimisation, intimidation and retaliation in the context of restorative justice services (Article 12); the right to legal aid for victims who have the status of parties to criminal proceedings (Article 13); the right to reimbursement of expenses incurred as a result of the victims' active participation in criminal proceedings, in accordance with their role in the relevant criminal justice system (Article 14); the right to the return of the property seized in the course of criminal proceedings, unless it is required for the purposes of criminal proceedings (Article 15); the right to decision on compensation from the offender in the course of criminal proceedings (Article 16), and the rights of victims resident in another Member State (Article 17), which are the same rights provided for by Article 11 of Council Framework Decision 2001/220/JHA.

Although in the Directive "particularly vulnerable victims" are mentioned several times throughout the text ${ }^{40}$, the act contains a chapter (Chapter 4 ) dedicated to both the protection of

\footnotetext{
${ }^{40}$ For instance, Article 10(1) explicitly refers to child victims: "Member States shall ensure that victims may be heard during criminal proceedings and may provide evidence. Where a child victim is to be heard, due account shall be taken of the child's age and maturity." On the other hand, Article 9(3) mentions victims with specific needs: "Unless otherwise provided by other public or private services, specialist support services referred to in Article 8(3), shall, as a minimum, develop and provide: [...] (b) targeted and integrated support for victims with
} 
victims in general and the recognition of victims with specific needs. As far as protection is concerned, the Directive establishes that victims and their family members should be protected from secondary and repeat victimisation, intimidation, retaliation, and the risk of emotional or psychological harm, and their dignity should be protected during questioning and testifying (Article 18). Moreover, Article 19 regulates the victims' right to avoid contact between victims and their family members and the offender within the premises where the criminal proceedings are conducted, unless in cases where the criminal proceedings require such a contact, and establishes that new court premises should have separate waiting areas for victims. As regards criminal investigations, victims are interviewed only where strictly necessary for the purposes of the criminal investigation and without unjustified delay after they made a complaint with regard to a criminal offence to the competent authority. Moreover, the number of interviews and medical examinations is kept to a minimum and interviews and medical examinations are carried out only where strictly necessary for the purposes of the criminal investigation, and victims may be accompanied by their legal representative and a person of their choice, unless otherwise established by the court. Victims are further entitled to the right to protection of their privacy, personal integrity and personal data during the criminal proceedings under the provisions of Article 21.

With regard to victims with specific protection needs, Article 22 provides for a timely and individual assessment in order to identify the victims' specific protection needs and determine whether and to what extent they would benefit from special measures in the course of criminal proceedings, depending on their particular vulnerability to secondary and repeat victimisation, intimidation and retaliation. In order to assess the victims' specific protection needs, three factors need to be taken into account, namely the personal characteristics of the victim, the type or nature of the crime, and the circumstances of the crime. Apart from these factors, Article 22 goes further in the specification of aspects to consider in the individual assessment, since other factors, such as the degree of harm suffered due to the severity of the crime and the bias or discriminatory motive which led to the crime, the victims' age or the relationship between the victim and the offender, are also considered as reasons for additional vulnerability.

Once the vulnerability of the victims is assessed, in accordance with Article 23 victims with specific protection needs are entitled to benefit from special measures during criminal investigations and the court proceedings. Such measures are, for instance, interviews carried out in premises designed or adapted for that purpose, by or through professionals trained for

specific needs, such as victims of sexual violence, victims of gender-based violence and victims of violence in close relationships, including trauma support and counselling." 
that purpose, conducted by the same persons unless this is contrary to the good administration of justice, and interviews with victims of sexual violence, gender-based violence or violence in close relationships, unless conducted by a prosecutor or a judge, conducted by a person of the same sex as the victim on victim's request. Other measures belonging to this category are measures to avoid visual contact between victims and offenders, measures ensuring that the victim may be heard in the courtroom without being present, measures to avoid unnecessary questioning concerning the victim's private life not related to the criminal offence, and measures allowing a hearing to take place without the presence of the public.

Apart from the special measures for victims with specific needs, Article 24 adds a right specifically reserved to children, i.e. the right to protection of child victims This provision rules that in criminal investigations, interviews may be audiovisually recorded and used as evidence in criminal proceedings, in criminal investigations and proceedings, in accordance with the role of victims in the relevant criminal justice system. This article also establish that competent authorities appoint a special representative for child victims where, according to national law, the holders of parental responsibility are precluded from representing the child victim as a result of a conflict of interest between them and the child victim, or where the child victim is unaccompanied or separated from the family, and where the child victim has the right to a lawyer, to legal advice and representation.

As in the case of its predecessor, i.e. Council Framework Decision 2001/220/JHA, the Directive provides for both general and specialist training of practitioners who are likely to come into contact with victims (e.g. police officers, court staff, judges, prosecutors, lawyers, providers of victim support and restorative justice services). Such training is performed for the purpose of increasing "their awareness of the needs of victims and to enable them to deal with victims in an impartial, respectful and professional manner" (European Parliament \& European Council 2012: Article 25). The Directive also takes a step further as regards cooperation between Member States compared to the Framework Decision, since in Article 26 a series of minimum standards for cooperation is set which shall include the exchange of best practices, the consultation in individual cases, and the assistance to European networks working on matters directly relevant to victims' rights. As noted above with reference to other articles, also in this Article groups that are particularly at risk such as children, victims of gender-based violence and violence in close relationships are explicitly mentioned. 



\section{Chapter 3. METHODOLOGY}

In Chapter 1 the main aim of the research project has been described, i.e. the creation of a collection of English and Italian terms that reflects the behaviour of the terminology referring to the area of victims of crime in context, while Chapter 2 illustrated such an area of law as conceptualised in the EU multi-level jurisdiction. This chapter illustrates the methodology employed for carrying out the research project presented in this thesis.

\subsection{THE METHODOLOGICAL FRAMEWORK}

In order to elaborate an appropriate methodology for the analysis of the terminology under examination, three preliminary remarks have been made on the type of terminographic work to be undertaken, the object of study, and the order of the phases to be followed in the methodology.

\subsubsection{THE TYPE OF TERMINOGRAPHIC WORK}

The aim of the study is to carry out a descriptive terminographic work on the terminology used in the EU multi-level jurisdiction in the area of law of victims of crime. In order to analyse the terminology used in this specific subdomain, an approach falling into what Picht and Draskau (1985: 175) called the first "constellation" of the possible solutions for undertaking a terminographic task has been chosen. In the first setting envisaged by the researchers ${ }^{41}$, the terminographic work is accomplished by a terminologist with linguistic training with the support of an expert adviser in the phases of text selection, validation and revision. The research project can also be considered as a new project, in the sense that it consists in a "[f]irst-time elaboration of a subject field" (Picht \& Draskau 1985: 176). A further specification should be made in relation to the type of terminographic work that has been carried out in this project. The terms related to the area of law under discussion here,

\footnotetext{
${ }^{41}$ The other two possible settings mentioned by Picht and Draskau (1985: 175) are: 1) a group of terminologists working with an expert adviser in multilingual projects, and 2) a group of experts and a terminologist with linguistic training as adviser on matters concerning language.
} 


\section{Chapter 3}

which have been collected and analysed following the methodology presented in this chapter, have also been recorded in a terminological resource that was specifically designed to fulfil the needs and expectations of a specific group of end users, i.e. legal translators, thus allowing for the recording of the peculiarities of legal terminology. For the purpose of identifying such peculiarities, a terminological perspective that is far from prescriptive has been adopted. As the approach to the analysis is textual, the methodology used in this project 1) allows for the examination of the terminology as it is actually used in context, and 2) makes it possible to record the collected terms in a descriptive way, so as to provide pragmatic information on how they are used in context (parole).

It goes without saying that, by adopting a textual approach, the starting point of the analysis is a collection of texts, i.e. a corpus. Though meant to be as exhaustive and comprehensive as possible, the terminological analysis is thus limited by two main factors: 1) all the terms that are analysed were extracted from a corpus which is by definition limited as regards word tokens and types, and, 2) as the area of law chosen for the analysis concerns victims of crime, the terms examined necessarily needed to have a semantic relation with this main topic. By adding other texts to the textual material analysed, new terms and/or term variants can always be found, since "[n] ew texts are always on the horizon" (Teubert 2005: 13). Hence, new term clusters and new terminographic entries can be created. In other words, although the aim was to provide an exhaustive overview of the terminology used in the legal sphere concerning victims of crime, the limits of the analysis are to be found in the constraints posed by the very adoption of a textual approach for the analysis of a textual corpus.

\subsubsection{THE OBJECT OF STUDY}

In order to understand how a term is conceived within this research project, it is necessary to take into account the criticism of the General Terminology Theory (GTT) by terminology theories ever since the early 1990s. In the traditional view of terminology, any terminographic work should be carried out starting from the analysis of the conceptual system - being considered as language-independent - in order to achieve the standardisation of the terms used within a specialised field of knowledge which is deemed to be necessary for reaching unambiguous communication. However, as several terminologists have pointed out (see Bourigault \& Slodzian 1999; Bowker 1998; Merkel 1998; Sager 1990; Temmerman 2000a, among others), such an approach to terminology is only one of the possible approaches to the study of the vocabulary of a specialised domain. The traditional approach leads to disregarding the actual behaviour of terms in context in favour of a "permanent assignment of 
a term to a concept" (Collet 2004a: 100). In this view, terminology should adhere to the principle of univocity, which consists of a "one-to-one reference between term and concept" (Faber 2009: 110).

However, as Collet critically points out, "if the meaning of a term is a language-independent concept, it follows that the term is a context-independent lexical item, i.e. a lexical item that always conveys the same meaning whatever the linguistic context in which it is employed" (Collet 2004a: 100). The traditional tenet contrasts also with language evolution, which affects both language for general purposes and language for special purposes and is necessary for assuring the evolution of meaning: several studies have been carried out which have questioned the permanent assignment of a term to a concept and the impossibility for the meaning of a term to be altered in discourse (see, for instance, Bowker \& Hawkins 2006; Cabré 2006; Condamines et al. 2004; Fernández-Silva et al. 2011; Picton 2011; Tartier 2003; Temmerman 1997). Moreover, as Collet notes, "if a term is assigned to a languageindependent concept on a permanent basis, it follows that the term is a label, i.e. a linguistic object that is so static that it refuses any modification of its relationship to this concept, even if this modification only concerns its linear structure" (Collet 2004a: 101). In regard to the formal aspect of terminology, several empirical studies have proved that terms are not immutable when used in discourse, but rather adapt to the cotext and the context they appear in (see Freixa 2002; Kerremans 2010; Messineo 2002, to name a few).

It can be therefore concluded that the univocity principle is a utopian tenet posed by the GTT rather than an empirically verifiable aspect of terminology, since terms are subject both to conceptual and formal variation (for a more detailed discussion on terminological variation see Chapter 4). In the light of the results of empirical studies on the behaviour of terms in their natural habitat, i.e. texts, the concept of 'term' as developed by the traditional terminology theory needed revision on the assumption that terms play "two distinct roles: as names of concepts in specific domains and as words in discourse" (Condamines 2010: 45). In Cabré's words,

Terms, like words in the general language lexicon, are distinctive and meaningful signs which occur in special language discourse. Like words, they have a systematic side (formal, semantic, and functional) since they are units of an established code; they also have a pragmatic side, because they are units used in specialized communication to refer to the objects of the real world. Terms do not seem to be very different from words when we consider them from the formal or semantic point of view; they differ from words when we consider them as pragmatic and communicative units. (Cabré 1999a: 81) 
Therefore, when the behaviour of a term in context is taken into consideration and a textual approach is adopted for its analysis, such as in this study, the most appropriate definition of "term", which has already been briefly discussed in Section 1.1, is that provided by Collet:

The term is:

- A semantically charged linear structure, which names an abstract or a concrete reality studied by a special-subject field;

- When used in a special text, it plays a dynamic and important part in the bringing about of text coherence and of text cohesion;

- This contribution to text coherence and to text cohesion may translate into variability both on the level of its meaning content and of its linear structure, especially if its linear structure is syntactically transparent;

- This variability may lead to polysemy on the one hand, and signals on the other hand that terms exhibiting syntactic transparency are, in fact, paradigms, i.e. sets of all the possible forms the linear structure can have in a text. (Collet 2004a: 109)

\subsubsection{THE ORDER OF THE METHODOLOGICAL PHASES}

The methodological framework developed for this study (see Section 3.3) is based on the methodology proposed by Cabré (see Section 3.2), though the steps envisaged by Cabré have been adapted to the peculiarities of the legal terminology embedded in the EU multi-level jurisdiction. The main reasons for modifying such steps and resorting to additional ones (from Step 2 to Step 5 presented in Figure 3.2) are extralinguistic: the precedence of EU law over domestic law and the innovation brought about by EU legal provisions in the legal subdomain of victims of crime compared to national legal provisions (see Section 2.4.1). Given this precedence, the EU corpus (see Section 3.3.2) has been taken as the starting point for the terminographic work and the terminology extracted from it has been considered to be the reference for identifying national terminology (see Section 3.3.5).

\subsection{CABRÉ'S METHODOLOGICAL FRAMEWORK}

The reference point for finding a methodology suitable for reaching the aims of this research has been the methodological model proposed by Cabré (1999a: 129-159) for "[t]erminological work done on a large set of terms belonging to the same subject field in a single language" (Cabré 1999a: 130). For this specific type of terminographic work, the author envisages at least six different stages, which are summarised in Figure 3.1 below. 
Though Cabré's method is designed for systematic searches in strictly monolingual contexts, this apparent contrast with the purpose of the present study - which is meant to be carried out on a bilingual basis - is overcome by Cabré herself, when adding that in "systematic multilingual searches" all the steps envisaged for monolingual searches are followed for each language involved and the starting point for this type of searches is "multiple, whereas the end point is unitary" (Cabré 1999a: 151).

With regard to the methodology proposed by Cabré, a further remark should be made. The scholar's methodology is applied to what she refers to as "systematic searches" (Cabré 1999a: 129), i.e. searches that "cover the terms of an entire special subject field or a subpart thereof" (Cabré 1999a: 129). Consequently, although the methodology selected for this study is based on Cabré's proposal, the limits posed by the textual approach (see Section 3.1.1) and the type of corpus (see Section 3.3.2) chosen as the starting point for the terminographic work make the type of work carried out here more similar to what Cabré calls "ad-hoc searches", i.e. searches that "are restricted to a single term or a small set of terms belonging to a subsection of a subject field, or to a group of terms belonging to different fields" (Cabré 1999a: 129).

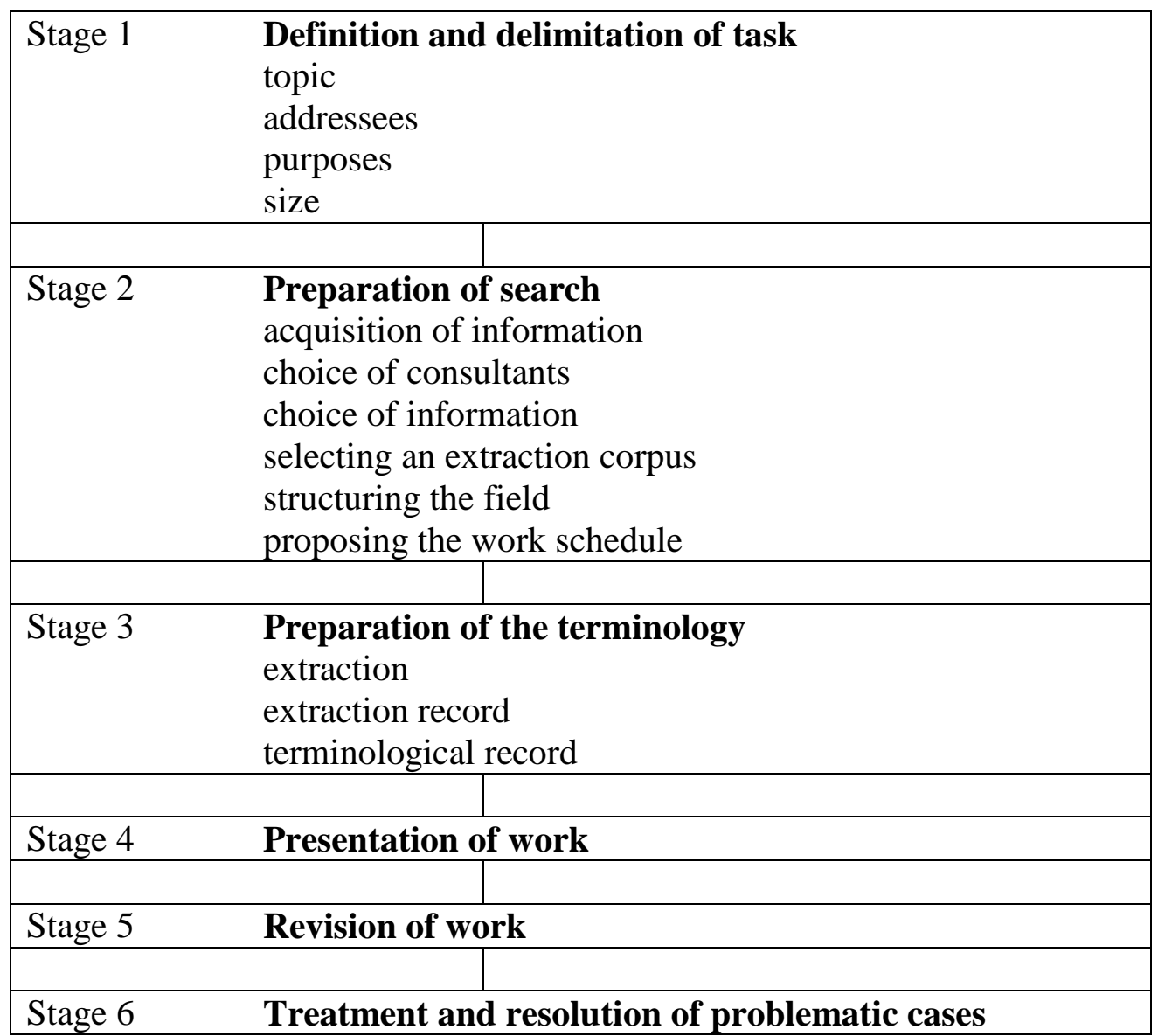

Figure 3.1. Stages followed in a systematic monolingual terminological work according to Cabré (1999: 131). 
The relevance of Cabré's methodological model to this study is also provided by its being embedded in the Communicative Theory of Terminology (CTT) (Cabré 1999b, 2000), which accounts for the most relevant aspects of modern terminology theories: the communicative element of terminology, terminological variation, the usage of corpora in terminographic tasks, and the need for adapting the methodology in order to take the end users' needs and the terminology's practical application into account. However, there are two main differences between Cabré's methodology and the methodology adopted here. The first is the final aim of the methodology, which in Cabré's case has been developed specifically for building comprehensive terminological collections or at least compile sets of terminographic records, while in this research is the study of two specific phenomena, i.e. terminological variation and equivalence in a multi-level jurisdiction. The second difference concerns the conceptual structuring of the field, which is carried out differently in the two methodological approaches (see Sections 3.3.1.3 and 3.3.6.3). Despite these differences, however, Cabré's methodology has served as a guiding light for the formulation of the methodological approach adopted in this study.

\subsection{METHODOLOGICAL FRAMEWORK FOR THE ANALYSIS OF MULTILINGUAL TERMINOLOGY IN THE EU MULTI-LEVEL JURISDICTION}

The following sections provide a step-by-step account of the methodology followed to obtain the results presented in Chapters 4 and 5. Before discussing these steps, the aims for which this methodological framework has been developed need to be briefly summarised. This research project consists in the terminographic analysis of a collection of textual material concerning the legal subdomain of victims of crime with the main aim of organising the linguistic and conceptual data related to the extracted terminology in a translation-oriented terminological knowledge base (TKB). In order to do so, a methodological framework is being proposed for carrying out a terminographic work leading to a collection of terminological data to be subsequently recorded in resources specifically designed for translators. This same methodology can also be adopted by translators themselves as a basis for the ad hoc terminological tasks they carry out in their everyday professional life.

Though the focus of the study is on the observation of terminology as used in vivo (see Dubuc \& Lauriston 1997: 85 and Cabré 2000: 45), i.e. as it is actually used in texts, to achieve a clear 
and exhaustive picture of the victim-related terminology the study cannot do without an in vitro analysis of the selected data against the existing terminographic/lexicographic resources. The methodology used for the study of terminology in vivo can be divided into seven main steps, which are further analysed in the following sections and summarised in Figure 3.2.

\section{DEFINITION OF THE TERMINOGRAPHIC WORK AND THE AREA OF KNOWLEDGE \\ 1.1 Definition of the pragmatic and linguistic variables (area of knowledge, addressees, languages and terminology, scope) \\ 1.2 Choice of IT tools, reference materials and consultants \\ 1.3 Acquisition of information about the area of knowledge \\ 1.4 Preliminary frame-based conceptual structuring of the area of knowledge}

\section{COMPILATION OF THE EU CORPUS}

2.1 Design of the parallel corpus

2.2 Retrieval of documents

2.3 Organisation and classification of texts

\section{TERMINOGRAPHIC PROCESSING OF THE EU PARALLEL CORPUS}

3.1 Semi-automatic extraction of candidate terms

3.2 Terminological analysis

\section{SELECTION OF NATIONAL COMPARABLE TEXTS}

\section{TERMINOGRAPHIC PROCESSING OF NATIONAL COMPARABLE TEXTS}

5.1 Selection of terms and terminological variants

5.2 Terminological analysis

\section{POPULATION OF A TRANSLATION-ORIENTED TERMINOLOGICAL KNOWLEDGE BASE}

6.1 Term clustering

6.2 Cross-linguistic term matching

6.3 Conceptual (re)structuring of the area of knowledge

\section{REVISION AND VALIDATION}

Figure 3.2. Stages followed in the terminological analysis of multilingual terminology in a multi-level jurisdiction.

\subsubsection{STEP 1. DEFINITION OF THE TERMINOGRAPHIC WORK AND THE AREA OF KNOWLEDGE}

The first step, i.e. the definition of the terminographic work and the area of knowledge, can be further divided into the following tasks: 
1.1. definition of the pragmatic and linguistic variables (area of knowledge, addressees, languages, scope);

1.2. choice of IT tools, existing terminological/lexicographical/encyclopaedic material and consultants;

1.3. acquisition of information about the area of knowledge;

1.4. preliminary frame-based conceptual structuring of the area of knowledge.

Each task is further discussed in the following sections.

\subsubsection{DEFINITION OF THE PRAGMATIC AND LINGUISTIC VARIABLES}

The pragmatic and linguistic variables established at the beginning of the terminographic work are the area of knowledge, the addressees, the languages, and the scope.

\subsection{DEFINITION OF THE AREA OF KNOWLEDGE}

Following Cabré (1999a:130), before starting a terminological search authors must first define the topic they want to address and then the end-user of the terminographic work. For the purpose of widening the knowledge on the behaviour of legal terminology in a multi-leveljurisdiction, a legal subdomain different from police cooperation in Europe (see Peruzzo 2006/2007) was needed, which:

a) was relevant both for the EU and the national legal systems involved (English and Italian),

b) was relatively new from a European perspective,

c) was sufficiently self-contained, at least within the EU, so as to allow for the collection of a limited but at the same time relatively high number of representative texts to build a corpus,

d) proved problematic from a terminological/translational perspective.

The choice has thus fallen on the area of law of victims of crime, as this legal subdomain meets almost all the requirements mentioned above. In fact, the topic of the standing of victims in criminal proceedings has been at the fore in debates within the EU institutions ever since the year 2000, when the Portuguese Republic submitted an initiative with a view to adopting a Council Framework Decision on the standing of victims in criminal procedure (Portuguese Republic 2000). Since then, this area of law has regained its status as a cuttingedge topic also at the national level, owing to the fact that national legislators are obliged to transpose and enforce EU legal acts into their own legal systems. As for the third requirement above, given that the emergence of major interest in this subdomain at the EU level can be dated back to 2000, the number of EU documents available on this topic is still limited and 
allows for terminographic work to be carried out by a single terminographer. Finally, the fulfilment of the last requirement above could not be established a priori, as the problematic nature of certain phenomena in terminological/translational terms can only be evaluated by means of analysis. However, a general tendency to consider legal terminology as a problematic element in the translation process has been observed in several authors (see Garzone 2000, Mattila 2006, Sagri \& Tiscornia 2009, Sandrini 1996 and Šarčević 1997, among others).

\subsection{DEFINITION OF THE ADDRESSEES}

The methodology adopted to analyse the terminology of a specialised domain changes according to both the end-users of the terminological repository where the terms are recorded and the function it is meant for in connection with the end-user. By way of example, it is not the same thing to carry out a descriptive study on the lexical variants used to refer to specific forms of bread in a given country as part of an ethnographic study and to use a prescriptive terminological method to standardise the terminology used by technical drafters for the products of a company bakery. Since the aim of this study is to examine legal terminology from a translational perspective and build a terminological knowledge base (TKB) suitable to contain the terminology analysed, the end-users envisaged in the study are professional translators who need multilingual terminological reference tools during their translation tasks. For this reason, the purpose is different from the scope for which other kind of resources containing legal terminology are built for, such as legal encyclopaedias and bilingual or multilingual legal resources, which are not created for translational purposes. Whereas the latter are designed so as to include as much encyclopaedic information as possible to serve both as a reference and knowledge acquisition tool, the purpose of the TKB developed in this study is threefold: 1) provide the essential information needed by translators to understand the meaning of the term they are looking for, 2) find a proposal for an equivalent term in another language, and 3) find all other possible information that can be useful in the determination of the most suitable equivalent, while at the same time keeping to a minimum the information load, the cognitive effort and the time spent in searching.

\subsection{DEFINITION OF THE LANGUAGES AND THE TYPE OF TERMINOLOGY}

Given the aims described in Section 3.3, the TKB that has been built in this study is populated with terminology that:

a) is bilingual (English and Italian), though rooted in a multi-level jurisdiction, which gives rise to intra- and inter-systemic variation (see Section 4.5.4); 


\section{Chapter 3}

b) concerns a specific legal subdomain, i.e. victims of crime;

c) contains both single-word and multi-word terms;

d) contains only nouns.

The reasons for focusing only on nouns are explained in the next two paragraphs and follow from the classification of terms operated by Cabré (1999a: 85) on the basis of four criteria: form, function, meaning and origin. From a strictly formal point of view, terms can be classified according to the number and type of their constituent morphemes, the combination of words following a syntactic structure to form a "terminological phrase" (Cabré 1999a: 85) and the like. From a functional point of view of the terms in discourse, the author classifies terms according to the grammatical category they belong to, i.e. nouns, adjectives, verbs and adverbs, and Cabré herself also states that there is a clear imbalance in the proportion of terminological units belonging to one or the other grammatical category, with the number of nouns being "highly disproportionate in relation to the number of adjectives or verbs" (Cabré 1999a: 87).

However, the choice of this research to concentrate only on nouns is more specifically based on the assumption that the terminology related to the main topic of the study can be mainly assigned to two of the categories identified by Cabre (1999a: 87-88) on the grounds of meaning, i.e. objects or entities and actions, both expressed by nouns. According to the features they share and the relationships they hold with one another, terms can in fact "be classified by the class of concept they designate" (Cabré 1999a: 87$)^{42}$. Within a specialized domain, concepts are organised in conceptual systems, i.e. collections of mental representations of the world. Conceptual systems are generally further organised into more or less rigid structures or concept fields. The terminology collected for this study falls into three concept fields (see Section 6.4.1.1.1), identified both by English and Italian labels according to the language the terms examined pertain to:

a) persons involved in criminal justice/soggetti della giustizia penale (e.g. VICTIM ${ }^{43}$, CROSSBORDER VICTIM and APPLICANT FOR COMPENSATION);

b) harm and damage suffered by victims of crime/pregiudizi subiti dalle vittime di reato (e.g. CRIMINAL DAMAGE, CRIMINAL INJURY and MATERIAL LOSS);

3) rights of victims of crime/diritti delle vittime di reato (e.g. COMPENSATION, MEDIATION and RESTORATIVE JUSTICE).

\footnotetext{
${ }^{42}$ The author initially recognises four main conceptual classes, each of which is generally expressed by a specific grammatical class: objects or entities (nouns); processes, operations and actions (verbs, nominalisation of verbs); properties, states and qualities (adjectives); relationships (adjectives, verbs and prepositions).

${ }^{43}$ In this thesis, terms included in the MuLex terminological knowledge base (Chapter 6) are indicated in italics, whereas the concepts designated by such terms are shown in uppercase.
} 
These three concept fields created for an easier management of the database are in fact suitable for classifying mainly concepts that identify objects or entities (e.g. APPLICATION FOR COMPENSATION, PARTICULARLY VULNERABLE VICTIM, EUROPEAN NETWORK OF NATIONAL CONTACT POINTS FOR RESTORATIVE JUSTICE) and - though only occasionally - actions, which are in any case generally expressed by means of a nominalised verb (e.g. SECONDARY VICTIMISATION). This explains why the terms selected to be included in the collection all fall into the grammatical category of nouns.

However, this does not mean that the other grammatical categories listed by Cabré (see Footnote 42) are missing from the collection. In fact, when examining legal terminology two grammatical categories come to the fore and require particular attention in the design of a translation-oriented terminological resource: verbs and adjectives. Despite their relevance from a translational perspective, however, they are not awarded the status of autonomous terms in this study. Verbs (as well as prepositions, though being less numerous) are generally dealt with as constituents of collocations, so they can be found in the "Phraseology" field of the TKB (see Section 6.4.1.2). For example, collocations such as to enforce, execute, forward, issue, receive, recognise, request, transfer, withdraw a European protection order can be found in the terminological record dealing with the concept EUROPEAN PROTECTION ORDER. As for adjectives, in the terminology examined here they fulfil a different function when compared to the classification proposed by Cabré (1999a: 88): while on the one hand the researcher suggests that adjectives are used to designate mainly properties, states and qualities, which is also the case in the victim-related terminology, on the other it should also be noted that adjectives cannot be considered as self-standing terms, because they are only meaningful with regard to the nouns accompanying them. Taking as an example the term particularly vulnerable victim, the presence of an adjective and an adverb not only qualifies the type of victim but also changes the type of treatment and services the victim is entitled to according to Article 2(2) of Council Framework Decision 2001/220/JHA. By the same token, in the terms pecuniary loss and non-pecuniary loss the adjective is fundamental for qualifying the type of loss suffered by the victim and the type of compensation s/he is entitled to, thus determining the procedure to be followed and the parties involved.

Among the criteria for classifying a term, Cabré (1999a: 88-90) also lists linguistic origin and formation patterns (e.g. derivation and conversion), which in fact are deemed superfluous in this study given the predominantly synchronic approach to terminology that has been adopted. 


\section{Chapter 3}

\subsection{DEFINITION OF THE SCOPE}

The aim of the terminographic work carried out in this study is to provide a terminological resource specifically designed for legal translators. For this reason, and owing to the fact that the legal terminology to be collected and presented in the TKB has domain-specific peculiarities, a proposal for a new TKB is presented (see Chapter 6) which accounts for both aspects. In this study, the terminographic work is carried out not only to collect the data relevant to the terms extracted, but also to identify the peculiarities that can be ascribed to the multi-level jurisdiction in which the selected terminology is embedded. By doing so, the design of the TKB can be better customised according to both the needs and expectations of the end-users and the peculiarities of the terminology under examination.

\subsubsection{CHOICE OF IT TOOLS, REFERENCE MATERIALS AND CONSULTANTS AND ACQUISITION OF INFORMATION ABOUT THE AREA OF KNOWLEDGE}

Since the textual material analysed is mainly stored in electronic format (and therefore processable by software), appropriate tools are needed to carry out the terminological analysis described in Sections 3.3.3 and 3.3.5. For the purposes of this study, three types of software have been selected: a concordancer, a term extractor and a terminology management system. The concordancer has been used for creating word lists and word clusters to support the term extraction phase, for searching the phraseology related to the extracted terminology and for spotting definitions and contexts, while the term extractor was useful for identifying candidate terms. Several freeware and commercial tools are available which make the above-mentioned operations possible. However, among them two open-access tools have been selected, namely AntConc and TermoStat Web 3.0, which are further discussed in Sections 3.3.3.1.1 and 3.3.3.1.2 respectively.

In regard to the terminology management system, the open-access solutions available did not seem to fit the purpose of this study of representing linguistic and conceptual information in terminographic entries that include a visual representation system for the conceptual information. Several attempts have been made to exploit some freely available visual representation tools and ontology editing tools ${ }^{44}$ to represent the conceptual structures obtained after identifying the conceptual relations between two or more concepts. However, all the tools tested for this purpose have been discarded because they were not sufficiently flexible to include both terminological and conceptual data referring to a multi-level legal

\footnotetext{
${ }^{44}$ Attempts to visualise the conceptual structures have been made by using concept mapping tools, such as CmapTools (http://cmap.ihmc.us/), EdrawMindmap (http://www.edrawsoft.com/freemind.php) and FreeMind (http://freemind.sourceforge.net/wiki/index.php/Main_Page), as well as the ontology editor Protégé (http://protege.stanford.edu/).
} 
system. In other words, in the attempts made with concept mapping tools, difficulties have been encountered in creating a separate concept map for each legal system under study and linking such conceptual maps with complex terminographic entries containing term clusters created on the basis of the genotype-phenotype distinction (see Section 3.3.6.1).

The same problems have also been faced when trying to adapt the functions of an ontology editor to terminographic needs. In this case two different solutions have been envisaged: either creating an ontology containing only genotypes shared by all the legal systems taken into consideration and specifying the differences among the systems in the relevant terminographic entries, or building a separate ontology for each legal system. In the first case, the visualised ontology would have been unique for all the legal systems, thus not allowing for anisomorphism to be easily identified by the end user in the visualisation system. For example, by inserting the concept VICTIM in a shared ontology, it would not have been possible to represent the distinction between the concepts PERSONA OFFESA DAL REATO and DANNEGGIATO typical of the Italian national legal system, thus leading to a rather simplified conceptualisation of the national system. In the second case, two separate ontologies would have been created and mapped to individual terminographic entries, with a consequent duplication of data in case of correspondence. This is the case, for instance, of the concepts developed by the EU legal system and imported into Member States' national legal systems, such as ASSISTING and DECIDING AUTHORITY. Another difficulty was represented by the need of linking the output obtained by either concept mapping tools or ontology editors with the data stored in the terminographic entries of a terminology management system and presenting both types of information (visual-conceptual and terminographic) via a single graphic user interface (GUI). Therefore, instead of resorting to already existing concept mapping and ontology editing tools, on the one hand, and terminology management systems, on the other, a TKB with an integrated visualisation system has been developed in which conceptual and linguistic information concerning the EU multi-level jurisdiction can be stored and presented in a translation-oriented GUI. The features of the MuLex TKB are illustrated in Chapter 6.

The acquisition of information about the area of knowledge is closely related to the choice of reference materials and consultants. Broadly speaking, reference materials are "the documents terminologists use to obtain background information on theoretical, methodological, practical or bibliographical aspects on the subject" (Cabré 1999a: 117). Though such materials can include also documents on documentation, such as bibliographies, and documents on methods (Cabré 1999a: 117), in this case documents on the selected area of law are considered, since they are a source of knowledge for the terminologist and "[p]ractical work in terminology 


\section{Chapter 3}

requires that a terminologist knows enough about the field in question" (Cabré 1999a: 118). Hence, reference materials have been selected consisting mainly in academic works, manuals for law students ${ }^{45}$, papers focusing on victim-related topics ${ }^{46}$ and legal encyclopaedias.

The process of acquiring additional knowledge on the subfield has benefitted from constant consultation with Professor Mitja Gialuz ${ }^{47}$, an expert on the subject of victims of crime. The involvement of a lawyer in the knowledge acquisition and validation process has been felt as a necessity, since "the expert is a source of fresh and updated information that can be used to broaden, explain, comment on and confirm more reliably the information object of terminological analysis" (Quiroz et al. 1999: 170). Finally, the knowledge acquisition process has also been promoted by attending an academic course in Italian criminal proceedings in the academic year 2010/2011 held at the Faculty of Law of the University of Trieste.

\subsubsection{PRELIMINARY FRAME-BASED CONCEPTUAL STRUCTURING OF THE AREA OF KNOWLEDGE}

On the basis of the information gathered by means of the reference materials mentioned in Section 3.3.1.2 and the knowledge acquired in the subject field, a preliminary conceptual structuring of the legal area of victims of crime has been carried out following the principles of Frame Semantics (Fillmore 1976, 1985). Such preliminary conceptual structuring was necessary for identifying the frame or conceptual template of occurrence of the concepts typical of this area of law and subdividing the area into narrower concept fields, which provide the initial scheme for the classification of concepts. Since these concept fields make up an individual field in MuLex terminographic entries, they are illustrated in greater detail in Section 6.4.1.1.1.

\subsubsection{STEP 2. COMPILATION OF THE EU PARALLEL CORPUS}

The second step, i.e. the compilation of the parallel corpus, is further subdivided into the following tasks:

2.1. design of the parallel corpus;

2.2. retrieval of texts;

2.3. organisation and classification of texts.

\footnotetext{
${ }^{45}$ Among others, Ashworth \& Redmayne (2005) for English, and Tonini (2010) for Italian.

${ }^{46}$ Among others, McEwan (2009) and Lewis (2001) for English, and Baldry (1998) and Mannozzi (2000) for Italian.

${ }^{47}$ Professor Mitja Gialuz, Department of Legal, Language, Translation and Interpreting Studies (IUSLIT), University of Trieste.
} 


\subsubsection{DESIGN OF THE PARALLEL CORPUS}

In order to carry out the terminographic work envisaged in Section 3.3, an approach that is based on textual terminology, i.e. "terminology based on real use in texts" (Condamines 2010: 46), has been adopted. For this reason, a preparatory stage was needed to collect the textual material to build a corpus, which is nowadays considered to be "the default resource for almost anyone working in linguistics", as "[n]o introspection can claim credence without verification through real language data" (Teubert 2005: 1). Several definitions of "corpus" are available in Corpus Linguistics and the reader is invited to refer to Pearson's overview (Pearson 1998: 42-43). Following Pearson's argumentation, in this study a corpus is an artefact - a "cross-section" of discourse (Teubert 2005: 4) - which is defined as "a collection of pieces of language that are selected and ordered according to explicit linguistic criteria in order to be used as a sample of the language" (Sinclair 1994: 2, quoted in Pearson 1999: 22). In addition to Sinclair's definition, however, in order for the collection to be a corpus in a modern sense, the naturally occurring pieces of language should be stored in electronic format (Zanettin 2002: 10) and also be used as a "representative of a given language, dialect, or other subset of language" (Francis 1979: 110). In this study, however, the "pieces of language" correspond to texts which were considered both in their full and a reduced form (see Section 3.3.2.3.1).

Following Clear (1992: 29), the selection of the texts to be included in a corpus should be based on external rather than internal criteria, in order to ensure that the linguistic characteristics of corpus data are kept independent of the selection process (McEnery et al. 2006: 14). External criteria are "essentially nonlinguistic" (Clear 1992: 29, emphasis in the original) and "concern the participants, the communicative function, the occasion and the social setting" (Pearson 1998: 52). Following Pearson, "there is no generally applicable set of design criteria for the compilation of special purpose corpora" (Pearson 1998: 41). Therefore, the design of the parallel corpus for this study has taken into account an internal criterion and different external criteria, which are described below.

\subsection{INTERNAL CRITERION}

Although at the beginning of the corpus-driven research of the texts to be included in the corpus external criteria were granted much more attention than internal criteria, in the last two decades two parameters falling into the latter have attracted increasing interest, i.e. topic and style (see Pearson 1998: 53). Given that in Section 3.3.1.1.1 it was stated that the object of the analysis is the area of victims of crime, the texts to be included in the corpus need to deal with this topic. As for the style of the texts, it is contended here that style can only be identified by 


\section{Chapter 3}

analysing the already compiled corpus rather than before its construction. For this reason, the style of the texts making up the corpus, whose register can be expected to be rather formal, has not been considered as a text selection criterion.

\subsection{EXTERNAL CRITERIA}

The compilation of a corpus is generally based on a series of external criteria, such as size, range of language varieties, time period covered and mode (Pearson 1998: 50). As the ways of compiling a corpus vary according to the scope of the corpus or the research to be performed on it, the external criteria taken into consideration may vary significantly. In this study, the following external criteria have been considered: time period, authors, origin, languages and technicality.

The time period the selected texts belong to is determined by the internal criterion determining the compilation of the corpus, i.e. the topic: the area of knowledge chosen for the study has been intensively dealt with by EU institutions since the publication of Council Framework Decision 2001/220/JHA. However, an earlier document ${ }^{48}$ has been selected due to its relevance to the area of law under discussion. Therefore, the publication date of the latter (1998) has been chosen as the starting point for the harvesting of victim-related texts from the EUR-Lex website. For the sake of precision, it needs to be said that the closing date for the collection of texts does not coincide with the end of the discussion on victim-related issues at the supranational level, as it is still on-going, but has been imposed by the time constraints of the $\mathrm{PhD}$ programme.

In the original design of the EU corpus, the envisaged authors of the texts were the EU institutions, among which the most prominent and most prolific in document production were expected to be the European Commission, the European Parliament, the European Council and the European Court of Justice (ECJ). With the only exception of judgments given in cases heard by the ECJ, where the names of the members of the Court - and therefore of the drafters - are known, all the other texts were assumed to be the result of a co-drafting process, with the authors coinciding with the EU institution publishing the document. However, this initial assumption has been reconsidered in the text selection phase, as other texts have been selected which are written by Member States or rapporteurs ${ }^{49}$. Despite the heterogeneity of

\footnotetext{
${ }^{48}$ European Council \& Commission of the European Communities (1999) Action Plan of the Council and the Commission on how best to implement the provisions of the Treaty of Amsterdam on an area of freedom, security and justice - Text adopted by the Justice and Home Affairs Council of 3 December 1998, Official Journal of the European Communities, C 019, 23.1.1999, pp. 1-15.

${ }^{49}$ See, for instance, Opinion of the Committee of the Regions on "The Stockholm programme: Challenges and opportunities in view of a new multi-annual programme on the EU area of freedom, security and justice", Official Journal of the European Union, C 79, 27.3.2010, pp. 37-44.
} 
their authors, all the texts deal with the same topic from a European perspective and therefore the geographic area which they belong to falls within the borders of the European Union. Moreover, the languages under examination in this study are English and Italian, meaning that the texts included in the EU corpus are necessarily written either in English or in Italian.

Apart from these criteria, in order to compile a corpus also formal and textual criteria should be taken into account (Durán Muñoz 2012: 181). The formal criterion refers to the degree of specialisation of the texts and the type of channel and medium used. In this regard, the texts included in the parallel corpus are limited to specialised texts, as less specialised texts published by the EU institutions, such as press releases on institutional websites ${ }^{50}$ and informative brochures and booklets available at EU informative points have not been taken into consideration in this study (for the classification of text types see Section 3.3.2.3.2.1). However, although the texts selected are considered to be specialised due to the topic they deal with and the technical knowledge of the author(s), they are not necessarily intended as a form of expert-to-expert communication. In fact, they are published on an open access website so as to be available to the general public, thus assuming heterogeneous technical knowledge on the part of the potential readership. Moreover, all the texts are in written form (written to be read) and are made available on the Internet in different formats (.doc, .html, .pdf, and .rtf) ${ }^{51}$.

As for the textual criterion, given that the guiding principle for the selection of the texts to be included in the corpus was their topic, no text type was established a priori, since the terminology related to victims of crime was supposed to be scattered in different text types (see also Biber 1993: 245).

Another criterion that is generally considered necessary in corpus design is the function of the texts. As in the case of text type, given the scope of the study and due to the fact that the leading principle for the selection of texts was their topic, their function could not be established before the texts were actually collected. Texts extracted from the EUR-Lex database are in fact designed to fulfil different functions, which range from the most strictly normative to more informative functions. Therefore, no specific function could be chosen as a text selection criterion and the function of the texts selected was identified a posteriori.

\footnotetext{
${ }^{50}$ See, for instance, http://europa.eu/newsroom/index_en.htm, http://www.europarl.europa.eu/news/en/pressroom/, http://www.consilium.europa.eu/press?lang=en.

${ }^{51}$ Although the texts retrieved on the Internet are available in different electronic formats, in order to make them processable by different software tools they have been converted into plain text format (.txt).
} 


\section{Chapter 3}

\subsubsection{RETRIEVAL OF DOCUMENTS}

The area of law of victims of crime is undergoing a large-scale revision and harmonisation process within the EU, which is progressively changing the national legal scenarios. The legal provisions which result from the EU law-making process and the terminology used in such provisions are therefore likely to influence national legal systems and their terminology. Owing to these relatively intense activities of law-making, consultation and reporting - which are still on-going within the EU institutions - text selection has not been a straightforward process, with all the texts making up the corpus being collected in a time span that started in January 2010 and ended in July 2012, and the earliest document included in the corpus dating back to $1998^{52}$ and the latest to $2012^{53}$ (the whole list of documents included in the EU corpus is available in Annex 1).

In this regard, before moving on with the thesis, a terminological issue needs to be addressed concerning the distinction proposed by Schubert and Link between texts and documents which has been employed here: "[w]hilst the term text focuses attention on the linguistic content of a written utterance no matter what its shape or form, the concept of the document comprises both the textual content and its mode of presentation to readers" (Schubert \& Link 2008: 139140). A document is thus considered as "a fixed oral or written text, including nonverbal components, which can be reread or reheard at any time" (Schubert \& Link 2008: 140). Bearing this distinction in mind, the material selected to build the corpus originally fulfilled the requirements imposed by the definition of "document", but after converting the selected documents in the format required by the software used to process them semi-automatically, the study was carried out on texts rather than documents.

The texts included in the EU parallel corpus have been retrieved primarily by using the simple and advanced search functions on the EUR-Lex website ${ }^{54}$. The text retrieval phase has been prompted by the initial suggestion provided by the subject field expert (see Section 3.3.1.2) to start from the document that is nowadays considered to be the cornerstone for EU victimrelated policy, namely Council Framework Decision of 15 March 2001 on the standing of victims in criminal proceedings (2001/220/JHA). Taking this document as the starting point for the retrieval and selection phases, two methods have been applied, the first exploiting cross-references and the second keywords.

\footnotetext{
${ }^{52}$ See footnote 48 .

${ }^{53}$ European Parliament \& Council of the European Union (2012) Directive 2012/29/EU of the European Parliament and of the Council of 25 October 2012 Establishing Minimum Standards on the Rights, Support and Protection of Victims of Crime, and Replacing Council Framework Decision 2001/220/JHA, Official Journal of the European Union, L 315, 14.11.2012, pp. 57-73.

${ }^{54}$ Available at http://eur-lex.europa.eu/en/index.htm.
} 
In the first method, the cross-references in the texts have been used to search for other documents dealing with the same topic. For instance, in Council Framework Decision 2001/220/JHA the Initiative of the Portuguese Republic with a view to adopting a Council Framework Decision on the standing of victims in criminal procedure is referred to, which has been included in the EU corpus. The same procedure has been followed to find more references to other domain-specific documents in newly added documents. However, in all EU documents also documents are recalled that constitute the legal basis for the legal instrument being adopted but are too general in comparison to the legal subfield under examination. In several documents included in the EU corpus, for instance, reference is made to the Treaty of Lisbon, which deals with manifold topics and refers only briefly to victims of crime in Article $69 \mathrm{~A}(2)(\mathrm{c})$. Owing to the relative scarcity of textual material devoted to the subfield of victims of crime in such documents, less documents have been chosen compared to the total amount of documents touching on the main research topic. Apart from the EU documents mentioning only marginally victims of crime, also non-EU documents are recalled in EU texts. For instance, in Recital 9 of Directive 2011/36/EU $U^{55}$, reference is made to the 2000 United Nations Protocol to Prevent, Suppress and Punish Trafficking in Persons, Especially Women and Children, supplementing the United Nations Convention against Transnational Organised Crime ${ }^{56}$ and the 2005 Council of Europe Convention on Action against Trafficking in Human Beings ${ }^{57}$. Without denying the importance of non-EU documents in the recent advances in the standing of victims within EU Member States, this study aims at providing a collection of EU and national victim-related terms. Therefore, these documents have not been taken into consideration for the compilation of the corpus, although it cannot be excluded that the terminology found in EU documents has been influenced by the terminology employed in other supra- or international documents.

In the second method, keywords have been used for document retrieval. As in the case of cross-references, Council Framework Decision 2001/220/JHA has been taken as the starting point. The terms in it that have been considered relevant to the topic, ranging from simple single-word terms such as victim to more complex multi-word terms like victim support organisation and mediation in criminal cases, have been used as keywords in the word search

\footnotetext{
${ }^{55}$ European Parliament \& Council of the European Union (2011) Directive 2011/36/EU of the European Parliament and of the Council of 5 April 2011 on preventing and combating trafficking in human beings and protecting its victims, and replacing Council Framework Decision 2002/629/JHA, Official Journal of the European Communities, L 101, 15.4.2011, pp. 1-11.

${ }^{56}$ UN General Assembly (2000b) United Nations Protocol to Prevent, Suppress and Punish Trafficking in Persons, Especially Women and Children, supplementing the United Nations Convention against Transnational Organised Crime, 15.11.2000.

${ }^{57}$ Council of Europe (2005) Convention on Action against Trafficking in Human Beings, Council of Europe Treaty Series, 197, 16.5.2005.
} 


\section{Chapter 3}

function available on the EUR-Lex website ${ }^{58}$. Again, the number of EU documents retrieved in such a way has increased substantially, resulting far higher than the actual number of documents focusing specifically on victims of crime. For this reason, documents that were only marginally relevant to the main subtopic have been discarded and not included in the corpus.

The two methods described above have been applied to both languages under examination, which means that both cross-references and keywords have been used either in English or Italian and, when a new document was retrieved in one of the two languages, the corresponding version in the other language was also searched in the EUR-Lex database. However, not all the documents were available in both languages, as is further explained in Section 3.3.2.3.

Before moving on to the details of the corpus used for the terminographic work, two remarks need to be made at this point. Firstly, due to the flexible approach adopted for document retrieval and the period of time when this task has been performed, the data analysed in the different stages of the research varied on the basis of the different size of the corpus as regards the number of documents and content. Consequently, terminological data such as definitions, contexts and phraseology have been collected in a variable linguistic context. However, in order to assure that the data recorded in the TKB were up-to-date, every time a new document was added the text was analysed in order to identify possible new definitions or information to be added to the existing definition or other data already recorded (e.g. new phraseology). Secondly, although the documents have been collected at different points in time and the analysis of the texts started before the document retrieval task was completed, all the data discussed in this thesis actually refer to the final version of the corpus.

\subsubsection{ORGANISATION AND CLASSIFICATION OF TEXTS}

The EU corpus consists of two subcorpora, an English subcorpus and an Italian one, both corresponding to the definition of "subcorpus" provided by Atkins et al., i.e. a subset of a corpus which constitutes "a static component of a complex corpus" (Atkins et al. 1992: 1). The complex bilingual EU corpus under examination also falls into what Hunston calls a "specialised corpus", as it is "used to investigate a particular type of language" (Hunston 2002: 14), which is also referred to as "domain-specific, special language or sublanguage corpus" (Vintar 2008: 44). As the EU corpus is designed to cover just one domain and is built for the specific goal of extracting victim-related terminology from it, it is also a special-

\footnotetext{
${ }^{58}$ Available at http://eur-lex.europa.eu/RECH_mot.do?ihmlang=en. 
purpose corpora, i.e. "a corpus whose composition is determined by the precise purpose for which it is to be used" (Pearson 1998: 48). In this regard, the EU corpus is also meant to be "representative of the domain in terms of the text types contained and the currency of the texts" (Vintar 2008: 44).

As stated in the previous section, the data presented here refer to the final version of the corpus. As regards the origin of the documents that constitute the EU corpus, they are to be considered as equally authentic versions of the same document due to the principle of equal authenticity of texts (Athanassious 2006: 9). In the EU context, "no single text (not even the original) should prevail in the event of an ambiguity or textual diversity between the various language versions" (Šarčević 2000), and such parallel texts are presumed to be "equal in meaning, effect and intent" (Šarčević 2000). Owing to the obligation to conform to the principle of equal authenticity in order to preserve multilingualism within the EU, it would seem difficult to subsume the corpus compiled for this study into the category of parallel corpora, as in Corpus Linguistics a parallel corpus is generally defined as "a corpus that contains some source texts and their translations" (McEnery \& Xiao 2007: 20). However, following McEnery and Xiao, parallel corpora can be not only bilingual or multilingual, but also unidirectional, bidirectional or multidirectional and, by adhering to the equal authenticity principle, EU texts can be said to make up a parallel corpus (see Hunston 2002: 15; McEnery \& Xiao 2007: 20).

The EU corpus used for this study is itself a subcorpus of the broader multilingual and multidirectional EU parallel corpus containing all the documents produced by the EU institutions in the 23 official languages and available online ${ }^{59}$. However, dealing with the entire EU corpus, regardless of the area of law or the subject matter of the documents in it, and with all the official languages of the EU was beyond the scope of this research project. For all the reasons above, the EU corpus compiled for this study is:

a) specialised, as it deals with the area of law of victims of crime;

b) special-purpose, as it is intended for extracting terminology related to victims of crime to populate a translation-oriented TKB;

c) parallel, as it is made of equally authentic documents;

d) bilingual, as the documents are written either in English or Italian;

e) multidirectional, as there is no original, source language version.

59 Access to EU documents is granted on http://eur-lex.europa.eu/en/index.htm and http://ec.europa.eu/transparency/regdoc/registre.cfm?CL=en, which have been also used to retrieve the texts selected to compile the EU corpus. 


\section{Chapter 3}

\subsection{SIZE AND STRUCTURE}

After the two-tiered document retrieval process presented in Section 3.3.2.2 and the final approval of the list of selected documents by the lawyer, a final version of the EU corpus was reached, the details of which are presented below and summarised in Table 3.1. Distribution of number of documents and types and tokens in the EU corpus.

EU corpus

EU English subcorpus

EU Italian subcorpus

\begin{tabular}{lcc}
\hline total number of documents & $\mathbf{7 4}$ & $\mathbf{7 0}$ \\
\hline tokens (with footnotes) & $\mathbf{4 7 5 , 8 7 8}$ & $\mathbf{4 7 3 , 9 2 9}$ \\
types (with footnotes) & 11,068 & 14,890 \\
tokens (without footnotes) & 455,140 & 456,951 \\
types (without footnotes) & 10,487 & 14,293 \\
\hline
\end{tabular}

Table 3.1. Distribution of number of documents and types and tokens in the EU corpus.

While the whole list of selected texts is available in Annex 1, it is worth highlighting that the number of selected documents for the EU English subcorpus is higher than the number of EU Italian documents. Multilingualism is a "new field of Commission policy that promotes a climate that is conducive to the full expression of all languages, in which the teaching and learning of a variety of languages can flourish" (European Commission 2005: 3) and one of the aims of the Commission's multilingualism policy is "to give citizens access to European Union legislation, procedures and information in their own languages" (European Commission 2005: 3). Because EU legislation is directly binding on EU citizens, it is their right to be able to communicate with the EU institutions and access EU legislation in one of the $23 \mathrm{EU}$ official languages. However, in regard to multilingualism, in his recent Opinion in Case C-160/03 (Spain v Eurojust) of 16.12.2004, Advocate General Maduro stated that it is necessary to accept restrictions to the principle of linguistic diversity in practice - which must in any case be limited and justified - so as to meet the imperatives of institutional and administrative life. In Maduro's Opinion, a three-way distinction is drawn among communications between EU institutions and EU citizens or Member States, administrative procedures of EU institutions, and rules on the internal functioning of EU institutions (Athanassious 2006: 12-13). While the first type of communications deserve the highest adherence to the principle of multilingualism, in the second type of documents administrative 
requirements may bring about certain restrictions to the linguistic rights, as long as the interested parties "have been put in a position where they can properly take note of the position of the institution concerned" (European Court of Justice 2004: Paragraph 44). Finally, in the last type, EU institutions are responsible for choosing "the language to be used for internal communication purposes" (European Court of Justice 2004: Paragraph 46). Therefore, even in a linguistic regime governed by the principle of multilingualism there may be cases where not all the documents issued by EU institutions are available in all the 23 official languages. This is actually the case of the EU corpus compiled for this study: compared to the EU English subcorpus, the Italian subcorpus contains four documents less which were not available in Italian at the time of the document retrieval. The reason for this difference is to be found in the linguistic regime adopted by the EU, which tries to balance the linguistic rights of EU citizens and Member States with the optimisation of communication procedures within the EU institutions.

The corpus is therefore made of 74 documents in English and 70 documents in Italian, for a total of 475,878 word tokens and 11,068 word types in the former and 473,929 word tokens and 14,890 word types in the latter ${ }^{60}$. In Table 3.1, two figures for each data type are presented for the two subcorpora, as footnotes have been deleted from the corpus. In other words, the first group of figures reported in the table refers to the corpus made of whole texts as downloaded from the above mentioned websites, while the second group of figures refers to the corpus after the footnotes in the selected documents were deleted. The decision to delete the footnotes has been determined by two technical reasons based on the observation of the documents. First of all, most footnotes contained references to other EU documents and were very repetitive, which would have affected the semi-automatic term extraction process (see Section 3.3.3.1). Secondly, in the conversion of the texts from the .pdf, .html, .doc or other file formats into the .txt format for making the texts processable by software tools (see Section 3.3.3.1), the footnote numbers could have altered the results obtained by using the software tools. By removing the footnote numbers, the relationship between the text and the footnotes was in any case lost, which caused the footnotes to be removed from the cleaned EU corpus.

\subsection{TEXT TYPE}

\footnotetext{
${ }^{60}$ The figures reported in this study as regards word tokens and types in the EU corpus have been obtained by processing the EU corpus with the free concordancing tool AntConc 3.2.1w for Windows, developed by Laurence Anthony, Faculty of Science and Engineering, Waseda University, Japan.
} 


\section{Chapter 3}

Before describing in greater detail the text types included in the EU corpus, a step back needs to be taken to explain the classification of the texts contained in the EU corpus.

\subsection{LEGAL LANGUAGE AND TEXT CLASSIFICATION}

The authors having a research interest in legal language who tried to provide a classification of linguistic material that can be assimilated into the broad category of legal language are countless. One of the most frequently quoted classifications dates back to 1965 and is found in Kalinowsky (quoted in Tiscornia 2007: 191). According to it, a distinction is to be made between the "language of Law", i.e. the language used by the legislator to express a legal rule, and the "language of Jurists", i.e. the language used in legal literature and legal science. The same distinction is also found in Italian authors, among whom Mazzarese (1989) and Spagnesi (1978) can be mentioned, who highlight the difference between the "language of the law" ("linguaggio del diritto" or "lingua del diritto") and the "language about the law" ("linguaggio sul diritto"). Though the textual material collected for this study can be broadly divided into these two categories, such a distinction does not seem to be sufficiently comprehensive to allow for an appropriate classification of all the documents included in the corpus. For example, the judgments of the European Court of Justice can be attributed to both categories, as the judge provides an interpretation of the law (language about the law), but such interpretation has legal consequences for the party to whom the judgment is awarded (language of the law).

In order to classify the texts in the EU corpus with greater precision, Vijay Bhatia's more exhaustive classification has been used, although this research study does not take into consideration all the different subcategories included in it. Such a classification (Bhatia 1987: 227, see Figure 3.3) is based on two criteria, i.e. the medium and the genre on the background of the setting in which legal language occurs. For clarity's sake, it should be pointed out that the term used by Bhatia to refer to legal language in general is "language of the law" (Bhatia 1987: 227). This contrasts with the classifications mentioned earlier and with the terminology proposed by Mellinkoff, whose "language of the law" (Mellinkoff 1963) can be said to correspond to Bhatia's juridical and legislative language. For the purpose of maintaining the aforementioned difference between the language of the law and the language about the law, in what follows the term "legal language" will be used as a hypernym of "juridical language" and "legislative language". 


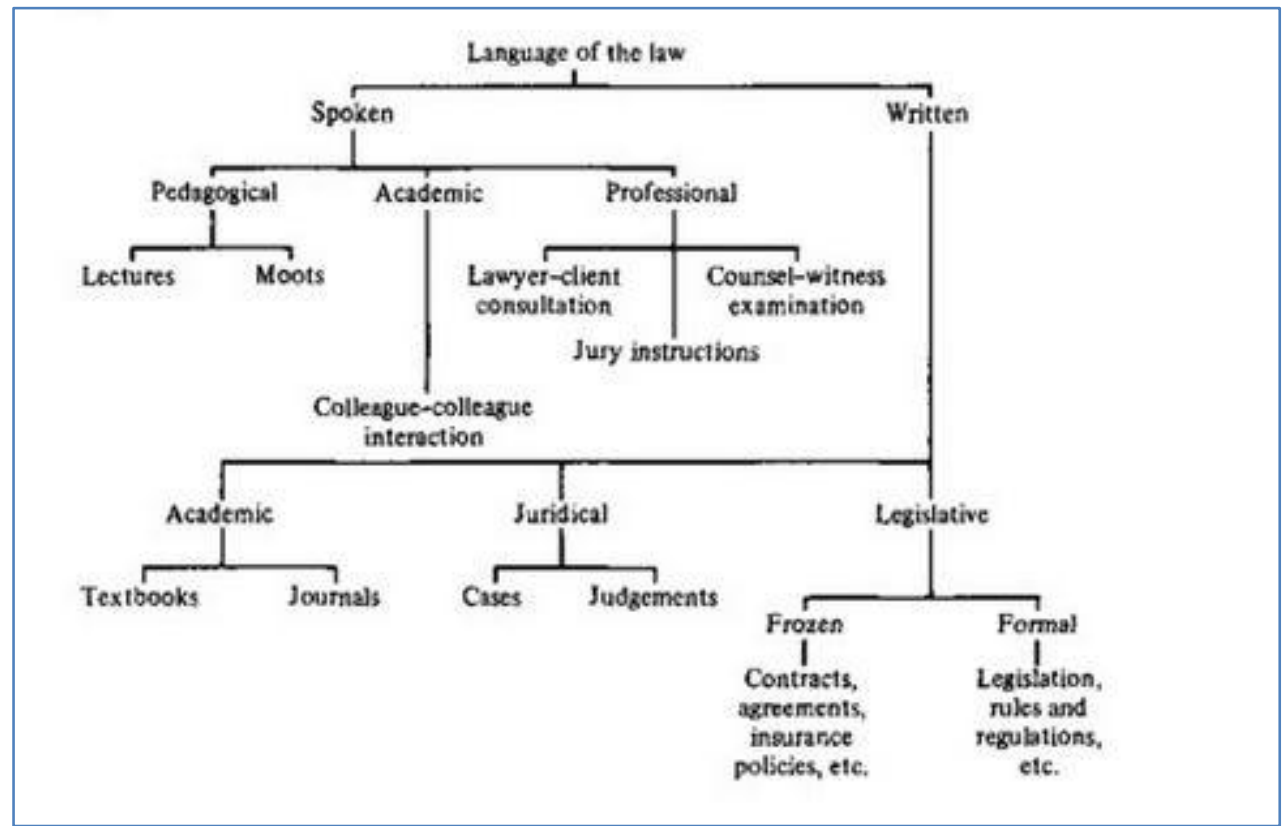

Figure 3.3. Bhatia's genre distinction in the legal language (Bhatia 1987: 227).

The EU corpus analysed in this study is made of written texts only. Consequently, the left part of Bhatia's model relating to spoken language is ignored in this research project. The classification of the language of the law proposed for written material by Bhatia is also generic enough to be applied to different legal orders and settings - which are generally ascribed to developed countries. However, the EU corpus built for the study contains a selection of texts that is not broad enough to cover all the subcategories belonging to the category of written legal texts envisaged by Bhatia. This is so because not all of the subcategories mentioned by Bhatia's model can be found in the EU corpus. For instance, what in Bhatia's model is referred to as "formal legislative language" is extremely frequent in the written acquis communautaire and makes up a considerable part of the corpus analysed, while "frozen legislative texts" - which are mostly used by natural and legal persons to establish a legal relationship among them - are much less common, with the sole main exception of agreements signed with candidate Member States, non-EU countries or other international bodies. These documents, however, are of no relevance for the topic of the research study.

When applying Bhatia's model to the EU corpus, a further remark needs to be made. In order to fully understand the difficulties of the categorisation of the EU legal texts, the different sources of legal language at the supranational level need to be taken into consideration. Written judicial language or, in Bhatia's terms, "juridical language", is used here to illustrate the complexity of the influence of EU's multi-jurisdictional nature on language. The main EU institution dealing with judicial issues and actually using this genre is the European Court of 


\section{Chapter 3}

Justice (ECJ). This is so for two main reasons: firstly, the ECJ is the highest court in the EU and decides on matters of EU relevance and, secondly, it is also responsible for issuing preliminary rulings on the interpretation of EU law at the request of a court of a Member State. Therefore, at the EU level judicial language is also used by Member States to refer to the ECJ. This already complex scenario is made even more problematic by the ECJ both describing the Member States' (legal) reality and trying to provide a uniform interpretation of EU law within its documents. Hence, when applied to the EU, judicial language is an umbrella term for national and supranational language varieties that merge when the ECJ is appealed to. The same can be said also for formal legislative language, as, for instance, lawmaking and legal drafting can be fostered by EU institutions as well as Member States (e.g. by means of initiatives), while the implementation and enforcement of EU legal rules are monitored and reported on by different EU institutions (mainly the European Commission) and committees.

When looking at what Bhatia refers to as "academic language", i.e. what other authors would classify as the language of the jurists, a difference can be seen as compared to the two genres of written legal language mentioned above. While the EU institutions are the primary bodies involved in the usage and production of juridical and formal language, they are not directly involved in the usage of academic language. In fact, academic language is generally used by scholars and authors who do not directly participate in the activities carried out by EU institutions, but use legal language to describe, discuss and analyse these activities. For this reason, the EU corpus does not contain texts falling into the category of academic language. Therefore, for the written EU legal language under examination, two possible communicative settings can be envisaged on the basis of Bhatia's classification, i.e. the legislative and the judicial setting. Academic texts dealing with victims of crime within the EU, which are written by Member States nationals rather than EU institutions' officers, have not been included in the EU corpus but have been used as reference material.

Going back to the first distinction between the language of the law and the language of jurists, the shortcomings of this first twofold classification become apparent for describing all the possible communicative settings of legal language usage as opposed to the more detailed model proposed by Bhatia. However, because even Bhatia's classification needs some further elaboration to allow for the inclusion of all the texts included in the EU corpus, for the purposes of the present study the twofold distinction between the language of the law and the language about the law has been kept and applied to written legal language. In order to 
categorise the texts that make up the EU corpus, this classification has however been combined with Bhatia's to produce the classification illustrated in Figure 3.4.

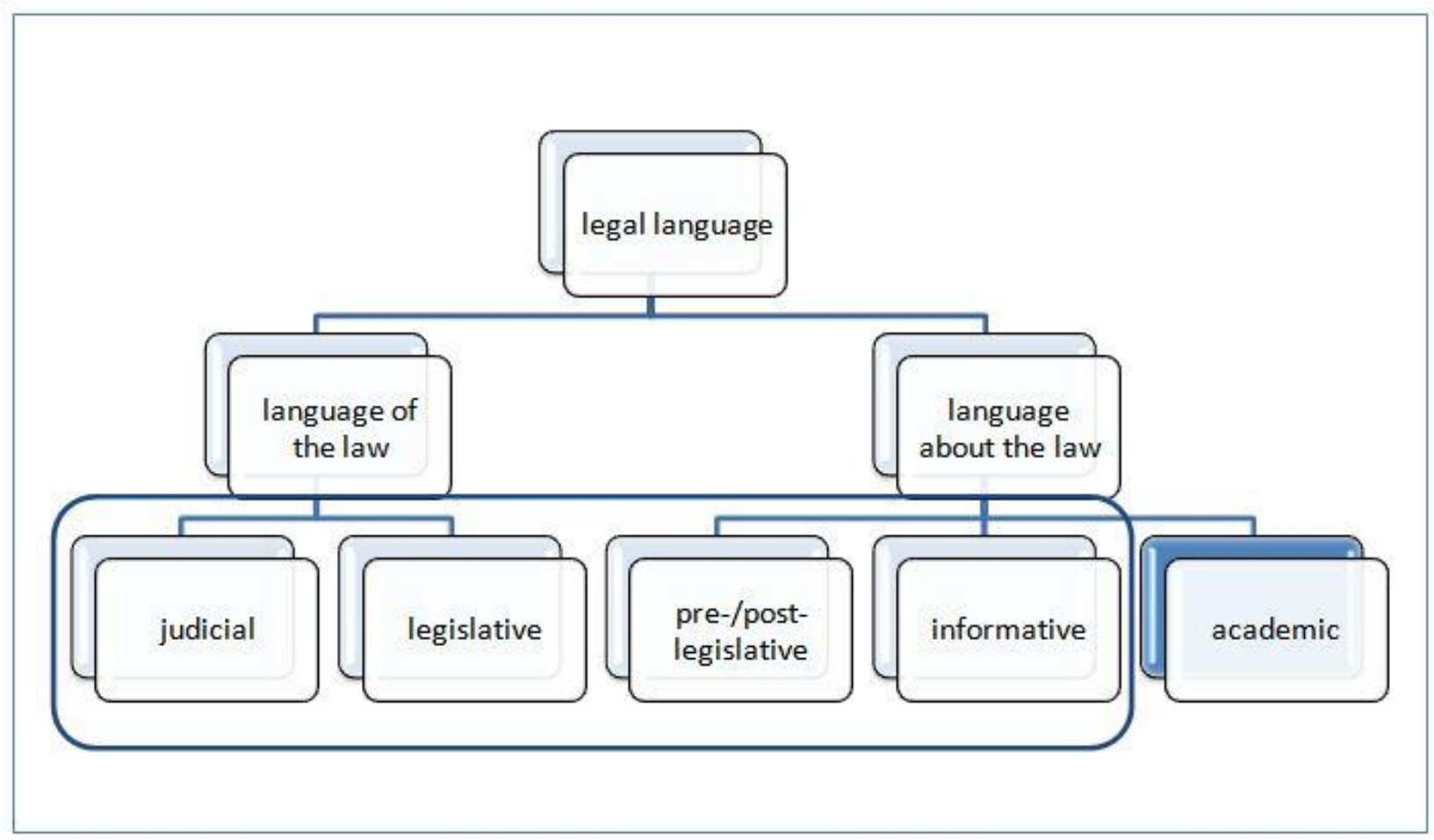

Figure 3.4. Genre distinction of the EU corpus in the classification of written legal language (blue box).

In the classification obtained by combining Kalinowsky's and Bhatia's models, judicial and legislative language are grouped together under the category of the language of the law. As stated earlier, Bhatia's further distinction between cases and judgments in the juridical setting and frozen and formal language in the legislative setting is irrelevant to the classification of EU texts. In this classification proposals for new legislation are grouped with existing legislation within the legislative subcategory, although their legal force is different: the former can still be modified and amended, while the latter have already been passed (even though their linguistic form and content can still be amended by means of further legislation). In the proposed classification academic language falls into the category of the language about the law and a new subcategory is introduced into the same category, i.e. informative language, which is used by the EU institutions for informing citizens of their legislative activity or the functioning of the EU. It includes, for instance, press releases published by EU institutions, mainly the European Commission, on their websites or (paper or electronic) informative booklets. 


\section{Chapter 3}

In order to provide an exhaustive classification of the texts that make up the EU corpus, one more subcategory is included which belongs to the language about the law according to the usage of the language, but the purpose of which is to have an impact on the content expressed via the language of the law. This subcategory is also informative in nature, but the target audience is different from that of informative language. In fact, while informative language addresses a broad audience, the second category, which is called here "pre-/post-legislative language", is generally directed to EU institutions themselves or the Member States. Therefore, the subcategory of pre-legislative language contains texts whose function is to launch consultations with the interested parties on possible measures to be taken at the EU level to develop new legislation or improve the existing one, such as in the case of green papers ${ }^{61}$, or to assess the impact of EU measures to be adopted to solve problems of supranational relevance, as is the case of documents accompanying proposals for new legislation ${ }^{62}$. On the other hand, the subcategory of post-legislative language also contains texts serving as follow-up documents to keep the progress made towards the implementation of the adopted measures under review, assess the meeting of the established deadlines and obligations and suggest further proposals or amendments ${ }^{63}$.

For the reasons mentioned above, the texts making up the EU corpus falling into the category of the language about the law actually belong to the subcategories of informative language and pre-/post-legislative language and cannot be ascribed to the academic language subcategory.

On the basis of the classification illustrated in Figure 3.4, the texts included in the EU corpus are classified as shown in Table 3.2.

\begin{tabular}{|c|c|c|c|c|c|}
\hline Text type & & $\begin{array}{c}\text { EU } \\
\text { English } \\
\text { subcorpus }\end{array}$ & & $\begin{array}{l}\text { EU Italian } \\
\text { subcorpus }\end{array}$ & \\
\hline \multirow{3}{*}{ judicial } & $\begin{array}{l}\text { reference for } \\
\text { preliminary ruling }\end{array}$ & 5 & & 5 & \multirow{3}{*}{15} \\
\hline & $\begin{array}{l}\text { opinion of Advocate } \\
\text { General }\end{array}$ & 5 & 15 & 5 & \\
\hline & judgment & 5 & & 5 & \\
\hline \multirow{4}{*}{$\begin{array}{c}\text { pre-post } \\
\text { legislative } \\
\& \\
\text { informative }\end{array}$} & action plan & 1 & & 1 & \multirow{4}{*}{33} \\
\hline & amended proposal & 1 & & 1 & \\
\hline & $\begin{array}{l}\text { Commission staff } \\
\text { working paper }\end{array}$ & 3 & 37 & 1 & \\
\hline & $\begin{array}{l}\text { communication from } \\
\text { the Commission }\end{array}$ & 5 & & 5 & \\
\hline
\end{tabular}

\footnotetext{
${ }^{61}$ See, for example, Commission of the European Communities 2001.

${ }^{62}$ See, for example, European Commission 2009.

${ }^{63} \mathrm{See}$, for example, European Commission 2003.
} 


\begin{tabular}{|c|c|c|c|c|c|}
\hline & manual & 2 & & 1 & \\
\hline & Opinion & 5 & & 5 & \\
\hline & Report & 7 & & 7 & \\
\hline & green paper & 2 & & 2 & \\
\hline & initiative & 3 & & 3 & \\
\hline & $\begin{array}{l}\text { proposal for a } \\
\text { decision of the } \\
\text { European Parliament } \\
\text { and of the Council }\end{array}$ & 1 & & 1 & \\
\hline & $\begin{array}{l}\text { proposal for a } \\
\text { Council Directive } \\
\text { proposal for a }\end{array}$ & 2 & & 2 & \\
\hline & Council Framework & 2 & & 2 & \\
\hline & $\begin{array}{l}\text { proposal for a } \\
\text { directive of the } \\
\text { European Parliament } \\
\text { and of the Council }\end{array}$ & 3 & & 2 & \\
\hline \multirow{9}{*}{ legislative } & Commission decision & 1 & & 1 & \multirow{9}{*}{21} \\
\hline & Council decision & 1 & & 1 & \\
\hline & Council directive & 2 & & 2 & \\
\hline & $\begin{array}{l}\text { Council framework } \\
\text { decision } \\
\text { decision of the }\end{array}$ & 3 & & 3 & \\
\hline & $\begin{array}{l}\text { European Parliament } \\
\text { and of the Council } \\
\text { directive of the }\end{array}$ & 1 & 21 & 1 & \\
\hline & $\begin{array}{l}\text { European Parliament } \\
\text { and of the Council }\end{array}$ & 3 & & 3 & \\
\hline & programme & 1 & & 1 & \\
\hline & $\begin{array}{l}\text { Parliament legislative } \\
\text { resolution }\end{array}$ & 3 & & 3 & \\
\hline & Parliament resolution & 6 & & 6 & \\
\hline
\end{tabular}

Table 3.2. Distribution of documents in text-type categories in the EU corpus.

\subsubsection{STEP 3. TERMINOGRAPHIC PROCESSING OF THE EU CORPUS}

The terminographic processing of the EU corpus consists of two phases, i.e. the semiautomatic extraction of candidate terms and the proper terminological analysis, which are both explained in the following sections.

\subsubsection{SEMI-AUTOMATIC EXTRACTION OF CANDIDATE TERMS}

According to Condamines, a new perspective on terminology emerged in the mid-nineties of the twentieth century which "proposed to derive terminology from texts, that is to say, basing the choice and description of terms on authentic linguistic productions" (Condamines 2010: 
45). Such a textual approach was made possible by NLP, which "had developed methods for corpus analysis, specifically for the extraction of terms and conceptual relations", and by textual semantics, which "had proposed new ways of analyzing specialized texts" (Condamines 2010: 45). Despite the fact that since then IT tools specifically designed for linguistic analysis in general and terminological analysis in particular have been under constant evolution and improvement, the data obtained by processing corpora with such tools are always to be evaluated, interpreted and, if necessary, revised by the linguist or terminologist/terminographer. As for the term extraction activity, the following statement by Gamper et al. is still valid today:

While a completely automatic term extraction is not realistic with today's technology, tools produce candidate lists for post-editing by human experts, which is a clear improvement over manual scanning of the entire corpus. (Gamper et al. 1999: 157)

As a matter of fact, no list of candidate terms produced by any term extraction software can be considered as a "final list" of terms belonging to the corpus analysed. In order to reach such a final list of terms, the aims of the term extraction (i.e. its skopos) and the terminographic work need to be clearly established. In other words, since the output of a term extraction process may serve different purposes, which range from the construction of ontologies to the creation of document indexes (see Bernier-Colborne 2012), in order to achieve those purposes the list of candidate terms needs to be post-edited. Moreover, it is necessary to consider that term extraction is employed for different aims by different disciplines, such as Natural Language Processing (NLP) or Artificial Intelligence (AI), which fail to share a common view of what a term is, both from a linguistic and a computational point of view (Pazienza et al. 2005: 156). In such a context, although provided with a terminological definition, termhood, i.e. "the degree to which a linguistic unit is related to [...] domain-specific context" (Kageura \& Umino 1996: 260-261), is still a blurred notion due to the difficulties of measuring it.

Bearing this in mind, the term extraction performed in this study falls into one of the four subcategories of term-based NLP proposed by Jacquemin and Bourigault (2003: 604). The two authors actually divide term-oriented NLP into two broad activities: term discovery and term recognition. Term discovery can be further subdivided into term enrichment, if prior terminological data is available, and term acquisition, when no prior terminological data is available. Based on the same distinguishing features, term recognition is subdivided into controlled indexing and free indexing. As the examination of these four subcategories is 
beyond the scope of this study, suffice it to say that the term extraction process performed to achieve the aims set for this study falls into the subcategory of term acquisition, i.e. the process of "discovering candidate terms in corpora" (Jacquemin \& Bourigault 2003: 605), since no prior terminological data on the legal domain chosen for terminological analysis was available before the term extraction process from the EU corpus was started.

Within the subcategory of term acquisition, the term extraction process carried out in this study aims at identifying those terms that are relevant to the legal domain of victims of crime. A further remark is therefore needed which is linked to the skopos of term extraction. Being the topic of the study the area of law of victims of crime, it seems quite obvious that the corpus is studded with legal terminology. However, the legal terminology that can be found in the corpus can be more or less relevant to the domain under examination. For instance, legal terms such as "regulation", "directive", "decision" and "legislation", which are frequently found in EU documents, have been considered not to be sufficiently relevant to the central research topic and have therefore been discarded from the list of candidate terms.

As stated at the beginning of this section, the term extraction process has been carried out in a semi-automatic way by combining the usage of software tools with human expert post-editing for term validation. The software tools employed in the study are non commercial ${ }^{64}$, a choice which has been dictated by the intent to propose a term extraction methodology that could be replicated by translators. Therefore, the proposed methodology makes it possible to avoid the constraint of buying any additional tool to those translators are generally provided with. Although it is common knowledge that professional translators work under time pressure and, as a consequence, additional - albeit translation-related - activities are generally left aside, the reasons for translators to perform a term extraction task are manifold, such as populating an existing terminological repository with new terminology that could prove useful in the translation process, gaining a preliminary overview of the terminology in a text they are supposed to translate or the terminology of a specialised domain the text they are supposed to translate belongs to, etc. The software tools chosen for carrying out the term extraction task are thus freely available online and belong to two different categories: concordancers and proper automatic term extraction tools. The first tool used is the concordancer AntConc 3.2.1.w, while the second is the automatic term extractor TermoStat Web $3.0^{65}$.

\footnotetext{
${ }^{64}$ For commercial systems available for term extraction, see Zielinski \& Ramírez Safar (2005).

${ }^{65}$ For a list of free term extraction tools available online visit http://termcoord.wordpress.com/about/testing-ofterm-extraction-tools/free-term-extractors/.
} 


\section{Chapter 3}

\subsection{AnTCONC $^{66}$}

AntConc is "a corpus analysis toolkit designed specifically for use in the classroom" (Anthony 2005: 7). It is a freeware application which includes a concordancer, a word and a keyword frequency generator, tools for cluster and lexical bundle analysis, and a word distribution plot. For the purposes of this study, not all the tools included in the application have been used and only three tools have been employed, i.e. the concordancer, the word list generator and the word cluster tool. For term extraction, the word list generator has been used to sort the words into alphabetical or frequency order. The two subcorpora without footnotes have been processed separately, in combination with a stop list for each language to avoid counting high frequency functional words. The words included in the stop lists are available in Annex 2. In the generation of word lists, all the data in the subcorpora have been treated in lowercase. In Figures 3.5 and 3.6 two screenshots of the word lists generated with AntConc are presented.

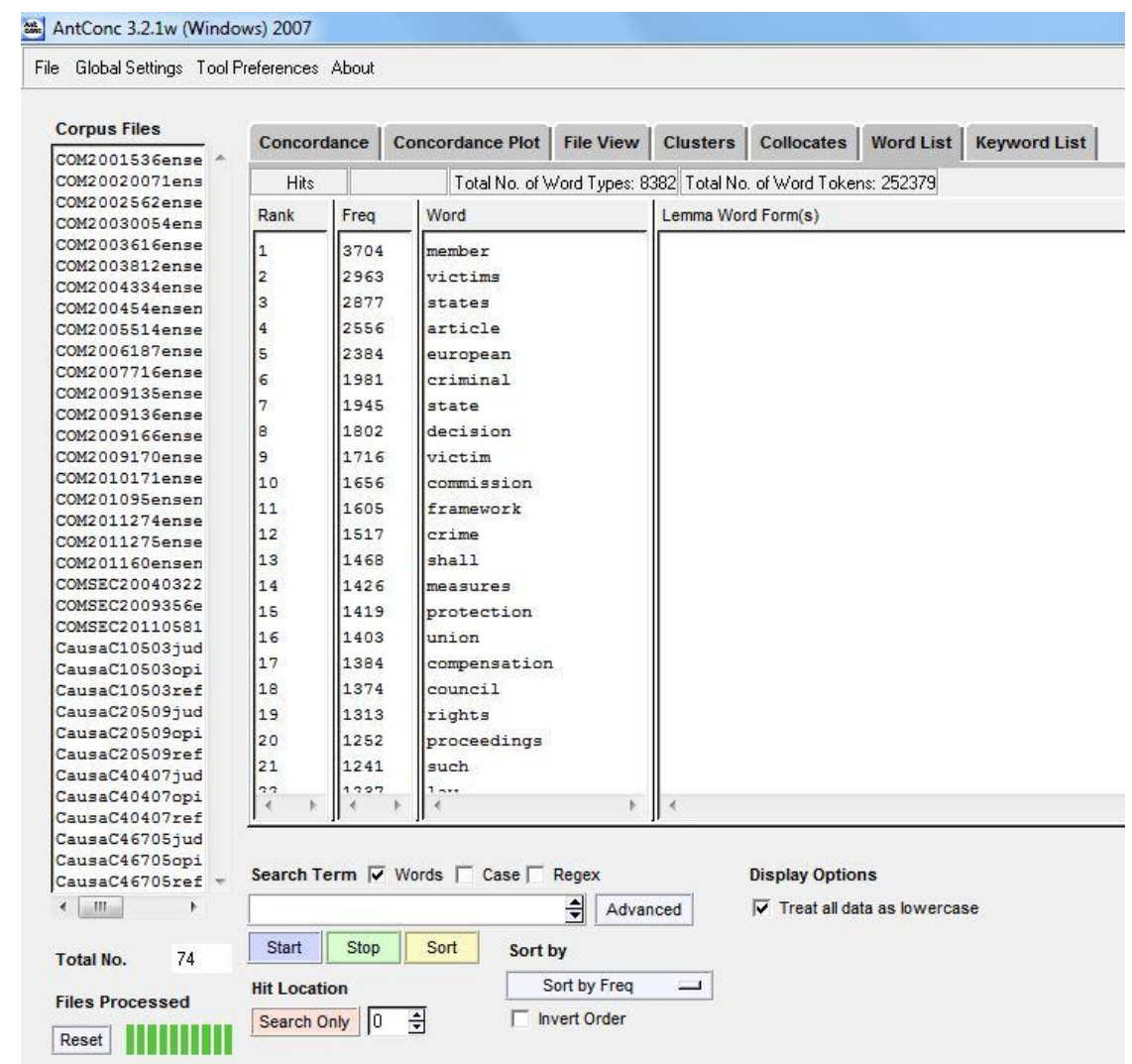

Figure 3.5. Screenshot of the word list (ranks 1-21) of the English subcorpus without footnotes generated with AntConc.

\footnotetext{
${ }^{66}$ Anthony, L. (2007). AntConc (3.2.1.w) [Computer Software]. Tokyo, Japan: Waseda University. Available at http://www.antlab.sci.waseda.ac.jp/. Note that a newer version of the software is available at the time of writing on http://www.antlab.sci.waseda.ac.jp/software.html.
} 


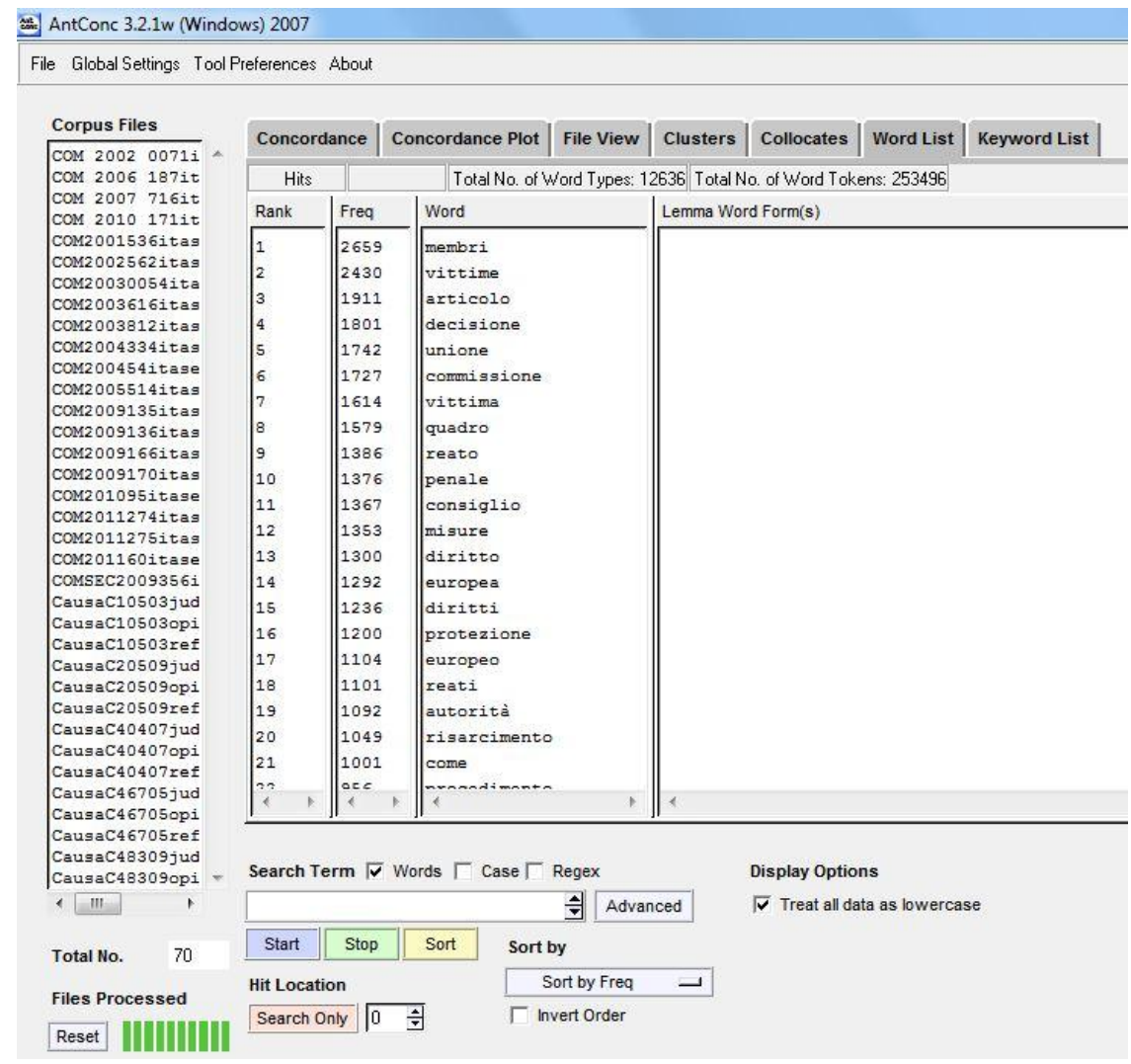

Figure 3.6. Screenshot of the word list (ranks 1-21) of the Italian subcorpus without footnotes generated with AntConc.

Once the most frequent words in the subcorpora were identified, candidate single-word terms or elements of candidate multi-word terms were manually selected. For instance, in Figure 3.6, which reproduces the most frequently occurring words in the Italian subcorpus, five candidates were selected: “vittima" (singular), "vittime” (plural), "protezione", "autorità" and "risarcimento". The lists of the first 100 results for each language obtained in this way are available in Annex 3. To verify whether the candidates were single-word terms or part of longer multi-word terms the Word Clusters Tool has been used: in this tool, the selected candidates have been used as keywords to identify the clusters of words that surround them in the corpus. The keyword was thus specified in the tool and the cluster size was established between a minimum size of two words and a maximum size of eight words, as the length of candidate terms should be limited (Drouin 2003: 105). The position of the searched candidate was not specified, as the keyword could function both as a head element of the term, i.e. refer to "the general (semantic) category to which the whole word belongs" (Hippisley et al. 2005: 130), and as a modifier, i.e. as an element which "distinguish[es] this member from other members of the same category" (Hippisley et al. 2005: 130). The result provided by the Word Clusters Tool is very similar to the results obtained by using a common concordancing function. The only relevant difference between the Word Cluster Tool and the Concordance 


\section{Chapter 3}

Tool lies in the fact that the former enables the user to choose the size of the portion of text to be displayed, which makes it better suited for identifying both multi-word candidate terms and collocations.

Limiting the discussion to the identification of multi-word terms and taking the most frequent Italian candidate term "vittime" as an example, using the Word Cluster Tool made it possible to quickly spot the following multi-word terms: vittime di reati, vittime di reato, protezione delle vittime and, among the maximum-length clusters, risarcimento delle vittime da parte dello Stato. As can be seen from the example provided, the searched candidate term can have either a head function (e.g. vittime di reati) or act as a modifier (e.g. protezione delle vittime) and can appear in several terminological variants (e.g. vittime di reati, vittime di reato).

\subsection{Termostat Web 3.0 $0^{67}$}

Besides a concordancing tool, for the purposes of term extraction also an automatic term extraction tool was used. Research in automatic term extraction for terminological purposes dates back to the beginnings of the 1990s, when this activity was generally referred to as "automatic term recognition" (ATR), starting with the work of numerous researches, such as Ananiadou (1994), Dagan and Church (1994), Daille et al. (1994), Damerau (1993), Justeson and Katz (1995), Kageura and Umino (1996), among others. Since then, different term extraction techniques have been developed which are nowadays generally categorised as linguistic, statistical, or hybrid (see Drouin 2003: 99; Ha et al. 2008: 108). In linguistic term extraction tools, the identification of candidate terms is based on the terms' linguistic structure, although the extraction process also relies on basic statistical data, such as their frequency. Term extraction tools following a statistical approach are based on the assumption that "specialised documents are characterised by the repeated use of certain lexical units or morpho-syntactic constructions" (Ha et al. 2008: 108). Extraction tools exploit statistical data to either select those items which occur with a frequency higher than a given threshold or compare their frequency in a specialised text or corpus to their frequency in a general language text or corpus. Both linguistic and statistical techniques have advantages and disadvantages. On the one hand, linguistic tools are likely to generate noise, with too many candidate terms being extracted compared to the actual number of terms present in the text or corpus, and are language-dependent, which means that they can only be used for the languages they were developed for (which are generally major languages). On the other hand, statistical tools yield the opposite result, i.e. silence, with less frequent candidate terms often

\footnotetext{
${ }^{67}$ Available at http://olst.ling.umontreal.ca/ drouinp/termostat_web/.
} 
being missed, though they can be generally used also for those lesser-used languages for which linguistic term extraction tools are not available, such as minority languages (see Streiter et al. 2003). However, these two approaches are not necessarily mutually exclusive and can be merged into a hybrid approach to term extraction (see, for instance, Daille et al. 1994; Frantzi et al. 1998; Justeson \& Katz 1995), where both statistical and linguistic information is used to retrieve terms from a text/corpus, with the statistical part consisting mainly in the usage of algorithms and shallow linguistic information acting as a syntactic filter in the recognition of candidate terms (Ha et al. 2003: 1819).

The automatic term extraction tool used for the purposes of this study, i.e. TermoStat Web 3.0 (Drouin 2003), falls into the third category of term extraction techniques presented above. The hybrid technique employed in TermoStat Web 3.0 has been developed for the identification of both single-word and multi-word terms in technical corpora. The extraction is performed by statistically comparing the frequencies of lexical items in a technical and a non-technical corpus, assuming that the comparison of the behaviour of lexical units in different types of corpora reveals the units that are specific to the technical corpus. In order to do so, TermoStat Web 3.0 uses "a virtual corpus, called the global corpus (GC), built at run time from a reference corpus (RC) and an analysis corpus (AC)", where "the reference corpus is a non-technical corpus while the analysis corpus is a domain-specific, technical corpus" (Drouin 2003: 100). For the purposes of this study, there is no need to describe in detail the functioning of TermoStat Web 3.0 and the algorithms implemented in it, which are thoroughly illustrated in Drouin (2003). Suffice it to say that in TermoStat Web 3.0 a linguistic constraint has been imposed on the statistically-based term extraction technique, which limits the lexical items to be retrieved to two parts of speech only, i.e. nouns and adjectives. TermoStat Web 3.0 allows for the identification of both single- and multi-word candidate terms and, in the latter case, the maximum length of the candidate term corresponds to six words, which, according to Drouin, is sufficient to "cover most cases of complex terminological units" (Drouin 2003: 106). As a consequence, the a priori established constraints on part of speech and candidate term length can lead to the failure of identifying some candidate terms, though the combination of the outcome of this software with the results obtained by using AntConc (see Section 3.3.3.1.1), followed by human validation, can be considered to provide a reliable list of terms.

TermoStat Web 3.0 was used to process the two versions of both subcorpora, i.e. the English and the Italian EU subcorpora with and without footnotes, in order to obtain lists of candidate terms to submit to human validation. As stated in Section 3.3.2.3.1, the footnote-free versions 


\section{Chapter 3}

of the subcorpora were used with the aim of excluding from the list of candidate terms some repetitive lexical items that are typically found in the footnotes of EU documents, such as the titles of the documents which generally contain head elements such as "Regulation", "Proposal", "Green Paper", "Directive", "Decision", "Communication" and the like. However, the observation of the lists obtained by processing the subcorpora by means of TermoStat Web 3.0 has revealed that the differences in the candidate terms extracted were not as remarkable as expected, with the only major difference being observed in the frequency of the single items rather than in the items themselves. For this reason, the lists obtained from the subcorpora including footnotes have been subjected to further manual validation. The results obtained by means of TermoStat Web 3.0 are much more reliable for the English language as compared to the Italian language, as also confirmed by the developer of the software $^{68}$. In any case, also the Italian results have been taken into consideration and manually validated. The lists of the first 100 candidate terms for each language provided by TermoStat Web 3.0 are available in Annex 4.

\subsubsection{TERMINOLOGICAL ANALYSIS}

In the following sections, the terminological analysis of the terms extracted from the EU corpus is presented.

\subsection{BILINGUAL CROSS-CHECK AND IDENTIFICATION OF TRANSLATION EQUIVALENTS}

Using the lists of candidate terms obtained by using the concordancing tool AntConc and the automatic term extraction tool TermoStat Web 3.0, a list of candidate terms was obtained for each language. In order to reach the final list of terms extracted from the EU parallel corpus, the terms in these provisional lists were used as a starting point for a further cross-checking task: each term in one language was searched in the bilingual display of the parallel corpus to find out possible equivalents for the searched term in the other language: these equivalents could in fact represent candidate terms that had not been recognised during one of the two previous steps. This phase was carried out for both languages separately and led also to the identification of other forms of expression that cannot be classified as terminological units, but can rather be considered as anaphoric devices. To exemplify the process, some examples of the bilingual cross-checking are presented in the figures below as well as some examples of non terminological units.

\footnotetext{
${ }^{68}$ Personal e-mail communication from Patrick Drouin, 11.10.2012. 


\begin{tabular}{|c|c|c|c|}
\hline \multicolumn{2}{|r|}{ EN-EU subcorpus } & \multicolumn{2}{|r|}{ IT-EU subcorpus } \\
\hline \multicolumn{4}{|c|}{ Document: COM 2001536 final } \\
\hline EN & $\begin{array}{l}\text { 3. Overview of state compensation } \\
\text { schemes in the Member States }\end{array}$ & & $\begin{array}{l}\text { 3. PANORAMICA DEI SISTEMI DI } \\
\text { RISARCIMENTO STATALE NEGLI } \\
\text { STATI MEMBRI }\end{array}$ \\
\hline EN & 3.1. Introduction & IT & 3.1. Introduzione \\
\hline EN & $\begin{array}{l}\text { This chapter will give an overview of } \\
\text { state compensation schemes in the } \\
\text { Member States of the EU. }\end{array}$ & IT & $\begin{array}{l}\text { Questo capitolo fornisce una } \\
\text { panoramica dei sistemi statali di } \\
\text { risarcimento negli Stati membri } \\
\text { dell'UE. }\end{array}$ \\
\hline EN & $\begin{array}{l}\text { The purpose is to identify the main } \\
\text { features of the different schemes, not } \\
\text { to go in-depth on the particular } \\
\text { characteristics of each scheme. [...] }\end{array}$ & IT & $\begin{array}{l}\text { Lo scopo è quello d'identificare le } \\
\text { principali caratteristiche dei vari } \\
\text { sistemi, non di approfondire le } \\
\text { particolarità di ciascun sistema. }[. . .]\end{array}$ \\
\hline EN & $\begin{array}{l}\text { When references below are made to } \\
\text { all Member States, this means all } \\
\text { Member States that have state } \\
\text { compensation schemes with a general } \\
\text { scope of application in place. }\end{array}$ & IT & $\begin{array}{l}\text { Quando ci si riferisce a "tutti" gli Stati } \\
\text { membri, s'intende tutti quegli Stati } \\
\text { membri che hanno istituito dei sistemi } \\
\text { di risarcimento d'applicazione } \\
\text { generale. }\end{array}$ \\
\hline EN & $\begin{array}{l}\text { Greece and Italy are therefore not } \\
\text { included in the overview, although it } \\
\text { should be noted that the latter has a } \\
\text { scheme in place compensating } \\
\text { victims suffering serious injury as a } \\
\text { result of a terrorist act or of } \\
\text { organised crime. }\end{array}$ & IT & $\begin{array}{l}\text { Grecia e Italia pertanto non sono } \\
\text { contemplate nella panoramica, anche } \\
\text { se è opportuno notare che l'Italia } \\
\text { possiede un sistema di risarcimento } \\
\text { per le vittime di lesioni gravi } \\
\text { conseguenti ad azioni terroristiche o } \\
\text { imputabili alla criminalità organizzata. }\end{array}$ \\
\hline EN & $\begin{array}{l}\text { For the United Kingdom, the } \\
\text { description is based on the scheme in } \\
\text { place for England, Scotland and } \\
\text { Wales, thus not taking into account } \\
\text { the differences that exists with regard } \\
\text { to the scheme applicable in Northern } \\
\text { Ireland. }\end{array}$ & IT & $\begin{array}{l}\text { Per quanto riguarda il Regno Unito, la } \\
\text { descrizione si basa sui sistemi istituiti } \\
\text { in Inghilterra, Scozia e Galles, senza } \\
\text { prendere in considerazione le } \\
\text { differenze esistenti per quanto } \\
\text { concerne il sistema applicabile } \\
\text { all'Irlanda del Nord. }\end{array}$ \\
\hline
\end{tabular}

Figure 3.7. Cross-check for translation equivalents and terminological variants in the EU corpus bilingual display. Searched candidate terms: state compensation scheme, scheme.

As can be seen from the example provided in Figure 3.7. Cross-check for translation equivalents and terminological variants in the EU corpus bilingual display. Searched candidate terms: state compensation scheme, scheme.

, by searching a multi-word term and its head element in the English EU subcorpus it has been possible to spot its translation equivalents in the Italian EU subcorpus. However, bearing in mind the equal authenticity principle, it is also possible to perform the opposite operation and thus start the searches with Italian terms to find English equivalents, as in Figure 3.8. Cross- 
check for translation equivalents and terminological variants in the EU corpus bilingual display. Searched candidate terms: vittima/e particolarmente vulnerabile/i. below.

IT-EU subcorpus

EN-EU subcorpus

Document: DEC 2001/220/JHA

IT 2. Ciascuno Stato membro assicura che le vittime particolarmente vulnerabili beneficino di un trattamento specifico che risponda in modo ottimale alla loro situazione.
EN 2. Appropriate measures shall be taken for victims who are particularly vulnerable on account of their age, their sex or other circumstances.

Document: DEC 2002/629/JHA

IT 2. I bambini che siano vittime di un reato di cui all'articolo 1 dovrebbero essere considerati vittime particolarmente vulnerabili ai sensi dell'articolo 2, paragrafo 2, dell'articolo 8, paragrafo 4 e dell'articolo 14, paragrafo 1, della decisione quadro 2001/220/GAI del Consiglio, del 15 marzo 2001, relativa alla posizione della vittima nel procedimento penale.
EN 2. Children who are victims of an offence referred to in Article 1 should be considered as particularly vulnerable victims pursuant to Article 2(2), Article 8(4) and Article 14(1) of Council Framework Decision 2001/220/JHA of 15 March 2001 on the standing of victims in criminal proceedings.

Figure 3.8. Cross-check for translation equivalents and terminological variants in the EU corpus bilingual display. Searched candidate terms: vittima/e particolarmente vulnerabile/i.

Figure 3.8. Cross-check for translation equivalents and terminological variants in the EU corpus bilingual display. Searched candidate terms: vittima/e particolarmente vulnerabile/i. shows an example of cross-checking by means of the bilingual display allowing for the identification of cases where a terminological unit in one language does not correspond to a terminological unit in the other language. In the example presented above, the Italian multiword term vittime particolarmente vulnerabili corresponds to a noun followed by a verbal form in the earliest English document in which the concept of PARTICULARLY VULNERABLE VICTIM appears. In later English documents the concept has undergone a terminologisation process resulting in the terminological unit particularly vulnerable victim. Therefore, the bilingual cross-checking can also prove useful in discovering "short-period diachronic phenomena" (Picton 2011). This method can also help identify anaphoric mechanisms, such as short forms of multi-word terms and pronouns. Though the study of non-terminological forms of expression, both quantitatively and qualitatively, is beyond the scope of this research study, Figure 3.9 provides an example of the variety of the phenomena that can be observed 
by cross-checking the EU corpus. The example includes an extract from the European Commission Communication (COM(2011) 60 final) on "An EU Agenda for the Rights of the Child", where children are the main topic. In the extract reported in Figure 3.9, the concept of CHILD VICTIM is designated by a single English term, namely child victims, whereas in Italian the same concept is referred to by using two terminological variants, i.e. giovani vittime and minori vittime di reato, the clitic pronoun "ne" and the short form "minore".

\begin{tabular}{|c|c|c|}
\hline \multicolumn{2}{|r|}{ EN-EU subcorpus } & IT-EU subcorpus \\
\hline \multicolumn{3}{|c|}{ Document: COM 201160} \\
\hline EN & $\begin{array}{l}\text { Children often participate as vulnerable } \\
\text { witnesses or victims in criminal } \\
\text { judicial proceedings. They may be } \\
\text { exploited in criminal activities, such as } \\
\text { trafficking of illicit drugs. Legal and } \\
\text { practical arrangements should be put in } \\
\text { place to avoid unnecessary multiple } \\
\text { interrogations, and to reduce the } \\
\text { negative experience of being involved } \\
\text { in criminal proceedings. Child victims } \\
\text { should be given the opportunity to play } \\
\text { an active part in criminal proceedings } \\
\text { so as to have their testimony taken into } \\
\text { account. The use of Information and } \\
\text { Communication Technology (ICT) } \\
\text { tools, and especially video- } \\
\text { conferencing, can allow child victims } \\
\text { to take an active part in the } \\
\text { proceedings while not being put in } \\
\text { direct contact with the accused } \\
\text { persons. Child victims should receive } \\
\text { adequate support leading to their } \\
\text { recovery and compensation for the } \\
\text { harm inflicted on them. }\end{array}$ & $\begin{array}{l}\text { IT I minori sono spesso coinvolti nei } \\
\text { procedimenti penali in qualità di } \\
\text { testimoni o vittime vulnerabili. } \\
\text { Possono ad esempio essere sfruttati } \\
\text { per attività criminali come il traffico di } \\
\text { droga. Occorrono pertanto modalità } \\
\text { giuridiche e pratiche che evitino } \\
\text { l'inutile ripetersi degli interrogatori e } \\
\text { attenuino l'esperienza negativa insita } \\
\text { nel partecipare a un procedimento } \\
\text { penale. Le giovani vittime dovrebbero } \\
\text { avere la possibilità di contribuire } \\
\text { attivamente al procedimento penale, in } \\
\text { modo da far valere la propria } \\
\text { testimonianza; le tecnologie } \\
\text { dell'informazione della } \\
\text { comunicazione (TIC), in particolare la } \\
\text { videoconferenza, possono garantirne } \\
\text { la partecipazione attiva senza che il } \\
\text { minore entri in contatto diretto con } \\
\text { l'imputato. I minori vittime di reato } \\
\text { dovrebbero poi ricevere un sostegno } \\
\text { adeguato che consenta loro di } \\
\text { ristabilirsi ed essere indennizzati per il } \\
\text { danno subito. }\end{array}$ \\
\hline
\end{tabular}

Figure 3.9. Cross-check for translation equivalents and terminological variants in the EU corpus bilingual display. Searched candidate terms: child victim(s).

As mentioned earlier, the study of alternative forms of expression that cannot be classified as terminological units goes beyond the purposes of this study, which is intended to focus on proper legal terminology only. As regards the bilingual cross-checking task, another phenomenon that is incidentally worth mentioning is exemplified in Figure 3.10. Despite the validity of the equal authenticity principle among different language versions, in one case the cross-checking has shown the inconsistency of one term employed in the Italian version of an 
EU document compared to the English version. While looking for the translation equivalents of the term violent intentional crime, a term that was retrieved conveys a different meaning, referring to an "international crime" rather than an "intentional crime". Since the paragraph in which the prima facie inappropriate term has been found referred back to Council Directive 2004/80/EC, a further examination of the Directive confirmed that a substitution of the adjective "intenzionale" with "internazionale" had occurred, causing a conceptual discrepancy among the equally authentic versions. However, it ought to be said that the case presented in Figure 3.10. Cross-check for translation equivalents and terminological variants in the EU corpus bilingual display. Searched candidate terms: violent intentional crime.

is in fact the only instance of such conceptual discrepancy identified in the analysed EU corpus and should therefore be considered as marginal.

\section{EN-EU subcorpus}

\section{Document: DIR 200480 EC}

EN Member States shall ensure that where a violent intentional crime has been committed in a Member State other than the Member State where the applicant for compensation is habitually resident, the applicant shall have the right to submit the application to an authority or any other body in the latter Member State.
IT-EU subcorpus

IT Gli Stati membri assicurano che, se un reato intenzionale violento è stato commesso in uno Stato membro diverso da quello in cui il richiedente l'indennizzo risiede abitualmente, il richiedente ha diritto a presentare la domanda presso un'autorità o qualsiasi altro organismo di quest'ultimo Stato membro.

\section{Document: COM 2009170}

EN Article 1 of the Directive requires Member States to ensure that the victim of a "violent intentional crime" committed in a Member State other than the Member State where the applicant for compensation is habitually resident has the right to submit an application for compensation in that state. The competent authority in the Member State in which the applicant is currently residing (the "Assisting Authority") assists the applicant; its obligations towards the victim are set out in Articles 5
IT L'articolo 1 della direttiva obbliga gli Stati membri ad assicurare che la vittima di un "reato internazionale violento" commesso in uno Stato membro diverso da quello in cui il richiedente l'indennizzo risiede abitualmente abbia diritto a presentare la domanda di indennizzo in quello Stato. L'autorità competente dello Stato membro in cui il richiedente risiede abitualmente ("autorità di assistenza") gli dà assistenza; gli obblighi della suddetta autorità nei confronti della vittima sono stabiliti 


\begin{tabular}{lll|}
\hline-11 of the Directive. The & dagli articoli da 5 a 11 della \\
Assisting Authority does not make & direttiva. L'autorità di assistenza non \\
any assessment of the application. & compie alcuna valutazione della \\
domanda. Tale valutazione compete \\
This assessment is left to the & all'autorità dello Stato membro ai \\
authority of the Member State & sensi del quale sistema di indennizzo \\
under whose compensation & la vittima ha presentato domanda \\
scheme the victim is applying (the & ("autorità di decisione"). \\
"Deciding Authority"). &
\end{tabular}

Figure 3.10. Cross-check for translation equivalents and terminological variants in the EU corpus bilingual display. Searched candidate terms: violent intentional crime.

\subsection{EXTRACTION OF LINGUISTIC, PRAGMATIC, AND CONCEPTUAL INFORMATION}

Once all the terms in the provisional lists were submitted to the bilingual cross-checking process, the final lists of terms and terminological variants were elaborated and discussed with the lawyer for the purpose of field-expert validation.

The following task consisted in the collection of relevant linguistic, pragmatic and conceptual information to be included in the MuLex terminological knowledge base. The information collected at this stage is presented in greater detail in Chapter 6. The retrieval of such information was mainly based on the EU corpus described above, with only minor exceptions. In other words, the information provided for the selected terminology was primarily extracted from the same corpus from which the terminology itself had been extracted. Taking linguistic and pragmatic information as an example, both the EU terminology and the relevant contexts presented in MuLex were extracted from the EU corpus, as well as the pragmatic information relevant to the register, which is based on the information that could be inferred from the corpus. As regards conceptual information, the definitions provided for the EU victim-related terminology presented in MuLex were mainly retrieved or elaborated from EU documents, although in some cases also external documentation (e.g. $\operatorname{IATE}^{69}$, EU glossary ${ }^{70}$ ) was consulted for both further refinement and confirmation of the content of the definitions. What is interesting here is the identification of text-based conceptual relations and the conceptual structuring of the area of law under discussion. Unlike Cabré's methodological framework (see Section 3.2), where the conceptual structuring was performed during the initial stages of terminographic projects, in this study this task was performed at two separate points in time,

\footnotetext{
${ }^{69}$ The terminological database IATE (InterActive Terminology for Europe) is available at http://iate.europa.eu/iatediff/switchLang.do?success=mainPage\&lang=en.

70 The glossary available on the http://europa.eu/legislation_summaries/glossary/ website contains 233 terms relating to European integration and the institutions and activities of the EU.
} 


\section{Chapter 3}

the first of which refers to the EU legal system and the second to the national legal systems. In order to do so, neither the entire legal system nor the entire area of law were considered, but only the terms recorded in the final lists were taken into account and the conceptual relations that hold among them as expressed in the EU corpus were identified. Therefore, the representation of conceptual relations as reported in MuLex can be considered to be partial, as it is only based on those relations that could be retrieved from the in vivo documents included in the EU corpus. In this sense, the conceptual representation is not dissimilar from the terms extracted from the EU corpus, because it illustrates the reality that is crystallised in existing textual material rather than in an abstract, not linguistically represented sphere of knowledge. As for the other terminologically relevant information, concept fields and conceptual relations are further discussed in Section 6.4.1.1.

\subsubsection{STEP 4. SELECTION OF NATIONAL COMPARABLE TEXTS}

As explained so far, the term extraction process was carried out monolingually in the EU corpus and the translation equivalents were matched manually by using the bilingual display of equally authentic versions of the EU documents of the corpus. However, the aim of the research project was to extract and analyse the victim-related terminology used not only within the EU legal system, but also in the English and the Italian national legal systems. Therefore, apart from the EU corpus described above, also national texts were taken into consideration for the identification of relevant terminology. In this regard, a difference needs to be highlighted concerning the methodology adopted for text selection. The selection of national texts has followed a different path as compared to the selection of EU texts for two main reasons. First of all, similar databases from which documents on a given legal topic as regulated and discussed by national legal systems are not available for the English and the Italian legal systems. Secondly, one of the aims of the research study was to correlate victimrelated EU terminology with the national terminologies. Therefore, the texts to be collected should contain terms referring to concepts which coincide with or are similar to those designated by EU terminology.

National texts were collected also bearing in mind that the variety of text types dealing with legal topics at the national level is wider than that produced by EU institutions. Going back to the classification of written legal language in the EU presented in Section 3.3.2.3.2.1 and comparing it to the variety of national text types presented in Figure 3.11, in the national setting academic texts can be found in addition to all the other text types found in the EU setting. However, although some categories are shared by the different legal systems, they do not necessarily include perfectly corresponding text types. Taking the legislative category as 
an example, both EU and national texts that fall into this category can be found, but the difference among these texts may still prove significant.

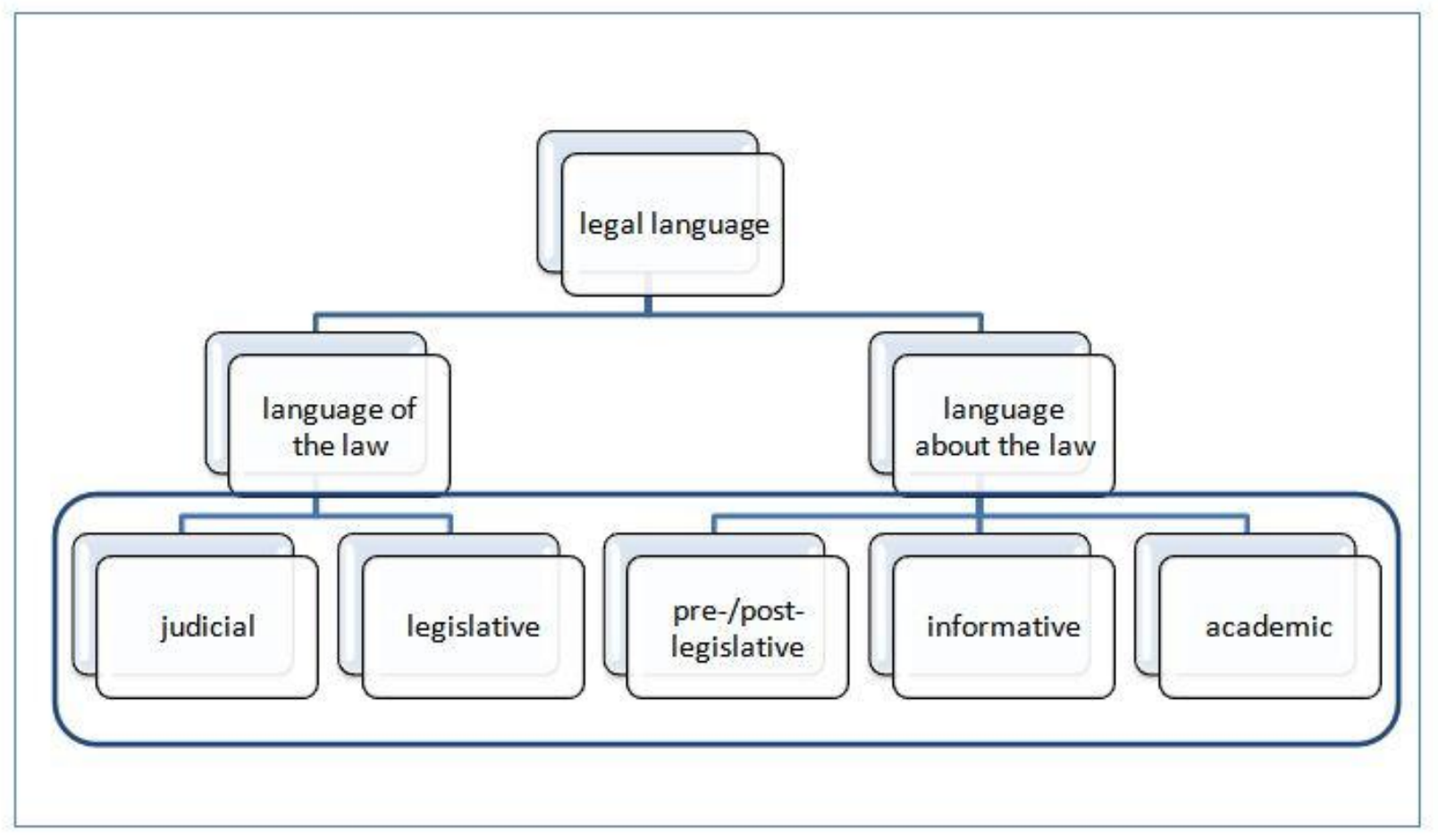

Figure 3.11. Genre distinction of national texts in the classification of written legal language (blue box).

As regards the classification of national texts, whereas judicial and legislative texts are generally related to the relevant national legal system (e.g. UK Public General Acts are to be enforced only in the UK and Italian laws only in Italy), the texts that fall into the category of the language about the law can refer to both the national and the EU legal systems. This is especially true for academic texts, which can deal with national, supranational or international legislation. Although this consideration may not seem essential, it is actually relevant when considering the reference of a term to a certain legal system and its diatopical distribution. This preliminary remark on the classification of national texts is necessary in order to understand the diversity in the textual material used in this study.

The texts available on the EUR-Lex website differ from national legal documentation. The differences concern the text type and language, as well as the availability, quantity, systematicity in classification, and reference legal system of the texts. In order to collect national texts containing terms having a connection with the EU terminology extracted following the methods presented above, both the language of the law and the language about the law were taken into consideration, including academic language. However, unlike the EU corpus, in which there are no informative documents, in some cases national informative texts 
were also considered. The English and Italian EU terms selected were thus used as keywords for collecting the national documents. Owing to the wide range of text genres, the collection of national documents was carried out at different points in time and using different sources, including more traditional, paper-based ones, also depending on the category of the searched texts, i.e. the language of the law and the language about the law.

As for online resources, the two main websites used to collect legislative texts are normattiva.it ${ }^{71}$ for the Italian legislation and legislation.gov. $u k^{72}$ for the English legislation. Both websites are search engines for legislation and have an advanced search function that allows for searching keywords either in titles or in context and selecting the desired year or time span and type of legal instrument ${ }^{73}$. However, although the two websites work in a similar way, major differences between the two are due to the characteristics of the two legal systems involved in the research project: while normattiva.it does not provide the user with either linguistic or geographic options, legislation.gov.uk makes it possible to choose between English and Welsh and specify the geographic boundaries within which the legal instruments are applicable, namely United Kingdom, Great Britain, England and/or Wales, Scotland, and Northern Ireland. Despite these differences, the two websites were used for document collection in the same way. The EU terms extracted (see Section 3.3.3.1) were used as keywords to search for national legislation and the documents obtained in such a way were validated manually in order to establish their relevance to the main topic of the study and saved in their electronic format. However, since the Italian website turned out to be insufficient for retrieving the legislative documents necessary for a thorough terminological analysis of the selected area of law, the Italian Codice Penale (Criminal Code) and Codice di Procedura Penale (Code of Criminal Procedure) were also taken into consideration.

Besides this documentation, other sources were considered to be necessary to reach a similar, or even a wider coverage of text types as compared to the EU corpus. Among online resources, further websites need to be mentioned owing to their relevance to the topic and their availability of information on victims of crime, which are mainly the official websites of the following government departments or organisations: the Crown Prosecution Service $(\mathrm{CPS})^{74}$, which has a whole section devoted to victims and witnesses ${ }^{75}$, Victim Support $^{76}$, the

\footnotetext{
${ }^{71}$ Available at http://www.normattiva.it/.

${ }^{72}$ Available at http://www.legislation.gov.uk/.

${ }^{73}$ In legislation.gov.uk it is possible to choose between "All legislation", "Primary legislation", "Secondary legislation" or selected types of legal instruments, whereas in normattiva.it only specific legal instruments can be selected, e.g. "costituzione", "decreto-legge", "decreto legislativo" and "legge”.

${ }^{74}$ Available at http://www.cps.gov.uk/.

${ }_{75}^{75}$ Available at http://www.cps.gov.uk/victims_witnesses/index.html.

${ }^{76}$ Available at http://www.victimsupport.org.uk/.
} 
charity giving free and confidential help to victims of crime, witnesses, their family, friends and anyone else affected by crime in England and Wales, and the Criminal Injuries Compensation Authority (CICA) ${ }^{77}$, the government body responsible for administering the Criminal Injuries Compensation Scheme in England, Scotland and Wales. Although these websites and the legal instruments collected deal with the same topic, the information that can be found in these websites is quite different from that contained in the legal instruments: the texts available on these websites can be classified as texts belonging to the language about the law, more precisely the subcategory of informative texts. However, the information found in these informative texts may be of two different types: while they provide information about the department, body or organisation itself, describing its policies, values and goals, the services provided to the victims and - occasionally - the internal functioning (e.g. details about the staff employed), they can also provide the legal basis which regulates the area of law they are concerned with.

For example, the CPS website contains a whole subsection devoted to codes of practice relating to victims and witnesses, among which the most interesting from the standpoint of this study is the Code of Practice for Victims of Crime ${ }^{78}$. The Victim Support website contains a subsection called Victims: the legal background ${ }^{79}$, where the most significant laws and sets of guidance across the English criminal justice system are provided, whereas on the CICA website the Criminal Injuries Compensation Scheme can be found. These websites are also conceived as a user-friendly resource providing practical information on what the rights of victims and witnesses are. On the CICA website, for instance, the Criminal Injuries Compensation Scheme and a guide explaining the details concerning the application for compensation, the payment of awards and other issues relevant to compensation are available. Moreover, the CPS website provides a whole range of useful leaflets explaining how to report a crime to the police and what happens before, during and after the trial. Given the increasing attention devoted to vulnerable victims both at the supranational and national level, it comes as no surprise that the CPS website also has an entire subsection dedicated to young victims and witnesses ${ }^{80}$, where a distinction is made between young people and children and different materials responding to the needs of the two age groups are available ${ }^{81}$.

\footnotetext{
${ }^{77}$ Available at http://www.justice.gov.uk/about/criminal-injuries-compensation-authority.

${ }^{78}$ Available at http://www.cps.gov.uk/victims_witnesses/victims_code.pdf.

${ }^{79}$ Available at http://www.victimsupport.org.uk/About-us/What-we-do/victims-legal-background.

${ }^{80}$ Available at http://www.cps.gov.uk/victims_witnesses/young_victims/index.html.

${ }^{81}$ The content of this subsection is adapted to different age groups: for instance, a step-by-step description of the criminal proceedings in its broadest meaning, ranging from the commission of the crime to the contacts with the Crown Prosecutor and the lawyer and the actual trial, is provided to children by means of pictures and to young people by means of textual material reproducing a hypothetical criminal case involving a teenager.
} 
On the basis of the examples reported so far, it can be concluded that the victim-related informative material available online is very heterogeneous and, although its macro-function is to inform the reader about different victim-related issues, the micro-functions can vary significantly, especially according to the activity the victim is involved in (e.g. reporting a crime to the police, giving a witness statement, applying for compensation) and the victim's age and vulnerability.

Looking for online informative material in the Italian context, the situation is rather different. The website of the Ministero della Giustizia (Ministry of Justice) ${ }^{82}$, for example, has a section called Schede pratiche (Practical files) ${ }^{83}$, where two subsections are found which could be expected to relate to the main topic of this study, namely Minori (Minors) and Processi $e$ cause (Trials and lawsuits), but in fact do not dealt with victims of crime. The subsection concerning minors is mainly devoted to adoption and kidnapping, and no mention is made of children as victims or witnesses of a crime, while in the second subsection only partial information about the rights granted to people involved in criminal proceedings is given, such as the right to legal aid (patrocinio a spese dello Stato). On the website of the Italian police force (Polizia dello Stato ${ }^{84}$ ) no useful information for a hypothetical victim of a crime is provided, although by searching in the news archive a leaflet containing some information on the main rights of crime victims can be found. On the website of the other Italian police force, i.e. the Arma dei Carabinieri ${ }^{85}$, no practical guidance for crime victims has been found.

As for victim support organisations, in Italy there is no organisation comparable to Victim Support. Support to victims in Italy is provided by different charities that generally focus on a single type of victims or crime, such as child abuse or domestic violence. These charities are usually local and provide their services to the municipal communities, although some of them can be included in government-funded projects, such as the Rete Nazionale Antiviolenza ${ }^{86}$ (National Network Against Violence) activated by the Dipartimento per le Pari Opportunità (Department for Equal Opportunities) of the Presidenza del Consiglio dei Ministri (Presidency of the Council of Ministers) to fight gender-based violence. Given the lack of an organisation committed to offering nation-wide support to all victims of crime, irrespective of their gender, age, or other personal circumstances and the crime they have been the victims of, no website of any Italian victim support organisation was into account for the collection of

\footnotetext{
${ }^{82}$ Available at http://www.giustizia.it/giustizia/it/homepage.wp.

${ }^{83}$ Available at http://www.giustizia.it/giustizia/it/mg_3.wp.

${ }^{84}$ Available at http://www.poliziadistato.it/.

${ }^{85}$ Available at http://www.carabinieri.it.

86 Available at http://www.pariopportunita.gov.it/index.php/numeri-di-pubblica-utilita-sezione/117-numeroverde-1522-antiviolenza-donna.
} 
informative material. Therefore, it can be concluded that there is more informative material concerning victim-related issues available in British than in Italian websites.

Unlike the EU corpus, during the collection of national documents also academic texts were gathered, which were available either in electronic or paper format. The authors of these texts are always known (see, for instance, Allegrezza 2012; Ashworth \& Redmayne 2005; Cendon 1998), since also each entry in legal encyclopaedias is generally accompanied by the name of its author. This leads to a further remark on the authorship of texts that make up the EU corpus and the collection of national texts. Irrespective of their belonging to the language of the law or about the law, EU documents can be divided into three groups according to their author:

1) documents written by EU institutions whose names of the drafters are unknown;

2) documents written by Member States whose names of the drafters are unknown (e.g. the above mentioned Initiative of the Portuguese Republic);

3) documents written by known authors (e.g. the above mentioned opinions of Advocates General).

As for national documents, the variety of texts and therefore of sources selected corresponds to a variety of authors, according to which the national documents can be divided into:

1) legislative documents whose names of the drafters are unknown;

2) (mainly informative) documents written by governmental bodies, organisations and charities whose names of the drafters are unknown;

3) academic and pre-/post-legislative documents written by lawyers whose names are known.

So far, the national documents collected have never been referred to as a set of documents making up a corpus and in what follows this set is always referred to as a collection of national texts, because it does not meet the requirements of a corpus mentioned in Section 3.3.2.1, since not all the texts are available in electronic format nor can be processed by software for linguistic data management and analysis. The choice of keeping the texts in their original formats and treating them as a collection of texts rather than a proper corpus has been determined by practical reasons that have not been considered to influence the terminological analysis.

\subsubsection{STEP 5. TERMINOGRAPHIC PROCESSING OF NATIONAL COMPARABLE TEXTS}

The terminographic processing of national comparable texts exhibits some similarities and some differences with the analysis carried out for EU terminology (see Section 3.3.3). The 
two approaches are similar in the aim they pursue, since in both cases the scope is to identify terms and relevant linguistic and conceptual information, as well as information about the terminological equivalence, but they differ in the steps followed to reach this goal owing to the differences in the textual material analysed. Comparing Step 3 and Step 5 in Figure 3.2, it can be seen that the first two sub-steps almost coincide: the first sub-step allows for the identification of the terms to submit to terminological analysis, while the second consists in the terminological analysis itself. However, the method used for term identification is different. For EU terminology, a semi-automatic extraction process was carried out (see Section 3.3.3.1), while the extraction of national terminology followed a different path. As mentioned in Section 3.3.4, the national texts were collected on the basis of a list of key EU terms, which means that the extraction of national terms started with the verification of the presence of the EU terms in national contexts. The national textual material was then also manually analysed in order to identify possible term variants and, in the case a terminological vacuum emerged, a further check was carried out to identify possible lexical variants or a conceptual vacuum. Once national terms were selected, a terminological analysis was carried out in a similar fashion as the analysis described in Section 3.3.3.2, with the only difference that no bilingual cross-checking was possible due to the lack of parallel texts.

This phase is exemplified by the English term victim and the Italian term vittima. The former term was used to retrieve national victim-related texts, such as the Youth Justice and Criminal Evidence Act $1999^{87}$ and the Victims' Code of Practice ${ }^{88}$. By searching for the term victim in such documents, the actual usage of the term in national contexts was checked. By means of the same technique it was also possible to identify the terminological variants in which the term victim is the head element, such as victim of criminal conduct and victim of crime, and other terminological units which either contain the searched key term, such as vulnerable and intimidated victim, or co-occur frequently with it, such as Criminal Injuries Compensation Authority. Since the presence of the same term in legal texts of different origin is not a sufficient criterion to declare absolute correspondence between the concepts designated by the term itself, the collected texts were also examined in order to identify possible definitions of the terms searched. A definition for the term victim was found in the Victims' Code of Practice, according to which a victim is a person "who has made an allegation to the police, or had an allegation made on his or her behalf, that [s/he has] been directly subjected to

87 Youth Justice and Criminal Evidence Act 1999 (c.23), London, HMSO, available at http://www.legislation.gov.uk/ukpga/1999/23/pdfs/ukpga_19990023_en.pdf.

${ }^{88}$ Home Office, Crown Prosecution Service \& Department for Constitutional Affairs (2004) The Code of Practice for Victims of Crime, available at http://www.cps.gov.uk/victims_witnesses/victims_code.pdf. 
criminal conduct under the National Crime Recording Standard" (CJS 2005: Paragraph 3.1) and is therefore entitled to receive services under the Victims' Code of Practice. This definition slightly differs from the definition provided by Article 1(a) of Council Framework Decision 2001/220/JHA, which states that a victim is "a natural person who has suffered harm, including physical or mental injury, emotional suffering or economic loss, directly caused by acts or omissions that are in violation of the criminal law of a Member State". Therefore, a further conceptual analysis of the EU and the national concept designated by the term victim was carried out to identify the common traits and the distinguishing elements of the EU and the national concept ${ }^{89}$ and establish the degree of conceptual correspondence between them. Before moving on to the Italian example, it should be noted that in the present study the term "correspondence" is used to refer to the relationship that holds between the terms used to refer to the same concept or two very similar concepts in a single language, while the term "equivalence" is used to designate the same relationship holding among concepts belonging to different languages.

The same procedure was adopted for the Italian term vittima. Unlike the equivalent English term, which was found in national texts belonging both to the language of the law and the language about the law and refers to a concept that can be considered quite similar to the concept designated by the same term in EU documents, in the Italian national context the term vittima deserves a deeper terminological and conceptual analysis. The search for this term in the major Italian sources of criminal law, i.e. the Codice Penale and the Codice di Procedura Penale, revealed that the term itself is only used twice in Article 498(4-ter) of the latter $\operatorname{code}^{90}$, although in these cases it is to be considered as a modifier of two head elements, namely "minore" (minor) in the first case and "maggiorenne infermo di mente" (mentally disabled adult) in the second case. However, on the grounds of the preliminary frame-based conceptual structuring of the area of knowledge described in Section 3.3.1.3, and owing to the purposes for which it was conceived, it is reasonable to assume that the Codice di Procedura Penale also takes into account the concept of VICTIM or at least a similar concept. To identify the terms that could refer to such a concept, the Codice di Procedura Penale was examined and an entire part (Articles 1-108) devoted to the persons involved in criminal proceedings was found where Title VI (Articles 90-95) specifically deals with what is known in Italian as

\footnotetext{
${ }^{89}$ For an in depth examination of the conceptual differences between the EU and the national concept of victim see the terminographic entry "victim" in MuLex.

${ }^{90}$ The text of Article 498 (4-ter) of the Codice di procedura penale reads as follows: "Quando si procede per $\mathrm{i}$ reati di cui agli articoli 600 600-bis, 600-ter, 600-quater, 600-quinquies, 601, 602, 609-bis, 609-ter, 609-quater e 609-octies e 612-bis del codice penale, l'esame del minore vittima del reato ovvero del maggiorenne infermo di mente vittima del reato viene effettuato, su richiesta sua o del suo difensore, mediante l'uso di un vetro specchio unitamente ad un impianto citofonico."
} 


\section{Chapter 3}

persona offesa dal reato. This term designates a concept that can be - at least partially compared to the concept of VICTIM. At this point, a conceptual analysis was necessary to verify the similarities and differences in the EU concept VICTIM and the Italian concept PERSONA OFFESA DAL REATO and the intralingual (an)isomorphism identified in this phase was recorded in the MuLex TKB base during when compiling the terminographic entries.

The terminological analysis of national terms against the background of an already existing list of EU terms therefore required the adoption of a comparative approach, which allowed for the identification of similarities and discrepancies in the legal concepts belonging to different legal systems. Such an approach made it necessary to resort to additional textual material as a source of conceptual information and consult the field expert to check for the appropriateness of the conclusions reached. The need for additional reference material mainly emerged from the lack of definitions and/or sufficient knowledge-rich contexts from which conceptual information could be extracted to elaborate comprehensive definitions. Taking the alreadymentioned example of the Italian term persona offesa dal reato into consideration, it would be plausible to think that the Codice di Procedura Penale, which provides the basis for criminal proceedings in Italy, also provides a sort of definition of the key players taking part in them. However, this is not the case for the term in question. Therefore, although the code can be considered a reliable source for contexts and information on the rights and powers of the persona offesa dal reato, the information in it was insufficient for formulating a definition and support was sought by resorting to additional material, mainly academic works (see Section 3.3.1.2).

When comparing the national terminology with the EU terminology, the terminological analysis also required that, both when there was lexical identity between EU terms and national terms as in the victim example discussed above and when new terms were identified as in the case of persona offesa dal reato, a search for possible terminological variants of the searched terms or the new terms identified was carried out. For instance, while searching for the English term victim in English national texts, the term and its three EU term variants (i.e. victim of a crime, victim of the offence and crime victim) were found also in the national context, but the search also revealed the presence of another variant, i.e. victim of criminal conduct, which had not been detected in the EU corpus. A further cross-check in the EU corpus confirmed the exclusive usage of the latter variant only in national texts.

Going back to the Italian example and limiting the discussion to the search for terminological variants of the Italian national term persona offesa dal reato, in the Codice di Procedura Penale a short form of the term was detected, i.e. persona offesa, while in the Codice Penale 
the short form offeso was found. Further examples which fall into the category of term variants (see Chapter 4) were found, namely soggetto leso in legislative documents and soggetto passivo del reato in academic texts and pre-legislative texts. The term vittima was identified in pre-legislative texts ${ }^{91}$ and academic texts, especially those dealing with the sociological and psychological aspects of victimisation rather than the normative elements regulating the victim's role in criminal proceedings, where the term persona offesa dal reato and its short forms are preferred. The term parte offesa was also detected in all the national text genres considered but, despite its usage in legislative documents, the terminological analysis revealed that, from the strict standpoint of the Italian criminal procedure, the term is inappropriate to designate the concept PERSONA OFFESA DAL REATO, because its head element, i.e. parte (party), entails a range of rights, powers and duties reserved to those that are allowed to have an active role in the criminal proceedings, while the persona offesa dal reato is only considered a proper party when s/he is also the person who has been injured or damaged by the crime (danneggiato) and can therefore claim compensation during the criminal proceedings (parte civile). In all the other cases, s/he is simply considered to be a soggetto del procedimento penale (person involved in criminal proceedings).

While searching for national terminology, although no automatic term extraction tool was used, it was observed that some terms frequently co-occurred with the searched key terms and terminological variants identified in the collection of national texts. This is the case of the above mentioned term persona offesa dal reato, which was frequently found in contexts where the term danneggiato occurred. Based on this observation, some frequently cooccurring terms were selected and added to the MuLex TKB as their frequency in conjunction with the searched terms seemed to indicate the existence of a close conceptual relationship ${ }^{92}$. In these cases, a terminological vacuum leading to a conceptual vacuum was observed at the EU level, as a further cross-check in the EU corpus proved that these terms were only used in national contexts. Consequently, for these terms the conceptual analysis was not performed inter-systemically by taking into consideration two legal systems expressed by the same

\footnotetext{
${ }^{91}$ See, for example, Boato \& Cima 2002.

92 The English terms belonging to this category are: application for compensation and its synonym claim for compensation, applicant and its full form applicant for compensation, Criminal Injuries Compensation Authority and its variant CICA, Criminal Injuries Compensation Scheme and its variant CICS, qualifying claimant, and Victim Support. Given that for the last term mentioned the variants Victim Support England \& Wales and Victim Support England and Wales were also found, although they do not seem to be very frequent, for the sake of completeness also the terms Victim Support Northern Ireland and its variants Victim Support NI and VSNI, and Victim Support Scotland and its variant VSS were included in MuLex. The Italian terms falling into this category are: danneggiato and its variants parte danneggiata, persona danneggiata dal reato and danneggiato dal reato, and the term elargizione and its full form elargizione a carico dello Stato.
} 
Chapter 3

language, i.e. by comparing the Italian national concept with the EU concept and the English national concept and the EU concept.

\subsubsection{STEP 6. POPULATION OF A TRANSLATION-ORIENTED TERMINOLOGICAL KNOWLEDGE BASE}

In order to record all the linguistic and conceptual data gathered during Steps 3 and 5 (see Sections 3.3.3 and 3.3.5 respectively), the MuLex TKB was developed. Though the specific features of MuLex are described in Chapter 6, the procedure followed to populate it, especially as regards the clustering of term variants in terminographic records and the crosslinguistic matching of term equivalents, will be briefly illustrated below.

\subsubsection{TERM CLUSTERING}

In MuLex, terminographic entries are concept-oriented, meaning that every entry is created to collect all the possible terminological units referring to a single concept. However, as has been illustrated by means of the examples provided in Section 3.3.5, the terminological analysis of national terms against the background of an already existing list of EU terms revealed similarities and discrepancies in the legal concepts belonging to different legal systems. In order to record the extracted terms in MuLex, the concept of 'term cluster' was introduced to group terminological units in concept-oriented terminographic entries. In this research study, a term cluster is a group of terminological units created on the basis of the genotype-phenotype distinction introduced by Sacco (1991: 27). Such distinction allows for a certain degree of conceptual anisomorphism within the term cluster, in which terms not always meaning the same thing but often meaning almost the same thing are grouped.

Following Sacco (1991: 27), when analysing the concepts designated by EU and national terms the general features of these concepts were identified to find the underlying "genotype", i.e. the super-abstract legal notion the concepts refer to. Therefore, if an EU concept and a national concept shared the same genotype, they were considered to be "phenotypes" of that genotype, i.e. the embodiment of the super-abstract notion in one of the legal systems involved. In this study, the terms designating these phenotypes were regarded as terminological units to be included in the same term cluster. Term clusters recorded in MuLex may thus contain terms that refer to phenotypes among which conceptual correspondence is not absolute, as in the examples of victim and vittima discussed in Section 3.3.5. By adopting the genotype-phenotype distinction, 108 term clusters have been created, which contain a total of 346 terminological units, of which 149 are English and 197 are Italian terms. 
In the cases exemplified in Section 3.3.5, when comparing the legal systems expressed in the same language common genotypes being instantiated by national and EU phenotypes were found. However, when searching for national terminology another phenomenon was observed, i.e. the lack of both the searched term and an alternative to it in the national context. To illustrate this phenomenon, the English term cross-border victim found in the EU corpus is taken as an example. The concept designated by this term is an EU concept. Given its definition, according to which a cross-border victim is an EU citizen who becomes the victim of a crime in a Member State other than that where s/he is habitually resident, and owing to the implementation in the UK of Council Directive 2004/80/EC which relates to compensation to crime victims in cross-border situations, it is clear that the lack of a term to refer to the concept is not justified by a conceptual vacuum in the British legal system. Therefore, an alternative linguistic form can be expected to be used in national contexts, as is the case of the following example from the When Things Go Wrong section in the Foreign and Commonwealth Office ${ }^{93}$ website, which reads "If you are unfortunate enough to be the victim of a crime of any kind overseas, our Embassies may be able to help you"94. Though the genotype is present in both the EU and the British legal systems, no national term was found to be included in the relevant term cluster.

So far it has been said that all the terminological units in one language referring to a shared genotype were gathered in a term cluster. However, among the terms forming a term cluster, a main term needed to be selected for terminographic purposes (e.g. presentation of terminological data, cross-linguistic term matching, etc.). In order to do so, in this research project some criteria were followed which depended on the characteristics of the terminology analysed, the multi-level jurisdiction in which the terminology was rooted and the envisaged end users of the TKB used for recording the terms. If a legal concept was referred to by only one term, such term corresponded to the main term, but when more than one terminological unit were gathered in a term cluster, the following criteria were considered to identify the main term among them. First of all, if both EU and national terms belonged to the same cluster, the former were preferred on the basis of the methodological approach adopted in the research study, which started with the terminological analysis of the EU legal system. In case terms were found both in legally binding and non-legally binding texts, the terms rooted in the former were preferred due to the higher degree of control on terminology in such documents (see European Parliament et al. 2003: Guideline 5). If more than one term was available in normative texts, then the term used in the latest document was selected as the main term.

\footnotetext{
${ }^{93}$ Available at http://www.fco.gov.uk/en/.

${ }^{94}$ Available at http://www.fco.gov.uk/en/travel-and-living-abroad/when-things-go-wrong/crime/.
} 


\section{Chapter 3}

Finally, if the terms were found in non-legally binding texts only, then the most frequent term was selected.

\subsubsection{CROSS-LINGUISTIC TERM MATCHING}

In order to analyse national terms and identify the linguistic and conceptual similarities and differences between EU and national terminology, the two languages have been treated separately, so as to generate distinct term clusters for each language. Since the terminological analysis presented in this study is translation-oriented, term clusters needed a further step, i.e. cross-linguistic term matching, which was carried out on the basis of the identification of shared genotypes and terminological equivalents in the EU corpus. The reason for taking into account two aspects for the cross-linguistic matching was determined by the different origins of the terms under study. As discussed in Section 3.3.2.3, the equal authenticity principle governing EU documents made it possible to identify the translation equivalents used in EU documents. However, given that one aim of the terminological analysis was to establish a connection between EU and national terms and that there was no absolute correspondence between them, as in the case of vittima and persona offesa dal reato discussed above, the identification of translation equivalents in parallel texts was not enough. Therefore, while equivalence between EU terms was established on the basis of their usage in parallel texts, for national terminology a different approach was adopted.

The differences between the two approaches are illustrated by taking the example of the terms legal aid and patrocinio gratuito. The two terms are used as equivalents in EU documents and refer to the legal assistance provided free of charge to those who lack sufficient resources in so far as such aid is necessary to ensure effective access to justice. Being embedded in the EU legal system, the concept the two terms refer to is sufficiently broad so as to include all the forms of legal aid encountered in the Member States' legal systems. The focus in the EU term is primarily on the fact that such assistance is free of charge for the person who is entitled to it. However, when compared to the terminology used in the Italian national setting, a conceptual divergence due to the usage of the modifier "gratuito" (free) is observed. If, on the one hand, in the EU context the modifier "gratuito" shows that the victim is entitled to legal assistance free of charge, without preventing any authority from paying it, in the Italian national context the same modifier is provided with an additional meaning, i.e. patrocinio gratuito and its variant gratuito patrocinio refer to a form of legal assistance that is free for the person entitled to it and no payment is due to the lawyer providing it. Therefore, although the EU term and the national term form part of the same term cluster based on the genotype 
they are associated with, there are conceptual differences to be taken into account both within one language, as in the case just mentioned, and from a bilingual perspective.

Looking at the English term, while in the EU context the payment of the expenses for legal aid is not mentioned, in the English national legal system it is clear that these legal costs are paid by the government. Therefore, in the process of cross-linguistic term matching, after the EU translation equivalents were identified, a comparative analysis of the characteristics specific to the legal systems needed to be carried out to identify the differences and similarities in the phenotypes associated to a common genotype. In so doing, it was possible to first establish the degree of terminological correspondence within the legal systems expressed by the same language and, secondly, establish the degree of equivalence within the legal systems that are expressed in different languages. Such differences are further discussed in Chapter 5 on terminological equivalence.

\subsubsection{CONCEPTUAL (RE)STRUCTURING OF THE AREA OF KNOWLEDGE}

When all the terminological data were recorded in the MuLex TKB and the degree of intralingual correspondence and interlingual equivalence among terms was established, the conceptual relations among the recorded concepts, which are discussed in greater detail in Section 6.4.1.1.2.1, could be included in the TKB. These relations were first identified by consulting the textual material analysed, i.e. the same material from which terms were extracted, and were later validated by the subject field expert. In so doing, differences in the conceptualisation among the legal systems were depicted. For instance, in the example provided in Figure 3.12, the CHILD VICTIM genotype is conceptualised differently in the EU and the Italian legal system: while in the EU legal system there is a conceptual relation between this genotype and the CHILD-FRIENDLY JUSTICE genotype, in the Italian legal system such relation was not found, since the latter lacks a phenotype in the Italian system.

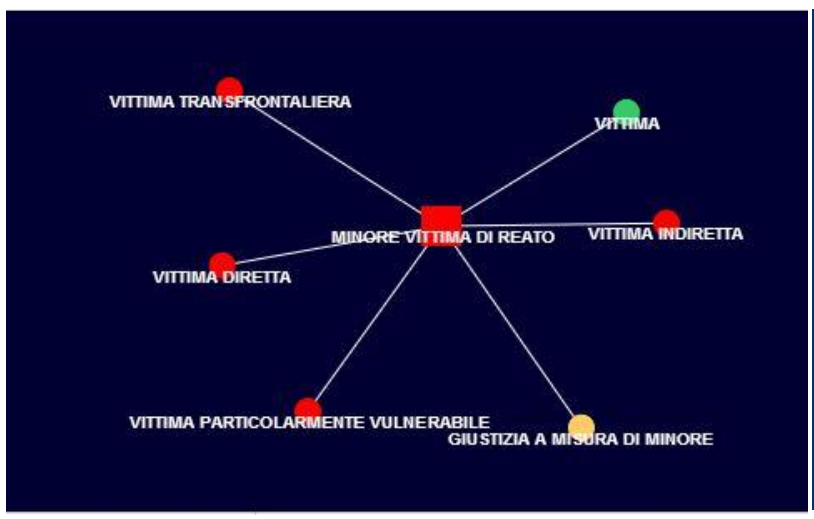

Legal system: EU

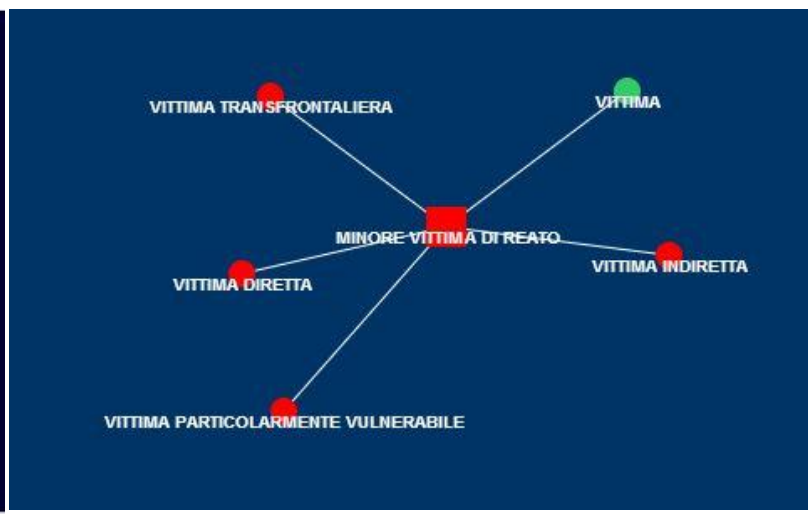

Legal system: Italy 
Figure 3.12. Example of anisomorphism in conceptual relations. genotype: CHILD VICTIM.

On the basis on the information gathered in the terminological analysis (see Sections 3.3.3 and 3.3.5), the preliminary conceptual structure elaborated before the actual terminological analysis could be reconsidered and redefined, also by consulting the subject field expert, in order to include the conceptual information in the TKB.

\subsubsection{STEP 7. REVISION AND VALIDATION}

The final step in the methodology proposed for carrying out a terminographic work in the field of legal terminology embedded in a multi-level jurisdiction is the revision and validation phase. In this phase, the subject field expert plays a central role, since "[b]oth the terms and the term relations require to be controlled by the expert" (Hamon \& Nazarenko 2001: 188). Therefore, the expert was consulted not only in the text selection phases (Steps 2 and 4), but also throughout the terminological analysis phases (Steps 3 and 5) with the aim of fixing concepts, establishing the conceptual systems, solving problems concerning discrepancies in the legal systems and phenotypes referring to common genotypes, and validating the equivalents established in the term-matching phases (see Quiroz et al. 1999: 169). The expert was also consulted for the final revision and validation of the terminological collection, especially for the purpose of revising the definitions included in MuLex in light of the latest development in the area of law of victims of crime.

In this thesis, an emblematic case of the essential role of the expert in the validation phase is provided by the Italian and English term clusters related to the VICTIM WITH SPECIAL PROTECTION NEEDS genotype. During the first text selection phase of the research, Council Framework Decision 2001/220/JHA was first selected among EU texts, from which the Italian term vittima particolarmente vulnerabile (already discussed in Section 3.3.3.2.1) was extracted, which was initially selected as the main term on the basis of the criteria illustrated in Section 3.3.6.2. The relevant genotype identified was PARTICULARLY VULNERABLE VICTIM, for which Italian term variants and the English equivalent and relevant term variants were searched. However, once the Council Directive 2012/29/EU was included in the EU corpus, another term was found in each language, i.e. victim with specific protection needs and vittima con esigenze specifiche di protezione. The terminological analysis carried out on these two terms revealed a strong connection with the PARTICULARLY VULNERABLE VICTIM genotype, though a conceptual difference was identified. Therefore, the expert was consulted for verifying whether: a) the terms could be considered to belong to same term cluster, and $b$ ) the genotype needed revision on the basis of the conceptual evolution occurred in a time span of 
11 years. On the basis of expert consultation, it was determined that: a) the terms could actually be considered to belong to the same term cluster, in spite of the conceptual differences among the phenotypes in the EU legal system, and b) since the conceptual evolution produced a conceptual shift and the 2001 Council Framework Decision was replaced by the 2012 Directive, the original genotype should have been replaced by the VICTIM WITH SPECIFIC PROTECTION NEEDS genotype.

Though the final version of the terminological collection underwent revision and validation by a domain expert, it should not be overlooked that "term bases $[\ldots]$ are prone to continuous evolutions: creation, modification, semantic shifts, neologisms, etc. Therefore, term databases need to be constantly rebuilt, maintained, and enriched in order to follow the thematic drifts in scientific and technical areas" (Jacquemin \& Bourigault 2003: 604). As a consequence, though being revised and validated by a subfield expert, the data contained in the terminological collection need to be considered provisional in nature.

\subsection{Summary}

In Chapter 3, the methodology adopted for the terminographic work which is the focus of the research study presented in this thesis has been illustrated. The methodological framework was developed on the basis of Cabré's methodological model (Cabré 1999a: 129-159), although some substantial differences can be identified when comparing the two models, which are mainly due to the type of terminology subject to terminological analysis. Cabré's model is intended as a general model for systematic multilingual searches in areas of knowledge where the underlying conceptual system is assumed to be shared, regardless of the language that is used to refer to the conceptual system. The methodological framework presented here, on the other hand, was specifically developed for the terminological study of legal terminology embedded in a multi-level jurisdiction. Due to the co-existence of different legal systems, it was assumed that there were both similarities and discrepancies in the conceptual systems under discussion, corresponding to two national legal systems and a supranational legal system. The similarities could be identified mainly at the genotype level, i.e. when the super-abstract legal notions were taken into account, while discrepancies emerged especially at the phenotype level.

The type of terminology selected for carrying out a terminographic work affected the methodological approach also from another perspective. Owing to the precedence of EU law 


\section{Chapter 3}

over national law within the boundaries of the EU, the terminology extracted from the EU corpus was analysed before the same analysis was carried out for national terminology, which had two methodological consequences: firstly, the textual material to be analysed was gathered at different points in time and in different ways (Steps 2 and 4), and secondly, the terminological analysis was performed in two different moments, since it was first carried out on EU terminology (Step 3) and only afterwards on national terminology (Step 5).

The terminological analysis carried out following the methodology presented in this chapter revealed that cases of terminological and conceptual anisomorphism can be observed both within a single language and interlingually when comparing EU terminology with national terminology. Such cases prove the existence of terminological dynamism in the legal terminology rooted in a multi-level jurisdiction, which is reflected in different types of terminological variation presented in Chapter 4 and different degrees of terminological equivalence discussed in Chapter 5. 


\section{Chapter 4. ViCTIMS OF CRIME FROM A MONOLINGUAL Terminological Perspective: Terminological VARIATION}

Chapter 4 illustrates the first phenomenon in which terminological dynamism in the EU multi-level jurisdiction is reflected, i.e. terminological variation. The term "terminological variation" comprise different linguistic phenomena according to different authors. In this study, the term is used to refer to two correlated phenomena: the first of which occurs when one and the same concept is referred to by means of different denominations (denominative variation), while the second occurs when a concept lacks cleat-cut boundaries and the differences in the conceptualisation reflect in denominative variation (conceptual variation).

\subsection{STATE OF THE ART IN THE STUDY OF TERMINOLOGICAL VARIATION}

In order to understand how terminological variation is conceived in this thesis, first of all some points of view on this topic of different currents of thought and authors are presented, and then a tentative definition of this phenomenon is provided that fits the purposes of this study.

\subsubsection{THE EXCLUSION OF TERMINOLOGICAL VARIATION FROM STANDARDISATION- ORIENTED TERMINOLOGY THEORIES}

Ever since the beginning of scientific studies in the field of Terminology in the 1930s, which can be said to be unanimously attributed to Eugen Wüster, the existence of diverse singleword or multi-word terms ${ }^{95}$ to refer to a single concept has been recognised as a linguistic phenomenon characterising specialised language as well as general language. However, the approach adopted by early terminologists to deal with this phenomenon was considerably different from those developed mainly in the last two decades. The approach adopted by Wüster (1979), who was a "fierce proponent of unambiguous professional communication"

\footnotetext{
${ }^{95}$ In this thesis, the terms "single-word terms" and "multi-word terms" are used interchangeably with "monolexical terms" and "polylexical terms".
} 
(Cabré 2003: 165), reflects the author's personal experience in terminographic tasks, which at the time were carried out mainly in the field of engineering. Out of such experience and with a view to reach unambiguous communication among experts, the "father of terminology science" developed a conviction in the need for the systematisation and standardisation of specialised lexical units on the basis of international principles. Such principles should be applied in practical terminographic tasks, i.e. the description and the recording of terminological units, and should suit all the languages for special purposes. However, in order for practical international principles to be formulated, more general and abstract principles were needed which could give birth to a general theory of Terminology ${ }^{96}$. In later references to Wüster's work and principles, which were further elaborated and disseminated by Helmut Felber, these abstract principles were generally referred to as the General Theory of Terminology (GTT), and are still known by this name today. However, since several authors (see further) criticised these principles and acknowledged the impossibility to consider them as general, the GTT is also referred to as "traditional Terminology" (see, for example, Temmerman 1997) or "classical Terminology" (see, for instance, Bouveret 1998).

The most prominent features of terminology that are commonly attributed to Wüster's work, but were actually collected in a comprehensive volume published posthumously by Felber, i.e. Einführung in die allgemeine Terminologielehre und terminologische Lexikographie (1979), derive from Wüster's differentiation between Terminology and Linguistics. These features are summarised by Cabré (2003: 166) and regard three different spheres, namely language (e.g. priority of the concept over its designation(s), monosemy, univocity, synchronic treatment of terms, priority of written registers), assumptions about the evolution of terminology (e.g. conscious control of evolution by means of language planning and standardisation, priority of international designations), and working methods (e.g. exclusive use of the onomasiological approach as opposed to the semasiological approach used in lexicography, preference for systematic ordering) (see Cabré 2003: 166). According to Wüster's approach, prominence is given to concepts and terms that are conceived as labels in different languages, all referring to an underlying conceptual model which is universal and standardised. In such a conceptual model, cultural differences are not contemplated and therefore terms referring to a concept are considered as equivalent, regardless of the language they belong to. As already mentioned, Wüster's principles originated from his own experience with scientific and technical communication mainly in the engineering domain, which explains why his ambitious aim was that of assuring unambiguous communication in every

\footnotetext{
${ }^{96}$ For the sake of precision, it is worth noting that Wüster himself preferred the term "Terminologielehre", highlighting the practical aspect of the principles proposed, to the term "Theorie", which he actually never used. 
scientific and technical field. Two observations can be made in this regard. First of all, although the principles proposed by Wüster and collected and elaborated by Felber are generally referred to as "the General Theory of Terminology", they arose from the practical experience in a specific domain only. Secondly, these principles can be applied only when the specific aim is that of standardising a domain-specific terminology to achieve unambiguous communication in this domain. This means, however, that the terminographic task being set is prescriptive and excludes any form of descriptive approach which would allow to keep trace of the terminology actually used by field experts. As Cabré pointed out, since Wuster's application-oriented approach based on allegedly general terminological principles became subject to much criticism, later authors supporting the GTT modulated its principles by admitting controlled synonymy (although preference was still given to the avoidance of synonymy in standardisation tasks), complementing the study of terminological units with that of phraseology, considering spoken forms as well as written ones, and introducing the description of the process of term formation and the representation of conceptual structures which are not necessarily ordered hierarchically (see Cabré 2003: 167-168). In the same article, Cabré enumerates also the GTT principles that were kept almost unaltered by the authors belonging to the Vienna School of Terminology (Arntz \& Picht 1989; Felber \& Budin 1989; Felber 1984; Wüster 1979), which are: the priority of concepts over their designations, and the consequent adherence to the onomasiological approach in terminography; the precision of the concept; the need for a prescriptive approach in standardisation and languageplanning tasks; the control of the evolution of terms by means of planning, unification and standardisation; the priority of international forms of designation; and the authority of the written over the spoken form (see Cabre 2003: 168). Therefore, in the GTT approach, the focus on unambiguous communication has led to a prescriptive and standardisation-oriented view in which alternative linguistic designations of a concept are seen as a threat to effective specialised communication.

\subsubsection{THE INCLUSION OF TERMINOLOGICAL VARIATION IN TERMINOLOGY STUDIES}

As stated before, the early studies in Terminology, covering however a time span of more than 50 years (from the 1930s to the mid 1980s), were carried out for standardisation purposes and, from this perspective, terms were seen as lexical units with specific characteristics, among which bi-univocity was certainly of primary importance. According to the GTT, the designation of a concept and the relevant concept are linked via a bi-univocal relation, which means that one term only can designate a concept (monosemy) and one concept can only be 
denoted by one term (mononymy). However, since the early 1990s, owing to the application of specialised corpora to terminological studies, the ideal of the bi-univocity holding between terms and concepts has been questioned by several authors, and polysemy has been recognised as a linguistic phenomenon characterising not only the language for general purposes but also written specialised discourse (see, for instance, Cabré 2003; Condamines \& Rebeyrolle 1997; Eriksen 2002; Ferrari 2002; Zawada \& Swanepoel 1994). Among the alternative paradigms which have extensively criticised the GTT's monosemy/mononymy postulate, three schools of thought are worth mentioning here, namely Socioterminology (Gaudin 1993, 2003), the Communicative Theory of Terminology (Cabré 1999b), and Sociocognitive Terminology (Temmerman 2000a). In general, it can be said that these three alternative approaches to the GTT share some common aspects, in that they are descriptive, thus relying on empirical evidence provided by text and corpus analysis, and they all follow a mainly semasiological line, which can be occasionally complemented by some onomasiological contributions.

Let us now take a closer look at the three alternative approaches trying to countermeasure the postulates of the GTT. Though not completely abandoning the prescriptive perspective, Socioterminology has criticised the GTT for not taking into account the social dimension of terms, which are embedded in an LSP - itself a form of natural language - and are therefore subject to variation depending on the social context in which they appear. Being a social science, Terminology addresses social issues and is thus compelled to reckon with all the social aspects concerning terminological units, including variation. The acceptance of variation in terminology theory also allows for the recognition of the concept systems as being ever-changing rather than static.

In the second of these approaches, the Communicative Theory of Terminology (CTT) developed by Cabré (1999b), terminology is observed from the perspective of a general theory of language (Ferrari 2002: 222) and is conceived as an interdiscipline whose attention is focused on terminological units. Compared to the words in general language, terminological units are therefore not considered to be lexical units with completely different characteristics. In Cabré's words, "a lexical unit is by itself neither terminological nor general but $[\ldots]$ it is general by default and acquires special or terminological meaning when this is activated by the pragmatic characteristics of the discourse" (Cabré 2003: 189-190), meaning that any lexical unit is to be considered as "inherently polyhedral" (Cabré 2000: 49), i.e. simultaneously integrating linguistic, cognitive and social aspects. Not only lexical units have the potential of being terminological units based on the "specific selection of semantic 
features according to the conditions of every speech act" (Cabré 2003: 190), but terminological units share the same features that are generally attributed to words in the general language. Since "[a]ny process of communication involves variation of lexical forms, which manifest themselves as alternative denominations for the same concept (synonymy) or in the semantic openness of one form (polysemy)" (Cabré 2000: 49-50), and given that terminological units are lexical items used in specialised communication settings, it follows that variation also concerns terminological units, "although in different degrees, according to the type of communicative situation" (Cabré 2000: 50). Therefore, Cabré insists that the GTT "cannot account for the complexity of actual terminological phenomena occurring in texts" (Cabré 2000: 39), and that its most unsatisfactory element is "its reductionist character, which makes it unable to explain the complexities occurring in special communication" (Cabré 2000: 39). The author also recognises that since the GTT has introduced a standardisationoriented methodology which is considered universally valid, regardless of the specialised domain, the aim, the languages and the communicative setting or context involved, the terminographic activities carried out following this methodology provide the end user with an idealised rather than realistic view of the usage of terminological units in authentic, spontaneous specialised communication.

The Sociocognitive Terminology developed by Temmerman (2000a) made a further step in the questioning of the bi-univocity principle postulated by the GTT by drawing upon the distinction between concepts on the one hand and categories on the other. While concepts are clear-cut and can therefore show a natural tendency towards univocity (Temmerman 1997: 62), categories are prototypically structured, which makes univocity impossible for three reasons (Temmerman 1997: 67). First of all, in the sociocognitive theoretical framework polysemy is considered functional for LSP discourse, as it derives from the evolution of meaning and allows for conveying changes in meaning. Terminological units are therefore not necessarily addressed from a synchronic perspective as in the GTT, but can be analysed from a diachronic point of view so as to see their development in time. Secondly, besides polysemy, also synonymy is considered functional for LSP discourse, since it is used to express different perspectives on the same subject. Thirdly, the GTT postulate that literal language can replace figurative language is confutated on the grounds that the latter "is a motor to make the thoughts move" (Temmerman 1997: 67). From the sociocognitive perspective, therefore, "understanding is a never-ending process in which synonymy and polysemy play a role" (Temmerman \& Kerremans 2003: 2) rather than being "perturbing factors" (Temmerman 2009: 107). 
The GTT approach seems to be too restricted also from a translator's perspective. As pointed out by Collet, "les traducteurs et rédacteurs consultent les dictionnaires spécialisés dans le but de se renseigner sur la terminologie ayant cours dans un domaine ou afin d'acquérir un minimum de connaissances encyclopédiques ou conceptuelles pertinentes" (Collet 2004b: 247-248), an observation that can be extended from specialised dictionaries to traditional terminological resources as well. The reason for this resides in the fact that such resources often focus more on conceptual information, usually provided in the form of a definition, than on the linguistic information their users are looking for. They can be thus considered to respond appropriately to the need for encyclopaedic information translators may have, but the acquisition of this type of knowledge is not the only reason for consulting them. Indeed, traditional terminological resources often lack the necessary information related to the behaviour of words, and more specifically terms, in context, which is the information that translators, representing one of the groups of users who most frequently resort to lexicographical and terminographic resources, need most (Durán Muñoz 2012). Therefore, while on the one hand lexicographical and terminographic resources may prove useful for translators from a conceptual or encyclopaedic perspective, " $[\mathrm{t}]$ heir usefulness $[\ldots]$ - like any general language dictionary - is limited to represent the 'langue' or 'norm' level of language and not the individual actual text level" (Gerzymisch-Arbogast 2008: 20), which is the level translator have to come to terms with. It follows that "[q]uestions such as 'are there any collocational restrictions?' or 'what term fits best in the context of my translation?' remain very often unanswered" (Kerremans 2010). Therefore, dictionaries and other terminographic resources can be said to accomplish their referential function only partially because they are developed on the basis of a normative, prescriptive structuring which makes them inadequate in reflecting the language, and consequently the terminology, as it is used in authentic contexts of specialised discourse, where the univocity principle has been empirically proven not to be the rule. Therefore, it is fundamental for translators, whose professional environment is the multifaceted specialised discourse, to know a concept's various designations that are used in different communicative settings, and to be provided with all the necessary information so as to be able to choose the most appropriate solution according to the variables affecting their task (e.g. source text, target text, genre, register, target audience, intended function).

As noted earlier, in the last two decades the focus of studies in Terminology has moved away from the predominantly standardisation-oriented approach proposed by the GTT. Thanks to the development of IT tools and consequently of Corpus Linguistics, corpus analysis has 
become a fundamental part of the terminological activity, leading to the development of more descriptive approaches that fall within the so-called "textual Terminology" (Bourigault \& Slodzian 1999), which aims at reflecting the actual use of terminological units in authentic specialised contexts. According to Bourigault and Slodzian, there are two main reasons for this significant shift. On the one hand, "[1]es applications de la terminologie sont le plus souvent des applications textuelles (traduction, indexation, aide à la rédaction)"; therefore, "la terminologie doit 'venir' des textes pour mieux y 'retourner"' (Bourigault \& Slodzian 1999: 30). On the other hand, “[c]'est dans les textes produits ou utilisés par une communauté d'experts, que sont exprimées, et donc accessibles, une bonne partie des connaissances partagées de cette communauté, c'est donc par là qu'il faut commencer l'analyse" (Bourigault \& Slodzian 1999: 30). It follows that the inclusion of a textual approach into the study of terminology has allowed for a shift from a prescriptive orientation towards a more descriptive one that has shed new light on the actual usage of terminology in LSP texts and therefore on terminological variation as well.

\subsection{TERMINOLOGICAL VARIATION: A POLYSEMOUS TERM}

So far, the terms "terminological variation", "polysemy" and "synonymy" have been used without a clear qualification of their meaning or definition. In this regard, it should be noticed that the term terminological variation has been introduced in terminological studies only recently, while the terms polysemy and synonymy have a longer tradition. A review of the relevant literature shows that there is no unanimous definition of terminological variation, polysemy and synonymy. Therefore, what follows will provide a brief description of the evolution of the usage of these terms and a proposal for a definition of terminological variation which is functional for the purposes of describing the behaviour of terminological units in a multi-jurisdictional setting.

Starting with synonymy, a definition that reconciles the points of view of many authors is the one provided by the international standard ISO-1087-1, according to which synonymy is the "relation between or among terms in a given language representing the same concept" (ISO 1087-1 2000: Section 3.4.19). The standard goes further in distinguishing proper synonyms, which are those terms that are interchangeable in all contexts, from quasi-synonyms, which are interchangeable only in some contexts. It should be noted that the standard does not provide any clue to neither the exact meaning of context nor the factors that may determine 
the interchangeability, which can be bound to either the specific features of the terms involved (e.g. diatopic or diaphasic aspects) or to conceptual differences (e.g. inclusion, overlapping) (see Magris 2012: 163; Rogers 1997: 219). Therefore, the definitions provided by this standard seem insufficient to describe the phenomena under discussion and it should not come as a surprise that, in order to avoid the difficulties posed by the proliferation of definitions for synonymy and quasi-synonymy (or near or partial synonymy), in recent studies (see, for instance, Bowker \& Hawkins 2006; Condamines 2010; Daille 2005; Freixa et al. 2002; Freixa 2005; Kerremans 2010) resort is made to the term terminological variation, which in fact also needs further consideration. While the term terminological variation seems quite useful in the view of overcoming the negative connotation that synonymy and polysemy have acquired in terminological studies due to the denial attitude promoted by the GTT, it needs to be pointed out that it is not used to refer to a single observable linguistic phenomenon, but is rather an umbrella term covering a series of phenomena. Indeed, even with the introduction of this new term, the definitional difficulties encountered previously have not been fully overcome, since there is no shared view on what phenomena fall into the category of terminological variation. In what follows, the position on terminological variation of four authors is presented and a tentative definition which is functional for the research study is provided.

\subsubsection{TERMINOLOGICAL VARIATION ACCORDING TO IBEKWE-SANJUAN}

In the early days of the discussion on terminological variation, Ibekwe-SanJuan conceived it in a restricted sense, i.e. as "changes affecting the structure and the form of a term producing another textual unit close to the initial one" (Ibekwe-SanJuan 1998: 564). According to the author, these changes can be obtained by means of permutation, expansion and substitution, thus leading to very different results in terms of the variants produced. In her 1998 paper on terminological variation, Ibekwe-SanJuan (1998: 566-567) focused on noun phrases and the syntactic variations that can occur in them when:

a) a term's structure is changed from a syntagmatic structure into a compound one: Permutation, e.g. accession of azolla-anabaena $\rightarrow$ azolla-anabaena accession;

b) a component word in Term 1 is replaced by another word in Term 2 in terminological units of equal length and the words replaced occupy the same position in the term: substitution, e.g. head substitution: nodule development regulation $\rightarrow$ nodule development arrest; modifier substitution: alfalfa root hair $\rightarrow$ curled root hair; 
c) a word component is added in an existing term: Expansion, e.g. left expansion: self-licking $\rightarrow$ refractory self-licking; right expansion: blue light $\rightarrow$ blue light-induced expression; insertion: conserved domain $\rightarrow$ conserved central domain.

As it appears clear from the examples provided by the author, by having recourse to different syntactic transformations the results obtained differ significantly concerning the meaning of the terminological units involved in the transformation. Whereas in the case of permutation the order of the elements constituting the terminological units change leaving their meanings unaltered, in the case of substitution the element may be substituted by a synonymous element. However, according to Ibekwe-SanJuan for the term that has undergone a transformation to be classified as a terminological variant synonymy is not a requirement, as shown in the examples provided by the author herself. The same can be said for terminological units that are subject to one of the three possible forms of expansion, since the meaning of the term is changed according to the component that is added. This means that the terminological units obtained by means of permutation, substitution and expansion are conceptually linked but not necessarily synonymous, since these transformations can yield three types of conceptual relations according to Ibekwe-SanJuan: equivalence (here termed “correspondence", see Section 3.3.5), "class_of" and generic/specific relations (IbekweSanJuan 1998: 568). As stated earlier, among the range of transformations proposed by the author, conceptual correspondence can only be produced by permutation. On the other hand, substitution can engender "class_of" relations because the type of relation changes according to the component (modifier or head) that is replaced within the terminological unit. If the component to be replaced is the modifier, then the concept class remains the same and the properties of the class are modified, as in the example of template DNA, genomic DNA and target DNA (see Ibekwe-SanJuan 1998: 568). If, on the other hand, the head element is substituted, the class of property remains the same, while the concepts associated to that class of property change, such as in DNA fragment, DNA sequence and DNA fingerprinting (see Ibekwe-SanJuan 1998: 568). Finally, expansion results in generic/specific relations that are hierarchical and allow for the construction of families of concepts or objects and families of properties (see Ibekwe-SanJuan 1998: 568). As far as the transformations leading to terminological variation considered by Ibekwe-SanJuan are concerned, three more points should be made: firstly, the author focuses on one language only, i.e. English; secondly, only one-directional transformations are envisaged in permutation; and thirdly, the opposite transformation to expansion, i.e. reduction, is not taken into consideration. In other words, in 
permutation the transformation is only possible from a syntagmatic structure to a compound one and not vice versa, and a terminological variant can be expanded, but not reduced.

\subsubsection{TERMINOLOGICAL VARIATION ACCORDING TO DAILLE}

The approach to terminological variation adopted by Ibekwe-SanJuan and discussed so far is functionalist, in the sense that the author observed three possible ways of syntactically transforming existing terminological units for the specific purpose of identifying research topics from texts. A more comprehensive view on the phenomenon of terminological variation is provided by Daille et al., who offer the following definition: "A variant of a term is an utterance which is semantically and conceptually related to an original term" (Daille et al. 1996: 201). Following Daille (2005), this definition contains three fundamental elements. First of all, a term variant is an utterance, which means that it is a form that is attested, i.e. found in a text; secondly, the definition refers to an original term, which means that a term can only be considered a variant if an authorised term (the so-called original term) is recorded either in a thesaurus or in a terminological resource; and finally, the fact that the variant is semantically or conceptually related to the original term can be interpreted differently, since a variant can be a synonym of the original term or present some semantic distance from it or even refer to another concept on the basis of a conceptual relation (see Daille 2005: 182-183). Again, as in the range of terminological variants proposed by Ibekwe-SanJuan, also this model of terminological variation allows for term variants to be linked to the original term through different relations other than synonymy, thus considering as term variants also hyponyms and hypernyms. As in the case of Ibekwe-SanJuan, Daille herself concedes that "the adopted definition of term variation is highly dependent on the foreseen application" and that " $[\mathrm{m}]$ ost of the researchers working on application-oriented terminology engineering who face term variation choose not to give a definition of term variation but rather present the kind of variations they handle or aim to handle" (Daille 2005: 183).

In order to illustrate how the different types of variation depend on the application, the computer techniques applied and the type of data analysed, Daille presents four possible settings in which the focus is on terminological variation, namely information retrieval, text indexing, terminology watch and controlled terminology for computer-assisted translation systems. As pointed out by Cabré et al., "a dichotomy seems to emerge from Daille's survey: variations defined for terminology resource-building or language-related applications (translation) versus variations defined for end applications in other fields using terminological resources" (Cabré et al. 2005: 12). 
For the purposes of information retrieval based on term mining, which falls into the second category, Daille considers that only those forms which preserve a synonymy relation with the base term can be considered as proper terminological variants (Daille 2003a: 33), where a base term is a syntactic structure or a grammatical pattern shared by the most common multiword terms (Daille 2005: 183). The other setting relevant for the second category in which terminological variation plays a central role is machine-aided text indexing, which consists of retrieving documents on the basis of a control vocabulary. In this case, Daille draws on Jacquemin and Tzoukermann, who define a variant as "a text occurrence that is conceptually related to a term (the original term) and that can be used [for] researching information within text databases" (Jacquemin \& Tzoukermann 1999: 27, italics in the original). The definition provided by Jacquemin and Tzoukermann resembles Dailles's definition of term variant in considering the original term and its variants as being conceptually related. In other words, both definitions state that, regardless of its selection criteria, the original term is linked to its variants by a conceptual relation, whose type is however not specified. Therefore, according to this definition, a term such as translational or transcriptional inhibition is considered as a variant of translation inhibitor (see Jacquemin \& Tzoukermann 1999: 3-4).

The third setting identified by Daille (2005: 187) is scientific and technological watch (STW) (Ibekwe-SanJuan \& SanJuan 2002: 181), which falls into the category of terminology resource-building or language-related applications. The purpose of STW is to achieve a global view of research topics in a certain scientific and technological field in order to capture "topic emergence, growth, shifts and obsolescence" (Ibekwe-SanJuan \& SanJuan 2002: 183). Ibekwe-SanJuan \& SanJuan (2002) do not provide a definition of variant as in the cases illustrated above, but discuss the two possible transformations that lead to the creation of term variants and prove useful for STW purposes. In fact, given the specific phenomena that STW is intended to get a grasp of, which are all connected to the idea of topic development in time, it should not be surprising that the conceptual relations holding among the term and its variants are not limited to the correspondence relation (synonymy), but can be of different types, such as "type_of” relations. Therefore, Ibekwe-SanJuan \& SanJuan (2002) limit their consideration to two syntactic transformations, i.e. expansion and substitution, which both allow for the identification of terms designating different concepts, such as glutenin subunit and its variant apparent polymerisation of glutenin subunit (expansion) and protein content of bread and protein content of bun (substitution) (see Ibekwe-SanJuan \& SanJuan 2002: 186). The last setting identified by Daille and relevant for translation tasks is controlled terminology for computer-assisted translation systems (Daille 2005: 188). In this regard, 
Daille draws on Carl et al. (2004), who focus on term extraction and the identification of term variants in bilingual texts. Since their starting point is controlled language (i.e. technical writing), Carl et al. distinguish between "preferred base forms of terms" and "unauthorized variants" (Carl et al. 2004: 102) and suggest a method for detecting term variants and their translations in aligned texts on the basis of term variation patterns. These patterns are "omission, insertion, permutation, coordination, synonymy, derivation, and typographical variation" (Carl et al. 2004: 106). As can be seen, these authors too consider several types of transformations that lead to the creation of term variants linked to each other by different types of relations, among which synonymy is only one type. This means that also in this case correspondence is not the only relation possible among the original or base term and the variants that derive from it.

Therefore, even though Daille agrees with the definition of terminological variant provided by Daille, Habert and Jacquemin (1996), she admits that, according to the specific practical activity where term extraction is used, only certain types of relations are to be taken into consideration for terms to be considered as terminological variants.

\subsubsection{TERMINOLOGICAL VARIATION ACCORDING TO JACQUEMIN}

Jacquemin identifies two sources of variation on the basis of the elements that are subject to modification in the original terminological unit (Jacquemin 1996). In his classification, type 1 variants are defined as "occurrences where the content words of the original terms are not modified (except inflections)" (Jacquemin, 1996: 448), but where the structure of the variant as compared to the original term may vary. Therefore, by means of compositional modification variants such as tumor target cells and cells in subcutaneous tumors can be obtained from the original term tumor cell (see Jacquemin 1996a). Type 2 variants originate from the existence of synonyms in technical languages. Jacquemin points out that while "[s]ome synonyms preserve the stems of the reference term as in arterial pressure/pressure of the arteries [...] some others substitute content words by semantically related ones such as renal/kidney (Dunham et al. 1978)" (Jacquemin, 1996: 448). Again, as in the classifications of terminological variation seen earlier, also Jacquemin implicitly recognises that different types of relations can hold among original terms and their variants. In the example provided by the author for type 1 variants, for instance, a hierarchical (hypernymy-hyponymy) relation can be observed, while in type 2 variants the morpho-syntactic modifications affect not the meaning, which remains the same both in the original term and in its variant, but only the morpho- 
syntactic structure of the variants. In other words, in type 2 variants the original term and its variants are connected by a correspondence relation (synonymy).

As seen so far, according to several authors term variation is a broad term which can refer to different phenomena on the basis of the different applications term variation is studied for. Therefore, on the one hand, term variation can be useful for deriving additional terms (term variants) from an original term by means of different operations such as insertion, coordination, morphological and syntactic alterations. These operations result in term variants which are semantically linked to the original term without being necessarily synonyms. Consequently, he relations that hold between the original term and its variants can be either hierarchical (hypernymy-hyponymy) or non hierarchical, and formal modifications are accompanied by conceptual changes. On the other hand, the above mentioned authors also acknowledge the existence of another type of term variation, i.e. the syntactical and/or morphological transformation of an original term into a variant which maintains the identity of the concept represented by the original term. Such a wide range of terminological units falling into the category of term variants may prove useful for different types of research and applications, such as in information retrieval and text indexing. However, such variety seems inappropriate for practical terminographic work, since, for instance, it hinders the classification and recording of terminological data in a term base.

\subsubsection{TERMINOLOGICAL VARIATION ACCORDING TO FREIXA}

An author who clearly distinguishes terminological variation into two different types and adopts an approach that is more functional for practical terminographic work is Freixa. The author advocates a division of terminological variation into denominative variation (variación denominativa), which affects denominations, and conceptual variation (variación conceptual), which affects the concept variants refer to ${ }^{97}$ (Freixa et al. 2002: 2).

Freixa et al. include in conceptual variation "toda clase de heterogeneidades que se dan en el plano de contenido de un término" (Freixa et al. 2002: 2), but acknowledge that while it concerns the conceptual layer, it has also consequences for the formal, linguistic or, rather, expressive layer. In this regard, however, a further point needs to be made. According to Freixa, conceptual variation differs from the variation affecting concepts described by the authors mentioned above. In fact, in line with Ibekwe-SanJuan, Daille and Jacquemin, in Freixa's view terms deriving from an original term by means of different morphological or syntactic modifications, regardless of the semantic or conceptual relation holding between

\footnotetext{
${ }^{97}$ Note that Freixa does not refer to one of the terms as the original term and the other terms as conceptual or denominative variants, but rather considers all the terms referring to a single concept as term variants.
} 
them and the original term, should be considered variants of the original term. On the contrary, conceptual variation is limited to a single concept, which can be approached in different ways giving rise to different designations. Every single designation is therefore developed in order to stress the conceptual aspects that are more relevant in a given context (Freixa 2002: 55). Therefore, while for Ibekwe-SanJuan, Daille and Jacquemin terminological variation can concern terms designating different concepts, Freixa excludes this possibility and considers only the phenomenon in which a shift in the conceptualisation can be observed but where the concept designated by the original term and its variant(s) can be said to be the same. Such a conceptual variation can be attributed to what Condamines and Rebeyrolle refer to as different points of view (Condamines \& Rebeyrolle 1997) or to the multidimensionality of concepts (Bowker 1997; Meyer et al. 1992; Rogers 2004), but also to the degree of specialisation of the text (Cabré 2003) or the target audience (Bowker \& Hawkins 2006).

From the perspective of practical terminographic work and for the purposes of this study, both conceptual and denominative variation are of paramount importance. Denominative variation is defined by Freixa as follows:

[...]the phenomenon in which one and the same concept has different denominations; this is not just any formal variation (variation between a term and a periphrasis, or a definition, for example), but is restricted to variation among different denominations, i.e., lexicalised forms, with a minimum of stability and consensus among the users of units in a specialised domain. (Freixa 2006: 51)

Again, as in the case of conceptual variation, the relation that holds among denominative variants is correspondence (expressed in different degrees of synonymy). Therefore, it can be concluded that, according to Freixa, terminological variation is a phenomenon that can affect the conceptual or the formal layer of terms, but only when the relation that links the relevant terms is a correspondence relation, which means that the term variants have a co-referential status (Kerremans 2010: 2). Consequently, in Freixa's view, terminological variation diverges from the notion of terminological variation proposed by previous authors who admitted also hierarchical and non hierarchical relations as a linking factor between an original term and its variant(s).

\subsubsection{FREIXA'S CLASSIFICATION OF CAUSES OF DENOMINATIVE VARIATION}

Apart from describing the two forms of terminological variation, Freixa also engages in a deeper investigation of the causes of denominative variation by first distinguishing between 
what she terms self-variation and hetero-variation (Freixa 2006: 52). The first type of variation occurs when a specialist expresses the same idea or names a concept in different ways, while the second type occurs when different specialists express the same idea in different ways (Freixa 2006: 52). After establishing this dichotomy between self- and heterovariation, which helps understanding the causes of denominative variation, Freixa proposes a classification of causes, which she divides in the following groups: dialectal (caused by the different origins of the authors), functional (caused by different communicative registers), discursive (caused by different stylistic and expressive needs of the authors), interlingual (caused by the contact between languages), and cognitive (caused by different conceptualisations and motivations) (Freixa 2006: 52). Apart from the causes included in this classification, Freixa also acknowledges that languages have certain characteristics or behaviours which enable variation to exist (which she terms preliminary causes). The first characteristic identified by Freixa is linguistic redundancy, i.e. the possibility of referring to a certain idea, concept, object, etc. by different linguistic forms, a phenomenon that reflects different discursive and cognitive strategies. The second characteristic is the arbitrariness of the linguistic sign, although the author admits that "terminological units are often motivated units" (Freixa 2006: 54).

Within dialectal causes, Freixa identifies three subcategories, namely geographical, chronological and social variation. As the author admits herself (Freixa 2006: 55), while geographical differences can be observed synchronically, chronological differences are to be considered on a temporal axis and the denominative variation observed often implies conceptual variation as well, since it is produced by progress in the knowledge area. As for social variation, Freixa points out that this phenomenon is more widespread in nonspecialised communicative settings than in specialised discourse. This type of variation has been studied in depth by Socioterminology (Gambier 1991; Gaudin 1993, 2003), which focused on the social (socioeconomic, sociocultural and socioprofessional) and therefore extralinguistic factors affecting specialised discourse in general and terminology in particular. In line with social dialectal variation, according to Freixa functional variation is again less frequent in specialised communicative settings than in general discourse (Freixa 2006: 57). Nevertheless, following Rey (1983: 283), she points out that this type of variation is highly dependent on the following factors: the terminology domains, the types of conceptualisation, the constitution of term systems, the social conditions of the discourse production and the environment in which terms are used. Unlike the GTT, which limited the discussion to the terminology used in specialised communication among specialists of a specific knowledge 
area, the theories of Terminology most recently developed have included in their research also other communicative settings in which LSPs are used. This means that functional variation is observed by taking into consideration parameters that were ignored by the GTT, such as the tone, which presupposes that the content and the expressive means of the message are modified so as to adapt to the supposed degree of specialisation of the target recipient. An even greater attention paid to the influence of the level of specialisation on the occurrence of denominative and conceptual variation can be found in Cabré's Communicative Theory of Terminology (CTT). According to Cabré, the degree of specialisation is inversely proportional to the amount of expressive variation used to refer to a unique concept. In other words,
A highly specialised text tends to be precise, concise, and systematic; and the terminology it uses tends toward monosemy and univocity. As the degree of specialisation decreases, the discourse exhibits characteristics more akin to general expression: semantically, there will be more conceptual variation, redundancy, ambiguity, and lack of precision; formally, it will have greater variation of lexical synonymy, and, above all, a wider use of paraphrastical formulae containing analytical explanations of concepts which, on a more specialised level, would be explained synthetically. (Cabré 2000: 53)

The hypothesis of an inverse proportionality between the degree of specialisation and terminological variation postulated by Cabré was confirmed by Freixa herself in her doctoral thesis on environmental terminology (Freixa 2002). Therefore, on account of the specialist's level of knowledge and the recipient's expected level of education, different types of discourse are produced, which affect the terminology used and produce what is generally known as vertical variation (Cabré 2003: 179; Freixa et al. 2002: 5; Montero Martínez 2000: $5)$.

The third type of causes of denominative variation identified by Freixa are the so-called discursive causes, which consist of rhetorical and stylistic modifications in denominations. There are several reasons for operating this type of changes, such as avoiding repetition, being more economical, emphatic, creative or expressive, or achieving lexical cohesion (Freixa 2006: 60). In order to reach these goals and depending on the variables of the communicative setting, specialists and technical writers can resort to different strategies, among which synonymy is one of the most frequent. There is no doubt that, for rhetorical and stylistic reasons, denominative variation is intrinsically linked to the types of denominative variation illustrated above, i.e. dialectal and functional variation. To put it differently, discursive 
variation may be caused by the writers' personal preferences for a specific style or their intention to find a more adequate terminological unit for the concept they want to refer to as compared to the existing terms (self-variation), the linguistic norms imposed by the communicative setting (e.g. specialist communication or science popularisation), the topic under discussion as well as the state of the art of the topic. Depending on the variables affecting the communicative setting, the type of discursive variants selected may be different: for example, in Freixa's words, "in highly specialised texts the most usual method is the use of acronyms and the reductions of terms next to properly developed forms" (Freixa 2006: 61). Apart from acronyms, Freixa also mentions two other forms of anaphoric reduction, i.e. nonlexicalisable reductions, which are shortened forms of a multi-word term (which is not generally recognised as a terminological unit), and already lexicalised reductions, which are shortened forms generally considered as proper terms (Freixa 2006: 62). In the case of discursive variants used for reaching specific goals in terms of expressiveness, creativity and originality, following Irgl's conclusion (in the language of business and economics), it can be said that the "unusual, striking colourful or contrastive expressions [...] are practically never true synonyms, even if they may occur in the field of terminology" (Irgl 1987: 278) and are therefore to be considered as quasi-synonyms.

Furthermore, Freixa identifies interlingual causes which produce synonymy on the basis of the geographical and cultural closeness of both the languages and the sender(s)/recipient(s) involved. Unlike the causes of denominative variation illustrated earlier, which are all to be found in a monolingual setting, interlingual/intercultural causes can be observed from a bi- or multi-lingual perspective. The contact of two languages and the consequent terminological transfer occurring between them may therefore produce different results, ranging from the creation of loanwords in the recipient language to the development of neologisms on the basis of existing terms in the donor language.

The last category of causes of denominative variation illustrated by Freixa are cognitive causes (Freixa 2006: 64), which depend on the different perspectives or perceptions of reality by language users and are closely linked to the discursive causes of variation. Freixa attributes cognitive variation to different factors, among which the first is represented by conceptual imprecision, i.e. the blurred boundaries of concepts, which can be an actual feature of the concept itself but may also be determined by the lack of denominative and conceptual fixation of the term at a certain point in time. Another cognitive factor causing denominative variation is the ideological distance between the specialists/technical writers, who are in a halfway position "between conceptual necessity and a wish for ideological differentiation" (Freixa 
2006: 65), and the already-existing theories or among different schools of thought or currents. Freixa also mentions a special case of ideological differentiation researched by Gómez De Enterría (2000: 79, quoted in Freixa 2006: 65), i.e. the usage of attenuated denominations or euphemisms to avoid existing forms that have assumed a negative connotation. Freixa includes in this category also other types of cognitive variants, i.e. variants caused by cultural factors, which influence the observation of reality quoted in Freixa 2006: 65); variants caused by "different domains approaching the same references from different perspectives" (Freixa 2006: 66); and variants caused by different levels of importance attributed to the constitutive elements of a concept. Given that the cognitive causes leading to denominative variation concern the interpretation (or point of view or vision) of the concept, denominative variation may be said to be a consequence of conceptual variation which can manifest itself in different degrees.

\subsection{TERMINOLOGICAL VARIATION FROM A BI- AND MULTILINGUAL PERSPECTIVE}

This brief and by no means exhaustive overview of the main authors who have been engaged in the research of terminological variation shows that the main approach adopted to study this phenomenon is monolingual, i.e. term variation is predominantly observed within a single language only. Despite this general tendency, however, some authors have also centred their attention on terminological variation in bilingual contexts. Daille (2005: 182), for instance, recalls three studies which approach this topic from a contrastive point of view by taking into consideration two languages, namely French and English. The first study mentioned by Daille is found in Daille et al. (1994), who investigated term extraction from a bilingual parallel corpus and source and target term mapping. Secondly, Daille mentions Carl et al. (2004)'s study on the potentialities of what they call an Abductive Terminological Database for detecting term equivalents and their variants in bilingual texts. Finally, Daille also mentions Grabar \& Zweigenbaum (2004), who focus on terminology structuring, i.e. the identification of hierarchical or non-hierarchical relations holding between terms extracted from an existing resource, performed on a parallel resource, namely the French version and the original version of the US National Library of Medicine thesaurus. By taking a closer look at the objectives and the materials employed in these studies, some similarities and differences can be observed. As far as the objectives are concerned, the first two studies can be said to share the 
common goal of matching source terms with target terms without leaving out their possible variants, while the third study exploits term identification for detecting relations among terms rather than interlingual equivalence. As regards the materials used, the first two studies use bilingual texts, whereas in the third study a thesaurus is employed.

The goal pursued by the third study and the type of materials used in the first two are indeed combined in another paper (Rogers, 2004), which deals with a different language combination because it analyses an automotive handbook written in German and translated into English. In this article Rogers stresses the multidimensionality of conceptual relations that can be observed in the terms and phraseological structures of bilingual texts. Such multidimensionality hinders the possibility of establishing one-to-one equivalence relations among terms in different languages used in context and, from a translational perspective, produce term variation both in the source and in the target text.

Rogers carried on with researching variation in source and target texts (Rogers 2007a, 2007b, 2008) by explicitating the link between terminological variation (here expressed in terms of lexical chains) and terminological equivalence. The object of study in this case is a user manual for an electrically powered breathing aid for patients suffering from sleep apnœia originally written in German and translated into French and English. The aim of this line of research is to bring to the fore the differences in the way conceptual relations are modelled in parallel texts and to discuss the difficulties in codifying equivalence in bilingual and multilingual termbases designed for specialist translators.

Another study on terminological variation focusing on cognitively motivated terminological variants in parallel corpora was conducted by Fernández-Silva \& Kerremans (2011). In this case, the analysis is on scientific articles in Galician on the economic effects of environmental disasters on fisheries and their English translations. The aim of this study was to establish the cognitive distance, i.e. the difference in conceptual information, between the source terms and their translation equivalents. On the basis of the cognitive distance and the frequency of translation units in the aligned texts, an interlingual variation index (IVI) is computed, indicating whether the translation equivalent used in the target text tends towards a more literal or a freer translation.

In 2010, an ongoing project on terminological variation within specialised translation was presented by Kerremans (2010) who, as in Rogers' second line of research presented above, adopted a multilingual perspective for his research. In this study, a comparative analysis is carried out of terminological variation in a trilingual parallel corpus (English, French and Dutch) dealing with biodiversity. The results presented in this article indicate that the 
Chapter 4

terminological variation encountered in source texts is reflected in the translations and confirm the author's hypothesis that "specialised translations contain at least as many terminological variants for a given unit of understanding as in the source texts or even more" (Kerremans 2010: 13).

\subsection{TERMINOLOGICAL VARIATION FROM A MULTI-JURISDICTIONAL TEXTUAL PERSPECTIVE}

From what has been said so far, terminological variation is a polysemous term whose definitions greatly depend on the specific application it is studied for and are at the same time rare, being rather replaced by classifications and taxonomies of term variants. In order to discuss terminological variation in the textual material described in Sections 3.3.2 and 3.3.4, a stance needs to be taken with regard to the phenomena that are considered to be textual manifestations of terminological variation. Following the dichotomy identified by Cabré et al. (2005: 12) in Daille (2005) and discussed earlier in Section 4.2.2, terminological variation in this research project falls into the first line of research that has been identified, i.e. the study of terminological variation for terminology resource-building (term bases, lexicons, ontologies, thesauri) or language-related applications (translation), rather than for end applications in other fields exploiting terminological resources (Cabré et al. 2005: 12). This is so because the end application, i.e. the terminological knowledge base MuLex (for a closer insight, see Chapter 6) in which the collected terminology has been recorded, is designed for legal translators. However, in the dichotomy outlined by Cabré et al., the terminological variation included in the first category - which follows the viewpoint proposed by Daille (2003b), Jacquemin \& Tzoukermann (1999) and Jacquemin (2001) - includes phenomena such as synonymy, hypernymy, hyponymy and morphological variants of the same term, taking in no account the shift in the semantic class of the variant as compared to the original term.

In this research project, however, an even narrower perspective is adopted which harks back to the definition of "denominative variation" provided by Freixa (2006: 51). As illustrated in Section 4.2.4, Freixa calls "denominative variation" the phenomenon where one and the same concept is referred to by means of different denominations, which are lexicalised forms that have reached a minimum of stability and consensus among the users in the relevant specialised domain. The author uses this term so as to differentiate it from "conceptual 
variation", which implies a modification of the concept referred to by different variants. As the author acknowledged herself, however, the boundary line between the two types of variation is not always clear-cut in reality, since denominative variation can be the result of a conceptual modification driven by cognitive causes or other motivations. Since the two types of variation are actually closely related, in what follows terminological variation is used as a hypernym, as variation is observed both at a conceptual and a denominative level. Given the specific purposes of this study, which considers the behaviour of terms in a multi-level jurisdiction, terminological variation specifically refers to two phenomena:

a) one where a set of different terms is used to refer to a concept that is shared by the legal systems taken into account for the study (denominative variation in a multi-level jurisdiction, see Section 4.5);

b) the other where terms are used in more than one legal system to refer to concepts that are not necessarily shared by the relevant legal systems (conceptual variation in a multi-level jurisdiction, see Section 4.6).

In this study, the co-referent terms which fall into the first category of terminological variation are grouped into term clusters (see Section 3.3.6.1) or, in Fernández-Silva and Kerremans’s words (Fernández-Silva \& Kerremans 2011: 320), “cluster[s] of terminological variants". The terms that fall into the second category, however, are also likely to form separate term clusters on the basis of the differences existing among the concepts they refer to. Before moving on to the discussion of the term variants encountered in the terminological analysis (Steps 3 and 5 in Chapter 3), a digression is needed at this point to clarify what is meant by "concept" in this study, since the term can be interpreted in many possible ways.

\subsubsection{THE CONCEPT OF 'CONCEPT' IN TERMINOLOGY THEORY}

So far, the term "concept" has been used without a precise qualification. In this regard, it should be noted that the notion has been the object of much critical debate in the last two decades in the terminology field. In the GTT, a concept is defined as "an element of thinking" or "a mental construct representing a material or immaterial individual object" (Felber 1984: 103). From the viewpoint of the GTT, a concept is construed as "an aggregate of characteristics which we can cognize as being common to a number of individual objects, and which we use as means for mental ordering and communication" (Felber 1984: 103). Concepts are therefore considered to exist independently of the term (Felber 1984: 103). Consequently, from this standpoint concept systems are independent from term systems (Temmerman 1997: 53). 
A similar function to the one attributed to concepts by the GTT can be found in Sager, who formulates his own preliminary definition of concepts, which in his view are "constructs of human cognition which assist in the classification of objects by way of systematic or arbitrary abstraction" (Sager 1990: 22). The marked diversity emerging from a comparison of this definition with others formulated by different committees involved in terminology standardisation admittedly reflects, according to the author, a "considerable divergence of opinion on the matter" (Sager 1990: 23). Consequently, he prefers to consider the notion of 'concept' as an axiomatic principle and abandon the preliminary definition by leaving the notion undefined.

The same conclusion is reached by Draskau Kewley, who follows (Budin 1988, quoted in Draskau Kewley 1991: 270) in stating that "[i]n the soft sciences, [...], concepts frequently remain theoretical and incapable of convincing empirical demonstration, murky and obscure rather than decisively defined" (Draskau Kewley 1991: 270). Even though concepts and the relations obtaining among them are "[t]he fundamental bricks-and-mortar of any theory" (Draskau Kewley 1991: 270), a classification of concepts is only possible on the basis of their characteristics, the sum of which constitute a concept, or rather its intension (see, for instance, Wright \& Budin 1997: 101, (ISO 1087-1 2000: Section 3.2.9). Since characteristics are themselves concepts, "the nature of any concept is a relational complex" (Draskau Kewley 1991: 270), leading to concepts lacking a clear-cut definition.

A similar position is held also by Kageura, who leaves "the problem of what 'concept' is to the safe hands of philosophers and psychologists" (Kageura 2002: 56). He actually rejects providing a proper definition and prefers considering a concept as "something that "exists" "or a "descriptive device", which can be either a mental or a social construct which is necessary to attribute the concept a "minimal explanatory substance" (Kageura 2002: 56).

While, on the one hand, there are authors who choose to avoid defining the concept of 'concept' as in the cases presented above, on the other hand, there are some international organisations and scholars working in the field of Terminology who have tried to coin their own definitions. Among them, Cabré defines a concept as "an element of thought, a mental construct that represents a class of objects [...] [c]oncepts consist of a series of characteristics that are shared by a class of individual objects" (Cabré 1999a: 42). Following her train of thought, it follows that "[c]oncepts are mentally independent of terms and exist before they are named" (Cabré 1999a: 42). Cabré acknowledges that the conceptual structures "in which each concept occupies a specific place and acquires a functional value" (Cabré 1999a: 43) reflect the knowledge that one or more specialists share on a specialized subject and are 
therefore variable. However, despite admitting the possible multidimensionality of conceptual structures - thus opposing the view held by the GTT (see Faber 2009: 111) - she advocates a standardisation approach by stating that "the work of the terminologist begins with establishing the structure of concepts which summarizes the knowledge of a discipline and then searches for the names of each concept in this structure" (Cabré 1999a: 43).

All the definitions seen above seem to indicate that the idea of concepts being independent from terms and consisting of characteristics seems to permeate the discussion on what a concept is. As a matter of fact, characteristics are also fundamental in the definition provided by ISO standard $\mathrm{n}^{\circ} 1087-1$ on Terminology work, according to which a concept is a "unit of knowledge created by a unique combination of characteristics" (ISO 1087-1 2000: Section 3.2.1), and a characteristic is an "abstraction of a property of an object or of a set of objects" (ISO 1087-1 2000: Section 3.2.4). The same standard also distinguishes between individual concepts ${ }^{98}$ and general concepts. Individual concepts are those concepts which correspond to only one object, such as Saturn and the Eiffel Tower (ISO 1087-1 2000: Section 3.2.2), and which are referred to by means of appellations (ISO 1087-1 2000: Section 3.4.2). On the contrary, general concepts are those concepts which correspond to two or more objects which form a group by reason of common properties, such as planet or tower (ISO 1087-1 2000: Section 3.2.3), which are designated by a term (ISO 1087-1 2000: Section 3.4.3).

In the brief and far from exhaustive overview of the attempts of definition of the concept of 'concept' within the field of Terminology presented so far ${ }^{99}$, two common elements can be identified: on the one hand, the need to depict and gather the characteristics of a concept so as to identify it and differentiate it from other concepts within the same specialised field, and, on the other, the supposed independent status of concepts and conceptual structures from the language expression, i.e. terms. However, empirical studies in different specialised fields carried out since the early 1990s within the currents of Socioterminology, Textual Terminology, Communicative Terminology and Sociocognitive Terminology have proved that the bedrocks of the GTT and more traditional terminological approaches following the GTT rest on an idealized vision of specialized communication rather than on the observation of the actual behaviour of terminology in authentic communicative contexts. Such studies allowed modern terminology theories to abandon the traditional conception of 'concept' as the intension obtained by summing up its characteristics, since "[t]he concepts to which terms

\footnotetext{
${ }^{98}$ In this thesis, "named entity" is used to refer to what is called "individual object" in the ISO 1087-1 standard (see Section 5.3.1).

${ }^{99}$ For a more detailed overview on the definition of "concept" in the second half of the $20^{\text {th }}$ century, refer to Antia (2000: Chapter 4).
} 
refer are not well-defined, clear-cut entities" and they "have been shown not to be language independent" (L'Homme et al. 2003: 153).

Contrary to the key role in terminology management attributed to the concept by Wüster, who considered it as the starting point for all modern work on the problems in Terminology (see Wright \& Budin 1997: 100), in more recent terminology theories the concept of 'concept' has lost its centrality and left room for terminological units, which "constitute the central object of the knowledge field of terminology" (Cabré et al. 2005: 1-2). Such a change in the focus of terminology theories has been possible due to the fact that, on the one hand, a textual approach was adopted and corpus linguistics methods were included in practical terminological work and, on the other, the theory of Terminology experienced a cognitive shift (Faber 2009). Such a shift was the partial replacement in terminological practice of the merely onomasiological approach, which professed the precedence of concepts over terms, by a semasiological approach, in which the meaning is analysed of terms usually extracted from large specialised corpora.

The most critical view against the centrality of the notion of 'concept' as conceived by the GTT and traditional terminology theorists was probably expressed by Temmerman. Although multidimensionality in Terminology had been dealt with by several authors before her (see, among others, Bowker \& Meyer 1993; Bowker 1997; Kageura 1997; Meyer et al. 1992; Skuce \& Meyer 1990; Zawada \& Swanepoel 1994), Temmerman is the first author to propose an alternative view on concepts which implies a change in the terminology being used. In her sociocognitive approach, instead of concepts, it is "units of understanding" that should be considered "as items which need definitions" (Temmerman 2000a: 73), where units of understanding include both concepts, i.e. clearly delineated abstractions that are attributed a position in a logical or ontological concept structure (see Temmerman 2000a: 73, 2000b: 453), and categories, which are "all the units of understanding which are impossible to describe according to the principles of traditional Terminology" (Temmerman 2000a: 73). Contrary to clear-cut concepts, constituting the minority of units of understanding, categories have a prototype structure and lack the precision required in the classical concept theory, since they present "scalar/graded characteristics" (Temmerman 2000a: 28).

\subsubsection{THE CONCEPT OF 'CONCEPT' IN THIS STUDY}

So far, an overview of the discussion on the concept of 'concept' in the field of Terminology has been presented. In the early days of theoretical studies in Terminology, a definition of "concept" was essential since in the onomasiological approach proposed by Wüster and 
traditional terminology theorists concepts needed to be clearly identified and distinguished from other concepts in the same domain. In more recent days, the change in the methodologies applied to practical terminological work and the theoretical shifts driven by different contributions from various multidisciplinary fields have removed concepts from their privileged position in terminology theory. This has led to the two different standpoints illustrated above. On the one hand, some authors question the traditional definition of "concept", but prefer not to provide their own definition since concepts are useful for terminology description and defining them would inevitably put boundaries to entities whose boundaries cannot always be determined. On the other hand, other authors propose an alternative view on concepts and, as in the case of Temmerman, accompany it with an alternative definition and terminology.

Having seen all these different approaches to the concept of 'concept' and in the light of the shifts the concept itself has undergone in terminology theory, it should be noted that in this thesis the term "concept" is still used. In Sowa's words,

\begin{abstract}
Concepts are inventions of the human mind used to construct a model of the world. They package reality into discrete units for further processing, they support powerful mechanisms for doing logic, and they are indispensable for precise, extended chains of reasoning. But concepts and percepts cannot form a perfect model of the world, -- they are abstractions that select features that are important for one purpose, but they ignore details and complexities that may be just as important for some other purpose. (Sowa 1984: 344)
\end{abstract}

Following his train of thought, which is nevertheless closer to the standpoint of the GTT and standardisation-oriented terminology theories than to modern terminology theories, it is interesting to note the emphasis Sowa laid on purpose. Taking purpose as a starting point for an application-oriented reflection on the concept of 'concept' and with no ambition to formulate a general definition to explain what a concept is, in this thesis concepts are conceived pragmatically as units belonging to the cognitive sphere which manifest themselves by means of terminological units, with which they have a close relation. The formation of concepts and terminological units depends on a series of factors, such as different purposes, perspectives, world views and theories, which determine the multidimensionality and the variation that can be observed in the parole aspect of language. The close relation between terminological units and concepts also allows for concepts to be subject to modification and negotiation through the usage of the terms that designate them in discourse. By admitting that concepts are multidimensional, in the sense that they can be approached and constructed from 
different points of view and they can experience modifications, three axioms maintained by the GTT turn out to be questionable.

The first is the principle of univocity holding between terms and concepts, according to which "a concept can only be named by one term and a term can only refer to one concept" (Collet 2004b: 100). As has been seen throughout this Chapter, terminological variation (both in terms of conceptual and denominative variation) is a feature that characterises specialised discourse in general and specialised texts in particular, meaning that univocity should be considered as an ideal in certain standardisation and language planning tasks rather than as a principle observable in real-life discourse. The second GTT axiom to be questioned is the universal nature of terms and therefore of concepts. By ceasing to consider a terminological unit as the designation for labelling a concept that is part of a universally accepted and (language-, culture- etc.) independent concept system, terms and concepts are seen as the result of a combination of factors that come into play in specialised discourse, such as the topic and the specific perspective taken to approach the topic, the degree of knowledge of the participants in the communicative situation and the purpose of the communicative act, among others. The third GTT axiom to be brought into question is the synchrony principle deriving from the central position attributed to the study of concept systems in traditional Terminology, which is carried out synchronically. Once concept systems are withdrawn from that position, attention can be given also to the study of the development and evolution of terminology, which is carried out diachronically.

To sum up, by moving from a traditional approach to terminology towards communicative and cognitive text-based approaches, the building blocks of the GTT have undergone considerable revision, allowing for multidimensionality, dynamism and variation to be considered as 'physiological' features characterising terms and concepts rather than as an impediment to unambiguous communication. And it is in the light of modern terminology theories that, in this thesis, concepts are conceived as "a flexible entity within a multidimensional concept system" (Fernández-Silva et al. 2011: 52).

\subsection{DENOMINATIVE VARIATION IN A MULTI-LEVEL JURISDICTION}

As has been highlighted several times so far, terminology as a set of terms used within a specialised domain can be approached from different perspectives and can therefore be regarded as a multidimensional object of study. Since terminological variation is a 
multifaceted phenomenon that characterises terminology, variation as well can be considered multidimensional and can be approached from various angles. These angles are determined by the same variables that are taken into consideration for analysing the behaviour of terms in context. In order to analyse the victim-related terminology extracted following the methodology described in Chapter 3, four different variables have been employed in this study, the first two of which come into play in all specialised domains, the third is only relevant when the same language is used to refer to different conceptual systems and the fourth when legal texts with different legal force are considered. If these variables are applied in the study of denominative variation, two types of variation can be observed in relation to each variable.

\begin{tabular}{|l|l|l|}
\hline \multicolumn{2}{|c|}{ Variable } & \multicolumn{1}{c|}{ Type of variation } \\
\hline $1^{\text {st }}$ variable & degree of specialisation & vertical variation vs. horizontal variation \\
\hline $2^{\text {nd }}$ variable & time span & synchronic variation vs. diachronic variation \\
\hline $3^{\text {rd }}$ variable & $\begin{array}{l}\text { conceptual } \\
\text { system(s) }\end{array}$ & $\begin{array}{l}\text { intra-systemic variation vs. inter-systemic } \\
\text { variation }\end{array}$ \\
\hline $4^{\text {th }}$ variable & legal force & $\begin{array}{l}\text { variation among texts with equal legal force vs. } \\
\text { variation among texts with different legal force }\end{array}$ \\
\hline
\end{tabular}

Table 4.1. Types of variation according to the different variable taken into consideration.

In the following sections, each variable and the observable types of variation are discussed in greater detail and provided with examples extracted from the EU corpus (see Section 3.3.2) and the collection of national texts (see Section 3.3.4). However, to illustrate terminological variation, a term variant needs to be compared with a reference term. Therefore, in order to examine terminological variation, in this research project the reference term that will be used to describe the modifications occurring in the co-referring terms coincides with the main term identified according to the criteria described in Section 3.3.6.1. However, in some cases it has been impossible to find concrete examples of the types of variation described by taking the main term as a reference term and consequently some types of denominative variation are illustrated through examples taking into consideration two term variants.

\subsubsection{FIRST VARIABLE: DEGREE OF SPECIALISATION}

Ever since multidimensionality and its consequent variation were identified as prominent features of terminology, several authors have emphasised the role of the degree of specialisation in the occurrence of terminological variation and terminological density. As far 
as the impact of this variable on denominative variation is concerned, Cabré, for instance, speaks of a "greater variation of lexical synonymy" (Cabré 2000: 53) in less specialised texts and says that not only does the degree of specialisation reflect in the quantity of terminology contained in texts, but it also determines the type of terminology texts contain (Cabré 2003: 179).

The same view is held by Freixa, who devoted her doctoral thesis to the study of denominative variation in texts of different degrees of specialisation dealing with environmental issues (Freixa 2002). Starting from the general hypothesis that "el grau d'especialització (GE) dels textos condiciona quantitativament i qualitativament la variació denominativa (VD)" (Freixa 2002: 11), Freixa carries out an empirical research that leads to the same conclusion as Cabré. The researcher actually confirms that denominative variation is more frequent in less specialised texts than in texts with a higher degree of specialisation, i.e. that in more specialised texts there are less notions represented by more than one designation (which she refers to as "nocions polidenominatives" (Freixa 2002: 12)) and the polidenominative notions are referred to by a smaller number of denominative variants. Freixa also shows that there is a correlation between the degree of specialisation of texts and, on the one hand, the specific type of denominative variation and, on the other, the different degree of conceptual correspondence characterising denominative variants, resulting in a higher degree of correspondence in more specialised texts than in less specialised ones (Freixa 2002: 365-366).

As has been seen so far, the degree of specialisation has been considered as a factor producing vertical variation by Cabré and Freixa, among others (see, for instance, Ahmad \& Rogers 1992; Ciapuscio 1999), who implicitly include in this factor also the recipients of the text. Some other authors, however, consider the recipients of the text as a separate cause of vertical variation from the degree of specialization of the text (see, for instance, Gómez GonzálezJover 2006; Montero Martínez 2000).

Given the features of the EU corpus (see Section 3.3.2) and of the national texts collected to carry out the comparison between EU terms and national terms (see Section 3.3.4), it is not possible to take into account the factor of vertical variation in this research study, where the methodology adopted requires the degree of specialisation to be as homogeneous as possible. Consequently, as has been pointed out in Section 3.3.2.1.2, both the EU and national contexts taken into consideration for this study do not contain any texts dealing with the topic of victims of crime which have a low degree of specialisation (e.g. summaries of EU legislation 
on the Europa website ${ }^{100}$, practical information for victims and witnesses on Victim Support web pages ${ }^{101}$, etc.). Therefore, though being heterogeneous as regards text type, legal force, author, geographical and legal relevance, the texts selected for this research study can be considered rather homogeneous with regard to the degree of specialisation, since they are all concerned with a specific legal topic and the expected level of knowledge in legal issues of their target readers is high.

\subsubsection{HORIZONTAL DENOMINATIVE VARIATION}

Although vertical denominative variation cannot be observed in the textual material selected for this study, what can in fact be observed is what is here referred to as horizontal denominative variation, which consists of the coexistence of more than one designation for the same concept in a set of texts having a homogeneous degree of specialisation (Peruzzo 2010: 183). In Peruzzo (2010), five different categories of horizontal denominative variation were identified, namely inflectional, syntactic, morphosyntactic, paradigmatic and anaphoric variation, which could also combine in a single terminological unit and thus give rise to a further category of combined horizontal denominative variants. The textual material used, the methodology adopted and the types of variants analysed in Peruzzo (2010) are however different from those adopted in the present research project. First of all, the documents considered for the study carried out in 2010 had an EU origin but made up a smaller corpus as compared to the EU corpus built for this study. Secondly, the time span covered by the texts ranged from 2000 to 2010, while the EU corpus described in Section 3.3.2 covers a longer time span (1998-2012). Thirdly, in the previous study a contrastive examination of the Italian terminological units used to reproduce English units was carried out. In other words, the English versions of the texts in the corpus were taken as the starting point from which denominative variation was analyzed in the Italian texts. Conversely, in this research project the two EU subcorpora and the collections of national texts are considered separately on a linguistic basis, which means that the phenomenon of horizontal denominative variation is observed intralingually. This does not imply that parallel texts are not taken as a reference point for the identification of term variants. In fact, as pointed out in Section 3.3.3.2.1, a cross-check has been carried out interlingually by means of the bilingual display function so as to spot all the possible variants of a main term to be included in a term cluster. However, in order to adhere to the principle of equal authenticity (see Section 3.3.2.3), i.e. not considering

\footnotetext{
${ }^{100}$ Available at http://europa.eu/legislation_summaries/index_en.htm.

101 Available at http://www.victimsupport.org.uk/Home/Help-for-victims and http://www.victimsupport.org.uk/Home/Help-for-witnesses.
} 
one of the two language versions of the same document as the source text and the other as the target text, and given that the textual material under examination is not made of parallel texts only, but also includes documents of national origin, the analysis of term variants is carried out from a monolingual perspective. Moreover, as stated in Section 4.4, in this research project only those term variants are taken into consideration which have a lexicalised form that makes it possible to link them to the main term even in a decontextualised setting regarding the legal area under discussion. Consequently, some categories of variation examined here differ from the categories identified in the 2010 study and the category of anaphoric variation (see Daille 2005: 185; Peruzzo 2010: 185) is not examined.

\subsection{INFLECTIONAL VARIATION}

As conceived in Peruzzo (2010), inflectional variation presupposed the existence of variants "in which an orthographic modification occurs in the target text term due to an inflectional process which is not justified by a change in the source text term and does not modify the semantic content of the original term" (Peruzzo 2010: 184). As pointed out in Section 4.5.1.1, according to the equal authenticity principle all the texts are to be considered as equally authentic and no priority can be given to original texts over their translations for the purpose of legal interpretation. Though the process of translation is implied in the drafting of legal documents at the EU level, the translated documents are to be considered in the same way as originals, i.e. as the linguistic expression of a supranational legal order. Therefore, there are no grounds for considering the terms in one language version of a certain EU document as source terms to be contrasted with the target terms in another language version.

However, it is possible to identify cases of inflectional variation even without taking one language version as a starting point for the analysis. In this particular case, the inflectional modifications that are relevant to the research project concern the number of one of the constituents of the terminological unit. In fact, inflectional variation is not considered to be relevant if it implies a change in the number of the terminological unit because such a change is required by the cotext or the stylistic conventions of the language under examination. For instance, Article 3(3) of Directive 2012/29/EU (emphasis added) states that:

Unless contrary to the interests of the victim or unless the course of proceedings would be prejudiced, Member States shall allow victims to be accompanied by a person of their choice in the first contact with a competent authority where, due to the impact of the crime, the victim requires assistance to understand or to be understood. 
The example provided illustrates how the shift from the singular to the plural form and vice versa does not jeopardise the connection of the terms to a single concept. Since the modification does not imply a change in the lemma, the two forms are not considered terminological variants. The example provided, however, concerns a single-word term. Indeed, the same line of reasoning can be extended to multi-word terminological units where the modification occurs in the head element, such as in the following examples extracted from the same Directive (emphasis added):

Member States shall ensure that victims may be heard during criminal proceedings and may provide evidence. Where a child victim is to be heard, due account shall be taken of the child's age and maturity.

The right of child victims to be heard in criminal proceedings should not be precluded solely on the basis that the victim is a child or on the basis of that victim's age.

For the purposes of this research project, inflectional variation is in fact considered to occur when a modification in the number can be observed in one of the modifiers constituting the terminological unit. In other words, to be relevant for this study, inflection needs to concern the number of the modifier (a content word) in a terminological unit rather than that of the head element. When such a modification occurs and the concept underlying the lexical manifestation does not undergo any changes then there is correspondence among variants. As far as this specific type of inflectional variation is concerned, it should be noted that in the textual material analysed this type of denominative variation has only been observed in Italian, e.g. the main terms diritti delle vittime, protezione delle vittime, risarcimento da parte dello Stato and sistema di risarcimento statale.

As for the first main term, it should be noted that in the analysed textual material several lexicalised forms have been found, of which four fall into the category of inflectional variation. First of all, the genotype VICTIM's RIGHTS in Italian is referred to by means of the main term diritti delle vittime and its inflectional variant diritti della vittima, which implies a shift from the plural to the singular form. However, the same genotype is also designated by the full form (see Section 4.5.1.1.5) of the main term, i.e. diritti delle vittime di reato and diritti delle vittime di reati. In this case, the modifier of the modifier rather than the direct modifier of the head element undergoes an inflectional modification. However, it needs to be said that the alternation of the elements "reato" and "reati" in the analysed textual material is 
very limited, since the term variant diritti delle vittime di reati has been found in one text only ${ }^{102}$.

The same type of variation also applies to the other main terms mentioned above and concerns the same modifiers as in the example of diritti delle vittime. In the case of protezione delle vittime, the main term has two full forms, i.e. protezione delle vittime di reato and protezione delle vittime di reati, where the alternation concerns the modifiers. The same happens with the lexical variants (see Section 4.5.1.1.4) tutela delle vittime di reato and tutela delle vittime di reati, where the main term is subject to more than one variation: the head element "protezione" is replaced by the synonym "tutela" and the short modifier "vittime" by its full forms where the inflectional variation occurs, namely "vittime di reato" and "vittime di reati".

Also in the case of risarcimento da parte dello Stato the inflectional variation concerns the lexical variants indennizzo delle vittime and indennizzo della vittima, although the latter has been found in one text only ${ }^{103}$. Finally, inflectional variation has also been observed in the lexical variants of the main term sistema di risarcimento statale, i.e. sistema nazionale di risarcimento delle vittime di reato and sistema nazionale di risarcimento delle vittime di reati, with the former occurring in one text only ${ }^{104}$.

Apart from the examples provided for Italian, a case in which inflectional variation occurs in the modifier of a terminological unit was also found in English, although the variation also implies the insertion of a pronoun. The inflectional variants under discussion are two lowfrequency variants (only one occurrence each) of the main term mediation in criminal cases, namely mediation between the offender and his victim and mediation between victims and offenders.

\subsection{SYNTACTIC VARIATION}

Following Daille (2005: 184), the category of syntactic variation can be said to include different subcategories, namely shallow syntactic variation and proper syntactic variation. Although acknowledging some correspondence between the types of syntactic variation

\footnotetext{
${ }^{102}$ Regno del Belgio (2002) Iniziativa del Regno del Belgio in vista dell'adozione di una decisione del Consiglio che istituisce una rete europea di punti di contatto nazionali per la giustizia riparatoria, Gazzetta ufficiale delle Comunità europee, C 242, 8.10.2002, pp. 20-23.

${ }^{103}$ Parlamento europeo (2000) Relazione sulla Comunicazione della Commissione al Consiglio, al Parlamento europeo e al Comitato economico e sociale "Vittime di reati nell'Unione europea - Riflessioni sul quadro normativo e sulle misure da prendere", 25.4.2000.

${ }^{104}$ Parlamento europeo \& Consiglio dell'Unione europea (2012) Direttiva 2012/29/UE del Parlamento europeo e del Consiglio del 25 ottobre 2012 che istituisce norme minime in materia di diritti, assistenza e protezione delle vittime di reato e che sostituisce la decisione quadro 2001/220/GAI, Gazzetta ufficiale dell'Unione europea, L $315,14.11 .2012$, pp. 57-73.
} 
examined in this research study and those identified by Daille, her classification cannot be fully applied to the terminological variation observed in this research project. Therefore, in what follows discrepancies with Daille's classification of syntactic variation can be observed. Daille defines shallow syntactic variation as the variation which modifies the function words of the base terms, i.e. "noun phrases composed of a head noun and a nominal or adjectival modifier" (Daille 2005: 183), whereas in syntactic variation proper it is the internal structure of the base form to be modified (Daille 2005: 184). In this regard, the categorisation she proposes derives from the study of French terminology, which means that her categorisation may be expanded if the behaviour of terminology in other languages is observed. A further remark needs to be made with reference to Daille's classification of syntactic variation. As has been discussed in Section 4.2.2, according to the author terminological variation may imply a conceptual shift from one concept to one or more different concepts in the passage from an original term to its variant, which is also the case in the syntactic variants obtained using insertion and coordination. According to Daille, however, variants are also those terms which are obtained by inserting a modifier such as an adjective in a 'noun+preposition+noun' sequence, as in the case of the base term lait de brebis and its variant lait cru de brebis (Daille 2005: 184), and those in which the base term is expanded by coordination, as in the case of alimentation humaine and alimentation animale et humaine (Daille 2005: 185). Since the notion of terminological variation in this research project differs from Daille's and her classification cannot be accepted, the three categories grouped within what she refers to as "shallow syntactic variation" are here assimilated to the broader concept of syntactic variation and those modifications that result in a conceptual shift are not taken into consideration. Moreover, Daille includes in her classification of shallow syntactic variation what she refers to as "predicative variants" (Daille 2005: 184), which consist of a noun and an adjective where the latter plays a predicative role. The example she provides is that of the term pectine mêthylêe and its predicative form ces pectines sont mêthyêes. Although examples of this sort can be found in the textual material examined in this research project, such as in the case of the progressive lexicalisation of the phrase victims who are particularly vulnerable into the terminological unit particularly vulnerable victims ${ }^{105}$, for the purposes of this research project those expressions in which the adjective has a predicative role are not considered lexicalised forms, i.e. terms, and are therefore not considered term variants. On the other hand, in this

\footnotetext{
${ }^{105}$ The first document in which the expression victims who are particularly vulnerable was found is the 2000 Initiative of the Portuguese Republic with a view to adopting a Council Framework Decision on the standing of victims in criminal procedure and the same expression was used in different documents until 2003. Instead, the term particularly vulnerable victim appeared two years later and the latest document in which it could be found dates back to 2011 .
} 
research project the umbrella category of syntactic variation contains two subcategories and, due to the nature of the modifications involved, can only be applied to multi-word terms. The first subcategory comprises syntactic modifications that affect the function words belonging to a certain terminological unit without requiring a change in its content words, whereas the second subcategory affects the distribution of content words in a multi-word terminological unit.

The first type of syntactic variation ${ }^{106}$ falling into the first subcategory, which has been identified in the data being analysed in both languages, is the substitution of the preposition. As far as English is concerned, for instance, in the main term compensation from the offender the preposition "from" is replaced by the preposition "by", resulting in compensation by the offender, while the preposition "for" is substituted by "to" in the main term state compensation for victims. Another example is provided by the main term compensation of material losses, in which the preposition "of" is replaced by "for". As for compensation, a similar case has been identified in Italian, where the contracted preposition "dei" in the main term risarcimento dei danni non materiali is replaced by a simple preposition followed by an article, thus resulting in risarcimento per i danni non materiali.

The second type of variation falling into the first subcategory derives from the "optional character of the preposition and of the article" (Daille 2005: 184). Due to typological differences in the languages under examination, however, the variation observed varies according to the language. Accordingly, in the English data there is greater alternation between term variants with either a 'noun1+noun2' or a 'noun1+preposition+noun2' or a 'noun1+preposition+article+noun2' sequence. On the other hand, in Italian the alternation is mainly between the 'noun1+preposition+noun2' and 'noun1+preposition+article+noun2' patterns. An English example in which a 'noun+noun' structure alternates with a 'noun1+preposition+noun2' structure is provided by the terms victims' rights, victims rights and rights of victims, while in the term cluster referring to the VICTIM genotype the pattern including the article has also been found, as there is alternation among the terms crime victim, victim of crime and victim of a crime. As regards Italian, an example involving the presence or absence of prepositions and articles was retrieved, i.e. the term cluster referring to the MEDIATION IN CRIMINAL CASES genotype. In this cluster, two term variants are found which fall into the category of shallow syntactic variation, but they also imply some changes that can be ascribed to other types of syntactic variation and can therefore be said to be combined variants (see Section 4.5.1.1.7). These variants are mediazione tra vittima e autore del reato

\footnotetext{
${ }^{106}$ The first two types of syntactic variation described here correspond to the first two types of shallow syntactic variation mentioned by Daille (2005: 184).
} 
and mediazione tra l'autore del reato e la vittima. Comparing the first term with the second, while in the latter the preposition is not modified, in the former there are some missing articles. However, the examples provided both for English and Italian show how these variations do not occur in isolation but are accompanied by another type of syntactic variation. This falls into the second subcategory of syntactic variation and comprises those variants obtained by changing the order of the content words in the main term. Therefore, whereas in English the alternation between 'noun1+noun2' and 'noun1+preposition+noun2' structures is only possible by replacing noun1 with noun2 and vice versa, in Italian the absence or presence of articles has been observed together with the permutation of the multiple modifiers linked to a single head element in the terminological unit.

As for the second subcategory of syntactic variation proper, i.e. variation consisting in the permutation of content words with no further modifications in the terminological unit, only a pair of term variants for the term cluster referring to the STATE COMPENSATION SCHEME genotype has been found. This is the case of the Italian terms sistema di indennizzo nazionale and sistema nazionale di indennizzo. In the first variant the adjective "nazionale" is linked to the modifier "indennizzo", while in the second variant the adjective refers to the head element. Although a conceptual difference is brought about due to the different position held by the modifier moving the focus from the compensation provided by the state in the first variant to the compensation scheme established and financed by the state in the second variant, such a difference is negligible in the contexts where the variants are used and, as a consequence, the two terms can be said to be variants belonging to the same term cluster.

\subsection{MORPHOSYNTACTIC VARIATION}

The third category of variation is represented by morphosyntactic variants, in which both the content and the functional words of a terminological unit are modified without producing a semantic change. Italian examples of this category refer to state compensation to crime victims, such as risarcimento statale delle vittime di reati / risarcimento da parte dello Stato delle vittime di reati (STATE COMPENSATION genotype) and sistema di risarcimento statale I sistema di risarcimento da parte dello Stato (STATE COMPENSATION SCHEME genotype). In these examples, the alternative forms are semantically equivalent but syntactically different: the first variant follows a 'noun+adjective+modifier' pattern, while the second is an example of a 'noun+prepositional phrase+modifier' sequence. The same difference can be noticed in the second example, in which the alternation between an adjective and a prepositional phrase is found in the modifier rather than in the head element. 


\section{Chapter 4}

\subsection{LEXICAL VARIATION}

The fourth category of horizontal denominative variation is represented by lexical variation, also referred to by Daille (2005: 185) as "paradigmatic variation", consisting in the substitution of one of the constituents of the terminological unit by a synonym preserving at the same time the semantic correspondence of the unit. As stated by Freixa and Montané, the substitution can occur either in the head element of a terminological unit or in its modifier (see Freixa \& Montané 2006: 201). Due to the substitution of an element of the terminological unit with a synonym, in the literature lexical variation is generally assimilated to the phenomenon of synonymy, as noted by Freixa (2002: 279). However, because different types of lexical variation can be observed in the textual material, in this research project the term lexical variation is preferred to synonymy, since the latter is used to refer to a subcategory of lexical variation where a terminological unit is entirely replaced by a synonymous terminological unit, while lexical variation includes also other forms of variation which are described below.

Before moving to the description of the examples identified in the data which have been analysed, it should first be noted that different criteria have been used by different authors to classify synonyms or, following the line of reasoning above, lexical variants ${ }^{107}$. In what follows, two criteria are taken into account (see Freixa 2002: 279). The first is the number of constituents of the terminological units (single-word or multi-word units) and is more general in nature, since it can be applied to all terminological units. The second criterion coincides with the element (head or modifier or both) that is substituted within a multi-word term, and can therefore be applied to polylexical terminological units only. The lexical variants that can be obtained by taking into consideration these criteria are the following:

\begin{tabular}{|l|l|l|}
\hline Criterion & Reference term & Lexical variant \\
\hline \multirow{2}{*}{$\begin{array}{l}\text { number of elements } \\
\text { constituting the } \\
\text { terminological units }\end{array}$} & single-word terminological unit & single-word terminological unit \\
\cline { 2 - 3 } & single-word terminological unit & multi-word terminological unit \\
\cline { 2 - 3 } & multi-word terminological unit & single-word terminological unit \\
\cline { 2 - 3 } & multi-word terminological unit & multi-word terminological unit \\
\hline
\end{tabular}

Table 4.2. Possible lexical variants obtained considering a variable number of elements constituting the terminological units.

\footnotetext{
${ }^{107}$ A review of classifications of synonyms provided by different authors can be found in Freixa (2002: 164175).
} 
Victims of Crime from a Monolingual Terminological Perspective: Terminological Variation

\begin{tabular}{|l|l|l|}
\hline Criterion & Reference term & Lexical variant \\
\hline $\begin{array}{l}\text { element being } \\
\text { modified }\end{array}$ & head1+modifier1 & head2+modifier1 \\
\cline { 2 - 3 } $\begin{array}{l}\text { in a multi-word } \\
\text { terminological unit }\end{array}$ & head1+modifier1 & head1+modifier2 \\
\cline { 2 - 3 } & head1+modifier1 & head2+modifier2 \\
\hline
\end{tabular}

Table 4.3. Possible lexical variants obtained considering a the elements being modified in multi-word terminological units.

With regard to the first criterion, because the number of multi-word terms generally exceeds the number of single-word terms, also in the textual material analysed the examples involving polylexical terminological units are more abundant than those concerning monolexical terminological units. Nevertheless, examples of the first type of lexical variation have been identified in Italian as regards the terms testimone and teste (term cluster referring to the WITNESS genotype). As for the second type of lexical variation produced by the change in the number of the elements constituting co-referring term variants, this has not been found in the research data. Although multi-word terms are more frequent than single-word terms, in the victim-related terminology an example of the third type of lexical variation can be found in Italian, i.e. the terms indennità and indennizzo (term cluster referring to the STATE COMPENSATION genotype), which are both used as lexical variants of the main term risarcimento statale.

The far more frequent type of lexical variation related to the first criterion observed in the textual material analysed is the fourth type, i.e. lexical variation in which a multi-word term is replaced by a synonymous multi-word term. However, in order to describe this type of variation the second criterion needs to be accounted for, namely the element of the reference term that is substituted in the variant. Having a look at the English term clusters identified, different patterns of multi-word lexical variation can be observed. Considering the 'head1+modifier $1 \rightarrow$ head2+modifier1' pattern first and bearing in mind that in this type of pattern the head and the modifier in English are linked by means of a preposition, examples are provided by the main term application for compensation and its lexical variant claim for compensation. However, in most of the English multi-word terms examined, the modifier is either a noun or an adjective preceding the head. Therefore, the standard lexical variation pattern for English polylexical terms is 'modifier1+head1 $\rightarrow$ modifier1+head2'. An examples is provided by the pair composed of the main term victim support organisation and its variant victim support group. The objection that in this example the head element in the variant is not

\footnotetext{
${ }^{108}$ Note that the order of the elements can be inverted according to the typological conventions of the languages under discussion, thus producing other possible combinations, such as 'modifier1+head $1 \rightarrow$ modifier2+head1' or 'head1+modifier $1 \rightarrow$ modifier2+head1'.
} 
a perfect synonym of the head element of the main term may be valid in principle, since denominative variation can suggest a conceptual variation. However, given the specialised domain in which the variants are used and the contexts in which they have been found, not only these variants can be considered contextual synonyms (see Sager 1990: 59), but also the conceptual difference can be neglected and the terms can be said to belong to the same term cluster.

Among the 'multi-word term $\rightarrow$ multi-word term' variation pattern, the pattern which is more frequent is the one in which the head element remains unchanged while the modifier changes regardless of its position. As far as the 'modifier1+head1 $\rightarrow$ modifier2+head1' pattern is concerned, the following English examples can be given in which the first terminological unit corresponds to the main term: material loss, economic loss, pecuniary loss and financial loss; immaterial damages and moral damages; and central contact point and national contact point. However, since in English the modifier can also occur after a head element followed by a preposition (and possibly by an article introducing the modifier), other possible patterns of lexical variation can be observed where the modifier itself can be a single-word or a multiword unit. As a consequence, the number of patterns increases alongside the increase of the number of constituents of the polylexical term. The main term mediation in criminal cases and its variant mediation in criminal proceedings illustrate a simpler case in which the head element of the modifier is replaced. A more complex case is exemplified by the main term compensation for immaterial damages and its variants compensation for non-pecuniary losses and compensation for pain and suffering, in which the head element is kept unvaried, while the whole modifier is substituted with a synonymous expression.

The last 'multi-word term $\rightarrow$ multi-word term' variation pattern identified in the English victim-related terminology collected is the 'head1+modifier $1 \rightarrow$ head2+modifier2' pattern. In this case, the type of link holding among the head element and the modifier can be ignored, since both are replaced in the shift from the main term into its variant. In this regard, it should be noted that this pattern and the 'single-word term $\rightarrow$ single-word term' pattern are sometimes acknowledged as proper synonyms in literature, while the other patterns described earlier are thought to produce lexical variants rather than proper synonyms. An example of an English term cluster containing this type of lexical variation is the one referring to the IMMATERIAL DAMAGES genotype, in which the main term immaterial damages discussed above also has the lexical variant non-pecuniary loss. As for this last type of lexical variation, another case has been retrieved which, however, differs from all the other examples mentioned so far. In fact, the terms at issue, i.e. the main term Victim Support Europe and its 
Victims of Crime from a Monolingual Terminological Perspective: Terminological Variation

variants European Forum for Victim Services and European Forum for Victims' Services, designate an organisation, i.e. a named entity, and the usage of the terms is determined by the organisation itself. In other words, the victim support organisation which was once called European Forum for Victim Services changed its name into Victim Support Europe, making the alternation between the two terms within the same text impossible.

The lexical variation pattern in which alternation is produced among multi-word terms is frequent in the Italian textual material analysed as well. Contrary to the pattern valid for English in which the modifier generally comes before the head element, in the most frequent pattern in Italian the modifier comes after the head element. An example of this pattern is provided by the main term protezione delle vittime and its variant tutela delle vittime. However, the most frequent variation pattern observed in the Italian textual material is the 'head1+modifier1 $\rightarrow$ head1+modifier2' pattern, in which the modifier can be either an adjective or a noun/noun phrase introduced by a preposition (and possibly an article). Examples of the pattern in which the modifier is an adjective are: danno materiale, danno pecuniario, danno economico and danno patrimoniale (referring to the MATERIAL LOSS genotype) and giustizia riparativa, giustizia restaurativa, giustizia restitutiva, giustizia riparatrice, giustizia risarcitoria and giustizia riparatoria (referring to the RESTORATIVE JUSTICE genotype). Examples of the pattern in which the modifier is a noun or a noun phrase introduced by a preposition (and an article) are: domanda di risarcimento and its variant domanda di indennizzo, organizzazione di assistenza alle vittime and its variant organizzazione di sostegno alle vittime, sistema di risarcimento statale and its variant sistema nazionale di indennizzo, among others. A further form of multi-word lexical variation is represented by the case in which the main term follows a 'head1+modifier1(adjective)' pattern and the variant has a 'head1+modifier2(noun phrase)' pattern, such as the term cluster referring to the MEDIATION IN CRIMINAL CASES genotype, in which the main term mediazione penale is accompanied by a whole range of variants, namely mediazione nell'ambito dei procedimenti penali, mediazione nelle cause penali, mediazione tra vittima e autore del reato, mediazione tra l'autore del reato e la vittima, mediazione tra la vittima e l'autore del reato nell'ambito dei procedimenti penali, mediazione tra vittima e autore del reato nel procedimento penale and mediazione tra autore e vittima del reato. The last type of multiword lexical variation discussed for the English victim-related terminology, i.e. the form of lexical variation where a whole multi-word term alternates with a lexically different multiword term, has also been found in Italian. The examples of this type of variation are: mancato guadagno and lucro cessante, sistema di risarcimento statale and regime d'indennizzo delle 
vittime and, as already seen for English, Victim Support Europe and Forum europeo per $i$ servizi alle vittime.

Finally, a sui generis type of lexical variation is represented by the alternation of a term with an equivalent term in a different language, i.e. a loan word. This type of variation has been considered as a marginal phenomenon, since in the textual material analysed only one example of this alternation has been found in the English EU subcorpus. The example includes the main term civil party, which is itself a loan translation of "partie civile", which indicates a genotype which is typical for Civil Law jurisdictions but is absent in Common Law systems, and the French variant partie civile.

\subsection{VARIATION THROUGH EXPANSION/REDUCTION}

The fifth category of horizontal denominative variation is obtained by means of reduction or expansion of the main term. In this category of variation, the fact that a term variant is obtained either by reduction or by expansion depends on the selection of the reference term. In her proposal for a formal classification of term variants, for instance, Freixa (2002: 277279) contemplates only reduction as a possible form of variation (Freixa 2002: 277-279). Such an approach is due to her methodological choice of comparing a multi-word term composed of a higher number of elements with shortened forms of the same term (Freixa 2002: 269-270). In order to classify cases of reduction, Freixa introduces three criteria: the component of the terminological unit in which reduction occurs (i.e. head or modifier), the number of elements that are reduced, and the structure of the terminological units (Freixa 2002: 278). In Freixa's methodology the starting point for the examination of variation through reduction is always a multi-word term, while the term variant obtained can be either a multi-word term or a single-word term.

In contrast with Freixa's approach, in this study the reference term coincides with the main term identified on the basis of the criteria illustrated in Section 3.3.6.1. Taking the main term as the starting point for the analysis of terminological variation and confronting term variants against it, both expansion and reduction are possible forms of variation. As a consequence, there are no restrictions on the number of elements in the term serving as the main term, since this can be either a multi-word or a single-word terminological unit. As far as variation via reduction/expansion is concerned, however, in line with Freixa (2002: 278) it should be highlighted that this category of variation is mainly anaphoric, meaning that the main term and the term variant(s) can be considered as being linked by a contextual relation. An example of anaphoric variation is provided by the Italian term cluster referring to the CHILD 
VICTIM genotype discussed in Peruzzo (2010: 186), where the full form of the main term is replaced either by a short form or a pronoun. However, in this study the focus is on cases where the term variant(s) can be linked to the main term via non-anaphoric relations, provided that such a link can be drawn if the domain remains unchanged, i.e. if the terms under discussion occur in victim-related texts. Moreover, it is interesting to note here that, in the terms that are subject to reduction and expansion, the head element remains unchanged, the only exception being the Italian term richiedente, which has been discussed below.

Starting the analysis of this category of variation with expansion, it is worth mentioning that in most of the cases observed expansion occurs between a multi-word main term and a multiword variant, while the cases in which a single-word main term is expanded into a multi-word variant represent a minority. This is so because of the specific approach that has been adopted and described above: the main term needs to be specific enough so as to allow for a conceptual correspondence relation to be drawn between it and its variants. Therefore, a single-word term deprived of relevant modifiers can result too vague or ambiguous to be recorded as the main term to which more specific multi-word term variants can be linked. For example, in the Italian EU corpus the concept APPLICATION FOR COMPENSATION is often referred to by using the short form domanda rather than its full form domanda $d i$ risarcimento. However, the short form is not included in the relevant term cluster and cannot serve as a main term because the same term can refer to other types of applications. Therefore, the only cases in which a monolexical term can be considered as a main term on the basis of the selected criteria, even though there are polylexical variants for that term, are those cases in which the single-word term is specific enough within the domain under discussion to be linked to its multi-word variants. Two cases of this kind have been observed in the Italian EU corpus (richiedente $\rightarrow$ richiedente il risarcimento, richiedente l'indennizzo, soggetto richiedente un risarcimento statale; vittima $\rightarrow$ vittima di reato), and three in the English EU corpus (applicant $\rightarrow$ applicant for compensation, applicant for state compensation; reparation $\rightarrow$ victim reparation; victim $\rightarrow$ crime victim, victim of a crime, victim of the offence). In all the other cases of variation by means of expansion, the main term is a multi-word terminological unit that corresponds to a short form of its variants. Such variants are obtained by adding modifiers to the head element or the modifiers already present in the short form. The cases in which this type of variation is observed are exemplified in the following tables: 


\begin{tabular}{|c|c|c|c|}
\hline Main term & Term variant & $\begin{array}{l}\text { Variation } \\
\text { pattern }^{109}\end{array}$ & Type of expansion \\
\hline $\begin{array}{ll}\text { application } & \text { for } \\
\text { compensation } & \end{array}$ & $\begin{array}{l}\text { application for state } \\
\text { compensation }\end{array}$ & $\begin{array}{l}\mathrm{H}(\mathrm{N} 1)+\text { Prep + } \\
\mathrm{M}(\mathrm{N} 2) \rightarrow \mathrm{H}(\mathrm{N} 1)+ \\
\text { Prep + M(N3) + } \\
\mathrm{M}(\mathrm{N} 2)\end{array}$ & insertion \\
\hline $\begin{array}{ll}\text { compensation } & \text { for } \\
\text { immaterial damages } & \end{array}$ & $\begin{array}{l}\text { compensation awarded } \\
\text { for immaterial damages }\end{array}$ & $\begin{array}{l}\mathrm{H}(\mathrm{N} 1)+\text { Prep + } \\
\mathrm{M}(\text { Adj1) + M(N2) } \\
\rightarrow \mathrm{H}(\mathrm{N} 1)+ \\
\mathrm{M}(\text { Adj2) + Prep } \\
\mathrm{M}(\text { Adj1) }+\mathrm{M}(\mathrm{N} 2)\end{array}$ & insertion \\
\hline $\begin{array}{l}\text { European network of } \\
\text { national contact points } \\
\text { for restorative justice }\end{array}$ & $\begin{array}{l}\text { European network of } \\
\text { national contact points } \\
\text { for mediation in } \\
\text { criminal cases and } \\
\text { restorative justice }\end{array}$ & $\begin{array}{l}\mathrm{M}(\text { Adj1 })+\mathrm{H}(\mathrm{N} 1) \\
+ \text { Prep + M(Adj2) } \\
+\mathrm{M}(\mathrm{N} 2)+\mathrm{M}(\mathrm{N} 3) \\
+ \text { Prep + M(Adj3) } \\
+\mathrm{M}(\mathrm{N} 4) \rightarrow \\
\mathrm{M}(\mathrm{Adj} 1)+\mathrm{H}(\mathrm{N} 1) \\
+ \text { Prep + M(Adj2) } \\
+\mathrm{M}(\mathrm{N} 2)+\mathrm{M}(\mathrm{N} 3) \\
+ \text { Prep + M(N5) + } \\
\text { Prep + M(Adj4) + } \\
\mathrm{M}(\mathrm{N} 6)+\mathrm{C}+ \\
\mathrm{M}(\text { Adj3) + M(N4) }\end{array}$ & insertion \\
\hline legal aid & free legal aid & $\begin{array}{l}\mathrm{M}(\operatorname{Adj} 1)+\mathrm{H}(\mathrm{N}) \\
\rightarrow \quad \mathrm{M}(\operatorname{Adj} 2)+ \\
\mathrm{M}(\operatorname{Adj} 1)+\mathrm{H}(\mathrm{N})\end{array}$ & left expansion \\
\hline protection of victims & $\begin{array}{l}\text { protection of victims of } \\
\text { crime }\end{array}$ & $\begin{array}{l}\mathrm{H}(\mathrm{N} 1)+\text { Prep }+ \\
\mathrm{M}(\mathrm{N} 2) \rightarrow \mathrm{H}(\mathrm{N} 1)+ \\
\text { Prep }+\mathrm{M}(\mathrm{N} 2)+ \\
\text { Prep }+\mathrm{M}(\mathrm{N} 3)\end{array}$ & right expansion \\
\hline \multirow[t]{3}{*}{ state compensation } & $\begin{array}{l}\text { state compensation for } \\
\text { victims }\end{array}$ & $\begin{array}{l}\mathrm{M}(\mathrm{N} 1)+\mathrm{H}(\mathrm{N} 2) \rightarrow \\
\mathrm{M}(\mathrm{N} 1)+\mathrm{H}(\mathrm{N} 2)+ \\
\text { Prep }+\mathrm{M}(\mathrm{N} 3)\end{array}$ & right expansion \\
\hline & $\begin{array}{l}\text { state compensation for } \\
\text { victims of crime }\end{array}$ & $\begin{array}{l}\mathrm{M}(\mathrm{N} 1)+\mathrm{H}(\mathrm{N} 2) \rightarrow \\
\mathrm{M}(\mathrm{N} 1)+\mathrm{H}(\mathrm{N} 2)+ \\
\text { Prep }+\mathrm{M}(\mathrm{N} 3)+ \\
\text { Prep }+\mathrm{M}(\mathrm{N} 4)\end{array}$ & right expansion \\
\hline & $\begin{array}{l}\text { state compensation to } \\
\text { victims }\end{array}$ & $\begin{array}{l}\mathrm{M}(\mathrm{N} 1)+\mathrm{H}(\mathrm{N} 2) \rightarrow \\
\mathrm{M}(\mathrm{N} 1)+\mathrm{H}(\mathrm{N} 2)+ \\
\text { Prep }+\mathrm{M}(\mathrm{N} 3)\end{array}$ & right expansion \\
\hline
\end{tabular}

Table 4.4. English term variants through expansion.

\footnotetext{
${ }^{109} \mathrm{Adj}=$ adjective, $\mathrm{Adv}=$ adverb, Art $=$ article, $\mathrm{C}=$ conjunction, $\mathrm{H}=$ head, $\mathrm{M}=$ modifier, $\mathrm{N}=$ noun, Prep $=$ preposition, PrepArt $=$ contracted preposition + article, $\mathrm{PrepP}=$ prepositional phrase, $\mathrm{V}=$ verb .
} 
Victims of Crime from a Monolingual Terminological Perspective: Terminological Variation

\begin{tabular}{|c|c|c|c|}
\hline Main term & Term variant & $\begin{array}{l}\text { Variation } \\
\text { pattern }^{110}\end{array}$ & Type of expansion \\
\hline $\begin{array}{ll}\text { domanda } & \mathrm{di} \\
\text { risarcimento } & \end{array}$ & $\begin{array}{l}\text { domanda per ottenere } \\
\text { un risarcimento }\end{array}$ & $\begin{array}{l}\mathrm{H}(\mathrm{N} 1)+\text { Prep + } \\
\mathrm{M}(\mathrm{N} 2) \rightarrow \mathrm{H}(\mathrm{N} 1)+ \\
\text { Prep }+\mathrm{M}(\mathrm{V})+\text { Art } \\
+\mathrm{M}(\mathrm{N} 2)\end{array}$ & insertion \\
\hline $\begin{array}{l}\text { rete europea di punti di } \\
\text { contatto nazionali per } \\
\text { la giustizia riparatoria }\end{array}$ & $\begin{array}{l}\text { rete europea di punti di } \\
\text { contatto nazionali per } \\
\text { la mediazione nei } \\
\text { procedimenti penali e } \\
\text { per la giustizia } \\
\text { riparatoria }\end{array}$ & $\begin{array}{l}\mathrm{H}(\mathrm{N} 1)+\mathrm{M}(\text { Adj1 }) \\
+ \text { Prep }+\mathrm{M}(\mathrm{N} 2)+ \\
\text { Prep + M(N3) + } \\
\mathrm{M}(\text { Adj2) + Prep + } \\
\text { Art + M(N4) + } \\
\mathrm{M}(\text { Adj3) } \rightarrow \text { H(N1) } \\
+\mathrm{M}(\text { Adj1) + Prep } \\
+\mathrm{M}(\mathrm{N} 2)+\text { Prep + } \\
\mathrm{M}(\mathrm{N} 3)+\mathrm{M}(\text { Adj2) } \\
+ \text { Prep + Art + } \\
\mathrm{M}(\mathrm{N} 5)+\text { PrepArt + } \\
\mathrm{M}(\mathrm{N} 6)+\mathrm{M}(\text { Adj4) } \\
+\mathrm{C}+\text { Prep + Art + } \\
\mathrm{M}(\mathrm{N} 4)+\mathrm{M}(\text { Adj3) }\end{array}$ & insertion \\
\hline $\begin{array}{l}\text { risarcimento da parte } \\
\text { dell'autore del reato }\end{array}$ & $\begin{array}{l}\text { risarcimento alle } \\
\text { vittime da parte } \\
\text { dell'autore del reato }\end{array}$ & $\begin{array}{l}\mathrm{H}(\mathrm{N} 1)+\text { PrepP }+ \\
\mathrm{M}(\mathrm{N} 2)+\text { PrepArt }+ \\
\mathrm{M}(\mathrm{N} 3) \rightarrow \mathrm{H}(\mathrm{N} 1)+ \\
\text { PrepArt }+\mathrm{M}(\mathrm{N} 4)+ \\
\text { PrepP }+\mathrm{M}(\mathrm{N} 2)+ \\
\text { PrepArt }+\mathrm{M}(\mathrm{N} 3)\end{array}$ & insertion \\
\hline \multirow[t]{3}{*}{ diritti delle vittime } & $\begin{array}{l}\text { diritti delle vittime } \\
\text { della criminalità }\end{array}$ & $\begin{array}{l}\mathrm{H}(\mathrm{N} 1)+\text { PrepArt }+ \\
\mathrm{M}(\mathrm{N} 2) \rightarrow \mathrm{H}(\mathrm{N} 1)+ \\
\text { PrepArt }+\mathrm{M}(\mathrm{N} 2)+ \\
\text { PrepArt }+\mathrm{M}(\mathrm{N} 3)\end{array}$ & right expansion \\
\hline & $\begin{array}{l}\text { diritti delle vittime di } \\
\text { reati }\end{array}$ & $\begin{array}{l}\mathrm{H}(\mathrm{N} 1)+\text { PrepArt + } \\
\mathrm{M}(\mathrm{N} 2) \rightarrow \mathrm{H}(\mathrm{N} 1)+ \\
\text { PrepArt }+\mathrm{M}(\mathrm{N} 2)+ \\
\text { Prep + M(N3) }\end{array}$ & right expansion \\
\hline & $\begin{array}{l}\text { diritti delle vittime di } \\
\text { reato }\end{array}$ & $\begin{array}{l}\mathrm{H}(\mathrm{N} 1)+\text { PrepArt + } \\
\mathrm{M}(\mathrm{N} 2) \rightarrow \mathrm{H}(\mathrm{N} 1)+ \\
\text { PrepArt }+\mathrm{M}(\mathrm{N} 2)+ \\
\text { Prep }+\mathrm{M}(\mathrm{N} 3)\end{array}$ & right expansion \\
\hline \multirow[t]{2}{*}{$\begin{array}{ll}\text { domanda } & \mathrm{di} \\
\text { risarcimento } & \end{array}$} & 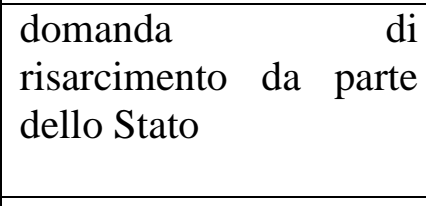 & $\begin{array}{l}\mathrm{H}(\mathrm{N} 1)+\text { Prep + } \\
\mathrm{M}(\mathrm{N} 2) \rightarrow \mathrm{H}(\mathrm{N} 1)+ \\
\text { Prep + M(N2) + } \\
\text { PrepP + M(N3) }\end{array}$ & right expansion \\
\hline & $\begin{array}{ll}\text { domanda } & \mathrm{di} \\
\text { risarcimento statale }\end{array}$ & $\begin{array}{l}\mathrm{H}(\mathrm{N} 1)+\text { Prep + } \\
\mathrm{M}(\mathrm{N} 2) \rightarrow \mathrm{H}(\mathrm{N} 1)+ \\
\text { Prep + M(N2) + } \\
\mathrm{M}(\text { Adj) }\end{array}$ & right expansion \\
\hline protezione delle vittime & $\begin{array}{l}\text { protezione delle vittime } \\
\text { di reati }\end{array}$ & $\begin{array}{l}\mathrm{H}(\mathrm{N} 1)+\text { PrepArt + } \\
\mathrm{M}(\mathrm{N} 2) \rightarrow \mathrm{H}(\mathrm{N} 1)+ \\
\text { PrepArt }+\mathrm{M}(\mathrm{N} 2)+\end{array}$ & right expansion \\
\hline
\end{tabular}

\footnotetext{
${ }^{110}$ See footnote 109.
} 


\begin{tabular}{|c|c|c|c|}
\hline & & Prep + M(N3) & \\
\hline & $\begin{array}{l}\text { protezione delle vittime } \\
\text { di reato }\end{array}$ & $\begin{array}{l}\mathrm{H}(\mathrm{N} 1)+\text { PrepArt + } \\
\mathrm{M}(\mathrm{N} 2) \rightarrow \mathrm{H}(\mathrm{N} 1)+ \\
\text { PrepArt }+\mathrm{M}(\mathrm{N} 2)+ \\
\text { Prep }+\mathrm{M}(\mathrm{N} 3)\end{array}$ & right expansion \\
\hline \multirow[t]{2}{*}{$\begin{array}{l}\text { risarcimento da parte } \\
\text { dello Stato }\end{array}$} & $\begin{array}{l}\text { risarcimento da parte } \\
\text { dello Stato alle vittime } \\
\text { di reati }\end{array}$ & $\begin{array}{l}\mathrm{H}(\mathrm{N} 1)+\text { PrepP }+ \\
\mathrm{M}(\mathrm{N} 2) \rightarrow \mathrm{H}(\mathrm{N} 1)+ \\
\text { PrepP }+\mathrm{M}(\mathrm{N} 2)+ \\
\text { PrepArt }+\mathrm{M}(\mathrm{N} 3)+ \\
\text { Prep }+\mathrm{M}(\mathrm{N} 4)\end{array}$ & right expansion \\
\hline & $\begin{array}{l}\text { risarcimento da parte } \\
\text { dello Stato alle vittime } \\
\text { di reato }\end{array}$ & $\begin{array}{l}\mathrm{H}(\mathrm{N} 1)+\text { PrepP }+ \\
\mathrm{M}(\mathrm{N} 2) \rightarrow \mathrm{H}(\mathrm{N} 1)+ \\
\text { PrepP }+\mathrm{M}(\mathrm{N} 2)+ \\
\text { PrepArt }+\mathrm{M}(\mathrm{N} 3)+ \\
\text { Prep }+\mathrm{M}(\mathrm{N} 4)\end{array}$ & right expansion \\
\hline
\end{tabular}

Table 4.5. Italian term variants through expansion.

As can be seen from the examples above, the patterns for terminological variation through expansion vary greatly. The term variants are derived from the main term by adding an additional modifier either to the head element or to the modifier of the main term. According to the position occupied by the additional modifier, expansion is obtained via three types of shifts: right expansion (when the additional element is added on the right of the main term), left expansion (when the additional element is added on the left of the main term) and insertion (when the additional element is added in between the components of the main term). Among the possible shifts, left expansion has been observed only in the English textual material, and specifically the main term legal aid, to which the additional adjective "free" can be added. It should be noted that in this example, as well as in the other cases of expansion reported in Tables 4.4 and 4.5, the additional elements found in the expanded term variants may supplement the main term with conceptual aspects that are not made explicit in the textual manifestation of the main term but are implied in the concept the main term refers to. In other words, the addition of "free" only makes explicit what is implicit in the main term legal aid, since in the narrow legal area of victims of crime as well as in the broader legal area of criminal proceedings legal aid is a right granted to those persons involved in criminal proceedings who are eligible for it.

The other two shifts, namely right expansion and insertion, have been identified both in English and Italian. In both types of shift, the additional modifier can be added either to the head element or to the modifier that qualifies the head element. As regards right expansion, the term variants of the main term state compensation exemplify both types of right expansion. Indeed, two term variants have been found in which the modifier "victims" is 
added to the head element by means of two different prepositions, i.e. state compensation for victims and state compensation to victims, as well as a third variant in which the modifier is further complemented by the modifier "crime" introduced by a different preposition, i.e. state compensation for victims of crime.

As regards Italian, the only type of right expansion that has been identified in the textual material is the second type, that is the type in which a further modifier is added to the modifier already part of the main term. This is the case, for instance, of the variants of the main term domanda di risarcimento, i.e. domanda di risarcimento da parte dello Stato and domanda di risarcimento statale. As in the term legal aid above, the conceptual aspect added to the main term was already implicit in the main term, since the only possible case in which the victim can apply for compensation is when compensation is awarded by the State, whereas in criminal or civil proceedings (depending on the legal system) it is the judge who decides whether compensation should be provided by the offender.

Like right expansion, insertion can concern the head element or the modifier of the main term. Examples of the first type of insertion are European network of national contact points for restorative justice $\rightarrow$ European network of national contact points for mediation in criminal cases and restorative justice, and the Italian equivalents rete europea di punti di contatto nazionali per la giustizia riparatoria $\rightarrow$ rete europea di punti di contatto nazionali per la mediazione nei procedimenti penali e per la giustizia riparatoria. Although the insertion of the elements "mediation in criminal cases" in English and "mediazione nei procedimenti penali" in Italian assigns an additional conceptual facet to the term, the correspondence relation among the terms is maintained, since both refer to the same named entity. The second type of insertion also adds a conceptual aspect to the modifier, as in the case of application for compensation $\rightarrow$ application for state compensation, without for this reason hindering the correspondence relation between the main term and its variant, in the same way as in the Italian equivalent domanda di risarcimento discussed above as regards right expansion. As for Italian, examples of the second type of insertion have not been found in the textual material analysed, since the modification of the modifier is usually obtained by right expansion.

The opposite operation to expansion to obtain term variants is reduction, which consists in the elimination of a constituent element of the main term to produce a shortened form of it. Unlike the cases of expansion, the examples of this type of variation are not very frequent. This is so due to the criteria established for the selection of the main term and the variants to be included in the terminological knowledge base MuLex and submitted to terminological 
variation analysis. Therefore, only those variants which are not contextual variants and thus do not depend on anaphoric relations within the texts are taken into consideration also in the discussion of terminological variation via reduction. The cases of reduction found in the textual material analysed that fulfil these criteria are summarised in the following tables:

\begin{tabular}{|l|l|l|l|}
\hline Main term & Term variant & $\begin{array}{l}\text { Variation } \\
\text { pattern }\end{array}$ & Type of reduction \\
\hline $\begin{array}{l}\text { application } \\
\text { compensation }\end{array}$ & $\begin{array}{l}\mathrm{H}(\mathrm{N} 1)+\text { Prep }+ \\
\mathrm{M}(\mathrm{N} 2) \rightarrow \mathrm{H}(\mathrm{N} 1)\end{array}$ & $\begin{array}{l}\text { multi-word term } \rightarrow \\
\text { single-word term }\end{array}$ \\
\hline $\begin{array}{l}\text { state compensation } \\
\text { scheme }\end{array}$ & compensation scheme & $\begin{array}{l}\mathrm{M}(\mathrm{N} 1)+\mathrm{M}(\mathrm{N} 2)+ \\
\mathrm{H}(\mathrm{N} 3) \rightarrow \mathrm{M}(\mathrm{N} 2)+ \\
\mathrm{H}(\mathrm{N} 3)\end{array}$ & $\begin{array}{l}\text { multi-word term } \rightarrow \\
\text { multi-word term }\end{array}$ \\
\hline
\end{tabular}

Table 4.6. English term variants through reduction.

\begin{tabular}{|c|c|c|c|}
\hline Main term & Term variant & $\begin{array}{l}\text { Variation } \\
\text { pattern }^{112}\end{array}$ & Type of reduction \\
\hline mediazione penale & mediazione & $\begin{array}{l}\mathrm{H}(\mathrm{N} 1)+\mathrm{M}(\mathrm{Adj} 1) \\
\rightarrow \mathrm{H}(\mathrm{N} 1)\end{array}$ & $\begin{array}{l}\text { multi-word term } \rightarrow \\
\text { single-word term }\end{array}$ \\
\hline $\begin{array}{lll}\text { punto di } & \text { contatto } \\
\text { centrale } & & \\
\end{array}$ & punto di contatto & $\begin{array}{l}\mathrm{H}(\mathrm{N} 1)+\text { Prep + } \\
\mathrm{M}(\mathrm{N} 2)+\mathrm{M}(\text { Adj1) } \\
\rightarrow \mathrm{H}(\mathrm{N} 1)+\text { Prep }+ \\
\mathrm{M}(\mathrm{N} 2)\end{array}$ & $\begin{array}{l}\text { multi-word term } \rightarrow \\
\text { multi-word term }\end{array}$ \\
\hline $\begin{array}{l}\text { vittima particolarmente } \\
\text { vulnerabile }\end{array}$ & vittima vulnerabile & $\begin{array}{l}\mathrm{H}(\mathrm{N} 1)+\mathrm{M}(\operatorname{Adv} 1) \\
+\quad \mathrm{M}(\mathrm{Adj} 1) \rightarrow \\
\mathrm{H}(\mathrm{N} 1)+\mathrm{M}(\operatorname{Adj} 1)\end{array}$ & $\begin{array}{l}\text { multi-word term } \rightarrow \\
\text { multi-word term }\end{array}$ \\
\hline
\end{tabular}

Table 4.7. Italian term variants through reduction.

As can be noted from the examples provided, in both English and Italian two types of terminological variation by means of reduction have been observed. The first type consists in the elimination of the modifier, leading to the shift of a multi-word term into a single-word term. Examples are the English main term application for compensation and its variant application, and the Italian main term mediazione penale and its variant mediazione. Although the shortened form of the head element can be said to be less specific than the main term which it is derived from, in the area of law of victims of crime the short form can still be considered to be specific enough to be linked to the same genotype as the main term. For instance, in cases where victims of crime are directly involved, it would be hard to find any other form of mediation other than mediation in criminal cases. On the other hand, the second

\footnotetext{
${ }^{111}$ See footnote 109 .

${ }^{112}$ See footnote 109.
} 
type of reduction presupposes the formation of a shorter version of the main term which is still a multi-word term. In this case, reduction is obtained by deleting a modifier that qualifies the modifier of the head element. In other words, in order to fall into this category, the main term needs to contain two modifiers ${ }^{113}$, of which the direct modifier of the head element is maintained in the term variant, while the modifier of the modifier is left out. As with the first type of term variation via reduction, however, the correspondence relation between the main term and its variants is preserved in the specific domain in which they are used even without depending on anaphoric relations within the text.

A further type of terminological variation through reduction is provided by the shift of a full form into an abbreviation (acronym or initialism). This type of variation is different from the forms of reduction seen above, since no constituent element of the main term is deleted in the variant derived from it, but rather each content word making up the main term is reduced to its initial. As regards abbreviations in the textual material analysed, it should be noted that the only cases that have been considered relevant to the area of law under discussion and suitable for recording into the terminological knowledge base MuLex are English abbreviations. This does not necessarily mean that such abbreviations are only used in English texts, but rather that they are of English origin. In order to illustrate this point, it is first necessary to distinguish between two types of abbreviations, a distinction that is needed to explain the occurrence of English abbreviations in Italian texts. The first type is represented by abbreviations resulting from terms referring to named entities, such as organisations, while the second type is represented by abbreviations referring to any other term apart from named entities. As far as the first type is concerned, the following examples have been retrieved in the English textual material analysed: Criminal Injuries Compensation Authority $\rightarrow$ CICA, Criminal Injuries Compensation Scheme $\rightarrow$ CICS, and Victim Support Scotland $\rightarrow$ VSS. Also the main term Victim Support Northern Ireland falls into the same group though, unlike the previous examples, it produces two different variants, i.e. the full initialism VSNI and the partial abbreviation Victim Support NI. The reason for finding only English abbreviations and no Italian ones in the textual material analysed lies in the fact that the abbreviations found in Italian texts refer to named entities peculiar to the UK reality, therefore it is hardly surprising that the abbreviations $C I C A$ and $C I C S$ are also present in texts written in Italian.

\footnotetext{
${ }^{113}$ The limit of two modifiers is determined by the empirical observation of the terminological data extracted from the textual material analysed. However, this does not impede the finding of further examples with main terms containing more constituent elements leading to the formation of different term variants obtained by reduction.
} 
The instance that embodies the second type of initialism is the main term restorative justice and its initialism $R J$. Unlike the first type of initialisms in which there is no modification in capitalisation, since the reduction leaves the uppercase of the elements involved unchanged, the second type may also imply a graphic variation: thus restorative justice $\rightarrow R J$ is an example of a combined terminological variation (see Section 4.5.1.1.7) rather than a variation via reduction only.

\subsection{GRAPHIC VARIATION}

Compared to the categories of horizontal denominative variation seen earlier, graphic variation does not imply a modification in terms of inflection, (morpho)syntactic and lexical change, expansion or reduction, but the only changes that affect the main term are, as the name suggests, graphic. These changes include both the alternation of uppercase/lowercase and orthographic modifications, although in the textual material analysed the selected terminology in both languages has not included any case of the latter and the only graphic variants involving an alternation of uppercase and lowercase have been found in the English texts. The examples are the following: European network of national contact points for restorative justice $\rightarrow$ European Network of national contact points for Restorative Justice, assisting authority $\rightarrow$ Assisting Authority, deciding authority $\rightarrow$ Deciding Authority, central contact point $\rightarrow$ Central Contact Point, and state compensation $\rightarrow$ State compensation. Interestingly, all the examples provided follow the same pattern, with the main term containing the relevant elements in lowercase and the term variants containing the same elements in uppercase. As stated earlier in Section 4.5, the directionality of terminological variation in this study is determined by the criteria applied for the selection of main terms and is therefore functional to the research project, although such directionality does not show the chronological evolution of terminology.

\subsection{COMBINED VARIATION}

Apart from the cases illustrated above, in which the term variant is obtained from a main term via a single type of shift, term variants can also be derived from a main term by a combination of shifts that can follow one another into more than one of the categories discussed above, as already seen for the example of restorative justice $\rightarrow R J$.

Therefore, for instance, in the Italian textual material the term variant sistema nazionale di risarcimento da parte dello Stato is obtained from the main term sistema di risarcimento statale through the insertion of the modifier "nazionale" and the morphosyntactic change of the adjective "statale" into the modifier introduced by a prepositional phrase "da parte dello 
Stato". The same main term also produces the variant regime di risarcimento delle vittime di reati, in which the head "sistema" is replaced by "regime" (lexical variation), the modifier "statale" is deleted (reduction), and the modifier "delle vittime di reati" is added (right expansion). Another example is provided by the main term rete europea di punti di contatto nazionali per la giustizia riparatoria, which through reduction and insertion is transformed into the variant rete europea per la mediazione e per la giustizia riparatoria.

An English example of combined variation is provided by the main term application for compensation and its variant claim for cross-border compensation, in which the head element "application" is replaced by the synonym "claim" (lexical variation) and an additional modifier is added to the already existing one (insertion). A further example is represented by the main term state compensation scheme and the variant Member State scheme to compensate crime victims, where the more generic modifier "state" is substituted by the more specific multi-word modifier "Member State" (lexical variation with conceptual shift) and the noun modifier "compensation" is replaced by a morphosyntactic variant, i.e. the verb "to compensate", which presupposes a syntactical change (permutation). Due to the transitive nature of the verb involved in this variation, a right expansion of the term is necessary, bringing about the addition of the further modifier "crime victim".

\subsubsection{SECOND VARIABLE: TIME SPAN}

The second variable considered in this research study for the purposes of describing denominative variation is time span, i.e. the period of time covered by the texts from which terminology is extracted. As pointed out by Picton, "[ $t$ ]he diachronic dimension has long been ignored in terminology" (Picton 2011: 134). According to Dury and Picton (2009), such a lack of interest for the diachronic dimension has two main reasons. The first is a theoretical cause, since the field of Terminology has long been monopolised by a single approach, i.e. that postulated by the GTT, which was centred on the standardisation of terminology and therefore excluded any possible research on variation. The second reason is technical in its nature and derives from the first one: since there was no need for studies in terminological variation, the resources and tools developed for studying this phenomenon were scarce. Nevertheless, since the 1990s, terminology theories have benefitted from the improvement of Natural Language Processing tools and techniques (Picton 2011: 136) as well as the incorporation into terminology studies of corpus linguistics methods and therefore of a textual approach. This new interest in carrying out studies on terminological variation has also entailed that the diachronic dimension of variation be also taken into account and used in a variety of studies. Kocourek (1982: 23, quoted in Picton 2011: 136), for instance, notes that 
early diachronic studies often consisted in the description of isolated terms spanning over a long period of time. However, Picton (2011: 136) points to a more varied research reality, where the diachronic perspective emerges from the study of neologisms as well as trends and technological innovations in scientific domains ${ }^{114}$.

In her article describing short-period diachronic phenomena in specialised corpora, Picton investigates four linguistic clues affecting terminology that point to the evolution of knowledge: frequency, knowledge-rich contexts, (co)existence of term variants and syntactic dependency (Picton 2011: 139-141). However, for the purpose of describing the diachronic perspective of denominative variation in this research study, the linguistic clues identified by Picton are not totally appropriate, since the aim here is not to provide evidence of knowledge evolution as provided by the conceptual changes in time which are discussed in Section 4.6, but rather to focus only on one of Picton's clues, i.e. the co-existence of term variants, with a focus on those term variants in which no conceptual shift can be identified.

In order to do so, it should be noted that the discussion here is limited to the EU corpus. This is so for two main reasons. Firstly, the texts making up the EU corpus cover all the victimrelated issues tackled by the EU from the beginning of the discussion on these issues at the EU level. Therefore, while the EU corpus can be considered as sufficiently comprehensive to represent the complete evolution of victim-related issues from the EU perspective, it does not include the conceptual variation which has been produced in this same terminology when used in different legal systems. Secondly, by limiting the analysis to EU texts, the time span covered by these texts is short (1998-2012) ${ }^{115}$, making the EU corpus a short-diachronic corpus (Picton 2011: 138). From this point of view, the co-existence of term variants in the EU corpus implies a simplification of the multi-level jurisdiction in which terminology nowadays evolves within the boundaries of the EU. Indeed, the permeability to legal concepts and terminology of the legal systems involved makes it impossible to prevent the migration of concepts and terms from one legal system to the other - regardless of whether such a system is national or supranational - which is anyway necessary for implementing and promoting EU policies. Therefore, even though in what follows the focus is on EU terminology, its evolution may have been caused by the influence exercised by some national terminology.

As regards the study of EU terminology from a diachronic perspective, three term behavioural patterns were identified, of which one concerns univocal terms and the remaining two regard terms subject to terminological variation.

\footnotetext{
${ }^{114}$ For a brief overview of diachronic studies in Terminology, see Picton (2011: 136).

${ }^{115}$ See the list of EU documents included in the EU corpus in Annex 1.
} 
Victims of Crime from a Monolingual Terminological Perspective: Terminological Variation

\subsubsection{UNIVOCAL TERMS}

The first behavioural pattern consists in the existence of a single term to refer to a given concept, i.e. mononymy. This is, however, the least frequent pattern in the terminology extracted from the EU corpus. As far as the English EU subcorpus is concerned, no term variant has been spotted for the terms child-friendly justice (2011), criminal injuries (20012012), witness (2000-2010), and secondary victimisation (2000-2011). In the Italian EU subcorpus, the terms autorità di assistenza (2002-2009), autorità di decisione (2002-2009), and parte civile (2001-2009) have been found to follow the mononymy principle. Apart from these examples, where there is no correspondence between mononymy/terminological variation in the two languages ${ }^{116}$, there are also cases where mononymy is reflected in both languages for the same genotype. These cases are summarised in the following table:

\begin{tabular}{|l|l|l|}
\hline English univocal term & Italian univocal term & Time span \\
\hline bystander & passante & $2001-2002$ \\
\hline cross-border victim & vittima transfrontaliera & $2001-2002$ \\
\hline mediatore & mediator & $2004-2011$ \\
\hline samaritano & samaritan & $2001-2002$ \\
\hline European protection order & ordine di protezione europeo & $2010-2012$ \\
\hline executing State & Stato di esecuzione & $2010-2011$ \\
\hline issuing State & Stato di emissione & $2010-2011$ \\
\hline person causing danger & persona che determina il pericolo & $2010-2011$ \\
\hline protected person & persona protetta & $2010-2011$ \\
\hline protection measure & misura di protezione & $2010-2012$ \\
\hline State of supervision & Stato di sorveglianza & $2010-2011$ \\
\hline
\end{tabular}

Table 4.8. Correspondence of univocal terms in the EU corpus.

The cases of mononymy extracted from the EU corpus allow us to draw some inferences. First of all, by observing the English examples, it is possible to see that univocal terms occur almost synchronically, such as in the case of child-friendly justice (2011), which has been found in texts written during one single year only, or over a longer time span, such as the example of secondary victimisation (2000-2011), which covers almost the whole period under consideration. The fact that a term can be found in texts issued over a very short period of time can be attributed to the marginal relevance of the concept the term refers to within the specialised domain. Therefore, from the data available in the EU corpus it can be concluded

\footnotetext{
${ }^{116}$ For instance, whereas in the English EU subcorpus the genotype CHILD-FRIENDLY JUSTICE is referred to by using child-friendly justice only, in the Italian EU subcorpus two terms are found, i.e. giustizia a misura di minore and giustizia adattata ai bambini.
} 
that, whereas children play a central role in the victim-oriented EU legislation ${ }^{117}$, the concept of CHILD-FRIENDLY JUSTICE is not as relevant, although this does not prevent a renewed interest in the topic to grow in the future. The same can be said also for those terms which are univocal both in English and Italian, such as bystander and samaritan.

On the other hand, for the example of cross-border victim a different line of thinking should be followed. In fact, though the EU corpus is focused on the figure of the victim of crime and the term victim and its variants all refer to the genotype VICTIM, the genotype itself is multidimensional. Put differently, the EU deals with victims of crime, but different documents deal with different aspects of the victim and therefore the term victim can be interpreted differently according to the focus of the document. To illustrate this point, Council Directive 2004/80/EU can be taken as an example. The Directive specifically concerns compensation to crime victims in cross-border situations, meaning that the person applying for compensation has been a victim of a crime committed in a Member State other than the Member State where the person is habitually resident. In other words, in order to be eligible for compensation, according to this Directive the person needs to be a cross-border victim. It follows that, even though the term cross-border victim itself is not used in this act, the concept is still relevant for the topic.

Another conclusion can also be reached by observing the second part of Table 4.8, starting from the term European protection order. As has already been noted for the term childfriendly justice, the fact that certain terms are used only during a short period of time does not preclude a future development of the same topic. This can be considered even more likely if the time span covered is very recent, as in the case of the term European protection order and the other terms with a time span 2010-2011 or 2010-2012, which are, inter alia, all related to the concept of EUROPEAN PROTECTION ORDER. Indeed, all these terms were introduced by Directive 2011/99/EU to refer to new concepts created within the framework of the EU legal system and - given that the deadline for the enforcement of laws, regulations and administrative provisions to comply with this Directive is 11 January 2015 (European Parliament \& Council of the European Union 2011a: Article 21(1)) - it is more than likely that these terms will be used (or modified through terminological variation) in future documents.

The examples provided so far are all related to univocal terms found in the EU corpus. However, it should not be overlooked that the same conclusions on topic relevance and

\footnotetext{
${ }^{117}$ Several EU victim-related legal acts and non-legally binding documents have been issued in which child victims are specifically mentioned and considered as victims with specific protection needs, such as Directive 2011/92/EU and Directive 2012/29/EU .
} 
possible future usage can be drawn for non-univocal terms, such as those presented further below.

\subsubsection{NON-UNIVOCAL TERMS}

The second and third behavioural patterns were observed in non-univocal terms, i.e. in those terms which are subject to terminological variation. The difference between the two patterns lies in the time span in which the term variants are found; however, both behaviours can be observed in the same term cluster, meaning that the patterns are not mutually exclusive. The first, and less frequent, pattern concerning non-univocal terms consists in the co-existence of term variants during the same period of time. It should however be noted that the time span considered is not an objective variable but is rather established by the observer. Therefore, in the specific case of this research study, within the short-diachronic EU corpus the occurrence of a term in the corpus in a specific year or time span is attested via the publication date of the document the term has been found in.

On the other hand, the second pattern concerning non-univocal terms involves the substitution, in the course of time, of a term with another term which is linked to the former by a correspondence relation. Again, within the time span considered for this research project, the reference time for attesting the occurrence of a term in the EU corpus is a year, established on the basis of the publication date of the document the term has been found in.

The terms that present these two types of diachronic variation are listed in Annex 5, while in the following tables only three examples for each language have been listed in order to clarify the point.

\begin{tabular}{|c|c|c|c|}
\hline Genotype & Phenotype & Time span & \\
\hline \multirow{8}{*}{$\begin{array}{ll}\text { MEDIATION IN } \\
\text { CRIMINAL } \\
\text { CASES }\end{array}$} & mediation in criminal cases & 2001-2009 & \\
\hline & mediation in criminal proceedings & 2009 & \\
\hline & $\begin{array}{l}\text { mediation between the offender } \\
\text { and his victim }\end{array}$ & $\begin{array}{l}2002 \\
2003\end{array}$ & \\
\hline & $\begin{array}{l}\text { mediation between victims and } \\
\text { offenders }\end{array}$ & 2002 & $\begin{array}{l}\text { found in one document } \\
\text { only }\end{array}$ \\
\hline & $\begin{array}{l}\text { penal mediation in the course of } \\
\text { criminal proceedings }\end{array}$ & $\begin{array}{l}2001 \\
2009\end{array}$ & \\
\hline & penal mediation & $\begin{array}{l}2004 \\
2009\end{array}$ & \\
\hline & victim-offender mediation & $2002-2012$ & \\
\hline & mediation in penal matters & $2000-2004$ & \\
\hline \multirow{2}{*}{$\begin{array}{l}\text { STATE } \\
\text { COMPENSATION }\end{array}$} & state compensation & $2001-2011$ & \\
\hline & State compensation & 2002,2004 & \\
\hline
\end{tabular}




\begin{tabular}{|l|l|l|l|}
\hline & $\begin{array}{l}\text { State compensation for crime } \\
\text { victims }\end{array}$ & 2002 & $\begin{array}{l}\text { found in one document } \\
\text { only }\end{array}$ \\
\cline { 2 - 4 } & state compensation for victims & $\begin{array}{l}2001, \\
2002\end{array}$ & \\
\cline { 2 - 4 } & $\begin{array}{l}\text { state compensation for victims of } \\
\text { crime }\end{array}$ & 2002 & $\begin{array}{l}\text { found in one document } \\
\text { only }\end{array}$ \\
\cline { 2 - 4 } & state compensation to victims & 2002 & \\
\hline \multirow{2}{*}{ VICTIM } & victim & $2000-2012$ & \\
\cline { 2 - 4 } & crime victim & $2000-2011$ & \\
\cline { 2 - 4 } & victim of the offence & 2009 & \\
\cline { 2 - 4 } & victim of a crime & $2000-2009$ & \\
\hline
\end{tabular}

Table 4.9. Examples of behavioural patterns of English non-univocal terms.

\begin{tabular}{|c|c|c|c|}
\hline Genotype & Phenotype & Time span & \\
\hline \multirow{7}{*}{$\begin{array}{l}\text { PROTECTION } \\
\text { OF VICTIMS } \\
\text { OF CRIME }\end{array}$} & protezione delle vittime & $2000-2012$ & \\
\hline & tutela delle vittime & $2000-2012$ & \\
\hline & tutela delle vittime di reato & $2002-2012$ & \\
\hline & tutela delle vittime di reati & 2002 & $\begin{array}{l}\text { found in one document } \\
\text { only }\end{array}$ \\
\hline & protezione delle vittime di reati & 2001-2011 & \\
\hline & protezione delle vittime di reato & 2011-2012 & \\
\hline & $\begin{array}{l}\text { tutela delle vittime della } \\
\text { criminalità }\end{array}$ & $2000-2009$ & \\
\hline \multirow{6}{*}{$\begin{array}{l}\text { RESTORATIVE } \\
\text { JUSTICE }\end{array}$} & giustizia riparativa & 2011-2012 & \\
\hline & giustizia restaurativa & 2006 & $\begin{array}{l}\text { found in one document } \\
\text { only }\end{array}$ \\
\hline & giustizia restitutiva & 2002 & $\begin{array}{l}\text { found in one document } \\
\text { only }\end{array}$ \\
\hline & giustizia riparatrice & 2006 & $\begin{array}{l}\text { found in one document } \\
\text { only }\end{array}$ \\
\hline & giustizia risarcitoria & 2004 & $\begin{array}{l}\text { found in one document } \\
\text { only }\end{array}$ \\
\hline & giustizia riparatoria & $2002-2004$ & \\
\hline \multirow{5}{*}{$\begin{array}{ll}\text { RIGHTS } & \text { OF } \\
\text { VICTIMS } & \text { OF } \\
\text { CRIME } & \\
\end{array}$} & diritti delle vittime & $2000-2012$ & \\
\hline & $\begin{array}{l}\text { diritti delle vittime } \\
\text { criminalità }\end{array}$ & $2000-2012$ & \\
\hline & diritti delle vittime di reati & 2002 & $\begin{array}{l}\text { found in one document } \\
\text { only }\end{array}$ \\
\hline & diritti delle vittime di reato & $2011-2012$ & \\
\hline & diritti della vittima & $2000-2012$ & \\
\hline
\end{tabular}

Table 4.10. Examples of behavioural patterns of Italian non-univocal terms.

In the English EU subcorpus, no example of the first type of pattern described above has been found. Among the English examples in Table 4.9, the variant pair that is closer to the 
described behavioural pattern is the victim (2000-2012) and crime victim (2000-2011) pair, since these two terms have coexisted for a relatively long time. Conversely, in the Italian examples provided in Table 4.10, the two cases of non-univocal terms coexisting for the same time span are protezione delle vittime / tutela delle vittime (2000-2012) and diritti delle vittime / diritti delle vittime della criminalità (2000-2012).

All the other examples provided in Tables 4.9 and 4.10 fall into the second behavioural pattern of non-univocal terms. Taking a look at the first genotype reported in Table 4.9, i.e. MEDIATION IN CRIMINAL CASES, the following observations can be made (see Table 4.11). First of all, the terms included in the cluster make their first appearance in the EU corpus at different points in time, e.g. mediation in criminal cases is firstly attested in 2001 and penal mediation in 2004. Secondly, some terms occur in the EU corpus for one year only, such as mediation in criminal proceedings and mediation between victims and offenders. Thirdly, among the terms occurring only in one specific year, some can be found in one document only, such as the last term mentioned.

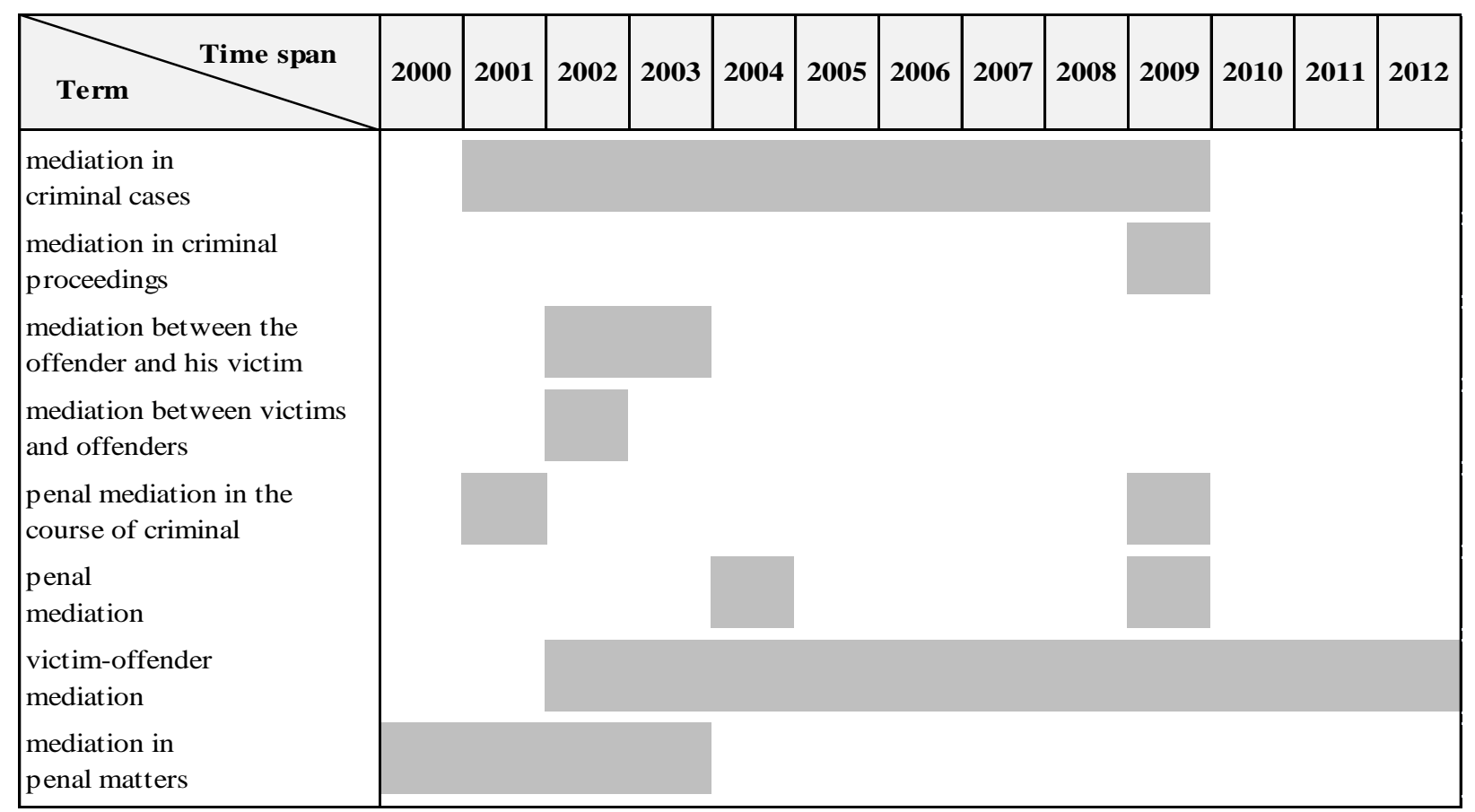

Table 4.11. Diachronic variation in the term cluster referring to the MEDIATION IN CRIMINAL CASES genotype.

Some of the terms that occur in one document only within the EU corpus, such as the term mediation between victims and offenders, are also hapaxes Even though hapaxes are not generally considered for inclusion in most terminological resources, for the purposes of this research study all the term variants that fall in one of the categories of terminological 
variation described in Chapter 4 are recorded and included in the MuLex terminological knowledge base. The reasons for this choice are better explained in Section 4.5.4, in which the influence on terminology of the fourth variable, namely the legal force of the documents included in the textual material analysed, is discussed.

\subsubsection{THIRD VARIABLE: CONCEPTUAL (LEGAL) SYSTEM(S)}

For the purposes of this research project, the third variable taken into consideration for the description of denominative variation is the conceptual system or, since in this specific case conceptual systems coincide with legal systems, the legal system the terminology analysed maps to. The denominative variation produced in a multi-level jurisdiction such as the EU and observed by considering legal systems as a variable has a peculiar nature which derives from the particular linguistic context characterising the multi-level jurisdiction. What makes the study of denominative variation in this context different from mono-jurisdictional settings is that terminological variation is studied within one individual language (either English or Italian), but such language is used in different legal systems. This means that, in order to study denominative variation, two language varieties are taken into consideration, i.e. the national variety and the supranational (EU) variety. Therefore, a methodological approach is adopted which is similar to the methodology used to analyse multilingual terminology even though it is applied to a monolingual setting: the language varieties are first treated separately and, once the conceptual data regarding the underlying legal systems are collected, the terms belonging to different language varieties are clustered on the basis of a shared genotype (see Section 3.3.6.1).

In order to describe denominative variation from the point of view of the legal systems in which the terminology is embedded, term clusters are taken as the starting point for the discussion. As described in Section 3.3.6.1, term clusters in this study are obtained on the basis of the identification of a common genotype for a series of phenotypes, each of which can belong either to the national or to the EU legal system or to both. Another aspect to consider is that, even when the genotype is not shared by both the national and the EU legal system, a term used to refer to that specific genotype can be used in texts embedded in legal systems where the genotype is lacking. In other words, when considering the third variable for the description of terminological variations, two factors need to be taken into account. The first factor is conceptual in its nature, and consists in the embeddedness of genotypes in legal systems, whereas the second factor is textual, and refers to the embeddedness of terms in legal 
texts. By combining these two factors in the analysis of the term clusters, two different types of denominative variation were observed, namely intra-systemic and inter-systemic variation. Intra-systemic variation is produced when the terms within a term cluster refer to a genotype that is embedded only in a legal system and the terms are only found in texts that are embedded in that same legal system. This is generally the case for term clusters referring to genotypes embedded in national legal systems which are not shared by the EU legal system, rather than vice versa. This is so since EU lawmaking is typically aimed at producing effects within Member States. Therefore, genotypes which are generated within the EU are generally absorbed by national legal systems. Intra-systemic variation can be illustrated briefly by taking the English main terms Criminal Injuries Compensation Authority and Criminal Injuries Compensation Scheme and their variants CICA and CICS. These two clusters refer to two genotypes that are specific to the English national legal system only and the texts in which the terms are found are of national origin only. It follows that the variation is produced within a single legal system and is thus considered as intra-systemic.

Inter-systemic variation, on the other hand, occurs when the terms belonging to the same cluster refer to a genotype that is shared by (at least) two legal systems and are found in legal texts of different origins. Table 4.12 shows the Italian term cluster referring to the MEDIATION IN CRIMINAL CASES genotype shared by both the EU and the Italian national legal system. The third column indicates the regional label (see Section 6.4.1.2), i.e. the origin of the texts in which the term has been found. The first two terms, i.e. mediazione penale and mediazione, are used in both varieties of Italian, that is EU-Italian and national Italian, while the variants mediazione autore-vittima and mediazione fra autore e vittima di reato have only been found in the national variety of Italian, and the remaining term variants have been identified in EU texts only.

\begin{tabular}{|l|l|l|}
\hline Genotype & Phenotype & Regional label \\
\hline \multirow{3}{*}{ MEDIATION IN } & mediazione penale & EU, Italy \\
\cline { 2 - 3 } & mediazione & EU, Italy \\
\cline { 2 - 3 } & mediazione tra l'autore del reato e la vittima & EU \\
\cline { 2 - 3 } & $\begin{array}{l}\text { mediazione tra la vittima e l'autore del reato } \\
\text { nell'ambito dei procedimenti penali }\end{array}$ & EU \\
\cline { 2 - 3 } & $\begin{array}{l}\text { mediazione tra vittima e autore del reato nel } \\
\text { procedimento penale }\end{array}$ & EU \\
\cline { 2 - 3 } & mediazione tra autore e vittima del reato & EU \\
\cline { 2 - 3 } & mediazione nell'ambito dei procedimenti penali & EU \\
\cline { 2 - 3 } & mediazione nelle cause penali & EU \\
\hline
\end{tabular}




\begin{tabular}{|l|l|l|}
\hline & mediazione tra vittima e autore del reato & EU \\
\cline { 2 - 3 } & mediazione vittima-reo & EU \\
\cline { 2 - 3 } & mediazione autore-vittima & Italy \\
\cline { 2 - 3 } & mediazione fra autore e vittima di reato & Italy \\
\hline
\end{tabular}

Table 4.12. Inter-systemic denominative variation in the Italian term cluster referring to the MEDIATION IN CRIMINAL CASES genotype.

The example illustrated in Table 4.12, however, leads to a further consideration as regards inter-systemic variation. In the cases of inter-systemic denominative variation where more than one term is used in texts of a single origin, such as the two terms used only in the national Italian variety described above, among such terms also intra-systemic variation is produced. This means that in terminological clusters such as the Italian one referring to the MEDIATION IN CRIMINAL CASES genotype, inter-systemic variation coexists with intra-systemic variation.

\subsubsection{FOURTH VARIABLE: LEGAL FORCE}

The last variable considered for the purposes of describing denominative variation in this study is the legal force of the document from which a term has been extracted. As already illustrated in Section 3.3.2.3.2.1, the textual material analysed has been classified according to the legal force of the selected documents. A first distinction can therefore be made between legally binding and non-legally binding texts. On the basis of the legal force of the documents from which terms are extracted, a term is provided with a specific style label (see Section 6.4.1.2) in the MuLex knowledge base. The field devoted to the style label makes it possible to choose among a range of labels, which are discussed in Section 6.4.1.2. However, since the degree of specialisation of the textual material is rather homogeneous (see Section 4.5.1), what is interesting for the discussion on denominative variation is that terms belonging to the same term cluster can be classified on the basis of the legal force of the documents from which they have been extracted. Therefore, terms belonging to a term cluster which has been found in legally-binding texts are labelled as "official" terms, whereas the others may feature different style labels.

The choice of labelling a term as "official" has two reasons. Firstly, before being adopted and published, both the content and form of legally-binding texts undergo several amendments, which means that the terminological choices in such documents are deeply pondered, while the same degree of accuracy is not necessarily expected from non-legally binding texts. Secondly, the decision to label such terms as "official" is in line with the main aim of MuLex, which is designed for translators. For instance, drafters of EU legislation (and consequently 
translators) are expected to make a consistent use of terminology, both within the document they are working on and with acts already in force, especially when such acts deal with the same field. Therefore, when designing MuLex, there was a strong need for creating a clear indicator of the occurrence of terms in legally-binding texts.

As regards the impact of legal force on denominative variation, two further considerations should be made. Legal force can also be seen in the light of both the second variable, i.e. the diachronic dimension, and the third variable, i.e. the legal system dimension. As for the combination of legal force and the diachronic dimension, it should not be overlooked that the migration of terms among text types is a very frequent phenomenon. Consequently a term which is used in legally-binding texts can also be found in non-legally binding texts and vice versa at different points in time. However, since the analysis carried out in this study provides a snapshot of the behaviour of terms in a short-diachronic corpus, what is interesting to note is that in a corpus that is rather homogeneous as regards content but at least as heterogeneous as regards text types, for some documents of the corpus the legal force is still provisional. This is the case, for example, of proposals for new legislation that are published and available to the general public, but have not reached their final version yet. This means that these texts, and consequently their terminology, are still subject to potential modifications and amendments, which made their linguistic form provisional at the moment in which the analysis was carried out. Apart from the diachronic perspective, however, also the legal system plays a role in the denominative variation linked to the documents' legal force. In other words, a term may be official in one legal system but not in another, or different official terms can be used in different legal systems. In order to illustrate this point, an example is provided in Table 4.13.

\begin{tabular}{|l|l|l|l|}
\hline Genotype & Phenotype & Regional label & Style label \\
\hline $\begin{array}{l}\text { RIGHTS OF } \\
\text { VICTIMS OF } \\
\text { CRIME }\end{array}$ & EU, Italy & $\begin{array}{l}\text { official EU, } \\
\text { potentially } \\
\text { official Italy }\end{array}$ \\
\cline { 2 - 4 } & diritti delle vittime & official EU \\
\cline { 2 - 5 } & diritti delle vittime della criminalità & EU & $\begin{array}{l}\text { potentially } \\
\text { official EU }\end{array}$ \\
\cline { 2 - 4 } & diritti delle vittime di reati & EU & $\begin{array}{l}\text { potentially } \\
\text { official Italy }\end{array}$ \\
\cline { 2 - 4 } & diritti delle vittime di reato & EU, Italy & official EU \\
\cline { 2 - 4 } & diritti della vittima & EU, Italy & \\
\hline
\end{tabular}

Table 4.13. Denominative variation in terms of legal force in the Italian term cluster referring to the RIGHTS OF VICTIMS OF CRIME genotype. 
As can be seen from the example in Table 4.13, the terms diritti delle vittime, diritti delle vittime della criminalità and diritti della vittima are official in EU documents while, at the time of writing this thesis, the term diritti delle vittime di reati is potentially official in the EU context. As far as the Italian context is concerned, however, no term included in the term cluster has been found to be used in legally binding texts, whereas in the same context the term diritti delle vittime di reato is considered potentially official.

\subsection{CONCEPTUAL VARIATION IN A MULTI-LEVEL JURISDICTION}

In Section 4.5, a classification of the instances of denominative variation observed in the area of law of victims of crime has been proposed. In denominative variation, a set of terms forming a term cluster refers to a concept that is supposed to be shared. On the other hand, in this section the second type of terminological variation is presented: conceptual variation. In this case, the variation concerns the conceptual sphere, but produces consequences for the designations used. In order to understand what is meant here by conceptual variation, the genotype-phenotype distinction and the embeddedness of legal terms and concepts in a specific legal system need to be taken into account.

As seen in Section 3.3.6.1, the terminological units found to refer to phenotypes that can be linked to a common genotype have been grouped in term clusters. However, although they are all related to the same genotype, phenotypes can differ from each other on a conceptual basis. Therefore, in the study of conceptual variation those terms are accounted for which refer to phenotypes that feature some conceptual discrepancy but can still be grouped in the same term cluster on a genotype basis. Since the relevant phenotypes can be rooted in different legal systems, two types of conceptual variation can be observed, i.e. intra-systemic and intersystemic conceptual variation.

Before illustrating some examples of the two types of conceptual variation mentioned above, it should be noted that all the types of denominative variation based on the four variables described (degree of specialisation, time span, reference legal system(s), and legal force) can be observed when examining conceptual variants. What is meant here is that the discrepancies at the conceptual level reflect in the linguistic level, producing term variants that can be classified according to the typology presented in Section 4.5. Therefore, a classification of conceptual variation is not provided in this section. 
The occurrences of conceptual variation in the terminological analysis carried out in this study are fewer compared to the occurrences of denominative variation. The reason for this is to be found in the methodological approach adopted. Since the selection of terms is performed at two different stages (Step 2 and 4 in Chapter 3), with EU terms being extracted first and national terms retrieved on the basis of the collection of EU terms, the national terms are supposed to have a close conceptual relation with the identified genotypes.

\subsubsection{INTRA-SYSTEMIC CONCEPTUAL VARIATION}

Intra-systemic conceptual variation is observed in terms referring to phenotypes belonging to the same legal system which can be grouped in the same genotype, notwithstanding the slight conceptual differences that can be observed among them. Generally, such conceptual differences can be ascribed either to the degree of specificity of the term used to refer to the phenotype or to the different perspective from which the same genotype is approached.

In order to illustrate intra-systemic conceptual variation based on the degree of specificity of the term, the Italian terminological units used within the EU legal system to refer to the CHILD VICTIM genotype are provided as an example. In EU legal texts, this genotype is referred to by using three terminological units, which are minore vittima di reato (main term), minore vittima del reato and giovane vittima. Among these terms, the first and the second term show the same degree of specificity, since they convey the same phenotype: a person who is victimised and is below 18 years of age (for the sake of precision, the age limit was established by Council Directive 2012/29/EU, although the terms had been used in earlier documents as well). Unlike these two terms, however, giovane vittima, which implies a lexical variation (see Section 4.5.1.1.4), cannot be said to express the same degree of specificity, since the adjective "giovane" is not generally used in legal contexts to convey a specialised meaning that can be linked to an age limit regulated by law. A similar example is found in the same subcorpus, in which the SECONDARY VICTIMISATION genotype is referred to by the terms vittimizzazione secondaria (main term) and its lexical variant pregiudizio secondario. As in the previous example, the main term is more specific, since it refers to a specific action ("vittimizzazione") and qualifies it by using an adjective ("secondaria") which allows to distinguish it from primary victimisation, whereas in the second term the head "pregiudizio" is not as specific, referring to any kind of consequences deriving from the commission of an offence and not necessarily caused by the justice system.

In order to illustrate the second type of intra-systemic conceptual variation, an example from the English EU subcorpus can be mentioned in which a difference in perspective is identified. 
Unlike the examples provided above, here the conceptual shift can be said to be motivated by the evolution experienced by the phenotype in the course of time. Therefore, the time span variable in this case is relevant, since the evolution of the area of law produces a conceptual change in the phenotype with a consequent denominative variation. The example is the VICTIM WITH SPECIFIC PROTECTION NEEDS genotype. Ever since the beginning of the EU discussion on the rights of victims of crime, the existence of some categories of victims who are more vulnerable than others on account of their age, gender, or other personal circumstances has been acknowledged. In the attempt to adopt specific measures to account for their specific condition, several legal provisions have been drafted in which they were originally referred to as particularly vulnerable victims. By trying to provide a general classification of the conditions that can lead a victim to be considered particularly vulnerable and resorting to this term, the legal principle that could be inferred from the wording of different provisions ${ }^{118}$ is that certain victims are particularly vulnerable $a$ priori and are thus entitled to a set of special measures. However, such an approach could have led to a discriminating situation in which victims who would have drawn much benefit from such measures could not access them due to their personal circumstances. For this reason, the original phenotype of PARTICULARLY VULNERABLE VICTIM has been modified so as to allow for a case-by-case evaluation of the circumstances that can give rise to the right to benefit from special measures. Consequently, a conceptual shift from the intrinsic vulnerability to the actual needs of the victim has been made which resulted in the term victim with specific protection needs.

A similar example that refers to the Italian legal system is found in the LEGAL AID genotype. In this case, in the Italian legislation two terms are found, i.e. gratuito patrocinio and patrocinio a spese dello Stato. The phenotypes implied in the national legal system conceptually differ: the first term refers to the legal aid victims were entitled to in the past and for which lawyers received no payment, while the second term designates the legal aid granted to victims by lawyers who are paid by the State for the service provided. Therefore, although the phenotypes diverge, from the victim's perspective they produce the same result and, from the terminographic perspective adopted in this thesis, they are grouped in the same term cluster.

${ }^{118}$ See, for instance, Article 2(2) of Council Framework Decision 2001/220/JHA. 


\subsubsection{INTER-SYSTEMIC CONCEPTUAL VARIATION}

The examples provided in the previous section illustrate cases of conceptual variation reflected in denominative variation that occur within a single legal system. Inter-systemic conceptual variation, on the other hand, is observed when terms referring to conceptually diverging phenotypes belonging to different legal system can be grouped in the same genotype. Unlike the previous type of conceptual variation, inter-systemic conceptual variation occurs when a shared genotype is actualised differently in the legislations observed. An emblematic case consists in the different phenotypes embedded in the EU and the Italian legal systems that relate to the VICTIM genotype. In the EU Italian subcorpus, the person who is affected by a crime or injured by an offender is referred to as vittima. A similar phenotype can be found in the Italian national system, and, more specifically, in the Italian Codice di Procedura Penale, where it is termed persona offesa dal reato. Nevertheless, the term vittima is not a neologism in Italian. Indeed, within the national boundaries the term vittima is a common word in general language and it is also the main term to refer to the this concept in both criminology and victimology. Moreover, it can also be occasionally found in some Italian bills and laws ${ }^{119}$. Despite these occasional occurrences, the term vittima is not considered a proper technical term within the specialised domain of criminal law due to a lack of clear-cut boundaries. Notwithstanding the "deliberate vagueness of legal concepts" (Liebwald 2007: 134), which is considered essential for adapting the content of legal provisions to cases in the concrete reality (see Section 1.4.2), the absence of a definite semantic content for the term victim makes the term itself generally unsuitable for being used in specialised texts. Furthermore, there is also another reason for resorting to a different term in the national setting. In fact, when the term vittima is used, it is implied that the person can suffer a physical or mental injury and/or loss, which can be pecuniary or non pecuniary. In the Italian legal system, on the contrary, a distinction is drawn between the person who is passively involved in the actual commission of the crime (persona offesa dal reato) and the person who bears the consequences of the crime (danneggiato). Only the latter can take part to the criminal proceedings as a proper party. In most cases, the two figures coincide, but there may be also cases in which they do not, such as in the event of murder, where the danneggiato can be a family member, for instance. Therefore, when comparing the EU and the Italian phenotype, a conceptual difference is observed that corresponds to a case of inclusion, since according to the definition of vittima or victim provided in Council Directive

\footnotetext{
${ }^{119}$ See, for instance, Legge 26 marzo 2001, n. 128, Interventi legislativi in materia di tutela della sicurezza dei cittadini, and Proposta di Legge n. 2802, Norme per la tutela delle vittime di reati per motivi di omofobia e transfobia, 14.10.2009.
} 


\section{Chapter 4}

2012/29/EU both the direct victim and the family of the victim are considered victims and no terminological distinction is made between a victim and the person having the right to participate in criminal proceedings by reason of being victimised.

\subsection{Summary}

In Chapter 4, the phenomenon of terminological variation in the EU multi-level jurisdiction has been examined. Given the polysemy that characterises the term "terminological variation" in recent studies in terminology, first of all a definition has been provided, according to which terminological variation occurs when more than one designation is used to refer to a concept. Since the legal terminology in which this phenomenon has been observed is embedded in a multi-jurisdictional setting, the genotype-phenotype distinction has been introduced. On the basis of such distinction, terminological variation has been subdivided into two main categories, i.e. denominative variation and conceptual variation. In the former, variation occurs without implying a conceptual difference in the phenotypes involved. In order to describe denominative variation, four different variables have been introduced: the degree of specialisation of the documents in which the terms occur, the time span in which the documents have been written, the legal system the documents belong to and their legal force. On the basis of these variables, two types of variation for each variable have been identified. On the other hand, variation can be observed on the basis of a conceptual shift which affects the phenotypes related to a shared genotype. Such conceptual shift produces a variation in the denomination used to refer to the phenotypes. Given that phenotypes can be embedded either in the national or the EU legal system, conceptual variation can be subdivided into two categories: intra-systemic conceptual variation and inter-systemic conceptual variation. 


\section{Chapter 5. ViCTims of CRIME From a MULTILINGUAL Terminological Perspective: Terminological EQUIVALENCE}

In Chapter 5, the second phenomenon in which dynamism in terminology emerges is presented, i.e. terminological equivalence,. Due to the embeddedness of the legal terminology collected in three legal systems, intra-systemic and inter-systemic terminological equivalence can be observed, which can be expressed in different degrees: absolute equivalence, relative equivalence and non-equivalence.

\subsection{TERMINOLOGICAL EQUIVALENCE AND TRANSLATIONAL EQUIVALENCE}

The methodological framework illustrated in Chapter 3 and the TKB MuLex described in Chapter 6 focus on the same common core, i.e. multilingual legal terminology embedded in a multi-level jurisdiction. Although their aims are different, with the methodology adopted for carrying out a terminological analysis and the TKB aiming at presenting the results of the terminological analysis, the envisaged end users who can benefit from these results of the analysis stored in MuLex are the same, i.e. professional translators. It follows that the terminological analysis is performed bearing in mind that the main reason for consulting MuLex is finding term equivalents for legal translation.

As a consequence, the matching of terms in different languages, which - due to the peculiarities of the legal context and terminology analysed in this research project consists of a two-step process (see Section 3.3.3 and 3.3.5) - plays a central role in any translationoriented terminographic project. Such a cross-linguistic term matching is possible by establishing the degree of equivalence between terms in different languages. However, both in Terminology and Translation Studies the concept of 'equivalence' has caused intense debate, leading Gerzymisch-Arbogast to state that "“[e]quivalence' is one of the most traditional and critical concepts in translation theory" (Gerzymisch-Arbogast 2001: 228). In this study, the concept of 'equivalence' as intended in Translation Studies is considered to be relevant for 


\section{Chapter 5}

understanding how 'equivalence' is conceived as regards legal terminology. As a comprehensive account of 'equivalence' in Translation Studies is beyond the scope of this chapter, only those aspects of translational equivalence which are useful for understanding terminological equivalence are going to be taken into account.

A first attempt of defining translation equivalence can be found in Catford's statement that "[t]ranslation equivalence occurs when a SL and a TL text (or item) are relatable to (at least some of) the same relevant features" (Catford 1965: 50). A similar position is held by Nord, who sees equivalence as "a static, result-oriented concept describing a relationship of 'equal communicative value' between two texts or, on lower ranks, between words, phrases, sentences, syntactic structures and so on" (Nord 1997: 35-36). According to both scholars, translation equivalence can be achieved both at the level of the text and at a lower level by taking into consideration different "items". As regards the textual level of translation equivalence, Bolaños Cuéllar considers it as "a text-bound relation which is linguistically realized in texts and whose only tangible, empirically apprehensible form is the SL and TL texts" (Bolaños Cuéllar 2002: 81). On the other hand, translation equivalence at a lower level is supported by Cheng and Sin, who consider it as "the similarity between a word or expression in one language and its translation in another" (Cheng \& Sin 2008: 35).

No matter what the unit taken into consideration for establishing equivalence is, be it a whole text or an "item", it is interesting to note that translational equivalence can be ascribed to what Catford (1965: 27) refers to as "textual equivalence" and Gerzymisch-Arbogast (2001: 237) calls "text-specific equivalence". This type of equivalence is parole-oriented, since it occurs in a communicative event in which several intertwined factors are to be taken into account, i.e. syntactic, lexical, semantic, pragmatic, and semiotic factors (see Bolaños Cuéllar 2002: 79). Therefore, the realisation (during translation as process) and evaluation (in translation as product) of translational equivalence depend on the selected criteria and change according to the variables taken into consideration at a textual and extra-textual level (e.g. participants in the communication, extra-linguistic context).

On the basis of the considerations made so far, terminological equivalence can be considered as being completely different from translational equivalence, just as completely different is the object of study of the two disciplines. As aptly summarised by Rogers, "[t]he focus in Translation Studies is clearly on text, whereas in Terminology Studies it has additionally been on system" (Rogers 2008: 102). Therefore, terminological equivalence does not fall into the category of textual equivalence, but can be rather assimilated to what Catford (1965:27) calls "formal correspondence", where a formal correspondent is "any TL category (unit, class, 
structure, element of structure, etc.) which can be said to occupy, as nearly as possible, the 'same' place in the 'economy' of the TL as the given SL category occupies in the SL". Hence, if textual equivalence is parole-oriented, formal correspondence is langue-oriented, since it can be established only "at relatively high levels of abstraction" (Catford 1965: 32), i.e. at a “systematic, virtual level" (Gerzymisch-Arbogast 2001: 228). It follows that, while on the one hand "translation equivalence is always equivalence-in-context" (Altenberg \& Granger 2002: 18), because the meaning of words does not depend only on their semantic content but "is also determined by their grammatical and lexical environment (syntagmatic relations like colligation and collocation), as well as by the situation in which they are used (style, pragmatics)" (Altenberg \& Granger 2002: 22), on the other, formal correspondence is context-independent. However, although the distinction between textual equivalence and formal correspondence is accepted and is considered to be necessary to understand the concept of 'equivalence' when applied to multilingual terminology, in this study the possible coincidence of formal correspondence and textual equivalence at the "item" level is not excluded.

\subsection{TERMINOLOGICAL EQUIVALENCE IN LEGAL TERMINOLOGY}

In order to examine the issue of terminological equivalence in relation to a collection of terms which are embedded in a multi-level jurisdiction, some preliminary remarks on terminological equivalence and translation in legal terminology are needed.

As observed by Cao (2007: 53), "[1] egal terminology is the most visible and striking linguistic feature of legal language as a technical language, and it is also one of the major sources of difficulty in translating legal documents", this being so because "many legal words in one language do not find ready equivalents in another, causing both linguistic and legal complications". The "lack of equivalent terminology" (Yankova 2007: 106) is due to the fact that every legal text is necessarily grounded in the laws of a certain country and, consequently, its translation cannot ignore the differences between the different legal systems the TL and SL refer to (see Arntz 1995: 137). Though the focus in Cao and Arntz is on textual equivalence among legal terms in translation, while in this thesis equivalence is approached from a purely terminological perspective, their observations about the lack of equivalents on account of inter-systemic differences are relevant also for the purposes of this research study. This is so because, if a lack of equivalents is acknowledged in the translation process, the 


\section{Chapter 5}

same lack will be encountered in carrying out a terminographic task. On the basis of what has been said so far, it can be concluded that relative and zero equivalence (see Section 5.3.2.2) rather than absolute equivalence are the most frequent types of equivalence observed in legal terminology. Therefore, also in the terminographic study carried out following the methodology presented in Chapter 3, examples of different types of terminological equivalence have been encountered as regards the collection of victim-related terminology in English and Italian which has been recorded in the MuLex TKB.

However, a further remark needs to be made as regards the peculiarities of the legal terminology recorded in MuLex. The victim-related terminology examined in this study is to be considered a sui generis terminology for two intertwined reasons: the first is the embeddedness of such terminology in both different and shared legal systems, while the second is its usage in the same language to refer to both a supranational and a national legal system. Owing to this overlap of languages and legal systems, the types of terminological equivalence which can be observed vary according to the legal system being taken as a reference point.

\subsection{TERMiNOLOGICAL EQUIVALENCE IN THE EU MULTI-LEVEL JURISDICTION}

According to Picht and Draskau, the assessment of equivalence is one of the central features of terminological analysis (Picht \& Draskau 1985: 172), be it bilingual or multilingual, though, when taking into consideration two languages, "it is not until after the completion of [...] unilingual operations that the two systems are compared, i.e. the degree of equivalence of the systems - and thus of the individual concepts - is examined" (Arntz 1993: 9). The same idea is expressed also by Šarčević in relation to the assessment of equivalence in legal terminology: in her view, "terminologists should not deal with isolated concepts but need to compare the conceptual structures of the functional equivalent and its source term by analyzing the conceptual hierarchies to which each belongs" (Šarčević 1997: 243). Therefore, in order to establish equivalence among legal terms, the first step must be the analysis and comparison of the underlying conceptual systems.

For the assessment of equivalence in this thesis, however, a slightly different approach has been taken due to the peculiarities of the terminology being examined. As explained in Chapter 3, the textual material used for term extraction and analysis has been collected in two 
separate stages (Steps 2 and 4 in Chapter 3) and the cross-linguistic matching, for which the degree of equivalence needed to be assessed, has also been carried out in two different steps (Steps 3 and 5 in Chapter 3). Moreover, because of the legal system involved in Step 2 and the linguistic regime regulating it, in Step 3 a different method has been applied from the one suggested by Picht and Draskau as well as Šarčević.

As briefly summarised by Cheng and Sin, "[f]or the differences in each and every legal system, it is natural that terminological incongruity exists between different legal systems" (Cheng \& Sin 2008: 34). However, though a term-matching task is involved in Step 3 (see Section 3.3.3.2.2), since the terms involved in this task all refer to the same legal system (the EU legal system), it is given for granted that the underlying conceptual system is unique. Therefore, this specific case can be ascribed to the following situation envisaged by Rodolfo Sacco:

Una corrispondenza totale, senza riserva, permanente, fra due espressioni appartenenti a due lingue diverse può essere creata solo da un elemento artificiale. Se vogliamo prescindere [...] dall'ipotesi di una lingua intieramente artificiale, il significato di una parola è artificiale se un'autorità superiore alla lingua si è pronunciata sul valore del termine, o sulla corrispondenza fra due vocaboli. Così avviene se un legislatore è bilingue, e con ciò impone che i due testi abbiano di necessità lo stesso significato. (Sacco 1992: 487)

Though Sacco does not specifically refer to the EU multilingual context, where the same legal system needs to find its textual expression in 23 languages, his view about "bilingual legislators" artificially establishing equivalence among terms can be considered to apply also to the European context. Besides the existence of a single conceptual system expressed in 23 languages, the EU legal system is also characterised by a tendency of introducing specific EU terminology into all EU languages in order to differentiate supranational from national terminology ${ }^{120}$. Therefore, on the basis of both the equal authenticity principle (see Section 3.3.2.3) and the possible control of EU institutions on language (and terminology in particular), an equivalence relation is presumed to hold among the terms used in EU texts. In Correia's words,

Where Community law is concerned [...], the term 'equivalence' not only remains valid but also has a rare chance to deploy its full semantic content. $[\ldots]$ the various language versions of the regulations and other European

\footnotetext{
${ }^{120}$ See the Joint Practical Guide (2003: Guideline 6), where it is stated that "concepts or terminology specific to any one national legal system are to be used with care".
} 
'laws' are 'equivalent' in the strict sense of the word, since they have the same legal value and can be invoked indiscriminately, in appelas to the Court of Justice for instance, by EU citizens or businesses, irrespective of their Member State of origin or that country's official language or languages. (Correia 2003: 41)

Though this type of equivalence is considered to hold among terms employed in legally binding texts, for the purposes of this study this relation is extended also to non-legally binding texts, since they are meant to serve the same purpose, provide the same information and address the same indended readers. Moreover, although the equivalence among EU texts - and terms - is given for granted, it should be noted that "[a]lthough widely accepted, in time the presumption of equal authenticity has [...] been subject to extensive criticism, as in many cases divergences in meaning between the different language versions of an international instrument do exist" (Garzone 2003: 209). A similar conclusion on the impossibility of absolute equivalence even in a multilingual legal system is reached by Correia, who states that equivalence "can only be an approximation because $-[\ldots]$ paradoxically - there are different degrees of equivalence. It is the translator's job to find the best linguistic equivalences, in order to safeguard the legal equivalence of multilingual law as far as possible" (Correia 2003: 41). Therefore, although a margin for non-absolute equivalence is left even in the EU multilingual legal system, in the methodology adopted in this research project the terms extracted from the English and Italian EU subcorpora by means of the bilingual display function (see Section 3.3.3.2.1) have been considered as equivalent.

On the other hand, in the assessment of equivalence concerning national legal terms carried out in Step 5 (see Section 3.3.5), a methodology similar to the approaches proposed by Picht and Draskau and Šarčević has been adopted, though, also in this case the peculiarities of the terminology and the legal systems involved have been taken into account. Before assessing interlingual equivalence, the conceptual correspondence among the terms retrieved in national texts has been established intralingually on the basis of a genotype-phenotype distinction (see Section 3.3.6.1). In this way, a term cluster for each genotype has been created, containing, where appropriate, both the national and EU legal terms in the same language. Therefore, interlingual equivalence could be established by using the genotypes as a tertium comparationis, i.e. a concept which lies outside the systems under examination (Draskau Kewley 1991: 272). As in Figure 5.1, on the basis of the terminological analysis carried out in Step 3, in the EU legal system individual phenotypes have been identified which were referred to by means of both English and Italian EU terms. When English and Italian national terms were retrieved and the relevant phenotypes were identified in Step 5, a common 
genotype was identified to which both EU and national genotypes could be linked. These genotypes are to be considered artefacts, since, unlike phenotypes which exist in legal systems, they need to be constructed by the observer during a comparison of legal systems. Such genotypes are created by examining the phenotypes, in order to identify the shared components and eliminate the differing properties (see Sagri \& Tiscornia 2009: 6). In so doing, the intralingual correspondence and the interlingual equivalence between EU and national terms were assessed and terms in the same language but belonging to different legal systems were grouped in terminological clusters.

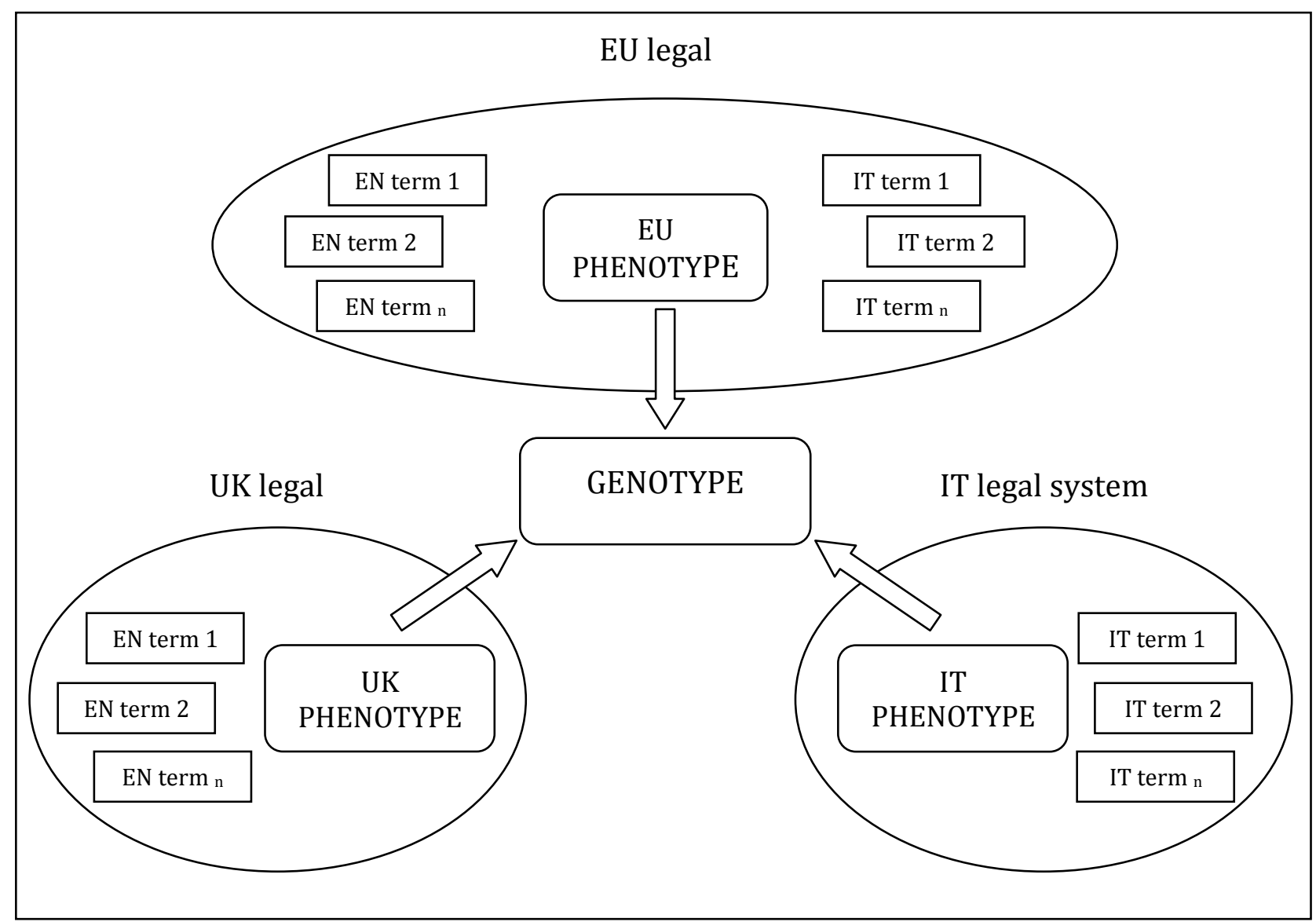

Figure 5.1. Assessment of interlingual equivalence on the basis of the genotype-phenotype distinction.

Figure 5.1 exemplifies a situation where all the following circumstances are realised:

- more than one term in English and Italian designate an EU phenotype;

- more than one term in English designate a UK phenotype;

- more than one term in Italian designate an Italian phenotype;

- a shared genotype can be derived from the comparison of the EU, UK and Italian phenotypes. 


\section{Chapter 5}

However, this is only one of the possibilities that can occur when observing the behaviour of terms in the EU multi-level jurisdiction. First of all, as regards the number of terms in each language referring to the same phenotype, in some cases - as in the one exemplified above more than one term is used and thus terminological variation can be observed (see Chapter 4), while in others only one term can be retrieved. However, more relevant for the discussion on terminological equivalence is the existence or lack of a phenotype that can be linked to a shared genotype in all the legal systems taken into consideration. In other words, two different situations can be envisaged. In the first, due to the different conceptualisation in the legal systems under study, there may be cases where in one of the legal systems there is no phenotype that relates to a genotype being shared by the other two legal systems. In the second situation, a similar conceptual anisomorhism results in a phenotype being found only in one legal system, leading to the phenotype and the genotype to coincide. These situations can in turn produce different consequences for the terminology used. In order to illustrate the three possible cases envisaged so far, some examples extracted from the victim-related terminological collection are presented below immediately after Table 5.1, summarising all the types of terminological correspondence and equivalence in this study.

\begin{tabular}{|l|l|}
\hline \multicolumn{1}{|c|}{ Language } & \multicolumn{1}{c|}{ Type of equivalence/correspondence } \\
\hline EU language + EU language & interlingual intra-systemic equivalence \\
\hline EU language + national language & intralingual inter-systemic correspondence \\
\hline national language + national language & interlingual inter-systemic equivalence \\
\hline
\end{tabular}

Table 5.1. Types of terminological equivalence and correspondence in the EU multi-level jurisdiction.

For the purpose of illustrating the case where a shared genotype can be found for phenotypes existing in the EU legal system and both the UK and the Italian legal systems, the terms referring to the LEGAL AID genotype are provided as an example in Table 5.2.

\begin{tabular}{|l|l|}
\hline \multicolumn{1}{|c|}{ Type of equivalence/correspondence } & \multicolumn{1}{c|}{ Example } \\
\hline interlingual intra-systemic equivalence & $\begin{array}{l}\text { legal aid and patrocinio gratuito are equivalent in } \\
\text { EU documents }\end{array}$ \\
\hline
\end{tabular}




\begin{tabular}{|l|l|}
\hline \multirow{5}{*}{$\begin{array}{l}\text { intralingual inter-systemic } \\
\text { correspondence }\end{array}$} & $\begin{array}{l}\text { legal aid in EU documents has a broader meaning } \\
\text { than legal aid in English national documents } \\
\text { since it can include all forms of legal aid }\end{array}$ \\
& $\begin{array}{l}\text { patrocinio gratuito in EU documents means that } \\
\text { the victim can benefit from legal assistance } \\
\text { without paying for it } \\
\text { patrocinio gratuito in Italian national documents } \\
\text { means that legal aid is free for the victim and the } \\
\text { lawyer providing it is not paid for it } \\
\text { in the national setting other terms are found to } \\
\text { refer to the LEGAL AID genotype for which legal } \\
\text { costs are paid by the government, i.e. patrocinio a } \\
\text { spese dello Stato per i non abbienti and its short } \\
\text { form patrocinio a spese dello Stato }\end{array}$ \\
\hline interlingual inter-systemic equivalence & $\begin{array}{l}\text { the English national term legal aid can be } \\
\text { considered equivalent to the Italian national term } \\
\text { patrocinio a spese dello Stato per } i \text { non abbienti }\end{array}$ \\
\hline
\end{tabular}

Table 5.2. Types of terminological equivalence and correspondence in the EU multi-level jurisdiction. Example: LEGAL AID.

In the example above, all the possible types of terminological equivalence and correspondence envisaged earlier are represented. However, as noted by Rogers, "in most cases it is a question of establishing the degree of equivalence" (Rogers 2008: 103). Actually, the only case where absolute equivalence is observed is when the English and Italian terms legal aid and patrocinio gratuito are used within the EU legal system, i.e. when interlingual intra-systemic equivalence is achieved. On the other hand, the conceptual variation (see Section 4.6) occurring when the EU phenotype is compared to the national phenotypes, though not hindering the possibility of linking the phenotypes to a shared genotype (LEGAL $\mathrm{AID}=$ legal assistance which is free for the victim), reduces the degree of interlingual intersystemic equivalence to a case of relative equivalence.

Apart from the case where in each legal system there is a phenotype that can be linked to a shared genotype, in the terminological analysis there are also cases where there is a conceptual vacuum in one of the legal systems under discussion. In order to illustrate such cases, the CIVIL PARTY genotype is taken as an example in Table 5.3. 


\begin{tabular}{|l|l|}
\hline \multicolumn{1}{|c|}{ Type of equivalence/correspondence } & \multicolumn{1}{c|}{ Example } \\
\hline interlingual intra-systemic equivalence & $\begin{array}{l}\text { civil party and parte civile are equivalent in EU } \\
\text { documents }\end{array}$ \\
\hline \multirow{2}{*}{$\begin{array}{l}\text { intralingual inter-systemic } \\
\text { correspondence }\end{array}$} & $\begin{array}{l}\text { terminological and conceptual vacuum in the } \\
\text { English legal system }\end{array}$ \\
\cline { 2 - 2 } & $\begin{array}{l}\text { parte civile in EU and Italian national documents } \\
\text { are equivalent }\end{array}$ \\
\hline interlingual inter-systemic equivalence & no equivalence \\
\hline
\end{tabular}

Table 5.3. Types of terminological equivalence and correspondence in the EU multi-level jurisdiction. Example: CIVIL PARTY.

In the example above, the CIVIL PARTY genotype is shared by the Italian and the EU legal systems, while it is lacking in the English legal system, a conceptual vacuum that is also accompanied by a terminological vacuum: while the genotype is designated by an English term in EU texts, in national texts no such term has been found. It can then be concluded that no intralingual equivalence has been assessed at the national level.

Yet a different case occurs when a phenotype and the term to designate it are only found in one of the legal systems involved in the terminological analysis. While searching for the national terms to refer to phenotypes similar to EU phenotypes, also some other terms that were bound to the national systems have been selected. Although further cross-checking in the EU corpus confirmed that no similar phenotypes could be identified in the EU legal system, some of these terms were recorded in MuLex anyway due to the frequent cooccurrence with other recorded terms and their relevance for the national legal system. An example of cases such as this is the QUALIFYING CLAIMANT phenotype, illustrated in Table 5.4, which refers to the persons other than the victim who are entitled to apply for compensation under the Criminal Injuries Compensation Scheme (CICS) in the UK.

\begin{tabular}{|l|l|}
\hline \multicolumn{1}{|c|}{ Type of equivalence/correspondence } & \multicolumn{1}{c|}{ Example } \\
\hline interlingual intra-systemic equivalence & $\begin{array}{l}\text { terminological and conceptual vacuum in the EU } \\
\text { legal system, no equivalence }\end{array}$ \\
\hline $\begin{array}{l}\text { intralingual inter-systemic } \\
\text { correspondence }\end{array}$ & $\begin{array}{l}\text { qualifying claimant refers to a British national } \\
\text { phenotype }\end{array}$ \\
\hline
\end{tabular}




\begin{tabular}{|l|l|}
\hline & $\begin{array}{l}\text { terminological and conceptual vacuum in the } \\
\text { Italian legal system }\end{array}$ \\
\hline interlingual inter-systemic equivalence & no equivalence \\
\hline
\end{tabular}

Table 5.4. Types of terminological equivalence and correspondence in the EU multi-level jurisdiction. Example: QUALIFYING CLAIMANT.

In the example above, the QUALIFYING CLAIMANT phenotype is only found in the British national legal system, since it specifically refers to the procedure for obtaining compensation by applying to the Criminal Injuries Compensation Authority, which is the organisation responsible for awarding compensation for blameless victims of violent crimes in the UK. Consequently, in this case the phenotype coincides with the genotype and in the EU and the Italian national legal systems no phenotypes can be matched to the relevant genotype.

However, yet another case has also been observed where the phenotype exists but no lexicalised form referring to it can be found in one or more legal systems. This generally happens when an EU concept is transposed without any conceptual modifications in the legal systems of the Member States, such as in the case of the EU concept cross-border victim presented in Table 5.5.

\begin{tabular}{|l|l|}
\hline \multicolumn{1}{|c|}{\begin{tabular}{c}
\multicolumn{1}{c}{ type of } \\
equivalence/correspondence
\end{tabular}} & \multicolumn{1}{c|}{ example } \\
\hline $\begin{array}{l}\text { interlingual intra-systemic } \\
\text { equivalence }\end{array}$ & $\begin{array}{l}\text { cross-border victim and vittima transfrontaliera are } \\
\text { equivalent in EU documents }\end{array}$ \\
\hline \multirow{2}{*}{$\begin{array}{l}\text { intralingual inter-systemic } \\
\text { correspondence }\end{array}$} & $\begin{array}{l}\text { the concept of CROSS-BORDER VICTIM has been } \\
\text { transplanted in the English legal system, although the } \\
\text { term cross border-victim is yet to be attested in }\end{array}$ \\
\cline { 2 - 2 } & $\begin{array}{l}\text { English national texts } \\
\text { the concept of CROSS-BORDER VICTIM has been } \\
\text { transplanted in the Italian legal system, but the term } \\
\text { vittima transfrontaliera is found in Italian academic } \\
\text { texts }\end{array}$ \\
\hline $\begin{array}{l}\text { interlingual inter-systemic } \\
\text { equivalence }\end{array}$ & $\begin{array}{l}\text { on the grounds of the data presented so far, no } \\
\text { equivalence between national terms can be } \\
\text { established }\end{array}$ \\
\hline
\end{tabular}

Table 5.5. Types of terminological equivalence and correspondence in the EU multi-level jurisdiction. Example: CROSS-BORDER VICTIM. 


\section{Chapter 5}

The CROSS-BORDER VICTIM genotype, which has already been discussed in Section 3.3.6.1 with reference to term clustering, can be considered to coincide with the phenotype found in the EU legal system on the grounds that the concept is only meaningful when the EU supranational legal dimension is taken into account to enforce the provisions of Council Directive 2004/80/EC. Due to the Member State obligation to "bring into force the laws, regulations and administrative provisions necessary to comply with [the] Directive by 1 January 2006 at the latest" (Council Directive 2004/80/EC: Article 18(1)), the same phenotype can be expected to be found in the Member States' national legal systems as well. However, this is not strictly true for the United Kingdom, at least from a terminological point of view. Though both the UK and Italy have implemented the Council Directive, in English national texts no term has in fact been identified to refer to the CROSS-BORDER VICTIM genotype, while in Italy the term vittima transfrontaliera has been found only in academic texts. It can therefore be concluded that, though the phenotype has been imported in all the Member States' national legal systems, such a "legal transplant" (Watson 1974) has not produced a "terminological transplant" in the British legal system, where a terminological vacuum has been observed.

The last case of terminological equivalence in the EU multi-level jurisdiction refers to nationspecific terminology extracted from national legal systems. As already mentioned in Section 3.3.5, some terms which are specific to the legal system of one of the Member States have been selected and included in MuLex owing to their co-occurrence and relevance to the main topic of the research. In other words, a cross-check of these terms in the EU corpus has revealed that in fact they are not EU terms and the genotype they refer to has no phenotype counterpart in the EU legal system. Given that the phenotypes designated by these terms are specific to only one of the legal systems taken into consideration and there is no shared genotype among all the legal systems, it would be plausible to expect that both a conceptual and a terminological vacuum should occur in the EU and the other national legal systems. However, the search for term equivalents has revealed that, though a conceptual vacuum in a legal system can indeed exist, it is not necessarily accompanied by a terminological vacuum. 


\begin{tabular}{|l|l|}
\hline \multicolumn{1}{|c|}{ Type of equivalence/correspondence } & \multicolumn{1}{|c|}{ Example } \\
\hline \multirow{2}{*}{ interlingual intra-systemic equivalence } & $\begin{array}{l}\text { lonceptual and terminological vacuum, no } \\
\text { equivalence }\end{array}$ \\
\hline \multirow{2}{*}{$\begin{array}{l}\text { intralingual inter-systemic } \\
\text { correspondence }\end{array}$} & $\begin{array}{l}\text { Criminal Injuries Compensation Authority refers } \\
\text { to a British phenotype }\end{array}$ \\
\cline { 2 - 3 } & $\begin{array}{l}\text { Criminal Injuries Compensation Authority is used } \\
\text { in Italian to refer to a British phenotype }\end{array}$ \\
\hline \multirow{2}{*}{ interlingual inter-systemic equivalence } & $\begin{array}{l}\text { no inter-systemic equivalence but interlingual } \\
\text { terminological equivalence }\end{array}$ \\
\hline
\end{tabular}

Table 5.6. Types of terminological equivalence and correspondence in the EU multi-level jurisdiction. Example: CRIMINAL INJURIES COMPENSATION AUTHORITY.

Table 5.6 shows the CRIMINAL INJURIES COMPENSATION AUTHORITY phenotype. As far as the conceptual vacuum is concerned, such phenotype can be considered to be identical to the QUALIFYING CLAIMANT example shown in Table 5.4, since the phenotype was created within the British legal system and, given the lack of similar phenotypes in the EU and Italian legal systems, can be said to coincide with its genotype. Between these two phenotypes there is, however, a difference at the terminological level. In the example in Table 5.4, a terminological and conceptual vacuum has been observed both in the EU and the Italian legal systems, resulting in a lack of equivalence (zero equivalence) at both levels, but the same does not apply to the CRIMINAL InJURIES COMPENSATION AUTHORITY phenotype. While comparing the British and the EU legal systems, a conceptual and terminological vacuum emerged in the latter system, since no similar phenotype, and, consequently, no term referring to it, were retrieved. Also the search for a similar phenotype in Italian national texts has revealed a conceptual gap in the Italian legal system, although the borrowing Criminal Injuries Compensation Authority has been found in non-legally binding texts. This is so because in such texts the reference legal system is not necessarily the Italian one and consequently the phenotype the term refers to is embedded in a jurisdiction other than the Italian one. For clarity's sake, the same example is also presented graphically in Figure 5.2. 


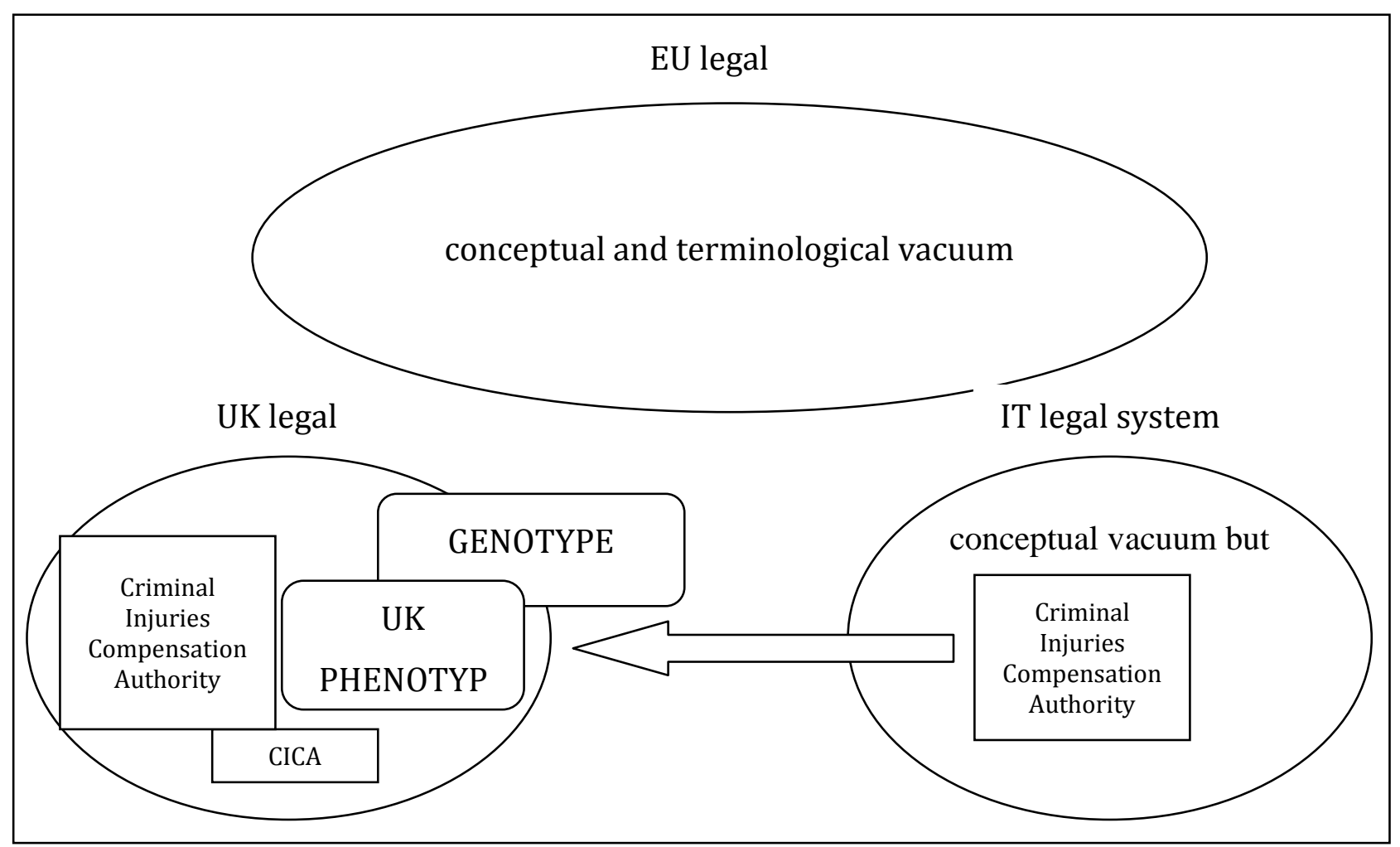

Figure 5.2. Assessment of interlingual equivalence on the basis of the genotype-phenotype distinction. A case of terminological and conceptual vacuum. Example: CRIMINAL INJURIES COMPENSATION AUTHORITY.

\subsubsection{TERMS AND NAMED ENTITIES}

The last example provided in Section 5.3 offers the opportunity to make a further comment on the type of terminology included in this research project. Notwithstanding the initial decision that all the terms to be included in the TKB should be nouns, when defining the type of terminology to be extracted and analysed (see Section 3.3.1.1.3), no specification was made of the type of concepts these terminological units should refer to, apart from the general requirement that the concepts should fall into one of the broad concept fields outlined in Section 3.3.1.3 and illustrated in Section 6.4.1.1.1. This entails that, in the term extraction process (Steps 3 and 5 in Chapter 3), some lexical units have been retrieved which are not universally acknowledged as being proper terms.

For instance, according to some authors who use term extraction for ontology learning from text and ontology population, these lexical units, which could be described as named entities and can be included in what Cao refers to as "words associated with areas of law and institutions" (Cao 2007: 65), should be kept separate from domain-specific terminology (see Velardi et al. 2001; Omrane, et al. 2011; Buitelaar et al. 2005, among others). In ontology learning from text, terms are seen as the "linguistic realizations of domain-specific concepts" 
(Buitelaar et al. 2005: 6), and are identified mainly on the basis of their intension, while named entities represent the extensional realisation of concepts (Buitelaar et al. 2005: 2). Therefore, it follows that terms are generally used in the learning or generation of an ontology, while named entities are more relevant for the population of an ontology. From an ontological perspective, named entities are considered as instances of concepts (Navigli \& Velardi 2008: 85), which generally come into play once the elaboration of the ontology is completed, because named entities or instances are used for "instantiating a knowledge base" (Buitelaar et al. 2005: 4), i.e. an ontology.

As far as this research study is concerned, however, the distinction between proper terminological units and named entities is not considered to be fundamental on the basis of two main reasons. The first lies in the approach adopted for term clustering and term matching, which is based on the genotype/phenotype distinction discussed in Section 3.3.6.1. As has been illustrated in the examples in Tables 5.4 and 5.6, because a phenotype is embedded in one legal system only and it is impossible to find a shared genotype for all the legal systems examined, in some cases phenotype and genotype coincide, since no superabstract legal notion can be identified. This is particularly true when named entities are taken into account, since in the legal domain this category frequently includes institutions and organisations operating within only one national legal system. Such a system-specificity applies not only to named entities referring to the British and the Italian national legal systems, but also to some EU named entities which in fact could be expected to be relevant to the legal systems of all the Member States. For instance, the term European network of national contact points for restorative justice refers to a network established by the EU which operates EU-wide and it is the very uniqueness of its nature that makes it difficult to identify a category of which the European network of national contact points for restorative justice could be an instance of. In other words, given the very specific and unique features of this network, the named entity under discussion can be said to designate both the concept and an instance of that concept, i.e. both a genotype and a phenotype, a fact that undermines the distinction between categories and instances postulated in the ontologists' view mentioned above.

The second reason why for the aims of this terminographic study the distinction between proper terminological units and named entities is not considered to be fundamental is that the starting and ending points of this terminographic research project are texts rather than the conceptualisation of domain-specific knowledge: the lexical units found in the textual material in one language are analysed in order to understand their underlying conceptual 


\section{Chapter 5}

features, which are in turn used to go back to the textual material and find possible equivalents in a different language. This is so because this research study is applicationoriented and the MuLex TKB has been designed for translators, which makes distinguishing between proper terms and named entities unnecessary, since translators are required to translate both types of lexical items, irrespective of the category they belong to. Therefore, in the term extraction and retrieval process (Steps 3 and 5 in Chapter 3) also some named entities (as well as their terminological variants, which are reported in the relevant terminographic entries) have been selected for inclusion in the TKB.

It should be noted that the selected named entities have been extracted from the EU corpus and the collection of English texts, but not from the Italian texts. The EU named entities are the already discussed European network of national contact points for restorative justice in English or rete europea di punti di contatto nazionali per la giustizia riparatoria in Italian and Victim Support Europe, which is used both in English and Italian. The named entities retrieved in the collection of English national texts are: Criminal Injuries Compensation Authority, Criminal Injuries Compensation Scheme, Victim Support, Victim Support Northern Ireland and Victim Support Scotland. The reasons why no national named entities have been selected from the collection of Italian national texts are the following two. First, in Italy there is neither a nation-wide victim support organisation nor a general compensation scheme which victims, no matter what crime they have suffered from, can apply to. Thus the lack of national named entities corresponds to a factual non-existence. Second, the decision not to include a named entity in the TKB has been determined by the type of named entity retrieved. Looking for the nation-specific instantiation of ASSISTING AUTHORITY, Article 1(2) of the Legislative Decree $n$. 204/2007 $7^{121}$ states that the assisting authority in Italy is the Procura generale della Repubblica (Public Prosecutor's Office), an office which in fact is in charge of a wide variety of duties that are not necessarily linked to the area of law related to victims of crime, hence the decision not to include this named entity in the TKB.

\subsubsection{DEGREES OF EQUIVALENCE AND TERMINOGRAPHIC PROCESSING}

The final part of this chapter is devoted to a series of conclusions on the different degrees of terminological equivalence in the EU multi-level jurisdiction that can be drawn from the examples provided in Section 5.3, as well as the observations concerning the conceptual nature of legal named entities and the methodology that has been used for both term

\footnotetext{
${ }^{121}$ Decreto Legislativo 6 novembre 2007, n. 204, Attuazione della direttiva 2004/80/CE relativa all'indennizzo delle vittime di reato, Gazzetta Ufficiale, 261, 9.11.2007.
} 
clustering ( intralingual correspondence) (see Section 3.3.6.1) and cross-linguistic term matching (interlingual equivalence) (see Section 3.3.6.2).

\subsubsection{INTERLINGUAL INTRA-SYSTEMIC EQUIVALENCE}

As shown in Table 5.1, interlingual intra-systemic equivalence has been assessed by identifying term equivalents in the English and Italian EU subcorpora. In this case, the degree of equivalence has been considered absolute, since the underlying legal system for both the English and the Italian terminology is the same, i.e. the EU legal system, and the linguistic versions of the same documents are the result of the process of an "interlingual text reproduction" (Kjær 2007: 7). However, it should not be overlooked that, while the legal system is one and the same, according to the multilingualism principle that the EU legal system should be expressed in 23 legal languages:

Il multilinguismo non è stato percepito come un problema fino a che la Comunità europea si è occupata di materie attinenti alle competenze sue proprie, quali la regolamentazione di parametri economici, di standard tecnici e di misure restrittive alla realizzazione del mercato comune. Anzi, nelle materie suddette, il diritto comunitario ha innovato anche la terminologia degli ordinamenti nazionali [...]. Quando il legislatore comunitario agisce in un settore di sua sicura competenza ne elabora anche i concetti giuridici e le unità lessicali in maniera tale che i concetti abbiano lo stesso significato in tutte le lingue anche a livello nazionale. (Rossi 2008: 367)

Though Rossi was referring to EU private law, his observations can also be applied to the EU legal area concerning victims of crime, due to the development of EU provisions, and thus EU legal concepts, in this domain. Considering that "[b]orrowing and neologism are much more common in legal systems that are in the process of establishment or developing than in more mature or established systems" (Cao 2007: 57), then the terms referring to concepts developed within the EU such as ASSISTING and DECIDING AUTHORITY, CENTRAL CONTACT POINT or CROSS-BORDER VICTIM are equivalent in the two languages taken into consideration and can be recorded as such in a terminographic entry as the one used in the MuLex TKB (see Chapter $6)$.

However, cases of diverging linguistic versions of the same document have been brought before the European Court of Justice ${ }^{122}$, proving that such a high degree of equivalence is not always realised at a textual level. Moreover, EU institutions do not always need to introduce

\footnotetext{
${ }^{122}$ For an overview on the issue of multilingualism and diverging linguistic versions in the EU, see Pozzo (2008) and Van Calster (1997).
} 


\section{Chapter 5}

new legal concepts in EU legislation and resort to neologisms. The standard procedure is rather the "readjustment of national terminology" (Buchin \& Seymour 2003: 111), i.e. using legal terms already existing in the national legal systems and adapting them to new specific communication needs (see Rossi 2008: 363). In such cases, equivalence is forced upon terms that in fact would not be equivalent if used within their national legal systems. An example of this "forced" equivalence is represented by the terms victim and vittima, two terms which, as seen in Section 3.3.5, at the EU level refer to the same phenotype and in the TKB are provided with a definition that sets the boundaries of this concept. Conversely, when the two terms are used in their respective national settings, the intralingual correspondence and intersystemic equivalence between them can be considered to be only relative.

\subsubsection{INTERLINGUAL INTER-SYSTEMIC EQUIVALENCE}

When terminological equivalence is considered from a national - and not supranational point of view, cases of absolute terminological equivalence among legal systems become very rare (Bullo 2007: 89): "[w]hen the target language and the source language relate to different legal systems, absolute equivalence is impossible" (De Groot 1996: 157). Not only is absolute equivalence impossible, but the search for it is even "futile" (Cao 2007: 59). Therefore, from a translational perspective, in all the cases when an inter-systemic translation is required, the methods and strategies to be adopted depend on several variables (e.g. skopos of the translation and intended reader) and lead to different types of translation, ranging from literal translation or functional equivalence to borrowing and descriptive equivalence (see Cao (2007: 59); Šarčević (1997: 235-237), among others). From a terminological point of view, however, rather than reached at a textual level, formal equivalence should be assessed among the available terminological units (see 5.1).

When considering legal terminology in this light, once it is established that

La parola esprime la nozione, ma diversamente da altri contesti tecnici, nel dominio giuridico certi concetti, creati, elaborati e definiti dal legislatore o dal giurista di un certo sistema giuridico, non necessariamente corrispondono a concetti elaborati per un differente sistema. (Sagri \& Tiscornia 2009: 6, referring to Sacco 2000: 126)

three possible cases are envisaged by Šarčević: near, partial and zero or non-equivalence. Legal terminology, Šarčević's definitions of these three types of equivalence are based on the distinction between essential and accidental characteristics of legal concepts (Šarčević 1997: 237): 
- near equivalence occurs when concepts A and B share all of their essential and most of their accidental characteristics or when concept A contains all of the characteristics of concept B, and concept $\mathrm{B}$ all of the essential and most of the accidental characteristics of concept A:

- partial equivalence occurs when concepts A and B share most of their essential and some of their accidental characteristics or when concept A contains all of the characteristics of concept B but concept B only most of the essential and some of the accidental characteristics of concept A;

- non-equivalence occurs when only a few or none of the essential features of concepts $\mathrm{A}$ and $\mathrm{B}$ coincide or if concept A contains all of the characteristics of concept B but concept B only a few or none of the essential features of concept $\mathrm{A}$ or when there is no functional equivalent in the target legal systemfor a particular source concept (see Šarčević 1997: 238-239).

However, as regards the distinction between near and partial equivalence, when the conceptual analysis of a legal concept is carried out it is not always possible to distinguish between essential and accidental characteristics. Therefore, in order to include all the cases which lie between the two ends of the equivalence spectrum (absolute equivalence vs. nonequivalence), the term "relative equivalence" (Sandrini 1999: 102) has been used in this thesis. For the aim of recording cases of relative equivalence and zero equivalence in MuLex (see Chapter 6), different approaches have been adopted on the basis of the genotype/phenotype distinction.

As far as relative equivalence is concerned, the terms that could be related to a common genotype have been recorded as part of the same terminographic entry and the non-absolute degree of equivalence has been clarified. For instance, the English term victim and the Italian term vittima feature an absolute equivalence at the EU level (absolute interlingual intrasystemic equivalence), but only a relative equivalence at the national level (relative interlingual inter-systemic equivalence). This is so because the English term is broader than the Italian one, since it may also include the concept of DANNEGGIATO which instead is kept separate in the Italian legal system.

A similar case of relative equivalence is represented by the terms state compensation and risarcimento da parte dello Stato. Unlike the EU level, where they are absolute equivalents, at the national level their equivalence is only relative by reason of the substantial differences existing in the regimes governing state compensation. In the UK, the Criminal Injuries Compensation Authority uses a specific tariff scheme to assess the amount of the award for 


\section{Chapter 5}

victims of crimes of violence, while in Italy no such scheme exists and only victims of specific crimes (extortion, terrorism, organised crime) are entitled to compensation.

The last type of equivalence, i.e. zero or non-equivalence, is exemplified by the Italian term elargizione, which designates the compensation awarded to victims of extortion, terrorist attacks and organised crime in Italy and has thus been regarded as a separate, national-specific phenotype. No similar notion has been found in the EU and British legal systems when looking for a comparable phenotype, resulting in a conceptual vacuum and a case of nonequivalence in the two systems. Because the aim of MuLex is to provide useful terminological material for legal translators, for any terminological gap encountered, a proposal for a possible equivalent should be suggested (see Section 6.4.1.2). In this case, the proposal is provided by a so-called "descriptive paraphrase" (Šarčević 1997: 252) - State compensation for victims of extortion, terrorism or subversion of the democratic order which is derived from the definition of the Italian concept. For these same reasons, this strategy was applied also to the English term qualifying claimant, discussed in Section 5.3, for which the proposed equivalent is soggetto avente $i$ requisiti necessari per richiedere il risarcimento statale. Suggesting a proposal for an equivalent term in case of a terminological gap in one of the languages is in fact in line with the scope and the multilingual approach of the TKB, requiring the completion of a terminographic entry that would otherwise provide information in one language only. However, given the non-prescriptive aims of MuLex, all proposals should be seen merely as a starting point for translators to appreciate the differences among the legal systems recorded in the TKB and either formulate their own proposals or opt for an altogether different translation strategy (Sandrini 1999: 109).

When a phenotype is absent in a legal system, to refer to the foreign legal notion an alternative strategy is that of using a borrowing (see Šarčević 1997: 256-259), which in this research study concerns mainly named entities (see Section 5.3.1). However, in the TKB a distinction has been made between Italian loan word equivalents of the English terms which were found in the analysed Italian texts and those which were not. In the example provided in Figure 5.2, the English borrowing Criminal Injuries Compensation Authority was found in an Italian text referring to the British legal system and was consequently recorded in MuLex as an Italian loan-word equivalent for the English term, while another borrowing, i.e. Victim Support, was labelled as a mere proposal. 


\subsection{Summary}

In Chapter 5, the issue of terminological equivalence in the EU multi-level jurisdiction has been discussed. In order to define the framework in which terminological equivalence is analysed, first of all a distinction has been drawn between terminological and translational equivalence, which, following Andrew Chesterman, can be considered as respectively formal and textual equivalence. In turn, the examination of terminological equivalence in the EU multi-layered legal setting has revealed two different types of equivalence. The first, which has been called here "interlingual intra-systemic equivalence", occurs between terms in different languages referring to a unique legal system (the EU), while the second, namely "interlingual inter-systemic equivalence", occurs between terms in different languages referring to different legal systems. While the first type of equivalence can be expected to be absolute on the grounds of the multilingualism principle, in the second an assessment of terminological equivalence is called for, since "[a]ny notion of equivalence is a matter of judgement" (Altenberg \& Granger 2002: 16). From such an assessment, which requires the evaluation of intralingual correspondence first, it emerged that, due to the intrinsic anisomorphism in legal systems, the main degrees of equivalence in an inter-systemic analysis are relative and zero equivalence. Such degrees of equivalence have then been discussed from a terminographic perspective and the solutions adopted for recording the cases identified in the textual material analysed on the basis of the genotype/phenotype distinction have been presented.

As regards the recording of relative and zero equivalence in MuLex, it was shown that, when no equivalent was available in the textual material analysed, both relative equivalents and proposals for term equivalents have been included in the TKB. Two remarks have been finally made concerning proposals for term equivalents, the first regarding the limits of an analysis of a limited number of texts and the second on the limits intrinsic in the proposal of a single term equivalent. As concerns the first, though the broadest possible amount of textual material concerning the legal area of victims of crime has been collected so as to carry out a comprehensive terminological analysis, this does not exclude in principle that for the terminological gaps which have been identified an equivalent could not be found if new textual material were considered. As for the second remark, bearing in mind that a single concept can very often be referred to my means of different terms (see Chapter 4 on terminological variation) - making translation a decision-making process where the translator is required to choose among different possible solutions - when suggested, the single 


\section{Chapter 5}

proposal's only function is to serve as a starting point for the terminological analysis that the translator should perform him/herself on a case-by-case basis (see Section 5.3.2.2). 


\section{Chapter 6. VICTIMS OF CRIME FROM A TERMINOGRAPHIC Perspective. MuleX: a Legal Translation-Oriented TERminological KNOWLEDGE BASE}

The terminology and the relevant terminological data collected following the methodology described in Chapter 3 have been recorded in the translation-oriented TKB MuLex. In Chapter 6, the specific features developed in MuLex for making the peculiarities of legal terminology observed in Chapters 4 and 5 accessible to end users. Such features have been specifically designed to make the differences among national and supranational legal notions clear and provide sufficient conceptual and linguistic information to assist legal translators in the retrieval or formulation of translation equivalents. A tool has been incorporated in the TKB to allow for the graphic representation of conceptual knowledge.

\subsection{From TERMINOLOGICAL DATABASES TO TERMINOLOGICAL KNOWLEDGE BASES}

Ever since the beginnings of studies in Terminology, the discussion has been devoted to terminological repositories which should contain domain-specific terminology. As pointed out by Meyer et al.,

Much of the world's terminological data is stored in large terminological databases (TDBs) [...]. These TDBs are useful only to humans, and even then to only a small subset of potential users: translators remain the principal user category, even though TDBs have obvious applications in technical writing, management information and domain learning, not to mention a wide variety of machine uses such as information retrieval, machine translation and expert systems. A major weakness of TDBs is that they provide mainly linguistic information about terms (e.g. equivalents in other languages, morphological information, style labels); conceptual information is sparse (limited to definitions and sometimes contexts), unstructured, inconsistent and implicit. (Meyer et al. 1992: 956, emphasis in the original) 
The authors acknowledge that, in the early 1990s, "a growing number of terminology researchers [were] calling for the evolution of TDBs into a new generation of terminological repositories that are knowledge-based" (Meyer et al. 1992: 956), which are generally referred to as "terminological knowledge bases" (TKBs). As Cabré puts it, knowledge databases are "knowledge repositories represented in a formal language that can be accessed by users via an expert system based on terminological units, which are organised into a conceptual network containing various types of relations" (Cabré 2006: 98). Though Cabré does not use the term "terminological knowledge base", the definition she provides suits the type of terminological repository under discussion.

The differences between TDBs and TKBs regard three different dimensions: the information contained in the repository, the support for the acquisition and the systematisation of information, and the facilities employed for retrieving information.

As regards the information, the main difference between TDBs and TKBs lies in the greater inclusion of specialised-domain knowledge in TKBs as compared to TDBs. In this regard, it is undeniable that any terminographic task is based on some sort of conceptual structuring, regardless of the type of terminological repository used for recording terminology. This is especially true if the traditional onomasiological approach proposed by the GTT is taken into consideration. However, while this conceptual structuring is exploited for populating both TDBs and TKBs (see Meyer et al. 1992: 959), in the former only the terminologists and the experts involved in the creation of TDBs have access to it, although such structuring is seen as having a great potential in increasing the domain-specific knowledge of the users of terminological repositories, since "[m]ost TDB users are not domain experts, and thus hope to acquire some domain knowledge when they look up a term" (Meyer et al. 1992: 957). Therefore, in TKBs such conceptual information is made explicit and available for end users, allowing for conceptual relations to be explicitly represented and possibly leading to a graphic representation of the knowledge domain. The possibility of representing graphically the information stored in a terminological repository also enhances the potential of these repositories to foster the acquisition and the systematisation of information. The conceptual information available in TKBs, usually presented as conceptual maps, can also be used for retrieving further information which is not accessible by means of already known terms used as keywords in the search facility of the repository. This, again, may lead to the further acquisition of knowledge.

In the evolution from TDBs to TKBs, terminological repositories have benefitted from the developments experienced more in general by linguistic resources in electronic format, 
Victims of Crime from a Terminographic Perspective. MuLex: a Legal Translation-oriented Terminological Knowledge Base

especially as regards the creation of dictionaries. The development of linguistic resources has been possible owing to the incorporation of large-scale, general-language textual corpora, which have gradually given way to smaller, more domain-specific corpora (see Cabré 2006: 95). Ever since the early 1990s, the methodologies used in terminographic tasks have also started to complement with electronically processable textual corpora. However, given the existing differences in terms of approaches adopted and goals pursued by the two disciplines, the incorporation of corpora in lexicology and terminography has led to the development of two different types of resources containing different types of information. As regards lexicology, lexical repositories such as WordNet (see Fellbaum 1998 and Vossen 1998) are being developed to record words and the existing relations among them on a lexical basis, while terminological knowledge bases are intended as repositories of terms rather than words. Given the close connection among terms and the underlying concepts, the relations contained in these repositories are conceptual in nature rather than lexical. The conceptual information available in TKBs can thus be used for acquiring knowledge about the domain the terms belong to and the relations holding among concepts, while lexical repositories provide their users with lexical and semantic information about general language.

\subsection{FROM TERMINOLOGICAL KNOWLEDGE BASES TO ONTOLOGIES}

As stated by Temmerman and Kerremans, "[m]ore recently and more frequently [...] TKBs are now referred to as ontologies" (Temmerman \& Kerremans 2003: 3). This statement can be considered valid depending on what is meant by "ontology". Several authors have proposed their answer to the question "What is an ontology?", thus leading to the proliferation of definitions, insomuch as Guarino described "ontology" as an overloaded term (Guarino 2006).

In order to explain the meaning attributed nowadays to the term "ontology", a step backwards needs to be taken. The term originally belongs to philosophy, where "it means a systematic explanation of Existence" (Gómez Pérez 1999: 33). In this sense, ontology is to be seen as a discipline, i.e. the study of what exists or can exist or the study of the nature and structure of reality. However, the term has been taken on in Artificial Intelligence (AI), where it has assumed a different meaning, though connected to the meaning it bears in philosophy. A first description of an ontology in AI is provided by Neches et al. (1991: 40), who state that ontologies are models of the world represented as frameworks in the form of top-level 
declarative abstraction hierarchies which are provided with sufficient information to lay down the ground rules for modelling a domain. According to them, "[a]n ontology defines the basic terms and relations comprising the vocabulary of a topic area as well as the rules for combining terms and relations to define extensions to the vocabulary" (Neches et al. 1991: 40). Two years later, Gruber formulated what has become the most quoted definition in the AI field: "[a]n ontology is an explicit specification of a conceptualization" (Gruber 1993: 199). Among the many authors who elaborated Gruber's definition, Borst defined an ontology as “a formal specification of a shared conceptualization" (Borst 1997: 12). In these and other definitions of "ontology", the term "conceptualisation" is intended as an abstract model of some phenomenon in the world or a domain, while the expressions "explicit" and "formal" mean respectively that the concepts included in this model are explicitly defined and that the content of the ontology is machine-readable. The addition of "shared" in Borst's definition refers to the knowledge captured in the ontology, which needs to be consensual, and therefore agreed upon by a group.

The enumeration of all the possible definitions which provide a different point of view on the meaning of ontology is out of scope here ${ }^{123}$, but the examples provided so far are sufficient to draw the difference between "ontology" as intended in philosophy and "an ontology" as conceived in Information Technology and, more specifically, Artificial Intelligence. While ontology in the philosophical sense is a science, an ontology in AI is an artefact, a hierarchical structure used for describing the shared conceptualisation underlying the knowledge represented in a knowledge base.

On the basis of the considerations presented so far, it comes as no surprise that contamination has occurred, with ontologies crossing the boundaries of AI and entering the realm of Computational Terminology. As noted by Faber, "[m]ore recently, sociocognitive terminology has also begun to focus on ontologies as a more viable way of implementing conceptual representations" (Faber 2009: 118). This has inevitably led authors in the field of Terminology to the formulation of their own definitions of ontology. For instance, Temmerman and Kerremans define an ontology as "a knowledge repository in which categories (terms) are defined as well as relationships between these categories", where "[i]mplicit knowledge (for humans) needs to be made explicit for computers" (Temmerman \& Kerremans 2003: 3). In this regard, it should not be overlooked that in AI ontologies should ideally represent the conceptualisation of either reality or a specialised domain independently from language. However, as stated by Jarrar and Meersman,

${ }^{123}$ Guarino and Giaretta (1995: 25), for instance, mention seven possible interpretations of the term "ontology". 
A correct understanding of ontologies must however reconcile that they are repositories of (in principle) language- and task-independent knowledge, while any effective use by e.g. software agents naturally requires interaction with some necessarily lexical representation. Also the creation of ontologies as (sets of) agreements about structure and semantics of a domain requires the use of - usually natural - language [...]. (Jarrar \& Meersman 2002: 1238)

Nowadays ontology engineering has encouraged the development of different types of ontologies, of which the most commonly used according to Gómez Pérez and Benjamins (1999: 3-4) are: knowledge representation ontologies, general/common ontologies, top-level ontologies, meta-ontologies, also known as generic ontologies or core ontologies, domain ontologies, linguistic ontologies, task ontologies, domain-task ontologies, method ontologies, and application ontologies. By way of simplification, it can be said that the theoretical premises on which ontologies are based have allowed for their widespread application in different research and practical fields, such as the Semantic Web, information retrieval and extraction, indexing and so on. Therefore, also Terminology has benefitted from the incorporation of ontology-oriented approaches, since "ontologies are considered as a valuable means to approach terminological work: the reason is that a substantial part of the terminologist's work needs a conceptual approach" (Bautista Zambrana 2011: 313). However, the cross-contamination experienced by the two disciplines does not justify the identification of ontologies with terminological knowledge bases, since in projects subsuming an ontological approach the conceptualisation represents only one of the components of the TKB, i.e. the "domain-dependent terminological network" (Aizawa \& Kageura 2001: 7), rather than the whole TKB.

\subsection{FROM ONTOLOGIES TO ONTOLOGICAL TERMINOLOGICAL KNOWLEDGE BASES}

The increasing importance of ontology "in contemporary terminology theory and applications, where it has gained a key role in the elaboration of terminological repositories" (Leonardi 2012: 19), has been recognised by several authors. Temmerman and Knops, for instance, state that 
At least three shifts have affected the discipline of terminology over the last decade: the shift towards computational terminology management, the linguistic shift in the theory of terminology and the ontology shift which combines the (semi-) formalised representation of semantic relationships with terminological management systems. (Temmerman \& Knops 2004: 11)

The first shift mentioned by the authors applies to the terminographic activity and the methodologies adopted for carrying out such activity, which have been deeply influenced by the integration of IT and computerised Applied Linguistics technologies. Following Vargas Sierra (2007: 47-48), terminology management has progressed qualitatively at least as regards four aspects. Firstly, the advent of Internet has made an ever-increasing number of documents and large amounts of information readily available. Secondly, on the basis of such textual material, the compilation of electronic corpora for terminological purposes is easier and faster. Thirdly, (semi-) automatic extraction tools are used to retrieve specialised knowledge from such corpora, and, finally, software tools specifically designed for the management of terminological information, i.e. TKBs, usually referred to also as terminology management systems, are developed and employed for the manipulation, storage and consultation of terminological data.

The second shift regards the theoretical foundations of Terminology and, consequently, the approaches used to study terminology, with a progressive moving away from the prescriptive approach supported by the GTT and the adoption of a descriptive standpoint (see Section 1.2). Following Vargas Sierra's reasoning, the third shift derives from the second shift. The reason for this lies in the need for improving TKBs so as to make it possible to explicitly represent the domain-specific knowledge acquired by terminologists during their terminographic work. Therefore, the third shift identified by Temmerman and Knops consists in the combination of two types of computerised systems: on the one hand, the (semi-) formalised representation of conceptualisations typical for ontologies, and on the other hand, the terminology management systems containing terminological data. The merging of these systems leads to the creation of what Vargas Sierra calls "termontological databases" ("bases de datos termontológicas") (Vargas Sierra 2007: 48). Therefore, whereas conceptual relations have always played a central role in the field of Terminology, as is evident from the primacy attributed to concepts by the GTT, the inclusion of explicit conceptual structuring in terminological repositories is a recent phenomenon. In the resulting terminology management systems,

los términos son objetos lingüísticos contenidos en una base de datos terminológica, y dichos objetos se relacionan a través de una red de relaciones conceptuales, que está contenida en una ontología, y mediante la 
Victims of Crime from a Terminographic Perspective. MuLex: a Legal Translation-oriented Terminological Knowledge Base

cual se asocian la base de datos terminológica y la ontología, formando, en su conjunto, una base de datos termontológica. (Vargas Sierra 2007: 48)

The merging of the two disciplines has brought about two main approaches: Ontoterminology (Roche 2007a) and Termontography (Temmerman \& Kerremans 2003). The aim of these multidisciplinary approaches, which can be considered both research- and applicationoriented, is to incorporate ontologies into terminological resources. However, some differences among the two approaches can be identified.

In Ontoterminology, ontology is placed at the core of the study of terminology and "[t]he main idea is to separate the linguistic dimension from the conceptual dimension of terminology and establish relationships between them" (Roche et al. 2009: 321). On the other hand, Termontography is embedded in the sociocognitive approach (see Section 1.2) and is based on the assumption that "a knowledge base analysis should ideally precede the methodological steps which are generally conceived as the starting-points in terminography" (Kerremans 2004: 268). Such an analysis leads to the construction of a "common knowledge base or categorisation framework" (Kerremans 2004: 268) containing units of understanding (see Section 4.4.1) and intracategorial relations. The main difference in these approaches is given by the goals envisaged by their advocates. According to Roche, in Ontoterminology ontology is placed at the centre of terminology and "l'ontologie joue un rôle fondamental à double titre: pour la construction du système notionnel et pour l'opérationnalisation de la terminologie" (Roche 2007a: 8). In other words, the construction of an ontology in the ontoterminological approach is seen as a goal in itself as well as a means for operationalising terminology. Conversely, the categorisation frameworks developed within Termontography are intended for helping terminographers in "the information gathering phase during which a corpus is developed" and allow them to "establish specific extraction criteria as to what should be considered a 'term': i.e. the natural language representation of a unit of understanding, considered relevant to given purposes, applications or groups of users" (Kerremans 2004: 268).

Finally, another important feature that distinguishes the two approaches is the type of ontology used. Ontoterminology relies on the onomasiological approach, which "consists in first defining the domain ontology and then identifying the most suitable terms to denote the concepts (if necessary, new normalised terms are proposed)" (Roche et al. 2009: 4). In order to produce such an ontology, the domain conceptualisation in carried out in a formal language which is independent from the words of usage (Roche 2007b: 51). In other words, the conceptualisation obtained consists in a shared, allegedly universal and objective model. 
However, once attempts are made to map such ontologies to the terminology found in textual corpora, problems emerge (see Leonardi 2012: 28-29). Conversely, in its first phases the termontographic approach also counts upon the development of a "culture- and languageindependent categorisation framework" (Kerremans et al. 2004: 565). However, Termontography is developed so as to account for cultural diversities as well, since "cultural differences may emerge from a multilingual terminological analysis and from a comparison of terms referring to the same category" (Kerremans et al. 2005: 102). Therefore, this approach "allows the framework to expand with a culture-specific layer during the search phase, provided that culture-specific categories (relevant for the purpose of the framework) are found in the textual material" (Kerremans et al. 2004).

More recently, a further methodological approach combining terminology and ontology, i.e. Ontoterminography, has been proposed by Durán Muñoz (2012). In the first methodology outlined earlier, i.e. Ontoterminology, the focus is on the building of the ontology and no end user of the terminological collection obtained by applying it is specified. Therefore, it should be assumed that the ontoterminological methodology is not designed for a specific application. Instead, both Termontography and Ontoterminography can be considered application-oriented. The incorporation of ontological analysis in the termontography workflow is useful for the compilation of a terminological dictionary containing multilingual data (Temmerman \& Kerremans 2003: 5). In the same line, the methodology illustrated in Durán Muñoz's proposal is intended for the elaboration of ontoterminographic collections specifically designed for translators (Durán Muñoz 2012: 19).

Apart from the methodologies incorporating ontologies in terminographic practice presented so far, several projects have been carried out which exploit ontological resources for the representation of domain-specific knowledge in multilingual TKBs. These projects are not necessarily designed for translation purposes. The project generally considered the pioneer in this field is COGNITERM (Меуег et al. 1992), led by professor Skuce at the University of Ottawa. COGNITERM "is essentially a hybrid between a term bank and a knowledge base, or a terminological knowledge base" (Meyer et al. 1992: 958), which uses a knowledge engineering tool, called CODE (Conceptually Oriented Description Environment), to manage the information about the concepts belonging to a specialized subject field. The usage of this tool, where "each concept is represented in a frame-like structure called a concept descriptor (CD)" (Meyer et al. 1992: 958), has led to the construction of a bilingual (French/English) TKB dealing with the domain of optical storage technologies. Apart from incorporating a 
Victims of Crime from a Terminographic Perspective. MuLex: a Legal Translation-oriented Terminological Knowledge Base

terminological repository with a knowledge base, this TKB also allows for the knowledge stored in it to be visualised graphically in various semantic net displays.

Another ontology-based terminological project is ONCOTERM ${ }^{124}$ (López Rodríguez et al. 2006), whose objective is the building of a bilingual (English-Spanish) online knowledge base dedicated to the medical subdomain of oncology. The purpose of this project is to share relevant information not only with medical doctors, patients and their families, but also with professional translators, technical writers and the public health system personnel. The development of such a TKB is based on the reference conceptual framework obtained by adapting to ONCOTERM's needs the open-access ontology MikroKosmos ( $\mu$ Kosmos) (Mahesh 1996), originally developed for the machine translation of Chinese texts on the domain of company mergers and acquisitions into English. The conceptual structure in this project is not available to end users, since the graphic user interface is not provided with a visualisation tool for the representation of concepts in a frame- or network-like structure, although hierarchical relations are collected in tables.

The design of the MikroKosmos ontology as adopted in the terminological management system OntoTerm ${ }^{125}$ (Moreno \& Pérez 2000) has also been exploited by the GENOMA-KB project $^{126}$ (Cabré et al. 2004, Feliu et al. 2004) for the purpose of developing a TKB on the human genome domain based on specialised information both provided by experts and extracted from textual material. The aim of this project is "to establish the main theoretical ground basis and some refined strategies in order to improve terminological units retrieval, the emergence of cognitive nodes from texts and the detection of conceptual relations among terms in a semiautomatic way" (Cabré et al. 2004: 87), in view of improving specialised information retrieval systems in the long run. Four modules are integrated in this terminological knowledge base: a textual database containing Catalan, Spanish and English documents on the human genome domain; a factographic and documental database including bibliographic information about the tagged documents stored in the textual database; a terminological database containing specialised linguistic units linked to the concepts stored in the ontology; and a human genome ontology, where concepts are organised on a set of hierarchical and non-hierarchical conceptual relations (Feliu et al. 2004: 32). All the four modules are accessible to end users, who are translators, technical writers and field experts.

\footnotetext{
${ }^{124}$ Available at http://www.ugr.es/local/oncoterm/.

${ }^{125}$ Available at http://www.ontoterm.com/.

${ }^{126}$ Available at http://genoma.iula.upf.edu:8080/genoma/index.jsp.
} 
Another project merging ontology and terminology is ONTODIC ${ }^{127}$, developed by the TecnoLeTTra group of the Universitat Jaume I de Castellón. The project aims at proposing "a systematic methodology for the elaboration of onomasiological terminological dictionaries using an ontology editor" (García \& Alcina Caudet 2009). The dictionaries resulting from the adoption of this approach, which are developed by combining various techniques, such as electronic corpora, text analysis tools, terminological databases, term extractors and ontology editors, aim at containing terminology and specialised knowledge, which can be accessed taking the meaning, and not only the lemma, as the starting point for consultation. The end users of such resources are primarily language experts (translators, interpreters and technical writers), though such dictionaries can also be used by field experts and the general public.

Finally, the last terminological resource based on ontological principles mentioned here is EcoLexicon $^{128}$ (Reimerink \& Faber 2009, Reimerink et al. 2010), developed by the LexiCon Research Group of the University of Granada. This terminological resource is the result of previous research projects carried out by the same group, namely PuertoTerm - Coastal Engineering: knowledge structure and generation of terminological resources (Tercedor \& López-Rodríguez 2008), MarcoCosta: Multilingual knowledge frames in the integrated management of coastal areas (León Araúz et al. 2008), and Ecosistema: Single information space for frame-based environmental data and thesaurus (López Rodríguez et al. 2010). This TKB contains Spanish, English and German terms related to environmental events and is designed mainly for translators, technical writers, and environmental experts. The resource is composed of various modules devoted to conceptual, linguistic and graphic information. The information stored in these modules is extracted from a specialized domain corpus and is organised in a frame-like structure, the so-called "Environmental Event (EE)" (Reimerink \& Faber 2009: 630), allowing for the conceptualisation of dynamic processes related to environmental issues. From our point of view, the most interesting part of the EcoLexicon projects is the user interface, through which users have access to the ontological structure and can see the exact position of the concepts in the domain hierarchy, visualise the conceptual relations in a dynamic network of related concepts, access the definitions and the terms designating the concepts in different languages, the contexts and concordances for the selected term and graphic resources, when available (Reimerink et al. 2010: 2327-2328).

So far, the evolution of electronic terminological resources from terminological databases to terminological knowledge bases relying on ontological premises has been presented and some examples of projects developing these resources have been provided. In the following section,

\footnotetext{
${ }^{127}$ Available at http://tecnolettra.uji.es/es/?page_id=35, http://tecnolettra.uji.es/es/?page_id=186.

${ }^{128}$ Available at http://ecolexicon.ugr.es/en/.
} 
Victims of Crime from a Terminographic Perspective. MuLex: a Legal Translation-oriented Terminological Knowledge Base

the MuLex terminological knowledge base developed for the storage of multilingual terminological information is illustrated.

\subsection{MULEX: A LEGAL-TRANSLATOR ORIENTED TERMINOLOGICAL KNOWLEDGE BASE}

As seen so far, nowadays ontology is playing an increasingly prominent role in terminology theory and applications. However, the methodologies and the projects exploiting ontological principles and tools for the development of ontology-oriented terminological knowledge bases (see Section 6.3) bring about both advantages and disadvantages. While the incorporation of ontologies in such resources allow for a clear classification of concepts within formally represented conceptual structures, thus helping the development of consistent terminological data, the presence of a shared ontology in the resource presupposes the existence of a shared conceptualisation of the domain the ontology is used to describe. Taking the last project mentioned in the previous section as an example, the creation of Environmental Events in EcoLexicon to describe environmental processes within a single ontology and the possibility to map the terms in different languages to the concepts stored in the ontology module imply a universally accepted, language- and culture-independent conceptualisation of the environmental event described. However, as admitted for the termontographic methodology by Kerremans et al. (2004), who seem to adopt a different perspective among the authors dealing with ontological terminological knowledge bases, the development of categorisation frameworks which are language- and culture-independent may be followed by an integrative phase in which culture- and language-specific categories are added to the previously developed framework (see Section 6.3).

A similar view is adopted also in this research project for the development of the MuLex TKB. This is so because MuLex is developed for managing and storing the multilingual terminology concerning a legal subdomain for which the cultural embeddedness cannot be denied (see Section 1.4), since "[n]o language can exist unless it is steeped in the context of culture; and no culture can exist which does not have at its center, the structure of natural language" (Bassnett 1991: 14). When applying the same assumption to the context of legal language in general and legal terminology in particular, "the 'body of culture' coincides with all aspects of the legal system governing and defining a given culture" (Kocbek 2008: 51-52). Therefore, a direct correlation is to be expected between the legal terminology used and the 
underlying legal system. The creation of a single ontology or conceptual system as a backbone for the setting up of a knowledge base containing multilingual terminological data as proposed in several ontological terminological projects (see Section 6.3) - is insufficient to represent the "body of culture" designated by legal terminology. This drawback is even more evident if applied to a TKB which is conceived as translation-oriented, since a lack of consideration for the anisomorphism between legal systems and thus between legal terminologies involved in the translation process may have serious consequences for the end product of the process, i.e. the target text. Moreover, Šarčević's statement that "concepts with a very high level of cultural context are frequently untranslatable" (Šarčević 1997: 70) provides further evidence for the impossibility of mapping multilingual legal terminology to a single reference ontology.

On the basis of the observations made so far, the approach adopted for the creation of the MuLex TKB takes into consideration the evolution experienced by terminological databases, which have progressively incorporated ontological principles for the analysis of the relevant specialised domain, without underestimating the importance of acknowledging the discrepancies among legal systems. Hence, for the purposes of creating a conceptual structure that would take into account the differences among the EU, English and Italian legal systems as far as victims of crime are concerned, an approach similar to the one adopted in the Legal Taxonomy Syllabus (LTS) project ${ }^{129}$ (Ajani, Boella et al. 2007, Ajani, Lesmo et al. 2007) has been selected. Several attempts to exploit the potentiality of ontologies in the legal field have been made so far (see, for instance, Despres \& Szulman 2004 and Tiscornia 2007). However, the LTS project seems to feature the highest degree of similarity with the research project presented in this thesis as regards the approach to the legal area and aims of the conceptual and terminological analysis. The $\operatorname{LTS}^{130}$ is an ontology-based tool designed to collect multilingual legal information on EU directives and build conceptual legal dictionaries following a bottom-up approach, i.e. basing the construction of conceptual structures on textual material. Starting from the assumption that the drafting (translation) and transposition of EU directives are complex processes where terminological and conceptual misalignments can occurs, the LTS is based on a conceptual backbone which "consists in a taxonomy of concepts (ontology) to which the terms can refer to express their meaning" (Ajani, Boella et

\footnotetext{
${ }^{129}$ Available at http://www.eulawtaxonomy.org/index_en.php.

${ }^{130}$ The LTS tool was developed during the Training and Mobility of Researchers research programme "Uniform Terminology for European Private Law" (2002-2006) carried out by a network of seven universities: University of Turin (Italy), University of Barcelona (Spain), University of Lyon 3 (France), University of Münster (Germany), University of Nijmegen (The Netherlands), University of Oxford (United Kingdom), and University of Warsaw (Poland).
} 
Victims of Crime from a Terminographic Perspective. MuLex: a Legal Translation-oriented Terminological Knowledge Base

al. 2007: 22). Nevertheless, the authors "do not assume the existence of a single taxonomy covering all languages" (Ajani, Boella et al. 2007: 22), and therefore "the LTS includes different ontologies, one for each involved national language plus one for the language of EU documents. Each language-specific ontology is related via a set of association links to the EU concepts" (Ajani et al. 2009: 20).

In line with the LTS project, MuLex is developed for the purpose of managing and storing multilingual terminological data belonging to a multi-jurisdictional setting, so it is designed to bring to the fore the differences in the conceptual systems involved in the research project by means of a distinct conceptual relational structure for each legal system(see Section 6.4.1.1.2). In this regard, it is interesting to acknowledge that the cultural embeddedness and language dependency of the legal system are relative when the EU legal system is taken into consideration. According to Ajani et al., the "various national ontologies have a reference language. This is not the case for the EU ontology. For instance, a given term in English could refer either to a concept in the UK ontology or to a concept in the EU ontology" (Ajani et al. 2009: 20). For this reason, in LTS lightweight ontologies are used, i.e. "simple taxonomic structures of primitive or composite terms together with associated definitions", and "the ontology can be limited to those structural relationships among terms that are considered as relevant" (Ajani, Lesmo et al. 2007: 43). Given the type of terminology analysed for the purposes of this research project, also in the design of MuLex account has been taken of the multi-jurisdictional context represented by the EU and its Member State. Consequently, three conceptual relational structures are developed, two of which are national (British and Italian) and one is supranational (EU).

Before moving on to the description of the features of MuLex, a terminological clarification is needed. In the ontological terminological projects illustrated in Section 6.3, the conceptual reference model has been referred to in many different ways, such as ontology and categorisation framework, and different authors refer to it by means of different expressions, such as conceptual map, conceptual model and so forth. As seen in section 0, the main term used nowadays, i.e. ontology, results overloaded and implies, even in the terminological field, the usage of specific ontology-development tools, while the other terms can be considered equivalent, since they all reflect a formal way of representing conceptual knowledge. However, in this thesis the term "conceptual relational structures" is preferred. The reason for this choice lies firstly in the fact that no ontology-development tool has been used for the representation of the conceptual content stored in MuLex. This means that the conceptual knowledge so far is not stored for possible artificial agents to access it, but is rather directed 
to human users only. Moreover, though in line with the current trends in ontology-oriented terminological resources, MuLex is developed for the management of terminological data extracted from texts and, consequently, it does not aim at constructing comprehensive ontologies containing all the concepts belonging to a specialised domain, but rather establishing relations among the concepts derived from the terms extracted from corpora. As pointed out by Cole, "[f]or descriptive terminology, the absence of a completely delineated concept network for a given field is not of particular importance. A complete analysis of this type, even where such is possible, is not necessary in order to identify individual concepts and the terms by which they are designated" (Cole 1991: 19). Therefore, since the conceptual focus of MuLex is on relations, the term used to refer to the networks of related concepts is "conceptual relational structures". Moreover, it should also be specified that at the time of writing of this thesis no common conceptual relational structure comprising all the concepts stored in MuLex in an ontology-like fashion was available for each legal system taken into consideration, but rather a single conceptual relational structure for each concept. These relational structures are, however, conceived within the frames developed in Fillmore's Frame Semantics (Fillmore 1976, 1985) (for further details on MuLex conceptual relational structures, see Section 6.4.1.1).

In spite of the similarities highlighted so far, some differences between the LTS and MuLex can also be observed. First of all, while both projects focus on the conceptualisation of legal domains covered by both the EU and national legal systems, the LTS constructs proper lightweight ontologies for the legal systems analysed and in MuLex conceptual relational structures are built for individual concepts. Secondly, the LTS is intended for supporting lawyers in their study, drafting and translation of "the peculiarities of European Union Directives concerning the polysemy of legal terms, and the terminological and conceptual misalignment" (Ajani, Lesmo et al. 2007: 43), while MuLex is not limited to a single text type such as the LTS, but is rather concept field-oriented. This means that the focus is on the terminology of a specific area of law, regardless of the text types dealing with it, rather than on a specific type of supranational act and its implementation acts. However, even though the LTS was originally intended as a thesaurus for EU directives in general, ever since its creation it has specialised mainly in consumer law. Thirdly, while the end users of the LTS are legal practitioners, who can anyway be involved in translation tasks, MuLex is primarily designed for specialised translators, though it may prove useful to other users as well. Finally, the two resources differ both in the languages covered and the type of linguistic and conceptual information provided: on the one hand, the LTS covers English, French, German, Italian and 
Spanish, while MuLex includes English and Italian, while on the other hand the LTS has a less fine-grained user interface, which means that there are less structured fields as compared to MuLex. By way of example, the "Description" field in the LTS can include different types of information, from definitions to notes on the usage of the selected term and descriptions of terminological difficulties. As regards the user interface, a further remark can be made: the ontological part of the LTS is represented in the form of relations, but the ontology is not available for all the terms included in the knowledge base, while in MuLex every terminological record is provided with at least one conceptual relational structure.

\subsubsection{MULEX: TERMINOGRAPHIC ENTRIES AND GRAPHIC USER INTERFACE}

Before proceeding to the detailed description of the internal features of the MuLex TKB, the assumptions on which it is conceived are briefly summarised below.

\section{Aim}

The aim of the MuLex TKB is to serve as a tool for the storage and managing of terminological (conceptual and linguistic) data on the legal subdomain of victims of crime in the EU multi-level jurisdiction.

\section{Intended users}

The intended users of MuLex are specialised translators, but the TKB can also be consulted by legal practitioners with an interest in linguistic/terminological issues.

\section{Approach}

The methodology for the retrieval of the terminological and conceptual data regarding the area of law under discussion have been illustrated in Chapter 3. However, it is important to recall here some fundamental assumptions concerning the approach adopted which influenced the design of the MuLex TKB.

The approach adopted for the retrieval and analysis of the conceptual material stored in MuLex is a middle-out approach, since it combines the bottom-up (from textual corpora to conceptual data) and top-down (from conceptual analysis to terms) approach (see also Faber et al. 2001: 182; Temmerman \& Kerremans 2003: 4). However, once the collection of the relevant terms in the selected languages is established, the concepts these terms refer to are classified using a two-tiered system. On the one hand, concepts are assigned to one category (i.e. concept fields, see Section 6.4.1.1.1) as conceived within the theoretical framework of Frame Semantics and applied for instance in Faber et al. (2007) and Faber et al. (2005). On the other hand, once the concepts are assigned to a concept field, the relations with the other concepts included in the MuLex terminological knowledge base are established and a conceptual relational structure is created. Every concept is therefore presented in a relational structure which may change according to the legal system involved (see Section 6.4.1.1.2). 
As concerns the design of MuLex, it should be borne in mind that, ever since 1997, the University of Trieste has been developing and populating the terminological database TERMit (Magris 2001), from which inspiration has been drawn for the building of MuLex. The need for the creation of a TKB specifically designed for the storage and the managing of conceptual and linguistic data concerning legal terminology has actually arisen from the results of an earlier research study in the field of legal terminology (Peruzzo 2006/2007). What emerged from the previous study was that the structure of the terminographic entries in the terminological database TERMit did not prove perfectly adequate for storing conceptual and terminological data embedded in a multi-jurisdictional setting, since it did not allow for distinguishing in a clear and user-friendly fashion the national from the supranational conceptual level on the one hand and terms which are used in national contexts from terms employed in EU contexts on the other hand. The impossibility of classifying terms and concepts according to the legal system and the geographic area they belong to in an intuitive manner led to the formulation of long descriptions of the differences in the usage of terms and the possible conceptual discrepancies among legal systems. This, in turn, resulted in very long terminographic entries, the consultation of which could be rather time consuming. Due to the problems faced in the previous research project as regards the recording of data which presented terminological and conceptual variation and given that cases of partial correspondence and equivalence were expected to emerge also in this project, the idea was to develop a new TKB where all the features of TERMit which fitted the data to be recorded in the TKB would be kept and new features would be added so as to adapt the TKB to the peculiarities of multilingual legal terminology in a multi-level jurisdiction. Consequently, some of the features described in the following sections were already present in TERMit, while others are new.

As regards the structure of the MuLex terminographic entries, the first feature to distinguish MuLex from TERMit is the fact that individual entries are concept-based but the data are presented separately according to the language. Although both repositories are conceptoriented, in the sense that every single entry is designed for containing the terms and the relevant data referring to a single concept, in TERMit an entry contains terminological information for all the languages taken into account. For instance, if languages $L_{1}$ and $L_{2}$ are examined, the terminographic entry concerning concept $\mathrm{C}$ contains at least one term for each language, a definition and a context for both languages $\mathrm{L}_{1}$ and $\mathrm{L}_{2}$. Given the large amount of information to be provided in a TKB devoted to multilingual legal terminology, in the design of MuLex a choice has been made to simplify the entries by splitting bilingual entries into two 
Victims of Crime from a Terminographic Perspective. MuLex: a Legal Translation-oriented Terminological Knowledge Base

separate, language-based entries. Therefore, the relation among two conceptually equivalent language-based term clusters is established by means of a hyperlink (for further details on the equivalence relation, see Section 6.4.1.1.5).

In the sections below a detailed description of the fields constituting MuLex terminographic entries and the graphic user interface (GUI) of the TKB is provided. In order to describe the entries, the fields that are visualised in the GUI are presented according to the data they are intended to store, i.e. conceptual information (see Section 6.4.1.1) and linguistic information (see Section 6.4.1.2). While for some fields the fact of belonging to one or the other category is obvious, such as the "Concept field" in which only conceptual information is stored, there are also fields in which conceptual and linguistic information are inextricably intertwined, such as the "Notes on terminological variation" field (see Section 6.4.1.1.6). Therefore, the classification as conceptual rather than linguistic information may be considered arbitrary.

\subsubsection{CONCEPTUAL INFORMATION}

In MuLex, conceptual information is mainly provided in the following fields: Subject, Subfield, Concept field, Legal system, Definition, Equivalence, Term variants and Notes on terminological variation. In these fields, the conceptual information is made explicit in a linguistic form, i.e. via an explanation. However, conceptual information on the relations existing among the concept the searched term refers to and the other concepts stored in MuLex is also available in the graphic visualisation boxes containing conceptual relational structures (see Section 6.4.1.1.2). 


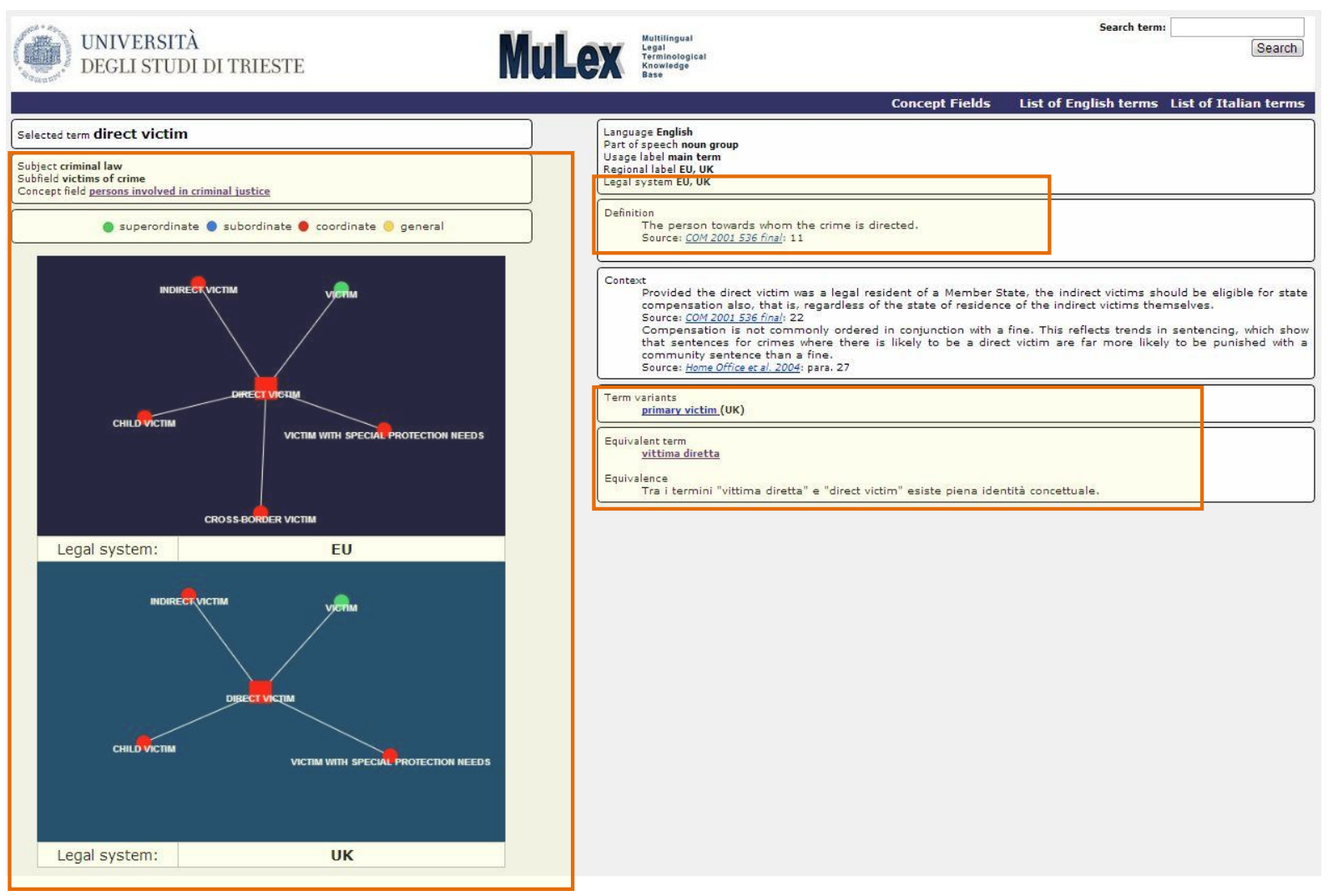

Figure 6.1. Fields containing conceptual information in the MuLex graphic user interface (highlighted in yellow).

The first two fields mentioned above, i.e. "Subject" and "Subfield", are the same as conceived in the original TERMit database (Magris 2002: 50). Their aim is to delimit the boundaries of the domain the term treated in the entry belongs to. Since this research study is mainly focused on the area of law of victims of crime, it seems quite obvious that all the terminographic entries relevant to this project bear the same Subject and Subfield, i.e. "criminal law/diritto penale" and "victims of crime/vittime di reato". Owing to the fact that the other fields containing conceptual information need further consideration as compared to these two fields, they are discussed in greater detail in the following sections.

\subsection{CONCEPT FIELDS}

Following Faber et al., "[t]he specification of the conceptual structure of specialized domains is a crucial aspect of terminology management" (Faber et al. 2006: 191). These conceptual structures can be considered abstractions which should, at least partially, reflect the complexity and the dynamic nature of the real-life events or processes of which the concepts constituting the event or the process are part. However, being only an abstract representation of what can be observed in reality, the events or processes these conceptual structures 
represent are to be conceived as prototypical (see Faber et al. 2006: 191-192). It follows that the concepts included in a TKB should be arranged in prototypical conceptual structures in the form of event templates, intended as "larger chunks of knowledge" (Geeraerts 2010: $222)^{131}$. In this regard, however, it should not be overlooked that "each knowledge area can be said to have its own event template" (Faber et al. 2006: 192).

In order to represent the victim-related concepts identified in the terminological analysis phase (Steps 3 and 5 in Chapter 3) in a conceptual structure that is adequate to the legal subdomain established by using the "Subject" and "Subfield" fields, an approach based on Frame Semantics has been adopted. According to Frame Semantics,

in order to truly understand the meanings of words in a language, one must first have knowledge of the semantic frames or conceptual structures that underlie their usage. Frames are a type of cognitive structuring device based on experience that provide the background knowledge and motivation for the existence of words in a language as well as the way those words are used in discourse. (Faber et al. 2006: 192)

Therefore, once the boundaries of the area of law are established, the concepts need to be organised according to a frame which represents prototypical, though flexible events in the victim-related domain. This frame consists in a metalanguage containing predefined relations between concepts (see Faber et al. 2001: 182). Given that the present study focuses on the terminological and conceptual differences among national and supranational legal systems, it would be legitimate to expect that different frames are developed in each legal system. However, as highlighted by Sagri and Tiscornia:

La parola esprime la nozione, ma diversamente da altri contesti tecnici, nel dominio giuridico certi concetti, creati, elaborati e definiti dal legislatore o dal giurista di un certo sistema giuridico, non necessariamente corrispondono a concetti elaborati per un differente sistema (Sacco 2000: 126). Le lingue di differenti paesi esprimono concetti che sovente non si equivalgono. La nozione giuridica, pur essendo all'origine di un numero indefinito di realizzazioni che maturano nelle diverse esperienze culturali e giuridiche, è incentrata su elementi considerati come invariabili da un sistema giuridico all'altro. Ad esempio la nozione di contratto è incentrata sull'accordo, la convenzione, il consenso, il patto, a prescindere dalla sua realizzazione linguistica. Secondo alcuni linguisti (Vanderlinden 1995: 23), dato che difficilmente una parola di una lingua corrisponde interamente ad un'altra parola di un'altra, una metodologia utilizzabile nella traduzione è

\footnotetext{
131 These chunks of knowledge are also referred to as "Idealized Cognitive Models" (Lakoff 1987) or "frames" (Fillmore 1976, 1985). For an in-depth examination of the differences between Lakoff's Idealized Cognitive Models and Fillmore's frames, see Geeraerts (2010: 222-225).
} 
rappresentata dal riuscire a decomporre le nozioni giuridiche, far figurare tra i componenti tutti gli elementi che non corrispondono ad uno o l'altro dei termini che si cerca di comparare, per poi individuare le caratteristiche comuni di entrambi al fine di estrapolare il concetto generale. (Sagri \& Tiscornia 2009: 6)

Although Sagri and Tiscornia's considerations regard the (im)possibility of translating legal terms, the acknowledgement of the fact that a legal notion ("nozione giuridica") can be decomposed into elements which can be considered invariable in all legal systems can be applied to the discussion on the creation of identical frames for different legal systems.

Therefore, as regards the area of law under discussion, the prototypical situation in which victims of crime are involved can be represented in a conceptual template (

Figure 6.2), where the main categories and interrelations are outlined.

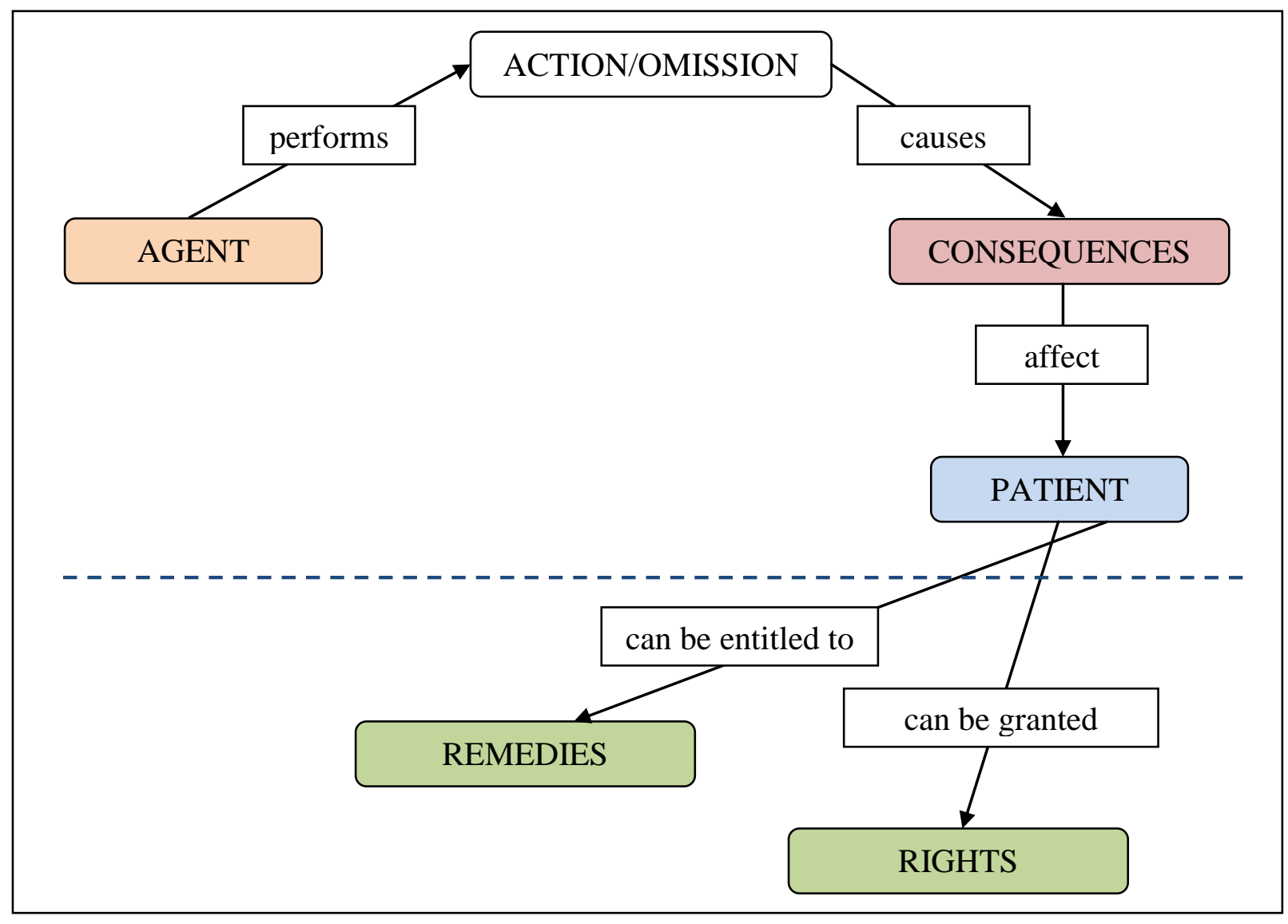

Figure 6.2. Conceptual template for the legal area of victims of crime.

The conceptual template in 
Figure 6.2 comprises six main categories (represented as nodes) that have been identified in the preliminary frame-based conceptual structuring of the area of knowledge described in Section 3.3.1.3. These categories are linked by means of conceptual relations (represented as arrows) and, together with conceptual relations, are considered fundamental for the understanding of the prototypical situation in the area of law of victims of crime, though such prototypical situation is highly simplified in the template.

In order for a prototypical situation to involve a victim of crime, the presence of certain categories is essential (upper part of the figure), while other categories can be considered accessory (lower part of the figure). In order for this prototypical situation to be considered acceptable, however, it has to be observed through the lens of criminal law, i.e. considering that it occurs within a jurisdiction where criminal conduct is both defined and punished. That said, the essential categories represented in

Figure 6.2 are "agent", "action/omission", “consequences" and "patient". The "agent" in the prototypical situation coincides with the offender who, by performing an "action" or "omission" which is considered criminal conduct according to the relevant legal system, produces "consequences", i.e. harm, suffering, damage to property, for the "patient", i.e. the victim. Once the "patient" is affected by the "consequences" of an "action" or "omission", depending on a series of circumstances, such as the legal system, the type of consequences, the degree of involvement in the offence, which are not relevant here for the understanding of the conceptual template, he or she can be granted certain "rights" (e.g. the right to compensation) and can be entitled to "remedies" (e.g. compensation).

On the basis of the conceptual template, the categories that were considered interesting from a terminological perspective were selected, i.e. "consequences", "patient", "rights" and "remedies". In the term extraction process described in Section 3.3.3.1, only those terms which could be ascribed to one of these categories were chosen. The reason for considering four categories instead of the six categories shown in

Figure 6.2 lies in the relevance given to the "patient" rather than to the "agent" or the "action" or "omission" that leads a person to become a "patient". The main focus of this research project is the figure of the victim of crime, therefore preference has been given to the consequences of the commission of a crime for the victim and the aftermath of a crime where the criminal justice system (or alternative forms for solving the victim-offender conflict, such 
as mediation) is involved. In so doing, the offender and the criminal conduct, together with the possible categorisation of crimes, have been ignored in this study.

In regard to the usage of the conceptual template in the term extraction phase, however, a remark needs to be made. Though in the conceptual template the "patient" category seems to include only one figure, i.e. the victim of a crime, in reality this figure is multifaceted and can assume different roles. Hence, the victim of crime can be considered either one of the possible figures that fall into this category or the figure encompassing all the possible facets. To put it differently, when a crime is committed, a person can be directly affected by the crime, therefore he or she will be considered the direct victim of the crime. However, the direct victim can be classified differently according to different criteria, such as age (e.g. child victim), or protection needs (e.g. victims of trafficking of human beings). The victim can also assume a different role in criminal proceedings, such as a victim acting as a witness or as a civil party in Civil Law jurisdictions. Moreover, other people can be involved in the commission of a crime without being directly affected by it, as in the case of samaritans and bystanders. Therefore, the "patient" category should be intended as broad enough to include all these figures.

The conceptual template has also been used to classify the extracted terms in MuLex. In order to do so, the "Concept field" field has been used. The categories included in this field slightly differ from the categories shown in

Figure 6.2. First of all, with regard to the "patient" category, due to the variety of figures that can be included in it, the label used to indicate that a term can be attributed to it is "persons involved in criminal justice/soggetti della giustizia penale", since those figures are considered from a criminal law perspective. In the same vein, in MuLex also the "consequences" category has been made more explicit by using the label "harm and damage suffered by victims of crime/pregiudizi subiti dalle vittime di reato". On the other hand, as for the last two categories considered, namely "rights" and "remedies", a single label has been used, i.e. "rights of victims of crime/diritti delle vittime di reato". The reason for merging the two categories into a single "Concept field" lies in the fact that the remedy a "patient" is entitled to generally derives from a right the patient has to obtain that remedy, therefore remedies and the relevant rights are seen as the two faces of the same coin. In the same category also other terms referring to concepts that are neither remedies nor rights have been included on the basis of their relevance for the latter, such as victim support organisation or application for 
Victims of Crime from a Terminographic Perspective. MuLex: a Legal Translation-oriented Terminological Knowledge Base

compensation, which refer to concepts that make the exercise of a right, and therefore the achievement of a remedy possible in the framework of criminal justice.

\subsection{CONCEPTUAL RELATIONAL STRUCTURES}

In recent years, Terminology has experienced a shift towards knowledge engineering (ontologies) and a need has emerged to include knowledge representation tools in terminology management systems. As noted by Picht and Draskau, what they call the "system of concepts" is considered

an instrument by which the following ends may be achieved:

1. The reconnaissance of the structure of the inventory of concepts of a special subject field as a preliminary to a systematic elaboration.

2. The recognition of the exhaustiveness of an inventory of concepts.

3. The comprehension of the relationship between concepts which may be important for the formation of terms.

4. The recognition of the degree of congruence between the systems of concepts of different languages; this in turn is indispensable for the recognition of equivalence.

5. The representation in a systematically organized dictionary, of the results of terminology work; the dictionary form may be available in hard-copy or on-line, in a termbank. (Picht \& Draskau 1985: 92)

It follows that the "system of concepts in terminology is not a goal in itself, nor an intellectual pastime" (Picht \& Draskau 1985: 92), but it constitutes an additional aid in several phases of a terminographic project. However, in this view, the elaboration of conceptual systems is seen useful from the terminographer's point of view, while the possible use of such systems by the users of terminological resources is neglected. Following Meyer et al., "terminological repositories have an important teaching function" (Meyer et al. 1992: 957) and, within terminological repositories, conceptual systems "have didactic value [...], for they allow a rapid review of the situation and a better understanding of the subject field, especially for the non-expert such as the student or the translator" (Picht \& Draskau 1985: 92). Therefore, once the didactic potential of concept systems within terminological resources is acknowledged, the representation of such conceptual systems needs to be taken into consideration, since "[i] is extremely useful for anyone acquiring subject-field knowledge to have access to a representation of the concept system" (Meyer et al. 1997: 104). Following Faber et al., such information should be included in termbases "in other formats to enhance textual comprehension" (Faber et al. 2006: 205).

As regards the choice of the most suitable way to represent a concept in a conceptual system intended as a "set of concepts structured according to the relations among them" (ISO 1087-1 
2000: Section 3.2.11), a consideration has been made with reference to the quantity of information to be displayed in an individual terminographic entry. Nowadays, the possibilities for knowledge representation are almost infinite, since knowledge representation resources $(\mathrm{KRRs})^{132}$ based on knowledge organisation systems (KOSs) ${ }^{133}$ are developed by different scientific and business communities for the widest possible range of applications. However, due to the type of conceptual information to be recorded in MuLex, which is embedded in the EU multi-level jurisdiction, when designing the legal translation-oriented terminological resource, the possibility to include a graphic representation of the concepts within a conceptual system for each legal system involved has been considered. In this regard, the TERMit termbase - of which MuLex represents a legal translation-oriented evolution - is not provided with any graphic knowledge representation system (Magris 2002: 52), and thus the presence of such a tool in MuLex constitutes a major development in the structure of the TKB.

In order to enrich terminographic entries with conceptual information about the existing relations among the terms recorded in MuLex, the needs of the end users of the TKB have been considered. While several knowledge representation resources allow for the visualisation of complex structures or whole conceptual systems or ontologies, the terminographic entries in MuLex are already rich in both conceptual and linguistic information organised in different fields. Therefore, the conceptual information provided in a graphic form integrates the conceptual information already existing within the terminographic entry while, at the same time, avoiding an information overload.

The choice has thus been to link a conceptual relational structure to each term included in MuLex. Unlike conceptual systems or conceptual maps capturing the entire structure of the domain, on the left-hand side of the MuLex GUI a structure is provided which represents the concept the searched term refers to as the central node and the conceptual relations that link this concept to other concepts recorded in MuLex. Therefore, the conceptual relational structure is not a network where all the concepts are interrelated and all the possible relations are represented, but it rather contains only first-level relations among the concept-node and other concepts. The types of relations that can be recorded and visualised in MuLex are discussed in Section 6.4.1.1.2.1. Since the terminology included in the TKB is embedded in a multi-level jurisdiction, when the concept belongs to both the supranational and the national legal system, two conceptual relational structures are visualised. These relational structures can differ according to the conceptual relations that have been identified in the conceptual

\footnotetext{
${ }^{132}$ For a classification of KRRs see Wright (2007: 159).

${ }^{133}$ For an overview on KOSs see Hodge (2000: Chapter 1). 
Victims of Crime from a Terminographic Perspective. MuLex: a Legal Translation-oriented Terminological Knowledge Base analysis phases described in Sections 3.3.3 and 3.3.5. It is precisely in the light of these differences that the didactic value of the graphic representation of conceptual information integrated into a TKB is best understood. An example of differing conceptual relational structures is presented in Figure 6.3.

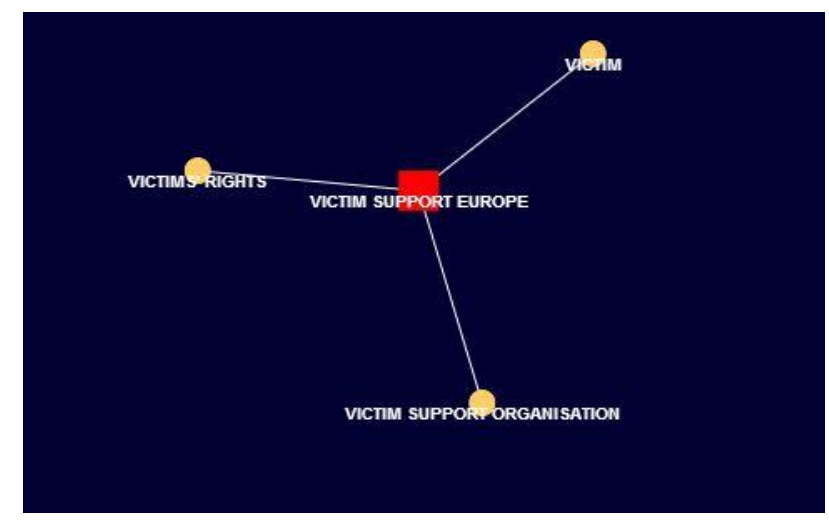

Legal system: EU

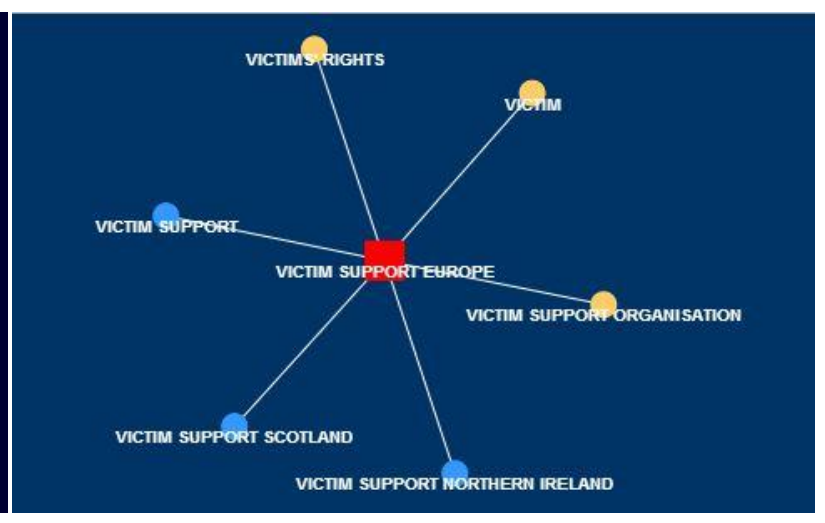

Legal system: UK

Figure 6.3. Differences in conceptual relational structures related to the same concept. Searched term: Victim Support Europe.

Conversely, when the concept belongs to one legal system only, a single conceptual relational structure is visualised. The absence of a conceptual structure for one of the legal systems involved in the study is thus a symptom of a conceptual vacuum, and such absence is in itself another important source of conceptual information for the end user of MuLex. An example is represented by the concept VICTIM SUPPORT which is provided in Figure 6.4.

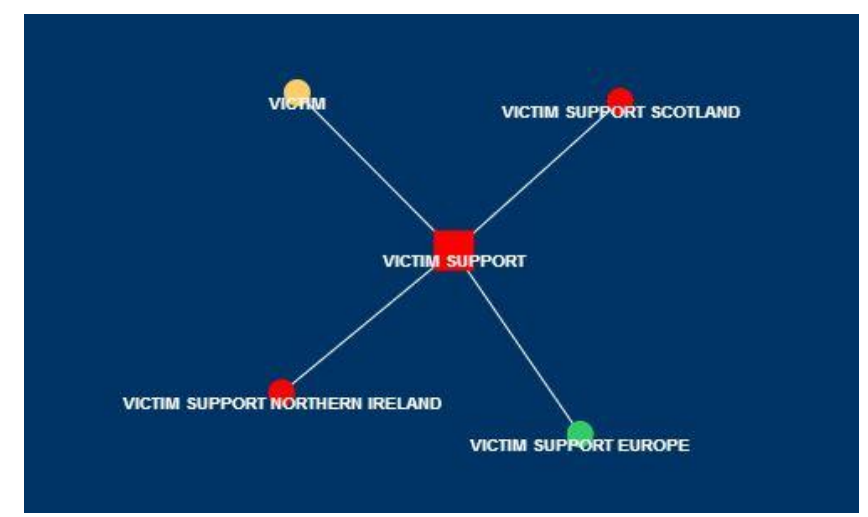

Legal system: UK

Figure 6.4. Presence of a conceptual relational structure related to a single legal system. Searched term: Victim Support.

In regard to the conceptual relational structures included in MuLex, however, two remarks must be made. The first concerns the synchronic nature of the visualisation: the structures 
included in the visualisation boxes are actually adequate for providing synchronic conceptual information, but are not suited for representing the diachronic evolution of concepts. Therefore, in order to understand cases where a legal concept undergoes conceptual revision in time, such as the VICTIM WITH SPECIAL PROTECTION NEEDS example discussed in Section 3.3.7, the conceptual relational structures are of no help and resort needs to be made to the explanations provided in other fields. The second remark regards the risk of subjectivity in the representation of conceptual relational structures. In this regard, Quiroz et al. state that "[t]he specialist in the subject-field, as any human being, can be dominated by subjectivity" (Quiroz et al. 1999: 173). Though being established on the basis of the textual material analysed and being revised and validated by a field expert, the conceptual relational structures can anyway be considered as a single "snapshot" of a larger conceptual system as conceptualised by the observer and partially biased by the scope of the terminographic project and the technical constraints of the knowledge representation resource used.

\subsection{CONCEPTUAL RELATIONS}

The typology of conceptual relations used to create conceptual relational structures in MuLex resembles the typology employed in TERMit (Magris 2002: 52), though one of the relations envisaged in the latter - antonymy - has not been used in MuLex. The reason for this lies in the fact that no instance of antonymy has been identified in the textual material analysed. Taking the central node, i.e. the concept the searched term refers to, as a starting point, the conceptual relations under discussion are identified by a label that is assigned to the concept the central node is related to. These labels are "superordinate", "coordinate", "subordinate", and "general. In order to distinguish the types of relations in the conceptual relational structures, a colour has been attributed to each label (Figure 6.5).

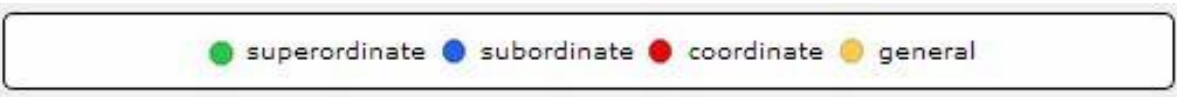

Figure 6.5. Colours associated to conceptual relations in MuLex.

The first three types of relation are used to identify hierarchical relations among terms, while "general" is an umbrella label which encompasses all non-hierarchical relations. The reason for using such a generic label is in line with the aim pursued by the TKB and its intended end users: a further classification of non-hierarchical conceptual relations would add complexity to the conceptual relational structure without necessarily providing more information. The "general" label is thus applied to all those cases where a conceptual relation is identified and 
such relation can determine the co-occurrence of the terms referring to correlated concepts in texts. In Figure 6.6, the usage of relations in the elaboration of the conceptual relational framework concerning the CHILD VICTIM concept is illustrated. The concept referred to by the searched term corresponds to the central node (red square), while the correlated concepts are represented by coloured circles. In the example provided, CHILD VICTIM is a type of VICTIM WITH SPECIAL PROTECTION NEEDS, therefore the latter concept is considered a superordinate of the selected concept. The concept CHILD VICTIM has three correlated concepts, since a child victim can be either a direct victim or an indirect victim and can also be victimised in a country where he or she is not habitually resident, therefore being a cross-border victim. Finally, CHILD-FRIENDLY JUSTICE holds a general type of relation with CHILD VICTIM, since there is a clear conceptual correlation between the two terms, but it cannot be classified as a hierarchical relation.

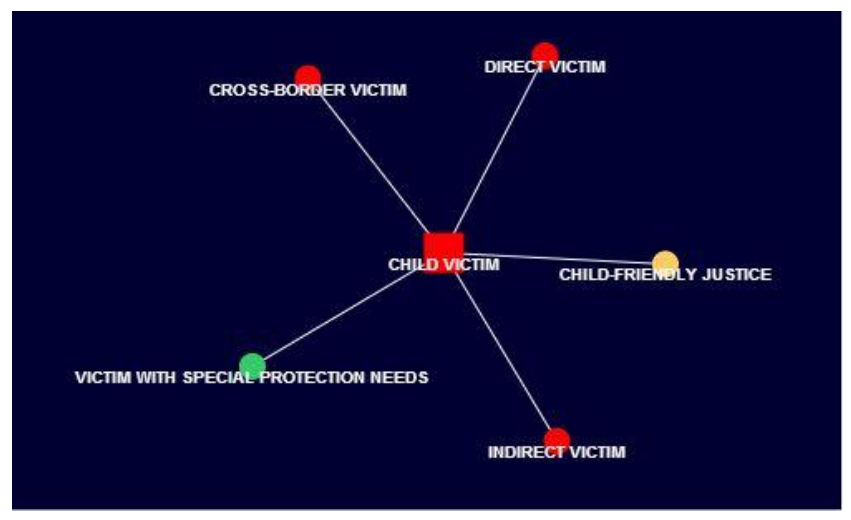

Legal system: EU

Figure 6.6. Different conceptual relations in a conceptual relational structure. Searched term: child victim.

\subsection{LEGAL SYSTEM}

Another field in MuLex terminographic entries intended for containing conceptual information is the "Legal system" field which constitutes another novelty as compared to TERMit. The pre-defined labels that can be used to fill this field are "EU", "Italy" and "UK", respectively indicating which legal system the concept corresponding to the central node in the conceptual relational structures belongs to. As can be seen in Figure 6.7, the "Legal system" field appears in two different positions within the terminographic entry: under the relevant conceptual relational structure, to identify the legal system the structure is intended to represent, and in the upper right-hand side of the terminographic entry. The reason for 
repeating the same information twice in an individual entry lies in the fundamental role played by the legal system in the area of law analysed. Since the type of information recorded is highly dependent of the multi-level nature of the jurisdiction within the EU boundaries, it is essential for this type of information to be provided clearly in the TKB.

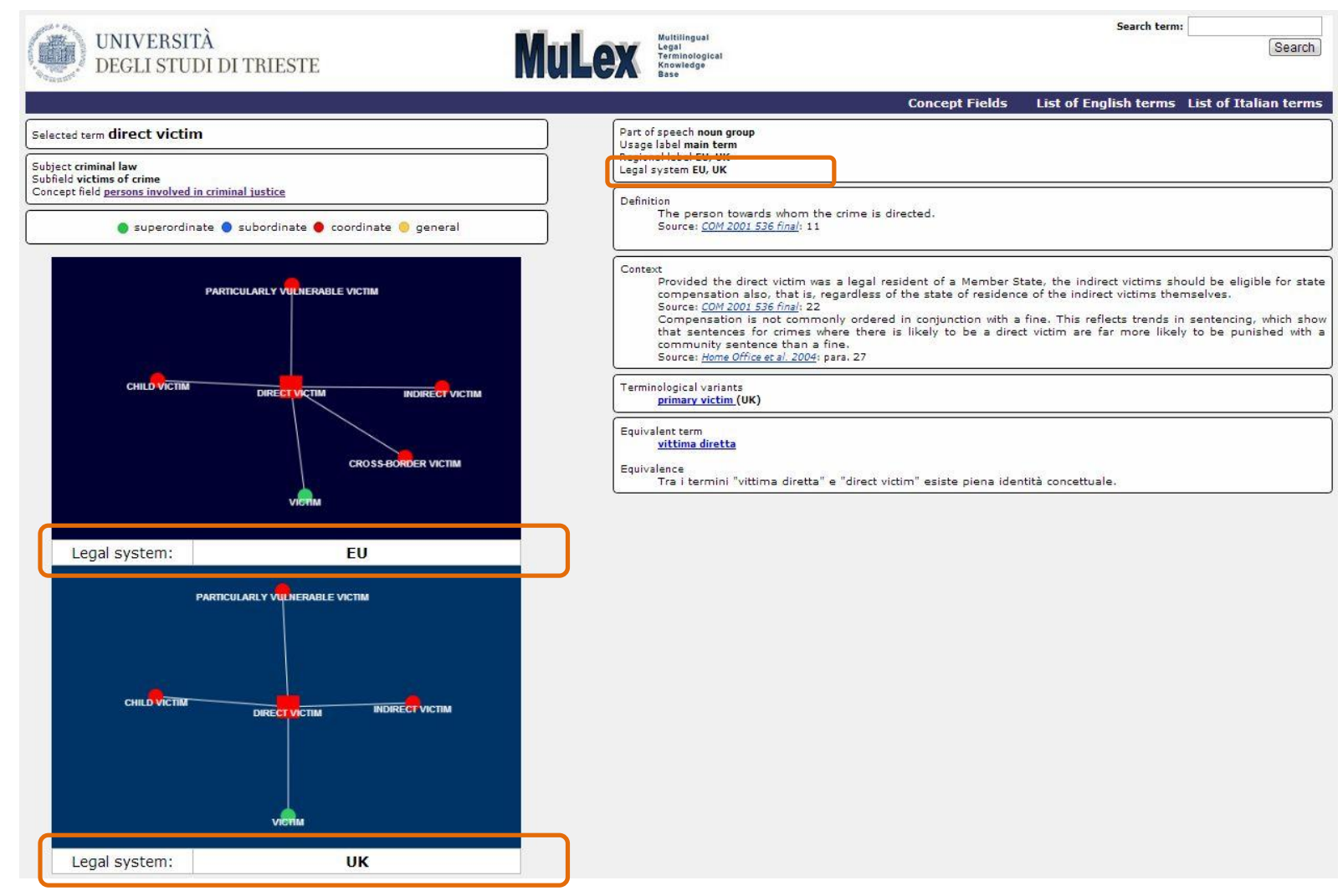

Figure 6.7. "Legal system” field in the MuLex graphic user interface.

\subsection{DEFINITION}

Apart from conceptual relational structures and the indication of the legal system a concept belongs to, another fundamental source of conceptual information in MuLex is provided by the "Definition" field. According to Béjoint (1997: 19-20, quoted in Faber et al. 2007: 41), definitions have never been given due consideration in terminology, with the result that, "[i]n many terminological databases, definitions are simply inserted in a cut-and-paste fashion from other dictionaries, term bases, or knowledge resources, without taking into consideration both their internal and external coherence" (Faber et al. 2007: 41).

In MuLex, definitions, i.e. the linguistic description of concepts which "seek to make statements about an extra-linguistic entity by use of linguistic means (words, terms, signs)" (Picht \& Draskau 1985: 49), are seen as fundamental since they can be used with two aims: on the one hand, for acquiring knowledge about a concept within the legal system it belongs to, and on the other, for identifying possible similarities and discrepancies when comparing 
the definitions of concepts referring to a common genotype but belonging to different legal systems. The embeddedness of the legal concepts treated in this study in different legal systems has lead to the inclusion of multiple definitions in individual MuLex terminographic entries. Given the methodological principles on which this study is based, according to which the EU legal system is taken as the starting point of the terminological analysis, in case two definitions need to be recorded in a MuLex terminographic entry so as to make the differences among legal systems clear, the definition of the EU phenotype always precedes the definition of the national phenotype. An example is provided by the term criminal injury, which is accompanied by two definitions (see below).

With the aim of populating the "Definition" field, both the EU corpus and the collections of national texts have been thoroughly scanned so as to identify already existing definitions for the selected terms. However, it can be said that "high-quality definitions are the exception rather than the rule in most of the corpora" (Meyer 2001: 284). In order to find definitions in the textual material, the concordancer AntConc (see Section 3.3.3.1.1) has mainly been used in combination with a series of keywords that generally indicate the presence of definitions which have been identified by observing the available material. For instance, in some of the legally-binding texts in the EU corpus, a whole article is devoted to definitions and bears the title "Definitions" as well ${ }^{134}$. As for the retrieval of definitions, however, a distinction needs to be made between the types of textual material used in this research study and its origin: the legally-binding texts included in the EU corpus can be said to be more constrained concerning the format and the information to be provided than national texts. It follows that this type of texts generally include a section with definitions and such definitions are introduced by standardised formulae, such as in Article 2 of Directive 2012/29/EU (emphasis added):

1. For the purposes of this Directive the following definitions shall apply:

(a) 'victim' means:

(i) a natural person who has suffered harm, including physical, mental or emotional harm or economic loss which was directly caused by a criminal offence;

(ii) family members of a person whose death was directly caused by a criminal offence and who have suffered harm as a result of that person's death;

(b) 'family members' means the spouse, the person who is living with the victim in a committed intimate relationship, in a joint household and on a stable and continuous basis, the relatives in direct line, the siblings and the dependants of the victim;

(c) 'child' means any person below 18 years of age;

(d) 'restorative justice' means any process whereby the victim and the offender are enabled, if they freely consent, to participate actively in the resolution of matters arising from the criminal offence through the help of an impartial third party.

${ }^{134}$ See, for instance, Article 1 in Council Framework Decision 2001/220/JHA and Article 2 in Directive 2012/29/EU. 
In regard to national legislation, however, Scarpelli notes that

mentre nei paesi anglosassoni è pacifico che, nel dar forma agli statutes, si possa dare definizioni dei termini impiegati, nei paesi di diritto codificato prevale tra gli studiosi l'idea che stabilir definizioni non sia compito del legislatore e, ove al contrario con la legge delle definizioni vengano stabilite, esse non partecipino al valore vincolante delle norme. (Scarpelli 1994: 319)

Therefore, a similar solution to the one adopted in EU legally binding texts is resorted to in British statutes. An example is provided by Section 1(4) of the Criminal Injuries Compensation Act 1995 (c. 53) (emphasis added), where it is stated that

In this Act

"adjudicator" means a person appointed by the Secretary of State under section 5(1)(b); "award" means an award of compensation made in accordance with the provisions of the Scheme;

"claims officer" means a person appointed by the Secretary of State under section 3(4)(b);

"compensation" means compensation payable under an award;

"criminal injury", "loss of earnings" and "special expenses" have such meaning as may be specified;

"the Scheme" means the Criminal Injuries Compensation Scheme;

"Scheme manager" means a person appointed by the Secretary of State to have overall responsibility for managing the provisions of the Scheme (other than those to which section 5(2) applies); and

"specified" means specified by the Scheme.

By comparing the two examples provided above, a common trait can be noted: the definitions provided are to be considered as relevant only for the document they refer to (e.g. "For the purposes of this Directive" and "In this Act"). In this way, the existence of a definition of a term in a legally-binding texts does not prevent the same term from being interpreted differently if used in another text, confirming the idea expressed by several authors that "legal concepts are subject to a certain degree of vagueness and, hence, legal definitions are open definitions" (Sandrini 1999: 105).

Moreover, an aspect that is featured in the second example provided and is very frequent in definitions found in normative texts is the presence of cross references (e.g. "appointed by the Secretary of State under section 5(1)(b)"). This type of information in definitions allows for the avoidance of repeating large chunks of texts which can be found elsewhere in the same documents or in other acts, while at the same time hindering the acquisition of knowledge by means of definitions if the content of the cross-reference is unknown and making the 
Victims of Crime from a Terminographic Perspective. MuLex: a Legal Translation-oriented Terminological Knowledge Base

definition unsuitable for recording in a TKB. It follows that reformulation is needed by taking into account the information available in the cross-reference.

As noted by Scarpelli (1994: 319), definition sections or articles are absent from the Civil Law normative texts, as can be confirmed also as regards the Italian texts taken into consideration in this thesis. This does not mean that conceptual information on which to base the elaboration of a definition is absent from these texts, but rather that such information needs to be inferred from the texts. For instance, the definition for the term parte civile available in MuLex has been derived from Article 74 of the Codice di Procedura Penale ${ }^{135}$, which contains neither the term itself nor a definition intended in the classical (Aristotelian) sense, i.e. a definition specifying the superordinate (genus) and the distinguishing features (differentia).

Therefore, a different approach towards definitions can be observed in normative texts embedded in different legal systems, with EU and British texts more prone to including a definition section and Italian texts generally avoiding formal definitions. This, however, needs to be considered as a general tendency rather than a rule, since also in EU and British normative texts not all the relevant terms are provided with a definition. Taking the EU legal system as an example, the term assisting authority, introduced by Directive 2004/80/EC, is not formally defined, though all the relevant information for understanding what the activities and the responsibilities of this authority are and formulating a definition suitable for a TKB is scattered in the text of the Directive itself.

Apart from normative texts, definitions have also been extracted or derived from non-legally binding texts. In this case, no general trends have been observed in the texts embedded in a certain legal system, although greater resort to academic texts has been made as far as Italian is concerned due to the lack of definitions in Italian national normative texts.

In regard to the definitions included in MuLex, another consideration on the type of definitions can be made. In traditional terminology theories, the definition par excellence is the classical, formal definition in which a concept is explained by means of a superordinate concept and the features that allow for a differentiation from other concepts. This type of definition is generally referred to also as "intensional definition" (see, for instance, Picht \& Draskau 1985: 52). In MuLex, an example of intensional definition is represented by the

\footnotetext{
${ }^{135}$ Article 74 of the Codice di Procedura Penale reads as follows: "L'azione civile per le restituzioni e per il risarcimento del danno di cui all'articolo 185 del codice penale può essere esercitata nel processo penale dal soggetto al quale il reato ha recato danno ovvero dai suoi successori universali, nei confronti dell'imputato e del responsabile civile."
} 
definition of the term risarcimento da parte dello Stato ${ }^{136}$, where the superordinate concept "risarcimento" is followed by the specification of the peculiarities of this type of compensation.

However, in the terminological analysis carried out in this research project other types of definitions are more frequent than intensional definitions. For instance, the definition for the term qualifying claimant $^{137}$ is an example of an extensional definition (see, for instance, Picht \& Draskau 1985: 52). In this type of definition, all the possible situations where a person can be classified as a qualifying claimant are listed. The above-mentioned EU definition of the term victim can also be considered an example of extensional definition. However, most definitions recorded in MuLex combine elements of intensional and extensional definitions, though they can include encyclopaedic information as well. By way of example, the definition of the term risarcimento del danno non patrimoniale ${ }^{138}$ can be considered neither an intensional nor an extensional definition because, on the one hand, it cannot provide the extension of the concept due to the type of concept involved, and on the other hand, the information in it is not limited to the genus plus differentia scheme (compensation + type of damage), since it includes also the function of the compensation and the way such compensation can be provided (restoration or replacement).

Finally, for several terms, no existing definition or textual material to be reformulated into a definition has been found. In such cases, a definition has been formulated ex novo and has been subject to thorough revision and validation by the field expert. Resort to the formulation of definitions from scratch has been made in two different situations, which depend on the presence or absence of a certain term and the corresponding concept in a given legal system. In the first situation, a term and the underlying concept were found and could be linked to a

\footnotetext{
136 The definition of the term risarcimento da parte dello Stato included in MuLex reads as follows: "Risarcimento erogato a favore delle vittime di reato attraverso fondi pubblici".

${ }^{137}$ The definition of the term qualifying claimant included in MuLex reads as follows: "In cases of fatal injury, the person entitled to apply for compensation who, when the victim died, was in one of the following groups:

- The victim's wife, husband or partner registered under the Civil Partnership Act 2004. The couple must have either been living together immediately before the victim died, or, if they were not living together, this must have been because of infirmity or ill health.

- The victim's former wife, husband or partner registered under the Civil Partnership Act 2004, but only if the victim was supporting them financially immediately before the date the victim died.

- The unmarried partner of the victim, if they were living together as husband and wife or as partners of the same sex (although not registered under the Civil Partnership Act 2004), immediately before the victim died and for at least two years before that.

- The natural parents of the victim, or the person or people the victim treated as their own parents.

- The children of the victim, or the people who the victim accepted as their children or who were dependent on the victim.

${ }^{138}$ The definition of the term risarcimento del danno non patrimoniale included in MuLex reads as follows: "Risarcimento spettante al soggetto leso da un danno non patrimoniale con funzione sanzionatoria, deterrente e compensativa, ossia di ripristino - almeno in una prima approssimazione - della situazione preesistente all'illecito, sia in forma specifica, ove possibile, sia per equivalente".
} 
legal system, but neither a definition nor textual material to be reformulated into a definition were found in the texts analysed. This is the case, for instance, of the Italian term danno derivante da reato, which can be considered a self-explanatory term, since it contains the genus and the differentia in the lexicalised terminological unit and is sufficiently clear so as not to deserve a definition ${ }^{139}$. The second situation, on the contrary, occurs when a conceptual vacuum accompanied by a terminological vacuum was identified in one of the legal systems taken into consideration and, consequently, a proposal for an equivalent term was suggested. This situation can be better clarified by means of an example, i.e. the term qualifying claimant referring to a concept belonging to the UK legal system. Given that the referent in this case is outside the Italian national legal system and the EU legal system, it comes as no surprise that the absence of an equivalent term corresponds to the conceptual vacuum and, consequently, a definition in Italian was not found neither in the textual material analysed nor in the specialised terminological resources consulted. Therefore, first of all a proposal for an equivalent term was suggested (soggetto avente $i$ requisiti necessari per richiedere il risarcimento statale), and afterwards a definition in Italian was formulated on the basis of the information available in English.

\subsection{EQUIVALENCE}

Another field in MuLex terminographic entries containing mainly conceptual information is the "Equivalence" field. Following the reasoning on the multidirectionality of terminographic entries in TERMit presented by Magris (2002: 53-54), and given the complexity posed as regards equivalence by the multi-level jurisdiction taken into consideration in this study, also in MuLex the degree of interlingual equivalence is expressed in a verbal form instead of by means of symbols.

Though the types of terminological equivalence as regards the terms analysed in this research project have already been discussed in Chapter 5, two further remarks need to be made on the "Equivalence" field. First of all, this field is only present in the record referring to the main term, while for terminological variants the field is replaced by a link to the main term, since the equivalence relation was established among the main terms identified in English and Italian. In case a translator in his or her translation process establishes that the main term is not the most appropriate equivalent for his or her text, then he or she can decide on the most suitable equivalent by consulting the "Terminological variants" field and the relevant notes on

\footnotetext{
${ }^{139}$ Given that MuLex is intended as a multilingual TKB for legal translators allowing them to acquire additional legal knowledge and compare the definitions in different languages so as to evaluate the possible differences in terms of equivalence, in MuLex every terminological entry is provided with a definition. Consequently, a definition was elaborated also for those terms which are considered self-explaining.
} 
terminological variation, where the information on the usage of the variants and possible conceptual differences among them are stored. Secondly, at the time of writing of this thesis, the explanation of the degrees of equivalence in the "Equivalence" field was expressed in Italian only, following the methodology used in TERMit, though in the future the possibility of explaining the degree of equivalence in the language of the main term is also envisaged.

\subsection{TERM VARIANTS AND NOTES ON TERMINOLOGICAL VARIATION}

To conclude the discussion on conceptual information recorded in MuLex terminographic entries, two further fields are mentioned here which, however, are to be considered borderline, since they can contain either conceptual or linguistic information or both. These two fields have been derived from the original structure of TERMit terminographic entries and its "Synonyms" field (Magris 2002: 52). In TERMit, the terminological data are presented in a sequential order. Conventionally, in a single concept-oriented terminographic entry the Italian main term with the relevant data and the "Equivalence" field is followed by the information concerning the synonyms and variants of the main term. Once the terminological data about the Italian main term and the possible synonyms and variants are presented, the same data are illustrated for the main term and the possible synonyms and variants for the other language(s) taken into account, except for the "Equivalence" field, which is repeated only once in each entry.

Given the graphic user interface used in MuLex, which is conceived as an Internet accessible TKB, the structure of TERMit entries did not suit the envisaged knowledge representation purpose, since it seemed likely to produce an information overload. Therefore, in the design of MuLex it has been preferred to keep the original concept- (in this case genotype-) oriented structure, in the sense that terms in one language are grouped in term clusters on the basis of their conceptual correspondence to a genotype and the main terms in the two languages are linked on the account of their conceptual equivalence established on the basis of a shared genotype. However, the terminological information is not provided all at the same time on the same webpage. Instead, every time a term is searched in MuLex, only the information relevant to that term is displayed, while other information can be reached by means of the hyperlinks provided. Therefore, as far as term variants are concerned, if the webpage of the relevant main term is displayed, in the "Term variants" field a list of variants is provided if the concept the main term refers to is a polydenominative notion. Conversely, if the webpage of a term variant is displayed, the link to the main term is provided. 
Victims of Crime from a Terminographic Perspective. MuLex: a Legal Translation-oriented Terminological Knowledge Base

The reason for substituting the "Synonyms" field in TERMit with the "Notes on terminological variation" field in MuLex derives from the observations on terminological variation discussed in Chapter 4. For the purposes of this study, the usage of the "Synonyms" field to indicate possible semantic and/or stylistic differences between the main term and its synonyms seemed reductive, since what are generally considered proper synonyms constitute only a minority of the term variants included in the terminological collection. Although TERMit admits the recording of variants as well as synonyms, on account of the observations on terminological variation in Chapter 4, in the design of the MuLex graphic user interface the labels "Term variants" and "Notes on terminological variation" have been used to name the relevant fields.

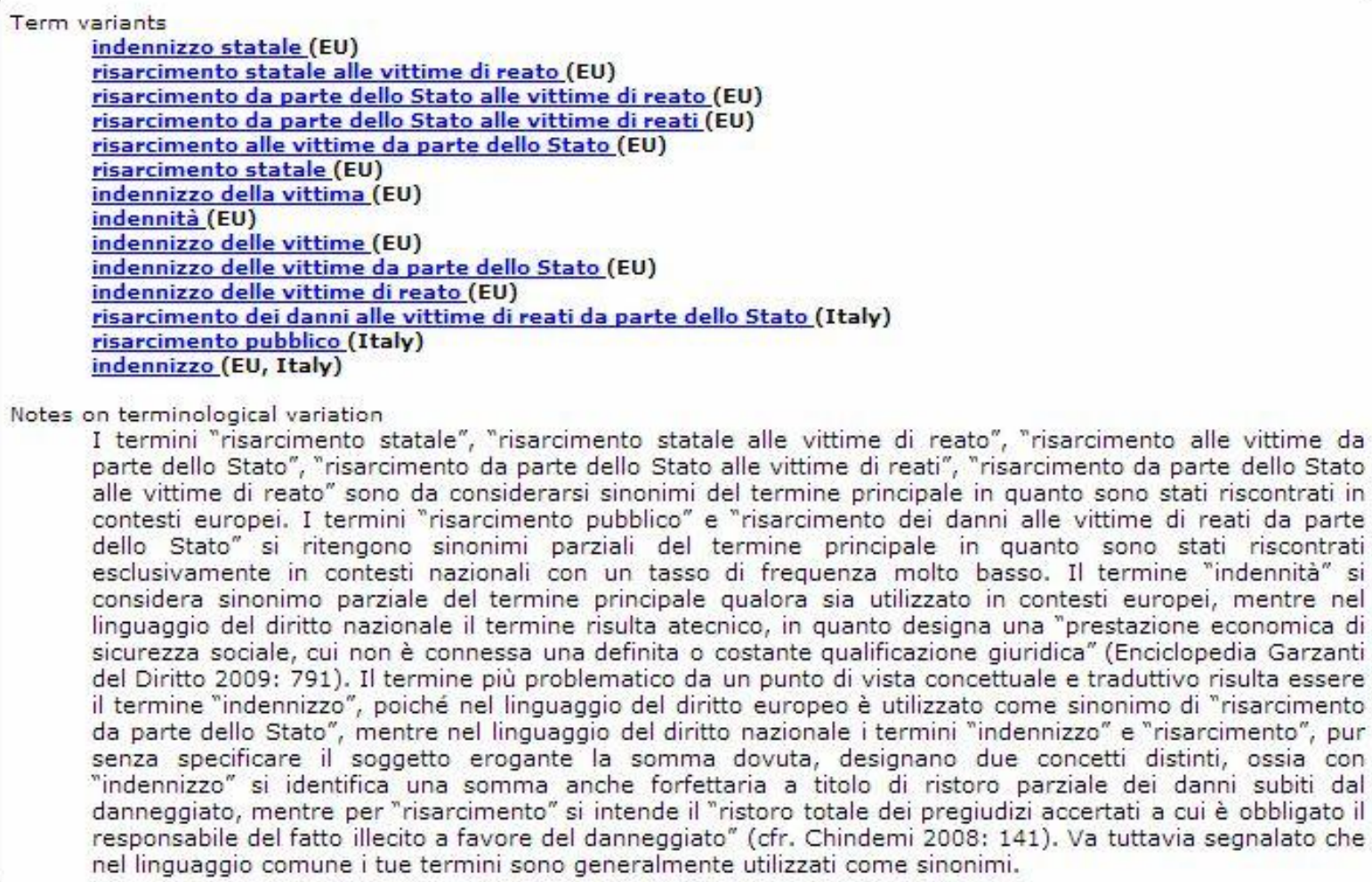

Figure 6.8. Visualisation of the "Term variant" an "Notes on terminological variation" fields for the Italian main term risarcimento da parte dello Stato.

In Figure 6.8, the information about terminological variation concerning the main term risarcimento da parte dello Stato as displayed in MuLex is provided. As can be seen from the example, the "Term variants" field contains the list of term variants in the form of hyperlinks which, if clicked, open a new webpage containing the terminological information relevant for the selected term variant. In the brackets next to each term variant, the regional label is shown, so as to facilitate the end users in the choice of which term variant to visualise 


\section{Chapter 6}

according to the origin of the text they need to translate. This indication is particularly useful in cases such as the example provided, where the number of variants is high.

As said earlier, in the "Notes on terminological variation" field both conceptual and linguistic information can be found. In the example provided, a note on the partial correspondence between the main term and the term indennità falls into the category of conceptual information, while the stylistic note on the usage of certain term variants only in EU contexts provides linguistic information.

\subsubsection{LINGUISTIC INFORMATION}

The linguistic information about the terminology recorded in MuLex is captured by means of the following fields: "Language", "Part of speech", "Gender", "Category”, "Usage label”, "Regional label”, “Style label”, “Origin”, "Lexica”, "Phraseology” and “Grammar”.

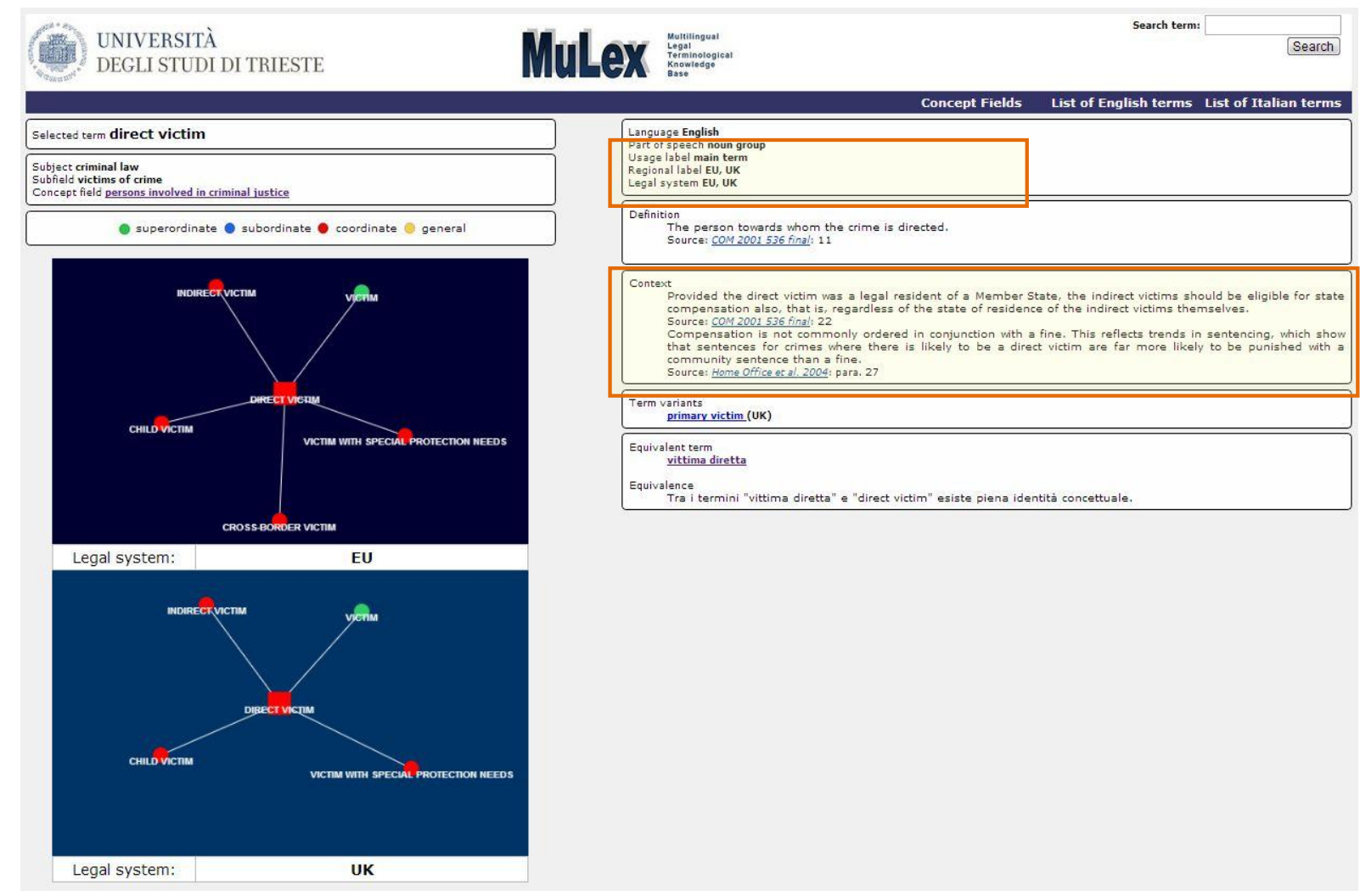

Figure 6.9. Fields containing linguistic information in the MuLex graphic user interface (highlighted in yellow).

With the only exception of the "Language" field, which in TERMit is subsumed in the label for the identification of the language (e.g. de, en, it) that precedes the term, all the other fields were already present in the first version of the TERMit termbase. The standard attributes used in these fields containing linguistic information in MuLex are summarised in Table 6.1. In 
Victims of Crime from a Terminographic Perspective. MuLex: a Legal Translation-oriented Terminological Knowledge Base

this regard, however, it should be noted that, while the indication of the language and the part of speech is compulsory for all the terms included in the TKB, the compilation of the other fields containing linguistic information is optional and depends on the type of terminological data retrieved in the textual material analysed.

\begin{tabular}{|l|l|}
\hline \multicolumn{1}{|c|}{ Field } & $\begin{array}{l}\text { Attributes used in MuLex for the terminological project on victims of } \\
\text { crime }\end{array}$ \\
\hline Language & English, Italian \\
\hline Part of speech & noun, noun group \\
\hline Gender & m., f. \\
\hline Usage label & main term, proposal, uncommon, rejected, recommended \\
\hline Regional label & EU, Italy, UK, CoE, UN \\
\hline Style label & $\begin{array}{l}\text { official (EU, Italy, UK) } \\
\text { potentially official (EU, Italy, UK) } \\
\text { obsolete }\end{array}$ \\
\hline Origin & $\begin{array}{l}\text { loan word } \\
\text { loan translation }\end{array}$ \\
\hline
\end{tabular}

Table 6.1. List of fields containing linguistic information in MuLex.

Though in most cases the attributes can be considered self-explanatory and some of them have already been discussed elsewhere, it is believed that some of them need further specification.

As regards the "Usage label" field, the attribute "main term" is used to refer to the term selected as the main term in a term cluster and the concept is a polydenominative notion. If, on the contrary, the term cluster consists of a single term, no such attribute is applied. Another attribute which can be used in this field is "proposal", which is assigned to those terms which are proposals of term equivalents in case of terminological vacuum (see also Section 5.3.2.2). In relation to the "Regional label" field, though the aim of this research study is to analyse the terminology used in the EU and British and Italian national legal systems, in some cases, due to the cross-references available in the EU corpus analysed, it has been possible to depict also some terms that are used in a jurisdiction other than those under study. Therefore, for the sake of completeness, in some cases the terms included in the MuLex TKB can be assigned the attribute "CoE" corresponding to the Council of Europe and "UN" corresponding to the United Nations. The choice to include also this kind of information has been taken in light of a possible future expansion of the research towards other legal systems. 
As far as the "Style label" field is concerned, the difference between the attribute "official", which was already available in the first version of TERMit, and the attribute "potentially official", which has been introduced specifically for the purposes of this study, has already been explained in Section 4.5.4 with reference to denominative variation from a diachronic perspective. However, in this regard it should be noted that the two attributes can also be followed by the indication of the regional label, so as to distinguish between the different types of usage in texts of different origin. For instance, the term protezione delle vittime di reati is labelled as official in the EU and potentially official in Italy. Another possible attribute concerning the style of the term is "obsolete", which indicates that the term in question is no longer used and has been replaced by another term, such as in the case of European Forum for Victim Services, which has been substituted by Victim Support Europe (see Section 4.5.1.1.4).

The other fields containing linguistic information are not summarised in Table 6.1 because they do not contain standard attributes which can be chosen from a list. The "Lexica" field, for instance, is intended for indicating the presence of the selected term in a dictionary about the specialised domain in question (see Magris 2002: 51). However, given that the EU terminology is not usually recorded in specialised dictionaries but rather in terminological resources developed by EU institutions, a frequent attribute which can be found in this field is "IATE", the interinsitutional EU termbase. Moreover, the "Phraseology" field contains collocations involving the selected term which have been collected by means of the concordancer AntConc (see Section 3.3.3.1.1) in the phases of term extraction and terminological analysis. For instance, for the term cross-border victim the following collocations have been recorded: to assist cross-border victims, to facilitate the access to state compensation for a cross-border victim, to improve the position of cross-border victims. Finally, the "Grammar" field is used to specify particular grammatical behaviours of the terms in the textual material analysed, such as in most EU variants of the term state compensation scheme, which have been only found in their plural form.

Apart from the fields containing linguistic information discussed above, another field which can contain both linguistic and conceptual information is the "Context" field, which is discussed in greater detail in the following section.

\subsection{CONTEXT}

As observed by Magris with regard to terminographic entries, 
Le voci non devono servire soltanto a reperire equivalenti, ma essere considerate piuttosto una chiave d'accesso a una varietà di informazioni di tipo linguistico, concettuale, enciclopedico, pragmatico. Oltre alla definizione, pertanto, risultano preziosi anche campi quali il contesto, le note linguistiche ed enciclopediche, le specificazioni corrispondenti alla suddivisione tematica ecc. (Magris 2004: 64)

In line with this reasoning, and bearing in mind that all the terms recorded in MuLex have been extracted from authentic legal texts, with the only exception of the proposals for term equivalents, the "Context" field is seen as an important source of information. Given the specific aim of this research study and the embeddedness of the terms in different legal systems, in the creation of terminographic entries the following approach has been followed: when a term could only be retrieved in texts regarding one legal system, only one context was recorded in MuLex (see example in Figure 6.10), whereas if two legal systems were involved, then two contexts were recorded (see example in Figure 6.11).

Context

Compensation may be paid in accordance with this Scheme: [...] (b) where the victim of a criminal injury sustained on or after 1 August 1964 has since died, to an applicant who is a qualifying claimant for the purposes of paragraph 38 (compensation in fatal cases).

Source: CICA 2008c; Paragraph 6(b)

Figure 6.10. Example of a term with one context only. Searched term: qualifying claimant.

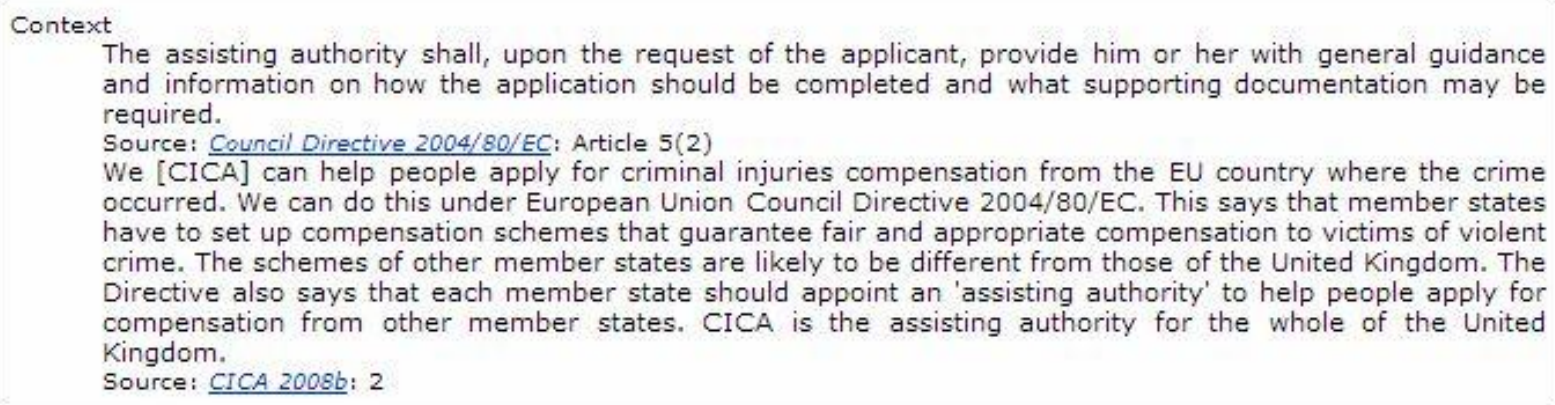
and information on how the application should be completed and what supporting documentation may be required.

Source: Council Directive 2004/80/EC: Article 5(2)

We [CICA] can help people apply for criminal injuries compensation from the EU country where the crime occurred. We can do this under European Union Council Directive 2004/80/EC. This says that member states have to set up compensation schemes that guarantee fair and appropriate compensation to victims of violent crime. The schemes of other member states are likely to be different from those of the United Kingdom. The Directive also says that each member state should appoint an 'assisting authority' to help people apply for compensation from other member states. CICA is the assisting authority for the whole of the United Kingdom.

Source: CICA 2008b: 2

Figure 6.11. Example of a term with two contexts. Searched term: assisting authority.

However, for the sake of completeness it should also be said that a marginal case has also been recorded in MuLex. This case is represented by the term penal mediation in the course of criminal proceedings, which is not provided with a context since it has only been found as the title of Article 10 in Council Framework Decision 2001/220/JHA.

The selection of the contexts to record in MuLex has been performed mainly by processing the textual material by means of the concordancer AntConc (see Section 3.3.3.1.1), which makes it possible to browse a corpus and visualise the searched term in its original contexts. 
The number of occurrences of the terms recorded in MuLex in the textual material analysed are very variable. For instance, the searched term victim occurs 1869 times in the English EU subcorpus, while the term national compensation scheme for criminal injuries constitutes a hapax in the same subcorpus. It follows that, in case of hapaxes, the only available context has been selected, while in the other cases selection criteria were needed. Therefore, two selection criteria were introduced. The first concerns the legal force of the text in which the term could be found: if the term appeared both in legally binding and in non-legally binding texts, then a context extracted from the former was preferred, since the text itself was supposed to have undergone a thorough drafting process and a linguistic revision.

The second criteria, on the other hand, regards the type of information provided by the context itself. As has been said earlier, the "Context" field can be generally said to provide linguistic information, since it is used to show how a term actually is used in authentic texts. However, following Meyer, some contexts can fall into the category of "knowledge-rich contexts" (KRCs), i.e. contexts which indicate "at least one conceptual characteristic, whether it be an attribute or a relation" (Meyer 2001: 281). Meyer distinguishes between two types of KRCs, namely defining and explanatory KRCs (Meyer 2001: 283-289). For the purposes of the selection of contexts in this research project, the second type of KRCs has been taken into consideration as a possible source of additional information. However, unlike Meyer, whose aim is to identify this information in contexts so as to formulate definitions or enhance the terminographer's knowledge of the domain (see Meyer 2001: 288), in this study the "didactic" potential of KRCs was seen from the point of view of the end user. In other words, the contexts selected for inclusion in MuLex were meant to provide the end user with additional information as compared to the information included in the definition. For instance, in Figure 6.11, two contexts are provided for the term assisting authority. The conceptual information that can be inferred from the first context is that there is a relation between the assisting authority and an applicant, who can expect a series of services (e.g. guidance, information) to be provided by the authority. On the other hand, from the second context it emerges that one of the tasks of the assisting authority is to help victims in applying for compensation in cross-border situations and that the assisting authority in the UK is the Criminal Injuries Compensation Authority.

\subsection{Summary}


Victims of Crime from a Terminographic Perspective. MuLex: a Legal Translation-oriented Terminological Knowledge Base

In Chapter 6, the MuLex TKB has been presented. This TKB has been developed taking into account recent practices in the terminological and terminographic field, which has experienced a gradual but fundamental evolution that can be attributed to four main reasons identified by Vargas Sierra (2007: 47-48): the advent of Internet, the building of electronic corpora and the development of software for corpus analysis, the development of term extraction tools and terminology management systems. On these premises, and given the growing importance of visual representation of specialised domain knowledge prompted by the increasing implementation of ontologies in different scientific and commercial communities, such as terminology management, the TERMit termbase has been taken as the starting point for the reflection on a possible legal-translation oriented TKB. This reflection has resulted in MuLex, which has been specifically designed for recording terminological data concerning legal terms which, on the one hand, are embedded in the EU multi-level jurisdiction, and, on the other hand, are characterised by the terminological dynamism described in Chapters 4 and 5.

MuLex shares several similarities with the TERMit database from which it derives; however, some substantial changes have been made so as to adapt the TKB to the terminology it was supposed to contain and the needs of the end users, i.e. legal translators. The main difference consists in the possibility to visually represent the conceptual knowledge by means of conceptual relational structures, i.e. maps containing the concept the selected term refers to and the relations it holds with other concepts included in the TKB. Another difference which is worth mentioning is the introduction of the new "Legal system" field which, together with the "Regional label" field, allows for the identification of the jurisdiction the concept is rooted in and the origin of the texts in which the relevant term is used. In this way, it is believed that the end users of the TKB have an easier access to the multidimensionality implied by a multilingual terminology used in a multi-jurisdictional setting. 



\section{Chapter 7. CONCLUSIONS AND FUTURE WORK}

Chapter 7 presents an overview of the findings of this study with regard to the aims set in Chapter 1 as well as suggestions for future work in the study of dynamism in terminology and the representation of legal terminology in the EU multi-level jurisdiction.

\subsection{CONCLUSIONS}

The first section of this chapter is devoted to the main conclusions of this thesis with reference to the aims established in Chapter 1. The main contribution of this research project can be summarised in the following four proposals that have been developed in this thesis:

- a methodological framework for carrying out a terminological analysis of the legal terminology embedded in the EU multi-level jurisdiction;

- a classification of terminological variation that can be observed in the legal terminology embedded in the EU multi-level jurisdiction;

- a classification of the terminological equivalence which can be established by comparing legal terms embedded in the EU multi-level jurisdiction;

- a legal translation-oriented terminological knowledge base (TKB) integrating a tool for the visual representation of conceptual knowledge in terminographic entries.

Throughout this research work, the main initial hypothesis that legal language is intrinsically characterised by a terminological dynamism, both at a linguistic and at a conceptual level, has been confirmed. The legal terminology analysed from a terminological perspective in this thesis was drawn from a single area of law, i.e. the area of victims of crime (Chapter 2). This legal area has become a cutting-edge topic at the EU level ever since the adoption of Council Framework Decision 2001/220/JHA and, since then, has undergone remarkable modifications and a major evolution, which resulted in the issuing of Council Directive 2012/29/EU. The consequences of the incorporation of these two legal acts and similar ones in the EU legal system have been at least three: firstly, the proliferation of other, (non-)legally binding texts of supranational origin focusing on the same area of law; secondly, the growing interest in the 


\section{Chapter 7}

figure of the victim of crime in the academic community; thirdly, the transposition of EU legal provisions in the national legal systems of the Member States and the further development of this area of law at the national level.

Given the relevance of the topic in both supranational and national legal texts, the methodological framework (Chapter 3) for this research study has been set up so as to allow for a terminological analysis of the terminology used in EU, British and Italian texts. However, contrary to methodological models developed for multilingual searches in which the languages and conceptual systems are treated separately, in this case the methodological framework had to account for the dependence of legal language to the legal system on the one hand and the prevalence of EU law over national legislation within the EU borders on the other. Starting from Cabré's model for multilingual terminographical tasks (Cabré 1999a: 129-159), a 7-step framework has been developed in which the genotype-phenotype distinction introduced by Sacco (1991) in comparative law has been integrated. In such a methodological approach, the term extraction process and the terminological analysis were performed at two different stages, a choice that was determined by the nature of the terminology examined. A first semi-automatic term extraction was carried out on a corpus of EU texts written in English and Italian. The candidate terms identified were validated by a lawyer and cross-checked by using the bilingual display of parallel texts so as to find possible term variants and establish term equivalents within the EU corpus. The selected EU terms were then individually analysed so as to gather all the conceptual and linguistic information to be recorded in a TKB. On the basis of the selected terms, national texts focusing on the figure of the victim of crime were collected and terms from the collections of national texts were retrieved. At this stage, a further terminological analysis was also performed so as to gather further terminological data to be included in the TKB. In so doing, it was also possible to identify the conceptual features of national terminology and proceed to the next step, which consisted in the actual population of the TKB.

In order to record the terminological data collected in the terminological resource, the terms extracted from the EU corpus and the collections of national texts were grouped in term clusters, i.e. sets of terminological units referring to individual concepts. Given that the terms taken into consideration are embedded in different legal systems, in order to proceed to the term clustering task Sacco's distinction (1991) for the study of comparative law was integrated in the process. According to this distinction, in the legal domain super-abstract notions can be identified which find their actual embodiment in phenotypes, i.e. the concrete actualisation of genotypes within the legal system. On the basis of this distinction, the terms 
designating phenotypes referring to a shared genotype were grouped in term clusters, which were matched cross-linguistically according to the degree of equivalence assessed among them. In the final stage, the content of the TKB was validated and revised by the field expert.

\subsubsection{TERMINOLOGICAL DYNAMISM: VARIATION}

By means of the 7-step methodological framework adopted in this research study, the terminological analysis proved to be dynamic on two different levels, i.e. intralingually and interlingually. The first type of terminological dynamism observed consisted in terminological variation (Chapter 4) within each of the two languages taken into consideration separately. Since in Terminology the term "terminological variation" has come to mean different phenomena according to different authors and different terminology-related applications, to suit the aims of this study variation was defined as the modification that affects the form of terminological units making up an individual term cluster. Such a variation can affect either the formal features of terminological units (denominative variation) or their conceptual as well as formal aspects (conceptual variation). While denominative variation involves terminological units in which no substantial difference in the phenotypes concerned is produced, in conceptual variation anisomorphism among the phenotypes can be observed. In both cases, however, all the terms affected by the phenomenon of terminological variation are part of the same term cluster and are therefore related to the same genotype.

The analysis of terminological variation in this study has been influenced by the methodological framework described in Chapter 3. Given the textual approach and the order of the phases concerning term selection and term analysis, the identification of phenotypes and the subsequent elaboration of genotypes has been prompted by the semi-automatic processing of a corpus made up of EU texts. Thus, the preliminary conceptual structuring of the legal area of victims of crime was based on concepts from the EU legal system and guided the search for both national phenotypes and the relevant terminology to be recorded in term clusters on the grounds of shared genotypes. A conceptual restructuring was then carried out on the basis of the terminological data extracted from national texts. Such a methodological approach ensured the high degree of conceptual correspondence displayed by the phenotypes examined and that the most frequent type of terminological variation in the corpus is denominative rather than conceptual. In order to describe denominative variation, four variables were considered: degree of specialisation, time span, legal system and legal force. The application of such variables produced two different types of denominative variation for each variable. 


\section{Chapter 7}

As regards the degree of specialisation, denominative variation has been classified as vertical variation, when the texts in which the terminology analysed are more or less specialised, and horizontal variation, when the degree of specialisation is considered as being homogeneous. Since both the texts included in the EU corpus and the collection of national texts are assumed to share a similar degree of specialisation, despite the heterogeneity of their text types and legal force, the examination of variation depending on the first variable has focused on the horizontal category of variation. On the basis of the terminology extracted from the EU corpus and the collections of national texts, six different types of horizontal variation have been identified: inflectional, syntactic, morphosyntactic, lexical, graphic and variation through expansion and reduction. Moreover, a further type of variation has also been described in which the modifications characterising for more than one type of horizontal variation co-occur in a single variant (combined variation).

For the time span variable, i.e. the period of time covered by the texts from which the terminology was extracted, two types of variation have been identified, i.e. synchronic variation and diachronic variation. The first occurs when variation is observed throughout the time span covered by the documents in which a specific term is found, while diachronic variation is observed when a change in the terms used to refer to a phenotype occurs on the diachronic axis, i.e. when a term is replaced by a variant in the course of time. However, with regard to the behaviour of terms from a diachronic perspective, within the EU corpus cases of univocity have also been identified, with some phenotypes not being affected by variation in the time span considered (1998-2012).

The third variable taken into consideration for the study of denominative variation is the reference legal system. Given the legal system of the texts from which terms were extracted, denominative variation has been classified as intra-systemic variation, if the terms refer to a single legal system, and inter-systemic variation, if variation is observed when comparing the terminology used in two different legal systems expressed in the same language. When this variable is taken into account, the type of variation (intra- or inter-systemic) depends on the number of legal systems taken into consideration and the type of phenotype the terms refer to. The example provided in Section 4.5.3 shows that the presence of one type of variation does not exclude the other, since variation can occur both intra- and inter-systemically.

The last variable consists in the legal force of the document from which the terms are extracted. In the classification of EU and national texts proposed in Chapter 3, the EU and national textual material analysed was subdivided into legally-binding texts and non legallybinding texts. After attributing the terms extracted for the purposes of this research project to 
either category, variation was observed within either texts with equal legal force or texts with different legal force. Based on such a distinction, terms were classified accordingly in the MuLex TKB. However, given the diachronic dimension introduced by considering the time span variable, another element was also considered as regards the legal force of the texts examined, i.e. the provisional nature of the legal force of certain documents. What is meant here is that in the textual material analysed also some documents aiming at promoting or amending the legal provisions regulating specific aspects of the legal area of victims of crime were included. Such documents are proposals or initiatives for the adoption or modification of legal acts that contain parts of text which could become normative in the future but do not have this function yet at the time of examination. Therefore, in the analysis of denominative variation also the provisional nature of the legal force of some legal texts, and consequently of the terminology used in them, was accounted for.

The second category of terminological variation considered in this study is conceptual variation, which involves a shift in the conceptual aspects of terminological units. In this case, variation affects not only the designations used, i.e. the terminological units grouped into a single term cluster, but also the phenotypes related to a single genotype. However, given the methodological approach adopted in this study, which considered the EU legal terminology as the starting point for the terminological analysis and the preliminary conceptual structuring of the area of law under discussion, the conceptual shifts in the phenotypes play a marginal role in the phenomenon of terminological variation. The reference legal system was considered as a relevant variable in this case too and on its basis conceptual variation has been subdivided into intra- and inter-systemic conceptual variation. In the former, examples were identified where variation can be ascribed to a conceptual shift due to the development of the legal notions in the course of time. This means that the area of law has been subject to a change leading to the shift from a phenotype to another without hindering the link between these two phenotypes and the more abstract genotype. On the other hand, inter-systemic variation has been observed when in the supranational and the national legal systems there are two conceptually different phenotypes which, in spite of these conceptual divergences, can be linked to the same genotype.

\subsubsection{TERMINOLOGICAL DYNAMISM: EQUIVALENCE}

The second type of terminological dynamism was observed from an intralingual perspective with terminological dynamism in the EU multi-level jurisdiction resulting in different degrees of terminological equivalence, which come to the fore when the terms in different languages 


\section{Chapter 7}

are compared at an abstract level. Given that the terminological analysis in this study was carried out on a set of terminological units embedded in a multi-layered legal setting, two different types of terminological equivalence have been identified. The first type consists in intra-systemic equivalence, which occurs between terms in different languages referring to a unique legal system (the EU). The second type is inter-systemic equivalence, which occurs when the terms taken into consideration refer to different legal systems. In the first, equivalence is expected to be absolute on the grounds of the two principles of multilingualism and equal authenticity holding among texts. In the second, the degree of equivalence in terminologies referring to two different legal systems needs to be evaluated on a graded scale, where the possible degrees identified in this setting are absolute equivalence, relative equivalence, and non-equivalence. In the inter-systemic cases examined in this thesis, absolute equivalence can occur when an EU legal concept is transferred into the Member States' national jurisdictions without any changes in the phenotype and, therefore, the national phenotypes are mutually corresponding on a conceptual level. If, on the other hand, a change affects two phenotypes that can be linked to a common genotype anyway, the degree of equivalence is only relative, while in the cases where the area of law is regulated differently and there is no correspondence between two phenotypes on a genotype basis, no equivalence can be established.

Absolute equivalence represents the ideal case in multilingual terminography and poses no problems in the recording of multilingual terminological data in a TKB, while instances of relative equivalence and non-equivalence require particular attention. In MuLex, both cases of relative and non-equivalence were recorded following two different procedures: in relative equivalence, the degree of equivalence was assessed on the basis of the shared genotype and explained in the "Equivalence" field, while in the cases of non-equivalence, different approaches were adopted according to the textual material available. The first approach consists in using a textual equivalent of the foreign concept, with the proposed equivalent corresponding to the term used in the foreign legal system and therefore consisting in a loan word. When, on the other hand, an equivalent could not been found, a proposal for an equivalent term was suggested and recorded. Such proposals can be subdivided into two groups according to the type of referent designated by the terms. The first group includes terms referring to named entities, for which the proposal consists in a loan word corresponding to the denomination of the named entity. The second group, on the other hand, is made by the terms referring to legal concepts which are specific for one of the legal 
systems involved in the study. For each of these concepts a term was proposed consisting in a descriptive paraphrase conveying the main characteristics of the foreign concept.

\subsubsection{CAPTURING TERMINOLOGICAL DYNAMISM IN MULEX}

The main traits of the terminological dynamism observed in Chapters 4 and 5, as well as other terminological data relevant for victim-related terminology, were all recorded in the MuLex TKB, which was developed for a specific group of end users, i.e. legal translators. In order to highlight the differences among the legal systems concerned in the study and the peculiarities of the usage of legal terminology within those systems, the most recent practices in terminology and terminography were taken into account. In terminography, the most remarkable evolution has led to the questioning of the terminological principles established by the General Theory of Terminology, the development of new terminographic methodologies and the spreading of electronic terminographic resources. This evolution has been driven by the advent of Internet, the building of electronic corpora and the development of software for the analysis of electronic corpora, term extraction tools and terminology management systems. Nowadays, designers of terminological resources are giving growing importance to the visual representation of specialised domain knowledge, which is made possible by the increasing implementation of ontologies in different scientific and commercial communities. Therefore, visual representation has been considered as a viable way to integrate conceptual information in the MuLex TKB.

In order to develop a legal translation-oriented TKB, the principles at the core of the TERMit termbase (Magris 2002) of the University of Trieste have been taken as the starting point for further elaboration and adaptation. Despite the similarities between TERMit and MuLex, some substantial changes have been made so as to adapt the TKB to the terminology it is supposed to contain and the needs of its end users, i.e. legal translators. Such differences specifically regard the selection of the main term, the way terminographic entries are displayed (i.e. the graphic user interface), and the way conceptual information is provided to the end user.

In order to select the main term, new criteria have been added to the frequency criterion. The decision to consider additional criteria, namely the occurrence of a term in legally binding rather than non-legally binding texts and the chronological criterion, was determined by the specialised domain which the terminology examined belongs to. Since terms used in normative texts are subject to a higher linguistic control, they are expected to be more reliable. Consequently, such terms are also considered as more suitable to be recorded as main 


\section{Chapter 7}

terms in a terminographic entry, even though they may result less frequent than other terms found in non-legally binding texts.

As concerns the graphic user interface, the terminographic entries in MuLex are presented as a set of web pages, with every entry being split in as many web pages as there are terms in it. This means that a terminographic entry actually consists of two term clusters, one for each language involved, which are linked on the basis of the genotype they refer to. Each cluster can contain one or more terms, which are related by means of hyperlinks. Therefore, instead of visualising a terminographic entry on a single web page, the information relevant to a genotype is distributed in several interlinked web pages so as to avoid information overload.

Another novelty introduced in MuLex as compared to TERMit consists in the possibility to provide the end user with a visual representation tool which is integrated in the graphic user interface. This tool allows for the visualisation of conceptual knowledge by means of conceptual relational structures. These structures are conceptual maps containing the concept the selected term refers to and the relations it holds with other concepts included in the TKB. The main concept is represented as the central node in the structure and the other concepts are linked to it by means of different relations. The relations included in these structures have been classified as hierarchical and non-hierarchical relations and reflect the types of relations identified in the textual material examined. The possible hierarchical relations are superordinate-subordinate relations and coordinate relations, while the only possible nonhierarchical relation is the general relation. The latter type of relation is associative and, for the purposes of the present study, carrying out a further classification of associative relations was not felt as necessary for visually representing conceptual knowledge.

What is interesting in reference to the conceptual relational structures developed in MuLex is that three structures can be created for each terminographic entry. The reason for the multiple representation of conceptual information lies in the embeddedness of legal concepts in three different jurisdictions. Therefore, when a legal concept can be found in more than one legal system, a conceptual relational structure for each system is available and displayed on the web page. The insertion of multiple relational structures in the MuLex graphic user interface has also implied the creation of a new field, i.e. the "Legal system" field, in which, as its designation suggests, the reference legal system is recorded. This field, together with the indication of the geographical area where the relevant term is used (recorded in the "Regional label" field), allows for the identification of the jurisdiction the concept is rooted in and the origin of the texts where the relevant term is used. In this way, the access to the 
multidimensionality implied by the usage of multiple terminologies in a multi-level jurisdiction is believed to have been made easier.

\subsection{FUTURE WORK}

In this last section, the envisaged future work and possible future lines of research that have emerged during this research project are presented.

The first direction that needs to be pursued is the further development of the MuLex graphic user interface. In spite of the incorporation of a tool for visually representing conceptual relational structures in the terminological knowledge base, at the time of writing no webbased input form which could be used for the online population of the TKB is available. Moreover, the conceptual relational structures also need further development, with the incorporation of hyperlinks among related concepts, so as to allow for a more dynamic type of browsing among terminographic entries.

Since the MuLex TKB was specially designed for legal translators, it would be very useful to have this resource tested by professional translators. Their feedback would prove essential to understand what further improvements to the TKB might be needed to adapt it even further to the real needs of translators. Moreover, in view of the practical use of the terminological data stored in MuLex, the development of an export function so as to allow for the export of data in the TermBase eXchange (TBX) format would be advisable in order to enhance a greater compatibility and interchange with other terminology management and computer-assisted translation (CAT) tools.

With reference to the methodology proposed in Chapter 3, it would be interesting to widen the research by expanding the study of the conceptualisation of the area of law of victims of crime. The research project presented in this thesis was in fact based on a preliminary framebased conceptualisation of this legal area, but not all the concept fields identified in the template illustrated in Figure 6.2 were explored, therefore the examination of victim-related terminology should be expanded by considering both the types of crimes in which victims are involved and the agent committing them, i.e. the author. Moreover, the TKB should be enriched with further national terms by using the EU terminology as the starting point in combination with the genotype-phenotype distinction.

Another aspect which was observed while carrying out the study but not given due consideration in this thesis is the relationship between genotypes, phenotypes and named 


\section{Chapter 7}

entities. In particular, it was noted that a different degree of vagueness is employed in the legal systems taken into consideration, with EU terms either tending towards a higher degree of vagueness than national terms or designating broad concepts that have concrete counterparts within national legal systems. The emblematic case found in the textual material analysed is represented by the EU term victim support organisation and the British term Victim Support, between which there is a close conceptual relation at the genotype level, but the former designates a general category and the latter a named entity, i.e. an instance of the general category. It would therefore be very interesting to explore the different degrees of vagueness in legal terminology and the relationship between genotypes, phenotypes and named entities in a multi-level jurisdiction in which one legislation has precedence over the other legislations involved.

The inclusion of more terms and concepts related to the national legal systems would also yield further results as regards the comparison of the legal systems involved. In Chapter 5, different degrees of terminological equivalence were identified when comparing the supranational and the national terminologies on the basis of the genotype-phenotype distinction. However, the selection of national terminology was limited by constraints imposed by the methodology selected. By extending the search for terminology to national texts, more differences in the conceptualisation of the area of law of victims of crime would emerge which would bring about more cases of relative and especially non-equivalence. Therefore, by including new textual material it would be possible to further elaborate the frame-based conceptual structure for each legal system taken into account. The discrepancies in these structures would reveal cases of non-equivalence, allowing a further reflection on the possible strategies for formulating terminological equivalents in a translational perspective. 
$\underline{\text { Annexes }}$ 



\section{Annex 1}

List of EU documents included in the EU corpus ${ }^{140}$

\begin{tabular}{|c|c|c|c|}
\hline $\begin{array}{c}\text { Issuing } \\
\text { institution(s) }\end{array}$ & Title & $\begin{array}{c}\text { Official Journal } \\
\text { Date }\end{array}$ & Main topic \\
\hline $\begin{array}{l}\text { Council of the } \\
\text { European Union, } \\
\text { European } \\
\text { Commission }\end{array}$ & $\begin{array}{l}\text { Action Plan of the Council and the } \\
\text { Commission on how best to implement } \\
\text { the provisions of the Treaty of } \\
\text { Amsterdam on an area of freedom, } \\
\text { security and justice - Text adopted by } \\
\text { the Justice and Home Affairs Council } \\
\text { of } 3 \text { December } 1998\end{array}$ & $\begin{array}{l}\text { OJEC C 019, } \\
23.1 .1999,1-15 .\end{array}$ & $\begin{array}{l}\text { area of freedom, } \\
\text { security and justice }\end{array}$ \\
\hline $\begin{array}{l}\text { European } \\
\text { Parliament }\end{array}$ & $\begin{array}{l}\text { Report on the Commission } \\
\text { communication to the Council, the } \\
\text { European Parliament and the } \\
\text { Economic and Social Committee on } \\
\text { crime victims in the European Union: } \\
\text { Reflexions on standards and actions } \\
\text { (A5-0126/2000) }\end{array}$ & 25.4.2000 & $\begin{array}{l}\text { standing of victims } \\
\text { in criminal } \\
\text { proceedings }\end{array}$ \\
\hline $\begin{array}{l}\text { Portuguese } \\
\text { Republic }\end{array}$ & $\begin{array}{l}\text { Initiative of the Portuguese Republic } \\
\text { with a view to adopting a Council } \\
\text { Framework Decision on the standing of } \\
\text { victims in criminal procedure }\end{array}$ & $\begin{array}{l}\text { OJEC C } 243, \\
24.8 .2000,4-8 .\end{array}$ & $\begin{array}{l}\text { standing of victims } \\
\text { in criminal } \\
\text { proceedings }\end{array}$ \\
\hline $\begin{array}{l}\text { European } \\
\text { Parliament }\end{array}$ & $\begin{array}{l}\text { European Parliament legislative } \\
\text { resolution on the initiative of the } \\
\text { Portuguese Republic with a view to } \\
\text { adopting a Council Framework } \\
\text { Decision on the standing of victims in } \\
\text { criminal procedure }(9650 / 2000 \text { - C5- } \\
0392 / 2000 \text { - 2000/0813(CNS) ) }\end{array}$ & 12.12 .2000 & $\begin{array}{l}\text { standing of victims } \\
\text { in criminal } \\
\text { proceedings }\end{array}$ \\
\hline $\begin{array}{l}\text { European } \\
\text { Parliament }\end{array}$ & $\begin{array}{l}\text { European Parliament resolution on the } \\
\text { Commission communication to the } \\
\text { Council, the European Parliament and } \\
\text { the Economic and Social Committee } \\
\text { on crime victims in the European } \\
\text { Union: Reflexions on standards and } \\
\text { action (COM(1999) } 349 \text { - C5- } \\
0119 / 1999-1999 / 2122(\text { COS }))\end{array}$ & $\begin{array}{l}\text { OJEC C } 67 \\
1.3 .2001,304- \\
308 .\end{array}$ & $\begin{array}{l}\text { standing of victims } \\
\text { in criminal } \\
\text { proceedings }\end{array}$ \\
\hline $\begin{array}{l}\text { Kingdom of } \\
\text { Belgium }\end{array}$ & $\begin{array}{l}\text { Initiative of the Kingdom of Belgium } \\
\text { with a view to the adoption of a } \\
\text { Council Decision setting up a } \\
\text { European network of national contact } \\
\text { points for restorative justice }\end{array}$ & $\begin{array}{l}\text { OJEC C } 242, \\
8.10 .2002,20-23 .\end{array}$ & $\begin{array}{l}\text { European network } \\
\text { of national contact } \\
\text { points for } \\
\text { restorative justice }\end{array}$ \\
\hline
\end{tabular}

${ }^{140}$ For the sake of practical convenience, the titles of the documents are given in English, although the EU corpus is made of English and Italian texts (see Section 3.3.2). In case the document is only available in English, the title is followed by a star $(*)$. 


\begin{tabular}{|c|c|c|c|}
\hline $\begin{array}{l}\text { Council of the } \\
\text { European Union }\end{array}$ & $\begin{array}{l}\text { Council Framework Decision of } 15 \\
\text { March } 2001 \text { on the standing of victims } \\
\text { in criminal proceedings } \\
(2001 / 220 / \mathrm{JHA})\end{array}$ & $\begin{array}{l}\text { OJEC L 82, } \\
22.3 .2001,1-4 .\end{array}$ & $\begin{array}{l}\text { standing of victims } \\
\text { in criminal } \\
\text { proceedings }\end{array}$ \\
\hline $\begin{array}{l}\text { European } \\
\text { Commission }\end{array}$ & $\begin{array}{l}\text { Green Paper - Compensation to crime } \\
\text { victims (COM (2001) } 536 \text { final) }\end{array}$ & 28.9.2001 & $\begin{array}{l}\text { compensation to } \\
\text { crime victims }\end{array}$ \\
\hline $\begin{array}{l}\text { European } \\
\text { Commission }\end{array}$ & $\begin{array}{l}\text { Proposal for a Council Directive on the } \\
\text { short-term residence permit issued to } \\
\text { victims of action to facilitate illegal } \\
\text { immigration or trafficking in human } \\
\text { beings who cooperate with the } \\
\text { competent authorities (COM (2002) } \\
\text { 0071 final) }\end{array}$ & 11.2.2002 & $\begin{array}{l}\text { trafficking in } \\
\text { human beings }\end{array}$ \\
\hline $\begin{array}{l}\text { European } \\
\text { Economic and } \\
\text { Social Committee }\end{array}$ & $\begin{array}{l}\text { Opinion of the Economic and Social } \\
\text { Committee on the 'Green Paper on } \\
\text { compensation to crime } \\
\text { victims' }\end{array}$ & $\begin{array}{l}\text { OJEC C 125, } \\
27.5 .2002,31-39\end{array}$ & $\begin{array}{l}\text { compensation to } \\
\text { crime victims }\end{array}$ \\
\hline $\begin{array}{l}\text { Council of the } \\
\text { European Union }\end{array}$ & $\begin{array}{l}\text { Council Decision of } 22 \text { July } 2002 \\
\text { establishing a framework programme } \\
\text { on police and judicial cooperation in } \\
\text { criminal matters (AGIS) } \\
(2002 / 630 / \mathrm{JHA})\end{array}$ & $\begin{array}{l}\text { OJEC L 203, } \\
1.8 .2002,5-8\end{array}$ & AGIS \\
\hline $\begin{array}{l}\text { Council of the } \\
\text { European Union }\end{array}$ & $\begin{array}{l}\text { Council Framework Decision of } 19 \\
\text { July } 2002 \text { on combating trafficking in } \\
\text { human beings (2002/629/JHA) }\end{array}$ & $\begin{array}{l}\text { OJEC L 203, } \\
1.8 .2002,1-4 .\end{array}$ & $\begin{array}{l}\text { trafficking in } \\
\text { human beings }\end{array}$ \\
\hline $\begin{array}{l}\text { European } \\
\text { Parliament }\end{array}$ & $\begin{array}{l}\text { European Parliament resolution on the } \\
\text { Commission Green Paper on } \\
\text { compensation to crime victims } \\
(\mathrm{COM}(2001) 536 \text { C5-0016/2002 } \\
2002 / 2022(\mathrm{COS}))\end{array}$ & 24.9.2002 & $\begin{array}{l}\text { compensation to } \\
\text { crime victims }\end{array}$ \\
\hline $\begin{array}{l}\text { European } \\
\text { Commission }\end{array}$ & $\begin{array}{l}\text { Proposal for a Council Directive on } \\
\text { compensation to crime victims (COM } \\
\text { (2002) } 562 \text { final) }\end{array}$ & 16.10 .2002 & $\begin{array}{l}\text { compensation to } \\
\text { crime victims }\end{array}$ \\
\hline $\begin{array}{l}\text { European } \\
\text { Commission }\end{array}$ & $\begin{array}{l}\text { Proposal for a Decision of the } \\
\text { European Parliament and of the } \\
\text { Council establishing a second phase of } \\
\text { a programme of Community action } \\
\text { (2004-2008) to prevent violence } \\
\text { against children, young people and } \\
\text { women and to protect victims and } \\
\text { groups at-risk (the DAPHNE II } \\
\text { programme) (COM (2003) } 54 \text { final) }\end{array}$ & 4.2 .2003 & $\begin{array}{l}\text { prevent violence } \\
\text { against children, } \\
\text { young people and } \\
\text { women and to } \\
\text { protect victims and } \\
\text { groups at-risk }\end{array}$ \\
\hline $\begin{array}{l}\text { European } \\
\text { Commission }\end{array}$ & $\begin{array}{l}\text { Amended proposal for a Decision of } \\
\text { the European Parliament and of the } \\
\text { Council establishing a second phase of } \\
\text { a programme of Community action } \\
\text { (2004-2008) to prevent violence } \\
\text { against children, young people and } \\
\text { women and to protect victims and } \\
\text { groups at-risk (the DAPHNE II } \\
\text { programme) (presented by the }\end{array}$ & 15.10 .2003 & $\begin{array}{l}\text { prevent violence } \\
\text { against children, } \\
\text { young people and } \\
\text { women and to } \\
\text { protect victims and } \\
\text { groups at-risk }\end{array}$ \\
\hline
\end{tabular}


Annex 1

\begin{tabular}{|c|c|c|c|}
\hline & Commission) (COM (2003) 616 final) & & \\
\hline $\begin{array}{l}\text { European } \\
\text { Parliament }\end{array}$ & $\begin{array}{l}\text { European Parliament legislative } \\
\text { resolution on the proposal for a } \\
\text { Council directive on compensation to } \\
\text { crime victims (COM }(2002) 562-\text { C5- } \\
0517 / 2002-2002 / 0247(\mathrm{CNS}))\end{array}$ & 23.10.2003 & $\begin{array}{l}\text { compensation to } \\
\text { crime victims }\end{array}$ \\
\hline $\begin{array}{l}\text { European } \\
\text { Commission }\end{array}$ & $\begin{array}{l}\text { Communication from the Commission } \\
\text { to the Council and the European } \\
\text { Parliament - Biannual Update of the } \\
\text { Scoreboard to Review Progress on the } \\
\text { Creation of an Area of "Freedom, } \\
\text { Security and Justice" in the European } \\
\text { Union (Second half of 2003) (COM } \\
\text { (2003) } 812 \text { final) }\end{array}$ & 30.12 .2003 & $\begin{array}{l}\text { area of freedom, } \\
\text { security and justice }\end{array}$ \\
\hline $\begin{array}{l}\text { Council of the } \\
\text { European Union }\end{array}$ & $\begin{array}{l}\text { Council Framework Decision } \\
\text { 2004/68/JHA of } 22 \text { December } 2003 \text { on } \\
\text { combating the sexual exploitation of } \\
\text { children and child pornography }\end{array}$ & $\begin{array}{l}\text { OJEU L 13, } \\
20.1 .2004,44-48 .\end{array}$ & $\begin{array}{l}\text { sexual abuse, } \\
\text { sexual exploitation } \\
\text { of children and } \\
\text { child pornography }\end{array}$ \\
\hline $\begin{array}{l}\text { European } \\
\text { Parliament }\end{array}$ & $\begin{array}{l}\text { European Parliament legislative } \\
\text { resolution on the initiative by the } \\
\text { Kingdom of Belgium with a view to } \\
\text { the adoption of a Council Decision } \\
\text { setting up a European network of } \\
\text { national contact points for restorative } \\
\text { justice }(11621 / 2002 \text { C5-0467/2002 } \\
2002 / 0821(\mathrm{CNS}))\end{array}$ & $\begin{array}{l}\text { OJEU } 64 \text { E, } \\
12.3 .2004,182- \\
194 .\end{array}$ & $\begin{array}{l}\text { European network } \\
\text { of national contact } \\
\text { points for } \\
\text { restorative justice }\end{array}$ \\
\hline $\begin{array}{l}\text { European Court of } \\
\text { Justice }\end{array}$ & $\begin{array}{l}\text { Opinion of Advocate General Kokott, } \\
\text { delivered on } 11 \text { November } 2004 \text { (Case } \\
\text { C-105/03) }\end{array}$ & 11.11.2004 & $\begin{array}{l}\text { standing of victims } \\
\text { in criminal } \\
\text { proceedings }\end{array}$ \\
\hline $\begin{array}{l}\text { European Court of } \\
\text { Justice }\end{array}$ & $\begin{array}{l}\text { Reference for a preliminary ruling by } \\
\text { the Tribunale di } \\
\text { Firenze by order of that Court of } 3 \\
\text { February } 2003 \text { in the } \\
\text { criminal proceedings against Maria } \\
\text { Pupino }\end{array}$ & $\begin{array}{l}\text { OJEU C 146, } \\
21.6 .2003,16 .\end{array}$ & $\begin{array}{l}\text { standing of victims } \\
\text { in criminal } \\
\text { proceedings }\end{array}$ \\
\hline $\begin{array}{l}\text { European } \\
\text { Commission }\end{array}$ & $\begin{array}{l}\text { Report from the Commission on the } \\
\text { basis of Article } 18 \text { of the Council } \\
\text { Framework Decision of } 15 \text { March } 2001 \\
\text { on the standing of victims in criminal } \\
\text { proceedings (COM (2004) } 54 \text { final) }\end{array}$ & 16.2.2004 & $\begin{array}{l}\text { standing of victims } \\
\text { in criminal } \\
\text { proceedings }\end{array}$ \\
\hline $\begin{array}{l}\text { European } \\
\text { Commission }\end{array}$ & $\begin{array}{l}\text { Commission Staff Working Paper- } \\
\text { The follow-up to the Tampere } \\
\text { Conclusions as concerns the protection } \\
\text { of victims of crime: the question of the } \\
\text { legal basis for the Commission's } \\
\text { proposal for a Council Directive on } \\
\text { compensation to crime victims (COM } \\
\text { SEC } 2004322)(*)\end{array}$ & 15.3 .2004 & $\begin{array}{l}\text { compensation to } \\
\text { crime victims }\end{array}$ \\
\hline $\begin{array}{l}\text { European } \\
\text { Commission }\end{array}$ & $\begin{array}{l}\text { Green Paper on the approximation, } \\
\text { mutual recognition and enforcement of } \\
\text { criminal sanctions in the European }\end{array}$ & 30.4 .2004 & $\begin{array}{l}\text { approximation, } \\
\text { mutual recognition } \\
\text { and enforcement of }\end{array}$ \\
\hline
\end{tabular}




\begin{tabular}{|c|c|c|c|}
\hline & Union (COM (2004) 334 final) & & criminal sanctions \\
\hline $\begin{array}{l}\text { European } \\
\text { Parliament, Council } \\
\text { of the European } \\
\text { Union }\end{array}$ & $\begin{array}{l}\text { Decision } 803 / 2004 / \mathrm{EC} \text { of the European } \\
\text { Parliament and of the Council of } 21 \\
\text { April } 2004 \text { adopting a programme of } \\
\text { Community action (2004 to 2008) to } \\
\text { prevent and combat violence } \\
\text { against children, young people and } \\
\text { women and to protect victims and } \\
\text { groups at risk (the } \\
\text { Daphne II programme) }\end{array}$ & $\begin{array}{l}\text { OJEU L 143, } \\
30.4 .2004,1-8 .\end{array}$ & $\begin{array}{l}\text { prevent violence } \\
\text { against children, } \\
\text { young people and } \\
\text { women and to } \\
\text { protect victims and } \\
\text { groups at-risk }\end{array}$ \\
\hline $\begin{array}{l}\text { Council of the } \\
\text { European Union }\end{array}$ & $\begin{array}{l}\text { Council Directive } 2004 / 80 / \mathrm{EC} \text { of } 29 \\
\text { April } 2004 \text { relating to compensation to } \\
\text { crime victims }\end{array}$ & $\begin{array}{l}\text { OJEU L 261, } \\
6.8 .2004,15-18 .\end{array}$ & $\begin{array}{l}\text { compensation to } \\
\text { crime victims }\end{array}$ \\
\hline $\begin{array}{l}\text { Council of the } \\
\text { European Union }\end{array}$ & $\begin{array}{l}\text { Council Directive } 2004 / 81 / \mathrm{EC} \text { of } 29 \\
\text { April } 2004 \text { on the residence permit } \\
\text { issued to third-country nationals who } \\
\text { are victims of trafficking in human } \\
\text { beings or who have been the subject of } \\
\text { an action to facilitate illegal } \\
\text { immigration, who cooperate with the } \\
\text { competent authorities }\end{array}$ & $\begin{array}{l}\text { OJEU L 261, } \\
6.8 .2004,19-23 .\end{array}$ & $\begin{array}{l}\text { trafficking in } \\
\text { human beings }\end{array}$ \\
\hline $\begin{array}{l}\text { European } \\
\text { Commission }\end{array}$ & $\begin{array}{l}\text { Manual 80/2004 - Compensation to } \\
\text { crime victims }(\mathrm{UK})(*)\end{array}$ & & $\begin{array}{l}\text { compensation to } \\
\text { crime victims }\end{array}$ \\
\hline $\begin{array}{l}\text { European } \\
\text { Commission }\end{array}$ & $\begin{array}{l}\text { Manual 80/2004 - Compensation to } \\
\text { crime victims (Italy) }\end{array}$ & & $\begin{array}{l}\text { compensation to } \\
\text { crime victims }\end{array}$ \\
\hline $\begin{array}{l}\text { European } \\
\text { Commission }\end{array}$ & $\begin{array}{l}\text { Communication from the Commission } \\
\text { to the European Parliament and the } \\
\text { Council - Fighting trafficking in } \\
\text { human beings - an integrated approach } \\
\text { and proposals for an action plan (COM } \\
\text { (2005) } 514 \text { final) }\end{array}$ & 18.10.2005 & $\begin{array}{l}\text { trafficking in } \\
\text { human beings }\end{array}$ \\
\hline $\begin{array}{l}\text { European Court of } \\
\text { Justice }\end{array}$ & $\begin{array}{l}\text { Judgment of the Court of Justice } \\
\text { (Grand Chamber) of } 16 \text { June } 2005 \text { in } \\
\text { Case C-105/03, Reference for a } \\
\text { preliminary ruling from } \\
\text { the Tribunale di Firenze (Italy), in } \\
\text { criminal proceedings } \\
\text { against Maria Pupino }\end{array}$ & $\begin{array}{l}\text { OJEU C 193, } \\
6.8 .2005,3-4 .\end{array}$ & $\begin{array}{l}\text { standing of victims } \\
\text { in criminal } \\
\text { proceedings }\end{array}$ \\
\hline $\begin{array}{l}\text { European Court of } \\
\text { Justice }\end{array}$ & $\begin{array}{l}\text { Reference for a preliminary ruling } \\
\text { from the Tribunale di } \\
\text { Milano by order of that court of } 6 \\
\text { October } 2005 \text { in Ministero } \\
\text { Pubblico v Giovanni Dell'Orto }\end{array}$ & $\begin{array}{l}\text { OJEU C 74, } \\
25.3 .2006,4\end{array}$ & $\begin{array}{l}\text { standing of victims } \\
\text { in criminal } \\
\text { proceedings }\end{array}$ \\
\hline $\begin{array}{l}\text { European } \\
\text { Commission }\end{array}$ & $\begin{array}{l}\text { Report from the Commission to the } \\
\text { Council and the European Parliament } \\
\text { based on Article } 10 \text { of the Council } \\
\text { Framework Decision of } 19 \text { July } 2002 \\
\text { on combating trafficking in human } \\
\text { beings (COM (2006) } 187 \text { final) }\end{array}$ & 2.5.2006 & $\begin{array}{l}\text { trafficking in } \\
\text { human beings }\end{array}$ \\
\hline $\begin{array}{l}\text { European } \\
\text { Economic and }\end{array}$ & $\begin{array}{l}\text { Opinion of the European Economic } \\
\text { and Social Committee on the }\end{array}$ & $\begin{array}{l}\text { OJEU C } 110 \\
9.5 .2006,75-82 .\end{array}$ & \\
\hline
\end{tabular}




\begin{tabular}{|c|c|c|c|}
\hline Social Committee & $\begin{array}{l}\text { prevention of juvenile delinquency. } \\
\text { Ways of dealing with juvenile } \\
\text { delinquency and the role of the } \\
\text { juvenile justice system in the European } \\
\text { Union }\end{array}$ & & \\
\hline $\begin{array}{l}\text { European } \\
\text { Commission }\end{array}$ & $\begin{array}{l}\text { Commission Decision 2006/337/EC of } \\
19 \text { April } 2006 \text { establishing standard } \\
\text { forms for the transmission of } \\
\text { applications and decisions pursuant to } \\
\text { Council Directive } 2004 / 80 / \text { EC relating } \\
\text { to compensation to crime victims }\end{array}$ & $\begin{array}{l}\text { OJEU L 125, } \\
12.5 .2006,25-30 .\end{array}$ & $\begin{array}{l}\text { compensation to } \\
\text { crime victims }\end{array}$ \\
\hline $\begin{array}{l}\text { European Court of } \\
\text { Justice }\end{array}$ & $\begin{array}{l}\text { Opinion of Advocate General Kokott, } \\
\text { delivered on } 8 \text { March } 2007 \text { (Case C- } \\
\text { 205/09) }\end{array}$ & 8.3.2007 & $\begin{array}{l}\text { standing of victims } \\
\text { in criminal } \\
\text { proceedings }\end{array}$ \\
\hline $\begin{array}{l}\text { European } \\
\text { Commission }\end{array}$ & $\begin{array}{l}\text { Report from the Commission based on } \\
\text { Article } 12 \text { of the Council Framework } \\
\text { Decision of } 22 \text { December } 2003 \text { on } \\
\text { combating the sexual exploitation of } \\
\text { children and child pornography (COM } \\
\text { (2007) } 716 \text { final) }\end{array}$ & 16.11.2007 & $\begin{array}{l}\text { sexual abuse, } \\
\text { sexual exploitation } \\
\text { of children and } \\
\text { child pornography }\end{array}$ \\
\hline $\begin{array}{l}\text { European Court of } \\
\text { Justice }\end{array}$ & $\begin{array}{l}\text { Judgment of the Court (Third } \\
\text { Chamber) of } 28 \text { June } 2007 \\
\text { (reference for a preliminary ruling } \\
\text { from the Tribunale di } \\
\text { Milano - Italy) - Criminal proceedings } \\
\text { against Giovanni } \\
\text { Dell'Orto }\end{array}$ & $\begin{array}{l}\text { OJEU C 199, } \\
25.8 .2007,9 .\end{array}$ & $\begin{array}{l}\text { standing of victims } \\
\text { in criminal } \\
\text { proceedings }\end{array}$ \\
\hline $\begin{array}{l}\text { European Court of } \\
\text { Justice }\end{array}$ & $\begin{array}{l}\text { Reference for a preliminary ruling } \\
\text { from the Hoge Raad der } \\
\text { Nederlanden, lodged on } 5 \text { September } \\
2007 \text { - Stichting } \\
\text { Centraal Begeleidingsorgaan voor de } \\
\text { Intercollegiale Toetsing v } \\
\text { Staatssecretaris van Financiën }\end{array}$ & $\begin{array}{l}\text { OJEU C 283, } \\
24.11 .2007,13 .\end{array}$ & $\begin{array}{l}\text { standing of victims } \\
\text { in criminal } \\
\text { proceedings }\end{array}$ \\
\hline $\begin{array}{l}\text { European Court of } \\
\text { Justice }\end{array}$ & $\begin{array}{l}\text { Opinion of Advocate General Kokott, } \\
\text { delivered on } 10 \text { July } 2008 \text { (Case C- } \\
404 / 07 \text { ) }\end{array}$ & 10.7.2008 & $\begin{array}{l}\text { standing of victims } \\
\text { in criminal } \\
\text { proceedings }\end{array}$ \\
\hline $\begin{array}{l}\text { European Court of } \\
\text { Justice }\end{array}$ & $\begin{array}{l}\text { Judgment of the Court (Third } \\
\text { Chamber) of } 9 \text { October } 2008 \\
\text { (reference for a preliminary ruling } \\
\text { from the Fővárosi } \\
\text { Bíróság, Republic of Hungary) - } \\
\text { Criminal proceedings } \\
\text { brought by Győrgy Katz against István } \\
\text { Roland Sós }\end{array}$ & $\begin{array}{l}\text { OJEU C 301, } \\
22.11 .2008,11 .\end{array}$ & $\begin{array}{l}\text { standing of victims } \\
\text { in criminal } \\
\text { proceedings }\end{array}$ \\
\hline $\begin{array}{l}\text { European } \\
\text { Parliament }\end{array}$ & $\begin{array}{l}\text { European Parliament resolution of } 16 \\
\text { January 2008: Towards an EU strategy } \\
\text { on the rights of the child } \\
(2007 / 2093(\text { INI) })\end{array}$ & $\begin{array}{l}\text { OJEU C 41 E, } \\
19.2 .2009,24-46 .\end{array}$ & children \\
\hline $\begin{array}{l}\text { European } \\
\text { Commission }\end{array}$ & $\begin{array}{l}\text { Commission Staff Working Document } \\
\text { - Accompanying document to the }\end{array}$ & 25.3.2009 & $\begin{array}{l}\text { sexual abuse, } \\
\text { sexual exploitation }\end{array}$ \\
\hline
\end{tabular}




\begin{tabular}{|c|c|c|c|}
\hline & $\begin{array}{l}\text { Proposal for a Council Framework } \\
\text { Decision on combating the sexual } \\
\text { abuse, sexual exploitation of children } \\
\text { and child pornography, repealing } \\
\text { Framework Decision 2004/68/JHA. } \\
\text { Impact Assessment (COM SEC } 2009 \\
356 \text { ) }\end{array}$ & & $\begin{array}{l}\text { of children and } \\
\text { child pornography }\end{array}$ \\
\hline $\begin{array}{l}\text { European } \\
\text { Commission }\end{array}$ & $\begin{array}{l}\text { Proposal for a Council Framework } \\
\text { Decision on combating the sexual } \\
\text { abuse, sexual exploitation of children } \\
\text { and child pornography, repealing } \\
\text { Framework Decision 2004/68/JHA } \\
\text { (COM (2009) } 135 \text { final) }\end{array}$ & 25.3.2009 & $\begin{array}{l}\text { sexual abuse, } \\
\text { sexual exploitation } \\
\text { of children and } \\
\text { child pornography }\end{array}$ \\
\hline $\begin{array}{l}\text { European } \\
\text { Commission }\end{array}$ & $\begin{array}{l}\text { Proposal for a Council Framework } \\
\text { Decision on preventing and combating } \\
\text { trafficking in human beings, and } \\
\text { protecting victims, repealing } \\
\text { Framework Decision } 2002 / 629 / \mathrm{JHA} \\
\text { (COM } 2009136 \text { final) }\end{array}$ & 25.3.2009 & $\begin{array}{l}\text { trafficking in } \\
\text { human beings }\end{array}$ \\
\hline $\begin{array}{l}\text { European } \\
\text { Commission }\end{array}$ & $\begin{array}{l}\text { Commission Staff Working Document } \\
\text { - Accompanying document to the } \\
\text { Report from the Commission to the } \\
\text { Council, the European Parliamentand } \\
\text { the European Economic and Social } \\
\text { Committee on the application of } \\
\text { Council Directive 2004/80/EC relating } \\
\text { to compensation to crime victims } \\
\text { (COM SEC } 20090495)(*)\end{array}$ & 20.4.2009 & $\begin{array}{l}\text { compensation to } \\
\text { crime victims }\end{array}$ \\
\hline $\begin{array}{l}\text { European } \\
\text { Commission }\end{array}$ & $\begin{array}{l}\text { Report from the Commission pursuant } \\
\text { to Article } 18 \text { of the Council } \\
\text { Framework Decision of } 15 \text { March } 2001 \\
\text { on the standing of victims in criminal } \\
\text { proceedings (2001/220/JHA) (COM } \\
\text { (2009) } 166 \text { final) }\end{array}$ & 20.4.2009 & $\begin{array}{l}\text { standing of victims } \\
\text { in criminal } \\
\text { proceedings }\end{array}$ \\
\hline $\begin{array}{l}\text { European } \\
\text { Commission }\end{array}$ & $\begin{array}{l}\text { Report from the Commission to the } \\
\text { Council, the European Parliament and } \\
\text { the European Economic and Social } \\
\text { Committee on the application of } \\
\text { Council Directive } 2004 / 80 / \text { EC relating } \\
\text { to compensation to crime victims } \\
\text { (COM (2009) } 170 \text { final) }\end{array}$ & 20.4.2009 & $\begin{array}{l}\text { compensation to } \\
\text { crime victims }\end{array}$ \\
\hline $\begin{array}{l}\text { European } \\
\text { Parliament }\end{array}$ & $\begin{array}{l}\text { Multi-annual programme } 2010-2014 \\
\text { regarding the area of freedom, security } \\
\text { and justice (Stockholm programme) } \\
\text { European Parliament resolution of } 25 \\
\text { November } 2009 \text { on the } \\
\text { Communication from the } \\
\text { Commission to the European } \\
\text { Parliament and the Council - An area } \\
\text { of freedom, security } \\
\text { and justice serving the citizen - } \\
\text { Stockholm programme }\end{array}$ & 25.11 .2009 & $\begin{array}{l}\text { Stockholm } \\
\text { programme }\end{array}$ \\
\hline
\end{tabular}




\begin{tabular}{|c|c|c|c|}
\hline $\begin{array}{l}\text { European } \\
\text { Parliament }\end{array}$ & $\begin{array}{l}\text { European Parliament resolution of } 25 \\
\text { November } 2009 \text { on the } \\
\text { Communication from the Commission } \\
\text { to the European Parliament and the } \\
\text { Council - An area of freedom, security } \\
\text { and justice serving the citizen - } \\
\text { Stockholm programme }\end{array}$ & $\begin{array}{l}\text { OJEU C } 285 \text { E, } \\
21.10 .2010,12- \\
35 .\end{array}$ & $\begin{array}{l}\text { Stockholm } \\
\text { programme }\end{array}$ \\
\hline $\begin{array}{l}\text { European Court of } \\
\text { Justice }\end{array}$ & $\begin{array}{l}\text { Reference for a preliminary ruling } \\
\text { from the Szombathelyi Városi Bíróság } \\
\text { (Republic of Hungary) lodged on } 8 \\
\text { June } 2009 \text { - Criminal proceedings } \\
\text { against Emil Eredics and Another }\end{array}$ & $\begin{array}{l}\text { OJEU C } 205, \\
29.8 .2009,20 .\end{array}$ & $\begin{array}{l}\text { standing of victims } \\
\text { in criminal } \\
\text { proceedings }\end{array}$ \\
\hline $\begin{array}{l}\text { Kingdom of } \\
\text { Belgium, Republic } \\
\text { of Bulgaria, } \\
\text { Republic of } \\
\text { Estonia, Kingdom } \\
\text { of Spain, French } \\
\text { Republic, Italian } \\
\text { Republic, Republic } \\
\text { of Hungary, } \\
\text { Republic of Poland, } \\
\text { Portuguese } \\
\text { Republic, Romania, } \\
\text { Republic of } \\
\text { Finland, Kingdom } \\
\text { of Sweden }\end{array}$ & $\begin{array}{l}\text { Initiative of the Kingdom of Belgium, } \\
\text { the Republic of Bulgaria, the Republic } \\
\text { of Estonia, the Kingdom of Spain, the } \\
\text { French Republic, the Italian Republic, } \\
\text { the Republic of Hungary, the Republic } \\
\text { of Poland, the Portuguese Republic, } \\
\text { Romania, the Republic of Finland and } \\
\text { the Kingdom of Sweden with a view to } \\
\text { the adoption of a Directive of the } \\
\text { European Parliament and of the } \\
\text { Council on the European Protection } \\
\text { Order }\end{array}$ & $\begin{array}{l}\text { OJEU C 69, } \\
18.3 .2010,5-18\end{array}$ & $\begin{array}{l}\text { European } \\
\text { Protection Order }\end{array}$ \\
\hline $\begin{array}{l}\text { European } \\
\text { Commission }\end{array}$ & $\begin{array}{l}\text { Proposal for a Directive of the } \\
\text { European Parliament and of the } \\
\text { Council on preventing and combating } \\
\text { trafficking in human beings, and } \\
\text { protecting victims, repealing } \\
\text { Framework Decision } 2002 / 629 / \mathrm{JHA} \\
\text { (COM (2010) } 95 \text { final) }\end{array}$ & 29.3.2010 & $\begin{array}{l}\text { trafficking in } \\
\text { human beings }\end{array}$ \\
\hline $\begin{array}{l}\text { European } \\
\text { Commission }\end{array}$ & $\begin{array}{l}\text { Communication from the Commission } \\
\text { to the European Parliament, the } \\
\text { Council, the European Economic and } \\
\text { Social Committee and the Committee } \\
\text { of the Regions - Delivering an area of } \\
\text { freedom, security and justice for } \\
\text { Europe's citizens Action Plan } \\
\text { Implementing the Stockholm } \\
\text { Programme (COM (2010) } 171 \text { final) }\end{array}$ & 20.4.2010 & $\begin{array}{l}\text { Stockholm } \\
\text { programme }\end{array}$ \\
\hline European Council & $\begin{array}{l}\text { The Stockholm Programme - An Open } \\
\text { and Secure Europe Serving and } \\
\text { Protecting Citizens }\end{array}$ & $\begin{array}{l}\text { OJEU C 115, } \\
4.5 .2010,1-38\end{array}$ & $\begin{array}{l}\text { Stockholm } \\
\text { programme }\end{array}$ \\
\hline $\begin{array}{l}\text { Committee of } \\
\text { Regions }\end{array}$ & $\begin{array}{l}\text { Opinion of the Committee of the } \\
\text { Regions on Combating the sexual } \\
\text { abuse, sexual exploitation of children } \\
\text { and child pornography and Combating } \\
\text { trafficking in human beings, and } \\
\text { protecting victims }\end{array}$ & $\begin{array}{l}\text { OJEC C 141, } \\
29.5 .2010,50-54 .\end{array}$ & $\begin{array}{l}\text { trafficking in } \\
\text { human beings }\end{array}$ \\
\hline
\end{tabular}




\begin{tabular}{|c|c|c|c|}
\hline $\begin{array}{l}\text { European Court of } \\
\text { Justice }\end{array}$ & $\begin{array}{l}\text { Opinion of Advocate General Kokott, } \\
\text { delivered on } 1 \text { July } 2010 \text { (Case C- } \\
205 / 09 \text { ) }\end{array}$ & 1.7.2010 & $\begin{array}{l}\text { standing of victims } \\
\text { in criminal } \\
\text { proceedings }\end{array}$ \\
\hline $\begin{array}{l}\text { European Data } \\
\text { Protection } \\
\text { Supervisor }\end{array}$ & $\begin{array}{l}\text { Opinion of the European Data } \\
\text { Protection Supervisor on the initiative } \\
\text { of the Kingdom of Belgium, the } \\
\text { Republic of Bulgaria, the Republic of } \\
\text { Estonia, the Kingdom of Spain, the } \\
\text { French Republic, the Italian Republic, } \\
\text { the Republic of Hungary, the Republic } \\
\text { of Poland, the Portuguese Republic, } \\
\text { Romania, the Republic of Finland and } \\
\text { the Kingdom of Sweden for a Directive } \\
\text { of the European Parliament and of the } \\
\text { Council on the European Protection } \\
\text { Order, and on the initiative of the } \\
\text { Kingdom of Belgium, the Republic of } \\
\text { Bulgaria, the Republic of Estonia, the } \\
\text { Kingdom of Spain, the Republic of } \\
\text { Austria, the Republic of Slovenia and } \\
\text { the Kingdom of Sweden for a Directive } \\
\text { of the European Parliament and of the } \\
\text { Council regarding the European } \\
\text { Investigation Order in criminal matters }\end{array}$ & $\begin{array}{l}\text { OJEU C 355, } \\
29.12 .2010,1-9 .\end{array}$ & $\begin{array}{l}\text { European } \\
\text { Protection Order }\end{array}$ \\
\hline $\begin{array}{l}\text { European Court of } \\
\text { Justice }\end{array}$ & $\begin{array}{l}\text { Judgment of the Court (Second } \\
\text { Chamber) of } 21 \text { October } 2010 \\
\text { (reference for a preliminary ruling } \\
\text { from the Szombathelyi Városi Bíróság } \\
\text { (Hungary)) - Criminal proceedings } \\
\text { against Emil Eredics, Mária Vassné } \\
\text { Sápi }\end{array}$ & $\begin{array}{l}\text { OJEU C } 346, \\
18.12 .2010,14 .\end{array}$ & $\begin{array}{l}\text { standing of victims } \\
\text { in criminal } \\
\text { proceedings }\end{array}$ \\
\hline $\begin{array}{l}\text { European Court of } \\
\text { Justice }\end{array}$ & $\begin{array}{l}\text { Reference for a preliminary ruling } \\
\text { from the Audiencia } \\
\text { Provincial de Tarragona (Spain) lodged } \\
\text { on } 30 \text { November } \\
2009 \text { - Criminal proceedings against } \\
\text { Magatte Gueye }\end{array}$ & $\begin{array}{l}\text { OJEU C 37, } \\
13.2 .2010,19 .\end{array}$ & $\begin{array}{l}\text { standing of victims } \\
\text { in criminal } \\
\text { proceedings }\end{array}$ \\
\hline $\begin{array}{l}\text { European } \\
\text { Commission }\end{array}$ & $\begin{array}{l}\text { Communication from the Commission } \\
\text { to the European Parliament, the } \\
\text { Council, the European Economic and } \\
\text { Social Committee and the Committee } \\
\text { of the Regions - An EU Agenda for } \\
\text { the Rights of the Child (COM (2011) } \\
60 \text { final) }\end{array}$ & 15.2 .2011 & children \\
\hline $\begin{array}{l}\text { European } \\
\text { Parliament, Council } \\
\text { of the European } \\
\text { Union }\end{array}$ & $\begin{array}{l}\text { Directive 2011/36/EU of the European } \\
\text { Parliament and of the Council of } 5 \\
\text { April } 2011 \text { on preventing and } \\
\text { combating trafficking in human beings } \\
\text { and protecting its victims, and } \\
\text { replacing Council Framework Decision } \\
\text { 2002/629/JHA }\end{array}$ & $\begin{array}{l}\text { OJEU L 101, } \\
15.4 .2011,1-11 .\end{array}$ & $\begin{array}{l}\text { trafficking in } \\
\text { human beings }\end{array}$ \\
\hline European Court of & $\begin{array}{l}\text { Opinion of Advocate General Kokott, } \\
\text { delivered on } 12 \text { May } 2011 \text { (Case C- }\end{array}$ & 12.5.2011 & $\begin{array}{l}\text { standing of victims } \\
\text { in criminal }\end{array}$ \\
\hline
\end{tabular}




\begin{tabular}{|c|c|c|c|}
\hline Justice & 483/09) & & proceedings \\
\hline $\begin{array}{l}\text { European } \\
\text { Commission }\end{array}$ & $\begin{array}{l}\text { Commission Staff Working Paper-- } \\
\text { Executive summary of the Impact } \\
\text { Assessment } \\
\text { Accompanying the document } \\
\text { Communication from the Commission } \\
\text { to the Eurropean Parliament, to the } \\
\text { Council, tothe European economic and } \\
\text { social Committee and to the } \\
\text { Committee of the Regions - } \\
\text { Strenghthening victim's rights in the } \\
\text { EU (COM SEC } 2011581 \text { final) }(*)\end{array}$ & 18.5.2011 & $\begin{array}{l}\text { standing of victims } \\
\text { in criminal } \\
\text { proceedings }\end{array}$ \\
\hline $\begin{array}{l}\text { European } \\
\text { Commission }\end{array}$ & $\begin{array}{l}\text { Communication from the Commission } \\
\text { to the European Prliament, the Council, } \\
\text { the Economic and Social Committee } \\
\text { and the Committee of the Regions - } \\
\text { Strengthening victims' rights in the EU } \\
\text { (COM (2011) } 274 \text { final) }\end{array}$ & 18.5.2011 & $\begin{array}{l}\text { standing of victims } \\
\text { in criminal } \\
\text { proceedings }\end{array}$ \\
\hline $\begin{array}{l}\text { European } \\
\text { Commission }\end{array}$ & $\begin{array}{l}\text { Proposal for a Directive of the } \\
\text { European Parliament and of the } \\
\text { Council establishing minimum } \\
\text { standards on the rights, support and } \\
\text { protection of victims of crime (COM } \\
\text { (2011) } 275 \text { final) }\end{array}$ & 18.5 .2011 & $\begin{array}{l}\text { standing of victims } \\
\text { in criminal } \\
\text { proceedings }\end{array}$ \\
\hline $\begin{array}{l}\text { Council of the } \\
\text { European Union }\end{array}$ & $\begin{array}{l}\text { Resolution of the Council of } 10 \text { June } \\
2011 \text { on a Roadmap for strengthening } \\
\text { the rights and protection of victims, in } \\
\text { particular in criminal proceedings }\end{array}$ & $\begin{array}{l}\text { OJEU C 187, } \\
28.6 .2011,1-5 .\end{array}$ & $\begin{array}{l}\text { standing of victims } \\
\text { in criminal } \\
\text { proceedings }\end{array}$ \\
\hline $\begin{array}{l}\text { European } \\
\text { Parliament, Council } \\
\text { of the European } \\
\text { Union }\end{array}$ & $\begin{array}{l}\text { Directive 2011/93/EU of the European } \\
\text { Parliament and of the Council of } 13 \\
\text { December } 2011 \\
\text { on combating the sexual abuse and } \\
\text { sexual exploitation of children and } \\
\text { child pornography, and replacing } \\
\text { Council Framework Decision } \\
\text { 2004/68/JHA }\end{array}$ & $\begin{array}{l}\text { OJEU L 335, } \\
17.12 .2011,1-14 .\end{array}$ & $\begin{array}{l}\text { sexual abuse, } \\
\text { sexual exploitation } \\
\text { of children and } \\
\text { child pornography }\end{array}$ \\
\hline $\begin{array}{l}\text { European } \\
\text { Parliament, Council } \\
\text { of the European } \\
\text { Union }\end{array}$ & $\begin{array}{l}\text { Directive 2011/99/EU of the European } \\
\text { Parliament and of the Council of } 13 \\
\text { December } 2011 \text { on the European } \\
\text { protection order }\end{array}$ & $\begin{array}{l}\text { OJEU L 338, } \\
21.12 .2011,2-18 .\end{array}$ & $\begin{array}{l}\text { European } \\
\text { Protection Order }\end{array}$ \\
\hline $\begin{array}{l}\text { European Court of } \\
\text { Justice }\end{array}$ & $\begin{array}{l}\text { Judgment of the Court (Fourth } \\
\text { Chamber) of } 15 \text { September } 2011 \\
\text { (reference for a preliminary ruling } \\
\text { from the Audiencia Provincial de } \\
\text { Tarragona - Spain) - Criminal } \\
\text { proceedings against Magatte Gueye } \\
\text { and Valentín Salmerón Sánchez }\end{array}$ & $\begin{array}{l}\text { OJEU C 319, } \\
29.10 .2011,5 .\end{array}$ & $\begin{array}{l}\text { standing of victims } \\
\text { in criminal } \\
\text { proceedings }\end{array}$ \\
\hline $\begin{array}{l}\text { European Data } \\
\text { Protection } \\
\text { Supervisor }\end{array}$ & $\begin{array}{l}\text { Opinion of the European Data } \\
\text { Protection Supervisor on the legislative } \\
\text { package on the victims of crime, } \\
\text { including a proposal for a Directive } \\
\text { establishing minimum standards on the }\end{array}$ & $\begin{array}{l}\text { OJEU C 35, } \\
9.2 .2012,10-15 .\end{array}$ & $\begin{array}{l}\text { standing of victims } \\
\text { in criminal } \\
\text { proceedings }\end{array}$ \\
\hline
\end{tabular}




\begin{tabular}{|l|l|l|l|}
\hline & $\begin{array}{l}\text { rights, support and protection of the } \\
\text { victims of crime and a proposal for a } \\
\text { Regulation on mutual recognition of } \\
\text { protection measures in civil matters }\end{array}$ & & \\
\hline $\begin{array}{l}\text { European } \\
\text { Economic and } \\
\text { Social Committee }\end{array}$ & $\begin{array}{l}\text { Opinion of the European Economic } \\
\text { and Social Committee on the } \\
\text { "Communication from the Commission } \\
\text { to the European Parliament, the } \\
\text { Council, the Economic and Social } \\
\text { Committee and the Committee of the } \\
\text { Regions - Strengthening victims' } \\
\text { rights in the EU" }\end{array}$ & $\begin{array}{l}\text { OJEU C 43, } \\
15.2 .2012,39-46 .\end{array}$ & $\begin{array}{l}\text { standing of victims } \\
\text { in criminal } \\
\text { proceedings }\end{array}$ \\
\hline $\begin{array}{l}\text { European } \\
\text { Parliament \& } \\
\text { Council of the } \\
\text { European Union }\end{array}$ & $\begin{array}{l}\text { Directive 2012/29/EU of the European } \\
\text { Parliament and of the Council of 25 } \\
\text { October 2012 establishing minimum } \\
\text { standards on the rights, support and } \\
\text { protection of victims of crime, and } \\
\text { replacing Council Framework Decision } \\
\text { 2001/220/JHA }\end{array}$ & $\begin{array}{l}\text { OJEU L 315, } \\
14.11 .2012,57-\end{array}$ & $\begin{array}{l}\text { 73. } \\
\text { in criminal } \\
\text { proceedings }\end{array}$ \\
\hline
\end{tabular}


Annex 2

\section{List of English and Italian stop words}

\section{English stop words}

\begin{tabular}{|c|c|c|}
\hline $\mathrm{a}$ & however & some \\
\hline about & $\mathrm{i}$ & still \\
\hline across & if & than \\
\hline after & in & that \\
\hline all & into & the \\
\hline almost & is & their \\
\hline also & it & theirs \\
\hline am & its & them \\
\hline among & just & then \\
\hline an & last & there \\
\hline and & least & these \\
\hline another & let & they \\
\hline any & like & this \\
\hline are & likely & those \\
\hline as & main & thus \\
\hline at & mainly & to \\
\hline be & many & too \\
\hline because & may & us \\
\hline been & me & wants \\
\hline being & might & was \\
\hline better & mine & we \\
\hline but & most & well \\
\hline by & must & were \\
\hline can & my & what \\
\hline cannot & neither & when \\
\hline concerning & no & where \\
\hline could & nor & which \\
\hline did & not & while \\
\hline do & now & who \\
\hline does & nowadays & whom \\
\hline either & of & whose \\
\hline else & off & why \\
\hline ever & often & will \\
\hline every & on & with \\
\hline for & only & without \\
\hline from & or & worse \\
\hline get & other & would \\
\hline getting & our & yet \\
\hline got & ours & you \\
\hline had & own & your \\
\hline has & rather & yours \\
\hline have & regard & \\
\hline having & regards & \\
\hline he & said & \\
\hline her & say & \\
\hline here & says & \\
\hline hers & she & \\
\hline him & should & \\
\hline his & since & \\
\hline how & so & \\
\hline
\end{tabular}




\section{Italian stop words}

\begin{tabular}{|c|c|c|c|}
\hline & deve & nostra & sulla \\
\hline $\mathrm{a}$ & devo & nostre & sulle \\
\hline abbia & di & nostri & suo \\
\hline abbiamo & dunque & nostro & suoi \\
\hline abbiano & $\mathrm{e}$ & nostro & tale \\
\hline abbiate & è & nuovi & tali \\
\hline ad & ecco & nuovo & tanto \\
\hline adesso & ed & o & te \\
\hline agli & essere & oltre & tra \\
\hline ai & fa & ora & tua \\
\hline $\mathrm{al}$ & fare & peggio & tue \\
\hline all' & fine & per & tuo \\
\hline alla & fino & però & tuoi \\
\hline alle & fra & più & tutta \\
\hline allo & gente & poco & tutte \\
\hline allora & giù & qua & tutti \\
\hline altra & gli & quale & tutto \\
\hline altre & ha & quali & ultimo \\
\hline altri & hai & quasi & un \\
\hline altro & hanno & quello & una \\
\hline anche & ho & questo & uni \\
\hline ancora & i & qui & uno \\
\hline avere & il & quindi & va \\
\hline avete & in & relativa & voi \\
\hline aveva & indietro & relative & volte \\
\hline avevamo & invece & relativi & vostra \\
\hline avevano & io & relativo & vostre \\
\hline avevate & 1' & riguardo & vostri \\
\hline avevi & la & rispetto & vostro \\
\hline avevo & lavoro & sarà & vostro \\
\hline ben & le & se & \\
\hline bene & lei & sei & \\
\hline buono & lo & sembra & \\
\hline che & loro & sembrava & \\
\hline chi & lui & senza & \\
\hline circa & lungo & si & \\
\hline con & $\mathrm{ma}$ & sia & \\
\hline $\operatorname{cosa}$ & me & siamo & \\
\hline cui & meglio & siano & \\
\hline $\mathrm{d}^{\prime}$ & $\mathrm{mi}$ & siate & \\
\hline $\mathrm{da}$ & $\operatorname{mia}$ & siete & \\
\hline dà & mie & solo & \\
\hline dagli & miei & sono & \\
\hline dai & mio & sopra & \\
\hline dal & molta & soprattutto & \\
\hline dall' & molti & sotto & \\
\hline dalla & molto & stati & \\
\hline dalle & negli & stato & \\
\hline dallo & nei & stesso & \\
\hline degli & nel & su & \\
\hline dei & nell' & sua & \\
\hline del & nella & subito & \\
\hline dell' & nelle & sue & \\
\hline della & nello & sugli & \\
\hline delle & no & sui & \\
\hline dello & noi & sul & \\
\hline dentro & non & sull' & \\
\hline
\end{tabular}




\section{Annex 3}

\section{Word lists obtained with AntConc ${ }^{141}$}

First 100 results for the English EU subcorpus

\begin{tabular}{|c|c|c|c|}
\hline Word & Frequency & Word & Frequency \\
\hline \multicolumn{2}{|c|}{ with notes } & \multicolumn{2}{|c|}{ without notes } \\
\hline member & 3845 & member & 3771 \\
\hline victims & 3205 & victims & 3141 \\
\hline states & 2998 & states & 2932 \\
\hline article & 2710 & article & 2572 \\
\hline european & 2556 & european & 2397 \\
\hline criminal & 2240 & criminal & 2118 \\
\hline state & 2003 & state & 1955 \\
\hline decision & 1967 & decision & 1852 \\
\hline victim & 1869 & victim & 1847 \\
\hline commission & 1785 & commission & 1649 \\
\hline framework & 1723 & framework & 1619 \\
\hline crime & 1624 & shall & 1573 \\
\hline council & 1612 & crime & 1565 \\
\hline shall & 1584 & protection & 1471 \\
\hline protection & 1515 & measures & 1461 \\
\hline measures & 1487 & union & 1425 \\
\hline union & 1469 & council & 1387 \\
\hline rights & 1423 & rights & 1363 \\
\hline proceedings & 1385 & proceedings & 1356 \\
\hline such & 1352 & such & 1328 \\
\hline compensation & 1346 & compensation & 1327 \\
\hline law & 1320 & law & 1262 \\
\hline $\mathrm{eu}$ & 1233 & eu & 1158 \\
\hline child & 1186 & child & 1108 \\
\hline national & 1112 & national & 1102 \\
\hline legal & 1074 & legal & 1063 \\
\hline information & 1064 & information & 1034 \\
\hline justice & 1024 & $\mathrm{~s}$ & 984 \\
\hline $\mathrm{S}$ & 1021 & justice & 976 \\
\hline children & 1009 & children & 948 \\
\hline directive & 964 & ensure & 934 \\
\hline ensure & 935 & directive & 921 \\
\hline court & 899 & court & 877 \\
\hline
\end{tabular}

${ }^{141}$ The highlighted cells in the tables show the candidate terms that have been further analysed according to the steps descibed in Sections 3.3.3 and 3.3.5. 


\begin{tabular}{|c|c|c|c|}
\hline person & 844 & person & 830 \\
\hline order & 833 & order & 816 \\
\hline under & 833 & under & 807 \\
\hline trafficking & 803 & against & 750 \\
\hline against & 792 & necessary & 745 \\
\hline $\mathrm{c}$ & 790 & particular & 744 \\
\hline human & 770 & support & 737 \\
\hline between & 763 & between & 734 \\
\hline particular & 762 & cooperation & 721 \\
\hline support & 757 & action & 714 \\
\hline cooperation & 752 & human & 707 \\
\hline necessary & 750 & trafficking & 705 \\
\hline action & 749 & right & 660 \\
\hline case & 693 & take & 639 \\
\hline right & 683 & authorities & 634 \\
\hline including & 652 & including & 633 \\
\hline provisions & 651 & provisions & 633 \\
\hline take & 649 & offences & 618 \\
\hline authorities & 644 & violence & 594 \\
\hline offences & 628 & within & 593 \\
\hline sexual & 613 & sexual & 583 \\
\hline violence & 603 & judicial & 582 \\
\hline within & 599 & persons & 579 \\
\hline judicial & 596 & appropriate & 570 \\
\hline persons & 596 & authority & 565 \\
\hline programme & 582 & case & 552 \\
\hline appropriate & 573 & programme & 550 \\
\hline paragraph & 573 & referred & 544 \\
\hline authority & 571 & level & 541 \\
\hline $\mathrm{p}$ & 566 & $\mathrm{~b}$ & 524 \\
\hline referred & 556 & treaty & 519 \\
\hline level & 550 & more & 518 \\
\hline more & 549 & out & 517 \\
\hline treaty & 547 & accordance & 496 \\
\hline $\mathrm{b}$ & 539 & offence & 487 \\
\hline out & 533 & need & 481 \\
\hline offence & 508 & application & 480 \\
\hline accordance & 506 & possible & 478 \\
\hline proposal & 500 & enforcement & 472 \\
\hline enforcement & 499 & offender & 470 \\
\hline application & 495 & made & 468 \\
\hline oj & 493 & access & 467 \\
\hline cases & 487 & area & 459 \\
\hline need & 487 & minimum & 458 \\
\hline possible & 481 & cases & 453 \\
\hline made & 480 & proposal & 452 \\
\hline
\end{tabular}


Annex 3

\begin{tabular}{|l|r|l|r|}
\hline offender & 480 & taken & 452 \\
\hline area & 478 & implementation & 447 \\
\hline data & 473 & procedure & 446 \\
\hline procedure & 471 & up & 445 \\
\hline access & 470 & specific & 444 \\
\hline convention & 468 & one & 443 \\
\hline implementation & 468 & paragraph & 442 \\
\hline minimum & 463 & data & 438 \\
\hline up & 461 & provided & 438 \\
\hline one & 460 & calls & 437 \\
\hline community & 459 & community & 437 \\
\hline taken & 459 & c & 436 \\
\hline specific & 457 & countries & 426 \\
\hline beings & 454 & rules & 423 \\
\hline provided & 448 & security & 422 \\
\hline security & 446 & assistance & 417 \\
\hline calls & 437 & convention & 417 \\
\hline countries & 433 & provide & 417 \\
\hline rules & 433 & question & 416 \\
\hline parliament & 423 & beings & 412 \\
\hline adopted & 421 & each & 408 \\
\hline
\end{tabular}

First 100 results for the Italian EU subcorpus

\begin{tabular}{|c|c|c|c|}
\hline Word & Frequency & Word & Frequency \\
\hline \multicolumn{2}{|c|}{ with notes } & \multicolumn{2}{|c|}{ without notes } \\
\hline membri & 2754 & membri & 2713 \\
\hline vittime & 2618 & vittime & 2582 \\
\hline articolo & 2006 & articolo & 1926 \\
\hline decisione & 1931 & decisione & 1832 \\
\hline commissione & 1812 & unione & 1763 \\
\hline unione & 1812 & vittima & 1753 \\
\hline vittima & 1770 & commissione & 1718 \\
\hline quadro & 1679 & quadro & 1592 \\
\hline consiglio & 1567 & reato & 1488 \\
\hline penale & 1557 & penale & 1472 \\
\hline reato & 1514 & misure & 1393 \\
\hline misure & 1410 & consiglio & 1377 \\
\hline diritto & 1404 & diritto & 1368 \\
\hline europea & 1363 & europea & 1296 \\
\hline diritti & 1339 & diritti & 1286 \\
\hline protezione & 1284 & protezione & 1250 \\
\hline europeo & 1191 & europeo & 1111 \\
\hline
\end{tabular}




\begin{tabular}{|c|c|c|c|}
\hline reati & 1130 & autorità & 1110 \\
\hline procedimento & 1065 & reati & 1109 \\
\hline risarcimento & 1057 & risarcimento & 1052 \\
\hline autorità & 1049 & procedimento & 1047 \\
\hline come & 1045 & come & 1028 \\
\hline quanto & 909 & quanto & 903 \\
\hline particolare & 895 & membro & 881 \\
\hline membro & 893 & particolare & 877 \\
\hline direttiva & 884 & assistenza & 868 \\
\hline assistenza & 872 & direttiva & 851 \\
\hline minori & 871 & minori & 836 \\
\hline materia & 851 & presente & 829 \\
\hline presente & 840 & materia & 809 \\
\hline giustizia & 839 & giustizia & 803 \\
\hline contro & 824 & parte & 787 \\
\hline parte & 795 & contro & 783 \\
\hline tratta & 762 & può & 770 \\
\hline cooperazione & 748 & tratta & 745 \\
\hline $\mathrm{c}$ & 739 & cooperazione & 727 \\
\hline può & 735 & persona & 711 \\
\hline persona & 718 & informazioni & 689 \\
\hline informazioni & 700 & disposizioni & 673 \\
\hline azione & 686 & livello & 673 \\
\hline disposizioni & 684 & azione & 668 \\
\hline art & 683 & persone & 654 \\
\hline esecuzione & 676 & ue & 652 \\
\hline livello & 674 & esecuzione & 644 \\
\hline ue & 669 & art & 634 \\
\hline persone & 667 & ambito & 626 \\
\hline paragrafo & 666 & paesi & 625 \\
\hline paesi & 643 & paragrafo & 625 \\
\hline ambito & 639 & caso & 591 \\
\hline caso & 604 & programma & 575 \\
\hline programma & 594 & applicazione & 563 \\
\hline applicazione & 580 & umani & 561 \\
\hline umani & 572 & cittadini & 555 \\
\hline cittadini & 571 & modo & 547 \\
\hline pag & 566 & pena & 531 \\
\hline pena & 558 & norme & 528 \\
\hline modo & 550 & proposta & 512 \\
\hline $\mathrm{n}$ & 536 & esseri & 509 \\
\hline proposta & 536 & sicurezza & 509 \\
\hline norme & 535 & trattato & 508 \\
\hline trattato & 531 & violenza & 505 \\
\hline sicurezza & 530 & nazionali & 500 \\
\hline punto & 521 & possono & 496 \\
\hline
\end{tabular}


Annex 3

\begin{tabular}{|c|c|c|c|}
\hline esseri & 519 & misura & 494 \\
\hline violenza & 507 & possibilità & 492 \\
\hline possono & 502 & domanda & 489 \\
\hline nazionali & 501 & libertà & 488 \\
\hline misura & 499 & dovrebbe & 482 \\
\hline dati & 497 & nazionale & 482 \\
\hline domanda & 489 & $\mathrm{~b}$ & 476 \\
\hline $\mathrm{b}$ & 486 & base & 469 \\
\hline relazione & 486 & dati & 469 \\
\hline nazionale & 484 & $\mathrm{n}$ & 468 \\
\hline dovrebbe & 483 & relazione & 465 \\
\hline base & 478 & valutazione & 447 \\
\hline possibilità & 458 & garantire & 438 \\
\hline attuazione & 454 & attuazione & 437 \\
\hline libertà & 452 & penali & 433 \\
\hline penali & 448 & bambini & 425 \\
\hline valutazione & 448 & sanzioni & 415 \\
\hline convenzione & 447 & convenzione & 413 \\
\hline $\mathrm{gu}$ & 447 & $\mathrm{c}$ & 411 \\
\hline garantire & 439 & giudice & 411 \\
\hline sanzioni & 437 & necessarie & 406 \\
\hline bambini & 436 & conto & 392 \\
\hline gai & 415 & mediazione & 390 \\
\hline giudice & 414 & devono & 389 \\
\hline necessarie & 411 & criminalità & 388 \\
\hline lotta & 405 & dovrebbero & 388 \\
\hline parlamento & 404 & sessuale & 388 \\
\hline mediazione & 398 & riguarda & 387 \\
\hline conto & 396 & sistema & 387 \\
\hline sessuale & 396 & accesso & 386 \\
\hline riguarda & 394 & inoltre & 386 \\
\hline settore & 394 & settore & 385 \\
\hline sistema & 393 & gai & 384 \\
\hline causa & 391 & lotta & 381 \\
\hline devono & 390 & necessario & 369 \\
\hline dovrebbero & 390 & fondamentali & 366 \\
\hline inoltre & 390 & nonché & 366 \\
\hline
\end{tabular}





\section{Annex 4}

\section{Candidate terms obtained with TermoStat Web 3.0 ${ }^{142}$}

First 100 results for the English EU corpus with notes

\begin{tabular}{|c|c|c|c|c|}
\hline $\begin{array}{c}\text { Candidate } \\
\text { (grouping variant) }\end{array}$ & Frequency & Specificity & Variants & Pattern \\
\hline victim & 4865 & 236.66 & victim. victims & Common_Noun \\
\hline proceeding & 1378 & 124.96 & proceeding. proceedings & Common_Noun \\
\hline measure & 1724 & 121.38 & measure. measures & Common_Noun \\
\hline compensation & 1281 & 117.67 & compensation & Common_Noun \\
\hline crime & 1804 & 117.59 & crime. crimes & Common_Noun \\
\hline protection & 1405 & 114.66 & protection. protections & Common_Noun \\
\hline offence & 1132 & 103.09 & offence. offences & Common_Noun \\
\hline criminal proceeding & 802 & 102.97 & $\begin{array}{lll}\begin{array}{l}\text { criminal proceeding. } \\
\text { proceedings }\end{array} & \text { criminal } \\
\end{array}$ & \begin{tabular}{|l|} 
Adjective \\
Common_Noun
\end{tabular} \\
\hline article & 1229 & 101.62 & article. articles & Common_Noun \\
\hline trafficking & 697 & 91.93 & trafficking & Common_Noun \\
\hline cooperation & 723 & 91.90 & cooperation & Common_Noun \\
\hline person & 1394 & 81.64 & person. persons & Common_Noun \\
\hline paragraph & 599 & 80.79 & paragraph. paragraphs & Common_Noun \\
\hline offender & 629 & 79.93 & offender. offenders & Common_Noun \\
\hline justice & 737 & 78.44 & justice & Common_Noun \\
\hline accordance & 506 & 75.50 & accordance & Common_Noun \\
\hline right & 1637 & 73.33 & right. rights & Common_Noun \\
\hline child & 2031 & 73.24 & child. children & Common_Noun \\
\hline provision & 889 & 71.11 & provision. provisions & Common_Noun \\
\hline enforcement & 477 & 69.36 & enforcement & Common_Noun \\
\hline law & 1305 & 68.76 & law. laws & Common_Noun \\
\hline mediation & 380 & 68.24 & mediation & Common_Noun \\
\hline human being & 418 & 67.25 & human being. human beings & \begin{tabular}{|l|} 
Adjective \\
Common_Noun
\end{tabular} \\
\hline penalty & 614 & 66.98 & penalty. penalties & Common_Noun \\
\hline competent authority & 341 & 66.97 & \begin{tabular}{|lrl}
$\begin{array}{l}\text { competent } \\
\text { authorities }\end{array}$ & authority. competent \\
\end{tabular} & \begin{tabular}{|l|} 
Adjective \\
Common_Noun \\
\end{tabular} \\
\hline implementation & 466 & 66.71 & implementation. implementations & Common_Noun \\
\hline crime victim & 338 & 66.55 & $\begin{array}{l}\text { crime victim. crime victims. crimes } \\
\text { victims }\end{array}$ & $\begin{array}{l}\text { Common_Noun } \\
\text { Common_Noun }\end{array}$ \\
\hline regard & 462 & 64.30 & regard. regards & Common_Noun \\
\hline authority & 1181 & 64.02 & authority. authorities & Common_Noun \\
\hline national law & 307 & 63.60 & national law. national laws & $\begin{array}{l}\text { Adjective } \\
\text { Common_Noun }\end{array}$ \\
\hline framework & 448 & 61.63 & framework. frameworks & Common_Noun \\
\hline exploitation & 343 & 60.06 & exploitation & Common_Noun \\
\hline procedure & 659 & 59.15 & procedure. procedures & Common_Noun \\
\hline
\end{tabular}

\footnotetext{
${ }^{142}$ The highlighted cells in the tables show the candidate terms that have been further analysed according to the steps
} descibed in Sections 3.3.3 and 3.3.5. 


\begin{tabular}{|c|c|c|c|c|}
\hline directive & 335 & 57.18 & directive. directives & Common_Noun \\
\hline legal person & 240 & 56.52 & legal person. legal persons & $\begin{array}{l}\text { Adjective } \\
\text { Common_Noun }\end{array}$ \\
\hline violence & 589 & 55.87 & violence & Common_Noun \\
\hline application & 562 & 55.07 & application. applications & Common_Noun \\
\hline objective & 479 & 54.88 & objective. objectives & Common_Noun \\
\hline necessary measure & 223 & 54.47 & $\begin{array}{|lll|}\begin{array}{l}\text { necessary } \\
\text { measures }\end{array} & \text { measure. } & \text { necessary } \\
\end{array}$ & $\begin{array}{l}\text { Adjective } \\
\text { Common_Noun }\end{array}$ \\
\hline sexual exploitation & 207 & 52.32 & sexual exploitation & \begin{tabular}{|l} 
Adjective \\
Common_Noun
\end{tabular} \\
\hline assistance & 391 & 52.25 & assistance & Common_Noun \\
\hline mutual recognition & 208 & 52.03 & mutual recognition & \begin{tabular}{|l|} 
Adjective \\
Common_Noun
\end{tabular} \\
\hline information & 998 & 51.29 & information & Common_Noun \\
\hline minimum standard & 207 & 51.21 & $\begin{array}{|lrr|}\begin{array}{l}\text { minimum } \\
\text { standards }\end{array} & \text { standard. } & \text { minimum } \\
\end{array}$ & $\begin{array}{l}\text { Adjective } \\
\text { Common_Noun }\end{array}$ \\
\hline prosecution & 275 & 50.66 & prosecution. prosecutions & Common_Noun \\
\hline decision & 886 & 50.31 & decision. decisions & Common_Noun \\
\hline proposal & 585 & 50.10 & proposal. proposals & Common_Noun \\
\hline residence & 329 & 49.88 & residence. residences & Common_Noun \\
\hline victim of crime & 191 & 49.80 & $\begin{array}{l}\text { victim of crime. victim of crimes. } \\
\text { victims of crimes }\end{array}$ & $\begin{array}{l}\text { Common_Noun } \\
\text { Preposition } \\
\text { Common_Noun }\end{array}$ \\
\hline preliminary ruling & 187 & 49.55 & 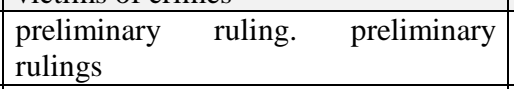 & \begin{tabular}{|l} 
Adjective \\
Common_Noun
\end{tabular} \\
\hline judicial cooperation & 184 & 49.45 & judicial cooperation & $\begin{array}{l}\text { Adjective } \\
\text { Common_Noun }\end{array}$ \\
\hline criminal matter & 185 & 49.43 & criminal matters & $\begin{array}{l}\text { Adjective } \\
\text { Common_Noun } \\
\end{array}$ \\
\hline judgment & 309 & 49.30 & judgment. judgments & Common_Noun \\
\hline area of freedom & 181 & 49.04 & area of freedom. areas of freedom & $\begin{array}{l}\text { Common_Noun } \\
\text { Preposition } \\
\text { Common_Noun }\end{array}$ \\
\hline child pornography & 182 & 49.03 & child pornography & $\begin{array}{l}\text { Common_Noun } \\
\text { Common_Noun }\end{array}$ \\
\hline third country & 181 & 48.89 & third country. third countries & $\begin{array}{l}\text { Adjective } \\
\text { Common_Noun } \\
\end{array}$ \\
\hline obligation & 313 & 48.84 & obligation. obligations & Common_Noun \\
\hline instrument & 344 & 48.75 & instrument. instruments & Common_Noun \\
\hline restorative justice & 178 & 48.63 & restorative justice & \begin{tabular}{|l} 
Adjective \\
Common_Noun
\end{tabular} \\
\hline recognition & 368 & 48.33 & recognition & Common_Noun \\
\hline principle & 564 & 47.95 & principle. principles & Common_Noun \\
\hline pornography & 193 & 47.87 & pornography & Common_Noun \\
\hline child victim & 171 & 47.19 & $\begin{array}{l}\text { child victim. child victims. children } \\
\text { victims }\end{array}$ & $\begin{array}{l}\text { Common_Noun } \\
\text { Common_Noun }\end{array}$ \\
\hline action & 825 & 47.12 & action. actions & Common_Noun \\
\hline protection measure & 167 & 47.10 & $\begin{array}{|lll|}\begin{array}{l}\text { protection } \\
\text { measures }\end{array} & \text { measure. } & \text { protection } \\
\end{array}$ & \begin{tabular}{|l|} 
Common_Noun \\
Common_Noun
\end{tabular} \\
\hline state & 885 & 46.62 & state. states & Common_Noun \\
\hline state compensation & 162 & 46.38 & state compensation & $\begin{array}{l}\text { Common_Noun } \\
\text { Common_Noun } \\
\end{array}$ \\
\hline personal datum & 160 & 45.77 & personal data & $\begin{array}{l}\text { Adjective } \\
\text { Common_Noun } \\
\end{array}$ \\
\hline protection order & 145 & 43.87 & protection order. protection orders & $\begin{array}{l}\text { Common_Noun } \\
\text { Common_Noun } \\
\end{array}$ \\
\hline access & 427 & 43.78 & access. accesses & Common_Noun \\
\hline fundamental right & 175 & 43.28 & fundamental right. fundamental rights & Adjective \\
\hline
\end{tabular}




\begin{tabular}{|c|c|c|c|c|}
\hline & & & & Common_Noun \\
\hline victim support & 141 & 43.25 & victim support & $\begin{array}{l}\text { Common_Noun } \\
\text { Common_Noun }\end{array}$ \\
\hline legislation & 402 & 43.05 & legislation. legislations & Common_Noun \\
\hline european protection & 138 & 42.79 & european protection & $\begin{array}{l}\text { Adjective } \\
\text { Common_Noun }\end{array}$ \\
\hline $\begin{array}{l}\text { european protection } \\
\text { order }\end{array}$ & 135 & 42.31 & european protection order & $\begin{array}{l}\text { Adjective } \\
\text { Common_Noun } \\
\text { Common_Noun }\end{array}$ \\
\hline criminal offence & 154 & 42.01 & criminal offence. criminal offences & $\begin{array}{l}\text { Adjective } \\
\text { Common_Noun }\end{array}$ \\
\hline national & 192 & 41.95 & nationals & Common_Noun \\
\hline sentence & 339 & 41.58 & sentence. sentences & Common_Noun \\
\hline jurisdiction & 213 & 40.74 & jurisdiction. jurisdictions & Common_Noun \\
\hline initiative & 314 & 40.56 & initiative. initiatives & Common_Noun \\
\hline protection of victim & 124 & 40.54 & protection of victims & $\begin{array}{l}\text { Common_Noun } \\
\text { Preposition } \\
\text { Common_Noun }\end{array}$ \\
\hline victimisation & 129 & 40.47 & victimisation & Common_Noun \\
\hline prevention & 231 & 39.30 & prevention & Common_Noun \\
\hline exploitation of child & 116 & 39.20 & $\begin{array}{l}\text { exploitation of child. exploitation of } \\
\text { children }\end{array}$ & $\begin{array}{l}\text { Common_Noun } \\
\text { Preposition } \\
\text { Common_Noun } \\
\end{array}$ \\
\hline adoption & 193 & 38.97 & adoption. adoptions & Common_Noun \\
\hline criminal law & 151 & 38.71 & criminal law. criminal laws & $\begin{array}{l}\text { Adjective } \\
\text { Common_Noun }\end{array}$ \\
\hline national court & 112 & 38.51 & national court. national courts & \begin{tabular}{|l|} 
Adjective \\
Common_Noun
\end{tabular} \\
\hline datum & 345 & 38.40 & data & Common_Noun \\
\hline framework decision & 111 & 38.34 & $\begin{array}{|lll|}\begin{array}{l}\text { framework } \\
\text { decisions }\end{array} & \text { decision. } & \text { framework } \\
\end{array}$ & \begin{tabular}{|l|} 
Common_Noun \\
Common_Noun \\
\end{tabular} \\
\hline sexual abuse & 128 & 38.34 & sexual abuse & \begin{tabular}{|l|} 
Adjective \\
Common_Noun \\
\end{tabular} \\
\hline freedom & 388 & 38.14 & freedom. freedoms & Common_Noun \\
\hline purpose & 489 & 38.10 & purpose. purposes & Common_Noun \\
\hline evaluation & 219 & 37.81 & evaluation. evaluations & Common_Noun \\
\hline asylum & 140 & 37.49 & asylum & Common_Noun \\
\hline court & 641 & 37.28 & court. courts & Common_Noun \\
\hline residence permit & 104 & 37.09 & residence permit. residence permits & $\begin{array}{l}\text { Common_Noun } \\
\text { Common_Noun }\end{array}$ \\
\hline natural person & 103 & 36.91 & natural person. natural persons & $\begin{array}{l}\text { Adjective } \\
\text { Common_Noun }\end{array}$ \\
\hline victim of trafficking & 102 & 36.73 & $\begin{array}{l}\text { victim of trafficking. victims of } \\
\text { trafficking }\end{array}$ & \begin{tabular}{|l|} 
Common_Noun \\
Preposition \\
Common_Noun \\
\end{tabular} \\
\hline imprisonment & 150 & 36.65 & imprisonment & Common_Noun \\
\hline
\end{tabular}

First 100 results for the English EU corpus without notes

\begin{tabular}{|l|r|r|l|l|}
\hline $\begin{array}{c}\text { Candidate } \\
\text { (grouping variant) }\end{array}$ & Frequency & Specificity & \multicolumn{1}{|c|}{ Variants } & \multicolumn{1}{|c|}{ Pattern } \\
\hline victim & 4795 & 242.22 & victim_victims & Common_Noun \\
\hline proceeding & 1349 & 127.39 & proceeding_proceedings & Common_Noun \\
\hline measure & 1697 & 124.06 & measure_measures & Common_Noun \\
\hline
\end{tabular}




\begin{tabular}{|c|c|c|c|c|}
\hline compensation & 1266 & 120.61 & compensation & Common_Noun \\
\hline crime & 1766 & 119.71 & crime_crimes & Common_Noun \\
\hline protection & 1374 & 116.71 & protection__protections & Common_Noun \\
\hline criminal proceeding & 779 & 104.66 & 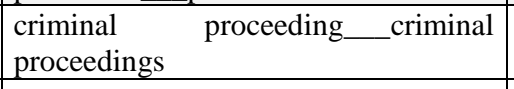 & \begin{tabular}{|l|l} 
Adjective \\
Common_Noun \\
\end{tabular} \\
\hline offence & 1101 & 104.56 & offence__offences & Common_Noun \\
\hline article & 1191 & 102.74 & article__articles & Common_Noun \\
\hline cooperation & 696 & 92.82 & cooperation & Common_Noun \\
\hline trafficking & 631 & 89.81 & trafficking & Common_Noun \\
\hline person & 1370 & 83.40 & person__persons & Common_Noun \\
\hline offender & 613 & 81.22 & offender__offenders & Common_Noun \\
\hline justice & 712 & 79.13 & justice & Common_Noun \\
\hline accordance & 496 & 77.03 & accordance & Common_Noun \\
\hline right & 1593 & 74.29 & right_rights & Common_Noun \\
\hline child & 1931 & 72.45 & child__children & Common_Noun \\
\hline provision & 868 & 72.22 & provision_provisions & Common_Noun \\
\hline paragraph & 471 & 72.11 & paragraph__paragraphs & Common_Noun \\
\hline mediation & 372 & 69.60 & mediation & Common_Noun \\
\hline enforcement & 451 & 69.14 & enforcement & Common_Noun \\
\hline law & 1251 & 68.65 & law_laws & Common_Noun \\
\hline competent authority & 336 & 68.56 & $\begin{array}{|ll|}\begin{array}{l}\text { competent } \\
\text { authorities }\end{array} & \text { authority__competent } \\
\end{array}$ & $\begin{array}{l}\text { Adjective } \\
\text { Common_Noun } \\
\end{array}$ \\
\hline implementation & 445 & 66.86 & implementation__implementations & Common_Noun \\
\hline penalty & 585 & 66.81 & penalty__penalties & Common_Noun \\
\hline crime victim & 319 & 66.65 & \begin{tabular}{|l} 
crime \\
victims_crimes victims
\end{tabular} & $\begin{array}{l}\text { Common_Noun } \\
\text { Commo__Noun }\end{array}$ \\
\hline human being & 384 & 65.96 & human beings & $\begin{array}{l}\text { Adjective } \\
\text { Common_Noun }\end{array}$ \\
\hline authority & 1169 & 65.94 & authority__authorities & Common_Noun \\
\hline regard & 457 & 65.94 & regard__regards & Common_Noun \\
\hline national law & 305 & 65.38 & national law__national laws & $\begin{array}{l}\text { Adjective } \\
\text { Common_Noun }\end{array}$ \\
\hline framework & 431 & 62.00 & framework_frameworks & Common_Noun \\
\hline procedure & 645 & 60.19 & procedure_procedures & Common_Noun \\
\hline exploitation & 310 & 58.26 & exploitation & Common_Noun \\
\hline legal person & 239 & 58.17 & legal person__legal persons & $\begin{array}{l}\text { Adjective } \\
\text { Common_Noun } \\
\end{array}$ \\
\hline violence & 582 & 57.33 & violence & Common_Noun \\
\hline objective & 475 & 56.44 & objective__objectives & Common_Noun \\
\hline directive & 312 & 56.40 & directive_directives & Common_Noun \\
\hline necessary measure & 222 & 56.05 & $\begin{array}{|ll|}\begin{array}{l}\text { necessary } \\
\text { measures }\end{array} & \text { measure__necessary } \\
\end{array}$ & \begin{tabular}{|l|} 
Adjective \\
Common_Noun \\
\end{tabular} \\
\hline application & 546 & 55.70 & application__applications & Common_Noun \\
\hline assistance & 389 & 53.85 & assistance & Common_Noun \\
\hline mutual recognition & 205 & 53.27 & mutual recognition & $\begin{array}{l}\text { Adjective } \\
\text { Common_Noun }\end{array}$ \\
\hline minimum standard & 206 & 52.69 & $\begin{array}{l}\begin{array}{l}\text { minimum } \\
\text { standards }\end{array} \quad \text { standard__minimum } \\
\end{array}$ & $\begin{array}{l}\text { Adjective } \\
\text { Common_Noun } \\
\end{array}$ \\
\hline information & 971 & 52.00 & information & Common_Noun \\
\hline prosecution & 272 & 51.96 & prosecution__prosecutions & Common_Noun \\
\hline sexual exploitation & 190 & 51.68 & sexual exploitation & $\begin{array}{l}\text { Adjective } \\
\text { Common_Noun }\end{array}$ \\
\hline
\end{tabular}




\begin{tabular}{|c|c|c|c|c|}
\hline victim of crime & 190 & 51.23 & $\begin{array}{l}\text { victim of crime_victim of } \\
\text { crimes_victims of crimes }\end{array}$ & \begin{tabular}{|l|} 
Common_Noun \\
Preposition \\
Common_Noun \\
\end{tabular} \\
\hline preliminary ruling & 187 & 51.11 & $\begin{array}{l}\text { preliminary ruling__preliminary } \\
\text { rulings }\end{array}$ & $\begin{array}{l}\text { Adjective } \\
\text { Common_Noun }\end{array}$ \\
\hline decision & 863 & 51.05 & decision__decisions & Common_Noun \\
\hline residence & 321 & 50.65 & residence__residences & Common_Noun \\
\hline obligation & 307 & 49.78 & obligation_obligations & Common_Noun \\
\hline judicial cooperation & 175 & 49.74 & judicial cooperation & $\begin{array}{l}\text { Adjective } \\
\text { Common_Noun }\end{array}$ \\
\hline restorative justice & 175 & 49.74 & restorative justice & $\begin{array}{l}\text { Adjective } \\
\text { Common_Noun }\end{array}$ \\
\hline third country & 176 & 49.72 & third country_third countries & $\begin{array}{l}\text { Adjective } \\
\text { Common_Noun }\end{array}$ \\
\hline instrument & 336 & 49.54 & instrument__instruments & Common_Noun \\
\hline child pornography & 173 & 49.29 & child pornography & $\begin{array}{l}\text { Common_Noun } \\
\text { Common_Noun }\end{array}$ \\
\hline recognition & 359 & 49.05 & recognition & Common_Noun \\
\hline area of freedom & 170 & 49.02 & area of freedom__areas of freedom & $\begin{array}{l}\text { Common_Noun } \\
\text { Preposition } \\
\text { Common_Noun }\end{array}$ \\
\hline criminal matter & 170 & 48.85 & criminal matters & \begin{tabular}{|l|} 
Adjective \\
Common_Noun
\end{tabular} \\
\hline child victim & 171 & 48.68 & \begin{tabular}{|lr} 
child & victim__child \\
victims_children victims
\end{tabular} & \begin{tabular}{|l|} 
Common_Noun \\
Common_Noun \\
\end{tabular} \\
\hline principle & 550 & 48.66 & principle_principles & Common_Noun \\
\hline protection measure & 167 & 48.58 & $\begin{array}{l}\text { protection measure__protection } \\
\text { measures }\end{array}$ & \begin{tabular}{|l|} 
Common_Noun \\
Common_Noun \\
\end{tabular} \\
\hline action & 810 & 48.22 & action_actions & Common_Noun \\
\hline proposal & 536 & 47.99 & proposal__proposals & Common_Noun \\
\hline state compensation & 160 & 47.54 & state compensation & $\begin{array}{l}\text { Common_Noun } \\
\text { Common_Noun }\end{array}$ \\
\hline pornography & 180 & 47.51 & pornography & Common_Noun \\
\hline state & 856 & 46.98 & state__states & Common_Noun \\
\hline judgment & 272 & 46.43 & judgment__judgments & Common_Noun \\
\hline protection order & 145 & 45.24 & protection order__protection orders & $\begin{array}{l}\text { Common_Noun } \\
\text { Common_Noun }\end{array}$ \\
\hline access & 424 & 45.15 & access__accesses & Common_Noun \\
\hline personal datum & 143 & 44.58 & personal data & \begin{tabular}{|l|} 
Adjective \\
Common_Noun
\end{tabular} \\
\hline fundamental right & 173 & 44.37 & $\begin{array}{l}\text { fundamental right__fundamental } \\
\text { rights }\end{array}$ & \begin{tabular}{|l|} 
Adjective \\
Common_Noun
\end{tabular} \\
\hline victim support & 139 & 44.29 & victim support & \begin{tabular}{|l} 
Common_Noun \\
Common_Noun \\
\end{tabular} \\
\hline european protection & 138 & 44.13 & european protection & $\begin{array}{l}\text { Adjective } \\
\text { Common_Noun }\end{array}$ \\
\hline $\begin{array}{l}\text { european protection } \\
\text { order }\end{array}$ & 135 & 43.64 & european protection order & $\begin{array}{l}\text { Adjective } \\
\text { Common_Noun } \\
\text { Common_Noun }\end{array}$ \\
\hline legislation & 391 & 43.58 & legislation & Common_Noun \\
\hline criminal offence & 152 & 43.03 & criminal offence__criminal offences & \begin{tabular}{|l|} 
Adjective \\
Common_Noun \\
\end{tabular} \\
\hline national & 186 & 42.43 & nationals & Common_Noun \\
\hline protection of victim & 123 & 41.64 & protection of victims & $\begin{array}{l}\text { Common_Noun } \\
\text { Preposition } \\
\text { Common_Noun }\end{array}$ \\
\hline victimisation & 128 & 41.57 & victimisation & Common_Noun \\
\hline jurisdiction & 204 & 40.82 & jurisdiction__ jurisdictions & Common_Noun \\
\hline sentence & 313 & 40.22 & sentence__sentences & Common_Noun \\
\hline
\end{tabular}




\begin{tabular}{|l|r|r|l|l|}
\hline initiative & 298 & 40.20 & initiative__initiatives & Common_Noun \\
\hline national court & 112 & 39.72 & national court_national courts & $\begin{array}{l}\text { Adjective } \\
\text { Common_Noun }\end{array}$ \\
\hline adoption & 189 & 39.68 & adoption__adoptions & Common_Noun \\
\hline criminal law & 148 & 39.47 & criminal law_criminal laws & $\begin{array}{l}\text { Adjective } \\
\text { Common_Noun }\end{array}$ \\
\hline framework decision & 110 & 39.36 & $\begin{array}{l}\text { framework_decision_framework } \\
\text { decisions }\end{array}$ & $\begin{array}{l}\text { Common_Noun } \\
\text { Common_Noun }\end{array}$ \\
\hline evaluation & 218 & 38.99 & evaluation_evaluations & Common_Noun \\
\hline sexual abuse & 124 & 38.86 & sexual abuse & $\begin{array}{l}\text { Adjective } \\
\text { Common_Noun }\end{array}$ \\
\hline prevention & 216 & 38.58 & prevention & Common_Noun \\
\hline purpose & 475 & 38.55 & purpose_purposes & Common_Noun \\
\hline asylum & 139 & 38.54 & asylum & Common_Noun \\
\hline exploitation of child & 104 & 38.26 & $\begin{array}{l}\text { exploitation of child_exploitation } \\
\text { of children }\end{array}$ & $\begin{array}{l}\text { Common_Noun } \\
\text { Preposition } \\
\text { Common_Noun }\end{array}$ \\
\hline court & 629 & 38.20 & court_courts & Common_Noun \\
\hline natural person & 103 & 38.08 & natural person_natural persons & $\begin{array}{l}\text { Adjective } \\
\text { Common_Noun }\end{array}$ \\
\hline freedom & 369 & 37.78 & freedom_freedoms & Common_Noun \\
\hline residence permit & 100 & 37.51 & residence permit_residence permits & $\begin{array}{l}\text { Common_Noun } \\
\text { Common_Noun }\end{array}$ \\
\hline & & & victim_of trafficking__victims & $\begin{array}{l}\text { Common_Noun } \\
\text { Preposition } \\
\text { Common_Noun }\end{array}$ \\
\hline victim of trafficking & 97 & 36.94 & Common_Noun \\
\hline tatum & 316 & 36.77 & data & Common_Noun \\
\hline possibility & 367 & 36.76 & possibility_possibilities & Common_Noun \\
\hline abuse & 244 & 36.75 & abuse_abuses & \\
\hline
\end{tabular}

First 100 results for the Italian EU corpus with notes ${ }^{143}$

\begin{tabular}{|c|c|c|c|c|}
\hline $\begin{array}{c}\text { Candidate } \\
\text { (grouping variant) }\end{array}$ & Frequency & Specificity & Variants & Pattern \\
\hline stati membro & 2459 & 358.65 & stati membri & \begin{tabular}{|l|} 
Adjective \\
Common_Noun
\end{tabular} \\
\hline vittima & 4076 & 313.4 & vittima_vittime & Common_Noun \\
\hline reato & 2528 & 274.56 & reato__reati & Common_Noun \\
\hline risarcimento & 1068 & 189.87 & risarcimento__risarcimenti & Common_Noun \\
\hline procedimento & 1257 & 185.03 & procedimento__procedimenti & Common_Noun \\
\hline decisione quadro & 803 & 181.03 & decisione quadro__decisioni quadro & $\begin{array}{l}\text { Common_Noun } \\
\text { Adjective }\end{array}$ \\
\hline procedimento penale & 713 & 179.82 & $\begin{array}{l}\text { procedimento penale_procedimento } \\
\text { penali__procedimenti penali }\end{array}$ & $\begin{array}{l}\text { Common_Noun } \\
\text { Adjective }\end{array}$ \\
\hline vittima di reato & 438 & 140.28 & $\begin{array}{l}\text { vittima di reato__vittima di } \\
\text { reati_vittime di reati }\end{array}$ & \begin{tabular}{|l|} 
Common_Noun \\
Preposition \\
Common_Noun \\
\end{tabular} \\
\hline presente direttiva & 367 & 138.39 & presente direttiva & \begin{tabular}{|l|} 
Adjective \\
Common_Noun \\
\end{tabular} \\
\hline decisione quadro & 495 & 138.04 & decisione quadro__decisioni quadro & \begin{tabular}{|l|} 
Common_Noun \\
Common_Noun \\
\end{tabular} \\
\hline dell'unione & 266 & 117.75 & dell'unione & Common_Noun \\
\hline
\end{tabular}

\footnotetext{
${ }^{143}$ When Italian texts are processed by TermoStat Web 3.0, the output contains a higher degree of noise as compared to the English results (see also Section 3.3.3.1.2), for instance when articles are not recognised as such, as in the case of "nell'ambito" or "all'articolo". Moreover, the software often changes the gender of the adjectives into the singular masculine form, such as in "stati membro" and "persona giuridico".
} 


\begin{tabular}{|c|c|c|c|c|}
\hline stato membro & 254 & 115.06 & stato membro & $\begin{array}{l}\text { Adjective } \\
\text { Common_Noun }\end{array}$ \\
\hline tratta & 500 & 104.69 & tratta & Common_Noun \\
\hline stato di esecuzione & 216 & 103.6 & stato di esecuzione & $\begin{array}{l}\text { Common_Noun } \\
\text { Preposition } \\
\text { Common_Noun }\end{array}$ \\
\hline nell'ambito & 193 & 100.23 & nell'ambito & Common_Noun \\
\hline articolo & 1903 & 99.81 & articolo__articoli & Common_Noun \\
\hline mediazione & 395 & 99.49 & mediazione & Common_Noun \\
\hline altro stato & 183 & 97.58 & altro stato__altri stati & $\begin{array}{l}\text { Adjective } \\
\text { Common_Noun }\end{array}$ \\
\hline giudice & 481 & 93.24 & giudice__giudici & Common_Noun \\
\hline persona giuridico & 233 & 90.42 & $\begin{array}{l}\text { persona } \\
\text { giuridiche }\end{array} \quad$ giuridica__persone & $\begin{array}{l}\text { Common_Noun } \\
\text { Adjective }\end{array}$ \\
\hline decisione & 2175 & 88.45 & decisione__decisioni & Common_Noun \\
\hline protezione europeo & 147 & 86.49 & \begin{tabular}{|l}
$\begin{array}{l}\text { protezione } \\
\text { europi }\end{array}$ \\
europeo__protezione \\
\end{tabular} & $\begin{array}{l}\text { Common_Noun } \\
\text { Adjective }\end{array}$ \\
\hline racc & 137 & 84.35 & racc & Common_Noun \\
\hline membro & 3578 & 81.48 & membro__membri & Common_Noun \\
\hline protezione & 1234 & 81.28 & protezione & Common_Noun \\
\hline dell'unione europeo & 127 & 81.19 & dell'unione europea & $\begin{array}{l}\text { Common_Noun } \\
\text { Adjective }\end{array}$ \\
\hline presente decisione & 123 & 79.89 & presente decisione & $\begin{array}{l}\text { Adjective } \\
\text { Common_Noun }\end{array}$ \\
\hline all'articolo & 119 & 78.57 & all'articolo & Common_Noun \\
\hline essere umano & 505 & 77.41 & esseri umani & $\begin{array}{l}\text { Common_Noun } \\
\text { Adjective }\end{array}$ \\
\hline l'art & 113 & 76.55 & l'art & Common_Noun \\
\hline lett & 113 & 75.18 & lett & Common_Noun \\
\hline riparatoria & 111 & 73.49 & riparatoria & Common_Noun \\
\hline $\begin{array}{l}\text { reciproco } \\
\text { riconoscimento }\end{array}$ & 103 & 73.05 & reciproco riconoscimento & $\begin{array}{l}\text { Adjective } \\
\text { Common_Noun }\end{array}$ \\
\hline giustizia riparatoria & 108 & 72.75 & giustizia riparatoria & $\begin{array}{l}\text { Common_Noun } \\
\text { Common_Noun }\end{array}$ \\
\hline misura di protezione & 168 & 72.33 & $\begin{array}{l}\text { misura di protezione__misure di } \\
\text { protezione }\end{array}$ & $\begin{array}{l}\text { Common_Noun } \\
\text { Preposition } \\
\text { Common_Noun }\end{array}$ \\
\hline pena|pene & 254 & 72.22 & pene & Common_Noun \\
\hline stato di emissione & 100 & 71.97 & stato di emissione & $\begin{array}{l}\text { Common_Noun } \\
\text { Preposition } \\
\text { Common_Noun }\end{array}$ \\
\hline esecuzione & 630 & 71.68 & esecuzione & Common_Noun \\
\hline piano d' azione & 99 & 71.6 & piano d' azione__piani d' azione & $\begin{array}{l}\text { Common_Noun } \\
\text { Preposition } \\
\text { Common_Noun }\end{array}$ \\
\hline condannato & 168 & 70.56 & condannato__condannati & Common_Noun \\
\hline ordine di protezione & 95 & 70.13 & $\begin{array}{l}\text { ordine di protezione__ordini di } \\
\text { protezione }\end{array}$ & $\begin{array}{l}\text { Common_Noun } \\
\text { Preposition } \\
\text { Common_Noun }\end{array}$ \\
\hline pubblico ministero & 93 & 69.38 & $\begin{array}{l}\begin{array}{l}\text { pubblico } \\
\text { ministeri }\end{array} \\
\end{array}$ & $\begin{array}{l}\text { Adjective } \\
\text { Common_Noun }\end{array}$ \\
\hline $\begin{array}{lll}\text { tratta di essere } \\
\text { umano }\end{array}$ & 201 & 69.23 & tratta di esseri umani & $\begin{array}{l}\text { Common_Noun } \\
\text { Preposition } \\
\text { Common_Noun } \\
\text { Adjective } \\
\end{array}$ \\
\hline pena & 554 & 67.94 & pena & Common_Noun \\
\hline maggiore parte & 88 & 67.47 & maggior parte & \begin{tabular}{|l|} 
Adjective \\
Common_Noun
\end{tabular} \\
\hline
\end{tabular}




\begin{tabular}{|c|c|c|c|c|}
\hline misura necessario & 265 & 67.21 & $\begin{array}{|lc|}\begin{array}{l}\text { misura } \\
\text { necessarie }\end{array} & \text { necessaria__misure } \\
\end{array}$ & $\begin{array}{l}\text { Common_Noun } \\
\text { Adjective }\end{array}$ \\
\hline $\begin{array}{l}\text { ordine di protezione } \\
\text { europeo }\end{array}$ & 86 & 66.69 & $\begin{array}{|lrrr|}\begin{array}{l}\text { ordine } \\
\text { europeo__ordini } \\
\text { europei }\end{array} & \text { di } & \begin{array}{l}\text { protezione } \\
\text { protezione }\end{array} \\
\end{array}$ & $\begin{array}{l}\text { Common_Noun } \\
\text { Preposition } \\
\text { Common_Noun } \\
\text { Adjective }\end{array}$ \\
\hline misura & 1827 & 66.48 & misura__misure & Common_Noun \\
\hline essere & 515 & 65.67 & essere__esseri & Common_Noun \\
\hline autorità di assistenza & 83 & 65.5 & autorità di assistenza & $\begin{array}{l}\text { Common_Noun } \\
\text { Preposition } \\
\text { Common_Noun }\end{array}$ \\
\hline pronuncia & 112 & 65.43 & pronuncia & Common_Noun \\
\hline assistenza & 729 & 65.33 & assistenza & Common_Noun \\
\hline artt & 85 & 65.11 & artt & Common_Noun \\
\hline tratta di essere & 178 & 65.02 & tratta di esseri & $\begin{array}{l}\text { Common_Noun } \\
\text { Preposition } \\
\text { Common_Noun }\end{array}$ \\
\hline minore & 142 & 64.78 & minore_minori & Common_Noun \\
\hline norma minimo & 215 & 64.22 & norma minima__norme minime & $\begin{array}{l}\text { Common_Noun } \\
\text { Adjective }\end{array}$ \\
\hline libero circolazione & 77 & 63.06 & libera circolazione & $\begin{array}{l}\text { Adjective } \\
\text { Common_Noun }\end{array}$ \\
\hline la commissione & 77 & 63.06 & la commissione & $\begin{array}{l}\text { Adjective } \\
\text { Common_Noun }\end{array}$ \\
\hline persona & 1350 & 63.03 & persona_persone & Common_Noun \\
\hline $\begin{array}{l}\text { pronuncia } \\
\text { pregiudiziale }\end{array}$ & 78 & 62.64 & pronuncia pregiudiziale & $\begin{array}{l}\text { Common_Noun } \\
\text { Adjective }\end{array}$ \\
\hline all'art & 76 & 62.64 & all'art & Common_Noun \\
\hline l'articolo & 75 & 62.22 & l'articolo & Common_Noun \\
\hline gepd & 74 & 61.8 & gepd & Common_Noun \\
\hline $\begin{array}{l}\text { sfruttamento } \\
\text { sessuale }\end{array}$ & 212 & 61.51 & sfruttamento sessuale & $\begin{array}{l}\text { Common_Noun } \\
\text { Adjective }\end{array}$ \\
\hline persona protetto & 75 & 61.38 & persona protetta & $\begin{array}{l}\text { Common_Noun } \\
\text { Adjective }\end{array}$ \\
\hline $\operatorname{sig}$ & 132 & 59.79 & sig & Common_Noun \\
\hline sanzione & 548 & 59.33 & sanzione__sanzioni & Common_Noun \\
\hline risarcimento statale & 68 & 58.76 & $\begin{array}{|ll|}\begin{array}{l}\text { risarcimento } \\
\text { statali }\end{array} & \text { statale__risarcimento } \\
\end{array}$ & $\begin{array}{l}\text { Common_Noun } \\
\text { Adjective }\end{array}$ \\
\hline assistenza al vittima & 92 & 58.55 & $\begin{array}{l}\text { assistenza alla vittima__assistenza } \\
\text { alle vittime }\end{array}$ & $\begin{array}{l}\text { Common_Noun } \\
\text { Preposition } \\
\text { Common_Noun }\end{array}$ \\
\hline materia penale & 153 & 57.89 & materia penale__materie penali & $\begin{array}{l}\text { Common_Noun } \\
\text { Adjective }\end{array}$ \\
\hline autorità di decisione & 65 & 57.86 & autorità di decisione & $\begin{array}{l}\text { Common_Noun } \\
\text { Preposition } \\
\text { Common_Noun }\end{array}$ \\
\hline cinque anno & 65 & 57.86 & cinque anni & $\begin{array}{l}\text { Adjective } \\
\text { Common_Noun }\end{array}$ \\
\hline titolo di soggiorno & 100 & 57.6 & 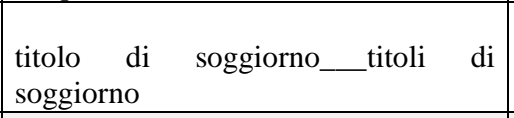 & $\begin{array}{l}\text { Common_Noun } \\
\text { Preposition } \\
\text { Common_Noun }\end{array}$ \\
\hline $\begin{array}{l}\text { sistema di } \\
\text { risarcimento }\end{array}$ & 68 & 57.47 & $\begin{array}{l}\text { sistema di risarcimento__sistemi di } \\
\text { risarcimento }\end{array}$ & $\begin{array}{l}\text { Common_Noun } \\
\text { Preposition } \\
\text { Common_Noun }\end{array}$ \\
\hline ce & 305 & 57.29 & ce & Common_Noun \\
\hline indennizzo & 213 & 57.23 & indennizzo__indennizzi & Common_Noun \\
\hline $\begin{array}{ll}\text { domanda } & \text { di } \\
\text { risarcimento } & \\
\end{array}$ & 63 & 56.95 & $\begin{array}{l}\text { domanda di risarcimento__domande } \\
\text { di risarcimento }\end{array}$ & $\begin{array}{l}\text { Common_Noun } \\
\text { Preposition } \\
\text { Common_Noun }\end{array}$ \\
\hline
\end{tabular}




\begin{tabular}{|c|c|c|c|c|}
\hline in & 200 & 56.64 & in & Common_Noun \\
\hline autorità competente & 234 & 56.64 & $\begin{array}{|lc|}\begin{array}{l}\text { autorità } \\
\text { competenti }\end{array} & \text { competente__autorità } \\
\end{array}$ & $\begin{array}{l}\text { Common_Noun } \\
\text { Adjective }\end{array}$ \\
\hline per & 170 & 56.42 & per & Common_Noun \\
\hline sentenza & 366 & 56.22 & sentenza__sentenze & Common_Noun \\
\hline deposizione & 79 & 56.2 & deposizione__deposizioni & Common_Noun \\
\hline giustizia & 798 & 55.93 & giustizia & Common_Noun \\
\hline giudice nazionale & 91 & 55.82 & giudice nazionale__giudici nazionali & $\begin{array}{l}\text { Common_Noun } \\
\text { Adjective }\end{array}$ \\
\hline l'autorità & 60 & 55.56 & l'autorità & Common_Noun \\
\hline diritto & 2591 & 55.39 & diritto__diritti & Common_Noun \\
\hline art & 140 & 55.23 & art & Common_Noun \\
\hline il & 477 & 55.09 & il & Common_Noun \\
\hline slsg & 60 & 55.08 & slsg & Common_Noun \\
\hline $\begin{array}{ll}\text { domanda } & \text { di } \\
\text { pronuncia }\end{array}$ & 57 & 54.13 & $\begin{array}{l}\text { domanda di pronuncia__domande di } \\
\text { pronuncia }\end{array}$ & $\begin{array}{l}\text { Common_Noun } \\
\text { Preposition } \\
\text { Common_Noun }\end{array}$ \\
\hline l'unione & 56 & 53.64 & l'unione & Common_Noun \\
\hline persona fisico & 116 & 53.2 & persona fisica__persone fisiche & $\begin{array}{l}\text { Common_Noun } \\
\text { Adjective }\end{array}$ \\
\hline dell'art & 55 & 53.15 & dell'art & Common_Noun \\
\hline paragrafo & 711 & 52.78 & paragrafo__paragrafi & Common_Noun \\
\hline stato di condanna & 54 & 52.66 & stato di condanna__stati di condanna & $\begin{array}{l}\text { Common_Noun } \\
\text { Preposition } \\
\text { Common_Noun }\end{array}$ \\
\hline $\begin{array}{l}\text { particolare } \\
\text { attenzione }\end{array}$ & 53 & 52.16 & particolare attenzione & $\begin{array}{l}\text { Adjective } \\
\text { Common_Noun }\end{array}$ \\
\hline $\begin{array}{l}\text { procedimento } \quad \mathrm{di} \\
\text { mediazione }\end{array}$ & 53 & 52.16 & $\begin{array}{|ll|}\begin{array}{l}\text { procedimento } \\
\text { mediazione_procedimenti } \\
\text { mediazione_pre }\end{array} & \text { di } \\
\end{array}$ & $\begin{array}{l}\text { Common_Noun } \\
\text { Preposition } \\
\text { Common_Noun }\end{array}$ \\
\hline $\begin{array}{l}\text { questione } \\
\text { pregiudiziale }\end{array}$ & 74 & 51.99 & $\begin{array}{l}\text { questione pregiudiziale__questioni } \\
\text { pregiudiziali }\end{array}$ & $\begin{array}{l}\text { Common_Noun } \\
\text { Adjective }\end{array}$ \\
\hline $\begin{array}{ll}\text { domanda } & \text { di } \\
\text { pronuncia } & \\
\text { pregiudiziale } & \\
\end{array}$ & 53 & 51.65 & 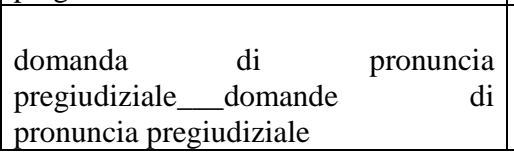 & $\begin{array}{l}\text { Common_Noun } \\
\text { Preposition } \\
\text { Common_Noun } \\
\text { Adjective }\end{array}$ \\
\hline
\end{tabular}

First 100 results for the Italian EU corpus without notes

\begin{tabular}{|c|c|c|c|c|}
\hline $\begin{array}{c}\text { Candidate } \\
\text { (grouping variant) }\end{array}$ & Frequency & Specificity & Variants & Pattern \\
\hline stati membro & 2423 & 365.45 & stati membri & Adjective Common_Noun \\
\hline vittima & 4023 & 318.76 & vittima_vittime & Common_Noun \\
\hline reato & 2481 & 278.23 & reato__reati & Common_Noun \\
\hline risarcimento & 1063 & 194.38 & risarcimento__risarcimenti & Common_Noun \\
\hline procedimento & 1229 & 186.91 & procedimento__procedimenti & Common_Noun \\
\hline decisione quadro & 774 & 181.73 & decisione quadro__decisioni quadro & Common_Noun Adjective \\
\hline procedimento penale & 691 & 181.36 & $\begin{array}{l}\text { procedimento } \\
\text { penale__procedimento } \\
\text { penali__procedimenti penali }\end{array}$ & Common_Noun Adjective \\
\hline vittima di reato & 426 & 141.75 & $\begin{array}{l}\text { vittima di reato__vittima di } \\
\text { reati_vittime di reati }\end{array}$ & $\begin{array}{l}\text { Common_Noun } \\
\text { Preposition } \\
\text { Common_Noun }\end{array}$ \\
\hline
\end{tabular}




\begin{tabular}{|c|c|c|c|c|}
\hline presente direttiva & 363 & 141.28 & presente direttiva & Adjective Common_Noun \\
\hline decisione quadro & 446 & 132.6 & decisione quadro_decisioni quadro & $\begin{array}{l}\text { Common_Noun } \\
\text { Common_Noun }\end{array}$ \\
\hline dell'unione & 254 & 118.11 & dell'unione & Common_Noun \\
\hline stato membro & 250 & 117.17 & stato membro & Adjective Common_Noun \\
\hline stato di esecuzione & 215 & 106.09 & stato di esecuzione & $\begin{array}{l}\text { Common_Noun } \\
\text { Preposition } \\
\text { Common_Noun }\end{array}$ \\
\hline tratta & 487 & 105.34 & tratta & Common_Noun \\
\hline nell'ambito & 188 & 101.54 & nell'ambito & Common_Noun \\
\hline mediazione & 387 & 100.62 & mediazione & Common_Noun \\
\hline altro stato & 178 & 98.78 & altro stato__altri stati & Adjective Common_Noun \\
\hline articolo & 1810 & 97.77 & articolo__articoli & Common_Noun \\
\hline giudice & 477 & 95.19 & giudice__giudici & Common_Noun \\
\hline persona giuridico & 232 & 92.59 & $\begin{array}{l}\text { persona } \\
\text { giuridiche }\end{array} \quad$ giuridica__persone & Common_Noun Adjective \\
\hline protezione europeo & 143 & 87.53 & $\begin{array}{l}\text { protezione } \\
\text { europei }\end{array}$ & Common_Noun Adjective \\
\hline decisione & 2065 & 86.41 & decisione__decisioni & Common_Noun \\
\hline membro & 3523 & 83.45 & membro__membri & Common_Noun \\
\hline protezione & 1200 & 81.55 & protezione & Common_Noun \\
\hline presente decisione & 121 & 81.34 & presente decisione & Adjective Common_Noun \\
\hline dell'unione europeo & 119 & 80.66 & dell'unione europea & Common_Noun Adjective \\
\hline all'articolo & 116 & 79.62 & all'articolo & Common_Noun \\
\hline l'art & 112 & 78.23 & l'art & Common_Noun \\
\hline essere umano & 495 & 78.22 & esseri umani & Common_Noun Adjective \\
\hline lett & 111 & 76.46 & lett & Common_Noun \\
\hline $\begin{array}{l}\text { reciproco } \\
\text { riconoscimento }\end{array}$ & 102 & 74.62 & reciproco riconoscimento & Adjective Common_Noun \\
\hline riparatoria & 108 & 74.34 & riparatoria & Common_Noun \\
\hline misura di protezione & 168 & 74.29 & $\begin{array}{l}\text { misura di protezione__misure di } \\
\text { protezione }\end{array}$ & $\begin{array}{l}\text { Common_Noun } \\
\text { Preposition } \\
\text { Common_Noun }\end{array}$ \\
\hline stato di emissione & 100 & 73.88 & stato di emissione & $\begin{array}{l}\text { Common_Noun } \\
\text { Preposition } \\
\text { Common_Noun }\end{array}$ \\
\hline giustizia riparatoria & 105 & 73.57 & giustizia riparatoria & $\begin{array}{l}\text { Common_Noun } \\
\text { Common_Noun }\end{array}$ \\
\hline pena|pene & 245 & 72.07 & pene & Common_Noun \\
\hline piano d' azione & 95 & 71.99 & piano d' azione__piani d' azione & $\begin{array}{l}\text { Common_Noun } \\
\text { Preposition } \\
\text { Common_Noun }\end{array}$ \\
\hline pubblico ministero & 93 & 71.22 & 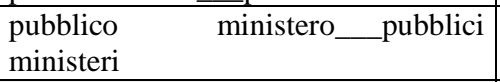 & Adjective Common_Noun \\
\hline ordine di protezione & 93 & 71.22 & $\begin{array}{l}\text { ordine di protezione__ordini di } \\
\text { protezione }\end{array}$ & $\begin{array}{l}\text { Common_Noun } \\
\text { Preposition } \\
\text { Common_Noun }\end{array}$ \\
\hline esecuzione & 600 & 70.4 & esecuzione & Common_Noun \\
\hline condannato & 161 & 70.28 & condannato__condannati & Common_Noun \\
\hline $\begin{array}{lll}\text { tratta } & \text { di } & \text { essere } \\
\text { umano } & & \\
\end{array}$ & 193 & 68.9 & tratta di esseri umani & $\begin{array}{l}\text { Common_Noun } \\
\text { Preposition } \\
\text { Common_Noun Adjective }\end{array}$ \\
\hline misura necessario & 264 & 68.89 & $\begin{array}{ll}\begin{array}{l}\text { misura } \\
\text { necessarie }\end{array} & \text { necessaria__misure } \\
\end{array}$ & Common_Noun Adjective \\
\hline maggiore parte & 86 & 68.45 & maggior parte & Adjective Common_Noun \\
\hline
\end{tabular}




\begin{tabular}{|c|c|c|c|c|}
\hline misura & 1805 & 68.2 & misura__misure & Common_Noun \\
\hline $\begin{array}{l}\text { ordine di protezione } \\
\text { europeo }\end{array}$ & 84 & 67.64 & $\begin{array}{lrrr}\begin{array}{l}\text { ordine } \\
\text { europeo__ } \\
\text { europei }\end{array} & \text { ordini } & \text { di } & \begin{array}{r}\text { protezione } \\
\text { protezione }\end{array} \\
\end{array}$ & $\begin{array}{l}\text { Common_Noun } \\
\text { Preposition } \\
\text { Common_Noun Adjective }\end{array}$ \\
\hline autorità di assistenza & 83 & 67.23 & autorità di assistenza & $\begin{array}{l}\text { Common_Noun } \\
\text { Preposition } \\
\text { Common_Noun }\end{array}$ \\
\hline assistenza & 725 & 67.1 & assistenza & Common_Noun \\
\hline pena & 527 & 66.66 & pena & Common_Noun \\
\hline pronuncia & 110 & 66.42 & pronuncia & Common_Noun \\
\hline essere & 505 & 66.4 & essere__esseri & Common_Noun \\
\hline minore & 141 & 66.2 & minore__minori & Common_Noun \\
\hline norma minimo & 213 & 65.51 & norma minima__norme minime & Common_Noun Adjective \\
\hline $\operatorname{artt}$ & 80 & 64.75 & artt & Common_Noun \\
\hline tratta di essere & 171 & 64.73 & tratta di esseri & $\begin{array}{l}\text { Common_Noun } \\
\text { Preposition } \\
\text { Common_Noun }\end{array}$ \\
\hline persona & 1330 & 64.35 & persona__persone & Common_Noun \\
\hline $\begin{array}{l}\text { pronuncia } \\
\text { pregiudiziale }\end{array}$ & 78 & 64.3 & pronuncia pregiudiziale & Common_Noun Adjective \\
\hline all'art & 76 & 64.3 & all'art & Common_Noun \\
\hline la commissione & 76 & 64.3 & la commissione & Adjective Common_Noun \\
\hline libero circolazione & 76 & 64.3 & libera circolazione & Adjective Common_Noun \\
\hline persona protetto & 75 & 63 & persona protetta & Common_Noun Adjective \\
\hline $\begin{array}{l}\text { sfruttamento } \\
\text { sessuale }\end{array}$ & 206 & 61.72 & sfruttamento sessuale & Common_Noun Adjective \\
\hline l'articolo & 70 & 61.67 & l'articolo & Common_Noun \\
\hline sig & 132 & 61.42 & sig & Common_Noun \\
\hline risarcimento statale & 68 & 60.32 & $\begin{array}{l}\text { risarcimento statale__risarcimento } \\
\text { statali }\end{array}$ & Common_Noun Adjective \\
\hline assistenza al vittima & 92 & 60.12 & $\begin{array}{l}\text { assistenza alla vittima__assistenza } \\
\text { alle vittime }\end{array}$ & $\begin{array}{l}\text { Common_Noun } \\
\text { Preposition } \\
\text { Common_Noun }\end{array}$ \\
\hline autorità di decisione & 65 & 59.4 & autorità di decisione & $\begin{array}{l}\text { Common_Noun } \\
\text { Preposition } \\
\text { Common_Noun }\end{array}$ \\
\hline $\begin{array}{l}\text { sistema di } \\
\text { risarcimento }\end{array}$ & 68 & 59 & $\begin{array}{l}\text { sistema di risarcimento__sistemi di } \\
\text { risarcimento }\end{array}$ & $\begin{array}{l}\text { Common_Noun } \\
\text { Preposition } \\
\text { Common_Noun }\end{array}$ \\
\hline $\begin{array}{l}\text { domanda } \\
\text { risarcimento }\end{array}$ & 63 & 58.46 & $\begin{array}{l}\text { domanda di risarcimento__domande } \\
\text { di risarcimento }\end{array}$ & $\begin{array}{l}\text { Common_Noun } \\
\text { Preposition } \\
\text { Common_Noun }\end{array}$ \\
\hline cinque anno & 63 & 58.46 & cinque anni & Adjective Common_Noun \\
\hline titolo di soggiorno & 98 & 58.34 & $\begin{array}{l}\text { titolo di soggiorno__titoli di } \\
\text { soggiorno }\end{array}$ & $\begin{array}{l}\text { Common_Noun } \\
\text { Preposition } \\
\text { Common_Noun } \\
\end{array}$ \\
\hline sanzione & 522 & 58.24 & sanzione__sanzioni & Common_Noun \\
\hline indennizzo & 210 & 58.13 & indennizzo_ indennizzi & Common_Noun \\
\hline autorità competente & 230 & 57.38 & $\begin{array}{lc}\text { autorità } \\
\text { competenti }\end{array}$ & Common_Noun Adjective \\
\hline giudice nazionale & 91 & 57.33 & 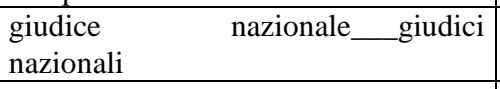 & Common_Noun Adjective \\
\hline l'autorità & 60 & 57.03 & l'autorità & Common_Noun \\
\hline deposizione & 77 & 56.79 & deposizione__deposizioni & Common_Noun \\
\hline slsg & 60 & 56.54 & slsg & Common_Noun \\
\hline materia penale & 143 & 56.33 & materia penale__materie penali & Common_Noun Adjective \\
\hline
\end{tabular}




\begin{tabular}{|c|c|c|c|c|}
\hline gepd & 57 & 55.56 & gepd & Common_Noun \\
\hline $\begin{array}{l}\text { domanda } \\
\text { pronuncia }\end{array}$ & 57 & 55.56 & $\begin{array}{l}\text { domanda di pronuncia__domande di } \\
\text { pronuncia }\end{array}$ & $\begin{array}{l}\text { Common_Noun } \\
\text { Preposition } \\
\text { Common_Noun }\end{array}$ \\
\hline diritto & 2502 & 55.42 & diritto__diritti & Common_Noun \\
\hline giustizia & 763 & 55.09 & giustizia & Common_Noun \\
\hline il & 462 & 55.02 & il & Common_Noun \\
\hline per & 159 & 54.81 & per & Common_Noun \\
\hline persona fisico & 116 & 54.67 & persona fisica__persone fisiche & Common_Noun Adjective \\
\hline dell'art & 55 & 54.56 & dell'art & Common_Noun \\
\hline l'unione & 54 & 54.05 & l'unione & Common_Noun \\
\hline stato di condanna & 54 & 54.05 & $\begin{array}{l}\text { stato di condanna__stati di } \\
\text { condanna }\end{array}$ & $\begin{array}{l}\text { Common_Noun } \\
\text { Preposition } \\
\text { Common_Noun }\end{array}$ \\
\hline in & 183 & 53.88 & in & Common_Noun \\
\hline $\begin{array}{l}\text { particolare } \\
\text { attenzione }\end{array}$ & 53 & 53.54 & particolare attenzione & Adjective Common_Noun \\
\hline $\begin{array}{l}\text { procedimento di } \\
\text { mediazione }\end{array}$ & 53 & 53.54 & $\begin{array}{lr}\text { procedimento } & \mathrm{di} \\
\text { mediazione_procedimenti } & \mathrm{di} \\
\text { mediazione_ } & \\
\end{array}$ & $\begin{array}{l}\text { Common_Noun } \\
\text { Preposition } \\
\text { Common_Noun } \\
\end{array}$ \\
\hline $\begin{array}{l}\text { questione } \\
\text { pregiudiziale }\end{array}$ & 74 & 53.39 & $\begin{array}{l}\text { questione pregiudiziale_questioni } \\
\text { pregiudiziali }\end{array}$ & Common_Noun Adjective \\
\hline $\begin{array}{ll}\text { domanda } & \text { di } \\
\text { pronuncia } & \\
\text { pregiudiziale } & \\
\end{array}$ & 53 & 53.02 & 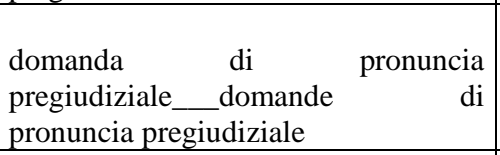 & $\begin{array}{l}\text { Common_Noun } \\
\text { Preposition } \\
\text { Common_Noun Adjective }\end{array}$ \\
\hline senso dell'art & 50 & 51.97 & sensi dell'art & Common_Noun Adjective \\
\hline sull'unione & 50 & 51.97 & sull'unione & Common_Noun \\
\hline pena detentivo & 78 & 51.79 & pena detentiva & Common_Noun Adjective \\
\hline comma & 140 & 51.73 & comma_commi & Common_Noun \\
\hline nell'ambito & 49 & 51.44 & nell'ambito & Common_Noun \\
\hline
\end{tabular}


Annex 5

English and Italian terms recorded in MuLex

\section{English terms}

\begin{tabular}{|c|c|}
\hline Genotype & Term \\
\hline \multirow{2}{*}{ APPLICANT } & applicant \\
\hline & applicant for compensation \\
\hline \multirow{3}{*}{ APPLICANT FOR COMPENSATION } & applicant for compensation \\
\hline & applicant \\
\hline & applicant for state compensation \\
\hline \multirow{4}{*}{ APPLICATION FOR COMPENSATION } & application for compensation \\
\hline & application \\
\hline & claim for compensation \\
\hline & claim for cross-border compensation \\
\hline \multirow{2}{*}{ APPLICATION FOR COMPENSATION } & application for compensation \\
\hline & claim for compensation \\
\hline \multirow{2}{*}{ ASSISTING AUTHORITY } & assisting authority \\
\hline & Assisting Authority \\
\hline \multirow{2}{*}{ BYSTANDER } & bystander \\
\hline & innocent bystander \\
\hline \multirow{3}{*}{ CENTRAL CONTACT POINT } & central contact point \\
\hline & Central Contact Point \\
\hline & national contact point \\
\hline \multirow{2}{*}{ CHILD VICTIM } & child victim \\
\hline & child victim of crime \\
\hline CHILD-FRIENDLY JUSTICE & child-friendly justice \\
\hline \multirow{2}{*}{ 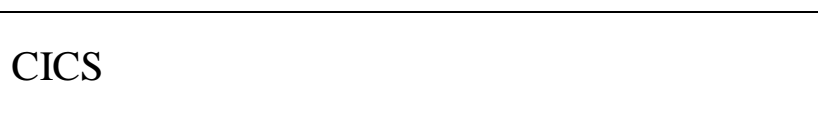 } & Criminal Injuries Compensation Scheme \\
\hline & CICS \\
\hline \multirow{2}{*}{ CIVIL PARTY } & civil party \\
\hline & partie civile \\
\hline \multirow{6}{*}{$\begin{array}{l}\text { COMPENSATION } \\
\text { DAMAGES }\end{array}$} & compensation for immaterial damages \\
\hline & $\begin{array}{llll}\begin{array}{l}\text { compensation awarded for immaterial } \\
\text { damages }\end{array} & & \\
\end{array}$ \\
\hline & compensation for non-material damage \\
\hline & compensation for non-pecuniary losses \\
\hline & compensation for pain and suffering \\
\hline & non-pecuniary compensation \\
\hline \multirow{2}{*}{ COMPENSATION FROM THE OFFENDER } & compensation from the offender \\
\hline & compensation by the offender \\
\hline \multirow{3}{*}{ COMPENSATION OF MATERIAL LOSSES } & compensation of material losses \\
\hline & compensation for material losses \\
\hline & compensation for pecuniary loss \\
\hline
\end{tabular}




\begin{tabular}{|c|c|}
\hline & pecuniary damages \\
\hline CRIMINAL DAMAGE & criminal damage \\
\hline \multirow{2}{*}{$\begin{array}{l}\text { CRIMINAL INJURIES COMPENSATION } \\
\text { AUTHORITY }\end{array}$} & Criminal Injuries Compensation Authority \\
\hline & \\
\hline CRIMINAL INJURY & criminal injury \\
\hline CROSS-BORDER VICTIM & cross-border victim \\
\hline \multirow{2}{*}{ DECIDING AUTHORITY } & deciding authority \\
\hline & Deciding Authority \\
\hline \multirow{2}{*}{ DIRECT VICTIM } & direct victim \\
\hline & primary victim \\
\hline \multirow{4}{*}{$\begin{array}{l}\text { EUROPEAN NETWORK OF NATIONAL } \\
\text { CONTACT POINTS FOR RESTORATIVE } \\
\text { JUSTICE }\end{array}$} & $\begin{array}{l}\text { European network of national contact } \\
\text { points for restorative justice }\end{array}$ \\
\hline & $\begin{array}{l}\text { European network for mediation and } \\
\text { restorative justice }\end{array}$ \\
\hline & $\begin{array}{l}\begin{array}{l}\text { European Network of national contact } \\
\text { points for Restorative Justice }\end{array} \\
\end{array}$ \\
\hline & $\begin{array}{l}\text { European network of national contact } \\
\text { points for mediation in criminal cases and } \\
\text { restorative justice }\end{array}$ \\
\hline EUROPEAN PROTECTION ORDER & European protection order \\
\hline EXECUTING STATE & executing State \\
\hline \multirow{4}{*}{ IMMATERIAL DAMAGE } & general damages \\
\hline & immaterial damage \\
\hline & moral damage \\
\hline & non-pecuniary loss \\
\hline \multirow{2}{*}{ INDIRECT VICTIM } & indirect victim \\
\hline & secondary victim \\
\hline \multirow{6}{*}{ INJURED PERSON } & injured person \\
\hline & injured party \\
\hline & aggrieved person \\
\hline & aggrieved party \\
\hline & person aggrieved \\
\hline & person injured \\
\hline ISSUING STATE & issuing State \\
\hline \multirow{2}{*}{ LEGAL AID } & legal aid \\
\hline & free legal aid \\
\hline \multirow{3}{*}{ LOSS OF EARNINGS } & loss of earnings \\
\hline & loss of income \\
\hline & lucrum cessans \\
\hline \multirow{4}{*}{ MATERIAL LOSS } & material loss \\
\hline & economic loss \\
\hline & financial loss \\
\hline & pecuniary loss \\
\hline \multirow{3}{*}{ MEDIATION IN CRIMINAL CASES } & mediation in criminal cases \\
\hline & mediation in criminal proceedings \\
\hline & $\begin{array}{l}\text { mediation between the offender and his } \\
\text { victim }\end{array}$ \\
\hline
\end{tabular}




\begin{tabular}{|c|c|}
\hline & mediation between victims and offenders \\
\hline & mediation in penal matters \\
\hline & penal mediation \\
\hline & $\begin{array}{l}\text { penal mediation in the course of criminal } \\
\text { proceedings }\end{array}$ \\
\hline & victim-offender mediation \\
\hline & Victim-Offender Mediation \\
\hline & VOM \\
\hline \multirow{2}{*}{ MEDIATOR } & mediator \\
\hline & facilitator \\
\hline PERSON CAUSING DANGER & person causing danger \\
\hline PROTECTED PERSON & protected person \\
\hline PROTECTION MEASURE & protection measure \\
\hline \multirow{2}{*}{ PROTECTION OF VICTIMS } & protection of victims of crime \\
\hline & protection of victims \\
\hline QUALIFYING CLAIMANT & qualifying claimant \\
\hline \multirow{2}{*}{ REPARATION } & reparation \\
\hline & victim reparation \\
\hline \multirow{2}{*}{ RESTORATIVE JUSTICE } & restorative justice \\
\hline & RJ \\
\hline \multirow{5}{*}{ RIGHTS OF VICTIMS } & rights of victims \\
\hline & rights of crime victims \\
\hline & rights of victims of crime \\
\hline & victims rights \\
\hline & victims' rights \\
\hline SAMARITAN & samaritan \\
\hline SECONDARY VICTIMISATION & secondary victimisation \\
\hline \multirow{8}{*}{ STATE COMPENSATION } & state compensation \\
\hline & State compensation \\
\hline & State compensation for crime victims \\
\hline & state compensation for victims \\
\hline & state compensation to victims \\
\hline & state compensation for victims of crime \\
\hline & $\begin{array}{l}\text { compensation from the government to } \\
\text { victims of a crime of violence }\end{array}$ \\
\hline & compensation from public funds \\
\hline $\begin{array}{l}\text { STATE COMPENSATION } \text { FOR VICTIMS } \\
\text { OF EXTORSION, TERRORISM OR } \\
\text { SUBVERSION OF THE DEMOCRATIC } \\
\text { ORDER }\end{array}$ & $\begin{array}{l}\text { State compensation for victims of } \\
\text { extorsion, terrorism or subversion of the } \\
\text { democratic order }\end{array}$ \\
\hline \multirow{5}{*}{ STATE COMPENSATION SCHEME } & state compensation scheme \\
\hline & compensation scheme \\
\hline & compensation to victims system \\
\hline & $\begin{array}{l}\text { Member State scheme to compensate crime } \\
\text { victims }\end{array}$ \\
\hline & $\begin{array}{l}\text { State compensation scheme for victims of } \\
\text { crime }\end{array}$ \\
\hline
\end{tabular}




\begin{tabular}{|c|c|}
\hline & $\begin{array}{l}\text { state compensation scheme for criminal } \\
\text { injuries }\end{array}$ \\
\hline & state scheme to compensate victims \\
\hline & $\begin{array}{l}\text { national compensation scheme for criminal } \\
\text { injuries }\end{array}$ \\
\hline & national compensation scheme \\
\hline & $\begin{array}{l}\text { national scheme on compensation for } \\
\text { crime victims }\end{array}$ \\
\hline & $\begin{array}{l}\text { national scheme on compensation to } \\
\text { victims of violent intentional crimes }\end{array}$ \\
\hline & victim compensation scheme \\
\hline STATE OF SUPERVISION & State of supervision \\
\hline \multirow{5}{*}{ VICTIM } & crime victim \\
\hline & victim \\
\hline & victim of a crime \\
\hline & victim of criminal conduct \\
\hline & victim of the offence \\
\hline \multirow{3}{*}{ VICTIM SUPPORT } & Victim Support \\
\hline & Victim Support England \& Wales \\
\hline & Victim Support England and Wales \\
\hline \multirow{3}{*}{ VICTIM SUPPORT EUROPE } & Victim Support Europe \\
\hline & European Forum for Victims' Services \\
\hline & European Forum for Victim Services \\
\hline \multirow{3}{*}{ VICTIM SUPPORT NORTHERN IRELAND } & Victim Support Northern Ireland \\
\hline & VSNI \\
\hline & Victim Support NI \\
\hline \multirow{2}{*}{ VICTIM SUPPORT ORGANISATION } & victim support organisation \\
\hline & victim support group \\
\hline \multirow{2}{*}{ VICTIM SUPPORT SCOTLAND } & Victim Support Scotland \\
\hline & VSS \\
\hline \multirow{5}{*}{$\begin{array}{l}\text { VICTIM WITH SPECIAL PROTECTION } \\
\text { NEEDS }\end{array}$} & victim with specific protection needs \\
\hline & victim with specific needs \\
\hline & particularly vulnerable victim \\
\hline & particularly vulnerable person \\
\hline & vulnerable victim \\
\hline WITNESS & witness \\
\hline
\end{tabular}


Italian terms

\begin{tabular}{|c|c|}
\hline Genotype & Term \\
\hline AUTORITÀ DI ASSISTENZA & autorità di assistenza \\
\hline AUTORITÀ DI DECISIONE & autorità di decisione \\
\hline CICS & CICS \\
\hline \multirow{2}{*}{$\begin{array}{l}\text { CRIMINAL INJURIES COMPENSATION } \\
\text { AUTHORITY }\end{array}$} & Criminal Injuries Compensation Authority \\
\hline & CICA \\
\hline \multirow{4}{*}{ DANNEGGIATO } & danneggiato \\
\hline & danneggiato dal reato \\
\hline & persona danneggiata dal reato \\
\hline & parte danneggiata \\
\hline \multirow{4}{*}{ DANNO DERIVANTE DA REATO } & danno da reato \\
\hline & danno derivante da reato \\
\hline & danno ex delicto \\
\hline & danno procurato da reato \\
\hline \multirow{4}{*}{ DANNO MATERIALE } & danno materiale \\
\hline & danno economico \\
\hline & danno patrimoniale \\
\hline & danno pecuniario \\
\hline \multirow{4}{*}{ DANNO NON MATERIALE } & danno non materiale \\
\hline & danno morale \\
\hline & danno non patrimoniale \\
\hline & danno non pecuniario \\
\hline \multirow{5}{*}{ DIRITTI DELLE VITTIME } & diritti delle vittime \\
\hline & diritti delle vittime della criminalità \\
\hline & diritti delle vittime di reati \\
\hline & diritti delle vittime di reato \\
\hline & diritti della vittima \\
\hline \multirow{5}{*}{ DOMANDA DI RISARCIMENTO } & domanda di risarcimento \\
\hline & richiesta di risarcimento \\
\hline & domanda di indennizzo transfrontaliero \\
\hline & domanda di indennizzo \\
\hline & domanda di risarcimento statale \\
\hline \multirow{2}{*}{ ELARGIZIONE } & elargizione \\
\hline & elargizione a carico dello Stato \\
\hline \multirow{5}{*}{ GIUSTIZIA A MISURA DI MINORE } & giustizia a misura di minore \\
\hline & giustizia adatta ai bambini \\
\hline & giustizia adatta ai minori \\
\hline & giustizia adattata ai bambini \\
\hline & giustizia adattata ai minori \\
\hline \multirow{4}{*}{ GIUSTIZIA RIPARATIVA } & giustizia riparativa \\
\hline & giustizia restaurativa \\
\hline & giustizia restitutiva \\
\hline & giustizia riparatrice \\
\hline
\end{tabular}




\begin{tabular}{|c|c|}
\hline & giustizia riparatoria \\
\hline & giustizia risarcitoria \\
\hline \multirow{3}{*}{ MANCATO GUADAGNO } & mancato guadagno \\
\hline & lucro cessante \\
\hline & lucrum cessans \\
\hline MEDIATORE & mediatore \\
\hline \multirow{13}{*}{ MEDIAZIONE PENALE } & mediazione penale \\
\hline & mediazione \\
\hline & mediazione autore-vittima \\
\hline & mediazione fra autore e vittima di reato \\
\hline & $\begin{array}{l}\text { mediazione nell'ambito dei procedimenti } \\
\text { penali }\end{array}$ \\
\hline & mediazione nelle cause penali \\
\hline & mediazione tra autore e vittima del reato \\
\hline & $\begin{array}{l}\begin{array}{l}\text { mediazione tra l'autore del reato e la } \\
\text { vittima }\end{array} \\
\end{array}$ \\
\hline & $\begin{array}{l}\text { mediazione tra la vittima e l'autore del } \\
\text { reato nell'ambito dei procedimenti penali }\end{array}$ \\
\hline & mediazione tra vittima e autore del reato \\
\hline & $\begin{array}{l}\text { mediazione tra vittima e autore del reato } \\
\text { nel procedimento penale }\end{array}$ \\
\hline & mediazione vittima-reo \\
\hline & VOM \\
\hline \multirow{6}{*}{ MINORE VITTIMA DI REATO } & minore vittima di reato \\
\hline & giovane vittima \\
\hline & minore vittima del reato \\
\hline & persona offesa minorenne \\
\hline & persona offesa minore \\
\hline & vittima minorenne \\
\hline MISURA DI PROTEZIONE & misura di protezione \\
\hline ORDINE DI PROTEZIONE EUROPEO & ordine di protezione europeo \\
\hline \multirow{2}{*}{$\begin{array}{l}\text { ORGANIZZAZIONE DI ASSISTENZA ALLE } \\
\text { VITTIME }\end{array}$} & organizzazione di assistenza alle vittime \\
\hline & organizzazione di sostegno alle vittime \\
\hline PARTE CIVILE & parte civile \\
\hline PASSANTE & passante \\
\hline \multirow{5}{*}{ PATROCINIO A SPESE DELLO STATO } & gratuito patrocinio \\
\hline & assistenza legale gratuita \\
\hline & patrocinio a spese dello Stato \\
\hline & $\begin{array}{l}\text { patrocinio a spese dello Stato per i non } \\
\text { abbienti }\end{array}$ \\
\hline & patrocinio gratuito \\
\hline $\begin{array}{llll}\text { PERSONA } & \text { CHE } & \text { DETERMINA } & \text { IL } \\
\text { PERICOLO } & & & \end{array}$ & persona che determina il pericolo \\
\hline \multirow{3}{*}{ PERSONA INFORMATA SUI FATTI } & persona informata sui fatti \\
\hline & $\begin{array}{l}\text { persona che può riferire circostanze utili ai } \\
\text { fini delle indagini }\end{array}$ \\
\hline & persona in grado di riferire circostanze utili \\
\hline
\end{tabular}




\begin{tabular}{|c|c|}
\hline & ai fini dell'attività investigativa \\
\hline & possibile testimone \\
\hline PERSONA PROTETTA & persona protetta \\
\hline & protezione delle vittime \\
\hline & protezione delle vittime di reati \\
\hline & protezione delle vittime di reato \\
\hline & tutela del soggetto passivo del reato \\
\hline PROTEZIONE DELLE VITTIME & tutela delle vittime \\
\hline & tutela delle vittime della criminalità \\
\hline & tutela della vittimalità \\
\hline & tutela delle vittime di reati \\
\hline & tutela delle vittime di reato \\
\hline & punto di contatto centrale \\
\hline PUNTO DI CONTATTO CENTRALE & punto di contatto \\
\hline & punto centrale di contatto \\
\hline & $\begin{array}{l}\text { rete europea di punti di contatto nazionali } \\
\text { per la giustizia riparatoria }\end{array}$ \\
\hline & $\begin{array}{l}\text { rete europea per la mediazione e per la } \\
\text { giustizia riparatoria }\end{array}$ \\
\hline $\begin{array}{l}\text { RETE EURUPEA DI PUNTI NAZIONALI } \\
\text { PER LA GIUSTIZIA RIPARATORIA }\end{array}$ & $\begin{array}{l}\text { rete europea di punti di contatto nazionali } \\
\text { per la mediazione nei procedimenti penali } \\
\text { e per la giustizia riparatoria }\end{array}$ \\
\hline & $\begin{array}{l}\text { rete europea di punti di contatto nazionali } \\
\text { per la giustizia risarcitoria }\end{array}$ \\
\hline & richiedente \\
\hline RICHIFDFNTF & richiedente il risarcimento \\
\hline KICHIEDENIE & richiedente l'indennizzo \\
\hline & soggetto richiedente un risarcimento statale \\
\hline RICHIEDENTE & richiedente \\
\hline RICHIESTA DI INDENNIZZO & richiesta di indennizzo \\
\hline & riparazione \\
\hline RIPARAZIONE & restituzione \\
\hline & riparazione del danno \\
\hline & risarcimento da parte dell'autore del reato \\
\hline $\begin{array}{lrr}\text { RISARCIMENTO } & \text { DA } & \text { PARTE } \\
\text { DELL'AUTORE DEL REATO } & \end{array}$ & \begin{tabular}{|llll}
$\begin{array}{l}\text { risarcimento alle vittime da parte } \\
\text { dell'autore del reato }\end{array}$ & & & \\
\end{tabular} \\
\hline & risarcimento del danno da parte del reo \\
\hline & risarcimento da parte dello Stato \\
\hline & indennità \\
\hline & indennizzo \\
\hline & indennizzo della vittima \\
\hline RISARCIMENTO & indennizzo delle vittime \\
\hline STATO & $\begin{array}{l}\text { indennizzo delle vittime da parte dello } \\
\text { Stato }\end{array}$ \\
\hline & indennizzo delle vittime di reato \\
\hline & indennizzo statale \\
\hline & risarcimento alle vittime da parte dello \\
\hline
\end{tabular}




\begin{tabular}{|c|c|}
\hline & Stato \\
\hline & $\begin{array}{l}\text { risarcimento da parte dello Stato alle } \\
\text { vittime di reati }\end{array}$ \\
\hline & $\begin{array}{l}\text { risarcimento da parte dello Stato alle } \\
\text { vittime di reato }\end{array}$ \\
\hline & $\begin{array}{l}\text { risarcimento dei danni alle vittime di reati } \\
\text { da parte dello Stato }\end{array}$ \\
\hline & $\begin{array}{l}\text { risarcimento delle vittime di reati da parte } \\
\text { dello Stato }\end{array}$ \\
\hline & risarcimento erogato dallo Stato \\
\hline & risarcimento pubblico \\
\hline & risarcimento statale \\
\hline & risarcimento statale alle vittime di reato \\
\hline & risarcimento dei danni materiali \\
\hline & risarcimento dei danni patrimoniali \\
\hline RISARCIMENTO DEI DANNI MATERIALI & risarcimento del danno patrimoniale \\
\hline & risarcimento delle perdite materiali \\
\hline & risarcimento materiale \\
\hline & risarcimento dei danni non materiali \\
\hline & risarcimento dei danni morali \\
\hline RISARCIMENTO DEI & risarcimento del danno non patrimoniale \\
\hline MATERIALI & risarcimento morale \\
\hline & risarcimento per danni non pecuniari \\
\hline & risarcimento per i danni non materiali \\
\hline SAMARITANO & samaritano \\
\hline & sistema di risarcimento statale \\
\hline & regime di risarcimento delle vittime di reati \\
\hline & regime d'indennizzo delle vittime \\
\hline & $\begin{array}{l}\text { regime nazionale di risarcimento delle } \\
\text { vittime della criminalità }\end{array}$ \\
\hline & sistema di indennizzo \\
\hline & $\begin{array}{l}\text { sistema di indennizzo delle vittime di reati } \\
\text { intenzionali violenti }\end{array}$ \\
\hline & sistema di indennizzo nazionale \\
\hline & sistema di risarcimento \\
\hline SISTEMA DI RISARCIMENTO STATALE & sistema di risarcimento a spese dello Stato \\
\hline & sistema di risarcimento da parte dello Stato \\
\hline & sistema di risarcimento delle vittime \\
\hline & $\begin{array}{l}\begin{array}{l}\text { sistema di risarcimento statale per le } \\
\text { vittime di reati }\end{array} \\
\end{array}$ \\
\hline & sistema nazionale di indennizzo \\
\hline & sistema nazionale di risarcimento \\
\hline & $\begin{array}{l}\text { sistema nazionale di risarcimento da parte } \\
\text { dello Stato }\end{array}$ \\
\hline & $\begin{array}{l}\text { sistema nazionale di risarcimento delle } \\
\text { vittime di reati }\end{array}$ \\
\hline & sistema nazionale di risarcimento delle \\
\hline
\end{tabular}




\begin{tabular}{|c|c|}
\hline & vittime di reato \\
\hline & $\begin{array}{l}\text { sistema nazionale in materia di indennizzo } \\
\text { delle vittime di reati intenzionali violenti }\end{array}$ \\
\hline $\begin{array}{lccc}\text { SOGGETTO } & \text { AVENTE } & \text { I } & \text { REQUISITI } \\
\text { NECESSARI } & \text { PER } & \text { RICHIEDEREIL } \\
\text { RISARCIMENTO STATALE } & \\
\end{array}$ & $\begin{array}{l}\text { soggetto avente i requisiti necessari per } \\
\text { richiedere il risarcimento statale }\end{array}$ \\
\hline STATO DI EMISSIONE & Stato di emissione \\
\hline STATO DI ESECUZIONE & Stato di esecuzione \\
\hline STATO DI SORVEGLIANZA & Stato di sorveglianza \\
\hline & testimone \\
\hline TESTIMONE & testimonio \\
\hline & teste \\
\hline VICTIM SUPPORT & Victim Support \\
\hline & Victim Support Europe \\
\hline VICTIM SUPPORT EUROPE & Forum europeo per i servizi alle vittime \\
\hline & Forum Europeo per i Servizi alle Vittime \\
\hline VICTIM SUPPORT NORTHERN IRELAND & Victim Support Northern Ireland \\
\hline VICTIM SUPPORT SCOTLAND & Victim Support Scotland \\
\hline & offeso \\
\hline & persona offesa \\
\hline & persona offesa dal reato \\
\hline VITTIMA & soggetto leso \\
\hline & soggetto passivo del reato \\
\hline & vittima \\
\hline & vittima di reato \\
\hline & $\begin{array}{l}\text { vittima con esigenze specifiche di } \\
\text { protezione }\end{array}$ \\
\hline & persona offesa vulnerabile \\
\hline & persona particolarmente vulnerabile \\
\hline VITTIMA CON ESIGENZE SPECIFICHE DI & vittima a tutela rafforzata \\
\hline PROTEZIONE & vittima con esigenze particolari \\
\hline & vittima con esigenze specifiche \\
\hline & vittima di reato particolarmente vulnerabile \\
\hline & vittima particolarmente vulnerabile \\
\hline & vittima vulnerabile \\
\hline VITTIMA DIRETTA & vittima diretta \\
\hline VI I IIVA DIRE I I A & vittima primaria \\
\hline VITTIMA INDIRETTA & vittima indiretta \\
\hline VII IIVA INDIKE I I A & vittima secondaria \\
\hline VITTIMA TRANSFRONTALIERA & vittima transfrontaliera \\
\hline & vittimizzazione secondaria \\
\hline VITTIMIZZAZIONE SECONDARIA & pregiudizio secondario \\
\hline & seconda vittimizzazione \\
\hline & ulteriore vittimizzazione \\
\hline
\end{tabular}



$\underline{\text { References }}$ 



\section{References}

Achilles M. \& Zehr H. (2001) Restorative Justice for Crime Victims: The Promise, The Challenge, in Restorative Community Justice: Repairing Harm and Transforming Communities, G. Bazemore \& M. Schiff (eds), Cincinnati $(\mathrm{OH})$, Anderson Publishing, pp. 87-99.

Ahmad K. \& Rogers M. (1992) Terminology Management: A Corpus-based Approach, Proceedings of Translating and the Computer 14 (London, 10-11 November 1992), London, Aslib, pp. 33-44.

Aizawa A. \& Kageura K. (2001) A Graph-based Approach to the Automatic Generation of Multilingual Keyword Clusters, in Recent Advances in Computational Terminology, D. Bourigault, C. Jacquemin \& M.-C. L'Homme (eds), Amsterdam/Philadelphia: John Benjamins, pp. 1-27.

Ajani G., Boella G., Lesmo L., Mazzei A., Radicioni D. P. \& Rossi P. (2009) Multilevel Legal Ontologies, in Semantic Processing of Legal Texts: Where the Language of Law Meets the Law of Languag, E. Francesconi, S. Montemagni, W. Peters \& D. Tiscornia (eds), Berlin, Springer, pp. 13-28.

Ajani G., Boella G., Lesmo L., Mazzei A. \& Rossi P. (2007) Multilingual Ontological Analysis of European Directives, Proceedings of the 45th Annual Meeting of the Association for Computational Linguistics (ACL 2007) (Prague, 23-30 June 2007), pp. 21-24.

Ajani G. \& Ebers M. (2005) Uniform Terminology for European Contract Law: Introduction, in Uniform Terminology for European Private Law, G. Ajani \& M. Ebers (eds), Baden Baden, Nomos, pp. 11-20.

Ajani G., Lesmo L., Boella G., Mazzei A. \& Rossi P. (2007) Terminological and Ontological Analysis of European Directives: Multilinguism in Law, Proceedings of ICAIL '07 (Palo Alto, 4-8 June 2007), pp. 43-48.

Akhmanova O. (1974) When is a Word a "Term" and How do We Distinguish Between Terms and Words of "Everyday" Language?, in Terminology: Theory and Method, O. Akhmanova \& G. Agapova (eds), Moscow: Moscow State University, pp. 22-30.

Alcaraz Varó E. \& Hughes B. (2002) Legal Translation Explained, Manchester, St. Jerome.

Allegrezza S. (2012) La riscoperta della vittima nella giustizia penale europea, in Lo scudo e la spada. Esigenze di protezione e poteri delle vittime nel processo penale tra Europa e Italia, S. Allegrezza, H. Belluta, M. Gialuz \& L. Lupária (eds), Torino: Giappichelli Editore, pp. 1-31.

Allegrezza S., Belluta H., Gialuz M. \& Lupária L. (2012) Introduzione, in Lo scudo e la spada. Esigenze di protezione e poteri delle vittime nel processo penale tra Europa e Italia, S. Allegrezza, H. Belluta, M. Gialuz \& L. Lupária (eds), Torino: Giappichelli Editore, pp. IX-XI. 
Altenberg B. \& Granger S. (2002) Recent Trends in Cross-linguistic Lexical Studies, in Lexis in Contrast. Corpus-based Approaches, B. Altenberg \& S. Granger (eds), Amsterdam/Philadelphia, John Benjamins, pp. 3-48.

Ananiadou S. (1994) A Methodology for Automatic Term Recognition, Proceedings of the 15th International Conference on Computational Linguistics (COLING '94) (Kyoto, 5-9 August 1994), pp. 1034-1038.

Anthony L. (2005) AntConc: A Learner and Classroom Friendly, Multi-Platform Corpus Analysis Toolkit, Proceedings of IWLeL 2004: An Iteractive Workshop on Language eLearning (Tokyo 10 December 2004), L. Anthony, S. Fujita, Y. Harada \& W. Daigaku (eds), Tokyo: Waseda University, pp. 7-13.

Antia B. E. (2000) Terminology and Language Planning: An Alternative Framework of Practice and Discourse, Amsterdam/Philadelphia, John Benjamins.

Arntz R. (1993) Terminological Equivalence and Translation, in Terminology. Applications in Interdisciplinary Communication, H. B. Sonneveld \& K. L. Loening (eds), Amsterdam/Philadelphia, John Benjamins, pp. 5-19.

Arntz R. (1995) Confrontare, valutare, trasporre: metodi e problemi della traduzione giuridica, in La traduzione. Nuovi approcci tra teoria e pratica, R. Arntz (ed.), Bolzano/Napoli: Accademia Europea Bolzano/CUEN, pp. 137-162.

Arntz R. \& Picht H. (1989) Einführung in die Terminologiearbeit, 2nd ed., Hildesheim/Zürich/New York, Georg Olms Verlag.

Ashworth A. \& Redmayne M. (2005) The Criminal Process (3rd ed.), Oxford, Oxford University Press.

Athanassious P. (2006) The Application of Multilingualism in the European Union Context, Frankfurt am Main, European Central Bank.

Atkins S., Clear J. \& Ostler N. (1992) Corpus Design Criteria, Literary and Linguistic Computing, 7(1), pp. 1-16.

Baldry A. C. (1998) Assistenza alle vittime di reato. Obiettivi, proposte e realtà, Rassegna penitenziaria e criminologica, 1/3, pp. 161-176.

Barents R. (2004) The Autonomy of Community Law, The Hague, Kluwer Law International.

Bassnett S. (1991) Translation Studies, revised ed., London/New York, Routledge.

Bautista Zambrana M. R. (2011) Using Ontologies for the Teaching of Terminology: The Case of a Package Travel Ontology, Proceedings of TISLID'10: Technological Innovation in the Teaching and Processing of LSPs (Madrid, 21-22 October 2010), N. Talaván Zanón, E. Martín Monje \& F. Palazón Romero (eds), Madrid: Editorial UNED, pp. 311-323.

Béjoint H. (1997) Régards sur la définition en terminologie, Cahiers de Lexicologie, 70(1), pp. 19-26.

Bernier-Colborne G. (2012) Defining a Gold Standard for the Evaluation of Term Extractors, Proceedings of the ColabTKR Workshop, LREC 2012 (Istanbul, 21-27 May 2012).

Bhatia V. (1987) Language of the Law, Language Teaching, 20(4), pp. 227-234. 
Bhatia V., Engberg J., Gotti M. \& Heller D. (2005) (eds) Vagueness in Normative Texts, Bern, Peter Lang.

Biber D. (1993) Representativeness in Corpus Design, Literary and Linguistic Computing, 8(4), pp. 243-257.

Bolaños Cuéllar S. (2002) Equivalence Revisited: A Key Concept in Modern Translation Theory, Forma y Función, 15(1), pp. 60-88.

Borst W. N. (1997) Construction of Engineering Ontologies for Knowledge Sharing and Reuse, $\mathrm{PhD}$ Thesis, University of Twente.

Bourigault D. \& Slodzian M. (1999) Pour une terminologie textuelle, Terminologies Nouvelles, 19, pp. 29-32.

Bouveret M. (1998) Approche de la dénomination en langue spécialisée, Meta: journal des traducteurs, 43(3), pp. 393-410.

Bowker L. (1997) Multidimensional Classification of Concepts and Terms, in Handbook of Terminology Management. Basic Aspects of Terminology Management, S. E. Wright \& G. Budin (eds), Amsterdam/Philadelphia, John Benjamins, pp. 133-143.

Bowker L. (1998) Variant Terminology: Frivolity or Necessity?, Proceedings of the 8th European Association for Lexicography Conference (EURALEX '98) (Liège, 4-8 August 1998), pp. 487-496.

Bowker L. \& Hawkins S. (2006) Variation in the Organization of Medical Terms: Exploring Some Motivations for Term Choice, Terminology, 12(1), pp. 79-110.

Bowker L. \& Meyer I. (1993) Beyond "Textbook" Concept Systems: Handling Multidimensionality in a New Generation of Term Banks, Proceedings of the 3rd International Congress on Terminology and Knowledge Engineering (TKE '99) (Cologne, 25-27 August 1993), K.-D. Schmitz (ed.), Frankfurt, Indeks Verlag, pp. 123137.

Buchin N. \& Seymour E. (2003) Equivalences or Divergences in Legal Translation? In Crossing Barriers and Bridging Cultures. The Challenges of Multilingual Translation for the European Union, A. Tosi (ed.), Clevedon/Buffalo/Toronto/Sydney, Multilingual Matters, pp. 111-116.

Budin G. (1988) Möglichkeiten und Grenzen der Terminologieforschung in den Sozialwissenschaften, Vienna, University of Vienna.

Buitelaar P., Cimiano P. \& Magnini B. (2005) Ontology Learning from Text: An Overview, in Ontology Learning and Population: Methods, Evaluation and Applications, P. Buitelaar, P. Cimiano \& B. Magnini (eds), Amsterdam, IOS Press, pp. 3-12.

Bullo F. (2007) Il lavoro terminologico tra comparazione e diritto europeo: coerenza o contraddizione?, Atti del convegno La traduzione del diritto comunitario ed europeo: riflessioni metodologiche (Trento, 10-11 March 2006), E. Ioriatti Ferrari (ed.), Trento, Università degli Studi di Trento, pp. 87-110.

Cabré M. T. (1999a) Terminology: Theory, Methods and Applications, Amsterdam/Philadelphia, John Benjamins. 
Cabré M. T. (1999b) La terminología: Representación y comunicación. Elementos para una teoría de base comunicativa y otros artículos, Barcelona, Institut Universitari de Linguística Aplicada.

Cabré M. T. (2000) Elements for a Theory of Terminology: Towards an Alternative Paradigm, Terminology, 6(1), pp. 35-57.

Cabré M. T. (2003) Theories of Terminology. Their Description, Prescription and Explanation, Terminology, 9(2), pp. 163-199.

Cabré M. T. (2006) From Terminological Data Banks to Knowledge Databases: The Text as the Starting Point, in Lexicography, Terminology and Translation. Text-based studies in honour of Ingrid Meyer, L. Bowker (ed.), Ottawa, Ottawa University Press, pp. 93-106.

Cabré M. T., Bach C., Estopà R., Feliu J., Martínez G. \& Vivaldi J. (2004) The GENOMAKB Project: Towards the Integration of Concepts, Terms, Textual Corpora and Entities, Proceedings of the 4th International Conference on Language Resources and Evaluation (LREC '04) (Lisbona, 26-28 May 2004), pp. 87-90.

Cabré M. T., Condamines A. \& Ibekwe-SanJuan F. (2005) Introduction. Application-driven Terminology Engineering, Terminology, 11(1), pp. 1-19.

Calavita K. (2010) Invitation to Law \& Society. An Introduction to the Study of Real Law, Chicago, University of Chicago Press.

Cao D. (2007) Translating Law, Clevedon/Buffalo/Toronto, Multilingual Matters.

Carl M., Rascu E., Haller J. \& Langlais P. (2004) Abducing Term Variant Translations in Aligned Texts, Terminology, 10(1), pp. 101-130.

Catford J. C. (1965) A Linguistic Theory of Translation: An Essay in Applied Linguistics, London, Oxford University Press.

Cendon P. (1998) Non di sola salute vive 1'uomo, in Studi in onore di P. Rescigno, Milano, Giuffrè Editore, pp. 138-139.

Chalmers D., Davies G. \& Monti G. (2010) European Union Law, 2nd ed., Cambridge, Cambridge University Press.

Cheng L. \& Sin K. K. (2008) Terminological Equivalence in Legal Translation: A Semiotic Approach, Semiotica, 172(1), pp. 33-45.

Ciapuscio G. E. (1999) Variación conceptual del término y grado de especialidad de los textos, Revista Argentina de Lingüística, 11, pp. 49-83

CJS (2005) The Code of Practice for Victims of Crime, London, Office for Criminal Justice Reform.

Clear J. (1992) Corpus Sampling, in New Directions in English Language Corpora. Methodology, Results, Software Developments, G. Leitner (ed.), Berlin/New York, Mouton de Gruyter, pp. 21-32.

Cole W. D. (1991) Descriptive Terminology: Some Theoretical Implications. Meta: journal des traducteurs, 36(1), pp. 16-22.

Collet T. (2004a) What's a Term? An Attempt to Define the Term within the Theoretical Framework of Text Linguistics, Linguistica Antverpiensia New Series, Special Issue on the Translation of Domain Specific Languages and Multilingual Terminology 
Management, R. Temmerman \& U. Knops (eds), 3, Hoger Instituut voor Vertalers en Tolken, Hogeschool Antwerpen, pp. 99-111.

Collet T. (2004b) Esquisse d'une nouvelle microstructure de dictionnaire spécialisé reflétant la variation en discours du terme syntagmatique, Meta: journal des traducteurs, 49(2), pp. 247-263.

Condamines A. (2010) Variations in terminology. Application to the management of risks related to language use in the workplace, Terminology, 16(1), pp. 30-50.

Condamines A. \& Rebeyrolle J. (1997) Point de vue en langue spécialisée, Meta: journal des traducteurs, 42(1), pp. 174-184.

Condamines A., Rebeyrolle J. \& Soubeille A. (2004) Variation de la Terminologie dans le Temps: une Méthode Linguistique pour Mesurer l'Évolution de la Connaissance en Corpus, Proceedings of the 11th European Association for Lexicography Conference (EURALEX '04) (Lorient, 6-10 July 2004), pp. 547-557.

Correia R. (2003) Translation of EU Legal Texts, in Crossing Barriers and Bridging Cultures. The Challenges of Multilingual Translation for the European Union, A. Tosi (ed.), Clevedon/Buffalo/Toronto/Sydney, Multilingual Matters, pp. 38-66.

Cortelazzo M. A. (1994) Lingue speciali. La dimensione verticale, Padova, Unipress.

Cosmai D. (2007) Tradurre per l'Unione europea, 2nd ed., Milano, Hoepli.

Craig P. \& De Búrca G. (2011) EU Law. Text, Cases, and Materials, 5th ed. Oxford, Oxford University Press.

Dagan I. \& Church K. (1994) Termight: Identifying and Translating Technical Terminology, Proceedings of the fourth conference on Applied natural language processing (ANLC '94) (Stroudsburg (PA), 13 October 1994), pp. 34-40.

Daille B. (1994) Study and Implementation of Combined Techniques for Automatic Extraction of Terminology, Proceedings of the ACL 1994 Workshop on The Balancing Act: Combining Symbolic and Statistical Approaches to Language (Las Cruces, 27-30 June 1994), pp. 29-36.

Daille B. (2003a) Terminology Mining, in Information Extraction in the Web Era, M. T. Pazienza (ed.), Berlin/Heidelberg, Springer Verlag, pp. 29-44.

Daille B. (2003b) Conceptual Structuring through Term Variations, Proceedings of the ACL 2003 Workshop on Multiword Expressions: Analysis, Acquisition and Treatment (Sapporo, 7-12 June 2003), F. Bond, A. Korhonen, D. MacCarthy \& A. Villacicencio (eds), pp. 9-16.

Daille B. (2005) Variations and Application-oriented Terminology Engineering, Terminology, 11(1), pp. 181-197.

Daille B., Gaussier É. \& Langé J.-M. (1994) Towards Automatic Extraction of Monolingual and Bilingual Terminology, Proceedings of the 15th International Conference on Computational Linguistics (COLING '94) (Kyoto, 5-9 August 1994), pp. 515-521.

Daille B., Habert B. \& Jacquemin C. (1996) Empirical Observation of Term Variations and Principles for Their Description, Terminology, 3(2), pp. 197-258.

Damerau F. J. (1993) Generating and Evaluating Domain-Oriented Multi-Word Terms from Texts, Information Processing and Management, 29(4), pp. 433-447. 
De Bessé B., Nkwenti-Azeh B. \& Sager J. C. (1997) Glossary of terms used in terminology, Terminology, 4(1), pp. 117-156.

De Groot G.-R. (1996) Law, Legal Language and the Legal System: Reflections on the Problems of Translating Legal Texts, in European Legal Cultures, V. Gessner, A. Hoeland \& C. Varga (eds), Dartmouth, Aldershot, pp. 155-161.

Del Tufo M. (2003) Linee di Politica criminale europea e internazionale a protezione della vittima, Questione Giustizia, 4, pp. 705-725.

Despres S. \& Szulman S. (2004) Construction of a Legal Ontology from a European Community Legislative Text, in Legal Knowledge and Information Systems, Jurix 2004: The Seventeenth Annual Conference, T. Gordon (ed.), Amsterdam, IOS Press, pp. 79-88.

Draskau Kewley J. (1991) Some Reflections on "Equivalence/Äquivalenz" as a Term and a Concept in the Theory of Translation, Meta: journal des traducteurs, 36(1), pp. 269274.

Drouin P. (2003) Term extraction using non-technical corpora as a point of leverage, Terminology, 9(1), pp. 99-115.

Dubuc R. \& Lauriston A. (1997) Terms and Contexts, in S. E. Wright \& G. Budin (eds), Handbook of Terminology Management. Basic Aspects of Terminology Management, Amsterdam/Philadelphia, John Benjamins, pp. 80-88.

Durán Muñoz I. (2012) La ontoterminografía aplicada a la traducción. Propuesta metodológica para la elaboración de recursos terminológicos dirigidos a traductores, Frankfurt am Main, Peter Lang.

Dury P. \& Picton A. (2009) Terminologie et diachronie: vers une réconciliation théorique et méthodologique? Revue Française de Linguistique Appliquée (RFLA), 14(2), pp. 31-41.

Endicott T. (2000) Vagueness in Law, Oxford, Oxford University Press.

Eriksen L. H. (2002) Die Polysemie in der Allgemeinsprache und in der juristischen Fachsprache Oder: Zur Terminologie der "Sache" im Deutschen, Hermes, Journal of Linguistics, 28, pp. 211-222.

Faber P. (2009) The Cognitive Shift in Terminology and Specialized Translation, in A (SelfCritical Perspective of Translation Theories, A. Vidal Claramonte \& F. Aixelá (eds), pp. 107-134.

Faber P., León Araúz P., Prieto Velasco J. A. \& Reimerink A. (2007) Linking Images and Words: the Description of Specialized Concepts, International Journal of Lexicography, 20(1), pp. 39-65.

Faber P., López Rodríguez C. I. \& Tercedor Sánchez M. I. (2001) Utilización de técnicas de corpus en la representación del conocimiento médico, Terminology, 7(2), pp. 167-198.

Faber P., Márquez Linares C. \& Vega Expósito M. (2005) Framing Terminology: A ProcessOriented Approach, Meta: journal des traducteurs, 50(4), CD-ROM.

Faber P., Montero Matínez S., Castro Prieto M. R., Senso Ruiz J., Priesto Velasco J. A., León Araúz P., Márquez Linares C., Vega Expósito M. (2006) Process-oriented Terminology Management in the Domain of Coastal Engineering, Terminology, 12(2), pp. 189-213.

Felber H. (1984) Terminology Manual, Paris: United Nations Educational, Scientific and Cultural Organization, Infoterm. 
Felber H. \& Budin G. (1989) Terminologie in Theorie und Praxis, Tübingen, Gunter Narr Verlag.

Feliu J., Giraldo J. J., Vidal V., Vivaldi J. \& Cabré M. T. (2004) The GENOMA-KB Project: A Concept Based Term Enlargement System, Proceedings of Workshop on Computational and Computer-Assisted Terminology, in association with LREC '04 (Lisbon, 25 May 2004), pp. 32-35.

Fellbaum C. (1998) WordNet: An Electronic Lexical Database, Cambridge, MIT Press.

Fernández-Silva S., Freixa J. \& Cabré M. T. (2011) A proposed method for analysing the dynamics of cognition through term variation, Terminology, 17(1), pp. 49-74.

Fernández-Silva S. \& Kerremans K. (2011) Terminological Variation in Source Texts and Translations: A Pilot Study, Meta: journal des traducteurs, 56(2), pp. 318-335.

Ferrari L. (2002) ¿Un caso de polisemia en el discurso jurídico? Terminology, 8(2), 221-244.

Fillmore C. J. (1976) Frame Semantics and the Nature of Language, Annals of the New York Academy of Sciences: Conference on the Origin and Development of Language and Speech, 280, New York, New York Academy of Sciences, pp. 20-32.

Fillmore C. J. (1985) Frames and the Semantics of Understanding, Quaderni di Semantica, 6, pp. 222-254.

Francis W. N. (1979) Problems of Assembling and Computerizing Large Corpora, in Empirische Textwissenschaft: Aufbau und Auswertung von Text-Corpora, $\mathrm{H}$. Bergenholtz \& B. Schaeder (eds), Königstein im Taunus, Scriptor, pp. 110-123.

Frantzi K. T., Ananiadou S. \& Tsujii J. (1998) The C-value/NC-value Method of Automatic Recognition for Multi-Word Terms, Proceedings of the Second European Conference on Research and Advanced Technology for Digital Libraries (ECDL '98) (Heraklion, 21-23 September 1998) London, Springer Verlag, pp. 585 - 604.

Freixa J. (2002) La variació terminològica. Anàlisi de la variació denominativa en textos de diferent grau d'especialització de l'àrea de medi ambient. Filologia Catalana, Universitat de Barcelona, Barcelona.

Freixa J. (2005) Variación terminológica: ¿Por qué y para qué?, Meta: journal des traducteurs, 50(4), CD-ROM.

Freixa J. (2006) Causes of Denotative Variation in Terminology. A Typology Proposal, Terminology, 12(1), pp. 51-77.

Freixa J., Kostina I. \& Cabré M. T. (2002) La variación terminológica en las aplicaciones terminográficas, Actas del VIII Simposio Iberoamericano de Terminología (Cartagena de Indias, 28-31 October 2002).

Freixa J. \& Montané A. (2006) Variación denominativa y biounivocidad en el lenguaje de las matemáticas, Revista Española de Lingüística, 36, pp. 189-215.

Fuertes-Olivera P. A. (2005) Specialized Communication and English Studies: Research Proposals on Specialized Lexicography and English for Specific Purposes, Atlantis. Journal of the Spanish Association of Anglo-American Studies, 27(2), pp. 41-55.

Gambier Y. (1991) Travail et vocabulaire spécialisés: prolégomènes à une socio-terminologie, Meta: journal des traducteurs, 36(1), pp. 8-15. 
Gamper J., Nejdl W. \& Wolpers M. (1999) Combining Ontologies and Terminologies in Information Systems, Proceedings of the 5th International Congress on Terminology and Knowledge Engineering (TKE '99) (Innsbruck, 23-27 August 1999), P. Sandrini (ed.), Vienna, Termnet, pp. 152-168.

García N. M. \& Alcina Caudet A. (2009) Conceptual Relations Established by Processes: The Case of Cocción (Firing) in Industrial Ceramics, Proceedings of 8th International Conference on Terminology and Artificial Intelligence (TIA 2009) (Tolouse, 18-20 November 2009).

Garzone G. (2000) Legal Translation and Functionalist Approaches: A Contradiction in Terms?, Actes du Colloque International "La traduction juridique. Histoire, théorie(s) et pratique” (Geneva, 17-19 February 2000), ASTTI/ETI, pp. 395-414.

Garzone G. (2003) Arbitration Rules across Legal Cultures: An Intercultural Approach, in Legal Discourse in Multilingual and Multicultural Contexts. Arbitration Texts in Europe, V. Bhatia, C. N. Candlin \& M. Gotti (eds), Bern, Peter Lang, pp. 177-220.

Gaudin F. (1993) Pour une socioterminologie: des problèmes pratiques aux pratiques institutionnelles, Rouen, Université de Rouen.

Gaudin F. (2003) Socioterminologie: une approche sociolinguistique de la terminologie, Brussels, Éditions Duculot.

Geeraerts D. (2010) Theories of Lexical Semantics, Oxford, Oxford University Press.

Gerzymisch-Arbogast H. (2001) Equivalence Parameters and Evaluation, Meta: journal des traducteurs, 46(2), pp. 227-242.

Gerzymisch-Arbogast H. (2008) Fundamentals of LSP Translation, MuTra, LSP Translation Scenarios. Selected Contributions to the EU Marie Curie Conference, H. GerzymischArbogast, G. Budin \& G. Hofer (eds), 2, Vienna, ATRC Group, pp. 7-64.

Gómez De Enterría J. (2000) Últimas tendencias neológicas en la prensa económica, in La neologia en el tombant de segle, M. T. Cabré, J. Freixa \& E. Solé (eds), Barcelona, Institut Universitari de Lingüística Aplicada, pp. 75-84.

Gómez González-Jover A. (2006) Meaning and anisomorphism in modern lexicography, Terminology, 12(2), pp. 215-234.

Gómez Pérez A. (1999) Ontological engineering: a state of the art, Expert Update, 2(3), pp. $33-43$.

Gómez Pérez A. \& Benjamins V. R. (1999) Overview of Knowledge Sharing and Reuse Components: Ontologies and Problem-Solving Methods, Proceedings of the IJCAI-99 workshop on Ontologies and Problem-Solving Methods (KRR5) (Stockholm, 2 August 1999), pp. 1-15.

Gotti M. (2007) Legal Discourse in Multilingual and Multicultural Contexts, in Language and the Law: International Outlooks, K. Kredens \& S. Goźdź-Roszkowski (eds), Frankfurt am Main, Peter Lang, pp. 21-33.

Grabar N. \& Zweigenbaum P. (2004) Lexically-based Terminology Structuring, Terminology, 10(1), pp. 23-53.

Gruber T. R. (1993) A Translation Approach to Portable Ontology Specifications, Knowledge Acquisition, 5(2), pp. 199-220. 
Guarino N. (2006) Ontology and Terminology. How Can Formal Ontology Help Concept Modeling and Terminology?, Presentation delivered at EAFT-NordTerm Workshop on Terminology, Concept Modelinf and Ontology (Vaasa,10 February 2006).

Guarino N. \& Giaretta P. (1995) Ontologies and Knowledge Bases, in Towards Very Large Knowledge Bases: Knowledge Building \& Knowledge Sharing, N. J. I. Mars (ed.), Amsterdam, IOS Press, pp. 25-32.

Ha L. A., Fernandez G., Mitkov R. \& Corpas G. (2003) Mutual Bilingual Terminology Extraction, Proceedings of the 6th International Conference on Language Resources and Evaluation (LREC '08) (Marrakech, 26 May-1 June 2008), pp. 1818-1824.

Ha L. A., Mitkov R. \& Corpas G. (2008) Mutual Terminology Extraction Using a Statistical Framework, Procesamiento del lenguaje natural, 41, pp. 107-112.

Hamon T. \& Nazarenko A. (2001) Detection of Synonymy Links between Terms: Experiments and Results, in Recent Advances in Computational Terminology, D. Bourigault, C. Jacquemin \& M.-C. L'Homme (eds), Amsterdam/Philadelphia, John Benjamins, pp. 185-208.

Hippisley A., Cheng D. \& Ahmad K. (2005) The Head-modifier Principle and Multilingual Term Extraction, Natural Language Engineering, 11(2), pp. 129-157.

Hodge G. (2000) Systems of Knowledge Organization for Digital Libraries: Beyond Traditional Authority Files, Washington, DC, Digital Library Federation.

Hoffmann L. (1987) Language for Special/Specific Purposes, in Sociolinguistics. An International Handbook of the Science of Language and Society, U. Ammon, N. Dittmar \& K. J. Mattheier (eds), Berlin/New York, de Gruyter, pp. 298-302.

Hunston S. (2002) Corpora in Applied Linguistics, Cambridge, Cambridge University Press.

Ibekwe-SanJuan F. (1998) Terminological Variation, a Means of Identifying Research Topics from Texts, Proceedings of the 17th International Conference on Computational Linguistics (COLING '98) (Montreal, 10-14 August 1998), Stroudsburg (PA), University of Montreal, pp. 564-570.

Ibekwe-SanJuan, F. \& Sanjuan E. (2002) From Term Variants to Research Topics, Knowledge Organisation, 29(3/4), pp. 181-197.

International Organization for Standardization (2000) International Standard ISO 1087-1. Terminology Work: Vocabulary. Part 1: Theory and application, Geneva, International Organization for Standardization.

Irgl V. (1987) Synonymy in the Language of Business and Economics, in Special Language. From Human Thinking to Thinking Machines, C. Laurén \& M. Nordman (eds), Clevedon/Philadelphia, Multilingual Matters, pp. 275-282.

Jacquemin C. (1996) What Is the Tree That We See Through the Window: A Linguistic Approach to Windowing and Term Variation, Infomation Processing and Management, 32(4), pp. 445-458.

Jacquemin C. (2001) Spotting and Discovering Terms through Natural Language Processing, Cambridge, MIT Press. 
Jacquemin C. \& Bourigault D. (2003) Term Extraction and Automatic Indexing, in The Oxford Handbook of Computational Linguistics, R. Mitkov (ed.), Oxford, Oxford University Press pp. 599-615.

Jacquemin C. \& Tzoukermann E. (1999) NLP for Term Variant Extraction: Synergy between Morphology, Lexicon, and Syntax, in Natural Language Processing Information Retrieval, T. Strzalkowski (ed.), Boston, Kluwer, pp. 25-74.

Jarrar M. \& Meersman R. (2002) Formal Ontology Engineering in the DOGMA Approach, in On the Move to Meaningful Internet Systems, Proceedings of the DOA/CoopIS/ODBASE 2002 Confederated International Conference (Irvine, 30 October-1 November 2002), R. Meersman \& Z. Tari (eds), Berlin/Heidelberg, Springer Verlag, pp. 1238-1254.

Justeson J. S. \& Katz S. M. (1995) Technical Terminology: Some Linguistic Properties and an Algorithm for Identification in Text, Natural Language Engineering, 1(1), pp. 9-27.

Kageura K. (1995) Toward the Theoretical Study of Terms: A Sketch from the Linguistic Viewpoint, Terminology, 2(2), pp. 239-257.

Kageura K. (1997) Multifaceted/multidimensional Concept Systems, in Handbook of Terminology Management. Basic Aspects of Terminology Management, S. E. Wright \& G. Budin (eds), Amsterdam/Philadelphia, John Benjamins, pp. 119-132.

Kageura K. (2002) The Dynamics of Terminology: A Descriptive Theory of Term Formation and Terminological Growth, Amsterdam/Philadelphia, John Benjamins.

Kageura K. \& Umino B. (1996) Methods of Automatic Term Recognition: A Review, Terminology, 3(2), pp. 259-289.

Kalinowsky G. (1965) Introduction à la logique juridique, Paris, Pichon \& Durand-Auzias.

Kerremans K. (2004) Categorisation Frameworks in Termontography, Linguistica Antverpiensia New Series, Special Issue on the Translation of Domain Specific Languages and Multilingual Terminology Management, R. Temmerman \& U. Knops (eds), 3, Hoger Instituut voor Vertalers en Tolken, Hogeschool Antwerpen, pp. 263-277.

Kerremans K. (2010) A Comparative Study of Terminological Variation in Specialised Translation, Reconceptualizing LSP. Online proceedings of the XVII European LSP Symposium (Aarhus, 17-21 August 2009), C. Heine \& J. Engberg (eds), pp. 1-14.

Kerremans K., Desmeytere I., Temmerman R. \& Wille P. (2005) Application-oriented Terminography in Financial Forensics, Terminology, 11(1), pp. 83-106.

Kerremans K., Temmerman R. \& Tummers J. (2004) Discussion on the Requirements for a Workbench supporting Termontography, Proceedings of 11th European Association for Lexicography Conference (EURALEX '04) (Lorient, 6-10 July 2004), G. Williams \& S. Vessier (eds), pp. 559-570.

Kjær A. L. (2007) Legal Translation in the European Union: A Research Field in Need of a New Approach, in Language and the Law: International Outlooks, K. Kredens \& S. Goźdź-Roszkowski (eds), Frankfurt am Main, Peter Lang, pp. 69-95.

Kocbek A. (2008) The Cultural Embeddedness of Legal Texts, Journal of Language \& Translation, 9(2), pp. 49-70.

Kocourek R. (1982) La langue française de la technique et de la science, Zurich, Brandstetter Verlag. 
L'Homme M.-C., Heid U. \& Sager J. C. (2003) Terminology during the Past Decade (19942004) An Editorial Statement, Terminology, 9(2), pp. 151-161.

Lakoff G. (1987) Women, Fire and Dangerous Things: What Categories Reveal about the Mind, Chicago, University of Chicago Press.

León Araúz P., Faber P. \& Pérez Hernández C. (2008) LSP Dictionaries and Their Genuine Purpose: A Frame-based Example from MARCOCOSTA, Proceedings of the 13th European Association for Lexicography Conference (EURALEX '08) (Barcelona, 15-19 July 2008), pp. 997-1006.

Leonardi N. (2012) "Ontology" and Terminological Frameworks: An Overview of Issues and Term(s), Hermes, Journal of Language and Communication in Business, 48, pp. 19-33.

Lewis R. (2001) Increasing The Price Of Pain: Damages, The Law Commission And Heil v Rankin, The Modern Law Review, 64(1), pp. 100-111.

Liebwald D. (2007) Semantic Spaces and Multilingualism in the Law: The Challenge of Legal Knowledge Management, Proceedings of LOAIT '07. II Workshop on Legal Ontologies and Artificial Intelligence Techniques (Stanford, 4 June 2007), P. Casanovas, M. A. Biasiotti, E. Francesconi \& M. T. Sagri (eds), pp. 131-148.

López Rodríguez C. I., Faber P., León Araúz P., Prieto Velasco J. A. \& Tercedor Sánchez M. (2010) La Terminología basada en marcos y su aplicación a las Ciencias Ambientales: los proyectos MarcoCosta y Ecosistema, Arena Romanistica, 7(10), pp. 52-75.

López Rodríguez C. I., Tercedor Sánchez M. \& Faber P. (2006) Gestión terminológica basada en el conocimiento y generación de recursos de información sobre el cáncer: el proyecto Oncoterm, RevistaeSalud.com, 2(8).

Magris M. (2001) TERMit, la banque de données terminologique de la SSLMIT, Terminometro, 5, pp. 50-55.

Magris M. (2002) La banca dati terminologica TERMIT della S.S.L.M.I.T. dell'Università di Trieste, in La terminologia in Italia, D. Prado (ed.), Unione Latina, pp. 48-57.

Magris M. (2004) Verso una terminografica per il traduttore giuridico, Linguistica Antverpiensia New Series, Special Issue on the Translation of Domain Specific Languages and Multilingual Terminology Management, R. Temmerman \& U. Knops (eds), 3, Hoger Instituut voor Vertalers en Tolken, Hogeschool Antwerpen, pp. 53-65.

Magris M. (2012) Variation in Terminologie, Terminographie und Phraseographie, JoSTrans - The Journal of Specialised Translation, 18, pp. 160-174.

Magris M., Musacchio M. T., Rega L. \& Scarpa F. (2002) Instroduzione, in Manuale di terminologia. Aspetti teorici, metodologici e applicativi, M. Magris, M. T. Musacchio, L. Rega \& F. Scarpa (eds), Milano, Hoepli, pp. i-ix.

Mahesh K. (1996) Ontology Development for Machine Translation: Ideology and Methodology, Las Cruces, New Mexico State University.

Mannozzi G. (2000) Problemi e prospettive della giustizia riparativa alla luce della "Dichiarazione di Vienna", Rassegna Penitenziaria e Criminologica, 1/3, pp. 1-28.

Mantle G., Fox D. \& Dhami M. K. (2005) Restorative Justice and Three Individual Theories of Crime, Internet Journal of Criminology, pp. 1-36. 
Mattila H. E. S. (2006) Comparative Legal Linguistics, Aldershot, Ashgate Publishing Limited.

Mazzarese T. (1989) Logica deontica e linguaggio giuridico, Padova, CEDAM.

McEnery T. \& Xiao R. (2007) Parallel and Comparable Corpora: What is Happening?, in Incorporating Corpora: the Linguist and the Translator, G. Anderman \& M. Rogers (eds), Clevedon, Multilingual Matters, pp. 18-31.

McEnery T., Xiao R. \& Tono Y. (2006) Corpus-based Language Studies: An Advanced Resource Book, London/New York, Routledge.

McEwan J. (2009) The Testimony of Vulnerable Victims and Witnesses in Criminal Proceedings in the European Union, ERA Forum, 10(3), pp. 369-386.

Megale F. (2008) Teorie della traduzione giuridica: fra diritto comparato e Translation Studies, Napoli, Editoriale scientifica.

Mellinkoff D. (1963) The Language of the Law, Boston, Little, Brown \& Co.

Merkel M. (1998) Consistency and Variation in Technical Translations. A Study of Translators' Attitudes, in Unity in Diversity? Current Trends in Translation Studies, L. Bowker, M. Cronin, D. Kenny \& J. Pearson (eds), Manchester, St. Jerome, pp. 137-149.

Messineo C. (2002) Variación conceptual y formal del término educación bilingüe intercultural (ebi) en distintos tipos de discursos, Terminology, 8(1), pp. 113-139.

Meyer I. (2001) Extracting Knowledge-rich Contexts for Terminography. A Conceptual and Methodological Framework, in Recent Advances in Computational Terminology, D. Bourigault, C. Jacquemin \& M.-C. L'Homme (eds), Amsterdam/Philadelphia, John Benjamins, pp. 279-302.

Meyer I., Eck K. \& Skuce D. (1997) Systematic Concept Analysis within a Knowledge-Based Approach to Terminology Terminology Management, in Handbook of Terminology Management. Basic Aspects of Terminology Management, S. E. Wright \& G. Budin (eds), Amsterdam/Philadelphia, John Benjamins, pp. 98-118.

Meyer I., Skuce D., Bowker L. \& Eck K. (1992) Towards a New Generation of Terminological Resources: An Experiment in Building a Terminological Knowledge Base, Proceedings of the 14th International Conference on Computational Linguistics (COLING '92) (Nantes, 23-28 August 1992), pp. 956-960.

Montero Martínez S. (2000) La unidad terminológica: de la uniformidad a la variación, Hermēneus. Revista de Traducción e Interpretación, 2, pp. 1-7.

Moreno A. \& Pérez C. (2000) Reusing the Mikrokosmos Ontology for Concept-based Multilingual Terminology Databases, Proceedings of the 2nd International Conference on Language Resources and Evaluation (LREC 2000) (Athens, 31 May-2 June 2000), pp. 1061-1067.

Myking J. (2007) No Fixed Boundaries, in Indeterminacy in Terminology and LSP: Studies in Honour of Heribert Picht, B. E. Antia (ed.), Amsterdam/Philadelphia, John Benjamins, pp. 73-91.

Меуег I., Bowker L. \& Eck K. (1992) COGNITERM: An Experiment in Building a Terminological Knowledge Base, Proceedings of the 5th European Association for Lexicography Conference (EURALEX '92) (Tampere, 4-9 August 1992), pp. 159-172. 
Navigli R. \& Velardi P. (2008) From Glossaries to Ontologies: Extracting Semantic Structure from Textual Definitions, in Ontology Learning and Population: Bridging the Gap between Text and Knowledge, P. Buitelaar \& P. Cimiano (eds), Amsterdam, IOS Press, pp. 71-87.

Neches R., Fikes R., Finin T., Gruber T., Patil R., Senator T. \& Swartout W. R. (1991) Enabling Technology for Knowledge Sharing, AI Magazine, 12(3), pp. 36-56.

Nord C. (1997) Translating as a Purposeful Activity. Functionalist Approaches Explained, Manchester, St. Jerome Publishing.

Omrane N., Nazarenko A. \& Szulman S. (2011) From Linguistics to Ontologies. The Role of Named Entities in the Conceptualisation Process, Proceedings of the International Conference on Knowledge Engineering and Ontology Development (Paris, 26-29 October 2011), J. Filipe \& J. L. G. Dietz (eds), pp. 249-254.

Palermo F. (2007) Lingua, diritto e comparazione nel contesto comunitario. Profili metodologici, tra opportunità e rischi, Atti del convegno La traduzione del diritto comunitario ed europeo: riflessioni metodologiche (Trento, 10-11 marzo 2006), E. Ioriatti Ferrari (ed.), Trento, Università degli Studi di Trento, pp. 133-159.

Pazienza M. T., Pennacchiotti M. \& Zanzotto F. M. (2005) Terminology Extraction: An Analysis of Linguistic and Statistical Approaches, in Knowledge Mining. Studies in Fuzziness and Soft Computing, S. Sirmakessis (ed.), Berlin, Springer, pp. 255-279.

Pearson J. (1998) Terms in Context, Amsterdam/Philadelphia, John Benjamins.

Pearson J. (1999) Comment accéder aux éléments définitoires dans les textes spécialisés?, Réseau international de néologie et de terminologie, 19, pp. 21-28.

Peruzzo K. (2006) Europol e la cooperazione di polizia in Europa: un'analisi terminografica in italiano e inglese, Master's Thesis, Trieste, Università degli Studi di Trieste.

Peruzzo K. (2010) Horizontal Denominative Variation in an EU Victim-related EnglishItalian Parallel Corpus, Rivista internazionale di tecnica della traduzione/International Journal of Translation, 12, pp. 177-188.

Pevehouse J. C. (2005) Democracy from Above: Regional Organizations and Democratization, Cambridge, Cambridge University Press.

Picht H. \& Draskau J. (1985) Terminology: An Introduction, Guilford, University of Surrey.

Picton A. (2011) Picturing Short-period Diachronic Phenomena in Specialised Corpora: A Textual Terminology Description of the Dynamics of Knowledge in Space Technologies, Terminology, 17(1), pp. 134-156.

Polese V. \& D'Avanzo S. (2010) Linguistic and Legal Vagueness in EU Directives Harmonising Protection for Refugees and Displaced Persons, in Researching Language and the Law, D. S. Giannoni \& C. Frade (eds), Bern, Peter Lang, pp. 89-111.

Pozzo B. (2008) L'interpretazione della Corte del Lussemburgo del testo multilingue: una rassegna giurisprudenziale, in Europa e linguaggi giuridici, B. Pozzo \& M. Timoteo (eds), Milano, Giuffrè Editore, pp. 383-433.

Quiroz G., Plested M. C., Muñoz C., Giraldo J. J. \& Zapata G. (1999) Some Considerations on the Relationship between the Terminologist and the Expert in the Building of a Database, in Proceedings of the 5th International Congress on Terminology and 
Knowledge Engineering (TKE '99) (Innsbruck, 23-27 August 1999), P. Sandrini (ed.), Vienna, Termnet, pp. 169-179.

Reimerink A. \& Faber P. (2009) EcoLexicon: A Frame-Based Knowledge Base for the Environment, Proceedings of the European conference TOWARDS eENVIRONMENT. Opportunities of SEIS and SISE: Integrating Environmental Knowledge in Europe (Prague, 25-27 March 2009), J. Hradec, E. Pelikán, O. Mirovský, W. Pillmann, I. Holoubek \& T. Bandholtz (eds), pp. 629-636.

Reimerink A., León Araúz P. \& Magaña Redondo P. J. (2010) EcoLexicon: An Environmental TKB, Proceedings of the 7th International Conference on Language Resources and Evaluation (LREC '04) (Malta, 17-23 May 2004), pp. 2322-2329.

Rey A. (1983) Synonymie, néonymie et normalisation terminologique, in Problèmes de la définition et de la synonymie en terminologie. Actes du colloque international de terminologie (Université Laval, Quebec, 23-27 May 1982), D. Duquet-Picard (ed.), Université Laval, Quebec, GIRSTERM, pp. 281-310.

Rey A. (1995) Essays on Terminology, translated and edited by J. C. Sager, Amsterdam/Philadelphia, John Benjamins.

Richards J., Platt J. \& Weber H. (1985) Longman Dictionary of Applied Linguistics, Essex, Longman.

Roche C. (2007a) Le terme et le concept: fondements d'une ontoterminologie, Proceedings of Terminology \& Ontology: Theories and applications (TOTh 2007) (Annecy, 1 June 2007), pp. 1-13.

Roche C. (2007b) Saying Is Not Modelling, Proceedings of the 4th International Workshop on Natural Language Processing and Cognitive Science (NLPCS 2007) (Funchal, 12-13 June 2007), pp. 47-56.

Roche C., Calberg-Challot M., Damas L. \& Rouard P. (2009) Ontoterminology: A New Paradigm for Terminology, Proceedings of the International Conference on Knowledge Engineering and Ontology Development (KEOD 2009) (Madeira, 5-8 October 2009), pp. 321-326.

Rogers M. (1997) Synonymy and Equivalence in Special-language Texts. A Case Study in German and English Texts on Genetic Engineering, in Text Typology and Translation, A. Trosborg (ed.), Amsterdam/Philadelphia, John Benjamins, pp. 217-245.

Rogers M. (2004) Multidimensionality in Concepts Systems: A Bilingual Textual Perspective, Terminology, 10(2), pp. 215-240.

Rogers M. (2007a) Lexical Chains in Technical Translation, in Indeterminacy in Terminology and LSP: Studies in Honour of Heribert Picht, B. E. Antia (ed.), Amsterdam/Philadelphia, John Benjamins, pp. 15-35.

Rogers M. (2007b) Terminological Equivalence in Technical Translation: A Problematic concept? St. Jerome and Technical Translation, SYNAPS, 20, pp. 13-25.

Rogers M. (2008) Terminological Equivalence: Probability and Consistency, MuTra, LSP Translation Scenarios. Selected Contributions to the EU Marie Curie Conference, H. Gerzymisch-Arbogast, G. Budin \& G. Hofer (eds), 2, Vienna, ATRC Group, pp. 101108. 
Rollason C. (2003) Opaque or User-friendly Language?, in Crossing Barriers and Bridging Cultures. The Challenges of Multilingual Translation for the European Union, A. Tosi (ed.), Clevedon/Buffalo/Toronto/Sydney, Multilingual Matters, pp. 117-119.

Rossi P. (2008) L'impatto del multilinguismo sull'armonizzazione del diritto privato europeo, in Europa e linguaggi giuridici, B. Pozzo \& M. Timoteo (eds), Milano, Giuffrè Editore, pp. 361-382.

Sacco R. (1991) La comparaison juridique au service de la connaissance du droit, Paris, Economica.

Sacco R. (1992) La traduzione giuridica, in Il linguaggio del diritto, U. Scarpelli \& P. Di Lucia (eds), Milano, Edizioni Universitarie di Lettere Economia Diritto, pp. 475-490.

Sacco R. (2000) Lingua e diritto, Ars Interpretandi. Traduzione e diritto, 5, pp. 117-134.

Sager J. C. (1990) A Practical Course in Terminology Processing, Amsterdam/Philadelphia, John Benjamins.

Sagri M. T. \& Tiscornia D. (2009) Le peculiarità del linguaggio giuridico. Problemi e prospettive nel contesto multilingue europeo, MediAzioni, http://www.mediazioni.sitlec.unibo.it.

Sandrini P. (1996) Comparative Analysis of Legal Terms: Equivalence Revisited, in TKE '96: Terminology and Knowledge Engineering, C. Galinski \& K. D. Schmitz (eds), Frankfurt, Indeks Verlag, pp. 342-351.

Sandrini P. (1999) Legal Terminology. Some Aspects for a New Methodology, Hermes, Journal of Linguistics, 22, pp. 101-111.

Šarčević S. (1997) New Approach to Legal Translation, The Hague, Kluwer Law International.

Šarčević S. (2000) Legal Translation and Translation Theory: A Receiver-oriented Approach, Proceedings of the International colloquium Legal Translation. History, Theory/ies and Practice (Geneva, 17-19 February 2000), University of Geneva.

Scarpelli U. (1994) La definizione nel diritto, in Il linguaggio del diritto, U. Scarpelli \& P. Di Lucia (eds), Milano, LED, pp. 311-324.

Schröder H. (1991) Linguistic and Text-theoretical Research on Languages for Special Purposes. A Thematic and Bibliographical Guide, in Subject-oriented Texts. Languages for Special Purposes and Text Theory, H. Schröder (ed.), Berlin/New York, de Gruyter, pp. 1-48.

Schubert K. \& Link L. (2008) Multidimensional Control in Technical Translation, MuTtra, LSP Translation Scenarios. Selected Contributions to the EU Marie Curie Conference, H. Gerzymisch-Arbogast, G. Budin \& G. Hofer (eds), 2, Vienna, ATRC Group, pp. 131165.

Simonnæs I. (2007) Vague Legal Concepts: A Contradictio in Adjecto?, in Indeterminacy in LSP and Terminology, B. E. Antia (ed.), Amsterdam/Philadelphia, John Benjamins, pp. 119-134.

Sinclair J. (1994) Corpus Typology: A Framework for Classification, EAGLES document, Pisa. 
Skuce D. \& Meyer I. (1990) Computer-assisted Concept Analysis: An Essential Component of a Terminologist's Workstation, Proceedings of the Second International Congress on Terminology and Knowledge Engineering (TKE '90) (Trier, 2-4 October 1990), H. Czap \& W. Nedobity (eds), Frankfurt am Main, Indeks Verlag, pp. 187-199.

Slapper G. \& Kelly D. (2011) The English Legal System, 12th ed., New York, Routledge.

Sowa J. F. (1984) Conceptual Structures: Information Processing in Mind and Machine, Reading/Menlo Park/London/Amsterdam/Don Mills/Sidney, Addison-Wesley Publishing Company.

Spagnesi E. (1978) Bibliografia delle edizioni giuridiche antiche in lingua italiana. Testi statutari e dottrinali dal 1470 al 1700, Firenze, Olschki.

Spaventa E. (2007) Opening Pandora's Box: Some Reflections on the Constitutional Effects of the Decision in Pupino, European Constitutional Law Review, 3(1), pp. 5-24.

Streiter O., Zielinski D., Ties I. \& Voltmer L. (2003) Term Extraction for Ladin, Proceedings of TALN 2003, Workshop on Natural Language Processing of Minority Languages with few computational linguistic resources (Batz-sur-Mer, 11-14 June 2003).

Tartier A. (2003) A Method for Observing Terminological Evolution, Proceedings of the Con-ference "Recent Advances in Natural Language Processing” (RANLP '03), pp. 467-471.

Temmerman R. (1997) Questioning the Univocity Ideal. The Difference between Sociocognitive Terminology and Traditional Terminology, Hermes, Journal of Linguistics, 18, pp. 51-93.

Temmerman R. (2000a) Towards New Ways of Terminology Description: The Sociocognitive Approach, Amsterdam/Philadelphia, John Benjamins.

Temmerman R. (2000b) Training Terminographers: The Sociocognitive Approach, Proceedings of the 9th European Association for Lexicography Conference (EURALEX 2000) (Stuttgart, 8-12 August 2000), pp. 453-460.

Temmerman R. (2009) Ways of Managing the Dynamics of Terminology in Multilingual Communication, Scolia, pp. 105-123.

Temmerman R. \& Kerremans K. (2003) Termontography: Ontology Building and the Sociocognitive Approach to Terminology Description, Proceedings of the 17th International Congress of Linguists (CIL17) (Prague, 24-29 June 2003), E. Hajicová, A. Kotešovcová \& J. Mírovský (eds), Prague, Matfyzpress, MFF UK (CD-ROM).

Temmerman R. \& Knops U. (2004) The Translation of Domain Specific Languages and Multilingual Terminology Management, Linguistica Antverpiensia New Series, Special Issue on the Translation of Domain Specific Languages and Multilingual Terminology Management, 3, Hoger Instituut voor Vertalers en Tolken, Hogeschool Antwerpen, pp. 11-18.

Tercedor M. \& López-Rodríguez C. I. (2008) Integrating Corpus Data in Dynamic Knowledge Bases. The Puertoterm project, Terminology, 14(2), pp. 159-182.

Teubert W. (2005) My Version of Corpus Linguistics, International Journal of Corpus Linguistics, 10(1), pp. 1-13.

Tiersma P. M. (1999) Legal Language, Chicago/London, University of Chicago Press. 
Tiscornia D. (2007) The Lois Project: Lexical Ontologies for Legal Information Sharing, Proceedings of $V$ Legislative XML Workshop (San Domenico di Fiesole, 14-16 June 2006), C. Biagioli, E. Francesconi \& G. Dartor (eds), Florence, European Press Academic Publishing, pp. 189-204.

Tonini P. (2010) Manuale di procedura penale (11th ed.) Milano, Giuffrè Editore.

Tosi A. (2003) Chapter 14. Conclusions, in Crossing Barriers and Bridging Cultures. The Challenges of Multilingual Translation for the European Union, A. Tosi (ed.), Clevedon/Buffalo/Toronto/Sydney, Multilingual Matters, pp. 128-131.

Van Calster G. (1997) The EU's Tower of Babel - The Interpretation by the European Court of Justice of Equally Authentic Texts Drafted in More than One Official Language, Yearbook of European Law, 17(1), pp. 363-393.

Vargas Sierra C. (2007) El léxico especializado y las ontologías, in Las lenguas profesionales y académicas, E. Alcaraz Varó, J. Mateo Martínez \& F. Yus Ramos (eds), Barcelona, Ariel, pp. 41-52.

Velardi P., Missikoff M. \& Basili R. (2001) Identification of Relevant Terms to Support the Construction of Domain Ontologies SymOntos: A Symbolic Ontology Management System, Proceedings of the Workshop on Human Language Technology and Knowledge Management (HLTKM '01) (Tolouse, 6-7 July 2001).

Vintar Š. (2008) Corpora in Translation: A Slovene Perspective, The Journal of Specialised Translation, (10), pp. 40-55.

Vossen P. (1998) (ed.) EuroWordNet: A Multilingual Database with Lexical Semantic Networks, Dordrecht, Kluwer Academic Publishers.

Wagner E., Bech S. \& Martínez J. M. (2002) Translating for the European Union institutions, Manchester, St. Jerome.

Watson A. (1974) Legal Transplants, Edinburgh, Scottish Academic Press.

Wright S. E. (2007) Coping with Indeterminacy: Terminology and Knowledge Representation Resources in Digital Environments, in Indeterminacy in Terminology and LSP: Studies in Honour of Heribert Picht, B. E. Antia (ed.), Amsterdam/Philadelphia, John Benjamins, pp. 157-179.

Wright S. E. \& Budin G. (1997) (eds) Handbook of Terminology Management. Basic Aspects of Terminology management, Amsterdam/Philadelphia, John Benjamins.

Wüster E. (1979) Einführung in die Allgemeine Terminologielehre und Terminologische Lexikographie, Wien/New York, Springer.

Yankova D. (2007) How Harmonious Is Harmonisation of Legislation? On the Concept of Term Equivalence, in Language and the Law: International Outlooks, K. Kredens \& S. Goźdź-Roszkowski (eds), Frankfurt am Main, Peter Lang, pp. 97-107.

Zanettin F. (2002) Corpora in Translation Practice, Proceedings of the 3rd International Conference on Language Resources and Evaluation (LREC 2002) (Las Palmas de Gran Canaria, 27 May-2 June 2002, E. Yuste (ed.), Las Palmas de Gran Canaria, University of Las Palmas de Gran Canaria, pp. 10-14.

Zawada B. E. \& Swanepoel P. (1994) On the Empirical Adequacy of Terminological Concept Theories: The Case for Prototype Theory, Terminology, 1(2), pp. 253-275. 
Zielinski D. \& Ramírez Safar Y. (2005) Research Meets Practice: T-survey 2005. An Online Survey on Terminology Extraction and Terminology Management, http://ecolotrain.unisaarland.de/download/publs/sdv/t-survey_aslib2005_zielinski.htm\#_ftn1.

\section{International, Supranational and National Documents}

Codice di Procedura Penale (Testo coordinato ed aggiornato del D.P.R. 22 settembre 1988, n. 447).

Codice Penale (Testo coordinato ed aggiornato del Regio Decreto 19 ottobre 1930, n. 1398).

Commission of the European Communities (2001) Green Paper. Compensation to crime victims COM (2001) 536 final, 28.9.2001.

Committee of Ministers of the Council of Europe (1977) Resolution (77) 27 on the Compensation of Victims of Crime, 275th Meeting of the Ministers' Deputies, 28.9.1977.

Committee of Ministers of the Council of Europe (1985) Recommendation No. R (85) 11 of the Committee of Ministers to Member States on the Position of the Victim in the Framework of Criminal Law and Procedure, 387th Meeting of the Ministers' Deputies, 28.6.1985.

Committee of Ministers of the Council of Europe (1987) Recommendation No. R (87) 21 of the Committee of Ministers to Member States on Assistance to Victims and the Prevention of Victimisation, 410th Meeting of the Ministers' Deputies, 17.9.1987.

Committee of Ministers of the Council of Europe (1999) Recommendation No. R (99) 19 of the Committee of Ministers to Member States concerning Mediation in Penal Matters, 679th Meeting of the Ministers' Deputies, 15.9.1999.

Committee of Ministers of the Council of Europe (2006) Recommendation Rec(2006)8 of the Committee of Ministers to member states on assistance to crime victims, 967th Meeting of the Ministers' Deputies, 14.6.2006.

Committee of the Regions (2010) Opinion of the Committee of the Regions on "The Stockholm programme: Challenges and opportunities in view of a new multi-annual programme on the EU area of freedom, security and justice", Official Journal of the European Union, C 79, 27.3.2010, pp. 37-44.

Council of Europe (1983) European Convention on the Compensation of Victims of Violent Crime, European Treaty Series, 116, 24.11.1983.

Council of Europe (2005) Convention on Action against Trafficking in Human Beings, Council of Europe Treaty Series, 197, 16.5.2005. 
Council of the European Union (2001) Council Framework Decision of 15 March 2001 on the standing of victims in criminal proceedings (2001/220/JHA), Official Journal of the European Communities, L 82, 22.3.2001, pp. 1-4.

Council of the European Union (2002) Council Framework Decision of 19 July 2002 on combating trafficking in human beings (2002/629/JHA), Official Journal of the European Communities, L 203, 1.8.2002, pp. 1-4.

Council of the European Union (2004) Council Directive 2004/80/EC of 29 April 2004 relating to compensation to crime victims, Official Journal of the European Union, L 261, 6.8.2004, pp. 15-18.

Council of the European Union (2010) Consolidated Version of the Treaty on the Functioning of the European Union, Official Journal of the European Union, C 83, 30.3.2010, pp. 47-199.

Criminal Injuries Compensation Act 1995 (c. 53), London, HMSO.

Decreto Legislativo 6 novembre 2007, n. 204, Attuazione della direttiva 2004/80/CE relativa all'indennizzo delle vittime di reato, Gazzetta Ufficiale, 261, 9.11.2007.

European Commission (2003) Communication from the Commission to the Council and the European Parliament, Biannual update of the scoreboard to review progress on the creation of an area of "freedom, security and justice" in the European Union, Second half of 2003, $\operatorname{COM}(2003) 812$ final.

European Commission (2005) Communication from the Commission to the Council, the European Parliament, the European Economica and Social Committee and the Committee of the Regions. A New Framework Strategy for Multilingualism (COM (2005) 596 final).

European Commission (2009) Commission Staff Working Paper Accompanying document to the Proposal for a Council Framework Decision on combating the sexual abuse, sexual exploitation of children and child pornography, repealing Framework Decision 2004/68/JHA, SEC(2009) 356.

European Commission (2011a) Communication from the Commission to the European Parliament, the Council, the Economic and Social Committee and the Committee of the Regions. Strengtheening Victims' Rights in the EU (COM (2011) 274 final).

European Commission (2011b) Proposal for a Directive of the European Parliament and of the Council Establishing Minimum Standards on the Rights, Support and Protection of Victims of Crime (COM (2011) 275 final).

European Commission (2011c) Proposal for a Regulation of the European Parliament and of the Council on Mutual Recognition of Protection Measures in Civil Matters (COM (2011) 276 final).

European Commission (2011d) Communication from the Commission to the European Parliament, the Council, the European Economic and Social Committee and the Committee of the Regions. An EU Agenda for the Rights of the Child (COM (2011) 60 final).

European Council \& Commission (1999) Action Plan of the Council and the Commission on how best to implement the provisions of the Treaty of Amsterdam on an area of freedom, 
security and justice - Text adopted by the Justice and Home Affairs Council of 3 December 1998, Official Journal of the European Communities, C 019, 23.1.1999, pp. $1-15$.

European Council (1999) Presidency Conclusions of Tampere European Council of 15 and 16 October 1999.

European Council (2005) The Hague Programme: Strengthening Freedom, Security and Justice in the European Union, Official Journal of the European Union, C 53, 3.3.2005, pp. 1-14.

European Council (2010) The Stockholm Programme - An Open and Secure Europe Serving and Protecting Citizens, Official Journal of the European Union, C 115, 4.5.2010, pp. 138.

European Court of Justice (1963) Case 26/62, Judgment of the Court of 5 February 1963. Van Gend en Loos v Netherlands Inland Revenue Administration, Reference for a preliminary ruling: Tariefcommissi, The Netherlands.

European Court of Justice (1964) Case 6/64, Judgment of the Court of 15 July 1964. Flaminio Costa v E.N.E.L., Reference for a preliminary ruling: Giudice conciliatore di Milano, Italy.

European Court of Justice (2004) Opinion of Advocate General Poiares Maduro delivered on 16 December 2004 (Spain v Eurojust).

European Parliament \& Council of the European Union (2011a) Directive 2011/99/EU of the European Parliament and of the Council of 13 December 2011 on the European Protection Order, Official Journal of the European Union, L 338, 21.12.2011, pp. 2-18.

European Parliament \& Council of the European Union (2011b) Directive 2011/92/EU of the European Parliament and of the Council of 13 December 2011 on Combating the Sexual Abuse and Sexual Exploitation of Children and Child Pornography, and Replacing Council Framework Decision 2004/68/JHA, Official Journal of the European Union, L 335, 12.12.2011, pp. 1-14.

European Parliament \& Council of the European Union (2011c) Directive 2011/36/EU of the European Parliament and of the Council of 5 April 2011 on preventing and combating trafficking in human beings and protecting its victims, and replacing Council Framework Decision 2002/629/JHA, Official Journal of the European Communities, L 101, 15.4.2011, pp. 1-11.

European Parliament \& Council of the European Union (2012) Directive 2012/29/EU of the European Parliament and of the Council of 25 October 2012 Establishing Minimum Standards on the Rights, Support and Protection of Victims of Crime, and Replacing Council Framework Decision 2001/220/JHA, Official Journal of the European Union, L 315, 14.11.2012, pp. 57-73.

European Parliament, Council of the European Union \& European Commission (2003) Joint Practical Guide of the European Parliament, the Council and the Commission for Persons Involved in the Drafting of Legislation within the Community Institutions, Luxembourg, Office for Official Publications of the European Communities. 
European Union (1997). Treaty of Amsterdam amending the Treaty on European Union, the Treaties establishing the European Communities and certain related acts, Official Journal of the European Union, C 340, 10.11.1997, pp. 1-308.

European Union (2006) Consolidated Version of the Treaty establishing the European Community, Official Journal of the European Union, C 321, 29.12.2006, pp. 37-186.

European Union (2007) Treaty of Lisbon Amending the Treaty on European Union and the Treaty Establishing the European Community, Official Journal of the European Union, C 306, 17.12.2007, pp. 1-271.

European Union (2010) Consolidated Version of the Treaty on European Union, Official Journal of the European Union, C 83, 30.3.2010, pp. 13-46.

Home Office, Crown Prosecution Service \& Department for Constitutional Affairs (2004) The Code of Practice for Victims of Crime, available at http://www.cps.gov.uk/victims_witnesses/victims_code.pdf.

Legge 26 marzo 2001, n. 128, Interventi legislativi in materia di tutela della sicurezza dei cittadini, Gazzetta Ufficiale, 91, 19.4.2001.

Parlamento europeo (2000) Relazione sulla Comunicazione della Commissione al Consiglio, al Parlamento europeo e al Comitato economico e sociale "Vittime di reati nell'Unione europea - Riflessioni sul quadro normativo e sulle misure da prendere".

Parlamento Europeo \& Consiglio dell'Unione europea (2012) Direttiva 2012/29/UE del Parlamento europeo e del Consiglio del 25 ottobre 2012 che istituisce norme minime in materia di diritti, assistenza e protezione delle vittime di reato e che sostituisce la decisione quadro 2001/220/GAI. Gazzetta ufficiale dell'Unione europea, L 315, 14.11.2012, pp. 57-73.

Portuguese Republic (2000) Initiative of the Portuguese Republic with a View to Adopting a Council Framework Decision on the Standing of Victims in Criminal Procedure, Official Journal of the European Communities, C 243, 24.8.2000, pp. 4-8.

Proposta di legge d'iniziativa dei deputati Boato e Cima, n. 3367, Legge quadro per l'assistenza, il sostegno e la tutela delle vittime di reati, Camera dei Deputati, 7.11.2002.

Proposta di Legge n. 2802, Norme per la tutela delle vittime di reati per motivi di omofobia e transfobia, 14.10.2009.

Regno del Belgio (2002) Iniziativa del Regno del Belgio in vista dell'adozione di una decisione del Consiglio che istituisce una rete europea di punti di contatto nazionali per la giustizia riparatoria, Gazzetta ufficiale delle Comunità europee, C 242, 8.10.2002, pp. 20-23.

UN General Assembly (1985) Declaration of Basic Principles of Justice for Victims of Crime and Abuse of Power, 96th Plenary Meeting, 29.11.1985.

UN General Assembly (2000a) United Nations Convention against Transnational Organized Crime, 62nd Plenary Meeting, 15.11.2000.

UN General Assembly (2000b) United Nations Protocol to Prevent, Suppress and Punish Trafficking in Persons, Especially Women and Children, supplementing the United Nations Convention against Transnational Organised Crime, 15.11.2000. 
UN General Assembly (2001) Vienna Declaration on Crime and Justice: Meeting the Challenges of the Twenty-first Century, 81st Plenary Meeting, 4.12.2000.

United Nations (1989) Convention on the rights of the child, adopted and opened for signature, ratification and accession by General Assembly resolution 44/25 of 20 November 1989 entry into force 2 September 1990, in accordance with article 49.

United Nations Office on Drugs and Crime (2006) Handbook on Restorative Justice Programmes, New York, United Nations.

Youth Justice and Criminal Evidence Act 1999 (c.23), London, HMSO. 